Université de Montréal

( en extension à l'Université du Québec à Chicoutimi )

La pastorale en milieu urbain et le devenir de la paroisse

( au Saguenay - Lac - Saint-Jean )

\author{
par \\ Eric Tremblay \\ Théologie - Études pastorales
}

Faculté de Théologie

Thèse présentée à la Faculté des études supérieures

en vue de l'obtention du grade de

Philosophiae Doctor (Ph.D.))

en Théologie - Études pastorales

juin 1994

* Éric Tremblay, 1994 


\section{Bibliothèque}

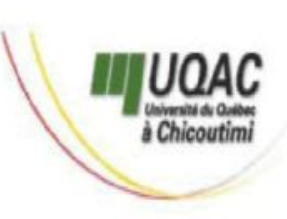

\section{Mise en garde/Advice}

Afin de rendre accessible au plus Motivated by a desire to make the grand nombre le résultat des results of its graduate students' travaux de recherche menés par ses research accessible to all, and in étudiants gradués et dans l'esprit des accordance with the rules règles qui régissent le dépôt et la governing the acceptation and diffusion des mémoires et thèses diffusion of dissertations and produits dans cette Institution, theses in this Institution, the I'Université du Québec à Université du Québec à Chicoutimi (UQAC) est fière de Chicoutimi (UQAC) is proud to rendre accessible une version make a complete version of this complète et gratuite de cette œuvre. work available at no cost to the reader.

L'auteur conserve néanmoins la The author retains ownership of the propriété du droit d'auteur qui copyright of this dissertation or protège ce mémoire ou cette thèse. thesis. Neither the dissertation or Ni le mémoire ou la thèse ni des thesis, nor substantial extracts from extraits substantiels de ceux-ci ne it, may be printed or otherwise peuvent être imprimés ou autrement reproduced without the author's reproduits sans son autorisation. permission. 


\title{
Université de Montréal
}

( en extension à l'Université du Québec à Chicoutimi )

Cette thèse intitulée:

La pastorale en milieu urbain et le devenir de la paroisse (au Saguenay - Lac St-Jean)

\author{
présentée par: \\ Éric Tremblay
}

a été évaluée par un jury composé des personnes suivantes:

Laval Létourneau

président-rapporteur

Simon Dufour . directeur de recherche

Rémi Parent codirecteur de recherche

Jean-Guy Girard... membre du jury

Lucien Robitaille examinateur externe

Thèse acceptée le: 3 novembre 1994 


\section{SOMMAIRE}

Cette thèse porte sur la pastorale en milieu urbain et le devenir de la paroisse au Saguenay-Lac-Saint-Jean. Cette recherche-action est davantage une problématique d'ensemble que l'approfondissement d'une seule composante de la réalité paroissiale en contexte urbain. Je considère la paroisse comme un réseau complexe d'éléments interreliés. Pour saisir la dynamique d'interrelation entre ces éléments, j'ai choisi l'approche systémique. Il s'agit d'une manière nouvelle et différente d'approcher le réel de plus en plus mise en oeuvre dans les sciences humaines et sociales. Depuis plus d'une trentaine années, on n'avait presque rien écrit sur l'institution paroissiale. En une seule année, celle de 1992, quatre études québécoises sur la paroisse ont été publiées. Cependant, aucune étude englobant les différentes problématiques de la pastorale en milieu urbain et le devenir de la paroisse n'a été faite. C'est à l'avènement de ce chantier que je désire apporter une contribution dans la présente thèse. L'originalité de celle-ci doit être recherchée dans l'interaction elle-même des divers enjeux.

Cette thèse comporte trois parties. L'observation systématique sur un terrain bien précis étant l'étape initiale de la méthode en praxéologie pastorale constitue alors la première partie de la thèse. Après une description des milieux d'observation, quatre paroisses du diocèse de Chicoutimi, des données recueillies nous ont permis de savoir ce que vivent les paroissiens "périphériques" et "nucléiques", les bénévoles et les permanents de l'institution paroissiale. La démarche méthodologique proposée en praxéologie pastorale prévoit une étape de problématisation de la situation observée. Cet essai de modélisation est le contenu de la première section de la deuxième partie intitulée: Herméneutique du temps présent et de la Tradition. La lecture de l'ensemble des données d'observation nous amène à croire qu'en Église, nous ne connaissons pas véritablement les paroissiens d'aujourd'hui ni leurs déplacements: ils sont ailleurs et autrement. Également, le territoire de la paroisse n'est plus représentatif, surtout dans le milieu urbain. Le phénomène de l'urbanisation a profondément marqué les assises de la vie paroissiale, particulièrement dans les villes. Mais la paroisse urbaine est restée "à l'heure de la campagne". Les paroisses actuelles sont devenues davantage des enclos territoriaux au lieu de devenir des réseaux de communautés diversifiées. Il n'y a pas seulement le phénomène de l'urbanisation qui remet en question la vie paroissiale et sa structure. Vatican II a voté le projet de réaliser un changement pour amener les baptisés à devenir des sujets chrétiennement plus libres et responsables. Mais ce tournant s'avère long et laborieux puisque l'ecclésiologie de communion dont Lumen Gentium a posé les assises n'a pas été traduite en une organisation juridique adéquate. De plus, le dialogue entre les paroissiens et les intervenants pastoraux fait problème. 
Un écart grandissant s'établit entre le sens cherché et le sens donné lors des demandes de service. Nous sommes confrontés ici à la fidèle opposition historique entre des intervenants pastoraux assoiffés d'une Église idéale (Église de type "confessante") et d'autres plus soucieux de bâtir une Église accueillante au tout-venant (Église de type "multitudiniste"). Des changements institutionnels sont certes essentiels pour renouveler la pastorale en milieu urbain mais ils ne suffisent pas. Il faut proposer un nouveau paradigme de pédagogie pastorale. La deuxième section de la deuxième partie fait une relecture des défis pastoraux explorés à partir de quelques disciplines des sciences humaines et de certaines pratiques de la Tradition chrétienne: l'historique de la paroisse, le phénomène de l'urbanisation et ses conséquences sur la structure paroissiale, le christianisme et la modernité, l'héritage des premières communautés chrétiennes dans la manière d'organiser leur vie fraternelle, les forces et les lacunes ecclésiologiques du Concile Vatican II, l'approche canonique de la paroisse et les enjeux dans les différentes pédagogies pastorales utilisées. La dernière facette de la démarche praxéologique vise à dégager l'horizon de la pratique et à en articuler la prévision et la vision. C'est ce que j'ai fait dans la troisième partie intitulée "Vers un réaménagement de la pastorale paroisiale en milieu urbain". Celle-ci constitue ainsi une synthèse pratique dégageant les conséquences concrètes pour l'agir pastoral des univers de sens que nous ont ouverts préalablement les outils théoriques de compréhension des défis observés.

L'ensemble de cette recherche doctorale autorise la confirmation de mon hypothèse de sens. Pour renouveler la paroisse dans le but de mieux assurer la mission de l'Église en réponse au phénomène de l'urbanisation en contexte moderne, deux défis doivent être affrontés: il faut une réforme institutionnelle pour faire surgir une structure pastorale qui soit fonctionnelle par rapport à la dynamique urbaine et il faut également un renouveau des pédagogies pastorales pour répondre à la culture actuelle et aux exigences d'incarnation de l'Évangile. C'est à ces conditions que l'Église et la paroisse elle-même pourront retrouver une pertinence en cette fin de $X \mathrm{X}^{\circ}$ siècle marquée par une soif spirituelle dont le phénomène du Nouvel Âge constitue une manifestation. Les orientations fondamentales de l'ecclésiologie conciliaire de Vatican II (la synodalité de l'Église, la dimension communautaire plus affirmée, le renouvellement des ministères, l'explicitation de la mission de l'Église) sont réellement des manières de répondre aux défis des phénomènes de l'urbanisation et de la modernité. Une remise en question en profondeur des pédagogies pastorales d'accompagnement de la foi est aussi un moyen privilégié pour une ressaisie de la mission de l'Église, en particulier celle de la paroisse, comme service du Royaume dans la croissance des personnes et le devenir des collectivités.

Mots clés: Paroisse - Urbanisation - Modernité - Ecclésiologie - Théologie pratique. 


\section{TABLE DES MATIÈRES}

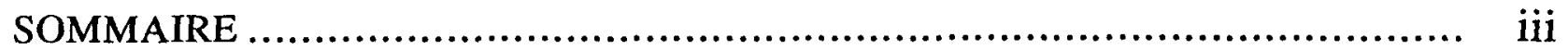

LISTE DES SIGLES ET ABRÉVIATIONS ...................................... xvi

REMERCIEMENTS ............................................................. xvii

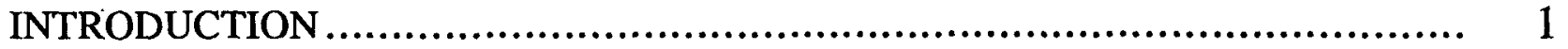

\section{PREMIÈRE PARTIE : REGARD SUR LE TERRAIN}

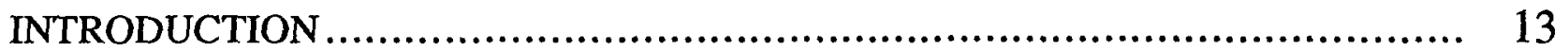

CHAPITRE 1:LES CHOIX MÉTHODOLOGIQUES ............................................ 14

1.1 La complémentarité des méthodes qualitative et quantitative ............. 14

1.2 La circularité dialectique de la méthode praxéologique.................... 22

1.3 L'importance de la liberté par rapport à toute méthode de recherche.... 24

1.4 Une option pour la théologie pratique....................................... 26

1.5 Une problématique d'ensemble par l'approche systémique ............... 28

1.6 Les limites de cette recherche ............................................ 34

CHAPITRE 2: DONNÉES RELATIVES AU MILIEU ......................... 36

2.1 Le Saguenay-Lac-Saint-Jean: la fabuleuse histoire d'un royaume........ 36

2.2 La région du Saguenay-Lac-SaintJean: "en voie de désintégration"?..... 37

2.3 Brève description des quatre paroisses observées ........................ 41

2.3.1 Saint-Dominique de Jonquière........................................... 41

2.3.2 Saint-Jean-l'Évangéliste de Bégin ................................. 45

2.3.3 Saint-Jude d'Alma...................................................... 47

2.3.4 Saint-Léon ............................................................ 49

2.4 Délimitation de mon champ d'observation................................. 51

CHAPITRE 3: LES POINTS DE VUE DES PAROISSIENS...................... 58

3.1 Une identification au territoire paroissial en constante diminution....... 60

3.2 Des intensités différentes d'attachement à la paroisse..................... 61

3.3 La pratique dominicale et l'appartenance paroissiale ...................... 64 
3.4 Une hausse du taux de mobilité des paroissiens dans le milieu urbain .... 68

3.5 Les services communautaires et les paroissiens......................... 69

3.6 La popularité des rites de passage............................................ 70

3.7 Les rites de passage et la paroisse territoriale ............................ 71

3.8 L'expansion d'une nouvelle approche pastorale............................. 75

3.9 Les effets néfastes d'un refus d'une demande de rite de passage.......... 77

3.10 L'mportance de l'approche pastorale ....................................... 79

3.11 Les attentes diverses des paroissiens envers les permanents ............. 82

CHAPITRE 4: À L'ÉCOUTE DES BÉNÉVOLES............................. 83

4.1 Des "forces vives" pour les paroisses...................................... 83

4.2 La croissance humaine ..................................................... 89

4.3 Un intérêt croissant pour le devenir de la paroisse ........................ 93

4.4 L'approfondissement de la foi chrétienne................................ 101

4.5 L'évaluation du travail pastoral.................................................. 104

4.6 La formation et l'accompagnement........................................ 108

CHAPITRE 5: LE TRAVAIL DES PERMANENTS.............................. 112

5.1 Les agents et agentes de pastorales laïques............................ 112

5.1.1 Une présence révélatrice d'une transformation ecclésiale ......... 114

5.1.2 Des richesses humaines pour les paroisses ......................... 115

5.1.3 De nombreuses souffrances....................................... 117

5.2 Les religieux et religieuses ................................................ 119

5.3 Les diacres permanents ................................................ 121

5.3.1 Des collaborateurs précieux..................................... 121

5.3.2 De réelles tensions avec les autres intervenants pastoraux........... 122

5.3.3 Une remise en question de la politique diocésaine sur le diaconat. 124

5.3.4 Une appropriation du diaconat encore insuffisante ................ 124

5.4 Les prêtres ........................................................... 125

5.4.1 Un vieillissement significatif du presbytérium .................... 126

5.4.2 Une situation du presbytérium précaire................................ 128

5.4.3 La croissance humaine du ministre ordonné au coeur de la paroisse ................................................................. 129

5.4.4 Dépassés par la situation paroissiale actuelle ....................... 133

5.4.5 Un travail d'équipe souvent difficile ................................. 135

5.4 .6 Le pouvoir du prêtre en paroisse..................................... 139

5.4 .7 L'équilibre humain du prêtre....................................... 141

5.4.8 Des tensions entre les ministres ordonnés eux-mêmes .............. 147 


\section{DEUXIÈME PARTIE: HERMÉNEUTIQUE DU TEMPS PRÉSENT ET DE LA TRADITION}

INTRODUCTION

\section{II.1 ESSAI DE MODÉLISATION DE LA DYNAMIQUE PASTORALE PAROISSIALE}

CHAPITRE 6: ÉLÉMENTS-CLÉS D'OBSERVATION .......................... 151

6.1 Une méconnaissance des paroissiens actuels et de leurs déplacements ... 152

6.1.1 Les paroissiens influencés par plusieurs phénomènes ............... 152

6.1.2 Une Église qui résiste encore à la modernité............................. 153

6.2 L'inadaptation structurelle de la paroisse territoriale causée par 1'urbanisation................................................................ 154

6.2.1 La paroisse, une plaine balayée par tous les vents urbains .......... 154

6.2.2 La paroisse à "l'heure de la campagne" .............................. 155

6.2.3 Un enclos territorial ................................................... 157

6.3 Les interpellations de Vatican II sur l'organisation paroissiale............. 158

6.3.1 L'Église-communion: un voeu pieux?................................ 158

6.3.2 Aucun renouveau paroissial sans changements institutionnels....... 160

6.3.3 La préférence de la paroisse: assurer sa survie ou promouvoir sa mission ....................................................................... 162

6.3.4 La nécessité de l'émergence de ministères nouveaux................ 162

6.4 Un dialogue paroissiens - intervenants qui fait problème ................. 163

6.4.1 Écart grandissant entre l'offre et la demande......................... 163

6.4.2 Des "distants" par rapport à qui? et à quoi? .......................... 166

6.4.3 Une mort nécessaire à notre imaginaire autour de l'appartenance paroissiale et de l'idéologie communautaire......................... 166

6.5 Un renouveau paroissial impossible sans renouveau des pédagogies pastorales........................................................................ 168

6.5.1 Une éducation de la foi qui tienne compte des étapes de la vie .... 168

6.5.2 L'éducation de la foi: le "comment faire" remonte sans cesse à la surface ............................................................. 169

6.6 Un pari ..................................................................... 170

6.7 Une réflexion qui arrive à point......................................... 171

6.8 Hypothèse d'interprétation de la situation paroissiale actuelle ............ 173

6.8.1 Hypothèse de sens ................................................ 173

6.8.2 Hypothèse à vérifier..................................................... 173 


\section{II.2 DES CLÉS DE COMPRÉHENSION ÉCLAIRANTES}

CHAPITRE 7: HISTORIQUE DE LA PAROISSE: L'HISTOIRE D'UNE LENTE DÉGRADATION ................................... 174

7.1 L'absence de paroisses dans l'Église apostolique .............................. 175

7.1.1 L'origine du mot paroisse................................................... 175

7.1.2 Une ville, un diocèse (une paroisse), un évêque.......................... 177

7.2 L'origine de nos paroisses 'rurales': aux $\mathrm{III}^{\circ}$ et $\mathrm{IV}^{\circ}$ siècle................... 179

7.2.1 Une décentralisation de l'unique paroisse-diocèse au profit des campagnes

7.2.2 L'unité du presbytérium: une priorité

7.3 La "constitution" du système paroissial à l'époque mérovingienne:

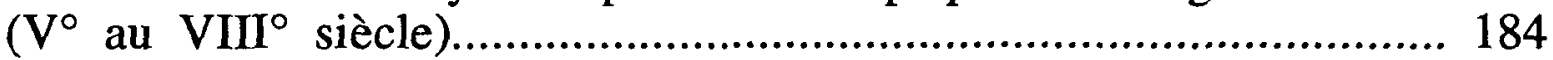

7.3.1 La fondation de nombreuses paroisses..................................... 184

7.3.2 Le patronage des grands propriétaires et de celui du saint............ 186

7.3.3 La création des paroisses: l'oeuvre des évêques.......................... 186

7.4 L'organisation de la paroisse à l'époque carolingienne.......................... 188

7.4.1 Une généralisation du régime paroissial ................................. 188

7.4.2 Les effets de la dîme sur l'institution paroissiale ....................... 190

7.5 Au Moyen Âge: la paroisse, une affaire de seigneurs! ....................... 191

7.5.1 La propriété privée d'un grand nombre de paroisses.................. 191

7.5.2 La paroisse est convoitée par les moines.................................... 194

7.6 La naissance des paroisses urbaines selon le modèle rural XI ${ }^{\circ} \mathrm{s}$. - XIII' ${ }^{\circ} \mathrm{s} 194$

7.6.1 L'envahissement du système rural en ville................................ 194

7.6.2 La paroisse: une "succursale" de l'Église ................................ 196

7.7 Les retombées' du Concile de Latran sur la paroisse (1215) ................ 198

7.7.1 L'obligation de se confesser à son curé et de faire ses Pâques dans sa paroisse .............................................................. 198

7.7.2 La naissance des fabriques ............................................... 198

7.7.3 Une querelle entre les séculiers et les religieux ......................... 199

7.8 "Canonisation" de la ruralisation des paroisses au Concile de Trente..... 200

7.8.1 L'obligation du morcellement du diocèse en paroisses ................ 200

7.8.2 Les motifs de la promotion du morcellement paroissial ............... 201

7.8.3 La fracture intervenue entre les catholiques et les protestants...... 202

7.9 XVII ${ }^{\circ}$ : L'influence "sulpicienne" sur l'institution paroissiale................ 204

7.9.1 Un modèle proposé: une vie commune pour les prêtres .............. 204

7.9.2 L'ampleur de la visite paroissiale , du régistre et du catéchisme... 205

7.9.3 Les retombées internationales d'une réforme........................... 206 
7.10 XVII's. - XIX ${ }^{\circ}$ s.: La poursuite de la multiplication des paroisses de type rural .......................................................................... 207

7.10.1 L'Église vit sur ses structures rurales ............................ 207

7.10.2 L'Église se tient sur ses gardes: centralisation et uniformité..... 208

7.10.3 Le problème de la pastorale paroissiale n'a jamais été aussi aigu................................................................. 209

7.10.4 Le code de 1917 décrète la paroisse territoriale.................. 211

7.11 La paroisse au Canada français ............................................... 212

7.11.1. Un contexte sociologique différent............................... 212

7.11 .2 L'Église-Nation....................................................... 214

7.11.3 La soudaineté des changements sociaux........................... 216

7.11.4 Une Révolution "tranquille" .......................................... 219

7.11.5 Une Église québécoise en recherche ............................. 221

7.12 Acquis de recherche éclairants.......................................... 224

7.12.1 Une "ruralisation" de la paroisse au cours des siècles ............. 224

7.12.2 La problématique de la paroisse urbaine toujours irrésolue...... 225

CHAPITRE 8: LE PHÉNOMÈNE DE L'URBANISATION ET SES CONSÉQUENCES SUR LA STRUCTURE PAROISSIALE

8.1 Un bref rappel historique............................................... 229

8.2 L'urbanisation, conséquence de l'industrialisation, bouleverse la société contemporaine....................................................... 231

8.2.1 L'urbanisation, un phénomène dynamique qualitatif et quantitatif d'organisation sociétale ................................................... 233

8.2.2 Urbanisation, urbanité, urbanisme................................ 234

8.2.3 L'urbanisation, un processus en trois étapes........................... 234

8.3 La mutation urbaine a ébranlé la "civilisation paroissiale" ............... 236

8.4 Le phénomène de l'industrialisation et de l'urbanisation au Québec...... 237

8.5 La paroisse québécoise marquée par le milieu rural ....................... 244

8.6 L'évolution du milieu rural au Québec ....................................... 246

8.7 La paroisse en contexte urbain............................................. 248

8.7.1 Différents types de villes ............................................. 249

8.7.2 Diversité des paroisses urbaines ................................... 249

8.7.3 L'intérêt du citadin dépasse les limites territoriales de la paroisse ............................................................. 250

8.7.4 La paroisse urbaine, plus une association qu'une communauté?... 251

8.7.5 La liberté, une valeur importante pour le citadin .................. 253

8.7.6 Une dévalorisation des relations de voisinage causée par la mobilité

8.7.7 La solution des Caisses populaires Desjardins: un exemple à suivre? 


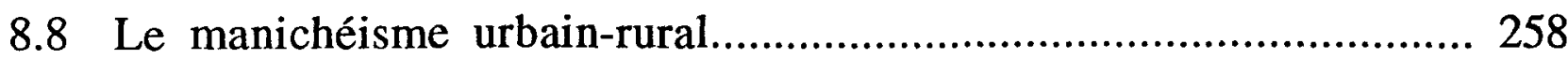

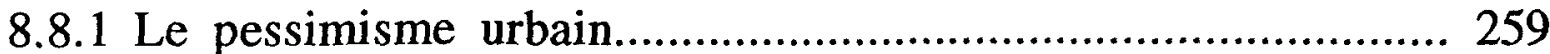

8.8.2 L'optimisme urbain ............................................................. 260

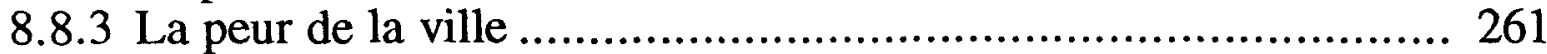

8.8.4 Notre Dieu: le Dieu de la campagne et de la ville ...................... 261

8.9 L'Église et l'urbanisation ............................................................ 263

8.9.1 Pie XII et "l'esprit de clocher"............................................. 263

8.9.2 Vatican II et sa clairvoyance ................................................... 264

8.9.3 La Conférence des évêques canadiens et son réalisme ................. 265

8.9.4 La vision pessimiste dans le document "Risquer l'Avenir"............ 266

8.9.5 L'analyse de quelques Église locales du Québec ........................ 266

8.9.6 Le catholicisme américain et sa réflexion sociologique ............... 271

8.9.7 L'urbanisation galopante en Amérique Latine........................... 273

8.10 Acquis de recherche éclairants................................................... 275

8.10.1 Les effets néfastes de la ruralisation des paroisses à l'ère contemporaine.............................................................. 275

8.10.2 Une remise en cause de la territorialité actuelle de la paroisse dans le contexte urbain ...................................................... 278

8.10.3 La dialectique institution-fonction........................................... 279

8.10.4 La structure pastorale souhaitée............................................ 280

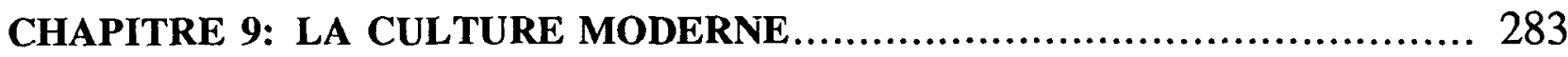

9.1 Caractéristiques de la modernité .................................................... 284

9.1.1 La révolution scientifique................................................. 286

9.1.2 La révolution politique......................................................... 287

9.1.3 La révolution culturelle........................................................ 288

9.1.4 La révolution industrielle .................................................... 289

9.1.5 L'explosion démographique et les communications de masse....... 291

9.1.6 L'avènement de l'individu ................................................... 292

9.1.7 La modernité et le temps ..................................................... 294

9.1.8 Peut-on parler de post-modernité?............................................ 295

9.2 Sécularisation et société moderne .................................................. 296

9.2.1 La sécularité, une dimension constitutive de la foi chrétienne...... 298

9.3 Le christianisme: la matrice de la modernité .................................... 299

9.4 L'Église catholique et la modernité: un mariage difficile!................... 301

9.4.1 Jean XXIII: le promoteur d'un dialogue entre l'Église et le monde moderne............................................................ 302

9.4.2 Â Vatican II, une confrontation profonde avec la modernité ....... 303

9.4.3 Une relation difficile entre Paul VI et la modernité.................... 306

9.4.4 La mode "post-conciliaire" est "au rétro"................................ 307 
9.4.5 Jean-Paul II, l'initiateur d'un nouveau divorce entre le catholicisme et la modernité? .......................................... 311

9.4.6 L'épiscopat québécois et la culture moderne........................ 314

9.5 Inculturer la foi: un dialogue toujours essentiel ......................... 317

9.5.1 Évangéliser, qu'est-ce-à-dire?..................................... 318

9.5.2 Le processus mystérieux de l'inculturation ......................... 319

9.6 Acquis de recherche éclairants.............................................. 323

9.6.1 Une Église appelée à mourir à "sa prétention" ........................ 323

9.6.2 Le rapport au monde de l'Église : une tâche permanente............. 325

CHAPITRE 10: LES RÉSEAUX D'INCARNATION DU CHRISTIANISME À L'ÉPOQUE DU NOUVEAU TESTAMENT.................... 331

10.1 La passion de Jésus: Le Règne de Dieu...................................... 333

10.2 L'Église et son origine................................................... 335

10.2.1 Aucune Église sans l'expérience pascale et le don de l'Esprit ... 336

10.2.2 La première communauté "chrétienne" naît grâce à un conflit.. 341

10.2.3 Les premiers chrétiens en ville ...................................... 342

10.2.4 La structure de base de la communauté: la maisonnée ............ 344

10.2.5 La communauté, une exigence de la foi personnelle............. 348

10.3 Le ministère dans le Nouveau Testament...................................... 351

10.3.1 Face à un nouveau besoin, les Douze font advenir une nouvelle structure ministérielle.................................. 351

10.3.2 La préoccupation de Paul: les besoins des communautés.......... 353

10.3.3 La place importante des femmes dans l'Évangile de Marc......... 358

10.3.4 L'option de Matthieu: "Tous frères et un seul Maître: le Christ" 360

10.3.5 Les Actes présentent la direction ecclésiale comme une grâce ... 363

10.3.6 Tous les croyants ont l'Esprit selon la tradition johannique...... 364

10.3.7 L'institutionalisation du ministère dans les Épîtres pastorales.... 366

10.3.8 Évolution du ministère à partir de l'édification de la communauté et non autour de l'eucharistie............................ 368

10.3.9 Le ministère et la période postapostolique.......................... 370

10.3.10 L'Église apostolique plus préoccupée des services que des styles de vie..................................................... 373

10.4 L'héritage légué par le Nouveau Testament: la liberté et l'audace....... 378

10.5 Acquis de recherche éclairants ........................................... 380

10.5.1 La paroisse, servante du Royaume au coeur du monde ........... 380

10.5.2 S'inspirer de la souplesse et de la malléabilité de l'organisation structurelle des premières communautés........................... 383 
CHAPITRE 11: FORCES ET LACUNES DE L'ECCLÉSIOLOGIE

11.1 La promotion de l'Église locale comme une Église-Sujet et de sujets... 391 11.1.1 L'acquis le plus déterminant........................................... 391 11.1.2 La revalorisation du sacerdoce baptismal.......................... 394

11.2 Une organisation structurelle juridique inadéquate à l'ecclésiologie conciliaire.......................................................................... 402

11.3 La théologie conciliaire du laïcat est lacunaire ............................. 408

11.3.1 Aux clercs l'Église, aux laïcs le monde.............................. 409

11.3.2 Un scandale évangélique: la place de la femme dans l'Église.... 414

11.4 Le prêtre, un frère (une soeur!) dans la foi .................................. 424

11.4.1 La théologie du presbytérat de Trente à Vatican II ................ 424

11.4.2 Le presbytérat, le service de la croissance de l'unité .............. 430

11.4.3 Une tentation du prêtre: se prendre pour la tête de l'Église....... 433

11.4.4 Une exigence du ministère ordonné: le décentrement .............434

11.4.5 Le prêtre, un capitaine d'équipe et un membre d'une ligue...... 437

11.4.6 Réflexion insuffisante sur le presbytérat ............................ 441

11.4.7 La crise d'identité du prêtre .......................................... 443

11.4.8 Le prêtre, un interprète dans son service de la Parole............ 446

11.4.9 Le prêtre, un "humoriste"............................................. 449

11.5 Acquis de recherche éclairants ........................................... 452

11.5.1 La plus belle ecclésiologie sans droit correspondant est une idéologie ...................................................... 452

11.5.2 Une nécessaire "dépapelisation" de l'Église ........................ 454

11.5.3 Un nouveau Concile: Vatican III et un Code renouvelé?.......... 458

CHAPITRE 12: L'APPROCHE CONCILIAIRE ET CANONIQUE DE LA PAROISSE ................................................ 460

12.1 La paroisse dans les Actes du Concile Vatican II.......................... 461

12.1.1 Une communauté locale, organisée sous un pasteur............... 461

12.1.2 Une "cellule" de l'Église ................................................. 464

12.1.3 La "communauté" paroissiale ........................................ 465

12.1.4 La grande oubliée à Vatican II: la paroisse.......................... 466

12.2 L'approche canonique de la paroisse........................................ 468

12.2.1 Les innovations canoniques ...................................... 468

12.2.2 Une conception juridique paroissiale toute centrée sur le curé... 473

12.2.3 Peut-on comparer le Code de 1983 et le Concile Vatican II?.... 476 
12.3 Acquis de recherche éclairants

12.3.1 La paroisse, une "cellule" véritablement atteinte du SCL

12.3.2 Les axes théologiques pour renouveler la paroisse selon

l'ecclésiologie de communion

12.3.3 Les possibles paroissiales actuelles porteuses d'avenir

CHAPITRE 13: UN NOUVEAU PARADIGME DE PÉgadogie PASTORALE

13.1. L'offre et la demande sacramentelle

13.1.1 Un écart grandissant entre le sens donné et cherché 496

13.1.2 L'importance d'"entretenir la foi". 498

13.2 Deux visions différentes concernant l'approche sacramentelle 501

13.2.1 Les nucléiques Vs les périphériques 502

13.2.2 Les puissants véhicules symboliques des sacrements 504

13.3 À la lumière de l'histoire:Hippolyte (235) et Calixte (222).............. 506

13.4 Les attitudes "pastorales" de Jésus................................................. 509

13.4.1 Jésus "converti" par la Cananéenne .................................... 509

13.4.2 La qualité du dialogue de Jésus .................................... 511

13.4.3 Le Seigneur part avec ce qu'il a en main.............................. 513

13.5 Une pédagogie axée sur l'accueil et une écoute "amoureuse" ............ 515

13.5.1 La vie, le lieu de la Révélation du Dieu Vivant..................... 516

13.5.2 Suivre le rythme de cheminement du paroissien ................. 518

13.5.3 Sortir de la forteresse "supérieure"................................. 520

13.5.4 Comprendre le langage de l'autre et non imposer le sien ......... 523

13.5.5 Le ritualisme ou une ritualité symbolique significative........... 528

13.6 Croissance humaine, croissance spirituelle.................................. 531

13.6.1 Le développement psychosocial de l'adulte........................... 532

13.6.2 L'insuffisance de la formation des intervenants pastoraux......... 536

13.7 Mourir à l'"idéologie" communautaire...................................... 539

13.7.1 Surgissement de différentes sortes de communautés.............. 540

13.7.2 Identité et identification chrétiennes "confondues" ................. 543

13.8 Acquis de recherche éclairants .............................................. 545

13.8.1 La paroisse, un lieu de "passage" pour le "tout-venant" ........... 546

13.8.2 La richesse des sacrements dans le catholicisme.................. 550 
TROISIÈME PARTIE: VERS UN RÉAMÉNAGEMENT DE LA PASTORALE PAROISSIALE EN MILIEU URBAIN

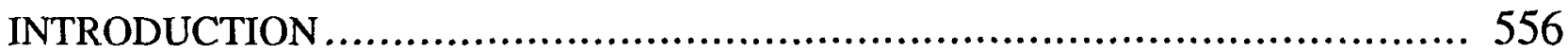

CHAPITRE 14: D'INCONTOURNABLES HORIZONS.................................. 559

14.1 La mission de la paroisse .............................................................. 559

14.1.1 La paroisse, une institution au service du Royaume de Dieu...... 560

14.1.2 La paroisse urbaine et la ville.............................................. 563

14.1.3 La paroisse urbaine et la liturgie.............................................. 565

14.1.4 Quatre dimensions de la vie communautaire se compénétrant.... 568

14.2 Une pédagogie pastorale construisant la "catholicité"........................ 569

14.2.1 Une paroisse de type "multitudiniste" .................................. 571

14.3 Une réorganisation ministérielle................................................. 573

14.3.1 Des acquis ecclésiologiques actuels à retenir et à perpétuer....... 574

14.3.1.1 Soutenir le "membership" .................................... 574

14.3.1.2 Encourager l'engagement des agents pastoraux et limplication des diacres permanents..................... 576

14.3.1.3 Gérer avec sagesse les ressources presbytérales .......... 578

14.3.1.4 Privilégier la structure de l'équipe pastorale .............. 581

14.3.1.5 Être audacieux dans la création de nouveaux ministères....................................................... 584

14.3.2 Une question capitale: celle du pouvoir en Église...................... 585

14.3.3 Suggestions concrètes ...................................................... 588

14.3.3.1 La gestion des ressources humaines au niveau diocésain .................................................... 588

14.3.3.2 Conditions de salaire et de travail pour les différents ministres......................................................... 589

14.3.3.3 Un Conseil des ministres..................................... 590

CHAPITRE 15: LES AVENUES PRATIQUES........................................ 591

15.1 Une priorité: une structure ecclésiale épousant le milieu

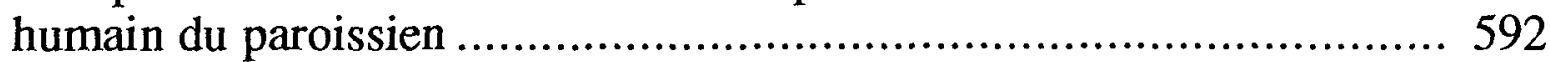

15.2 Différentes structures pastorales possibles ..................................... 598 15.2.1 La ville, une fédération de paroisses................................... 599 
15.2.2 La paroisse-ville, une fédération de communautés ...............6 602

15.2.2.1 La nécessité d'une analyse sociologique de la ville ...... 606

15.2.2.2 Un réseau de communautés diversifiées .................. 607

15.2.2.3 Un réaménagement ministériel dans une paroisse-ville 611

15.2.2.4 La ville et les lieux de culte............................... 614

15.2.3 La zone (région) pastorale avec de réels pouvoirs juridiques ... 616

15.3 Que sera l'Église à l'an 2000? ............................................... 619

15.4 Sur une note d'espérance .............................................. 621

CONCLUSION - INTÉGRATION .............................................. 623

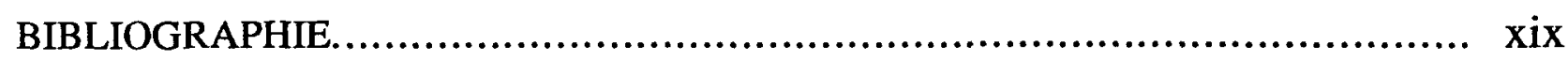




\section{LISTE DES SIGLES ET ABRÉVIATIONS}

Dans cette thèse, les abréviations utilisées pour la désignation des périodiques sont tirées de l'ouvrage de S. SCHWERTNER, Index international des abréviations pour la théologie et les matières affinissantes, New York, Walter de Gruyter, 1974, 348p.

Les abréviations suivantes sont également employées:

$L G$ : Constitution dogmatique Lumen Gentium

GS : Constitution pastorale Gaudium et Spes

SL: Constitution Sacra Liturgia

$A G$ : Décret Ad Gentes

AA : Décret Apostolicam Actuositatem

$C D$ : Décret Christus Dominus

$P O$ : Décret Presbyterorum Ordinis

Sigles:

- /.../ : dans une citation, changement de paragraphe

- LG 2,3 (exemple): Lumen Gentium, paragraphe 2, alinéa 3.

N.B.: - Sur le plan rhétorique, plutôt que d'uniformiser le texte en choisissant d'employer partout un "nous" qui prend des allures tantôt solennelles, tantôt formelles ou un "je" qui risque parfois d'être déplacé, "je-nous" avons préféré parler en faisant appel à l'un et à l'autre, selon que les propos tenus relevaient de l'opinion ou du jugement personnel ou qu'ils devenaient plus généraux ou plus pédagogiques. Par ailleurs, j'ai voulu éviter un niveau de langage trop hermétique sans pour autant céder à la vulgarisation facile. 


\section{REMERCIEMENTS}

Je voudrais remercier de tout coeur quelques personnes et certaines communautés ecclésiales qui ont contribué de façon particulière à la réalisation de cette thèse de doctorat. Je désire remercier premièrement les paroissiens et les intervenants pastoraux (bénévoles et permanents) des paroisses de Saint-Jean-l'Évangéliste de Bégin, de Saint-Dominique de Jonquière, de Saint-Léon et de Saint-Jude d'Alma pour leur précieuse collaboration. Ce travail de recherche-action a pu être réalisé parce que

ces femmes et ces hommes ont bien voulu ouvrir la porte de leur coeur pour me partager leurs joies et leurs souffrances de baptisés. J'aimerais aussi dire un merci spécial aux deux directeurs de recherche Simon DUFOUR et Rémi PARENT qui m'ont accompagné tout au long de ce parcours. Je me trouve privilégié d'avoir été supervisé par eux. J'ai grandement apprécié leur encouragement constant et la qualité de leur compétence professionnelle. J'ai été touché à plusieurs reprises de leurs délicates attentions à mon égard. Je remercie aussi Albert LEMAY et Jacques TELLIER pour la correction du français de mes premières épreuves et surtout Simone VOISINE, professeure en linguistique, qui a lu et relu chaque phrase de la présente thèse. Je termine en remerciant également tous ceux et celles qui m'ont soutenu "moralement" dans mes efforts pour passer à travers cet énorme défi. Je pense spécialement aux membres de ma famille, aux nombreux soeurs et frères dans la foi de mon Église locale, à quelques amis "fidèles", à certains confrères du presbytérium de Chicoutimi (particulièrement ceux du groupe des jeunes prêtres "Hibou") et à la famille élargie du Grand Séminaire de Chicoutimi, aux membres de la communauté dominicaine Saint-Jean de Montréal avec qui j'ai demeuré pendant deux ans et à ceux de la communauté du Grand Séminaire de Québec où j'ai habité quelques mois, aux professeurs du département des sciences religieuses de l'UQAC et de la Faculté de théologie de l'Université de Montréal. Je suis content d'avoir fait le choix de poursuivre 
mes études de troisième cycle au Québec. Mes quelques brefs séjours à l'étranger m'ont confirmé davantage dans mon choix. Nous n'avons pas à être complexés par rapport au "niveau" des études supérieures offertes dans les universités québécoises.

Durant cette "grossesse" doctorale, j'ai pu découvrir plus profondément qu'il est possible d"'accoucher" d'une thèse uniquement s'il y a des "sages-femmes" et des "sages-hommes" présents autour de soi au coeur des contractions, des provocations, des risques d'avortement et de l'émerveillement à chaque naissance nouvelle de la pensée. Seul dans la vie, on meurt. La vie n'a un sens que si nous sommes aimés et soutenus. Vive la communion fraternelle... J'aimerais écrire quelques lignes de remerciement pour le Dieu Vivant. Les autorités diocésaines de Chicoutimi m'avaient demandé de revenir aux études afin de pouvoir assumer dans les prochaines années des responsabilités au niveau de la formation de différents intervenants pastoraux. J'ai accepté en étant incertain de moi mais sûr de Lui. Je n'ai pas été déçu. Au contraire, à travers ces longues heures et ces longs mois de silence et de solitude, j'ai été à maintes reprises surpris de sa tendresse amoureuse et de sa sollicitude fidèle. Je rends grâce à ce Dieu discret qui nous demande d'être aux aguets pour être surpris de ses bienfaits! Que l'Homme de Galilée qui nous a révélé la profondeur de son amour nous accompagne de son Esprit pour que nous soyons courageux et inventifs dans les chemins de la révélation de cette incroyable nouvelle que nous sommes éternellement aimés. En cela réside sans doute le secret d'une énergie spirituelle capable d'aider l'humanité à relever les défis qu'il nous incombe d'assumer pour que celle-ci soit davantage juste et fraternelle. 


\section{INTRODUCTION}

Est-il possible qu'en notre temps, un jeune théologien puisse encore s'intéresser à un "vieux" sujet tel celui de la paroisse? Les défis de la pastorale paroissiale en milieu urbain sont-ils suffisamment importants et sérieux pour qu'on leur consacre une thèse de doctorat? Quelle est pour les chrétiens d'aujourd'hui la signification de la paroisse? Cette institution ecclésiale est confrontée aux attitudes les plus diverses: indifférence chez les uns, agressivité chez d'autres, enthousiasme chez quelques-uns, diagnostic de mort prochaine chez quelques autres, etc. Également, on ne retrouve chez à peu près personne la même conception ni les mêmes attentes face à la paroisse. Certains liidentifient à un lieu de culte et de services. Pour d'autres, parler de la paroisse, c'est parler des prêtres, de l'église, du presbytère, de la salle paroissiale. Plusieurs pensent à un territoire délimité où résident tant de familles, où sont célébrés un nombre déterminé de baptêmes et de mariages. D'autres parlent de communauté chrétienne pour l'ensemble d'un territoire ou encore en fonction des chrétiens participant aux assemblées dominicales. Quelques-uns ne savent plus trop ce que vient faire la paroisse dans le contexte d'aujourd'hui. Certains enfin sont portés à chercher l'avenir de l'Église en misant massivement sur les communautés de base d'origine latino-américaine. Je crois qu'en pastorale comme en économie, l'importation ne peut fournir une base durable à long terme pour renouveler la dynamique ecclésiale dans le contexte québécois.

Parler de la paroisse est toujours une tâche difficile. Devant une publication sur le sujet, surgit immédiatement une question: s'agit-il d'un plaidoyer ou d'un réquisitoire? J'aimerais dans la présente thèse de doctorat intitulée: "La pastorale en milieu urbain et le devenir de la paroisse au Saguenay-Lac-Saint-Jean", répondre à 
cette question, non sans quelques ambitions, en refusant le piège du 'pour ou contre', c'est-à-dire en essayant de défricher des sentiers qui pourraient conduire vers des horizons pastoraux nouveaux. Pour tenter pareille démarche, il faudra avant tout prendre acte d'un phénomène qui mérite d'être observé et que j'appellerai la résistance paroissiale. Depuis plus de trente ans, on annonce la mort de cette institution. Et pourtant, en 1994, elle dure encore! Comme bien d'autres, je suis conscient des lourdeurs et des lenteurs en paroisse. Mais il faut bien se dire qu'on ne change pas une institution du jour au lendemain, surtout lorsque celle-ci demeure la principale unité de base des chrétiens. Présentement, dans cette institution qu'est la paroisse, on retrouve des valeurs à conserver, des efforts à soutenir, des structures à faire éclater, des initiatives à encourager, des projets à promouvoir.

Cette thèse de doctorat sera divisée en trois parties et elle comportera quinze chapitres. Je compléterai chacun des chapitres de la deuxième partie par quelques acquis de recherche éclairants. L'observation systématique sur un terrain bien précis étant l'étape initiale de la méthode en praxéologie pastorale constituera la première partie de cette thèse (chapitre un à cinq: regard sur le terrain). J'expliquerai les choix méthodologiques au chapitre premier. Je montrerai tout d'abord la complémentarité des méthodes de recherche qualitative et quantitative. Je réfléchirai par la suite sur l'importance de respecter davantage la circularité dialectique de la méthode praxéologique. Une manière de faire théologie peut rendre "malade". Je prendrai donc quelques lignes pour donner des conditions aidantes afin que le chercheur puisse demeurer bien vivant au cours de ces "sérieuses" recherches théologiques. J'expliquerai également les raisons qui m'ont poussé à choisir l'option de la "théologie pratique". Je terminerai ce premier chapitre en clarifiant le fait que cette thèse de doctorat est davantage une problématique d'ensemble sur la pastorale en milieu urbain et le devenir de la paroisse que l'approfondissement d'une seule composante. Je 
prendrai le risque de considérer la paroisse comme un réseau complexe d'interrelations selon une perspective systémique laquelle est une manière nouvelle et différente d'approcher le réel. C'est dans ce paradigme systémique que se situera la présente recherche. L'approche systémique vise à perdre sur les détails et la précision causale pour gagner sur la globalité. Le chapitre deuxième décrira les milieux d'observation, quatre paroisses du diocèse de Chicoutimi: Saint-Jean-l'Évangéliste de Bégin, SaintDominique de Jonquière, Saint-Léon et Saint-Jude d'Alma. La première ressource d'une paroisse, avant ses permanents et ses ministres, c'est le peuple des croyants et des croyantes qui peinent, aiment, construisent, chantent, pleurent, espèrent, prient. Cependant, la plupart des recherches récentes sur la paroisse s'en tiennent quasi uniquement au fonctionnement et à l'évaluation des activités et des services paroissiaux. Elles partent de questions internes, à savoir celles des gens engagés dans les communautés paroissiales et non d'une observation de la situation actuelle des paroissiens sur leur terrain réel. Je consacrerai aux paroissiens "périphériques" et "nucléiques" la priorité dans la description des données d'observation. Leur point de vue constituera ainsi le chapitre troisième. Phénomène marquant depuis plus de trente ans: de nombreux croyants, femmes et hommes, participent à la vie et à la mission de l'Église. Voilà un point positif qu'il faut enregistrer: l'engagement de nombreuses personnes dans les paroisses. C'est à dessein que dans le chapitre quatrième, je poursuivrai la description des données d'observation recueillies auprès de ces chrétiens engagés tant il est vrai que la vitalité d'une Église ne se calcule pas d'abord au nombre de permanents à son service mais à l'engagement de ses membres. Même si les bénévoles constituent des ressources précieuses pour le dynamisme d'une paroisse, cette institution ecclésiale a besoin de "ministres permanents" engagés à son service: le chapitre cinquième leur sera consacré. 
La démarche méthodologique proposée en praxéologie pastorale prévoit une étape de problématisation de la situation observée (essai de modélisation). Elle constituera le contenu du chapitre sixième (la première section de la deuxième partie de la thèse: Herméneutique du temps présent et de la Tradition). Grâce à diverses notions empruntées au monde des sciences humaines, à certains champs de la théologie et fort d'un recul établi avec l'expérience acquise, je parviendrai à résumer en des propositions les résultats fournis par la recherche-action. La lecture de l'ensemble des données d'observation recueillies nous amènera à croire qu'en Église, nous ne connaissons pas véritablement les paroissiens d'aujourd'hui ni leurs déplacements:ils sont ailleurs et autrement. De plus, au lieu de chercher à comprendre les déplacements des paroissiens, l'Église institutionnelle est davantage préoccupée de dénoncer les valeurs modernes qu'ils portent en eux. Également, le territoire de la paroisse n'est plus représentatif, surtout dans le milieu urbain. Le phénomène de l'urbanisation a profondément marqué les assises de la vie paroissiale, particulièrement dans les villes. Mais la paroisse urbaine est restée "à l'heure de la campagne". Les paroisses actuelles sont devenues davantage des enclos territoriaux au lieu de devenir des réseaux de communautés diversifiées. Il n'y pas seulement le phénomène de l'urbanisation qui remet en question la vie paroissiale et sa structure. Vatican II a opéré un grand tournant dans la vie ecclésiale pour amener les baptisés à devenir des sujets chrétiennement plus libres et responsables. Mais ce tournant s'avère long et laborieux puisque l'ecclésiologie de communion dont Lumen Gentium a posé les assises n'a pas été traduite en une organisation juridique adéquate. Pour accéder au renouveau, des changements institutionnels ne seraient-ils pas nécessaires afin de susciter des chrétiens-sujets et des Églises-sujets, sans lesquels aucun changement paroissial véritable n'est possible? Le dialogue entre les paroissiens et les intervenants pastoraux fait problème. Un écart grandissant s'établit entre le sens cherché et le sens donné lors des demandes de service. Nous sommes confrontés ici à la fidèle opposition 
historique entre des intervenants pastoraux assoiffés d'une Église idéale (Église de type "confessante") et d'autres plus soucieux de bâtir une Église accueillante au toutvenant (Église de type "multutidiniste"). Une seule conception de la communauté semble meubler l'imaginaire de bien des acteurs en pastorale. Des changements institutionnels sont certes essentiels pour renouveler la pastorale en milieu urbain mais ils ne suffisent pas. Ne faudrait-il pas proposer un nouveau paradigme de pédagogie pastorale? Finalement, la paroisse est toujours confrontée entre vouloir assurer sa survie ou promouvoir sa mission au service de l'avènement du Royaume de Dieu. Globalement, j'en arriverai à me demander plus précisément comme hypothèse à vérifier si les orientations fondamentales de l'ecclésiologie conciliaire de Vatican II (la synodalité de l'Église, la dimension communautaire plus affirmée, le renouvellement des ministères, l'explicitation de la mission de l'Église) ne seraient pas une manière de répondre aux défis du phénomène de l'urbanisation et de la modernité? De plus, je me questionnerai à savoir si la ressaisie de la mission de l'Église, en particulier celle de la paroisse, comme service du Royaume dans la croissance des personnes et le devenir des collectivités, ne conduirait pas aussi à une remise en question en profondeur des pédagogies pastorales d'accompagnement de la foi. L'Église doit réviser ses aménagements sociaux et institutionnels ainsi que ses pédagogies. Une théologie plus élaborée sur la paroisse s'impose ainsi d'urgence puisqu'elle a été la plus oubliée à Vatican II par les Pères conciliaires et depuis ce concile, par les théologiens. Depuis plus d'une trentaine années, on n'avait presque rien écrit sur l'institution paroissiale. En une seule année, celle de 1992, quatre études québécoises sur la paroisse ont été publiées. Cependant, aucune étude englobant les différentes problématiques de la pastorale en milieu urbain et le devenir de la paroisse n'a été faite. C'est à l'avènement de ce chantier que je désire apporter une modeste contribution dans la présente thèse. L'originalité de celle-ci doit être recherchée dans l'interaction elle-même des diverses composantes. 
Les chapitres sept à treize feront une relecture de mes défis pastoraux explorés à partir de quelques disciplines des sciences humaines et de certaines pratiques de la Tradition chrétienne (partie II.2: des clés de compréhension éclairantes). C'est la partie de la thèse que je développerai davantage. Elle me permettra de vérifier mon hypothèse de sens. Avant d'analyser l'évolution historique de la paroisse canadienne-française, je replacerai cette institution dans l'ensemble de l'histoire de l'Église au chapitre septième pour y découvrir une forme de "ruralisation" de la paroisse en contexte urbain qui s'est propagée au cours des siècles jusqu'à aujourd'hui. Le monde industriel et urbain a transformé l'environnement dans lequel s'insère l'institution ecclésiale. Cette évolution n'est pas sans incidence sur le rôle de la paroisse. La révolution industrielle et l'urbanisation qui s'en est suivie ont amené des bouleversements profonds et durables dans la société. Le chapitre huitième se proposera d'analyser plus en profondeur le phénomène de l'urbanisation et ses conséquences sur la structure paroissiale. Nous disons que les paroissiens ont été influencés par les valeurs de la modernité. Mais qu'est-ce que la modernité? Le chapitre neuf montrera que l'être humain et le monde sont devenus modernes à l'issue de quatre révolutions majeures (scientifique, politique, culturelle, industrielle). Mais la modernité n'est pas seulement la réalité des bouleversements techniques, scientifiques et politiques depuis le $\mathrm{XVI}^{\circ}$ siècle, elle est aussi le jeu des signes, des moeurs et de la culture qui traduit ces changements de structure au niveau du rituel et de l'habitus social. L'arrivée de la modernité s'est accompagnée d'un phénomène de sécularisation. J'essayerai de démontrer par la suite à quel point le terme sécularité appliqué à la foi désigne une caractéristique fondamentale de la foi chrétienne. Il nous arrive souvent d'opposer christianisme et modernité. Un regard plus profond montre que les caractéristiques de la modernité ont trouvé dans la foi chrétienne une matrice sans laquelle elles seraient peu intelligibles. Cependant, le "mariage" entre le catholicisme et la modernité a toujours été difficile. Ce chapitre tâchera d'analyser l'évolution du 
rapport entre l'Église catholique et la société moderne, particulièrement durant la période du concile Vatican II et de la décade qui a suivi. Derrière le débat de l'acceptation ou non du paroissien "moderne" en lui-même, se joue l'enjeu fondamental du rapport entre l'Église et le monde. Cette partie interprétative sur la modernité se terminera par l'énumération de quelques conditions à respecter pour que le débat entre l'Église et la société moderne soit fécond évangéliquement. Les responsabilités pastorales sont tellement nombreuses en paroisse qu'il nous arrive souvent d'oublier le but de notre travail. Dans ces circonstances, il sera à propos de nous rappeler ce qu'a été la passion de Jésus: l'avènement du Règne de Dieu. La situation actuelle des paroisses exige aussi de faire advenir de plus en plus de ministères nouveaux. Toutefois, la version officielle de l'Église concernant cette problématique ne nous aide guère à la créativité mais elle favorise plutôt le statu quo. Pour sortir de ce cul-de-sac, il sera essentiel de retourner consulter les textes $\mathrm{du}$ Nouveau Testament pour analyser plus profondément l'héritage que les premières communautés chrétiennes ont légué à l'Église dans la manière d'organiser leur vie fraternelle. Le chapitre dixième tentera alors de montrer qu'à chaque étape de leur développement, les communautés ont été confrontées à de nouveaux besoins. C'est en fonction de ces besoins qu'elles ont créé des structures et des ministères, tandis que d'autres ont disparu parce qu'ils ne correspondaient plus à la situation nouvelle. Ces premières communautés croyantes ne nous inviteront-elles pas à plus d'audace dans la manière de renouveler l'organisation institutionnelle de l'Église, particulièrement en ce qui concerne nos paroisses actuelles? Le chapitre onzième permettra de réfléchir plus spécifiquement sur les forces et les lacunes ecclésiologiques du Concile Vatican II. La nouvelle conception de l'Église diocésaine et la revalorisation du sacerdoce baptismal constituent un grand tournant en ecclésiologie, qualifié même par bien des théologiens de "révolution copernicienne". Toutefois, une analyse critique de plusieurs décrets conciliaires met en lumière des lacunes sérieuses concernant la théologie du laïcat, du 
presbytérat et de l'institution paroissiale. Plusieurs lignes de ce chapitre seront consacrées à démontrer que l'ecclésiologie de communion dont Lumen Gentium a posé les assises au Concile n'a pas été traduite en une organisation structurelle juridique adéquate. Même si les Pères conciliaires n'ont pas beaucoup réfléchi sur l'institution paroissiale, le chapitre douzième cherchera à connaître quelle a été la conception de la paroisse à Vatican II. La paroisse est le cadre dans lequel les chrétiens rencontrent l'Église et c'est aussi le cadre à travers lequel la majorité des ministres ordonnés, reconnus et mandatés exercent leur action pastorale. Le pape Jean XXIII, avant le début des travaux conciliaires, avait déclaré que le prochain concile devait se concentrer avant tout sur la paroisse. Mais les Pères conciliaires ont privilégié la réflexion sur l'Église diocésaine. Ceci explique pourquoi la paroisse a été définie comme une "cellule" du diocèse. Il sera également important de considérer dans la deuxième partie du chapitre douzième les innovations canoniques touchant la paroisse dans le Code de 1983. Nous constaterons une fois de plus que le Nouveau Code est encore actuellement plus un frein qu'un accélérateur dans l'Église. L'analyse de l'approche canonique de la paroisse prouve d'une manière plus explicite à quel point les orientations ecclésiologiques de Vatican II n'ont pas véritablement trouvé une traduction juridique opérationnelle au niveau organisationnel, même dans ce nouveau Code publié presque vingt ans après ce Concile. Ce chapitre se terminera par la validation d'une partie de mon hypothèse de recherche: la paroisse est réellement une "cellule" de l'Église locale atteinte, comme tout l'organisme ecclésial, par le syndrome clerc-laiic ("SCL"). Je compléterai celui-ci en donnant certains axes théologiques pour renouveler la paroisse selon l'ecclésiologie de communion et en nommant les possibilités paroissiales actuelles porteuses d'avenir. Il nous arrive souvent d'entendre de la bouche de plusieurs intervenants pastoraux que l'Église est trop investie dans les tâches de sacramentalisation et que ce fait paralyse sa présence au monde et le plein accomplissement de sa mission. Ce diagnostic un peu court relève davantage d'un 
slogan facile que d'une réflexion à partir de la réalité. Des années d'expériences pastorales m'ont fait découvrir que la sacramentalisation pouvait être un lieu propice d'évangélisation selon la qualité du dialogue entre les intervenants pastoraux et les paroissiens et la qualité de la célébration. Dans le chapitre treizième, je réfléchirai sur quelques enjeux concernant la pédagogie pastorale en paroisse. Nous savons que la dimension spirituelle est située au sein de multiples dimensions de la personne. Il existe un lien étroit entre le développement humain et celui de la foi. Ce lien me motivera à consulter certaines études sur le développement psychosocial de l'adulte selon la perspective du cycle de vie avec ses périodes de transition, de changement et de crise. Je terminerai ce chapitre en réfléchissant sur des malentendus à dissiper concernant la conception de la communauté et celle de l'identité chrétienne. Enfin, j'inviterai les intervenants pastoraux à concevoir positivement la paroisse comme un lieu de "passage" pour le "tout-venant" et à considérer les demandes sacramentelles et les services offerts comme des "haltes de grâce" pour les paroissiens et les "accueillants". Mais un nouveau paradigme de pédagogie pastorale devra être suggéré pour que ceci se réalise davantage.

La méthode praxéologique est essentiellement un mode épistémologique axé sur une dialectique organique entre l'action à effectuer dans le milieu observé et la réflexion théorique aux plans phénoménologique et théologique. La dernière facette de cette démarche vise à dégager l'horizon de la pratique et à en articuler la prévision et la vision. C'est ce que j'essayerai de faire dans la troisième partie de cette thèse intitulée "Vers un réaménagement de la pastorale paroisiale en milieu urbain". Celle-ci constituera ainsi une synthèse pratique dégageant les conséquences concrètes pour l'agir pastoral des univers de sens auxquelles nous auront ouvert préalablement les outils théoriques de compréhension des défis observés. La critique est facile. Il est plus difficile de construire. La théologie ne peut plus se contenter de se déployer dans un 
ciel lointain et, de ce fait, serein. Elle doit aussi prendre des risques. La théologie pratique, la théologie contextuelle, la praxéologie pastorale nous poussent à aller dans ce sens. Ces manières de "faire théologie" prennent le risque d'un discours théologique répondant aux questions profondes posées par la pratique des personnes et des communautés pleinement insérées dans une culture particulière. La troisième partie de cette thèse sera de plus un moyen privilégié pour militer en faveur de l'émergence d'une ecclésiologie contextuelle (empirique) qui soit en liaison avec la réalité théologique, historique, pastorale, spirituelle et juridique de l'Église en un lieu. La réflexion sur la mission de la paroisse dans le contexte d'aujourd'hui constituera la première section du chapitre quatorzième. La paroisse n'a aucune raison d'exister si elle ne se vit pas comme servante du Royaume de Dieu. Pour réaliser cette mission, cette institution ecclésiale doit demeurer ouverte à tous et au service de tous. Je nommerai dans la seconde partie de ce chapitre des acquis ecclésiologiques actuels à retenir pour une réorganisation ministérielle dans le contexte urbain. Je soulignerai ainsi les domaines où les mentalités ont évolué au cours des dernières années favorisant l'acquisition progressive d'un certain nombre de convictions sur lesquelles nous pouvons nous appuyer pour vivre le présent et dont nous devons nous inspirer pour véritablement risquer l'avenir de la paroisse et de l'Église. Ce chapitre sera complété par des suggestions pratiques concernant la gestion des ressources pastorales dans une Église locale. Le chapitre quinzième sera divisé en quatre parties. Je montrerai premièrement l'importance de structurer la pastorale paroissiale en tenant compte du milieu naturel du paroissien et de sa manière d'être dans le contexte moderne d'aujourd'hui. J'analyserai ensuite trois manières différentes d'aménager la paroisse dans un contexte urbain tel celui de la région du Saguenay-Lac-Saint-Jean : -la ville comme fédération de paroisses, -la paroisse-ville (ou super-paroisse) comme fédération de communautés, -un renforcement de la zone (région) pastorale avec de réels pouvoirs juridiques. Je proposerai de terminer cette thèse sur une note 
d'espérance et en faisant un bilan de l'impact de l'ensemble de la démarche doctorale sur le "chercheur-acteur" que j'aspire à être d'une manière permanente. 


\section{PREMIÈRE PARTIE}

\section{REGARD SUR LE TERRAIN}


"Le moteur de la découverte
se trouve dans la passion du terrain!"(BERTAUX)

Dans la première partie de cette thèse qui constitue une synthèse des données d'observation, j'aurais pu proposer certaines "photos aériennes" de la paroisse, prises de très haut et d'incontestable valeur. Mais, il m'a semblé que cela ne pouvait absolument pas remplacer l'exploration du terrain paroissial "au ras du sol". L'écoute du terrain avec son vécu, son expérience et sa compétence apparaît donc comme un fondement de la pratique pastorale comme de la praxéologie. La pratique, lieu de responsabilité directe de l'agent, constitue le lieu réel, fondateur de la praxéologie. Le "pays réel" de l'intervenant pastoral aussi bien que celui des humains. C'est bien sûr leur société et leur culture, mais c'est aussi et d'abord leur pratique quotidienne, familiale, professionnelle et celle de leur communauté. Cette étape "d'écoute active" vise à dégager et analyser les éléments-clefs, déterminants de la pratique, à en identifier les forces et les faiblesses, à trouver "les mots pour le dire". Je commencerai tout d'abord au chapitre premier par expliquer les choix méthodologiques de cette recherche. Je décrirai par la suite au chapitre deuxième les quatre paroisses du diocèse de Chicoutimi où j'ai fait ma recherche-action. J'ai écouté attentivement le vécu des paroissiens. Le chapitre troisième résumera leurs différents points de vue sur la paroisse. Je poursuivrai la description des données d'observation en racontant l'expérience de quelques bénévoles oeuvrant sur le terrain paroissial. Je terminerai l'observation systématique en donnant la parole aux permanents ecclésiaux. Un résumé de leurs propos se retrouvera au chapitre cinquième. 


\section{CHAPITRE 1}

\section{LES CHOIX MÉTHODOLOGIQUES}

\subsection{La complémentarité des méthodologies qualitative et quantitative}

Une des étapes les plus importantes dans une recherche scientifique est celle de l'observation. ${ }^{1}$ Le "voir" oriente l'ensemble de la démarche. Le "savoir regarder" est un art. C'est pour cette raison que si nous voulons approfondir notre regard et mieux appréhender le réel nous devons maîtriser certaines méthodes d'observation systématique. Les sciences humaines nous en offrent deux types: les méthodes quantitative et qualitative. Il va sans dire que le paradigme de recherche joue un rôle important pour définir le cadre particulier suivant qu'il s'agit d'un paradigme de recherche qualitative centré sur le processus ou de la recherche quantitative qui porte davantage sur les résultats. Encore aujourd'hui, la méthode qualitative ou la méthode quantitative est privilégiée ou critiquée par les chercheurs. ${ }^{2}$ Lorsque le chercheur s'interroge sur la méthode de la recherche, son questionnement doit se situer non pas sur la seule dimension méthodologique mais sur les dimensions épistémologiques et

1

"L'observation est une étape importante du processus de recherche. Elle consiste à recueillir de l'information sur un objet pris en considération. Elle peut être un processus ou un résultat selon le paradigme dans lequel se situe l'objet de la recherche" (THERIAULT, Jacqueline, L'observation dans la recherche en éducation, Actes du Colloque tenu le 6 avril 1990 dans le cadre des programmes de Maîtrise et de doctorat en éducation, UQAC, Département des Sciences de I'Éducation, Printemps 1991, volume 1, p.4). Pour les sciences de l'humain, observer est construire une signification pour éclairer une situation, un rapport entre les personnes, mais nullement pour prédire, généraliser ou établir des lois. Cette nouvelle option épistémologique s'opppose radicalement au positivisme et s'appuie sur de nouveaux postulats métaphysiques, méthodologiques et sociaux. 2

On peut regretter la désaffection de l'ensemble des méthodologies qualitatives durant les années '50 et ' 60 . Ces années furent l'âge d'or de la sociologie néo-positiviste. Les événements de mai '68 en France et tous les mouvements américains de contestation de l'ordre établi ont paradoxalement ranimé l'intérêt des chercheurs pour les méthodes qualitatives. 
théoriques de cette méthodologie, puisque la façon de poser le problème de la connaissance est à l'origine même de la façon d'envisager les moyens techniques à utiliser pour recueillir des informations adéquates et pertinentes à l'objet de recherche. Le choix d'une méthodologie particulière pour la cueillette des données d'observation est toujours tributaire des dimensions épistémologiques et théoriques plus larges.

Pour ma part, tout en ayant utilisé quelque fois la méthodologie quantitative dans la recherche-action effectuée, j'ai privilégié la méthodologie qualitative pour observer le milieu paroissial et recueillir les données d'observation qui s'en dégageaient. Cette méthode d'observation s'intégrait mieux à la dynamique de la pratique que je voulais comprendre. ${ }^{3}$ Dans les prochains paragraphes, j'aimerais exprimer certains motifs qui m'ont poussé à privilégier cette méthode de recherche. Je trouve important de le faire puisque, encore de nos jours, certains critiques considèrent que la méthodologie qualitative ne peut répondre aux exigences de la recherche scientifique. Cependant, mon propos n'aura pas comme objectif de créer une polémique méthodologique. De toute façon, nous savons que l'oppposition entre recherche qualitative et recherche quantitative est toujours trompeuse car ces deux méthodes de recherche sont complémentaires plutôt qu'opposées. 4

3 Jean-Guy NADEAU a déjà établi la pertinence de la méthodologie qualitative en particulier dans une recherche praxéologique. Voir NADEAU, Jean-Guy ,"Pour l'observation praxéologique d'une pratique pastorale", in Sciences pastorales , \#3, 1984, pp.119-130.

4 J'ai participé à la conférence du théologien néerlandais Johannes A. VAN DER VEN qu'il a donnée aux professeurs de la section des études pastorales de l'Université de Montréal . Dans cette conférence, il a essayé de prouver cette hypothèse: "A hypothesis: the complementarity of quantitative and qualitative research in practical theology" (A. VAN DER VAN, Johannes, "The empirical approach in practical theology: why and How?", Nijmegen University - The Netherlands, Lecture at Montreal University, February 12, 1993, p.1). Selon lui, les deux méthodes aident à confirmer ou à falsifier les hypothèses de recherche. "...les attributs quantitatifs et qualitatifs ne sont pas par nature dichotomiques, mais s'étalent plutôt sur un continuum . I.../ La confrontation de l'approche quantitative et qualitative en analyse de contenu fait ressortir le dilemme méthodologique posé aux chercheurs /.../ Pour Holsti, les deux approches de l'analyse de contenu se complètent" (DESMARAIS, Danielle, Trajectoire professionnelle et expérience du chomâge ouvrier des récits 
Cinq motifs m'ont incité à privilégier la méthodologie qualitative dans cette recherche doctorale. En premier lieu, cette méthode n'abaisse pas à l'état de sociologie de l'insignifiance ou du trivial l'étude des situations banales d'interaction, des ritualisations du quotidien, des petits univers privés, des manières de dire et de faire.

"Le regain d'intérêt que connaissent des problématiques comme celle de l'École de Chicago est un indice probant de cette réappropriation du social proche et de cet éloignement du social construit. Tout ce que le souci de scientificité avait relégué aux oubliettes, souvent plus par incapacité à le saisir que par volonté délibérée, émerge alors: le sensible, l'ordinaire, le non-logique, le vécu, l'étrange, l'exubérant, le minuscule, l'anodin..." 5

"Se référer à la vie en général, voilà qui ne va pas sans risque /.../ on ne manquera pas d'aborder le rivage de cette existence concrète tellement étrangère aux ratiocinations désincarnées. /.../ proposer une sociologie vagabonde qui en même temps ne soit pas sans objet. /.../ Cela est d'autant plus important lorsqu'il s'agit du domaine de la vie courante. Là plus qu'ailleurs, nous n'avons pas à nous préoccuper de ce qui pourrait être la vérité ultime. La vérité en la matière est relative, tributaire de la situation. Il s'agit d'un 'situationnisme' complexe, car l'observation est en même temps, ne serait-ce que pour partie, intégré dans telle ou telle situation qu'il décrit. Compétence et appétence vont de pair, et l'herméneutique suppose que "l'on en est" de cela même que l'on décrit, elle nécessite une "certaine communauté de perspective. /.../ Préférer les "mini-concepts" ou les notions aux certitudes établies, même si cela peut choquer, me paraît être le gage d'une

de vie et leurs significations multiples, Thèse de doctorat en anthropologie, Université de Montréal, octobre 1989, pp. 167-168.).

5 SOULET, Marc-Henry, "La recherche qualitatitive ou la fin des certitudes" in La recherche qualitatitive: résurgences et convergences, DESLAURIERS, Jean-Pierre, dir., Chicoutimi, UQAC,1985, p.20. ( Coll. "Renouveau méthodologique" - [GRIR:Groupe de recherche et d'interventions régionales] ). Voir aussi HAMEL Jacques, DUFOUR Stéphane, et FORTIN Dominic, L'enquête de terrain en sciences sociales. L'approche monographique et les méthodes qualitatives, Montréal, Éd. Saint-Martin, 1992, 183p. "Si nous savons déceler sous les traits du géographe sa peur de la réalité, de la profondeur du sentiment, de la hauteur de l'enthousiasme, de la largeur du désir, sa phobie de tout ce qui n'est pas exactement définissable, du flou, du transitoire, nous réussirons peut-être à lui faire voir que l'immuable, l'éternel, se réflètent dans des réalités éphémères apparemment totalement dépourvues d'importance, dans les trivialités quotidiennes, et, au lieu de lui délivrer une simple information, nous pourrions lui apprendre, même à lui, l'art de vivre"(DREWERMANN, Eugen, L'essentiel est invisible * Une lecture psychanalytique du Petit Prince , Paris, Cerf, 1992, pp. 41-42). "On pourrait dire qu'on ne peut pas mettre l'autre sous le microscope, pour l'observer de façon neutre. Cela ne provoque qu'une prolifération de l'angoisse, au lieu de susciter la confiance. Au contraire, plus nous nous engageons personnellement, donc plus nous sommes soucieux de faire de notre âme et de ses sentiments le barometre, la caisse de résonance, le sismographe de ce que vit l'autre, et plus nous le comprenons intensément, en profondeur" (DREWERMANN, Eugen, La parole qui guérit, Paris, Cerf, 1991, p. 239). 
attitude d'esprit qui entend rester le plus près de la marche cahotante qui est le propre de toute vie sociale. /.../ Rêveuse sociologie ! /.../ En fait, ces entités, et les minuscules situations concrètes qu'elles représentent, se conjuguent pour produire une vie quotidienne qui de plus en plus échappe à la taxinomie simplificatrice à laquelle nous avait habitué un certain positivisme réducteur. Leur synergie produit cette société complexe qui mérite à son tour une analyse complexe. Le multidimensionnel et l'inséparable nous introduisent dans une "boucle" sans fin qui va rendre désuète la tranquille et bien ennuyeuse comptabilité des notaires du savoir."6

Par la suite, l'adhésion à la recherche qualitative requiert du chercheur une éthique de la connaissance qui place la fécondité même avant la rigueur.

"C'est que, plus inductive que l'approche quantitative, elle paraît plus respectueuse du terrain et plus adéquate à en saisir la réalité, particulièrement la réalité symbolique."7

"Mais comme tout ce qui est naissant est fragile, incertain, plein d'imperfections, notre approche doit avoir les mêmes qualités. D'où l'apparence de légèreté. Un terrain mouvant nécessite une démarche qui soit en conséquence et il n'est donc pas honteux de faire du "surf" sur les vagues de la socialité./.../ Ne vaut-il pas mieux, comme je le disais il y a un instant "en être" et pratiquer également la ruse. Au lieu d'aborder de front, en positivisant ou en critiquant, un donné social fuyant, utiliser une tactique tout en nuances, attaquer de biais. C'est la pratique de la théologie apophatique: de Dieu on en parle que par évitements. Ainsi, plutôt que de vouloir, d'une manière illusoire, saisir fermement un

MAFFESOLI, Michel, Le temps des tribus, Paris, Meridiens Klincksieck, 1988, pp. $10-11 ;$ p.13; p. $15 ;$ p. $18 ;$ pp.27-28. "Il y a la physionomie parfaite du penseur en chambre, du théoricien de l'encrier, drapé dans sa toge des grands jours. Il distingue admirablement le monde de la pensée et celui de l'expérience, le niveau de la "logique" comme aime à le dire Saint-Exupéry, et celui de l'existence, l'importance du savoir et l'exactitude de la science. La vraie vie, celle qui se passe dehors, ne lui apparaît que perte de temps, batifolage, et il considère comme infiniment plus valable l'expérimentation à laquelle il soumet la vie que l'expérience de la vie elle-même. Il est vrai que celleci ne pourrait que lui nuire, car il s'est donné pour spécialité de juger du travail des autres. Voir soimême, éprouver soi-même, apprendre soi-même, serait quelque chose d'insupportable pour quelqu'un dont l'existence est aussi active et aussi prenante que celle du Savant.; drapé dans l'attitude aristocrate de l'expert, il préfère, ou plutôt, il "se réserve" l'art du jugement. La valeur morale d'un homme? Il s'y connaît! Ce qui est valable ou non valable? C'est à lui de le dire! Ce qui relève de la science et ce qui en est indigne? C'est son affaire! Sans qu'il s'en aperçoive, cette manie de juger de tout, cette réduction de l'expérience au simple enregistrement des données de l'expérience des autres le condamnent à rester un perpétuel affamé d'une réalité à laquelle il reste d'ailleurs totalement imperméable, enfermé qu'il est dans le ghetto de sa spécialisation méthodologique. Lui qui ne vit que par procuration, il exalte sa vie de parasite en parlant de science de l'éternel, mais son abstinence quasi métaphysique de l'éphémère l'empêche de jamais rien découvrir de vivant et de réel. Loin de lui toute pensée d'aventure et de risque! Impensable l'idée que la vérité ne peut croître que là où quelqu'un a pris le risque de perdre sa vie en la semant comme une graine"(DREWERMANN, Eugen, L'essentiel est invisible * Une lecture psychanalytique du Petit Prince, pp. 37-38).

p.124.

NADEAU, Jean-Guy, Pour l'observation praxéologique d'une pratique pastorale, 
objet, l'expliquer et l'epuiser, se contenter d'en décrire les contours, les mouvements, les hésitations, les réussites et les divers soubresauts. Mais comme tout se tient, cette ruse pourra également être appliqué aux divers instruments que l'on utilise traditionnellement dans nos disciplines, pour en retenir ce qu'ils ont d'utile, mais également pour dépasser leur rigidité. "8

De plus, la méthodologie qualitative s'élabore sous le signe d'une observation participante dont le principe de base est l'insertion dans le milieu sans en perturber la vie. Elle prend les couleurs de la recherche-action reposant sur une intuition fort simple: pour connaître une société, un milieu, une communauté, un phénomène social, il faut essayer de s'en approcher et de les comprendre de l'intérieur. ${ }^{9}$ La chanson-thème de l'observation participante pourrait être $F u$ man $C h u$ de Charlebois, dont le refrain est 'Chu d'dans en plein d'dans jusqu'aux dents'. Cette méthode vise alors l'étude du milieu observé dans son ensemble: il faut en connaître la vie quotidienne du matin au soir, le travail, le loisir, les fêtes, etc. Elle est donc une méthodologie à plein temps!

"À cet égard, l'utilisation de la métaphore est parfaitement pertinente. /.../ L'on a dit de Beethoven qu'il trouvait dans la rue les motifs de ses plus belles citations, le résultat n'est pas négligeable. Pourquoi n'écririons-nous pas nos partitions à partir du même terreau? Tout comme la personne et ses masques dans la théâtralité quotidienne, la socialité est structurellement rusée, d'où le désarroi des universitaires, des hommes politiques, des journalistes qui la découvrent ailleurs, alors qu'ils croient l'avoir saisie." 10

Également, la richesse des observations devient dépendante de la qualité de l'intégration de l'observateur participant.

"L'observation participante, dans sa forme actuelle, remonte seulement à l'École de Chicago. Elle signifie que l'observateur ne peut plus se prévaloir d'un quelconque statut de classe (même supérieur), de son statut d'acteur, mais doit se plier aux règles et au consentement du groupe qu'il observe. /.../ L'observation implique un contrat par lequel l'observateur s'engage à respecter le code, les règles du groupe observé, en échange de quoi le groupe se laissera observer et fera comme si l'observateur était un acteur, un membre du groupe"( LECLERC, Gérard, L'observation de l'homme - Une histoire des enquêtes sociales, Paris, Seuil, 1979, p. 93, p. 95. ). 
"Le postulat de base de tout 'chercheuracteur' engage dans une 'recherchaction' interprétative, c'est qu'on ne change pas les autres et LEUR réalité mais qu'on chemine avec eux sur la route de LEUR changement, selon LEURS perceptions, LEURS objectifs, LEURS choix de moyens et LEUR rythme, faute de quoi on les manipule bassement par 'haut savoir' interposé." 11

Il nous est impossible de prétendre comprendre les gens sans entrer nous-mêmes dans le jeu. Entre humains, on ne peut songer à prétendre connaître l'autre en le réduisant à un objet qu'on pourrait fixer de façon neutre. La connaissance de la personne est toujours liée à un échange entre un "moi" et un "tu". Enfin, une dernière raison qui justifie le choix de cette méthode est que l'observation participante transforme l'observateur dans la manière où il est confronté à des valeurs, croyances, différentes des siennes. 12

Plusieurs chercheurs continueront certainement à considérer la méthodologie qualitative comme étant moins objective et moins scientifique que la méthodologie

CHARBONNEAU, Roland, "Vers une définition de la recherche-action", in La recherche qualitative: résurgences et convergences, p.118.

"...Il ne saurait en être autrement dans la religion. Et le pire, me semble-t-il, c'est que, en théologie, nous avons emmagasiné tout un fourbi de formules objectives qui ne servent à rien, sinon à nous assurer de bonnes notes aux examens, donc puissance et influence, mais tout cela sans grand rapport avec l'imitation du Christ /.../ Il me semble que nous, théologiens, nous en sommes depuis longtemps arrivé à ne plus faire que discuter entre nous de problèmes notionnels. Notre parole, même nos notions les plus importantes, ne disent plus rien à nos proches" (DREWERMANN, Eugen, La parole qui guérit, Paris, Cerf, 1991, p. 307, p. 323.).

12 "C'est ainsi que certains suggèrent de "réserver le nom de méthode à la démarche d'un esprit qui cherche et non d'un esprit qui retrouve ce qui a déjà été trouvé"(Claude:6). D'où les visées heuristiques de la praxéologie pastorale. /.../ Analyse critique et herméneutique de la pratique, la praxéologie pastorale s'élabore alors comme un processus de dévoilement et de transformation de la pratique aussi bien que du sujet."(NADEAU, Jean-Guy, "Pour une science de l'action pastorale. Le souci de la pertinence pratique", in Les études pastorales à l'Université - Pastoral Studies in the University Setting, Ottawa-Paris-Londres, Les Presses de l'Université d'Ottawa, 1990, p.137, p.143)."Le savoir scientifique n'est plus pensé dans les termes d'un savoir lecture, d'un savoir-reflet et d'un savoir vrai. Au contraire, il s'agit d'un savoir construit, provisoire et profondément évolutif. Le savoir n'existe que dans la mesure où l'activité humaine continue à le produire" (ANADON, Marta, GARNIER, Catherine, "De quelques fondements épistémologiques de l'observation", in Actes du Colloque "L'observation dans la recherche en éducation", p. 11). 
quantitative. Pour eux, l'introduction du sujet observateur est toujours perçue comme un obstacle à l'objectivité et à la scientificité de la recherche. Cependant, nous savons que cette objectivité fait l'objet de nombreux débats dans la procédure même de l'activité scientifique.

\begin{abstract}
"Actuellement, les épistémologues défendent une pluralité de projets scientifiques et mettent en cause la notion univoque de scientificité en refusant des critères d'objectivité et de neutralité absolus et dogmatiques. Ainsi, les épistémologues récusent de plus en plus l'idée d'une 'objectivité' d'un objet scientifique qui aurait évacué complétement le sujet connaissant et son contexte. Ils se refusent à obliger toutes les disciplines à se réaliser sur le patron des sciences empirico-formelles et reconnaissent aux sciences de l'homme des critères de scientificité spécifiques. En effet, ces sciences ont comme objet d'investigation ce qu'est un sujet: l'homme avec son intentionnalité, sa réflexivité, lui-même créateur des significations et de valeurs. Donc, dans toute science de l'homme on se trouve devant des comportements signifiants où la réflexivité propre à l'homme et leur intentionalité ne peuvent être réduites. En effet, elles sont la source de significations et de valeurs qui font la spécificité des sciences humaines. /.../ L'observation ne sera plus associée à l'enregistrement passif, "neutre" de faits et d'événements, mais plutôt, elle sera comme motivee, contingente de nos attentes conceptuelles ou autres. Elle comporte toujours un choix, conditionné par les conceptions théoriques ou idéologiques du chercheur, et déterminée par les finalités de l'expérience. L'observation est donc un processus actif au cours duquel la connaissance est construite par un sujet connaissant et non par une attitude passive d'un sujet qui enregistre les données de la réalité." 13
\end{abstract}

L'objectivité, reine du savoir scientifique, devient elle-même problématique. L'objectivité-neutralité se voit questionnée et par ses limites techniques, et par ses limites heuristiques. N'est-ce pas en se mettant personnellement en jeu que le chercheur peut accéder au langage et à la logique de pensée de l'autre, des membres du milieu et de ceux de la communauté? Si oui, cette position amène théoriquement et épistémologiquement un rapport différent entre le sujet et l'objet du savoir et du

13 ANADON, Marta, GARNIER, Catherine, op. cit. , p. 12-13. "Est-il vraiment nécessaire à la vision scientifique d'éliminer tout ce qui est projet, finalité, acteur, sujet? Est-ce scientifique de s'auto-éliminer soi-même, auteur de cette scientificité? Enfin, et surtout, est-ce que ce modèle de scientificité sur lequel se base la sociologie dite scientifique est vraiment scientifique?" (MORIN, E., Le sociologue doit-il s'exclure de sa vision de la société? , Document inédit... cité dans SOULET, Marc-Henry, La recherche qualitative ou la fin des certitudes, p.20.). 
discours, ce qui entraîne une redéfinition de 'l'objet sociologique' et de 'l'objet des sciences humaines' en général.

"D'embleee, on quitte l'objectivité telle qu'habituellement définie en terme de comparativité des résultats, de reproductibilité des expériences: on doit composer avec la subjectivité. Les questions d'ordre épistémologique soulevées seront d'ordre herméneutique, interprétatif et systématique; il faudra tenir compte de l'intentionalité des sujets-observants aussi bien que celle des sujets-observés. L'intéraction entre l'observateur participant et la communauté dans laquelle il observe et participe ne peut non plus être négligée; elle fait partie intégrante de ''objet d'étude'." 14

C'est donc sur la réintroduction de la subjectivité que toute une position épistémologique s'appuie. "La science pourra peut-être apparaître comme moins objective, mais en même temps, elle pourra s'avérer plus respectueuse des réalités sociales." 15 Nous savons également que l'analyse de contenu du matériel produit par l'observation participante a souvent été pointée comme la plus grande faiblesse de la recherche qualitative. Ce reproche était en partie justifié, sauf qu'on oubliait que la précision mathématique provoquait un assèchement des données et les réduisait. D'une certaine façon, c'est la manière de traiter les données qu'il faut critiquer plutôt que l'approche qualitative comme telle.

Je me suis ainsi inséré dans le milieu paroissial comme un observateur participant pour le comprendre dans son ensemble. J'ai préparé un plan provisoire dès que j'ai commencé la recherche-action. Des hypothèses ont été formulées dans le but de les confirmer ou les infirmer. Des dimensions ont été définies à partir desquelles je voulais interroger le milieu. J'ai identifié des lieux et des activités que je désirais examiner. Je suis content de l'avoir fait parce que j'aurais pu perdre pied dans mon

FORTIN, André, "L'observation participante: au coeur de l'altérité" , in La recherche qualitative: résurgences et convergences, p.33.

15 POUPART, Jean, "La méthode qualitative en sciences humaines: une approche à redécouvrir" in Apprentissage et Socialisation, volume 4, numéro 1, 1981, p.47. 
observation systématique, ne plus savoir que faire, me laisser flotter au gré des événements et des rencontres. Cependant, je n'ai cessé de garder une grande disponibilité afin de laisser place à l'imprévu. Pour analyser l'ensemble des données recueillies durant cette observation, j'ai utilisé la méthode praxéologique de recherche sur les pratiques pastorales développée à la section des études pastorales de l'Université de Montréal. Cette méthode comprend cinq étapes bien précises: l'observation, la problématique [l'interprétation factuelle], l'interprétation théologique, l'intervention et la prospective.

\subsection{La circularité dialectique de la méthode praxéologique}

Toutes les données d'observation ne se retrouvent pas dans la première partie de cette thèse. D'autres sont présentées dans les sections subséquentes. Les chapitres deux à cinq constituent une synthèse des observations réalisées. Ce choix a été fait pour respecter davantage la circularité dialectique de la méthode praxéologique. Quelques professeurs en théologie pastorale critiquent une certaine manière d'utiliser la méthode praxéologique. Dans plusieurs recherches pastorales, on écrit souvent de nombreuses pages d'observation et ensuite on va à l'interprétation théologique comme si on passait à toute autre chose. On en arrive à se demander s'il existe une relation entre l'observation, l'interprétation et la prospective. Il me semble que la redécouverte de la praxéologie pastorale a été de considérer déjà la pratique comme un contenu théologique. Nous sommes déjà en acte théologique lorsque nous observons un milieu. Des schèmes interprétatifs sont déjà en nous, sciemment ou non, même avant de voir une réalité. La fécondité de la méthode praxéologique (voir-juger-agir) se situe donc davantage dans sa circularité que dans sa linéarité.

"C'est évidemment ici s'écarter de la conception de la démarche linéaire de la recherche dans laquelle on doit établir sa question de recherche, puis définir son cadre conceptuel et 
théorique, énoncer sa méthodologie pour ensuite réaliser son étude, et finalement, livrer des résultats que l'on discute, et dont la modélisation courante et routinière se retrouve tout particulièrement dans les descriptions formelles qui apparaissent dans les cursus de formation à la recherche. On peut d'ailleurs se demander si la démarche linéaire telle que suggérée n'est autre que la résultante de la contrainte du langage et de la confusion entre l'agir et sa formalisation à des fins de communication. La séquence suivie et décrite n'étant pas du même ordre puisque dans un cas la simultanéité d'opérations, les boucles de feedback se font dans une dynamique interactive que le langage a beaucoup de mal à resituer à travers son débit temporalisé. La linéarité est ainsi remise en question par de nombreux méthodologues en sciences sociales et particulièrement par les ethnologues (Spradley,1980)."16

Le chercheur est dans un processus de dialectique herméneutique cyclique. Au cours de la collecte des données, les analyses lui permettent de reformuler ses questions pour pénétrer plus avant la situation qui l'intéresse et saisir les constructions qui émergent chez les répondants par des retours successifs dans le but de raffiner les modes de saisie et les constructions communes qui ressortent. Cette perspective de recherche introduit donc une relation étroite entre collecte et analyse des données, mais cette fois-ci, l'interdépendance n'est pas dans une relation globale données/analyse mais dans une succession de séquences d'analyse. Les questions émergent de l'analyse des premières données enregistrées de sorte que chaque période d'observation conduit à

ANADON, Marta , GARNIER, Catherine, "Relation entre prise de données et organisation de l'analyse dans le cadre de la méthodologie observationnelle", in Actes du Colloque "L'observation dans la recherche en éducation", p.18. "Tout processus de création se constitue progressivement, par approximations. Et la recherche est processus de création. La construction de l'objet est donc un processus d'élaboration progressive, non pas linéaire, non pas tout-à-fait par étapes, comme on monte les marches d'un escalier, mais plus justement un processus dynamique, en dents de scie, avec des moments d'hésitation, de recul même, et de reprise, en concomitance avec et en s'appuyant sur le terrain, les lectures, la réflexion, la discussion, un peu comme on exprime sa pensée, par approximations progressives de l'idée qu'on essaie de rendre la plus près possible de sa conception, mais qui se transforme dans le cours même de son expression. Tel un sculpteur qui "découvre", façonne l'oeuvre, progressivement, avec des retouches, de même, on bâtit l'objet de recherche, et on réalise l'ensemble d'une recherche. Le résultat comporte toujours une part d'inconnu. C'est ainsi dans toute oeuvre de création. Et le chercheur n'est pas un traducteur servile de la réalité, qui la retransmettrait fidèlement, comme certaines écoles ou courants théoriques l'ont professé et le professent encore, que ce soit en peinture, en sculpture ou en sciences humaines et sociales. Non, le chercheur est aussi une subjectivité, de même que son informateur, et la recherche se construit à partir de ces deux subjectivités, et de leur connaisssance de l'objet" ( DESMARAIS, Danielle, Trajectoire professionnelle et expérience du chomâge ouvrier des récits de vie et leurs significations multiples, p. 108.). 
des reformulations ayant une incidence sur la collecte qui suit. La nécessité de faire éclater le schéma traditionnel linéaire semble conduire à une vision dans laquelle la prise et l'analyse de données s'articulent et subissent des modifications au cours du déroulement de la recherche. Alors que la question de recherche s'inscrit dans le cadre de questionnements plus larges se définissant à travers les visées et les conceptions particulières du chercheur en termes épistémologiques et théoriques, elle motive et articule le reste de la démarche qui, dans un processus de va-et-vient interactif, contribue à pénétrer cette question elle-même et en conséquence, permet de la mieux formuler. Cette conception circulaire de la recherche approche avec plus de respect la complexité de la démarche que ne le font les modèles simplicateurs et linéaires.

\subsection{Limportance de la liberté par rapport à toute méthode de recherche}

Il me semble que, contrairement aux études de deuxième cycle, l'étudiant qui entreprend une thèse de doctorat doit risquer d'utiliser les méthodologies de recherche avec plus de liberté. La méthode en praxéologie pastorale offre un cadre qui aide le chercheur à structurer sa réflexion et son action. Elle est aidante lorsque les étapes de la méthode sont proposées comme des "balises de navigation" à considérer pour éviter une "noyade intellectuelle" . Cependant, elle peut rendre 'malade' si ces étapes sont imposées comme des "rails d'une voie ferrée" à suivre obligatoirement. ${ }^{17} \mathrm{Si}$ les cadres d'une méthode de recherche permettent d'organiser la démarche du chercheur, ils peuvent également devenir un carcan dont on suit les diktats à la lettre sans parvenir à $\mathrm{y}$ inscrire un sens et dans lequel est perdu à tout jamais l'espoir de pénétrer la complexité des relations humaines. Utilisée avec plus de liberté, cette méthode de termes de langage purement rationnel; car, ce faisant, il opère une réduction de son expérience en éliminant obligatoirement images, rêves, sentiments forts, passion, toute la grande poésie de la vie" (DREWERMANN, Eugen, La parole qui guérit, p.98). 
recherche nous aide à devenir "sujet" de notre réflexion et de notre pratique. ${ }^{18}$ Elle nous invite à une "fidélité intérieure" plus grande à l'égard de ce que nos expériences et nos lectures ont suscité comme questionnement. Elle nous aide à intégrer davantage l'ensemble de notre recherche-action. Si nous ne sommes pas vigilants, il peut arriver que comme étudiants au doctorat, nous soyons facilement atteints par le "sida intellectuel" qu'est "l'obsession méthodologique". 19 Un des premiers symptômes: vouloir calmer l'angoisse intellectuelle par la satisfaction d'avoir suivi fidèlement la méthode. Dans ce contexte, on risque d'être plus préoccupé de répondre aux exigences théoriques de la méthode que par ce qu'elle permet d'approfondir comme intervenant. Pour "condomiser" cette contagion, il faut donc prendre le risque d'utiliser avec liberté la méthode praxéologique. C'est ce que j'ai fait. Je ne sais pas à quel prix. Mais la fécondité et la créativité intellectuelles en valent le coût. Bernard LONERGAN signale à juste titre que

"la méthode n'est pas un ensemble de règles que n'importe qui ,voire un idiot, n'aurait qu'à suivre méticuleusement, c'est plutôt un cadre destiné à favoriser la créativité et la collaboration. La méthode met en relief les divers groupes d'opération que les théologiens doivent accomplir pour s'acquitter de leurs différentes tâches." 20

"Par son éducation, un jeune n'apprend à s'exprimer qu'à coups de citations et d'extraits de livre. Il ne peut donc articuler ses véritables problèmes qu'en langage savant, donc étranger à son expérience directe. Il ne peut même pas dire simplement, comme un fait brutal, le scandale qu'il ressent devant la destruction de la nature. Pour s'exprimer, il lui faut des statistiques, des programmes de solution. Il lui faut s'initier à des matières compliquées. Ceux qui entrent aujourd'hui à l'université doivent se taper un appareil qui conduit obligatoirement à une dissociation de la pensée et du sentiment, à une objectivité idéale interdisant en fait de devenir sujet" (DREWERMANN, Eugen, La parole qui guérit, Paris, Cerf, 1991, p.92.). En me lisant, vous découvrez sans doute que j'ai été moi-même marqué par ce système universitaire...

"Selon Georges Pitch, tous les savants qui se prennent au sérieux sont atteints d'"obsession" méthodologique. Nous savons comme lui que le motif caché de cette "obsession" c'est une peur que personne ne peut s'avouer aussi carrément: celle de la simple réalité, laquelle nous contraindrait à changer notre vie et les relations sociales" (DREWERMANN, Eugen, La parole qui guérit, p.218). 


\section{$1.4 \underline{\text { Une option pour la théologie pratique }}^{21}$}

La théologie pratique est une approche théologique qui accorde une priorité à la vie des personnes et des communautés sur la théorie pour voir comment la liberté de Dieu vient rejoindre la liberté humaine au coeur de sa praxis. ${ }^{22}$ Dans ce contexte, la

J'ai participé au Congrès international oecuménique et francophone de théologie pratique qui s'est tenu à Lausanne en Suisse du 26 au 31 mai 1992. C'est à ce congrès que j'ai pu approfondir davantage la théologie pratique. Depuis ce colloque, $j$ 'ai enrichi mes connaissances sur cette approche théologique par quelques lectures. Voir - AUDINET, J., "La théologie pastorale, une ecclésiologie pratique", in Témoin du Christ (P.A. Liégé), Paris, Cerf, 1980, pp. 153-169. - BOFF, Clodovis, Théorie et Pratique, La méthode des théologies de la libération, Paris, Cerf, 1990, 404p. DENIS, Philippe, "L'essor de la théologie contextuelle", in L'Actualité religieuse dans le monde, $\mathrm{n}^{\circ}$ 97, 15 février 1992, pp. 38-39. - DUFOUR, Simon et BOUCHARD, Nicole, "Les conditions d'une véritable andragogie et ses enjeux pour la théologie pratique", Intervention au Congrès Francophone de Théologie pratique à Lausanne, UQAC, mars 1992, 24p. - MARLÉ, René, "Théologie pratique et spirituelle", in Initiation à la pratique de la théologie, Tome I: Introduction, Paris, Cerf, 1982, pp.287-297. - MÉNARD, Camil, L'urgence d'une théologie pratique nordaméricaine comme théorie critique de l'agir chrétien au service de la société, in Seul ou avec les autres?, BRETON, Jean-Claude et PETIT, Jean-Claude., dir., Actes du $28^{\circ}$ congrès de la Société Canadienne de théologie tenu à Montréal du 25 au 27 octobre 1991, Montréal, Fides, 1992, pp.297318. (Héritage et projet \#48). -PELCHAT Marc, "Ecclésiologie théologique et ecclésiologie contextuelle. L'ecclésiologie dans les études pastorales", in Les études pastorales à l'Université Pastoral Studies in the University Setting, Ottawa-Paris-Londres, Les Presses de l'Université d'Ottawa, 1990, pp. 159-176).- SHEA, John, "Une approche de la théologie pastorale, Herméneutique pastorale", in Chicago Studies, 1973. - ZULEHNER, P.M., art "Théologie pratique", in Dictionnaire de théologie, Paris, Cerf, 1988, pp. 790-795.

22

"Pour ceux qui se consacrent à comprendre la foi d'une manière sacramentelle et par voie de participation, la théologie a une dimension essentiellement pratique. Elle ne saurait être la poursuite stérile de questions purement théoriques, sans rapport avec la foi vécue de nos jours" (DULLES, Avery, "L'Église, sacrement et fondement de la foi", in Problèmes et perspectives de théologie fondamentale, Paris- Montréal, R. LATOURELLE et G. O'COLLINS ed., 1982, p. 362.). "La praxéologie pastorale reconnaît cependant sa parenté avec la théologie pratique ou pastorale saisie comme lieu et process de transformation et d'engagement. Théologie pratique aussi, parce que, si elle vise, comme toute théologie, à rejoindre "les enjeux de base de l'existence humaine"(Ogletree: 85) c'est à travers un rapport critique à l'action qu'elle fait, émergeant de et retournant à des pratiques dont elle vise l'intelligence et l'amélioration (Kinast: 38; Hellwig 1982: 15s) " (NADEAU, Jean-Guy, 
théologie n'est plus perçue comme un bagage de connaissances mais comme un style d'interprétation répondant aux questions profondes posées par la pratique des personnes et des communautés. L'élaboration d'une théologie pratique convie à prendre au sérieux l'expérience concrète, vécue des croyants, pleinement insérés dans l'histoire et la culture. Une condition pour pouvoir identifier ces expériences humaines est que le théologien soit inséré au coeur d'une pratique concrète afin d'écouter avec empathie ses pulsations et faire monter à sa conscience ce qui la meut et l'influence. Le théologien prend le risque de construire un discours théologique vraiment collé à un contexte particulier. C'est d'ailleurs la seule façon de rejoindre l'universalité du salut.

La théologie pratique se développe selon des perspectives holistiques. Pour faire ses analyses, elle se donne des outils que la théologie classique ne peut lui donner et qu'elle emprunte aux sciences positives. Elle est ainsi ouverte par nécessité aux sciences sociales et aux sciences humaines. Elle vise à développer une pratique réelle de l'interdisciplinarité. 23 La rencontre de l'héritage chrétien, des autres sciences et de l'expérience produit une nouvelle compréhension dans la conscience ou la perception dans le but de conduire ultimement à une transformation personnelle et sociale. Le défi de la théologie pratique est de vivre la vie et la stratégie que l'expérience chrétiennement interprétée inspire et suggère. Le style et la stratégie d'intervention se déploient et s'incarnent de manières diverses dans les cultures variées. Le dire théologique est donc relié à un faire qui nourrit la foi et la questionne sans arrêt. Le

"Pour une science de l'action pastorale. Le souci de la pertinence pratique", in Les études pastorales à l'Université - Pastoral Studies in the University Setting, p.141.).

23 "Il nous parât clair aussi que l'élaboration d'une herméneutique pastorale ne saurait être qu'interdisciplinaire si elle veut être sensible à la complexité et aux requêtes des pratiques comme à celles de l'intelligence de notre temps (Lefebvre 1971 a.b.c.). Les sciences humaines sont nécessaires aussi bien à l'appréhension qu'à la compréhension d'une pratique, fut-elle évangélique. Avec l'histoire et l'exégèse qui relèvent aussi de leur dynamisme, elles balisent et orientent selon leurs perspectives propres tant l'herméneutique de la tradition chrétienne que celle de la pratique " (NADEAU, Jean-Guy, "Pour une science de l'action pastorale. Le souci de la pertinence pratique", p.146.). 
travail théologique reste alors une activité à base de contemplation nourrie par la vie des croyants. L'histoire de la notion de théologie nous apprend en effet que la conception de la théologie comme discipline pratique n'est pas une idée nouvelle. C'est tout simplement la redécouverte d'une pratique ancienne de la théologie. La conception du travail théologique comme habitus ou savoir pratique enraciné dans l'agir effectif de la foi au Dieu vivant a précédé la conception spéculativo-déductive de la démarche théologique. Actuellement, plus d'un théologien est convaincu que la théologie pratique peut contribuer à un renouveau en profondeur de l'entreprise théologique en repositionnant les questions et en ouvrant la créativité du processus de tradition. La source de l'entreprise théologique conduite dans cette perspective n'est plus le sens déjà codé, mais le sens qui s'exprime dans la vie du peuple croyant, au sein des pratiques historiques contextuelles. D'où l'urgence de former des théologiens pratiques qui soient des interprètes et des "signes de transcendance" au coeur de la culture, des serviteurs et des servantes du processus de révélation du Dieu vivant.

\subsection{Une problématique d'ensemble par l'approche systémique}

Je le dis d'entrée de jeu: ma recherche est moins sur l'institution paroissiale en milieu urbain en elle-même que sur ce qu'elle rend possible selon les manières de travailler. Il y a beaucoup de possibles en paroisse, dans une ville, mais à certaines conditions. Également, ma thèse de doctorat est davantage une problématique d'ensemble sur la pastorale en milieu urbain et le devenir de la paroisse que l'approfondissement très particulier d'une seule composante. M. Gabriel MARC disait au congrès annuel de l'Entraide missionnaire de 1992:

"Nous ne pouvons plus faire des études universitaires en sciences humaines qui approfondissent en pointu un seul aspect de la réalité. La réalité est plus complexe. Tout système s'articule en sous-systèmes mutuellement interactifs. Dans chacun d'eux et dans leurs liaisons s'accumulent des tensions, des forces explosives, et aussi d'imperceptibles 
détonateurs. Gérer tout cela constitue la somme des enjeux dans les années à venir particulièrement dans les recherches universitaires. Il faut initier les étudiants à s'entraîner à une lecture interactive des systèmes de la réalité. Les personnes et les institutions sont des organismes vivants. Nous ne pouvons plus analyser qu'une seule partie de l'organisme mais approfondir les interrelations entre les parties d'un système. Le risque de cette manière de recherche est celui de présenter un catalogue de réflexions d'apparence superficielles et décousues. Il vaut pourtant la peine de suggérer la fécondité d'une démarche d'ensemble qui évoque les liens de ces systèmes entre eux." 24

C'est le risque que je désire assumer dans la présente thèse en approfondissant la paroisse comme un réseau complexe d'interrelations selon une perspective systémique. 25

"Systémique" signifie à la façon d'un système, c'est-à-dire d'un ensemble dont tous les éléments sont en relation étroite les uns envers les autres, de telle sorte que si l'on déplace un élément, tous les autres sont déplacés." 26

24

MARC, Gabriel, "L'Évangile face aux enjeux de la prochaine décennie", in Actes du Congrès de l'Entraide missionnaire 1992: D'un "nouvel" ordre mondial à une "nouvelle" évangélisation , 11-13 septembre 1992, p.73.

25

La problématique de la paroisse n'est pas une pure question theologique. La paroisse est aussi une structure sociale dans un milieu particulier. Elle a des antécédents historiques, des conditionnements sociologiques qu'il nous faut connaître. Comme je le démontrerai, d'autres facteurs sociologiques l'emportent de plus en plus sur le facteur géographique qui fonde la paroisse, comme entité sociale. Sans une vision claire des nouveaux espaces humains, on élaborera une pastorale en circuit fermé, une politique de fourmilière où la moindre difficulté met en échec parce qu'on ne peut la situer dans l'ensemble. Dans ma thèse de doctorat, je situe l'institution paroissiale dans son contexte global. J'y vais peut-être "à doses massives", mais c'est à dessein. Devant un enjeu aussi important, on ne saurait être superficiel. L'analyse systémique me permettra de préciser une vision d'ensemble. Les enrichissements ecclésiologiques des dernières années et les grands changements sociaux, économiques et culturels du milieu canadien-français ont fait naître une pastorale plus complexe, plus spécialisée, plus diversifiée.

26 RUDGE, P. F., L'Église à l'heure du management, Traduction de S. Martineau, Paris, Mame-Fayard, 1971, p. 48. ["IPSC"]. Joël DE ROSNAY donne une définition similaire à RUDGE. "Un système est un ensemble d'éléments en interaction dynamique, organisés en fonction d'un but" (DE ROSNAY, Joël, Le macroscope: vers une vision globale, Paris, Seuil, 1975, p. 93.). John DILLON converge avec les définitions précédentes lorsqu'il définit le système comme: "A set or assemblage of things connected, associated or interdependent, so as to form a complete unity; a whole composed of parts in orderly arrangement according to some scheme or plan" (DILLON, John A. Jr. , Foundations of General Systems Theory, U.S.A., Intersystems Publications, 1983, p.1.).

En théologie, particulièrement en ecclésiologie, nous employons davantage le mot " structure". "Le terme de structure évoque avec plus de rigueur (que ceux d'idée ou d'essence), dans la recherche récente des mathématiques et des sciences humaines, une totalité organique d'éléments qui 
Tout système s'insère dans un système plus grand sur lequel il agit et qui, à son tour, agit sur lui. L'un des postulats de la théorie des systèmes stipule que tout système peut être divisé en une série de systèmes plus petits. Ces sous-systèmes sont des entités à la fois distinctes et interreliées. Par exemple, l'être humain est un système composé de plusieurs sous-systèmes spécifiques qui interagissent entre eux: le système respiratoire, le système nerveux, le système digestif, etc. Il en va de même pour une organisation. Pour réaliser le changement, il faudra intervenir au niveau des soussystèmes de l'organisation, sur un ou plusieurs éléments spécifiques. Cependant, parce que les sous-systèmes sont interreliés, une intervention à l'intérieur d'un sous-système a des effets sur les autres, comme l'aiguille de l'acupuncteur agit ailleurs qu'à l'endroit où elle est placée. Rarement pourra-t-on se contenter d'intervenir dans un seul soussystème parce que le changement provoqué quelque part aura une influence sur un autre élément dans un autre sous-système. La comparaison la plus juste pour représenter l'approche systémique est la suivante: il en va des systèmes, dans la perspective systémique, comme des sculptures dites "mobiles". Qui touche à un des éléments du mobile, fait bouger tous les autres. Autrement dit, les systèmes

entretiennent entre eux un jeu de relations tel que le déplacement ou la modification de l'un entraîne inévitablement le déplacement ou la modification des autres" (SESBOUÉ, B., "Ministères et structures de l'Église", in Le ministère et les ministères dans le Nouveau Testament, sous la direction de J. DELORME, Paris, Seuil, 1974, p. 349.). "La théorie générale du système évolua à partir du désir de quelques penseurs "d'établir des principes applicables à des entités non comprises dans la science conventionnelle" (Von Bertalanffy, 1968). Sa fonction est d'intégrer et d'expliquer le phénomène et les relations qui existent dans tous les systèmes /.../ la Théorie des Systèmes Généraux (Buckley, 1968) a démontré aux scientifiques et aux exécutants la nécessité de considérer toutes les variables en inter-action qui forment un certain phénomène"(LEMIEUX, André, Comment présenter un projet de recherche: approche systémique, Théorie et pratique, Montréal, Éd. Ville-Marie, 1981, p.23). Voir aussi LE MOIGNE, Jean-Louis, La théorie du système général: théorie de la modélisation, Paris, Presses universitaires de France, 1977, 258p.; MONGEAU, Pierre, La pensée systémique: historique et concept, Thèse de doctorat, Montréal, Université de Montréal, 1979.; DURAND, Daniel, La systémique, Paris, Presses universitaires de France, 1979, 127p. 
fonctionnent comme des roues dans un engrenage, chacun trouvant sa légitimité dans l'autre.

L'approche systémique se retrouve dans un grand nombre de domaines scientifiques et technologiques; elle s'est de plus démontrée très précieuse dans les sciences de la gestion. ${ }^{27}$ Cette approche nouvelle constitue en elle-même un nouveau paradigme dans la pensée scientifique. Le fait de se constituer en paradigme a pour conséquence que le concept de système peut se définir et se développer de différentes manières, dépendamment des objectifs de la recherche et selon les aspects variés de la réalité que l'on désire refléchir, ceci selon la théorie générale des systèmes. La philosophie des systèmes, c'est-à-dire la réorientation de la pensée et de la vision du monde issue de l'introduction du concept de système, comme nouveau paradigme scientifique, se distingue du paradigme analytique de la science classique. ${ }^{28}$ L'approche systémique offre ainsi un cadre de référence conceptuel qui aide à organiser la recherche au fur et à mesure de son avancement. Cette approche permet de dégager des balises pour affronter la complexité des phénomènes, de les situer dans des ensembles et des sous-ensembles. L'approche systémique est une manière nouvelle et différente d'approcher le réel. C'est dans ce nouveau paradigme systémique que je situe ma recherche doctorale. L'approche systémique que j'ai adoptée pour cette thèse se démarque aussi de l'approche analytique.

27

"L'analyse systémique est l'outil qui a le plus marqué les sciences de la gestion au cours des vingt dernières années. Un système se compose de sept éléments de base, à partir desquels il est possible de décrire le fonctionnement d'une organisation : la mission du système, les extrants du système, le processus de transformation, les intrants, le feed-back, la clientèle, l'environnement. /.../ (LE GROUPE CFC - Management et ressources humaines, Session : "Gestion du changement organisationnel", Document de travail \#2: Analyse systémique et changement organisationnel, Québec, Mai 1993, p 3, p.6, pp.12-13). J'ai suivi cette session pour me familiariser avec cette analyse utilisée de plus en plus dans des compagnies et des services gouvernementaux. 28

Voir BERTALANFFY, Ludwig von, Théorie générale des systèmes, Paris, Dumond, 1973, pp. 8-9. 
Depuis de nombreuses années, la recherche scientifique a valorisé graduellement la spécialisation dans les multiples disciplines. C'était la voie "supérieure" pour obtenir une connaissance en profondeur des phénomènes. Cette manière de connaître est encore importante. Elle correspond à l'approche analytique. Cependant, il ne semble pas suffisant de compléter la méthode analytique par l'élaboration synthétique. Même si la synthèse soit importante pour comprendre la logique interne des éléments reliés que l'analyse sépare, il y a souvent dans la réalité étudiée un aspect de la dynamique d'ensemble qui nous échappe. Seule une vision globale peut mieux nous faire découvrir la réalité complexe. L'approche systémique vient combler ce vide en considérant les interactions des sous-ensembles et les interactions des ensembles dans un grand ensemble. ${ }^{29}$ Elle ouvre de façon inventive à un approfondissement créatif dans l'étude des phénomènes complexes.

"Enfin, sur la création, parce que l'approche systémique catalyse l'imagination, la créativité, l'invention. Elle est le support de la pensée inventive, tandis que l'approche analytique est le support de la pensée connaissante. Tolérante et pragmatique, la pensée systémique s'ouvre à l'analogie, à la métaphore, au modèle. Jadis exclus de la "méthode scientifique", les voici aujourd'hui réhabilités. Pour l'approche systémique, tout ce qui décloisonne la connaissance et débloque l'imagination est bien venu: elle se veut ouverte, à l'image des systèmes qu'elle étudie." 30

J'aime conclure en présentant un tableau très éclairant de Joël DE ROSNAY dans son livre Le Macroscope où il démontre la complémentarité de ces deux approches analytique et systémique (pourtant irréductibles l'une à l'autre). 31

29

"Or il importe à celui ou celle qui entend mener une action efficace et responsable de connaître les composantes de sa pratique, système complexe d'interactions d'agents situés dans un environnement qui à la fois influence leur action, lui donne signification et en est affecté (Kinast: 34; Granger 6; Ricoeur 1983:108). I.../ Ce principe logique qui caractérise la démarche scientifique appelle la méthode comme "tentative (...) pour vaincre la complexité du monde" (Caude et Moles:437) " (NADEAU, Jean-Guy, "Pour une science de l'action pastorale. Le souci de la pertinence pratique", p.137.).

DE ROSNAY, Joël, La macroscope: vers une vision globale, p. 130

Ibid., p.109 


\section{"TABLEAU COMPARATIF DES DEUX APPROCHES}

\section{APPROCHE ANALYTIOUE}

Isole: se concentre sur les éléments

\section{APPROCHE ANALYTIOUE}

Considère la nature des interactions

S'appuie sur la précision des détails

Modifie une variable à la fois

Indépendance de la durée: les phénomènes considérés sont réversibles

La validation des faits se réalise par la preuve expérimentale dans le cadre d'une théorie

Modèles précis et détaillés, mais difficilement utilisables dans l'action

Approche efficace lorsque les interactions sont linéaires et faibles

Conduit à un enseignement par discipline

Conduit à une action programmée dans son détail

Connaissance des détails, buts définis

\section{APPROCHE SYSTÉMIOUE}

Relie: se concentre sur les interactions entre les éléments

\section{APPROCHE SYSTÉMIOUE}

Considère les effets des interactions

S'appuie sur la perception globale

Modifie des groupes de variables à la fois

Intègre la durée et la réversibilité

La validation des faits se réalise par comparaison du fonctionnement du modèle avec la réalité

Modèles insuffisamment rigoureux pour servir de base aux connaissances, mais utilisables dans la décision et l'action.

Approche efficace lorsque les interactions sont linéaires et fortes

Conduit à un enseignement pluridisciplinaire. La connaissance "avance" en quelque sorte sous la forme d'une spirale.

Conduit à une action par objectifs

Connaisance des buts, détails flous" 
1.6 Les limites de cette recherche

* Dans cette thèse, on retrouve en interaction des composantes qui chacune, urbanisation, sécularisation, modernité, se révèle difficile à maîtriser. Chaque composante aurait pu constituer en elle-même un sujet de thèse. Même si j'en ai appelé à des spécialistes fiables pour aborder ces composantes, il demeure que chacune d'elles aurait pu être davantage approfondie. Cependant, l'originalité de cette thèse doit être recherchée dans l'interaction elle-même.

* J'interroge surtout les structures ecclésiales présentes du point de vue d'un nouvel aménagement de l'espace. Il aurait été tout aussi important de soulever la question d'un nouvel aménagement du temps. Est-il réaliste, pour ne prendre qu'un exemple, de penser donner un certain avenir à la paroisse si celle-ci demeure le lieu de ce qu'il est convenu d'appeler "la pratique dominicale"? "Le temps" pose des questions aussi pressantes que "l'espace". Mais il me semble nécessaire de délimiter le cadre de cette thèse sans lequel ce projet doctoral n'aurait pas été viable.

* Mon sujet de recherche soulève des défis qu'il devient urgent de tenter de relever. Il m'apparaît évident, en effet, que les recherches fondamentales en ecclésiologie deviendront une sorte de rêve aliénant si la question des structures de la vie ecclésiale n'est pas vigoureusement soulevée, et si elle n'est pas soulevée à partir de ce que donnent à observer les structures et l'organisation présentes de l'Église.

* Je suis conscient que le type de ville et de paroisse au Saguenay-Lac-SaintJean est très différent de celui de Montréal ou de Boston... Il y a tout un monde entre une paroisse au centre d'une petite ville, d'une grande ville ou d'une métropole; entre 
une paroisse de banlieue, une paroisse rurale, une paroisse nationale, une paroisse universitaire, etc. Mais il est possible et nécessaire de faire une réflexion contextuelle.

* L'ensemble de cette recherche est influencée sciemment ou non par mon appartenance à un presbyterium diocésain. 


\section{CHAPITRE 2}

\section{DONNÉES RELATIVES AU MILIEU}

\subsection{Le Saguenay-Lac-Saint-Jean: la fabuleuse histoire d'un royaume! 1}

Les origines lointaines de la région du Saguenay-Lac-Saint-Jean remontent à la présence des Montagnais. Ils vivent en groupe de trente à soixante personnes dans un paradis terrestre un peu froid, sous la domination de "manitous" pas toujours favorables... Puis, arrive "l'homme blanc". Le poste de traite de Chicoutimi, établi vers 1676, constitue pendant longtemps le point de communication le plus avancé entre les deux peuples. Aussi loin que l'on peut remonter dans le temps, le territoire du Saguenay-Lac-Saint-Jean est appelé "Royaume". Aux $17^{\circ}$ et $18^{\circ}$ siècles, le "royaume" constitue un réservoir naturel de gibiers: on le surnomme donc "Royaume de la fourrure".

Peu à peu, le gibier recule devant les humains et la deuxième époque fastueuse du Royaume sera celle du bois: bois de construction, bois de charpente des navires, bois de mâtures. La Marine britannique fera du "Royaume de la fourrure", le "Royaume du bois" au milieu du $19^{\circ}$ siècle. ${ }^{2}$ Les colons viennent au "Royaume du

1

Je fais évidemment référence au titre du spectacle présenté et produit par Ville de La Baie depuis 1988 durant la saison estivale. Ce spectacle connaît un succès éclatant puisque, à ce jour, plus de 300000 personnes ont pu le voir et ce, grâce au travail infatigable de 200 comédiens bénévoles et à l'appui indéfectible du public québécois et européen. En 1986, la Corporation des Fêtes du $150^{\circ}$ anniversaire du Saguenay-Lac-Saint-Jean demande à M. Ghislain Bouchard, vieux routier du thêâtre régional, de coordonner les activités culturelles des Fêtes. M. Bouchard propose plutôt d'écrire et de mettre en scène un spectacle historique à grand déploiement. C'est ainsi que naît "La Fabuleuse Histoire d'un Royaume".

2 Voir aussi PARÉ, Marius Mgr, ancien évêque de Chicoutimi, L'Église au Diocèse de Chicoutimi, tome 1: Germination et Formation 1535-1888, Chicoutimi, 1983, 579p. 
bois", déguisés en bûcherons dans le cadre de la Société des Vingt et un. Ils se convertissent à l'agriculture une fois la première exploitation de la forêt. On défriche d'abord entre les souches et chacun s'acharne à "faire" sa terre pour que celle-ci devienne un "Royaume de l'agriculture".

Autour de 1900, le Saguenay-Lac-Saint-Jean devient "Royaume de papier", puis "Royaume de l'aluminium" au milieu du siècle. Excès d'enthousiasme ou mégalomanie des habitants, l'idée de grandeur a toujours été associée à l'histoire de ce pays. L'isolement aussi est une autre composante de sa vie. Isolement de l'habitant, donc obligation de créer son propre milieu culturel s'il ne veut pas mourir d'ennui. Petit à petit, le caractère de la région s'affirme: particularisme, nationalisme, forte identité, originalité, indépendance et tempérament frondeur. ${ }^{3}$

\subsection{La région du Saguenay-Lac-Saint-Jean: "en voie de désintégration"?}

Au recensement de juin 1991, la population du Saguenay-Lac-Saint-Jean était de 296496.4 Par rapport au total de la population en 1986 (297 090), cela représente une diminution de $0,2 \%$. Les données suivantes indiquent l'évolution au cours des trente dernières années de la population de cette région éloignée des grands centres urbains. Les chiffres illustrent la croissance ou la décroissance d'une période à une autre.

"Ça déborde : Ça déborde, ça déborde de talents saguenéens, Savoir-faire du bord du Lac, Du haut d'la côte jusqu'en bas du fjord, Ça déborde, ça déborde! Du p'tit ruisseau jusqu'à la grande rivière, Ça déborde, ça déborde! Et la rivière arrive droit au Lac, Il déborde, il déborde! Ça déborde de talents, etc..."(Chant choral progressif durant "La Fabuleuse Histoire d'un Royaume" in Dépliant publicitaire du spectacle, p.4).

4 STATISTIQUE CANADA, Profils- Rapport du recensement de 1991, Données intégrales, Catalogue \# 95-325, Canada, 1993, pp. 395- 449. 
Évolution de la population de 1961 à $1991^{5}$

$\begin{array}{lllllll}1961 & 1966 & 1971 & 1976 & 1981 & 1986 & 1991\end{array}$

$\begin{array}{lllllll}262426 & 267682 & 278187 & 293146 & 300091 & 297090 & 296496\end{array}$

Nous constatons qu'après avoir connu une hausse importante de 1971 à 1981 , la population au Saguenay-Lac-Saint-Jean n'augmente pas depuis une dizaine d'années.

À l'intérieur de cette région, on note des variations importantes dans l'évolution de la population. Celle-ci croît en certains endroits (Saguenay-Nord, Roberval, Dolbeau), alors qu'elle décroît ailleurs (Jonquière et autres petites municipalités). Les populations de Jonquière et de Chicoutimi-Sud se révèlent comme étant les plus âgées et vieillissant plus rapidement que les autres. ${ }^{6}$ On observe également un phénomène de croissance dans plusieurs municipalités de banlieue (par exemple Laterrière, Shipshaw, Saint-Honoré). La croissance des banlieues s'effectue en partie aux dépens des centres-ville qui se vident, mais qui accueillent de plus en plus de chambreurs et de personnes âgées.

5 $1971,1976,1981,1986$ et 1991.

6 "En 1991, il y avait 34\% de plus de gens âgés de 45 à 64 ans au Québec par rapport à 1971, mais l'augmentation a été de $51 \%$ dans la région du Saguenay-Lac-Saint-Jean. Cela fait que le poids démographique de ces personnes est passé de 17,9\% à $21 \%$ au Québec et de $14 \%$ à $19,9 \%$ ici. On constate que les gens âgés qui, au début des années 70, étaient sous-représentés dans la région par rapport au Québec, ont repris beaucoup de terrain, confirmant le phénomène de vieillissement. Enfin, les personnes de 65 ans et plus font partie du groupe d'âge qui a le plus augmenté au Québec en 20 ans. Il a presque doublé au Québec avec une hausse de $86,7 \%$ et il a plus que doublé dans la région, augmentant de $120 \%$. Malgré tout, le poids démographique de ces gens demeure, dans la région en deça de la moyenne provinciale, puisqu'il est passé de $4,2 \%$ à $8,7 \%$ contre des chiffres qui sont passés de 6,9\% à 11,2\% pour la province" (BOIVIN, Normand, "La population du Saguenay-LacSaint-Jean diminue légèrement et vieillit plus vite", in Progrès-Dimanche, le 9 mai 1993, p. 27. ). Pour rédiger son article, M. BOIVIN s'est inspiré du bulletin régional sur le marché du travail préparé par l'économiste Clément DESBIENS pour le compte de la Société québécoise de développement de la main-d'oeuvre (SQDM). 
Le phénomène de la migration de milliers de personnes vers l'extérieur de la région demeure un fait majeur des dernières décennies (17 674 entre 1966-1971, 11 223 entre 1971-1976, 17268 entre 1981-19867). S'agit-il surtout de jeunes qui choisissent de partir ou qui sont forcés de s'en aller? Est-ce la conséquence d'un chômage quasi endémique? S'agit-il d'un "brain drain"8 vers les grands centres? Les statistiques ne permettent pas de le dire mais ces migrations ont de quoi interpeller.

En vue d'établir un portrait de la situation socio-économique de la région, je propose d'utiliser les données contenues dans le rapport du Conseil des Affaires sociales et de la famille - le CASF. 9 Ce rapport est réalisé à partir des données du recensement de 1981. À cette époque, 19 municipalités étaient classées dans la catégorie désignée "en voie de désintégration" par les chercheurs. À la lumière du recensement de 1986, neuf municipalités s'ajoutent à la liste, pendant que deux autres en disparaissent. Ces chiffres révèlent l'existence, autour de la conurbation La BaieChicoutimi-Alma, d'une ceinture de municipalités en perte de croissance. D'après la recherche du CASF, les municipalités considérées "en voie de désintégration" ont des caractéristiques particulières. Ces municipalités qui diminuent de population seraient des communautés "réservoir" en ce sens qu'elles donnent vie à des personnes mais ne peuvent les retenir, les laissant se disperser, même s'il s'agit de forces vives. Plusieurs milieux ruraux sont donc en train de se désintégrer dans notre "royaume" du Saguenay-Lac Saint-Jean comme dans l'ensemble de la province du Québec.10 $1971,1976,1981,1986$ et 1991 .

STATISTIQUE CANADA, Rapports des recensements canadiens de 1961, 1966, 8 Traduction: "fuite des cerveaux"

9 Cet organisme du Gouvernement du Québec l'a rendu public en 1986. CONSEIL DES AFFAIRES SOCIALES ET DE LA FAMILLE, Rapport de la situation socio-économique de la région du Saguenay Lac-Saint-Jean, Gouvernement du Québec, Publications officielles, 1986. 10

S'agit-il vraiment d'une situation d'urgence? Des chercheurs le croient. C'est ainsi que Diane-Gabriel TREMBLAY et Vincent Van SCHENDEL écrivent que l'exode rural et le vieillissement de la population portent à penser que près de la moitié des municipalités et des villages 
Le sociologue québécois, Charles Côté, au service de la Régie régionale de la santé et des services sociaux de Chicoutimi, a étudié la question de la désintégration des régions. Il affirme dans son étude que sept régions du Québec sur onze amorcent actuellement le virage qui les mènera à leur extinction démographique. Selon ce chercheur, seul le retour des effectifs perdus depuis deux décennies pourrait les sauver. 11

\begin{abstract}
"La désintégration sociale et économique d'une région est un processus pervers qui a des conséquences néfastes sur les personnes et sur leur qualité de vie. /.../ C'est même une question de survie pour un territoire. Ce phénomène inquiétant ne constitue-t-il pas pour la foi chrétienne des "régionaux" un signe des temps apte à susciter réflexion et engagement, et à chercher ainsi à discerner le sens de l'histoire en train de s'écrire".12
\end{abstract}

C'est dire que l'avenir de l'Église au Saguenay-Lac-Saint-Jean est étroitement rattaché à l'avenir même de la région au plan socio-économique. Les deux ont partie liée dans une véritable communauté de destin.

du Québec seront, dans un proche avenir, menacés de fermeture. Voir TREMBLAY, Diane-Gabriel et VAN SCHENDEL, Vincent, Économie du Québec, Montréal, Éd. Saint-Martin, 1991.

11 CôTÉ, Charles, Désintégration des régions, Le sous-développement durable au Québec, Chicoutimi, Ed. JCL, 1991, pp. 30 et ss. Dans la région Saguenay-Lac-Saint-Jean, il constate qu'en 1971, on dénombrait 108,505 enfants entre 5 et 19 ans alors qu'en 1986, il n'en reste plus que 84,210 âgés entre 20 et 34 ans, ce qui est une perte de $22,3 \%$ en 15 ans. La région a perdu, au cours des 15 ou 20 dernières années, près du quart de la capacité de reproduction naturelle de sa population. Ceci met en péril, à long terme, son existence même, à l'instar d'ailleurs de plusieurs régions du Québec. D'autres études sont arrivées aux mêmes conclusions: COLLECTIF, VACHON, Bernard, Le Québec rural dans tous ses états, Montréal, Boréal, 1991, 311p. COLLECTIF, Actes des états généraux du monde rural, Tant vaut le village, tant vaut le pays, Montréal, les 3,4 et 5 février 1991, document rédigé sous la supervision du mouvement québecois Solidarité Rurale, 193p.

12

VILLENEUVE, Florent, Foi chrétienne et Région en voie de désintégration, in Pluralisme culturel et foi chrétienne, Actes du Congrès de la Société Canadienne française de Théologie tenu à Montréal du 30 octobre au 1 novembre 1992, MÉNARD, Camil et VILLENEUVE Florent., dir., Montréal, Fides, 1993, p.345 . [Héritage et Projet \# 50]. Ce professeur en éthique sociale à l'UQAC est beaucoup préoccupé par ce problème. 


\subsection{Brève description des quatre paroisses observées}

\subsubsection{Saint-Dominique de Jonquière}

Dans le processus de formation des séminaristes au diocèse de Chicoutimi, il est convenu que le futur prêtre aille faire un stage pastoral de deux ans dans une paroisse après ses études universitaires de premier cycle en théologie. Ce stage vise "la maturation de la vocation, l'intégration de l'apprentissage théologique, l'insertion dans le presbytérium et l'expérimentation du travail pastoral"13. J'ai fait un stage à la paroisse Saint-Dominique de Jonquière de septembre 1984 à août 1986. Nous étions quatre permanents dans l'équipe d'animation de cette paroisse: le curé, deux vicaires et moi comme stagiaire.

L'érection canonique de la paroisse Saint-Dominique de Jonquière a eu lieu en 1870. Les premiers colons de ce territoire ont construit une église en 1876, laquelle a été démolie en 1912 pour être remplacée pas l'église actuelle inaugurée en 1914. Depuis cette date, Saint-Dominique n'a cessé de croître pour devenir la plus grosse paroisse de la zone pastorale de Jonquière et du diocèse de Chicoutimi. Il y a quelques années, deux dessertes (Pibrac et Saint-Cyriac) ont été annexées à son territoire. Au 31 décembre 1992, on y dénombrait 4,025 familles et 12,500 habitants. 14 Cette paroisse est située dans la ville de Jonquière. La population de cette ville a légèrement

13

EQUIPE D'ANIMATION du Grand Séminaire de Chicoutimi, Politique des stages de premier cycle, document non-officiel, 1981, p.3.

14 Cette information est tirée de l'annuaire diocésain du diocèse de Chicoutimi de 1994, la section "Statistiques générales sur les paroisses au 31 décembre 1992" à la page 10. Selon moi, la paroisse Saint-Dominique de Jonquière dépasse actuellement les 15,000 habitants. J'ai appris, après une enquête à la 'Columbo', que les grosses paroisses ne donnent jamais le nombre juste de leurs paroissiens à la chancellerie pour éviter de payer un trop gros montant de tribut diocésain. La plus belle preuve, c'est que la paroisse Saint-Dominique déclare toujours les mêmes statistiques dans les annuaires diocésains depuis 1986 jusqu'à aujourd'hui soit: 4,025 familles et 12,500 habitants. C'est impossible de croire à ces données lorsque nous connaissons bien le territoire de cette paroisse et les nouveaux quartiers résidentiels qui se sont développés dans ce secteur depuis quelques années. 
diminué ces dernières années. Elle est passée de 58467 en 1986 à 57933 en 1991, soit une diminution de $0,9 \% .15$

Etant donné la grande superficie du territoire de la paroisse Saint-Dominique de Jonquière, nous y retrouvons plusieurs institutions scolaires (ex: trois écoles primaires, le C.E.G.E.P. de la ville, un centre linguistique), de nombreuses institutions publiques (ex: une station de télévision régionale, deux postes de radio, des maisons pour personnes retraitées, un énorme complexe sportif), plusieurs bureaux des gouvernements provincial et fédéral et quelques institutions religieuses et humanitaires (ex: une communauté de pères Oblats de Marie-Immaculée s'occupant plus spécifiquement de l'animation pastorale du C.E.G.E.P. de Jonquière, une communauté de religieux de Saint-Vincent-de-Paul animant un patro qui favorise le développement $\mathrm{du}$ jeune sous plusieurs aspects, une maison de quartier s'occupant des personnes dans le besoin [chômeurs, assistés sociaux, familles mono-parentales], une coopérative funéraire créée par les gens du milieu).

Les paroissiens adultes de Saint-Dominique travaillent dans divers milieux. Cependant, plusieurs sont des employés des trois grandes industries multinationales possédant des usines dans la ville de Jonquière: la société d'électrolyse et de chimie Alcan Ltée, la compagnie Abitibi-Price Ltée et la Cartonnerie Cascades. D'autres travaillent dans des P.M.E. régionales et plusieurs sont des fonctionnaires municipaux, provinciaux et fédéraux. Quelques-uns sont des producteurs agricoles. Il est évident que nous retrouvons dans ce territoire plusieurs chômeurs et assistés-sociaux. Des statistiques officielles viennent annuellement rappeler que Jonquière est l'une des villes où le taux de chômage est le plus élévé au Canada. ${ }^{16}$ Ce taux de chomâge devient de 
plus en plus inquiétant dans les régions éloignées, particulièrement en cette période de récession économique qui frappe encore plus durement ces territoires du Québec.

Dans la zone pastorale de Jonquière, Saint-Dominique est reconnue comme une paroisse dynamique. De nombreux bénévoles oeuvrent dans ses comités paroissiaux. En avril 1985, le comité de pastorale paroissiale (C.P.P.) de SaintDominique et les membres de l'équipe des permanents ont organisé deux rencontres pour échanger avec les principaux responsables de mouvements ou de services de la paroisse. Une évaluation de ces rencontres a fait prendre conscience aux membres du C.P.P. qu'environ 250 à 300 personnes travaillent bénévolement dans les différents comités paroissiaux et rencontrent annuellement au-delà de 2500 paroissiens.

Comme toutes les autres paroisses urbaines du Québec, le pourcentage de la pratique dominicale à Saint-Dominique de Jonquière est très faible. ${ }^{17}$ Les plus

trimestre d'avril, mai et juin, le taux de chômage a atteint 15,6 pour cent dans l'agglomération saguenéenne. Même s'il s'agit d'une légère baisse par rapport au trimestre précédent $(16,1)$, Chicoutimi et Jonquière conserve sa première place au triste palmarès du chômage. Fait à noter, les agglomérations qui suivent la région au classement, Saint-Jean de Terre-Neuve et Montréal, ont atteint un taux de chômage de 13,7 pour cent. "L'avance" du Saguenay est donc près de deux pour cent" (PRESSE CANADIENNE, "Le Saguenay conserve son record peu enviable", in Le Quotidien, 10 juillet 1993, p.7). "Dans l'est du Québec, avec des régions comme la Gaspésie, le Bas Saint-Laurent, la Côte-Nord et le Saguenay-Lac-Saint-Jean, c'est un peu plus compliqué du fait que ce sont des régions-ressources. "On dépend des ressources naturelles", explique Jean-Pierre LACHANCE, économiste de réseau pour Emploi et Immigration Canada dans la région. Depuis les deux dernières années, le secteur des ressources naturelles a fortement été touché, ainsi que le secteur primaire. Dans la région, cela s'est produit par des mises à pied massives dans les secteurs des pâtes et papier et de l'aluminium. "Jonquière est la zone la plus industrialisée de la région et Chicoutimi regroupe surtout des entreprises de services. Ils ont beaucoup été touchés." Ceci explique le haut taux de chômage de cette agglomération par rapport aux autres régions métropolitaines du Canada" (MÉNARD, Nathalie, "Dans la région - Le taux de chômage reste très élevé", in Le Quotidien, 7 août 1993, p.4).

17 La pratique de la foi chrétienne est beaucoup plus vaste que la pratique dominicale. Combien de fois ai-je entendu de la bouche de croyants: "J'ai la foi mais je ne pratique pas." Pratiquer la foi, est-ce uniquement aller à la messe? Pratiquer sa foi, ne serait-ce pas plutôt "accomplir la justice, aimer avec tendresse et marcher humblement avec Dieu" (Mi 6,8). Cette conception diffère de celle que nous retrouvons dans le récent catéchisme universel: "L'Eucharistie du dimanche fonde et sanctionne toute la pratique chrétienne. C'est pourquoi les fidèles sont obligés de participer à l'Eucharistie les jours de précepte, à moins d'en être excusés pour une raison sérieuse (par exemple la 
optimistes le chiffrent à environ $20 \%$. Mais, il serait peut-être plus réaliste de fixer son pourcentage à environ $10-12 \%$ de pratiquants réguliers. 18 Généralement, environ 1200 paroissiens de Saint-Dominique ou d'ailleurs participent à l'une ou l'autre des célébrations eucharistiques dominicales à l'église paroissiale ou à celle célébrée dans la

maladie, le soin des nourrissons) ou dispensés par leur pasteur (can. 515,\#1; 1245, 1247; 1248, 1-2). Ceux qui déliberément manquent à cette obligation commettent un péché grave"(CONSTITUTION APOSTOLIQUE, Catéchisme de l'Église catholique, Paris, Name/Plon, 1992, p.448). Les propos de l'archevêque de Québec, Mgr Maurice Couture, lus dans Le Devoir lors de la parution des premiers résultats concernant leur synode diocésain sont plus ouverts sur cette conception. "L'archevêque du diocèse, Mgr Maurice Couture, a mentionné que la messe dominicale n'est pas la seule façon de pratiquer pour un catholique /.../ La pratique peut revêtir d'autres formes. Les jeunes ne participent pas à la liturgie dominicale mais manifestent leur foi par d'autres dimensions comme la fraternité, le partage ou l'éducation /.../ La propagation de l'Évangile ne se résume pas à la pratique dominicale"(Le Devoir, 16 mars 1993, vol. LXXXIV, \#62, p. A-2).

18 Nous retrouvons des statistiques sur la pratique religieuse des catholiques du Québec dans le volume du sociologue Réginald BIBBY: La religion à la carte, Pauvreté et potentiel de la religion au Canada, Montréal, Fides, 1988, p.39. L'étude est fondée sur trois sondages menés en 1965,1975 et 1985. Les pourcentages des catholiques qui participent à la messe deux fois par mois ou plus souvent sont les suivants: en 1965: 88\%; en 1975: $46 \%$ et en 1985: 38\%. Une enquête scientifique réalisée par le Centre de sondage de l'Université de Montréal en 1984 arrive aux mêmes résultats: $38 \%$ des 2014 répondants ont affirmé qu'ils assistaient aux cérémonies religieuses à toutes les semaines (Le Devoir ,8 septembre 1984, p. A-8). En 1990, le sociologue Pierre BOUCHARD, est arrivé aux résultats suivants dans son sondage sur la pratique religieuse chez les catholiques francophones de Montréal publié dans la revue Prêtre et Pasteur de janvier 1991 aux pages 38 à 45: 29,5\% affirment être allés à la messe moins de 10 fois depuis un an, $14 \%$ affirment y être allés entre 10 et 40 fois, $23,2 \%$ disent être des pratiquants réguliers, c'est-à-dire au moins 40 fois depuis un an. Ce même sondage démontre qu'en effet plus un catholique est âgé, plus il a tendance à pratiquer. Si $51,9 \%$ des catholiques âgés de 55 ans ou plus affichent une pratique religieuse régulière, il n'en est pas ainsi pour les plus jeunes: $57,7 \%$ des 35 à 54 ans et $81,5 \%$ des plus jeunes ne pratiquent pas ou à peu près pas. Mais, même s'il existe une constante des résultats concernant la pratique religieuse depuis un dizaine d'années dans les différents sondages publiés au Québec, il semble que le pourcentage est moins élevé dans le concret. Presque l'unanimité des collègues travaillant en paroisse m'ont affirmé que ces résultats sont beaucoup trop élevés. Selon eux, il est plus réaliste de croire que le taux de pratique dans les milieux urbains est de l'ordre de $8 \%$ à $12 \%$ et dans les milieux ruraux, du moins dans le diocèse de Chicoutimi, est de l'ordre de $15 \%$ à $21 \%$, selon les paroisses elles-mêmes et leur histoire. Le diocèse de Québec, par l'intermédiaire d'un sondage effectué lors de son synode, a publié en mars 1993 les résultats concernant le taux de pratique religieuse. "Le sondage mené auprès de 39,000 personnes du diocèse de Québec indique que la participation à la messe du dimanche ne concerne plus que $17 \%$ des catholiques./.../ On constate également que la pratique est plus répandue dans certaines régions rurales du diocèse (30\%) que dans les grandes paroisses de banlieue (10 et 15\%)" (Le Devoir, 16 mars 1993, vol. LXXXIV, \#62, p. A-2). "Sur les quelque 885,000 personnes de tous âges qui se déclarent catholiques dans le diocèse, 151400 étaient à l'église lors de la fin de semaine des 6 et 7 novembre 1992, soit environ 17\%. Si on y ajoutait celles qui ont participé à la messe dans les hôpitaux, les foyers ou les communautés religieuses, le chiffre augmenterait un peu mais ne dépasserait sûrement pas 20\% (ÉQUIPE DIOCÉSAINE, CÔTÉ, Jacques., sec. gén., Rapport de la première étape du Synode de Québec, Québec, mars 1993, p.12). 
chapelle de la desserte Saint-Cyriac. Il y a en moyenne à chaque année dans cette paroisse 160 baptêmes, 45 mariages et 75 funérailles célébrés. 19

\subsubsection{Saint-Jean-l'Évangéliste de Bégin}

La paroisse Saint-Jean-l'Évangéliste de Bégin fait partie de la même zone pastorale que la paroisse Saint-Dominique. La municipalité de Bégin est située approximativement à $40 \mathrm{~km}$ de la ville de Jonquière. Je suis né dans cette paroisse et je m'y suis impliqué dans la municipalité tout au long de mes études secondaires, collégiales et universitaires de premier cycle. Cette paroisse a eu le même curé pendant dix-sept années (de 1973 à 1990). Selon l'ancienne législation concernant les nominations au diocèse de Chicoutimi, l'évêque titulaire désignait à vie un curé dans une communauté (curé inamovible). Cette législation a été révisée récemment par les différents conseils de l'évêque du diocèse. Il n'est plus possible à un prêtre d'être plus de 12 ans dans la même paroisse, c'est-à-dire deux mandats pastoraux de six années chacun. Cette politique semble s'être répandue dans tous les diocèses du Québec. 20 Actuellement, c'est un jeune prêtre qui assume le ministère de la présidence de deux

19

Statistiques officielles de la chancellerie du diocèse de Chicoutimi concernant le nombre de baptêmes, de mariages et de sépultures à Saint-Dominique de Jonquière:

$\begin{array}{lrrrrrrrrrr}\text { Année: } & 1981 & 1982 & 1983 & 1984 & 1985 & 1988 & 1989 & 1990 & 1991 & 1992 \\ \text { Baptêmes: } & 171 & 192 & 166 & 168 & 168 & 163 & 164 & 167 & 143 & 155 \\ \text { Mariages: } & 91 & 72 & 63 & 68 & 64 & 49 & 56 & 50 & 46 & 25 \\ \text { Sépultures: } & 52 & 78 & 70 & 68 & 70 & 50 & 89 & 54 & 99 & 69\end{array}$

Rappelons que j'ai recueilli ces statistiques dans les annuaires diocésains du diocèse de Chicoutimi de $1983,1984,1985,1986,1987,1990,1991,1992,1993,1994$. Il y a deux années qui séparent les statistiques de leur publication officielle.

20

"Pour ce qui est de la durée du ministère des curés dans leur paroisse actuelle, nous remarquons d'abord que $62 \%$ des curés au Québec en sont à leur premier mandat de six ans, tandis que $88,4 \%$ des curés sont dans la même paroisse depuis moins de douze ans. La mobilité des curés est donc importante, puisque seulement 11,6\% sont dans la même paroisse depuis plus de douze ans. Précisons que les curés qui ont plus de seize ans de ministère dans la même paroisse se retrouvent en proportion plus grande dans les paroisses de 1 à 999 paroissiens et surtout dans les paroisses de 9000 paroissiens et plus" (LEVASSEUR, Jean-Marie et TURMEL, André, L'évaluation pastorale au Québec, L'enquête sur les pratiques évaluatives en usage dans les paroisses catholiques du Québec, Trois-Rivières, Pastor, 1992, p.239). 
paroisses rurales incluant la communauté de Bégin. J'analyserai plus loin cette nouvelle manière de nommer les ministres ordonnés pour en faire ressortir les forces et les limites pour les paroisses et pour les permanents eux-mêmes.

L'érection canonique de la paroisse de Saint-Jean-l'Évangéliste de Bégin a eu lieu en 1932. La population de ce village a chuté de 8,8\% de 1986 (1045) à 1991 (953). ${ }^{21}$ Selon le rapport du CASF (le Conseil des Affaires sociales et de la famille), Bégin est considéré comme une municipalité dite "en voie de désintégration". Il y a en moyenne par année 20 baptêmes, six mariages et six funérailles dans cette communauté. 22 En 1980, j'ai été directeur d'un projet étudiant qui consistait à faire une étude socio-économique de la municipalité de Bégin sous la supervision du sociologue Jean-Marie Tremblay, professeur au CEGEP de Chicoutimi. À cette époque, nous avons visité toutes les familles pour faire remplir un questionnaire. ${ }^{23}$ Les résultats ont été publiés dans un volume intitulé: "Rapport de l'étude socio-économique de la municipalité de Bégin". 24 Nous avions découvert à cette époque que 63,58\% de la population adulte était composée des travailleurs saisonniers, spécialement dans le domaine de la foresterie et de la construction. ${ }^{25}$ Durant la saison hivernale, le taux de chomâge dépasse les $50 \%$ chez cette population.

21

22

Baptêmes:

Mariage:

Sépultures:

Ces données ont été encore une fois recueillies dans les annuaires diocésains du diocèse de Chicoutimi dont ceux de 1990, 1991, 1992, 1993, 1994.

23

194 entrevues ont été faites sur une possiblité de 237. Les 43 autres familles n'ont pu répondre au questionnaire pour deux raisons: elles étaient absentes lors du passage de l'interviewer ou elles ont refusé de répondre à l'étude-enquête pour différents motifs.

24

COLLECTIF, Rapport de l'étude socio-économique de la municipalité de Bégin, TREMBLAY, Eric, dir., Archives municipales, 1980, 199 p.

$25 \quad$ Rapport de l'étude socio-économique de Bégin, pp.22-23. "L'occupation principale des travailleurs de Bégin est la suivante: foresterie: $32,52 \%$; construction: $13,26 \%$; industriel: $12,75 \%$; à son compte: 9,69\%" [Ibid, p.24] ; "75,64\% des travailleurs travaillent à l'extérieur de la municipalité" [Ibid, p.44]. 


\subsubsection{Saint-Jude d'Alma}

J'ai travaillé pendant quatre ans ( août 1987 à août 1991) dans la paroisse Saint-Jude d'Alma. Après avoir complété mes études de second cycle universitaire et avoir déposé mon mémoire de maîtrise intitulé: "Dynamique de la paroisse et projet communautaire" 26, j'ai oeuvré à la paroisse Saint-Jude d'Alma comme diacre pendant un an. Après mon ordination presbytérale, j'ai servi pendant neuf mois comme vicaire dans cette même communauté. Il m'a été demandé par la suite de devenir curé de cette paroisse urbaine. J'ai exercé ce ministère pendant deux ans et trois mois avant que les autorités diocésaines me proposent de m'inscrire au doctorat en théologie pastorale. Durant ces quatres années, j'ai travaillé étroitement avec un prêtre plus agé que moi, avec un futur prêtre et deux diacres permanents.

La paroisse Saint-Jude est composée d'une équipe de bénévoles impressionnante. À chaque année, le Conseil de pastorale paroissiale (C.P.P.) et le Conseil de la Fabrique organisent conjointement une fête pour tous les bénévoles de la communauté. Près de trois cents paroissiens participent à cette soirée pour célébrer leur joie d'avoir collaboré ensemble pendant l'année pastorale afin de faire advenir une paroisse plus dynamisante pour la foi. Le C.P.P. organise également chaque année une rencontre de tous les responsables des comités paroissiaux, dans le but de favoriser une meilleure concertation entre les différents services communautaires. Les membres du Conseil de pastorale envoient une invitation aux responsables des comités paroissiaux (une trentaine). Ces rencontres entre tous les responsables de mouvements ont suscité l'organisation d'un colloque paroissial. Cette expérience 
d'Église a été vécue le 29 avril 1989. Je reviendrai sur cette enrichissante expérience "synodale".

L'érection canonique de la paroisse Saint-Jude d'Alma a eu lieu en 1954. Le territoire de cette paroisse est davantage composé de quartiers résidentiels. Peu d'industries sont implantées dans ce secteur. La majorité des paroissiens sont des travailleurs dans différentes usines d'Alma situées sur les territoires d'autres paroisses le long de la rivière séparant le Lac-Saint-Jean du Saguenay. Il s'agit évidemment de la compagnie Alcan et de la papetière Abitibi-Price. Un fort pourcentage d'habitants de cette paroisse sont aussi des professionnels de l'enseignement et du milieu hospitalier, puisque l'hôpital d'Alma, le CECEP et la polyvalente de la ville sont localisées entre la paroisse Saint-Jude et sa voisine, Saint-Joseph d'Alma. La population de Saint-Jude compte environ 4490 paroissiens et 1500 familles. 27 On y célèbre annuellement 80 baptêmes, 20 mariages et 25 funérailles. ${ }^{28}$ La population de la ville d'Alma est demeurée sensiblement stable pendant ces dernières années. Cette ville est passée de

27 Statistiques officielles parues dans les annuaires diocésains du diocèse de Chicoutimi de 1990, 1991, 1992, 1993, 1994:

$\begin{array}{lccccc} & 1988 & 1989 & 1990 & 1991 & 1992 \\ \text { Population totale: } & 4596 & 4445 & 4445 & 4474 & 4473 \\ \text { Nombre de familles: } & 1543 & 1478 & 1478 & 1498 & 1483\end{array}$

Comme je l'ai dit précédemment, nous devons considérer ces données comme approximatives. J'ai fourni les données à la chancellerie pour les années 1989 et 1990. Je me suis guidé sur les fiches de la capitation annuelle. Comme curé et comme président du Conseil de la fabrique, j'ai répété la tradition de mes ancêtres en évitant de trop augmenter le nombre de la population totale de la paroisse pour éviter de payer un tribut diocésain trop élevé! La situation financière des paroisses de plus en plus précaire parfois oblige à ... Que Dieu me pardonne!

28

$\begin{array}{lllll}1988 & 1989 & 1990 & 1991 & 1992\end{array}$

Baptêmes: $\quad \begin{array}{lllll}71 & 71 & 95 & 77 & 52\end{array}$

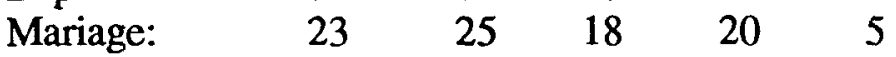

Sépultures: $\quad \begin{array}{lllll}28 & 19 & 25 & 28 & 21\end{array}$

Vous remarquez que les baptêmes à Saint-Jude ont augmenté de plus de $30 \%$ en 1990 . Pourquoi? Mon approche pastorale d'acceptation inconditionnelle de toutes les demandes sacramentelles s'est vite répandue dans la ville d'Alma. Le chapitre treizième vous permettra d'en savoir davantage sur ce sujet. 
25923 habitants en 1986 à 25910 selon les plus récentes statistiques officielles du gouvernement canadien de 1991, soit une baisse à peine significative de $0,1 \% .29$

\subsubsection{Saint-Léon}

Lorsqu'on m'a demandé d'assumer la cure de Saint-Jude d'Alma, on m'a également proposé de devenir solidairement responsable de la paroisse rurale de SaintLéon avec un collègue plus âgé. Cette municipalité est située à $30 \mathrm{~km}$ de la paroisse Saint-Jude d'Alma et fait partie de la même zone pastorale de l'Est-du-Lac.

L'érection canonique de cette communauté date de 1926. Le taux de la population de cette municipalité a diminué de 3,3\% entre 1986 (1219) et 1991 (1179). ${ }^{30}$ Dans cette paroisse, on célèbre en moyenne annuellement 20 baptêmes, six mariages et 10 sépultures. ${ }^{31}$ La pauvreté y a beaucoup augmenté comme dans tous les milieux ruraux de la région du Saguenay-Lac-Saint-Jean et ailleurs au Québec. Dès notre arrivée dans cette paroisse, nous avons réuni les dirigeants municipaux pour une réflexion sur la situation économique du milieu. Nous avons découvert que plus de $60 \%$ de la population vivait de l'aide-sociale ou de l'assurance-chomâge. Cette situation économique précaire dans les milieux ruraux préoccupe de plus en plus les intervenants pastoraux.

STATISTIQUE CANADA, Profils- Rapport du recensement 1991, p.404.

31 Statistiques officielles parues dans les annuaires diocésains du diocèse de Chicoutimi de 1990, 1991, 1992, 1993, 1994:

Baptêmes: 1988 1989

1120

Mariage:

Sépultures:

$8 \quad 12$

135

$1991 \quad 1992$

$27 \quad 15$

25

$13 \quad 11$


Dès notre nomination dans cette paroisse, les autorités diocésaines nous ont demandé de vivre avec cette communauté "l'opération AVENIR 8-8".32 Ce projet diocésain est ainsi décrit:

"1) aider les petites paroisses rurales à penser à long terme et apprendre à gérer leurs ressources humaines autrement; 2 ) reconnaître le droit d'exister à toute communauté qui veut vivre et est capable de vivre; 3) associer les paroisses à la définition de leur avenir; 4) aider les paroisses à se prendre en charge." 33

La première année est consacrée à un travail de sensibilisation et à une évaluation des besoins et des ressources du milieu. La formation et le choix d'une formule d'animation pastorale constituent le programme de la deuxième année. ${ }^{34}$ La dernière année (la troisième) devait être consacrée à la prise en charge de la communauté par elle-même. Aucune des paroisses vivant cette opération depuis quelques années n'est véritablement rendue à cette étape. ${ }^{35}$ Il semble qu'il soit irréaliste de croire qu'une telle

32

Pourquoi avoir intitulé ce projet "Avenir 8-8"? Le service diocésain des communautés chrétiennes du diocèse de Chicoutimi désirait se soucier davantage des petites communautés rurales en voie de désintégration. Les responsables voulaient par le fait même aller à l'encontre de certaines politiques gouvernementales qui encouragent la centralisation et négligent les petites municipalités. II a été décide, en concertation avec les responsables des 8 zones pastorales du diocèse, de choisir une paroisse dans chacun de leur secteur. Les responsables pouvaient alors se donner comme priorité de faire vivre dans le diocèse cette opération à 8 paroisses lesquelles pourraient mieux assumer leur avenir.

33 SERVICE DIOCÉSAIN DES COMMUNAUTÉS CHRÉTIENNES, Opération Avenir 8-8, Chicoutimi, Archives diocésaines, 1987, pp. 1-3.

34 La communauté est informée de cinq formules d'animation pastorale possibles: 1) un prêtre responsable de plusieurs paroisses; 2) une équipe de prêtres solidaire de plusieurs paroisses; 3 ) une equipe pastorale composée d'un prêtre à temps partiel ou à temps plein avec quelques paroissiens bénévoles mandatés par l'évêque; 4) Une personne 'laïque' ou un diacre ou un(e) religieux(se) plus particulièrement responsable de l'animation de la communaute; 5) un prêtre à temps partiel et un agent laïque permanent. Les autorités diocésaines favorisent la formule de l'équipe pastorale (\#3). La première question que les paroissiens posent lors des assemblées où le comité diocésain "Avenir 8-8" présente le projet est la suivante: "le prêtre va-t-il demeurer dans notre municipalité?". Les autorités diocésaines ont-elles été suffisamment soucieuses de cette continuelle préoccupation des paroissiens ruraux? Que nous disent ces paroissiens ruraux qui ne cessent de rappeler l'importance pour eux que leur pasteur demeure au coeur de leur municipalité ?

35 Le comité de l'opération "Avenir 8-8" a été transformé en 1993 pour centrer davantage leurs efforts pour aider les communautés paroissiales dans cettre troisième étape. Les membres ont rédigé un excellent document d'accompagnement pour les paroisses sur la route d'une 
opération se fasse en trois ans. Il est plus facile d'écrire des objectifs sur papier que d'accompagner une communauté dans une plus grande prise en charge de son avenir. Les mentalités, ce n'est pas comme le café, ça ne se change pas instantanément. La conversion d'une manière de voir et d'agir demande toujours un long cheminement. Il est rarement rentable à long terme de faire des changements brusques dans une communauté. Un 'mûrissement' communautaire exige parfois plusieurs années. ${ }^{36} \mathrm{La}$ patience est alors très importante pour les permanents qui accompagnent une paroisse. Quand on veut implanter un changement trop vite, on doit s'attendre à des effets prévisibles et nocifs d'incompréhension, d'opposition, voire de paralysie. Il est plus profitable de suivre de très près les réactions des gens et de chercher à s'y ajuster.

\subsection{Délimitation du champ d'observation}

C'est à partir de l'expérience vécue à Saint-Dominique de Jonquière que j'ai rédigé mon mémoire de maîtrise en théologiel études pastorales après avoir accompagné plusieurs comités paroissiaux dans cette paroisse. Cependant, à cette époque, j'avais cru important de ne sélectionner que quelques-uns des services paroissiaux aux fins d'observation systématique. J'avais alors choisi de faire une "biopsie" à l'intérieur de certains mouvements paroissiaux. Biopsie et non pas "autopsie", puisque j'ai observé le cheminement et l'agir des personnes bien vivantes

plus grande prise en charge communautaire. Voir COMMUNAUTÉ DIOCÉSAINE SUR L'AVENIR DES COMMUNAUTÉS, Bâtir ensemble... Collaborer pour l'avenir, document d'accompagnement, Diocèse de Chicoutimi, 1993, $101 \mathrm{p}$.

36 "Lorsqu'on procède trop rapidement à un changement, on crée des blessures, on ralentit le mouvement. Si on prend le temps nécessaire pour vivre le changement, le risque de se blesser est beaucoup moins grand. Lorsque des paroissiens-nes sentent qu'ils ont un mot à dire dans l'animation et l'avenir de leur paroisse, la perspective d'un changement est mieux acceptée. C'est tout autre chose lorsque les paroissiens sentent que tout est arrangé d'avance. La consultation permet de creer un espace de confiance entre tous et chacun" (JEAN, Daniel, La place des paroissiens et paroissiennes dans les aménagements des communautés paroissiales, Mémoire de maîtrise, UQAC-Université de Montréal, avril 1989, p.41). 
oeuvrant à Saint-Dominique de Jonquière. "Biopsie" qui m'a permis de découvrir la vitalité de cette paroisse et de diagnostiquer quelques symptômes pouvant mettre en lumière l'état de 'santé' de cette institution ecclésiale de même que les germes pathogènes. J'avais donc choisi pour cette recherche-action une soixantaine de personnes réparties dans trois groupes (paroissiens, bénévoles, agents pastoraux ${ }^{37}$ ) et six comités ou services paroissiaux différents: les services de préparation au baptême (S.P.B.) et de préparation au mariage (S.P.M.), le comité d'initiation sacramentelle (C.I.S.), le comité de pastorale paroissiale (C.P.P.), le comité de la co-éducation de la foi 38 et le comité homilétique. 39 Également, j'avais observé à Saint-Dominique de Jonquière plus particulièrement quelques paroissiens qui ont bénéficié de l'un ou l'autre

Le terme "agent et agente de pastorale" désigne ici les personnes qui, au titre de leur baptême, exercent au sein de la communauté chrétienne et en son nom une fonction de leadership dans un ou plusieurs champs de l'action pastorale. Ces personnes occupent les fonctions d'animateurs ou d'animatrices de pastorale dans les paroisses, les zones pastorales, les organismes diocésains, les écoles, les mouvements de jeunes et d'adultes, les centres hospitaliers, et autres lieux analogues. Elles sont rémunérées en conséquence par une institution ecclésiale. Cependant, certains ministres ordonnés n'aiment pas être considérés comme des agents de pastorale. Ils disent: "Nous ne sommes pas des agents pastoraux. Nous sommes des prêtres. Un agent de pastorale est un laïque qui a un poste régulier en Église". Pour les respecter, j'emploierai l'expression "agent pastoral" uniquement pour les "laïques". Il m'arrivera d'utiliser le mot "permanent" ou celui d' "intervenant" pour parler de l'ensemble des agents pastoraux, qu'ils soient 'laïques' ou 'prêtres'. Je rappelle que j'emploie l'expression "laïque" parce qu'elle est habituelle dans le circuit ecclésial. En fidélité aux intuitions concilaires de Vatican II, il me semble qu'il n'est plus possible d'employer cette expression. Le chapitre onzième sur l'ecclésiologie du deuxième concile en donnera les raisons theologiques.

38 La co-éducation de la foi est un service qui a été fondé par des personnes du diocèse de Chicoutimi. Les responsables décrivent la co-éducation de la foi comme étant une expérience de croissance personnelle vers une foi plus adulte. "Elle n'est pas des cours de catéchèse, des conférences, ni des cours de bible. C'est une démarche qui aide les parents à découvrir des moyens pédagogiques pour guider leur enfant dans son cheminement de foi... Le grand objectif de ces rencontres est de permettre à des croyants de devenir des 'éveilleurs de la foi' de leurs enfants. Eveiller la foi d'un enfant, c'est d'abord témoigner que l'on vit cette foi... C'est un essai d'apprentissage de six attitudes fondamentales de tout croyant: l'accueil, l'émerveillement, l'écoute, la confiance, la disponibilité et l'engagement... Ce cheminement dure en moyenne cinq ans" (Texte tiré du dépliant 'publicitaire' de la co-éducation de la foi publié par le Service des communautés chretiennes du diocèse de Chicoutimi).

Durant mon stage pastoral, j'ai mis sur pied un comité homilétique pour aider les prédicateurs aux messes dominicales à préparer l'homélie. Quelques croyants se réunissaient chaque lundi soir avec celui ou ceux qui assumaient la prédication du dimanche suivant. Les prédicateurs pouvaient s'inspirer de l'échange des participants. J'ai toujours apprécié les rencontres de ce comité. Les réflexions entendues par ces croyants venant de différents milieux sociaux m'ont toujours aidé dans la préparation des homélies que j'avais à prononcer. 
des services offerts. Je reprends quelques-unes de ces données d'observation dans la présente thèse en les confrontant toutefois à une hypothèse de recherche pétrie par des années supplémentaires d'expériences pastorales. Je me suis aperçu, en relisant mon mémoire de maîtrise, que cette recherche dépendait peut-être trop de quelques présupposés idéologiques. Ayant assumé par la suite de nouvelles responsabilités pastorales, j'ai été confronté à la fragilité de ces idéologies face à la complexité de la réalité pastorale. Il est facile à un stagiaire de critiquer 'son' curé. Mais, quand on le devient soi-même, c'est étonnant comment le point de vue change. Il est facile de critiquer le capitaine d'une équipe de hockey, lorsque on est sur le banc, comme journaliste ou plus haut dans l'estrade, comme spectateur. Mais lorsqu'on se retrouve sur la patinoire, on découvre que c'est beaucoup plus complexe. Les solutions magiques ou les recettes miracles deviennent plus rares. Il y a les mises en échec, les exigences de la ligue et il faut tenir compte du rythme et du style de jeu de chaque joueur. La sagesse populaire affirme que les responsabilités permettent à un être humain de devenir plus "sage" et moins 'idéaliste'. J'ai été souvent déçu dans ma pratique pastorale de stagiaire. Les gens n'étaient jamais rendus là où j'aurais voulu qu'ils soient. Le Pasteur des pasteurs, Jésus de Nazareth, a changé mon regard après quelques mois de ministère presbytéral. Il m'a appris à marcher au rythme des gens et non à leur imposer le mien. Cette attitude m'a permis de m'émerveiller à plusieurs reprises des personnes et des groupes communautaires. Tout n'est-il pas dans la manière de regarder?

Comme je l'ai dit précédemment, j'ai travaillé dans les paroisses Saint-Jude d'Alma et St-Léon de la zone pastorale Est-du-Lac après avoir complété mes études de deuxième cycle en praxéologie pastorale et avoir été ordonné. Connaissant la méthode de recherche praxéologique, j'avais pris l'habitude, dès le début de mon insertion au coeur de ces communautés ecclésiales, de tenir un journal de bord pour y noter mes 
observations et questionnements lors des réunions des différents comités paroissiaux, des rencontres de préparation aux sacrements, des réunions des agents pastoraux de la ville ou de toute la zone pastorale, des rencontres de niveau diocésain, etc. Je m'étais également donné comme discipline de consigner mes observations dans ce journal à la fin de chaque journée de travail pastoral. C'est étonnant ce qu'on peut découvrir lorsqu'on prend le temps de relire avec un 'second regard' ce qui a été vécu dans une journée: personnes rencontrées, célébrations animées, réunions vécues, etc. . Les personnes qui me côtoient régulièrement me surnomme "Colombo" avec calepin à la main et crayon (même encore aujourd'hui!). 40 La méthode praxéologique m'est vraiment devenue familière. En relisant tous mes journaux de bord durant ces quatre dernières années de travail pastoral à Saint-Jude et à Saint-Léon, j'ai eu la surprise de découvrir que j'avais écrit 1050 pages d'observations. ${ }^{41} \mathrm{La}$ vie devient riche lorsque nous sommes attentifs à ce que nous vivons. Nous recueillons au long des jours des données d'observation étonnantes qu'un questionnaire, même des plus sophistiqués, ne saurait contenir. 42 Les gens ouvrent leur coeur, lorsqu'un climat de confiance est créé avec eux. Ceci peut prendre parfois quelques mois ou quelques années. Oscar LEWIS

40

Je fais évidemment référence à la série policière américaine très connue "Colombo". J'ai essayé , très discrètement, d'être un 'Colombo' a l'affût des moindres 'scoops' de la présence du Dieu Vivant au coeur des personnes rencontrées ou des rencontres vécues. Le Dieu de Jésus-Christ est le Dieu de la discrétion. Sans une attention ou une vigilance constante, il est difficile de reconnaitre ses délicats clins d'oeil ou ses subtiles interpellations. Le Professeur Jacques GRAND'MAISON de la faculté de théologie de l'Université de Montréal, appelle cette manière de faire de la recherche: "la théologie de l'insight au quotidien". Pour lui, le théologien doit être très attentif pour être capable de saisir la profondeur de l'autre en peu de temps.

41

Il est bien évident que je ne peux pas faire écho dans cette thèse de toute la richesse des observations que j'ai notées dans mes 1050 pages de journal de bord. J'ai dû faire des choix. Cela a été excessivement difficile puisque c'est toujours douloureux de ne pas noter telle expérience significative vécue en paroisse, telle remarque 'juteuse' d'un croyant ou de ne pas parler de telle rencontre importante vécue avec des personnes demandant un rite de passage, etc.. Je n'ai retenu que quelques données d'observation me semblant plus pertinentes. J'aurais pu facilement choisir d'autres données aussi révélatrices que celles retenues. Elles demeureront malheureusement secrètes... Mais, il faut consentir à cette souffrance de ne pouvoir tout écrire dans une thèse.

42 En affirmant cela, je ne veux pas déprécier les recherches faites par le moyen de questionnaires. Comme j'en ai parlé dans le chapitre premier, les études qualitatives et quantitatives sont plutôt complémentaires qu'opposées. J'ai moi-même utilisé le questionnaire et consulté d'autres études quantitatives. On en retrouve dans les pages précédentes et subséquentes. 
n'a t-il pas déjà écrit que "les instruments les plus efficaces pour une recherche sont la sympathie et la compassion envers les gens que nous étudions."43

Ce journal de bord m'a servi à rédiger la première partie de cette thèse portant sur l'observation. D'autres données ont également été utilisées: par exemple, les questionnaires d'évalution que les membres de l'équipe pastorale dont j'étais membre, ont fait remplir aux bénévoles à la fin de l'année pastorale ou encore à quelques paroissiens qui avaient bénéficié de l'un ou l'autre des services communautaires. J'ai demandé à certains paroissiens de faire le "récit de vie" de leur engagement paroissial. ${ }^{44} \mathrm{Ce}$ récit demeure en effet un outil particulièrement bien adapté pour mener des recherches de type exploratoire (partir des faits). ${ }^{45}$ De plus, certaines observations ont été recueillies grâce à mes implications professionnelles dans trois autres secteurs d'activités. Durant ces six années d'expériences pastorales, j'ai toujours assumé diverses responsabilités (secrétaire, animateur, président) dans le secteur de la pastorale d'ensemble de la ville dont faisait partie la paroisse où j'exerçais mon ministère. La responsabilité d'élu à l'Office du Clergé du diocèse de Chicoutimi, en juin 1989, m'a permis de connaître plus en profondeur les joies et les préoccuptions des prêtres dans l'exercice de leur ministère auprès des différentes communautés York, Randow House, 1961, p. 28. Selon lui, la qualité de l'entretien dépend de la qualité de l'interaction qui s'établit entre le chercheur et l'informateur. Dans l'entretien, sommes-nous en présence d'un informateur qui reçoit un chercheur "savant", ou au contraire, d'un chercheur "ignorant" qui vient s'informer auprès d'un informateur "savant". Le chercheur accorde une légitimité à l'informateur. II reconnaît son savoir sans pour autant renoncer à lui-même.

J'ai recueilli un grand nombre de récits de vie car c'est de la confrontation de ce grand nombre que peut émerger progressivement leur dynamique interne. L'analyse détaillée des récits de vie permet de découvrir progressivement le réel sous l'apparence. Il est difficile de croire qu'un seul récit individuel, même génial, puisse décrire dans et par une pratique synthétique le foisonnement expressif et créatif, non seulement des faits et des situations dans les détails, mais encore la diversité des situations humaines.

45 Le récit de vie est un outil privilégié d'analyse de cette imbrication de l'individu et du collectif, dans le domaine du social comme dans celui du symbolique. Il permet au chercheur de saisir "sur le vif" le jeu des médiations. 
ecclésiales du diocèse. 46 J'ai aussi accompagné durant trois ans (de septembre 1988 à avril 1991) un groupe d'étudiants au certificat en animation pastorale de l'UQAC (Université du Québec à Chicoutimi). Ces étudiants sont majoritairement engagés dans les différentes paroisses de la zone pastorale de l'Est-du-Lac où j'exerçais la plupart de mes responsabilités pastorales. Ces expériences vécues dans ces trois secteurs m'ont enrichi énormément. En écrivant ces lignes, je suis encore touché de toute la confiance qui m'a été accordée dans les différents milieux où j'ai travaillé (municipalité, paroisse, ville, zone pastorale, diocèse, université). Souvent on m'a confié des responsabililés importantes malgré mon jeune âge et mon peu d'expérience. On devient capable de croire en soi lorsque des personnes osent nous faire confiance.

Au coeur de cette longue et patiente observation participante, j'ai voulu vérifier si la dynamique institutionnelle de la paroisse, en regard du projet ecclésial de Vatican II, faisait naître une communion de sujets croyants, ferments du Royaume de

46

"Nous pouvons affirmer que l'Office du Clergé a pour but de s'occuper de la personne et de la vie des prêtres sous tous les aspects: spirituel, intellectuel, matériel et autres. Son champ de compétence embrasse des domaines aussi divers que l'animation spirituelle, les retraites et recollections, le ressourcement intellectuel, les sessions d'étude, l'organisation de cours académiques, l'entraide par la mobilisation de ressources locales, l'hygiène du corps et de l'esprit, les relations fraternelles entre prêtres, la question des salaires et traitements. En un mot, rien de ce qui touche à la personne et à la vie des prêtres, au plan individuel ou au plan collectif, ne peut le laisser indifférent" (PARÉ, Marius Mgr, Ordonnance de Monseigneur Marius Paré pour instituer un Office diocésain du Clergé, Diocèse de Chicoutimi, 1 mai 1975, p.3). J'ai eu diverses responsabilités dans cet organisme diocésain. Les membres de l'Office du Clergé m'ont élu président dans ma deuxième année de fonction. Je n'ai pas pu toutefois terminer mon mandat de trois ans puisque j'ai dû quitter le diocèse pour pouvoir poursuivre des études doctorales selon la demande du Conseil des nominations. Cependant, j'ai continué à faire partie du groupe des jeunes prêtres de mon Église locale. Depuis 1987 , nous nous rencontrons une fois par mois pour partager nos expériences pastorales et les approfondir en utilisant la méthode très connue de l'Action catholique: voir-juger-agir. De plus, mes confrères ont tous obtenu leur maîtrise en praxéologie pastorale. Cette méthode, qui ressemble beaucoup à celle de l'Action Catholique, colore aussi nos partages et nos analyses. J'ai demeuré à l'extérieur de la région du Saguenay-Lac-Saint-Jean pendant mes trois années d'études doctorales. Cependant, j'ai tenu à me rendre à Chicoutimi régulièrement pour participer aux échanges de ce groupe. Ces confrères m'ont aidé à rester bien 'collé' aux défis du pays réel. C'est facile de 'flayer' dans les hautes études supérieures... Les confrères travaillent dans différentes paroisses. Grâce à eux, j'ai pu durant mes études doctorales, être informé mensuellement sur ce qui se passait dans 12 paroisses de l'Église de Chicoutimi et dans quatre zones pastorales. 
Dieu dans le monde. Une autre question bien spécifique s'est posée au cours de cette recherche participative, lorsque j'ai été nommé curé d'une paroisse urbaine: comment renouveler la paroisse pour assumer la mission de l'Église en réponse au phénomène de l'urbanisation en contexte "moderne"? C'est à travers le 'prisme' de ces deux questions que j'ai accumulé mes données d'observations. Les trois prochains chapitres regroupent ces données selon trois catégories de personnes: les paroissiens euxmêmes: les nucléiques et les périphériques 47 ; les bénévoles collaborateurs; les agents pastoraux (laïques, religieux, diacres permanents, prêtres ). Enfin, je débuterai la deuxième partie de ma thèse (le chapitre sixième) en rassemblant en cinq propositions, les éléments clés d'observation plus significatifs.

Dans une région à population restreinte comme celle du Saguenay-Lac Saint-Jean, il est assez facile d'identifier les personnes observées. Pour cette raison, je ne mentionnerai jamais le nom de la paroisse d'où telle ou telle donnée d'observation a été tirée. C'est la meilleure manière de respecter des personnes qui ne s'attendent sans doute pas à être citées nommément. De cette façon, les exigences de la loi sur la protection des renseignements personnels et du code déontologique.de la recherche utilisant des sujets humains sont respectées.

Nous nous retrouvons, en pastorale paroissiale, devant deux groupes de paroissiens. Les premiers sont des personnes pour qui linstitution paroissiale revêt une grande importance dans la façon d'aménager leur vie chrétienne. Ces paroissiens peuvent être considérés comme des "nucléiques", puisqu'ils constituent en quelques sortes le "noyau" de l'institution paroissiale. Ces gens disent "nous" en parlant de leur paroisse. Ils voient celle-ci comme un lieu de fraternité et de partage. En contrepartie, la grande majorité des paroissiens peuvent être vue comme des "périphériques" face à cette même institution. Pour la plupart d'entre eux, la paroisse a une faible importance dans leur façon d'aménager leur vie chrétienne: ils réduisent en général leurs contacts aux rites de passage (baptême, mariage, funérailles,...) et à une pratique dominicale occasionnelle (Noël, Pâques,...) ou quasi-inexistante. Ils voient la paroisse comme un service public avec un lieu de culte, des bureaux et quelques employés. Au cours des dernières années, nous avons assisté à un double mouvement. D'une part, le nombre de bénévoles a augmenté considérablement et a produit un noyau communautaire qui assure aujourd'hui le tonus des paroisses. D'autre part, le sens de l'appartenance paroissiale a diminué chez plusieurs catholiques. 


\section{CHAPITRE 3}

\section{LES POINTS DE VUE DES PAROISSIENS}

La première ressource d'une paroisse, avant ses permanents et ses ministres, c'est le peuple des croyants et des croyantes qui peinent, aiment, construisent, chantent, pleurent, espèrent, prient. ${ }^{1}$ Cependant, la plupart des récentes recherches sur la paroisse s'en tiennent à peu près uniquement au fonctionnement et à l'évaluation des activités et des services paroissiaux. Elles partent de questions internes, à savoir celles des gens engagés dans les communautés paroissiales, et non pas d'une observation de la situation actuelle des paroissiens sur leur terrain réel. Je suis donc d'accord avec les propos du professeur André CHARRON émis lors de la conférence donnée au congrès sur "Les voies d'avenir de la communauté chrétienne locale" qui s'est tenu les 9, 10 et 11 octobre 1992, au Collège Maisonneuve de Montréal, à l'initiative de l'Assemblée des évêques du Québec (AEQ).

"On étudie le fonctionnement de la paroisse dans ses pratiques de service, mais on oublie les paroissiens de toute appartenance avec leurs points de vue, leurs besoins, leurs frustrations, leur situation culturelle concrète. Car la paroisse comme lieu ecclésial public, ouvert au tout-venant, c'est d'abord les paroissiens, l'ensemble des baptisés habitant sur un territoire, c'est-à-dire non seulement les engagés du noyau mais aussi les pratiquants réguliers et les autres." 2

1

Il paraît impossible en effet de parler du salut en Jésus Christ qui vient rencontrer l'être humain sans re-lire la vie humaine avec ses aspirations et ses perplexites, ses joies et ses souffrances, ses appartenances et ses solidarités, ses univers symboliques, etc.

2 CHARRON, André, Réaction au rapport de recherche et aux politiques retenues, in L'Avenir des communautés chrétiennes, Rapport du congrès provincial tenu à Montréal en octobre 1992, Comité de recherche de l'Assemblée des évêques du Québec sur les communautés chrétiennes locales, Montréal, Fides, 1993, p.97. Le congrès a réuni près de 570 participants: 333 laïcs, 51 religieuses et religieux, 2 diacres, 128 prêtres, 25 évêques, 14 représentants de centres de formation pastorale ou de facultés de théologie, 5 délégués de la CRCQ et de la CECC. J'ai aimé entendre les paroles d'homélie du président de l'AEQ à la célébration eucharistique du congrès. Mgr Bernard 
André CHARRON a déjà exprimé cette idée dans un article qu'il a écrit quelques mois avant ce congrès :

"La première est l'attention à porter aux paroissiens. La paroisse est faite de paroissiens et elle existe pour eux. Il faut donc bien connaître leur situation culturelle et religieuse. /.../ Or il importe de faire une véritable cueillette d'informations puis une analyse sur les valeurs, aspirations, besoins, incertitudes, angoisses, souffrances, préjugés et rejets des gens aux plans humains, religieux, chrétien, puis ecclésial. Cette écoute des paroissiens permettra de les accueillir comme ils sont, sans faire acception des personnes. L'Esprit est présent dans le coeur de tout humain: il précède l'évangélisateur. Il faut partir de ce qu'ils portent, reconnaissant une valeur évangélique à leur questionnement autonome et à une multitude de gestes qu'ils posent."3

Hubert a déclaré: "Il me semble, cependant, que cette expérience d'Église, quelles que soient les conclusions que nous en tirions, porte en elle une réalité profonde et prometteuse pour l'avenir. Nous avons travaillé selon le mode synodal. En effet, notre assemblée est formée d'évêques et de prêtres; ils forment $34 \%$ de notre rassemblement. Neuf pour cent sont des personnes engagés en vie religieuse. Cinquante-sept pour cent sont des laïcs participant à la vie des communautés à titre de baptisés et portant avec les religieux, les religieuses, les prêtres et les évêques la responsabilité de la mission /.../ Bref, il me semble que la célébration d'aujourd'hui nous renvoie ce reflet de la lumière de la communauté de Jérusalem: nous sommes entrés dans un temps nouveau de l'Église du Québec, celui d'un travail selon le mode synodal " (HUBERT, Bernard Mgr., L'Église, communauté des disciples de Jésus, Homélie de Mgr Bernard Hubert, in Rapport du congrès provincial...., pp.7879).

3

CHARRON, André, "La paroisse évangélisatrice d'aujourd'hui", in Prêtre et Pasteur, vol. 94, ${ }^{\circ} 10$, novembre 1991, p. 621. Donc, saisir une pratique pastorale, ce n'est pas seulement ce que font, pensent, veulent et disent ses animateurs ou ses ministres, c'est-à-dire ceux qui sont au service de cette pratique. Une pratique pastorale est le fruit d'interactions, de réciprocité, de compromis entre ses différents acteurs. Lorsque nous offrons la possibilité aux paroissiens de s'exprimer, ils profitent de l'opportunité pour dire ce qu'ils portent. C'est ce que l'Église locale de Québec expérimente par son synode diocésain intitulé: "S'évangéliser pour évangéliser". La première étape de cette expérience voulait susciter une vaste prise de parole des gens sur leur vie, leur foi, leur perception de l'Église. À ce point de vue, elle a été incontestablement un succès puisque près de 39 000 personnes ont retourné le questionnaire au diocèse. "Les personnes ont quelque chose à dire! Voilà un énoncé qui peut sembler banal, mais il est toujours important de le rappeler. En dehors de toute contrainte, 40000 personnes ont pris de leur temps pour parler de leur vie, de leur foi, de leur doutes. Serons-nous capables de conserver ouvert ce canal de communication, tant au niveau local que diocésain? Dans une Église qui se veut un peuple, l'expression des idées et des convictions de tous et toutes est importante. Au moment de publier ce rapport, le nombre étonnant d'équipes synodales (plus de 1800) montre que cette prise de parole continue, cette fois avec une dimension collective. Il y a donc un réel désir chez beaucoup de gens d'avoir leur mot à dire dans l'avenir de leur Église" (COMITÉ ORGANISATEUR, PICHER, Jean., dir., Rapport de la première étape du synode, Québec, 27 mai 1993, section E, p.1). 
J'ai consacré aux paroissiens la priorité dans la description de mes données d'observation. J'ai tâché dans la recherche-action d'être attentif non seulement aux paroissiens 'nucléiques' mais aussi aux paroissiens 'périphériques' en allant sur leur terrain. Au début de mon travail pastoral, j'avais pris conscience que nos sources d'informations sont parfois infléchies par les gens qui gravitent constamment autour de nous. C'est à travers eux souvent qu'on voit la réalité. Les autres ne s'expriment pas. Mais ils ont quand même leur propre vision de la paroisse. Il faut les écouter.

\begin{abstract}
"Une théologie "contextuelle" part de ce que vivent les gens, en l'occurrence ceux qui sont à la marge des systèmes de pouvoir et de richesse, ceux qui n'ont guère l'habitude de porter au langage leur expérience et dont la vie est souvent bien loin des discours de l'Église. /.../ Ce travail théologique est fait d'abord d'écoute: une écoute longue et patiente de ce que vivent les gens, de leur expérience humaine, de leur expérience croyante: une écoute pour aider à dire et pour redire. D'où une première nécessité: vérifier constamment si j'ai bien entendu ce qui se dit, alors qu'ils vivent beaucoup de choses heureuses, difficiles ou dures, sans avoir guère l'habitude de les porter au langage; vérifier si les mots que j'utilise, les leurs et les miens, les miens plus généralisants et abstraits, disent bien pour eux-mêmes, et par là pour d'autres, ce qui se cherche à se dire: étape indispensable à la communication."4
\end{abstract}

\title{
3.1 Une identification au territoire paroissial en constante diminution
}

Pendant mes six années d'expérience paroissiale, il m'est arrivé à plusieurs reprises de demander aux gens à quel endroit ils résidaient. Ils me répondaient spontanément: "Je demeure dans la ville de Jonquière ou d'Alma ou dans le village de St-Léon ou de Bégin". La majorité des paroissiens, particulièrement dans le milieu urbain, ne s'identifient pas spontanément comme membres de telle paroisse. Ce n'est que très rarement qu'une personne utilise sa paroisse territoriale comme forme d'identification. Cependant, nous retrouvons cette identification chez quelques paroissiens nucléiques et plus régulièrement chez les personnes qui résident dans une 
paroisse rurale puisque dans cette réalité la paroisse coïncide dans plusieurs situations avec la communauté sociologique. J'ai constaté que dans certaines villes du SaguenayLac-Saint-Jean, quelques personnes s'identifient aux quartiers qui portent souvent le nom de la paroisse. "Je demeure à Ville de la Baie dans le quartier St-Édouard". Mais j'ai observé que cette identification est de moins en moins utilisée chez les jeunes générations. Il m'est arrivé souvent de répondre au téléphone dans les deux paroisses urbaines où j'ai travaillé. Les gens demandaient: "Je demeure dans telle rue, faisonsnous partie de votre paroisse?" Lorsque je leur disais "oui", ils me disaient: "Pourrions-nous recevoir tel service de votre paroisse?"5. Le sentiment d'appartenance à ce grand tout paroissial est ainsi de moins en moins fort chez la majorité des paroissiens, surtout en milieu urbain. Ce sentiment est un peu plus intense chez les paroissiens des milieux ruraux. L'expérience pastorale m'amène à conclure que globalement les paroissiens d'aujourd'hui s'identifient beaucoup plus à leur ville ou à leur village qu'à leur paroisse territoriale.

\subsection{Des intensités différentes d'attachement à la paroisse}

Même si les gens s'identifient de moins en moins à leur paroisse territoriale, il me semble qu'il faut faire attention avant de conclure trop rapidement à leur faible attachement à cette institution ecclésiale. Dans les paroisses où j'ai oeuvré, j'ai toujours été étonné de constater que près de $80 \%$ des adultes qui demeuraient dans le territoire

5

J'ai été surpris de lire les résultats des réponses à la question $n^{\circ} 8$ de l'étude-enquête que la compagnie SOM inc a fait pour le compte des Pères du Saint-Sacrement en mars 1990. "Connaissez-vous le nom de votre paroisse? " $88 \%$ des personnes interviewées ont répondu oui et $12 \%$ ont dit non" (SOM inc, Étude sur la pratique religieuse des catholiques de la région métropolitaine de Montréal pour les Pères du Saint-Sacrement, mars 1990, 115p - Synthèse in Prêtre et Pasteur, "Sondage sur l'eucharistie", vol. 95, n², février 1991, pp. 66-104). En parlant de ces résultats à plusieurs intervenants pastoraux, la majorité d'entre eux m'ont dit qu'ils trouvaient ces résultats irréalistes. Dans une enquête, c'est toujours gênant de dire que nous ne connaissons pas le nom de la paroisse où nous résidons. 
de la paroisse payaient annuellement leur contribution à la capitation. ${ }^{6}$ Nous ne pouvons pas rester indifférents à ces résultats. Comment les interpréter? J'ai posé la question à plusieurs paroissiens 'périphériques' . Voici les propos de l'un d'entre eux qui, à mon avis, est représentatif d'un bon nombre de paroissiens d'aujourd'hui:

". C'est vrai que je ne pratique pas ma religion mais c'est important pour moi de contribuer financièrement à l'église [ Les gens emploient plus le mot "église" que "paroisse"]. Un jour ou l'autre, nous avons besoin de vos services. Nous avons une responsabilité. Nous devons aussi soutenir notre patrimoine religieux et permettre à nos enfants de pouvoir profiter des sacrements quand ils en auront besoin. Nous savons que vous vous occupez aussi des pauvres. Je me dis que cet argent-là doit servir un peu à ça"(Un homme de 45 ans).

Une nouvelle méthode pour augmenter les revenus des fabriques se propage dans quelques paroisses du diocèse de Chicoutimi. Il s'agit de demander aux paroissiens l'autorisation de faire un retrait automatisé d'un certain montant par semaine dans leur compte bancaire. Les résultats dépassent les attentes des marguilliers. Les fabriques qui utilisent maintenant cette formule ont parfois augmenté leur revenu hebdomadaire de $50 \%, 100 \%$ et même plus. Lors d'une capitation à la paroisse Saint-Jude d'Alma, j'ai demandé aux paroissiens un montant supplémentaire pour engager un agent pastoral. Le montant de la capitation a augmenté de $25 \%$ cette année-là. Nous ne pouvons pas affirmer catégoriquement que l'ensemble des paroissiens, même périphériques, sont complètement indifférents à leur paroisse territoriale. Je ne suis pas d'accord avec certains chercheurs qui disent que les paroissiens donnent à leur paroisse dans le but de

6

Les Pères du Saint-Sacrement ont posé une question sur ce sujet dans l'étude-enquête dont j'ai parlé précédemment. À la question 11.11, "dites-moi si vous êtes tout à fait d'accord, plutôt d'accord, plutôt en désaccord avec l'idée suivante: contribuer financièrement à l'Église?" 88\% des personnes interviewées ont répondu qu'elles étaient tout à fait ou plutôt d'accord avec cette idée. (Étude sur la pratique religieuse des catholiques de la région métropolitaine de Montréal pour les Pères du Saint-Sacrement, p.70 .). Je suis bien conscient que ce n'est pas dans toutes les paroisses du Québec que les catholiques paient leur capitation dans l'ordre de $80 \%$. Mes enquêtes dans les autres diocèses du Québec m'ont démontré que ce pourcentage varie d'une Église locale à l'autre de l'ordre de $20 \%$ à $80 \%$. Le constat est le suivant: plus la population d'un diocèse est dense, moins le pourcentage de ceux qui contribuent financièrement à leur paroisse est élevé. 
lier les mains des agents pastoraux lorsqu'ils demandent un service à leur paroisse. ${ }^{7} \mathrm{De}$ telles affirmations prouvent que nous ne prenons pas suffisamment le temps d'aller vérifier les intentions des paroissiens. Nous interprétons souvent leur comportement avec notre vision ou plutôt notre lorgnette! Ces interprétations sont parfois très irrespectueuses des personnes concernées et je me demande si certaines de ces interprétations ne sont pas même purement méchantes à leur endroit. 8 La contribution financière d'un individu à une institution n'exprime-t-elle pas un intérêt réel à celle-ci?

7

"Comme les quêtes ne rapportaient plus suffisamment, pour aller chercher l'argent nécessaire à l'entretien et à la réparation des propriétés, on a misé sur des pratiques telles que les bingos, les bazars, les locations de l'église pour des concerts, des demandes systématiques de contribution à toutes les familles sur le territoire. En agissant ainsi, les communautés perdaient une part de leur liberté, se liaient les mains et s'exposaient à des compromis dangeureux: comment être exigeant pour l'accès aux sacrements quand, par exemple, les personnes sans appartenance ont versé de l'argent pour l'entretien de l'église? Nous voyons ainsi que les communautés auront à revoir leurs pratiques de gestion économique et d'abord, pour ce faire, à réorienter leur politique. Car on ne peut pas aller chercher de l'argent en dehors du réseau des membres de la communauté sans en payer le prix" (Comité de recherche de l'Assemblée des évêques du Québec sur les communautés chrétiennes locales, Risquer l'Avenir, Bilan d'enquête et prospectives, Montréal, Fides, 1992, p.176). L'Assemblée des évêques du Québec a demandé à l'Institut de pastorale de Montréal de réaliser cette recherche participative. Dix-sept des vingt-deux diocèses du Québec ont apporté leur contribution à cette recherche. Trente-six paroisses et deux communautés de quartier ont été choisies dans différentes régions du Québec. Certaines paroisses sont rurales, d'autres urbaines et quelques-unes "rurbaines", c'est-à-dire situées sur la frange des villes et participant autant à la vie rurale qu'à la vie urbaine. Cette recherche est intéressante même si elle a de sérieuses limites. "Je commence par une considération générale sur ce bilan d'enquête et ses visées propectives. Cette recherche constitue très certainement un événement. C'est, à ma connaissance, la première étude portant sur les communautés chrétiennes locales - en l'occurence principalement les paroisses - qui ait cette ampleur et ce sérieux. C'est une entreprise qui aboutit à un rapport substantiel, articulé, systématique. Les résultats, appuyés sur une large consultation de 36 paroisses et de deux communautés de quartier, sont déjà significatifs, même s'ils demeurent limités et tracent un portrait incomplet" (CHARRON, André, Réaction au rapport de recherche...., pp.95-96.).

8 "N'importe quel non-pratiquant, ou presque, peut se dire chrétien et exiger des services de la communauté sans donner de signes d'appartenance à la communauté et sans se préoccuper d'offrir en retour une quelconque contribution. D'où le sentiment chez certains d'encourager le parasitisme des non-pratiquants /.../ À vouloir garder tout le monde, ne risque-t-on pas de tout perdre I.../ Une Église à l'identité faible, à laquelle on peut appartenir à peu de frais, ne va attirer que des consommateurs qui se façonnent une religion à la carte sans vraiment s'impliquer dans un cheminement religieux. /.../ Bien des permanents et bénévoles s'essouflent à offrir des services sans lendemain et vivent des frustrations évidentes face au parasitisme de ces distants" ( Risquer l'avenir...., p.59; pp. 105-106; p. 141). "Si ces différences continuent de s'accentuer, notre vie d'Église est en danger. Ầ la limite, un noyau restreint de gens assez âgés continueraient de se rassembler et de "faire fonctionner l'organisation" avec un dévouement admirable - tandis qu'un grand nombre de 
J'ai pu vérifier à plusieurs reprises que les paroissiens 'nucléiques' sont liés affectivement à leur paroisse. Cet attachement est encore plus fort chez ceux et celles qui travaillent bénévolement dans l'un ou l'autre des services paroissiaux. Cependant, ceux-ci ont plus facilement tendance à avoir un 'esprit de clocher' et à s'ouvrir plus difficilement aux paroisses voisines, particulièrement dans le milieu urbain. Toutefois, leur générosité envers leur paroisse est bouleversante. Quelques bénévoles donnent un nombre d'heures considérable par semaine à leur communauté. J'ai entendu plusieurs fois des bénévoles dire: "Nous nous soucions régulièrement du devenir de notre paroisse. Nous la portons dans notre coeur."

\subsection{La pratique dominicale et l'appartenance paroissiale}

Pour les catholiques qui sont proches de l'institution paroissiale par la pratique dominicale l'attachement varie d'un paroissien à un autre. La parole de l'un d'eux est significative à ce sujet:

"Pour moi, je pense à la paroisse le dimanche. J'aime quand tu nous parles de ce qui se passe dans la paroisse au cours de la messe. Mais, c'est sûr que je viens surtout pour l'homélie. ${ }^{9} \mathrm{Si}$ le sermon était "dole", je ne sais pas si je reviendrais régulièrement. Ça m'aide à réfléchir. Durant la semaine, je n'ai pas le temps de m'arrêter pour penser à ma religion. Tu sais, la vie d'aujourd'hui est excessivement rapide. Nous sommes toujours à la course. La vie nous éparpille. La messe, c'est pour moi mon seul temps où je peux me

plus jeunes vivraient une vie honnête et serviable mais où la foi est une inspiration lointaine et l'Église une dispensatrice de services occasionnels" (Rapport de la première étape du synode, Québec, 27 mai 1993, section E, p.2). Nos interprétations sont remplies de préjugés idéologiques. Selon quels critères jugeons-nous si catégoriquement la qualité des demandes des paroissiens qui se rattachent à la tradition chrétienne?

9

Dans la même étude-enquête de SOM inc, les Pères du Saint-Sacrement ont formulé une question pour savoir si les gens trouvent important le 'sermon' à la messe. La question 26 était la suivante: "Devrait-on supprimer la prédication ou le sermon durant la messe?" 86\% des répondants ont dit non (Voir GARNEAU, Jean-Yves, "Des homélies pour vivre", in Prêtre et Pasteur, vol. 93, $\mathrm{n}^{\circ} 7$, juillet 1990, p. 385 et aussi in Prêtre et Pasteur, "Sondage sur l'eucharistie", vol. 95, n², février 1991, pp. 66-104). Ceci prouve à quel point l'homélie est importante pour les gens. 
ramasser, me réunifier de l'intérieur, me retrouver, être seul avec moi. Je trouve ça dur quand tu dis dans la messe, engagez-vous dans la paroisse ou dans la société. J'arrive essouflé à la messe. Je n'ai plus d'énergie pour m'engager. Le travail, l'éducation des enfants, la popotte, le marché, les réunions, etc...Si je ne prends pas du temps pour me reposer, comme aller à la messe par exemple, je vais craquer, je vais faire un burn-out. J'aime ça venir ici. Les messes dans cette paroisse me nourrissent et m'aident à garder un questionnement permanent sur le sens de la vie" (Un homme de 48 ans).

J'ai constaté que les messes dominicales pouvaient être un moyen privilégié pour créer un lien avec la paroisse et le christianisme. D'où l'importance d'investir dans la qualité des célébrations eucharistiques offertes et particulièrement dans la préparation de l'homélie. Mais la responsabilité pastorale de l'homéliste est très exigeante dans le contexte pastoral actuel. Elle peut même à la longue devenir inhumaine surtout lorsqu'un prêtre est seul dans une paroisse. Pourquoi faut-il que ça soit uniquement le ministre ordonné qui puisse prêcher durant les 52 dimanches de l'année? ${ }^{10} \mathrm{Il}$ m'est déjà arrivé de devoir composer six homélies différentes dans une seule fin de semaine. C'est impossible que nos paroles fassent toujours sens dans de telles circonstances. Il faut réfléchir plus profondément sur cette question. Même si le code de droit canonique le permet dans des circonstances bien particulières 11 , j'ai vécu plusieurs expériences intéressantes en faisant donner l'homélie par des croyants de la communauté.

Les paroissiens participant à l'eucharistie dominicale sont assoiffés de paroles qui goûtent l'eau vive. Si les célébrations sont pour eux des puits qui désaltèrent leur soif d'approfondissement de leur expérience spirituelle, ils deviennent

10

"Parmi les formes de prédication l'homélie, qui fait partie de la liturgie elle-même et est réservée au prêtre ou au diacre /.../ Il appartient au curé ou au recteur de l'église de veiller à ce que ces dispositions soient religieusement observées" (canon 767,1; 767,4).

11 "Les laïcs peuvent être admis à prêcher dans une église ou un oratoire si le besoin le requiert en certaines circonstances ou si l'utilité le suggère dans des cas particuliers, selon les dispositions de la conférence des Évêques et restant sauf le canon 767,1"(canon 764). 
plus intéressés au vécu de la communauté paroissiale. La compilation des données du questionnaire du synode diocésain de Québec confirme ces observations.

"Dans l'Église actuelle, qu'est-ce que vous aimez? Près du quart des réponses se regroupent autour des messes et de la liturgie qui sont vues comme vivantes et signifiantes. Les personnes de plus de $\mathbf{4 0}$ ans sont beaucoup plus affirmatives sur ce point que les jeunes /.../ Dans l'Eglise actuelle, qu'est-ce que vous n'aimez pas? Là aussi, un bon nombre de réponses se concentrent autour de la messe, de la liturgie en général et des sermons vus comme routiniers et peu nourrissants. Ce sont surtout les moins de 40 ans qui expriment cette critique. /.../ Qu'est-ce que l'Église doit changer rapidement? Près de $20 \%$ des réponses parlent d'aller vers les gens, en particulier les jeunes, d'accentuer l'évangélisation et le retour à l'essentiel de l'Évangile. Un nombre à peu près égal de réponses souhaite une amélioration marquée dans la manière de célébrer et de prêcher. Et, logiquement, ce sont les moins de 40 ans qui formulent le plus cette suggestion /...l Notons cette phrase: Faites place à la créativité, au prophétisme, même à la dissidence." 12

"En assistant à divers rassemblements d'Église, des répondants se sont sentis rejoints par les sermons, lesquels leur ont permis de se poser des questions, d'être attentifs à leur vécu et d'amorcer une réflexion. Pour un de nos répondants, "l'Église est là pour provoquer des questionnements" /.../ L'eucharistie, comme seule pratique religieuse effective, semble insuffisante à répondre aux besoins spirituels des répondants. L'ordre du déroulement de l'eucharistie n'est jamais différent, et est devenu monotone pour certains répondants. Ils disent ne pas s'y reconnaître." 13

Les eucharisties quotidiennes constituent pour quelques paroissiens une grande importance dans leur vie de foi. Ce moment de prière communautaire chaque jour de la semaine, permet à plusieurs croyants de vivre un attachement particulier à leur communauté paroissiale. La participation à la messe quotidienne les motive à suivre de plus près le devenir de leur paroisse. Ce sont eux qui sont souvent les plus touchés par les changements proposés dans l'organisation pastorale. Plusieurs personnes présentes régulièrement à l'eucharistie quotidienne disent porter dans leurs prières leur paroisse.

"Je suis une personne âgée et malade. Je ne peux plus m'impliquer activement dans l'un ou l'autre des comités paroissiaux. Cependant, je me sens appelée à soutenir ma paroisse 
par mes humbles prières. Comme les moines ont la vocation dans l'Église de porter le monde dans leurs prières, je me sens cette même vocation pour ma communauté d'appartenance. À chaque eucharistie ici à la paroisse, je prie pour l'ensemble des paroissiens et pour les bénévoles et les permanents. Je prie pour que tous et toutes aient le goût d'approfondir leur relation au Dieu d'Amour et de connaître davantage Jésus"(Une femme de 70 ans).

Étant donné la diminution du nombre de prêtres, il n'est pas toujours possible pour une paroisse de bénéficier de l'eucharistie quotidiennement. Cette situation pastorale affecte bien des paroissiens qui aiment vivre ce sacrement chaque jour. Il m'a semblé important d'être attentif à ce besoin de ces quelques paroissiens. J'ai proposé alors la possibilité aux gens de vivre une célébration de la parole (avec la communion) lorsqu'il n'était pas possible d'offrir l'eucharistie. Cette solution permettait aux intéressés de vivre un temps de prière communautaire chaque jour de la semaine. J'ai formé une équipe de président(e)s de célébrations de la parole pour animer ces temps de prières. J'ai été surpris des "retombées" spirituelles dans le coeur des paroissiens participants et des bénévoles responsables de l'animation de ces célébrations.

\begin{abstract}
"Au début, je n'aimais pas les célébrations de la parole puisque je voulais vivre ma messe. Maintenant j'aime beaucoup ces temps de prières. Les animatrices préparent bien leur célébration. Je préfère même une célébration de la parole bien présidée qu'une petite messe vite célébrée en 9 minutes par un prêtre que je ne connais pas."(Un homme de 70 ans qui avait été agressif envers moi lorsque j'ai proposé les célébrations de la parole). "J'ai été surprise que tu me demandes de faire partie de l'équipe des présidents de célébration de la parole. Je ne me sentais pas compétente pour ce service. Tu m'as fait confiance. J'ai trouvé ça difficile au début d'animer mes premières célébrations. J'étais nerveuse. Mais depuis deux ans, je peux dire que c'est l'engagement qui m'a le plus fait vivre depuis que je suis engagée dans la paroisse. Je dois m'arrêter pour préparer la célébration de la parole. Mon désir d'approfondissement de ma foi et mon attachement à la paroisse a augmenté. Et je suis devenu moins exigeante envers la prédication des prêtres. Ils font ce qu'ils peuvent comme moi. C'est exigeant de prendre la parole devant une communauté mais c'est passionnant" (Une femme d'une quarantaine d'années).
\end{abstract}

Ces témoignages entendus nous amènent à être plus attentifs aux besoins des paroissiens. Nos décisions de réaménagement pastoral ne tiennent pas 
suffisamment compte des attentes des croyants. Avec un peu de créativité, il est possible de trouver des solutions aux besoins spirituels de ceux et celles qui désirent célébrer plus régulièrement leur foi.

\subsection{Une hausse du taux de mobilité des paroissiens dans le milieu urbain}

Selon les membres du C.P.P. des deux paroisses urbaines avec qui j'ai collaboré, $30 \%$ des paroissiens venant à la messe dominicale ne résident pas à l'intérieur des limites territoriales de la paroisse. 14 Cette donnée démontre bien le taux élevé de la mobilité des paroissiens dans le milieu urbain. La recherche-action m'a appris que ceux-ci viennent à la messe à telle paroisse pour différentes raisons: l'heure et la durée des messes, l'homélie préférée, le genre de liturgie, le choix de tel prêtre, etc. Cependant, un bon nombre de paroissiens qui demeurent sur le territoire de la paroisse viennent vivre l'eucharistie dominicale dans leur église paroissiale. La principale raison évoquée par eux pour expliquer leur choix est la suivante: la proximité géographique du lieu de culte. 15 Mais, ce n'est pas parce qu'une église est proche de leur logement ou de leur résidence que celle-ci est automatiquement l'église de leur paroisse. Les limites territoriales de certaines paroisses urbaines ne sont pas très représentatives dans des villes de ma région. Je souriais toujours lorsqu'un

L'étude-enquête de SOM inc sur la pratique religieuse des catholiques francophones du Montréal métropolitain, pour le compte des Pères du Saint-Sacrement, confirme les données approximatives des C.P.P. consultés. À la question \#6 de cette étude quantitative: "Où allez-vous à la messe le plus souvent?", $65 \%$ ont répondu à leur paroisse, $25 \%$ disent y aller ailleurs et $10 \%$ affirment aller soit à leur paroisse ou ailleurs. (Étude sur la pratique religieuse des catholiques de la région métropolitaine de Montréal pour les Pères du Saint-Sacrement, p.72.) .

15 L'étude-enquête des Pères du Saint-Sacrement confirme mes résultats. La question 7: "Pour quelle (s) raison (s) choissisez-vous d'aller à la messe à un endroit plutôt qu'à un autre": à cause de la proximité de cette église: $62 \%$; à cause des gens que vous connaissez: $6 \%$; à cause de la qualité de la célébration: $6 \%$; à cause du prêtre qui dit la messe: $5 \%$; à cause de la qualité de la prédication: 2\%. (Étude sur la pratique religieuse des catholiques de la région métropolitaine de Montréal pour les Pères du Saint-Sacrement, p.73.). 
paroissien me disait: "Eric, j'ai reçu la feuille de la capitation. Je viens d'apprendre qu'ici ce n'est pas ma paroisse. Puis-je revenir à la messe dans cette église?" Toutefois, dans les milieux ruraux, le taux de mobilité des paroissiens est beaucoup plus faible. Une raison toute simple explique cette réalité. Les ruraux vont généralement dans leur église paroissiale puisqu'il y a parfois de nombreux kilomètres qui les séparent de l'autre paroisse la plus proche.

\subsection{Les services communautaires et les paroissiens}

Il est important d'observer les paroissiens qui viennent demander un des services communautaires offerts par les paroisses afin de prendre davantage conscience que c'est souvent grâce à ces services que nous pouvons avoir un contact avec eux. Les paroissiens s'adressent au secrétariat du presbytère pour pouvoir recevoir un service bien précis: un certificat de naissance, de mariage ou de décès, une 'petite' ou une 'grande' messe, un baptême, des funérailles, un mariage 16 , une bénédiction de médailles, etc. Nous recevons également par semaine plusieurs appels téléphoniques de paroissiens qui nous demandent de prier pour eux et même quelquefois de les bénir ou des les confesser 'par téléphone'! Cette pratique pastorale devient plus complexe avec le phénomène de l'enregistrement des conversations au téléphone cellulaire! Étant donné qu'aucune paroisse où j'ai travaillé ne possédait un 'fax', je n'ai pu être confronté personnellement aux enjeux éthiques de la confession par 'fax'!

16 "Dans votre vie actuelle, qu'est-ce qui vous tient le plus à coeur? Pour près de la moitié des personnes, c'est la vie familiale, l'amour du conjoint et des enfants" (Rapport de la première étape du synode, Québec, 12 mars 1993, p. 6). 


\title{
3.6 La popularité des 'rites de passage'
}

Les rites de passage sont encore beaucoup demandés dans les paroisses, autant chez les paroissiens 'périphériques' que chez les 'nucléiques'. Les intervenants pastoraux consultés s'entendent pour dire que dans notre région, à 99\% catholique, plus de 95\% des croyants demandent les différents rites de passage: le baptême, la première communion, la confirmation, le mariage et les funérailles. Ce phénomène est constaté partout dans l'ensemble des Églises du Québec. C'est ce que confirment les résultats de l'étude-enquête des Pères du Saint-Sacrement:

\begin{abstract}
"Dites-moi si vous êtes tout à fait d'accord, plutôt d'accord, plutôt en désaccord, ou tout à fait en désaccord avec les idées suivantes: 1) un catholique doit faire baptiser ses enfants: 93\% disent qu'ils sont tout à fait ou plutôt d'accord et ce pourcentage est très fort dans toutes les catégories d'âge (les jeunes de 18-24 ans ont répondu affirmativement dans l'ordre de $89 \%$ ) et même indépendamment des états civils (87\% de ceux qui vivent en union libre considèrent cette obligation comme importante); 2) se marier à l'église: $84 \%$ des répondants disent qu'ils sont tout à fait ou plutôt d'accord. Même les personnes divorcées ont répondu affirmativement à cette question dans l'ordre de $83 \%$;3) avoir des funerrailles religieuses: $86 \%$ affirment qu'ils sont tout à fait ou plutôt d'accord avec cette idée." 17
\end{abstract}

Ces statistiques révèlent que nos Québécois ont une foi enracinée en l'héritage chrétien. 18 Leurs liens à la mémoire chrétienne, si confus soient-ils, s'expriment dans certains moments plus ponctuels de la vie.

Étude sur la pratique religieuse des catholiques de la région métropolitaine de Montréal pour les Pères du Saint-Sacrement, SOM inc, p.73.

$18 \quad$ "Nous savons que d'autres formes visibles d'attachement à l'héritage chrétien existent dans notre peuple; il est bon de rappeler que $80 \%$ des jeunes parents inscrivent leurs enfants à des cours d'enseignement religieux et à l'initiation sacramentelle"(Rapport de la première étape du synode, Québec, 12 mars 1993, p. 6.). 


\subsection{Les rites de passage et la paroisse territoriale}

Durant les quatre années de travail à la paroisse Saint-Jude d'Alma, j'avais pris l'habitude d'inscrire le lieu de résidence des demandeurs des différents rites de passage. En comptabilisant ces données, j'ai pris conscience qu'en moyenne $46 \%$ des personnes demandant le baptême pour leur enfant résidaient à l'extérieur des limites territoriales de la paroisse. Plus de 50\% des couples qui désiraient se marier à l'église ne demeuraient pas dans la paroisse Saint-Jude.

Étant donné le peu d'emplois disponibles dans la région du Saguenay-LacSaint-Jean, les jeunes quittent de plus en plus leur lieu de naissance pour aller travailler dans les grands centres urbains (ex: Québec, Montréal, Toronto). Mais ceux-ci tiennent à revenir dans 'le lieu de leurs racines' pour vivre certaines étapes de leur cheminement. Ils trouvent de plus en plus important de revenir dans leur 'famille élargie ('clan') pour vivre les rites de passage. Le sociologue Michel MAFFESOLI qualifie ce phénomène du "retour aux tribus". 19 Danièle HERVIEU-LÉGER fait le même constat dans ses recherches. 20 Il m'est arrivé de présider plusieurs célébrations pour des jeunes adultes qui reviennent dans leur paroisse natale pour vivre un rite de passage. En les écoutant, j'ai découvert à quel point il était important d'être accueillant à ces demandes. Prenonsnous suffisamment au sérieux ces demandes de différents rites de passage? Avons-

MAFFESOLI, Michel, Le temps des tribus, le déclin de l'individualisme dans les sociétés de masse, Paris, Méridiens, Klincksieck et Cie, 1988, 283p. Je reviendrai sur ce point au chapitre treizième de la présente thèse.

20 HERVIEU-LÉGER, D., Vers un christianisme de communautés émotionnelles?, in L'État des religions dans le monde, Montréal et Paris, Boréal et La Découverte- Le Cerf, 1987, pp. 507-509. 
nous analysé comme intervenants pastoraux ce qu'il y a de "souterrain" dans cet attachement de plusieurs paroissiens 'périphériques' et 'nucléiques' à leur paroisse natale?

\begin{abstract}
"M. le curé... je réside actuellement à l'extérieur de ma région. Mais je suis né ici. C'est ma paroisse. Mes parents et plusieurs membres de ma famille et de ma belle-famille habitent ici. Serait-il possible de faire baptiser mon deuxième enfant dans ma paroisse natale? J'aimerais tellement que mon fils soit baptisé dans l'église où mon amie et moi avons été baptisés, où nous avons vécu notre première communion, notre confirmation, notre mariage. Nous avons fait baptiser notre premier bébé à ... et puis nous nous sommes dit... non plus jamais! Nous n'avons aucun lien avec cette paroisse de la grande ville de .... Notre fille a été baptisée durant une messe de dimanche. Ma famille était toute dispersée dans l'assemblée. Quand ça été le temps du baptême, ils nous ont appelés. Elle était le numéro 3! Nous connaissions personne. Le climat était froid. Mon amie et moi, nous nous sommes promis de retourner dans notre région pour le baptême de notre prochain bébé. Je ne vais pas souvent à la messe mais c'est important de faire baptiser mes enfants. Je désire leur donner ce qu'il y a de meilleur. Acceptez-vous notre demande?"(Un jeune père de 32 ans).
\end{abstract}

J'ai accepté et j'ai vécu une célébration très signifiante et émouvante avec l'ensemble de leur famille élargie ('tribu'). Cette célébration a été communautaire. Il me semble qu'en pastorale nous confondons le mot 'collectif' et le mot 'communautaire'. La célébration du baptême est en train de prendre une importance jamais égalée dans l'histoire du christianisme. Avons-nous suffisamment pris au sérieux ce déplacement des paroissiens 'périphériques' et 'nucléiques' dans l'intérêt accordé à la célébration du baptême. Je le répète. J'ai vécu de nombreuses célébrations avec des gens qui revenaient dans leur paroisse natale pour vivre un rite de passage et il s'est toujours passé des choses étonnantes. Les commentaires après la célébration me surprenaient toujours. Ce que j'ai vécu m'amène à remettre en question nos célébrations dites 'communautaires' où nous baptisons en série...21 À ce titre, certaines politiques

21

J'ai déjà vécu des célébrations avec 10 bébés à baptiser lorsque j'étais stagiaire. J'ai toujours souffert dans ce genre de célébration. Si les bébés pouvaient parler ou chanter, je me demande s'ils ne chanteraient pas la chanson du petit artiste français Jordy... "C'est dur... dur d'être baptisé avec autant de bébés...C'est dur... dur d'être un bébé!" Dans ces célébrations "à la chaîne", je me sentais plus dans une usine GM que dans une église! Dans une paroisse où j'ai travaillé, le 
pastorales mises en place au nom du principe communautaire doivent être revisées. Il y a un malentendu à dissiper. Une célébration pour plusieurs bébés n'est pas plus communautaire que la célébration pour un seul bébé. Communautaire n'est pas synonyme de collectif. Un réseau familial qui présente un bébé peut être très communautaire et même plus qu'un regroupement de cinq familles qui se connaissent très peu. Il peut arriver que ce soit plus pratique, mais ce n'est pas pour autant plus communautaire. Il existe alors dans les paroisses de fortes tensions. L'offre et la demande ne correspondent pas: les politiques collectivistes mises en branle par plusieurs intervenants pastoraux se heurtent à la recherche d'une démarche d'abord familiale et personnalisée du côté des demandeurs. Nous nous retrouvons alors en pastorale sacramentelle devant une situation complexe et délicate à traiter. Ce n'est pas parce que cette situation est difficile qu'il ne faut pas chercher à l'analyser. Il me semble que l'ensemble des intervenants pastoraux concluent trop rapidement lorsqu'ils affirment que les paroissiens-demandeurs sont des individualistes. N'y aurait-il pas quelque chose de plus profond que nous n'aurions pas perçu dans ce désir des gens de vivre une célébration d'abord familiale? L'expérience pastorale m'invite à penser que la fécondité spirituelle d'une demande sacramentelle dépend de la qualité de l'accompagnement offert et de la célébration vécue. Dans le contexte actuel, il est impossible d'offrir un accompagnement de qualité à ces gens vu le nombre trop élevé de baptêmes, particulièrement dans une paroisse urbaine. Que devrions-nous faire? Ne devrions-nous pas alors donner plus facilement la possibilité à des croyants de la 
communauté paroissiale de baptiser?22 Je crois la même chose pour la présidence d'une célébration du mariage même si je suis conscient que la question juridique est beaucoup plus complexe dans le cas des mariages. 23

Une autre expérience m'a permis de vérifier l'importance des rites de passage pour l'ensemble des paroissiens (qu'ils soient 'périphériques' ou 'nucléiques') et la relativité du lien avec leur paroisse territoriale. Lorsque j'ai été président des agents pastoraux de la ville d'Alma, j'ai défendu avec d'autres permanents la possibilité de laisser aux parents la liberté de choisir la paroisse où ils veulent faire vivre la première communion ou la confirmation à leur enfant. Plusieurs pasteurs étaient réticents. La raison évoquée: "comment allons-nous contrôler les demandes?" Cependant, étant donné que la majorité des agents pastoraux étaient d'accord, c'est la vision "pro-choix" qui a reçu le plus d'appui. Les parents ont pu choisir de faire vivre l'un ou l'autre des sacrements initiatiques dans leur paroisse territoriale ou dans la paroisse où était située l'école primaire ou dans une toute autre paroisse. La majorité des parents ont choisi la paroisse où est située l'école que fréquente leur enfant comme lieu de célébration pour

Service de préparation au baptême avait pris comme politique de ne pas accepter plus de trois enfants par célébration. Mais même avec seulement trois bébés, il est difficile de faire vivre une célébration signifiante à des paroissiens de différentes 'tribus' venant parfois d'univers tellement variés. Un jour, le couple-responsable du service de préparation au baptême d'une paroisse voisine m'a demandé de baptiser leur bébé. Ils désiraient vivre une célébration plus personnelle et significative. Ils n'osaient pas le demander à leur pasteur puisque la politique de 'leur S.P.B.' interdissait toute célébration individuelle.... quel paradoxe?

22 "Le ministre ordinaire du baptême est l'évêque, le prêtre et le diacre (can. 861 \#1). /.../ Ministre extraordinaire: Dans le cas où le ministre ordinaire est absent ou empêché, le catéchiste ou toute autre personne dûment déléguée par l'Ordinaire du lieu peut conférer le baptême (can. 861 \#2)" [ASSEMBLÉE DES ÉVEQUES DU QUÉBEC, Guide canonique et pastoral au service des paroisses, Montréal, Fides, 1991, pp.16-17].

23 "Seuls sont valides les mariages qui sont contractés devant: soit l'Ordinaire du lieu ou le curé ou le vicaire paroissial, - soit un prêtre ou un diacre délégué par l'un des précédents, - soit un laïc délégué par l'évêque diocésain, ainsi que devant deux témoins (can. 1108 \#1 et 1112 \#1, decret $n^{\circ} 3$ in: Document officiel de la CECC, n519 du 30-08-84)" (Ibid, p.142). 
ces sacrements initiatiques. ${ }^{24}$ Ils préférent la communauté d'appartenance que forme le groupe-classe de leur enfant. 25 Dans les célébrations de première communion et du sacrement de la confirmation, nous nous retrouvons alors avec des enfants venant d'un peu partout de l'ensemble de la ville et non pas uniquement avec des enfants venant de familles résidant dans le territoire de la paroisse.

\subsection{L'expansion d'une nouvelle approche pastorale}

À part les demandes concernant le secrétariat et la célébration des funérailles, les paroissiens qui demandent un service doivent généralement de plus en plus rencontrer un bénévole avant de rencontrer un permanent dans les différentes paroisses où j'ai travaillé. Un couple qui demande le baptême pour son enfant rencontre un autre couple, membre de l'équipe du Service de prépation au baptême (S.P.B.), pour parler de cet événement et des étapes à vivre avant la célébration. Un couple de fiancés rencontre un autre couple, membre du service de préparation au mariage (S.P.M.), pour parler de son projet de mariage et pour être informé de la procédure à suivre. Les parents désirant que leur enfant reçoive soit le sacrement du pardon, de l'eucharistie ou de la confirmation participent à quelques rencontres avant la célébration du sacrement demandé. Evidemment, un bon nombre de paroissiens-demandeurs est en désaccord

Les statistiques recueillies auprès de la Commision scolaire d'Alma confirment que 95\% des parents choisissent de faire vivre la première communion ou la confirmation à leur enfant à la paroisse où est située l'école primaire.

25

Je suis bien conscient que ce phénomène est moins répandu dans les autres diocèses du Québec plus populeux. Concernant les sacrements initiatiques, les paroisses prennent de plus en plus de distance avec les écoles primaires . Les inscriptions se font à la paroisse sans que les enfants de l'école primaire en soient parfois informés. Les parents apprennent l'événement par le moyen des annonces publiques (journaux, radio, télévision, bulletin paroissial, etc.). Cette manière de fonctionner ne conviendrait-elle pas mieux uniquement pour les paroisses situées dans les grands centres urbains comme Québec ou Montréal. Il existe encore des liens étroits entre les écoles primaires et les paroisses dans ma région. J'ai parfois l'impression que nous avons "montréalisé" les orientations pastorales ces dernières années au Québec. 
avec cette procédure. Ils disent: "Pourquoi ne pouvons-nous pas rencontrer le curé tout de suite ou régler la date au téléphone? Pourquoi faut-il assister à ces rencontres préparatoires avant la célébration du sacrement ...? N'avons-nous pas été baptisés et confirmés dans la religion catholique?" Mais la grande majorité des paroissiens acceptent (fidèlement) de répondre aux 'exigences' de la paroisse pour pouvoir recevoir le sacrement demandé.

La recherche-action m'a révélé que la satisfaction ou l'insatisfaction des paroissiens concernant ces rencontres dépend de la manière dont celles-ci sont animées et du contenu proposé. En relisant les centaines de rapports d'évaluation de ces rencontres préparatoires, je constate que les paroissiens-demandeurs sont satisfaits lorsqu'ils se sentent bien accueillis et considérés. Ils ressortent plus satisfaits encore lorsque la réflexion entendue part de ce qu'ils vivent concrètement. Les insatisfactions sont très grandes dans certaines circonstances pour trois raisons principales: lorsqu'on sent que les animateurs 1) désirent leur "bourrer le crâne" avec des enseignements ; 2) semblent vouloir profiter de la situation pour leur "mettre le grappin dessus" 3) proposent une démarche beaucoup trop exigeante en terme du nombre de rencontres avant de vivre le sacrement demandé. Je vous fais part de quelques commentaires écrits que j'ai cueillis dans les rapports d'évaluation des paroissiens :

"Je suis venu à reculons à cette rencontre préparatoire. Je repars très heureux. Je me suis
senti chaleureusement accueilli. J'ai aimé partagé avec d'autres /.../ Votre animation est
très dynamique. J'ai senti que ce que je disais était important pour vous. Je n'ai pas senti
que vous désiriez nous imposer 'votre salade' /.../ Je ne pensais pas que mes questions
sur la foi étaient les mêmes que celles de bien d'autres" (Une homme de 46 ans).
"J'ai beaucoup aimé qu'un couple vienne à la maison pour voir mon bébé et me parler du
service que vous offrez pour le baptême. Avant que ces gens arrivent, je me suis
demandé ce qu'ils venaient faire. Ça m'a fait peur. Mais nos échanges ont duré plus d'une
heure. Eux aussi avaient des enfants. Nous avons parlé de l'éducation de la foi des
enfants. C'est rare que je parle de ça. Mais ça m'a fait du bien d'en parler. Je me suis
aperçu que l'Église avait changé. J'ai aimé la rencontre en grand groupe de ce soir mais
j'ai beaucoup plus apprécié l'échange à la maison avec ..... Nous sommes allés 
profondếment dans le partage. J'ai été moi-même surprise de tout ce que j'ai partagé " (Une mère de 34 ans).

"J'ai trouvé cette réunion de préparation au baptême très éclairante. Vous vous êtes intéressés au début de la rencontre à ce que j'ai vécu dans ma grossesse et mon accouchement et de ce que je suis en train de vivre actuellement. J'ai été surprise. Ça m'a fait du bien de partager et de rencontrer des personnes vivant la même réalité que moi. Ce n'est pas toujours facile d'être mère aujourd'hui. Pour mettre un enfant au monde, il faut avoir la foi en la vie! J'ai hâte de vous revoir à la cérémonie "( Une femme de 31 ans).

"J'ai apprécié la rencontre préparatoire pour la confirmation de mon garçon. Je m'attendais qu'on parle de détails techniques: l'heure qu'on devrait arriver, la photo avec l'évêque, etc. Nous avons réfléchi sur les défis comme parents d'accompagner notre enfant dans sa période d'adolescence et sur notre rôle dans sa croissance spirituelle. J'ai été surpris de la qualité des échanges dans l'assemblée. Vos messes devraient être comme cela. Je comprendrais quelque chose. J'ai servi la messe en latin lorsque j'étais jeune. Maintenant c'est en français. J'y vais très occasionnellement mais je ne comprends pas plus /../ Bravo pour votre animation" (Un homme de 44 ans).

"Je ne sais pas dans quel monde vous vivez. Il ne m'a pas été possible de venir assister à vos quatre rencontres pour la préparation de la première communion de ma fille. Je suis mère d'un autre enfant plus jeune. Je travaille à l'extérieur. Je dois voyager. J'espère que ma fille pourra quand même avoir ce sacrement. Merci de votre compréhension"(Une femme de 34 ans).

"Je suis presque jamais à la maison. Je suis séparé de ma femme. Mais c'est moi qui ai la garde de mon enfant. Je travaille sur demande. Je n'ai pas pu participer à la rencontre d'information et d'inscription. Je suis donc allé au presbytère moi-même pour.inscrire mon enfant au sacrement.... Je me suis pensé à un poste des douanes ou à un poste de police. La personne qui était là n'a pas arrêté de me questionner. Ça finissait plus. 'L'interrogatoire' a duré plus d'une heure..... Pourquoi je me suis séparé de ma femme? Pourquoi je trouvais important de faire vivre la première communion à mon enfant en étant séparé? etc....etc.... Je me suis demandé si la personne travaillait pour la 'GRC'. J'avais tellement hâte de sortir du presbytère. Après l'enquête, la personne m'a informé des dates des rencontres préparatoires dans les différentes paroisses de la ville. J'ai décidé de choisir une autre paroisse, la vôtre. Mais j'ai hésité avant de venir puisque j'avais peur de subir une autre enquête. Je suis venu parce que j'ai la foi, sans ça jamais j'aurais remis les pieds à l'église. Ma femme m'a quitté. J'ai trouvé cela très difficile. Sans l'aide de Dieu, jamais je n'aurais pu passer à travers. Je désire que mon enfant connaisse le Seigneur. L'eucharistie est un moyen. Merci d'avoir accepté ma demande même si je suis un divorcé"(Un père de 43 ans).

\subsection{Les effets néfastes d'un refus d'une demande de rite de passage}

Il m'est arrivé d'accepter des demandes sacramentelles de paroissiens qui avaient été refusés dans d'autres paroisses pour différentes raisons. J'ai toujours été étonné à quel point un refus pouvait avoir des conséquences chez les paroissiens- 
demandeurs, lesquels sortent excessivement agressifs de cette expérience de refus. ${ }^{26} \mathrm{Il}$ est difficile par la suite d'amorcer un dialogue avec eux. C'est possible à condition de passer de longues minutes à aider ces personnes à liquider leur agressivité et leurs frustrations. Qu'est-ce qu'il y a derrière cette forte réaction des paroissiens qui ont été refusés lors d'une demande sacramentelle? Avons-nous pris le temps comme intervenant pastoral de nous laisser instruire par leurs réactions et de pas nous laissser coloniser par nos préjugés? J'ai souvent entendu des agents pastoraux dire: "Ils réagissent violemment parce qu'ils n'ont pas reçu leur bonbon sacramentel. Nous ne sommes pas des guichets sacramentels automatiques." Au lieu de les écouter et de chercher plus profondément à savoir pourquoi c'est aussi important pour eux de recevoir tel sacrement, certains intervenants pastoraux se ferment sur leur position et la relation pastorale devient presqu'impossible. Il est bien évident que certains demandeurs ne sont pas toujours faciles à accueillir. Il m'est arrivé à quelques reprises de me sentir considéré comme une distributrice à sacrement. Mais quand nous expliquons notre approche pastorale avec délicatesse, les paroissiens qui refusent l'accompagnement proposé sont très peu nombreux. Dans les premières minutes d'échange avec les paroissiens-demandeurs, ils peuvent sembler être uniquement des consommateurs de services, mais lorsque nous créons une bonne relation avec eux, nous découvrons leurs motifs profonds. Les pratiques pastorales ont changé ces derniers années. C'est normal que des paroissiens restent surpris des nouvelles manières de fonctionner en Église. Il ne faudrait pas oublier que, nous-mêmes comme intervenants pastoraux, nous sommes parfois perdus dans certains changements dans d'autres domaines de la vie. Dans ces situations, ne souhaitons-nous pas être accueillis

26

En effet, considérer chacun des participants d'une pratique comme sujet de celle-ci nous conduit aussi à prendre au sérieux la Règle d'or qui nous rappelle, selon les termes de Ricoeur, que "l'autre est potentiellement la victime de mon action." Combien de gens nos pratiques n'ont-elles pas blessés, le plus souvent à notre insu parce que, justement, nous n'étions pas attentifs au réel. (Voir RICOEUR, P. et al., MADEAU, J.G., dir., Etudes pastorales et interprétations, Montréal, Fides, 1989. [Cahiers d'études pastorales \#6] ). 
et être informés 'poliment'? Pourquoi ne faisons-nous pas la même chose envers des paroissiens qui n'ont pas suivi l'évolution ecclésiale des dernières années?

\subsection{L'importance de l'approche pastorale}

Durant mes six années d'expériences pastorales, j'ai rarement été déçu des rencontres que j'ai vécues avec les paroissiens demandant un sacrement ou un tout autre service communautaire. En écrivant ces lignes, reviennent à ma mémoire plusieurs rencontres vécues avec des mères célibataires, des couples divorcésremariés, des couples 'accotés', en somme avec ceux qu'on appelle malheureusement en Église 'les distants'. Plusieurs d'entre eux se sentent rejetés par l'Église 'officielle'. J'ai régulièrement été témoin de l'énorme souffrance vécue intérieurement par les personnes que l'institution ecclésiale marginalise. L'Église leur fait vivre une culpabilité disproportionnée qui empoisonne leur vie. 27

Voici une expérience vécue ( je pourrais vous en décrire des dizaines) laissant entrevoir qu'un moindre geste pastoral peut avoir une importance indéniable dans le cheminement des personnes. L'expérience m'a maintes fois permis de constater avec étonnement à quel point un geste d'accueil peut se révéler important pour le tout-venant qui sollicite un service pastoral.

"Il n'est donc pas étonnant que ces personnes souhaitent une Église où la qualité des relations humaines soit première, et qu'elles apprécient tout ce qui est signe d'ouverture, de respect, de compassion de la part des autres chrétiens et chrétiennes et spécialement des prêtres. Inversement, tout signe d'intransigeance, de condamnation, de froideur est durement ressenti." 28

27

"Autant les personnes qui ont vécu des échecs conjugaux que les autres, nous disent que la foi doit pouvoir se vivre dans cette variété de situations, sans que personne ne se sente exclu"(Rapport de la première étape du synode, Québec, 27 mai 1993, section E, p. 4). 
"Ce qui est certain, c'est que les mots les plus souvents employés pour décrire ce qu'on aime dans l'Église actuelle ou ce qu'on aimerait qu'elle devienne sont: "accueil", "écoute", "compassion". /.../ Ce qu'on apprécie chez beaucoup de prêtres, c'est leur attitude d'accueil, d'écoute, de non-condamnation." 29

On se sait jamais la valeur d'un geste, si petit soit-il. Un jour, je suis allé participer à une réunion de parents dans une école primaire. Au cours de la rencontre, je suis intervenu pour dire quelques mots. Après l'assemblée, un couple vient me voir pour dire qu'il avait apprécié mon intervention. Avant de nous quitter, ils me disent rapidement: "nous avons entendu dire que tu es un prêtre, est-ce vrai?" Je leur réponds affirmativement. "Serait-il possible que tu viennes chez nous, nous aimerions partager avec toi". Je fixe un rendez-vous. Je vais à leur maison (sur leur terrain!). Nous commençons à dialoguer. Vers la fin de la rencontre, ils me disent: "Ça fait plusieurs années que nous ne sommes pas allés à l'église. Nous avons trois enfants et aucun n'est baptisé. Mais nous aimerions peut-être les faire baptiser. Avant, te serait-il possible de nous accompagner. Nous avons beaucoup de questions sur la religion. Si après quelques rencontres, notre désir est toujours là, eh bien, tu nous diras ce que nous pourrions faire." J'ai accepté avec joie. Je suis allé prendre un repas chez eux à quelques occasions. Après chacune des rencontres, j'étais toujours émerveillé de la profondeur de leur questionnement et de leur qualité d'humanité. J'ai connu leurs enfants. Finalement, j'ai présidé la célébration de leurs baptêmes après avoir vécu quelques échanges ensemble. Je me rappellerai longtemps tout ce que j'ai vécu avec eux avant, pendant et après la célébration. Mais ce n'est pas terminé.... Imaginez... Ce couple a parlé de son expérience à quelques collègues de travail. J'ai vécu un cheminement similaire avec trois autres couples de leur milieu professionnel. Avant mon départ de la paroisse comme curé, ces couples se sont réunis pour me fêter en signe de reconnaissance. J'ai été ému par ce qu'ils m'ont écrit dans leurs cartes. En 
toute humilité, je vous partage certains de leurs écrits pour démontrer à quel point c'est surprenant tout ce qui peut se passer dans le coeur de croyants lorsqu'on prend le temps de les écouter.

"Pour nous, tu as été chaleur et lumière, nécessaire à une phase importante de notre croissance /.../ Grâce à toi, nous avons découvert que nous avons plus la foi que nous le pensions. Quelle joie d'avoir découvert que nous pouvions approfondir notre foi à travers les questions que la vie nous pose " (La famille $\mathrm{X}$ ).

"En faisant ta connaissance, nous nous sommes enrichis de ton naturel et de ton écoute /.../ Ça été éclairant de découvrir que ce que nous rejetons, ce ne sont pas les éléments de base de la foi chrétienne, mais certaines affirmations du Pape. La foi est plus vaste que les discours officiels de l'Église " (La famille Y).

"Nous avons toujours pensé que la foi c'était de quoi en dehors de notre vie. Avec ton aide, nous avons découvert que nous pouvions vivre notre foi au coeur de notre vie personnelle, familiale et dans notre milieu de travail. /.../ Nous ne sommes plus les mêmes depuis nos rencontres avec toi mais les mots nous manquent pour l'instant pour nommer clairement tout ce qui se passe en moi et chez .... Dieu n'est plus le même, Jésus non plus, l'Église non plus " (La mère de la famille Z).

Je pourrais écrire des pages et des pages d'expériences positives vécues lors des demandes sacramentelles. Mais pour que celles-ci puissent être dynamisantes autant pour les paroissiens-demandeurs que pour les intervenants pastoraux, il faut prendre du temps. Je le répète. La fécondité sacramentelle d'une demande est dépendante de la qualité de l'accompagnement offert et de la célébration vécue. Dans le contexte actuel où ce sont habituellement les diacres permanents et les prêtres seulement qui peuvent présider les sacrements, il est presque impossible d'offrir une qualité d'accompagnement aux paroissiens-demandeurs de rites de passage, surtout dans les paroisses situées en ville. Comment pouvons-nous être attentifs aux personnes lorsqu'il y a plus de 100 baptêmes, 100 funérailles et 50 mariages dans une paroisse urbaine avec uniquement deux ou trois "présidents mandatés"? Il faut obligatoirement réfléchir en profondeur sur cette question en théologie pastorale. J'ai accompagné des centaines de personnes lors de la mort d'un être cher. J'ai toujours été surpris de tout ce qui était réveillé dans le coeur des êtres humains quand ceux-ci 
perdent un membre important de leur famille. 30 Une écoute attentive d'un permanent dans ces situations peut parfois permettre à des êtres humains de passer à travers une épreuve avec un peu plus de douceur ou d'approfondir des questions existentielles importantes. 31 Une célébration de funérailles peut laisser des traces surprenantes dans le coeur des personnes affectées. Mais, pour faire sens à la célébration, il faut offrir un qualité de présence. Il est difficile de faire écho à ce que les personnes vivent dans un événement si nous ne prenons pas le temps de les écouter.

\subsection{Les attentes diverses des paroissiens envers les permanents}

Les paroissiens, surtout les 'nucléiques', ont des attentes diverses par rapport aux permanents et plus particulièrement par rapport au curé. Les uns veulent un curé confiné à un ministère cultuel, d'autres le désirent présent aux diverses activités sociales. Certains attendent de lui des directives morales. ${ }^{32}$ D'autres encore sont plus sensibles soit à ses qualités d'administrateur, soit à celles de conseiller. Ces attentes peuvent différer non seulement en fonction des individus, mais aussi des catégories sociales et des paroisses. Les uns apprécient un prêtre autoritaire, d'autres le veulent plus démocratique. Nous ne devons donc pas être surpris des critiques avec un tel éventail d'attentes....

\section{0}

"Qu'est-ce que vous trouvez souffrant, difficile? La maladie et la mort, pour soi et pour ses proches, est la cause principale de souffrance pour un cinquième des répondants"(Rapport de la première étape du synode, Québec, 12 mars 1993, p.7).

31 "Ta qualité d'attention lors du décès de ...... a contribué à adoucir mes blessures et à me donner le goût de poursuivre l'aventure de ma vie"(une femme de 50 ans).

32 "Ici, il faut souligner que pour une partie de nos répondants, peu nombreux, mais qui ont souvent fourni des réponses détaillées et des lettres très développées, le problème majeur actuel est le manque d'enseignement doctrinal et moral précis, exigeant et présenté avec autorité par le clergé" (Rapport de la première étape du synode, Québec, 27 mai 1993, section E, p. 11.). Nous constatons dans cette période d'incertitude économique une remontée de la droite non uniquement au niveau politique mais également au niveau religieux. 


\section{CHAPITRE 4}

\section{À l'ÉCOUTE DES BÉNÉVOLES 1}

Phénomène marquant depuis plus de trente ans: de nombreux croyants, femmes et hommes, participent à la vie et à la mission de l'Église. Voilà un point positif qu'il faut enregistrer: l'engagement de nombreuses personnes dans les paroisses. C'est à dessein que je poursuis la description de mes données d'observation par ces chrétiens engagés, tant il est vrai que la vitalité d'une Église ne se calcule pas d'abord au nombre de permanents à son service mais à l'engagement de ses membres.

\subsection{Des "forces vives" pour les paroisses}

La mise sur pied ces dernières années des divers comités pastoraux a eu un impact immédiat sur le nombre de bénévoles engagés dans la vie des communautés paroissiales. ${ }^{2}$ Mes responsabilités dans les différentes paroisses où j'ai travaillé m'ont

Je désigne, par "bénévoles" à l'action pastorale, les personnes qui s'engagent activement au service de leur communauté paroissiale, au titre de leur foi de baptisés et sans autre reconnaissance que leur sentiment d'appartenance ecclésiale. Ce sont les bénévoles qui forment ce qu'on peut appeler "le noyau" ou "le coeur" de chaque paroisse. Ce sont les gens de la place, comme on dit, "ceux qui restent alors que les curés passent".

2

Le comité de recherche de l'Assemblée des évêques du Québec sur les communautés locales montre dans son étude intitulée Risquer l'avenir cette augmentation considérable de bénévoles engagés dans les paroisses du Québec depuis quelques années. "Même dans les communautés qui avaient peu de ressources ou qui sont entrées tardivement dans le processus, on constate une différence sensible entre le nombre de personnes impliquées en 1970 et celui en 1990. Comme minimum, on observe habituellement une augmentation de $100 \%$. Mais dans la majorité des communautés, cette augmentation est de $200 \%, 300 \%$, $500 \%$ et plus. Voici quelques chiffres permettant des comparaisons.

\begin{tabular}{ccc} 
& Tableau III & \\
1970 & 1990 \\
\hline Laïcs engagés & Laïcs engagés
\end{tabular}


alors permis de faire route avec des centaines de bénévoles. Mon expérience de stagiaire à Saint-Dominique de Jonquière m'a donné une première occasion de connaître un peu plus les joies et les difficultés de plusieurs collaborateurs et collaboratrices à l'action pastorale. Comme je l'ai dit précédemment, lorsque j'ai travaillé dans cette paroisse, j'avais dénombré plus de 200 bénévoles dans l'un ou l'autre des vingt-sept comités paroissiaux. À cette époque, pour recueillir des données d'observation en vue de la rédaction de mon mémoire de maîtrise en praxéologie pastorale, j'avais choisi plus particulièrement une cinquantaine de bénévoles faisant partie de six comités paroissiaux. ${ }^{3}$ La majorité des personnes interrogées était des femmes. ${ }^{4}$ Cependant, dans deux des comités observés (le service de préparation au

$\begin{array}{llr}\text { Communauté 2B } & 30 & 250 \\ \text { Communauté 7B } & 6 & 15 \\ \text { Communauté 11B } & 85 & 325 \\ \text { Communauté 23B } & 50 & 275 \\ \text { Communauté 35B } & 40 & 125\end{array}$

3 J'avais cueilli ces données en faisant remplir un questionnaire ouvert à 8 couples travaillant dans les services de préparation au baptême (S.P.B.) et au mariage (S.P.M.), en interviewant personnellement 34 bénévoles impliqués dans le comité d'initiation sacramentelle (C.I.S.), le conseil de pastorale paroissiale (C.P.P.), le service de la co-éducation de la foi et le comité homilétique. De plus, la relecture de toutes les évaluations faites par les membres de ces six comités observés à la fin de chacune de ces deux années de travail pastoral comme stagiaire dans cette paroisse m'a apporté des éléments d'observation complémentaires. Je réutilise plusieurs de ces données dans la présente thèse en les passant toutefois au crible d'une hypothèse de recherche beaucoup plus vaste et pétrie par d'autres années d'expériences professionnelles à plein temps sur le terrain paroissial.

$4 \quad$ Les observations dans les quatre paroisses désignées m'ont permis de découvrir que plus de $80 \%$ des bénévoles sont des femmes. Une enquête menée par la responsable de la condition féminine du diocèse de Chicoutimi en 1986 confirme que les personnes qui s'engagent en paroisse sont à $90 \%$ des femmes. Le temps qu'elles accordent au bénévolat est extrêmement variable, souvent incalculable. La grande majorité consacre entre une à cinq heures par semaine. Voir Rapport de la consultation sur le bénévolat des femmes dans l'Église, Diocède de Chicoutimi, septembre 1986. D'autres recherches arrivent à des résultats similaires. "Le plus souvent, les bénévoles impliqués dans la vie de la communauté sont à $70 \%$ et parfois à $90 \%$ des femmes. Il y a donc là un double phénomène: d'une part la montée des laïcs dans l'animation pastorale et d'autre part l'implication imposante des femmes. Le visage des communautés s'est donc trouvé profondément transformé par ce phenomène" (Risquer l'Avenir, p.27). "Mais la grande nouveauté de ces vingt dernières années c'est que les femmes ont dans l'Église des postes de responsabilités. Selon une étude datant de 1984, menée par la Conférence des évêques catholiques canadiens dans soixante-cinq diocèses, les femmes 
baptême [S.P.B.] et le service de préparation au mariage [S.P.M.] ), on retrouvait autant d'hommes que de femmes en raison même de la structure de fonctionnement demandant que ce soit le couple qui s'engage. En général, ces bénévoles se sont impliqués en grande partie parce qu'ils ont été interpellés par l'un ou l'autre des permanents de la paroisse. Parfois, quelques-uns ont été recrutés par un autre bénévole engagé dans un comité. On en compte que deux, et ce sont des jeunes, qui sont venus d'eux-mêmes offrir leur disponibilité à s'engager dans la communauté paroissiale. La moyenne d'âge de ces bénévoles varie d'un comité à l'autre et on les retrouve dans différents groupes d'âge. Un nombre très limité est formé de jeunes entre 18 et 30 ans (six), quelques-uns ont de 30 à 40 ans (14) et les autres, en nombre supérieur (30), ont 40 ans et plus. ${ }^{5}$ Huit bénévoles interrogés ne demeuraient pas dans le territoire de la

forment $78 \%$ des collaborateurs laïcs et religieux non-prêtres travaillant à plein temps en pastorale " (HÉBRARD, Monique, "Connues mais pas reconnues", in L'actualité religieuse dans ce monde, $n^{\circ} 108,15$ février 1993, p. 35). Nous constatons le même phénomène aux Etats-Unis et en France. "Aux États-Unis, le quart des femmes catholiques sont engagées en paroisse dans un 'ministère' transmission de la foi, éducation, liturgie, administration. En France, sur les 220,000 catéchistes qui transmettent la foi aux enfants, plus de $80 \%$ sont des femmes. Sur les 12300 animateurs d'ADAP, $70 \%$ sont des femmes "( Ibidem ). Le fait de se trouver en présence d'une Église en grande partie féminine bien que presqu'entièrement dirigée par des hommes pose de sérieuses questions. Selon un sondage réalisé par la maison de recherche SOM pour le compte de La Presse et de TVA, les Québécois sont de plus en plus en faveur de l'ordination des femmes au presbytérat. "Plus des trois quarts (77 p. cent) des Québécois sont en faveur de l'ordination des femmes à la prêtrise. La participation des femmes aux tâches pastorales recueille chez eux un appui de $91 \mathrm{p}$. cent /.../ Le refus de l'Église catholique de permettre aux femmes d'accéder à la prêtrise est jugé discriminatoire par 68 p. cent des personnes interrogées." (BÉLIVEAU, Jules, "Oui massif des québéçois au sacerdoce des femmes, in La Presse, Montréal, 3 avril 1993, pp. A-1, A-2.). "Dans l'Eglise actuelle, qu'est-ce que vous n'aimez pas? /.../ L'autoritarisme, le pouvoir trop grand du clergé, l'absence d'une place suffisante pour les femmes sont évoqués par un nombre à peu près égal de répondants et de répondantes" (Rapport de la première étape du Synode, Québec, 12 mars 1993, p.10).

5 Mon échantillon de bénévoles était bien représentatif. Gilles GOSSELIN, docteur en andragogie, a fait une enquête quantitative auprès de toutes les personnes qui ont participé aux activités d'éducation de la foi du mini-synode du diocèse de Hearst en Ontario qui s'est déroulé en quatre sessions, du Carême 1989 au 8 décembre 1990. Il a recueilli 281 réponses. Il est arrivé aux mêmes résultats concernant le profil général des sujets impliqués en paroisse. " La première des quatre démarches préalables à l'étude de la question de recherche elle-même concerne le profil des sujets. En gros, le groupe comprend une majorité de femmes $(74,6 \%)$, de personnes mariées $(76,4 \%)$, relativement âgées $(67,9 \%$ de plus de 45 ans) et dont les trois quarts possèdent une formation au moins de niveau secondaire. Le fait que trois fois plus de femmes que d'hommes ont répondu au questionnaire semble correspondre à la proportion des hommes et des femmes qui 
paroisse. De cette cinquantaine de bénévoles, il y en avait une dizaine qui venait tout juste de s'impliquer dans la paroisse. La majorité d'entre eux offrait leur service à la paroisse Saint-Dominique de Jonquière depuis quelques années.

Durant ma première année d'expérience pastorale, j'ai constaté que les bénévoles aiment poursuivre leur bénévolat dans un autre comité après avoir oeuvré de trois à cinq années dans un service paroissial. Pour eux, le changement est important. II permet d'éviter la routine et d'affronter de nouveaux défis. Après un certain nombre d'années, quelques-uns préfèrent poursuivre leur bénévolat ailleurs qu'en paroisse. D'autres décident de prendre un temps d'arrêt, soit pour refaire " le plein", comme ils disent, soit pour consacrer davantage de temps à leur famille. Toutefois, il y a un petit nombre de bénévoles qui demeurent impliqués dans le même comité pendant plusieurs années. Les personnes qui travaillent en pastorale paroissiale savent bien que le phénomène d'une implication d'un bénévole à long terme dans un même comité n'est pas sans poser des problèmes. Ces bénévoles ont tendance à s'approprier le comité et freinent ainsi le changement parfois nécessaire à la vitalité pastorale d'un comité. 6

s'impliquent habituellement dans les activités pastorales, spirituelles, liturgiques ou de l'ordre de l'éducation de la foi, présentées par les paroisses. /.../ Aussi, plus des deux tiers des sujets sont d'un âge relativement avancé, proportion qui semble refléter la réalité non seulement au plan de l'éducation de la foi, mais aussi au plan de la pratique liturgique, et dont le déséquilibre pose aussi de sérieuses questions à notre Église" (GOSSELIN, Gilles, "Fondements psychosociaux des motifs de participation des adultes en éducation de la foi", in Sciences pastorales, $\mathrm{n}^{\circ} 11,1992$, pp.45-46; $\mathrm{p} .48$ ). $6 \quad$ Ce problème m'a fait prendre conscience qu'il n'y a pas seulement les prêtres qui pouvent être atteints par le 'cléricalisme'. Un des symptômes du cléricalisme est de vouloir tout contrôler. Certains bénévoles engagés depuis plusieurs années en paroisse ont parfois tendance à "attraper" facilement ce virus. Ils sont impliquếs partout. Nous nous demandons à la longue si ceuxci ne sont pas plus préoccupés par eux-mêmes que par le devenir de la communauté. Ils déplacent beaucoup d'air mais "leurs courants d'air" donnent parfois la grippe à d'autres paroissiens qui les côtoient. J'ai tenté de solutionner ce problème lorsque j'ai été nommé curé de la paroisse Saint-Jude d'Alma. J'ai proposé aux membres du C.P.P. de remettre, aux bénévoles impliqués dans certains comités, un mandat pastoral de trois ans renouvelable après une évaluation. Ils ont accepté. J'ai constaté la fécondité de cette orientation pastorale. 
Mon expérience de stagiaire à la paroisse Saint-Dominique de Jonquière et ma recherche-action pour la rédaction du mémoire de maîtrise m'ont permis de connaître le vécu de plusieurs bénévoles de l'action pastorale. Mais mon travail à temps plein, pendant quatre autres années, dans la paroisse Saint-Jude d'Alma comme diacre, vicaire et curé ainsi que dans la paroisse de Saint-Léon (pendant deux ans) comme solidairement responsable avec un collègue plus âgé, m'ont permis de connaître encore plus profondément ce que vivent les bénévoles en paroisse. Personnellement, j'ai toujours eu comme priorité pastorale de consacrer beaucoup de mon temps aux bénévoles, particulièrement lorsque j'ai été nommé curé de la paroisse Saint-Jude d'Alma. J'avais comme conviction (je l'ai encore!) que les communautés paroissiales peuvent avoir un avenir prometteur si de plus en plus de paroissiens deviennent des croyants autonomes et responsables. ${ }^{7}$ Et cela, me semble-t-il, advient difficilement sans une qualité d'accompagnement des bénévoles par les permanents. J'ai donc consacré beaucoup d'heures "de compagnonnage" aux bénévoles de SaintJude d'Alma. Je n'ai pas chômé puisque ce n'était pas le nombre de bénévoles qui manquait dans cette paroisse. Il y a approximativement plus de 250 bénévoles impliqués dans l'un ou l'autre des trente comités 8 : le Conseil paroissial de pastorale (C.P.P.), le Conseil de Fabrique, l'initiation sacramentelle (Première Communion et sacrement du pardon, Confirmation, rencontre des parents, catéchèses initiatiques), les Cursillos, le mouvement des Femmes chrétiennes, le comité des malades, la pastorale

Même si le noyau paroissial de 100, 200, 300 bénévoles a de quoi rassurer, n'oublions pas les symptômes qui se manifestent assez souvent parmi ces personnes: essoufflement, roulement rapide des effectifs, recrutement ardu. Ce noyau demeure un petit noyau: le nombre des engagés ne représente en effet guère plus de 2 à $3 \%$ de l'ensemble de la population de la paroisse. 8

J'Énumère les comités paroissiaux pour démontrer combien il sont nombreux dans une paroisse. Ceux-ci connaissent des périodes de croissance et de déclin au cours des années pastorales. Les comités paroissiaux rejoignent autant les paroissiens périphériques que ceux nucléiques. À des croyants fatigués ou confus, à des croyants en attente ou en retrait, certains de ces comités offrent une sorte de "seconde initiation" à la foi chrétienne. 
du mariage (les couples-accueil, les couples-animateurs, les personnes accompagnatrices), la pastorale du baptême (les couples-accueil, les couplesanimateurs, les personnes accompagnatrices), le Renouveau Charismatique, l'aide aux éprouvés par le deuil (service d'un repas après les funérailles), le comité de pastoralejeunesse, la pastorale missionnaire, le comité d'accueil des nouveaux arrivants, la coéducation de la foi, le service de la Saint-Vincent de Paul (nourriture et vêtement), la liturgie (le comité lui-même, les lecteurs, les servants, les organistes, les animateurs, la chorale paroissiale, le comité homilétique, les président(e)s des célébrations de la parole, la liturgie pour enfant, la garderie, les ministres extraordinaires de la communion, la garde paroissiale, les argentiers [les 'compteurs' de la quête dominicale], le comité de la décoration de l'église et de la confection des visuels), la pastorale des vocations, le comité de pastorale sociale, le journal paroissial ${ }^{9}$, le mouvement scout, les Chevaliers de colomb, les Filles d'Isabelle, le Tiers-Ordre, l'A.F.E.A.S., le mouvement Rencontre, le service aux couples en difficulté (Être un couple, les divorcés réengagés, etc.). Pour leur fonctionnement, tous ces comités reposent largement sur les bénévoles. C'est là une nouveauté radicale par rapport à un passé récent. Par le biais des comités et services qu'ils ont appris à animer, les bénévoles ont donc pris de plus en plus de place dans la gestion pastorale de leur paroisse.

Il est presqu'impossible pour les permanents de cheminer d'une manière assidue avec tous les bénévoles de tous les comités. La vie paroissiale, dans son

9

Un journal paroissial est publié à trois reprises durant l'année et est distribué dans toutes les maisons situées sur le territoire de la paroisse Saint-Jude d'Alma. Quelques exemplaires sont disponibles à l'église paroissiale pour les croyants qui ont choisi Saint-Jude comme communauté d'appartenance. J'ai beaucoup apprécié ce journal. Cet outil de communication permet à plusieurs paroissiens, qu'ils soient périphériques ou nucléiques, d'être informés sur la vie paroissiale. En rencontrant à plusieurs reprises des paroissiens 'périphériques' lors de demandes sacramentelles, j'ai pu constater à quel point ce journal était lu par plusieurs d'entre eux. Ceci prouve encore une fois que les 'périphériques' ne sont pas complètement indifférents à la vie paroissiale. 
organisation actuelle, amène les permanents à cheminer plus étroitement avec seulement quelques bénévoles de certains comités. Les personnes qui connaissent bien l'institution paroissiale savent que je parle évidemment des bénévoles travaillant dans les comités suivants: les membres du C.P.P., les croyants impliqués dans le domaine de la liturgie, les marguilliers, les services d'initiation sacramentelle, le S.P.B. (service de préparation au baptême), le S.P.M. ( service de préparation au mariage). Nous pouvons rencontrer ces bénévoles au rythme d'une fois par semaine ou une fois par mois. Des événements spéciaux ou quelques temps liturgiques particuliers obligent parfois les permanents à rencontrer des bénévoles à plusieurs reprises dans une courte période de temps.

\subsection{La croissance humaine}

Grâce aux différents comités paroissiaux, bien des bénévoles ont expérimenté, souvent pour la première fois, une Église fraternelle. Ces personnes ont appris à prendre des responsabilités à partir de leurs dons et intérêts, depuis les premiers contacts à établir jusqu'à l'animation d'un groupe et la conduite d'un projet, en passant par l'accueil et la préparation d'échanges ou de prières.

Les questionnaires, les interviews, la relecture des évaluations de fin d'année du travail pastoral des comités paroissiaux et l'accompagnement de plusieurs bénévoles m'ont fait découvrir que généralement les engagements des bénévoles les font croître humainement. Ceux-ci affirment que plus ils sentent de la confiance et de l'estime de la part des personnes qui les entourent dans leur engagement, plus celui-ci est source de dynamisme dans leur vie. Également, ils disent que les échanges avec les personnes rencontrées dans leur bénévolat leur permettent d'élargir leur conception 
personnelle sur plusieurs aspects de la vie et de la foi. Le fait d'avoir ou non atteint leurs objectifs fixés dans leur travail au début de l'année pastorale contribue aussi à rendre les bénévoles heureux ou malheureux. Voici quelques témoignages entendus ou lus concernant la croissance humaine des bénévoles grâce à leur engagement paroissial.

"Mon engagement me fait croître personnellement. Il m'a fait découvrir de nouveaux talents parce que des gens m'ont fait confiance. Je ne pensais pas avoir autant de capacité personnelle en moi "(Une jeune de 24 ans).

"Notre travail avec d'autres couples remet régulièrement en question la vie de notre propre couple. C'est précieux puisque nous sommes constamment interpellés à creuser notre vie personnelle et de couple. Également, nous nous trouvons privilégiés d'écouter le partage des jeunes couples que nous rencontrons"(Un couple d'une quarantaine d'années).

"Avec mon divorce, j'avais perdu confiance en moi et j'àvais de la difficulté à m'aimer. J'ai été tellement surpris quand le curé m'a demandé de m'impliquer dans le comité.... Pourtant, il savait mon état de vie. Les gens du comité m'ont accueilli chaleureusement. Cet engagement est en train de me faire renaître interieurement. J'ai repris le goût à la vie"(Une femme de 48 ans).

"Mon engagement me permet de me lancer des défis personnels et de les réaliser" (Un homme de 34 ans).

"C'est profitable pour moi de confronter mon expérience à celle des autres" (Un homme de 41 ans ).

"Mon engagement me permet d'agrandir mon réseau de relations. Il y a des bénévoles du comité... qui sont devenus mes amies. C'est important ça dans une vie" (Une femme de 32 ans atteinte d'une grave maladie).

"Ça me rend heureuse d'aider les autres. Je me sens utile et je trouve ça important" (Une femme de 55 ans).

"C'est valorisant de voir des baptisés faire un bout de chemin grâce à nous et nous de continuer à croître spirituellement grâce à eux"(Une femme de 46 ans ).

"Je donne ce que je peux. J'aimerais en faire plus mais j'y vais selon mes disponibilités. Mon engagement a augmenté la confiance en moi"(Une femme de 54 ans).

"Même si mon engagement est exigeant, je continue parce que je sens que j'évolue aux contacts des autres"(Un père de famille de trois enfants).

"Grâce à mon bénévolat, mon horizon s'est ouvert et j'ai pris davantage conscience de l'importance capitale du respect du cheminement de chacun"(Un homme de 48 ans ).

"Ce que j'aime dans mon engagement, c'est du concret. Nous dépistons certains problèmes dans la paroisse et nous essayons de les solutionner le mieux possible. J'ai expérimenté la force de la solidarité"(Une femme d'une trentaine d'années).

"Nous disons que nous donnons beaucoup mais c'est tellement peu comparativement à ce que nous recevons des personnes que nous rencontrons"(Une femme de 51 ans).

"Je n'étais pas habituée de travailler en équipe. J'ai trouvé ça dur au début dans le comité... J'ai appris à m'ouvrir davantage à d'autres points de vue. J'ai appris davantage à écouter. Mes enfants me disent que j'ai changé depuis que je suis engagée dans la paroisse..." (Une femme de 39 ans). 
"Mon implication dans le comité... me permet de rencontrer des gens et d'échanger sur des questions profondes de la vie. C'est rare qu'on parle de ça dans nos discussions quotidiennes. Mon engagement me garde en éveil. Je suis maintenant toujours en train de me poser des questions sur moi, sur le sens de la vie et sur la religion" (Un homme d'une quarantaine d'années).

-"Mon engagement me fait rencontrer des gens pas mal brisés par la vie. Ça m'émeut à chaque fois. Ça me fait plus apprécier ma situation humaine et ça m'interpelle à continuer de me donner pour les autres. Même si c'est difficile par bout; c'est ça qui me rend heureux. Je me sens utile" (Un homme de 55 ans).

De façon générale, les bénévoles déclarent se sentir valorisés dans leur engagement. La confiance et l'amour qu'ils reçoivent de la part des paroissiens et des paroissiennes leur indiquent que leur travail est apprécié. Le sentiment d'être utile, de donner, de recevoir aussi, de relever un défi, de découvrir de nouveaux talents les incite donc à poursuivre.

Cependant, il n'est pas rare d'entendre des bénévoles parler d'essoufflement et même d'épuisement dans leur engagement.

"En pastorale, c'est facile de brûler la chandelle par les deux bouts si nous ne sommes pas vigilantes. Les besoins sont tellement nombreux.... un baril sans fond" (Une responsable de comité engagée en paroisse depuis une quinzaine d'années).

Le système paroissial tel qu'il fonctionne actuellement épuise rapidement les bénévoles et les permanents. 10 Il fait rapidement d'eux des "tâcherons" ou des "faiseux de la pastorale". Dans les comités paroissiaux, le "faire-ensemble" prend beaucoup plus de place que "l'être-ensemble". Je me demande même si on ne recherche pas plus l'efficacité dans le travail que la fécondité de l'intervention. est un monde marqué par l'essoufflement, par la course à la quantité des choses à faire et parfois par la mauvaise organisation" (GAUTHIER, Jean-Marc, Entre l'arbre et l'écorce, un monde pastoral en tension, Montréal, Fides, 1993, p. 71. [Cahiers d'études pastorales \# 14]). 
J'ai entendu fréquemment des bénévoles se plaindre pour différentes raisons. Plusieurs de ces baptisés constatent après quelques mois d'engagement que le champ laissé à leur initiative demeure plutôt étroit. D'autres se sentent considérés par les permanents comme des exécutants. La coresponsabilité entre les permanents et les bénévoles demeurent difficile à vivre. 11 Il existe encore de nombreuses résistances de certains permanents face à la coresponsabilité. Dans ces circonstances, ce qui est ainsi entravé, ce n'est pas seulement la qualité du service pastoral offert à la communauté mais bien une possibilité de participation et de fraternisation des membres de la communauté. Certains permanents ne veulent pas intégrer la coresponsabilité dans leurs pratiques d'animation pastorale, ceci décourage plusieurs bénévoles dynamiques à s'engager plus étroitement au sein de leur communauté paroissiale. ${ }^{12}$ Là-dessus, quelques récits de bénévoles interviewés sont explicites.

"Il y a des agents pastoraux laïcs et des prêtres qui nous trouvent très précieux en paroisse pour répondre à leur vision et à leurs besoins. Lorsque nous nous affirmons plus fortement et surtout lorsque nous leur faisons part de notre désaccord sur certains points pastoraux, nous sommes moins bien considérés par eux. Quand on exécute tout fonctionne. Mais lorsque nous prenons un peu plus de place, ça réagit. Je comprends un peu plus pourquoi la hiérarchie qualifie les catholiques 'laïcs' de "fidèles". Fidèles pour les suivre... Je ne suis pas un 'suiveux' /.../ Ça dépend quand même du permanent avec qui nous travaillons. Certains nous considèrent comme des adultes. D'autres permanents se sentent toujours menacés. C'est pour cette raison que j'ai pensé plusieurs fois à démissionner au cours de mes nombreuses années d'engagement dans la paroisse et de m'engager dans d'autres organismes sociaux. Se faire considérer comme un enfant

"Plusieurs personnes se réjouissent des progrès accomplis dans la collaboration prêtres-laïcs; plusieurs soulignent aussi que bien des pas restent à faire" (Rapport de la première étape du Synode, Québec, 12 mars 1993, p.10). "Au cours de ce projet, la façon de vivre et d'agir entre prêtres et laïcs, reste une donnée fondamentale. Au cours des dix dernières années, c'est sous le mot "co-responsabilité" qu'on a exprimé l'objectif à atteindre en ce domaine. Les réponses nous décrivent plusieurs situations différentes: celles de personnes qui sont partie prenante des décisions pastorales, d'autres qui apportent leur collaboration aux projets des pasteurs; mais à certains endroits, on exprime encore que "notre curé fait les choses tout seul." La "co-responsabilité" est donc encore à créer dans bien des cas"(Rapport de la première étape du Synode, Québec, 27 mai 1993, section E, p.3).

12 La difficulté de vivre la coresponsabilité n'est pas seulement présente chez certains permanents. Des bénévoles, particulièrement quelques responsables de comités, ont tendance à vouloir tout faire. Les autres membres du comité ont beaucoup de difficulté à prendre la relève lorsque ceux-ci démissionnent. 
d'école, c'est pas toujours plaisant à mon âge. J'aurai bientôt 50 ans! En plus, je suis habitué aux grosses responsabilités. Professionnellement, je suis ..." (Un homme d'une cinquantaine d'années).

"J'te dis que nous les laïcs, on n'a pas grand poids dans les décisions prises dans notre comité. Depuis un an, je constate que c'est presque toujours l'avis de l'abbé ... qui passe... Lui, y'en a du poids "(Une femme 50 ans).

"Les décisions 'partent' trop d'en haut et ne laissent presqu'aucune initiative aux bénévoles dans les comités paroissiaux" ( Un femme de 47 ans).

"Je me sens comme un fonctionnaire. On organise un tas de choses mais on se demande rarement pourquoi on fait tout ça. Je n'aime pas seulement "exécuter" (Un homme d'une quarantaine d'années).

"Nous ne sommes jamais consultés quand vient le moment de nommer le nouveau curé de la paroisse. Ça fait plusieurs années que je suis impliquée dans la communauté. Qu'on veuille ou pas, un curé donne une coloration à une communauté. Je le sais puisque j'ai travaillé avec plusieurs curés" (Une présidente d'un C.P.P.).

\subsection{Un intérêt croissant pour le devenir de la paroisse}

J'ai vécu trois expériences pastorales significatives à la paroisse Saint-Jude d'Alma qui m'ont convaincu que de plus en plus de bénévoles se soucient du devenir de leur paroisse. J"ai vécu une expérience d'un colloque paroissial dès le début de ma nomination comme curé . Cent dix bénévoles ont vécu cette expérience "synodale" le 29 avril 1989. J'ai demandé aux deux responsables du Service de formation pastorale du diocèse de Chicoutimi d'animer ce colloque. MM. Paul TREMBLAY et Christian BOUCHARD étaient les responsables de ce service diocésain à cette époque. L'organisation de cette rencontre paroissiale a été supervisée par les membres du C.P.P., les marguilliers et les permanents. Deux grandes questions ont été discutées durant la journée. "Pour réussir à naviguer à travers les changements vers lesquels se destine la communauté de Saint-Jude: 1) quelles sont les convictions qui devraient nous habiter? 2) quels sont les actions ou les gestes à poser?"13 À la première question concernant les convictions, le secrétaire du C.P.P. a résumé l'ensemble des réponses entendues en ces termes: 


\begin{abstract}
"Nous devons nous donner des moyens pour devenir des chrétiens de plus en plus autonomes dans notre foi. L'avenir de notre paroisse exige de nous plus d'audace. Nous ne pouvons pas naviguer à travers les changements sans prendre des risques. La vitalité de notre paroisse dépend de notre capacité à risquer des solutions nouvelles." 14
\end{abstract}

À la deuxième question concernant les actions et les gestes à poser pour mieux préparer l'avenir, ce qui est ressorti par ordre de priorité a été:

"1) faire advenir une équipe pastorale (bénévoles-permanents) rémunérée et/ ou mandatée par l'évêque ; 2) Offrir plus de ressourcement et une plus grande formation aux bénévoles engagés dans la paroisse; 3 ) Recruter d'autres paroissiens pour être des bénévoles engagés dans la paroisse afin que la communauté de Saint-Jude devienne encore plus dynamique et davantage responsable; 4) Donner une plus grande information des services offerts aux paroissiens et solliciter une plus grande communication et entraide entre les comités paroissiaux et les paroisses voisines de la ville; 5) Être à l'écoute des besoins des paroissiens et être toujours attentif aux naufragés [aux plus démunis] de notre paroisse; 6) Être toujours persévérant et garder confiance en ce Dieu qui prend soin de notre paroisse depuis sa fondation [35 ans ......." 15

J"ai pu également découvrir l'intérêt grandissant des paroissiens pour leur communauté en faisant élire les membres du Conseil paroissial de pastorale (C.P.P.) par les participants des assemblées dominicales. Il est toujours difficile de recruter des croyants pour devenir membres du C.P.P. . Après avoir longuement réfléchi sur ce problème de recrutement avec les permanents et avec plusieurs bénévoles de différents comités paroissiaux, nous avons décidé de choisir le mode d'élection pour renouveler le C.P.P. . Nous nous sommes dits que procéder de la sorte pouvait être un bon moyen pour sensibiliser les paroissiens à leurs responsabilités dans le devenir de la communauté. Le dimanche 17 septembre 1989, j'en ai parlé à l'homélie des messes dominicales. J'ai été étonné des commentaires positifs entendus après les célébrations. Étant donné l'enthousiasme de plusieurs paroissiens pour cette suggestion de choisir

Ibidem

Ibid, pp. 2-3. 
les membres du C.P.P. par élection, nous avons déclenché l'opération aux messes de la fin de semaine suivante et ce processus électoral a été vécu en six étapes: 1) Nous avons réfléchi sur les défis actuels de la paroisse et sur le rôle d'un C.P.P. pendant quatre dimanches consécutifs 16 ;2) Nous avons invité les paroissiens présents aux messes dominicales du dimanche 29 octobre 1989 à écrire sur un bulletin de mise en candidature le nom d'une personne qu'ils considéraient apte à être membre du C.P.P.; 3) Le dimanche 12 novembre, nous avons présenté officiellement la liste des personnes choisies qui ont accepté d'être candidat(e) à l'élection; 4) Le dimanche 19 novembre, les paroissiens ont été invités à voter par scrutin au début de la messe pour l'un ou l'autre des candidats; 5) Le dimanche 26 novembre, nous avons rendu public le résultat de l'élection; 6) Le dimanche 10 décembre, nous avons remis un mandat officiel de trois ans aux membres élus du C.P.P. . 17 Toutes ces étapes se sont bien

16

Nous avons utilisé deux moyens pour sensibiliser les paroissiens: les homélies dominicales et le feuillet paroissial. J'ai toujours trouvé important de consacrer du temps pour écrire dans le bulletin communautaire. J'ai été plusieurs fois surpris des commentaires reçus par différents paroissiens concernant les textes publiés dans le feuillet paroissial. Je crois que plusieurs intervenants pastoraux mésestiment la valeur de ce bulletin. Il peut servir non seulement à de l'information mais également à de la formation. Voici ce que j'ai écrit dans le feuillet paroissial de la semaine du 23 au 29 octobre 1989 concernant justement l'élection du C.P.P.: "C.P.P. (élection) - Savez-vous qui peut faire partie du C.P.P.? 1- Tout croyant qui a choisi la paroisse Saint-Jude comme communauté d'appartenance ; 2- Une personne qui a le souci de réfléchir avec d'autres pour 'prendre soin' du devenir de la paroisse. Une personne qui désire être un peu comme un médecin. Elle aide à trouver les virus qui empêchent la paroisse d'être en santé et elle se soucie des organismes paroissiaux afin que ceux-ci conservent leur 'forme évangélique'. Les membres essaient de découvrir les germes du Royaume de Dieu dans la paroisse. Modalités d'élection: Nombre de membres élus: 6; Nombre de membres choisis par les permanents: 2; Durée des mandats: 3 ans réligible 1 fois; Moment d'élection de l'exécutif: dès les premières rencontres du nouveau C.P.P.; Durée des mandats des membres de l'éxécutif: 2 ans réligible; Membres ex officio: le ou les permanent(s); Calendrier des rencontres: 1 fois par mois sauf en juillet et en août".

17 Voici le texte du mandat officiel remis aux membres élus: "Paroisse Saint-Jude Conseil Paroissial de Pastorale (C.P.P.) - Mandat officiel- M.... ou Mme ..... De par leur vocation chrétienne, les baptisés ont une part active dans la vie et l'action de l'Église. Cette affirmation majeure du concile Vatican II illustre combien le travail des baptisés est important pour subvenir à l'ensemble des besoins pastoraux d'une communauté chrétienne. Les baptisés sont ainsi conviés à une collaboration étroite et effective dans l'élaboration du projet communautaire. Le deuxième concile du Vatican, dans $A L 26$, encourage la mise sur pied de conseil paroissial de pastorale dont la mission est de veiller tant à la vitalité de la paroisse qu'à son avenir. Par la présente un mandat vous est accordé comme membre élu du C.P.P. (Conseil paroissial de pastorale) de la paroisse Saint-Jude pour une 
déroulées. Les résultats obtenus ont été au-delà de nos espérances: $50 \%$ des participants aux messes dominicales ont proposé un candidat. 18 Sur ces bulletins de mise en candidature, 145 personnes ont été proposées! Quelques bénévoles ont téléphoné à ces candidats potentiels durant les jours suivants. 27 paroissiens ont accepté d'être candidat officiel à l'élection du C.P.P.. Les six qui ont reçu le plus de votes ont été élus membres du C.P.P. . Deux des membres élus n'étaient pas des résidants dans le territoire paroissiale de Saint-Jude, ce qui prouve encore une fois le peu d'importance que les paroissiens accordent aux limites territoriales des paroisses actuelles en milieu urbain. J'ai cheminé pendant deux ans avec ce nouveau Conseil de pastorale paroissiale. J'ai vécu une très belle expérience même si, en cours de route, ce mode de choix des membres par élection a suscité chez moi bien des questionnements sur le gestion du pouvoir en Église et sur le discernement communautaire. 19 Malgré ses limites, ce mode de fonctionnement a été un excellent moyen de conscientiser plusieurs croyants sur l'avenir de la paroisse et il a permis de mettre le C.P.P. "sur la

période de trois ans. Que le Seigneur fasse fructifier par son Esprit cet engagement au service de vos frères et de vos soeurs dans la foi. Donné à Alma le dimanche 10 décembre 1989."

Nous avons ramassé 802 bulletins de candidature. Nous avions calculé le nombre de personnes qui étaient présentes aux messes dominicales du 12 novembre 1989. 1019 croyants ont été dénombrés. Si nous déduisons le nombre d'enfants qui n'ont pas voté, nous pouvons croire que la majorité des adultes présents ont rempli un bulletin de candidature. 498 voteurs ont suggéré un nom et les 304 autres voteurs ont coché la case suivante: "Je ne connais pas suffisamment la communauté paroissiale pour proposer un candidat".

19 Trois paroissiens ont été élus membres du C.P.P parce qu'ils étaient des personnalités connues publiquement. Mais ceux-ci n'avaient pas beaucoup suivi l'évolution de l'Église ou de la paroisse depuis les dernières années. II a fallu plusieurs rencontres pour conscientiser ces personnes au fonctionnement de la pastorale paroissiale. Cependant, étant donné que ces personnes venaient de milieux humains différents, elles ont apporté des préoccupations particulières qui ont enrichi les échanges aux réunions mensuelles. Les sujets suggérés par eux ont permis aux membres du C.P.P. de rester 'collés' aux enjeux humains et sociaux du milieu. La formule idéale pour la constitution d'un C.P.P. ne serait-elle pas que la moitié des membres soit élue et l'autre moitié soit choisie par les permanents? Cela éviterait aux permanents de ne choisir que ceux ou celles qui pensent comme eux et de se laisser déranger par les paroissiens élus venant parfois d'horizons sociaux différents. La moitié des paroissiens élus au C.P.P. était des hommes. En général, nous avons de la difficulté à recruter des hommes pour faire du bénévolat en paroisse. Ils représentent uniquement $20 \%$ des bénévoles. Pourquoi les hommes acceptent-ils plus facilement de s'engager en paroisse lorsque nous utilisons le mode d'élection? 
"relève, recrutement, manque de disponibilité, sécuritè financière, difficulté à engager du personnel, formation, sensibilisation, essoufflement, parrainage, unité, respect, appartenance, reconnaissance des nouveaux ministères." 22

Cette rencontre s'est terminée par un échange sur cette question: "quelles pistes envisageons-nous pour l'avenir?" Voici quelques-unes des réponses émises par ces responsables:

\begin{abstract}
" Il faut trouver des moyens pour ne pas s'essouffler dans l'engagement. Nous sommes trop préoccupés par les tâches à accomplir et nous oublions de nous ressourcer avec les membres de notre comité. Nous cheminons avec quelques paroissiens mais nous ne les connaissons pas beaucoup puisque nous ne prenons pas beaucoup de temps de gratuité ensemble; Il faudrait que vous organisiez un ressourcement pour tous les bénévoles engagés;

Savez-vous ce qui se passe dans chacun des comités? Pourquoi le C.P.P. n'inviterait-il pas à l'occasion des responsables de comité à leurs réunions? Vous pourriez davantage nous accompagner dans nos défis; Les comités paroissiaux travaillent comme en parallèle, chacun isolément. $\mathrm{n}$ y aurait une saine et vivifiante circulation à assurer entre les comités de la paroisse. Autrement, les ressources vives des comités ne sont pas vraiment canalisées. Il manque de la solidarité entre nous. Il manque un projet commun, un projet communautaire.

Il se fait beaucoup de choses dans la paroisse. Il serait bon de faire connaitre à l'ensemble de la communauté tout ce qui se fait et inviter continuellement des paroissiens à s'engager. Il faut refaire d'autres rencontres comme celle de ce soir." 23
\end{abstract}

Cette rencontre m'a encore permis de constater à quel point de plus en plus de bénévoles assumant des responsabilités importantes dans la paroisse se préoccupent sérieusement du devenir de leur communauté. J'ai observé cette préoccupation non pas uniquement à la paroisse Saint-Jude d'Alma mais également à la paroisse SaintLéon lorsque nous avons déclenché "l'opération Avenir 8-8" décrite précédemment. Les paroissiens de cette municipalité ont pris à coeur d'élire trois des leurs pour faire partie du comité-pilote, responsable du fonctionnement de ce projet de prise en charge communautaire. Ils ont organisé une assemblée de paroissiens pour réfléchir sur

Ibid., p. 3

Ibid, p. 4 
l'avenir de leur paroisse. Un an plus tard, ils ont vécu un colloque pour réfléchir sur l'avenir socio-économique de leur municipalité en étroite relation avec la paroisse.

L'avènement des équipes pastorales dans mon Église locale est, à mon avis, une des plus belles preuves du désir réel de quelques bénévoles d'assumer de plus en plus des responsabilités importantes au coeur de cette cellule ecclésiale. 24 Mon espérance est nourrie par l'objectif du diocèse de Chicoutimi d'encourager les paroisses à s'articuler autour d'une équipe pastorale (cf. canon 517 \#2). Des équipes pastorales sont en voie d'être formées dans quelques paroisses de l'Église locale de Chicoutimi. Nous ne sommes pas le seul diocèse à opter pour cette solution. Plusieurs diocèses au Québec expérimentent ces équipes pastorales composées de quelques baptisés (trois à cinq) avec un prêtre-coordinateur. Ces baptisés sont choisis par les membres de la communauté paroissiale et le prêtre est collégialement responsable de la charge pastorale de la paroisse. L'équipe pastorale permet alors non pas de gérer la décroissance du nombre des prêtres, mais de préparer avec courage l'Église de demain. Le centre de gravité est placé dans la communauté, laquelle doit, comme telle, rendre dans la commune prise en main des responsabilités, un témoignage évangélique par le service et la proclamation de la Bonne Nouvelle. Plusieurs prêtres mettent sur pied

24

On peut définir l'équipe pastorale comme étant un groupe de personnes mandatées dont un prêtre qui assurent en co-responsabilité la charge pastorale d'une paroisse. Il ne s'agit pas d'une équipe qui aide le curé à remplir sa tâche devenue trop lourde, mais d'un groupe de quelques personnes portant ensemble et conjointement la charge pastorale. Ce ne sont pas des exécutants; chacun d'eux assume une réelle responsabilité. Les visées de l'équipe pastorale sont les suivantes:1) assurer à la paroisse des services pastoraux adéquats 2) assurer le ministère presbytéral 3) faciliter l'émergence de ministères variés 4) assurer la complémentarité des charismes et des ministères 5) préparer l'avenir des paroisses. [ Inspiré du document L'équipe pastorale en paroisse, Service pastorale aux communautés chrétiennes, diocèse de Saint-Jean-Longueuil, septembre 1985, 21 p; et édition revisée Évaluation et Prospectives, janvier 1990, 28p.]. Voir aussi Y. F. GUÉRARD, "L'équipe pastorale en paroisse: un fruit issu d'un projet diocésain.", in Prêtre et Pasteur, vol. 89, no 4 (avril 1986), pp.238-245. 
actuellement une équipe pastorale dans la ou les paroisses où ils travaillent. Ils sont surpris de l'intérêt des paroissiens pour ce nouvel aménagement pastoral. 25

Ce désir grandissant de plusieurs paroissiens 'nucléiques' de devenir de plus en plus responsables du devenir de leur communauté paroissiale n'est pas sans toutefois poser de sérieux problèmes. Il y a, dans certaines paroisses du diocèse, de fortes tensions entre des bénévoles et des permanents. Des permanents se sentent menacés par la place de plus en plus grande qu'occupent des baptisés dans 'leur' paroisse. Mes expériences pastorales dans les paroisses, mon travail comme chargé de cours au certificat en animation pastorale à l'UQAC et ma responsabilité à l'Office du clergé du diocèse m'ont à maintes fois permis de le constater. Certains intervenants pastoraux ont peur de perdre du pouvoir et en même temps, en fidélité à leur appel baptismal, des bénévoles réclament de plus en plus de reconnaissance dans les orientations futures de leur communauté paroissiale. Il arrive parfois que des situations de conflit éclatent au grand jour. Des bénévoles quittent leur engagement parce qu'ils n'ont plus d'énergie pour lutter. Ils ne veulent plus être considérés comme de simples

25

Un de mes confrères a été le premier de notre groupe des jeunes prêtres à être impliqué dans la mise en place d'une équipe pastorale paroissiale dans notre diocèse. Pour sensibiliser les paroissiens à ce projet d'une équipe pastorale dans leur communauté, lui et les autres membres du comité organisateur ont invité les paroissiens à une journée d'information. 90 personnes ont répondu à l'appel. Trois questions ont été posées aux participants à cette rencontre. "Question \#1: À la lumière de ce que nous venons d'entendre, voyez-vous des avantages à la formation d'une équipe pastorale? Question 2: Relever un défi, comme celui de la formation d'une équipe pastorale, entraîne des difficultés. Quels sont d'après vous les inconvénients d'un tel projet? Question 3: Sommes-nous prêts, ensemble, à prendre et à vivre cette responsabilté? " À cette troisième question, 87 ont répondu oui et 3 paroissiens ont dit non." (Compte-rendu de la rencontre paroissiale, 13 décembre 1987, paroisse Saint-Luc de Chicoutimi-Nord, p.1). Avec un tel résultat, une équipe pastorale a été mise sur pied. Elle fut la première de notre Église locale. Elle a lancé le mouvement puisqu'à la fin de l'année 1993, déjà 11 paroisses du diocèse étaient animées "officiellement" par des équipes pastorales et plusieurs autres paroisses sont en train de sensibilier leur population pour faire advenir une équipe pastorale dans leur communauté. Il nous arrive souvent de dire, comme intervenants pastoraux permanents, que les paroissiens ne sont pas prêts aux changements. Je me demande si les réticences aux changements ne viennent pas plus de la part des agents pastoraux, particulièrement de plusieurs prêtres, qui se sentent menacés dans l'exercice de leur fonction 'sacerdotale'. 
exécutants. Des prêtres demandent un nouvelle nomination parce qu'ils ne sont pas d'accord avec les nouveaux aménagements pastoraux. Ils préfèrent collaborer avec des bénévoles plus dociles. 26

\title{
4.4 L'approfondissement de la foi chrétienne
}

La recherche-action m'a révélé bien des surprises. 27 J'aurais cru, au début de mon expérience pastorale, que l'engagement permettait aux bénévoles d'approfondir leur expérience spirituelle. J'ai posé cette question à la cinquantaine de bénévoles interviewés à Saint-Dominique de Jonquière et à ceux de la paroisse Saint-Jude d'Alma par le moyen du questionnaire d'évaluation remis à la majorité des bénévoles à la fin de l'année pastorale. Les résultats ont été étonnants. La plupart des bénévoles ont été très silencieux sur cette question concernant l'approfondissement de leur foi grâce à leur engagement paroissial. Une ou deux phrases écrites dans le questionnaire... pas plus. Quelques réponses résument assez bien le point de vue de plusieurs répondants.

\begin{abstract}
"Moi, depuis que je me suis engagé dans la paroisse, je ne peux pas dire que j'ai fait de grosses découvertes au niveau de ma foi. Il y a tellement de choses à faire dans le comité... qu'il ne me reste pas beaucoup de temps pour réfléchir au niveau de ma foi" (Un homme de 52 ans).

"Je n'aime pas parler de ma foi. Ça me concerne personnellement. Je crois en Dieu et j'essaye de respecter mon prochain. C'est ça qui est important pour moi et c'est la raison qui m'a poussé à donner de mon temps pour la paroisse"(Un homme de 38 ans).

"Moi, j'ai toujours été mal à l'aise de parler de ma foi. En tout cas, j'peux te dire que, quand même, depuis mon engagement dans le comité ....ça m'a aidée à être un peu plus à l'aise avec ma foi mais j'ai encore du chemin à faire"(Une femme de 37 ans) .
\end{abstract}

26

Il demeure que dans les paroisses, en raison d'un passé ecclésial récent, il existe encore un bon nombre de bénévoles que nous sentons plus à l'aise à être au service de leur 'père-curé' que d'être au service de leur communauté.

27

À ce titre, la praxéologie pastorale est souvent une occasion de conversion de l'observateur-participant, conversion suscitée par l'écoute de l'autre dans la pratique. 
"Moi, ça fait plusieurs années que je suis impliquée dans le comité...; je ne me rappelle pas que nous ayons déjà partagé ensemble sur notre expérience de foi ou de la religion en général. De toute façon, il y a bien des réunions où nous avons même pas le temps de prendre une pause-café. Nos ordres du jour sont tellement remplis"(Une femme de 45 ans).

"Ce qui est grave dans notre engagement dans le comite... c'est que nous travaillons ensemble sans prendre le temps pour nous connaitre davantage et nous ressourcer ensemble. La petite prière au début de la réunion est vite dite " (Une femme de 31 ans).

Ces réponses m'ont laissé songeur dès la fin de mon stage pastoral. À cette époque, j'ai pris conscience que nous faisions beaucoup d'activités en pastorale et que nous ne nous souciions pas suffisamment de la croissance spirituelle des bénévoles au coeur de leur engagement. C'est pour cette raison que lorsque j'ai été nommé curé, j'ai proposé, à plusieurs membres des comités, d'échanger sur les résultats de la recherche de maîtrise concernant le vécu de foi des bénévoles. À la lumière des échanges, nous avons décidé dans quelques comités de réduire le nombre de sujets à l'ordre du jour et de nous donner du temps à chaque rencontre pour partager notre vécu et réfléchir ensemble sur l'un ou l'autre des aspects de la foi chrétienne. Les résultats obtenus ont été surprenants. J'ai demandé à quelques bénévoles de partager leur vécu depuis que nous avions changé la manière de travailler ensemble dans les quelques comités. Voici des témoignages indiquant qu'un engagement peut dynamiser davantage la foi et l'engagement des bénévoles lorsque nous sommes moins centrés sur le faire-ensemble mais plus sur l'être-ensemble.

"Ça fait cinq années que je chemine avec vous. Eh bien, j'en ai appris plus sur vous ces six derniers mois que dans les quatre autres années. Ça se peux-tu? Avant la nouvelle manière de travailler ensemble, nous arrivions à la rencontre et nous commencions tout de suite par la "job". Des fois, j'avais vécu des choses durant le mois, j'aurais aimé les partager un peu. Je l'ai fait ces derniers mois dans la partie de la réunion que nous avons intitulée: "la parole de gratuité est à nous ". J'ai savouré ces moments de partage. Ça me réchauffait mon coeur pour le reste de la réunion /.../ Nous disons que nous nous engageons pour le bon Dieu. Mais jamais il nous était arrivé de prier ensemble avant de vivre le nouvel aménagement de nos réunions. Les partages m'ont rejointe et ils ont éclairé mon vécu. Je ne vois plus certaines réalités de la vie et de la foi de la même manière. Merci pour votre ouverture de coeur et pour votre écoute attentive. Ce qui est 
surprenant, c'est que même si nous avons pris plus de temps dans nos rencontres pour partager notre vécu et notre foi et pris moins de temps pour les tâches à accomplir, il me semble que nous avons été plus productifs dans notre travail. Qu'en pensez-vous?"(Une femme de 41 ans).

"Je me suis impliquée comme catéchète dans le but de devenir capable de mieux accompagner mon enfant à sa première communion et au sacrement du pardon. Je me suis dit qu'en me donnant une formation pour être catéchète et en travaillant avec d'autres catéchètes, je pourrais répondre à mon désir d'être un meilleur témoin pour mon enfant. Je ne peux pas dire que les réunions de l'an passé m'ont aidée à le devenir davantage. Nous avons passé le temps à essayer de mieux assimiler le contenu des catéchèses initiatiques proposées dans le volume.... C'est tout. J'ai donné les catéchèses sur le pardon aux enfants. Ça bien été mais après les rencontres, j'avais toujours une boule à l'intérieur. J'ai allumé quand __ nous a demandé un jour: "vous donnez des catéchèses sur le pardon mais comment vous vivez la dimension du pardon dans votre vie?" J'ai pris concience que j'enseignais aux jeunes sur le pardon pourtant, dans ma vie personnelle, j'avais de la difficulté à pardonner à des personnes qui m'ont blessée. C'est pour cette raison que j'ai beaucoup apprécié les rencontres de cette année où nous avons consacré du temps pour partager sur nos propres difficultés de pardonner et pour approfondir comment le Seigneur nous accompagne dans notre cheminement vers le pardon. Je n'ai pas donné mes catéchèses comme l'an passé. J'ai eu moins besoin d'utiliser mon volume. Je suis toujours repartie dynamisée après chacune des réunions. Je pensais donner ma démission à la fin de l'année . Je m'étais dit que j'allais m'engager deux ans dans le comité...Mais, à cause de ce que nous avons vécu ensemble, je vous confirme ma disponibilité pour l'an prochain " (Une femme de 37 ans).

De tels témoignages m'ont convaincu de l'importance de la manière de travailler dans les comités paroissiaux. Un travail en comité plus sensible aux vécus des bénévoles leur permet de croître davantage spirituellement et d'offrir une plus grande qualité d'être dans le service offert aux paroissiens. Nous avons eu trop tendance en pastorale à distinguer entre les groupes de tâches et les groupes de ressourcement. Comme s'il était impossible de prendre du temps pour se ressourcer lorsque nous sommes engagés dans un service paroissial ou d'agir lorsque nous faisons partie d'un groupe de prière. Ne faudrait-il pas tendre vers un équilibre entre la contemplation et l'action quand nous nous engageons à la suite de Jésus? Ce questionnment a été le sujet d'une soirée de ressourcement offert à tous les bénévoles de la paroisse Saint-Jude d'Alma en mars 1991 par le C.P.P. . Les partages entendus ont permis de découvrir que derrière le silence des bénévoles concernant leur foi se cache un désir réel 
d'approfondir leur expérience spirituelle au coeur de leur engagement. Lorsque nous goûtons des rencontres plus axées sur l'être-ensemble que sur le faire-ensemble, nous désirons rarement revenir à une formule de travail où tout est centré sur le "boulot à faire".

\subsection{L'évaluation du travail pastoral}

Dès ma première expérience pastorale comme stagiaire à la paroisse SaintDominique de Jonquière, j'ai pris conscience que nous ne prenions pas beaucoup de temps pour évaluer notre travail pastoral dans les comités paroissiaux. J'ai constaté le même phénomène dans les autres paroisses où j'ai travaillé par la suite. Des chercheurs viennent de publier un rapport présentant une analyse factuelle des résultats d'une enquête sur les pratiques évaluatives en usage dans les paroisses catholiques du Québec. ${ }^{28}$ Les conclusions démontrent que l'évaluation pastorale est en train de

Cette équipe de recherche est supervisée par deux professeurs de théologie de I'Université du Québec de Trois-Rivières, M. André TURMEL et M. Jean-Marie LEVASSEUR. Ces derniers ont publié le premier volume d'une trilogie sur l'évaluation pastorale au Québec. L'enquête leur a permis de recueillir 473 réponses sur un échantillon de 650 paroisses parmi les 1916 paroisses catholiques du Québec. Après une description détaillée de la démarche utilisée dans l'enquête, les auteurs décrivent d'abord le contexte de l'évaluation pastorale en paroisse au Québec, en présentant le profil des curés et celui des paroisses. Les auteurs étudient le fait de l'évaluation en paroisse en comparant les paroisses qui font de l'évaluation dans leurs organismes à celles qui n'en font pas, puis celles qui en font régulièrement et celles qui en font quelquefois. Selon les chercheurs, il y a "évaluation" non pas quand toute la réalité paroissiale est évaluée mais lorsque des comités paroissiaux évaluent leurs activités pastorales. Les formes d'évaluation, les organismes où se fait l'évaluation, la fréquence et la durée de l'évaluation, l'objet de l'évaluation et l'opinion des curés face à l'évaluation constituent les autres parties de ce premier rapport. Ces auteurs sont habités tout au long de leur recherche par la conviction que l'évaluation est un élément déterminant pour l'efficacité de la pastorale. ( LEVASSEUR, Jean-Marie et TURMEL, André, L'évaluation pastorale au Québec, L'enquête sur les pratiques évaluatives en usage dans les paroisses catholiques du Québec, TroisRivières, Pastor, 1992, 264p.) 
s'institutionaliser dans les paroisses du Québec et que les tendances qui se manifestent sont une promesse pour l'avenir. Mais il reste encore des pas à franchir puisque cette enquête confirme qu'actuellement seulement six organismes paroissiaux évaluent leurs projets pastoraux: le Conseil paroissial de pastorale (C.P.P), le comité de liturgie (CL), le Service d'initiation sacramentelle (S.I.S.), le Conseil de fabrique (C.F.), le Service de préparation au baptême (S.P.B.), le Conseil de pastorale scolaire au primaire (C.P.S.). "Parmi ces six organismes, nous constatons d'abord que quatre d'entre eux sont des lieux où les projets pastoraux sont évalués dans $48 \%$ et plus des paroisses. Les deux autres organismes sont loin derrière avec $28 \%$ et $14 \%$."29

L'expérience m'amène à croire que pour une plus grande fécondité évangélique, les permanents doivent donner de plus en plus d'importance à l'évaluation dans le travail pastoral. Sans évaluation, il est beaucoup plus facile de s'installer dans une routine paroissiale et de perdre un sens critique indispensable à la vitalité d'une communauté. L'évaluation permet ainsi une remise en question permanente de l'animation pastorale dans les différents comités paroissiaux. Dès le début de ma nomination comme curé de Saint-Jude d'Alma, conscientisé par la richesse de l'évaluation pastorale, j'ai partagé à l'une des rencontres de l'équipe des permanents de cette paroisse mon désir d'offrir aux responsables de comités paroissiaux un questionnaire leur permettant d'évaluer, à la fin de l'année pastorale, le travail avec les membres. Ils ont accepté et nous nous sommes mis au travail pour rédiger un questionnaire-guide d'évaluation. 30 Les commentaires émis par plusieurs responsables particularité de leur comité paroissial.

Questionnaire d'évaluation

Sexe: Femme ( ) Homme () Age:

A- Le fonctionnement 
de comités paroissiaux et ma participation à de nombreuses séances d'évaluation avec les bénévoles me portent à croire avec plus de conviction à l'importance de l'évaluation pour un plus grand dynamisme communautaire.

Depuis quelques années dans le diocèse de Chicoutimi, les membres du Conseil des nominations proposent une évaluation à la communauté paroissiale là où un prêtre termine son mandat pastoral. Le mandat du curé venait à son terme lorsque j'ai été ordonné prêtre et nommé vicaire à la paroisse Saint-Jude d'Alma. Le vicaire épiscopal de la région du Lac-Saint-Jean m'a demandé de convoquer les paroissiens pour participer à cette rencontre d'évaluation le 16 juin 1988. Plus d'une centaine de paroissiens sont venus participer à la réunion d'évaluation. Nous avons vécu un échange très intéressant grâce aux questions de l'évaluation diocésaine interrogeant non pas uniquement le ministère du prêtre concerné mais surtout la santé de la communauté paroissiale. 31 J'ai pris une fois de plus conscience de l'importance de

Selon les degrés d'appréciation suivants: Excellent (1); Très bien (2); Bien (3); Passable (4); Insuffisant (5)

Nous apprécierions que vous puissiez justifier votre réponse en ajoutant des commentaires écrits. Quel est votre degré d'appréciation pour...1- la fréquence des rencontres; 2- la durée des rencontres; 3- l'heure des rencontres; 4 - le déroulement des rencontres au niveau du contenu (apprenons à mieux nous connaître et à mieux connaître notre paroisse); 5- le climat ou l'atmosphère des rencontres; 6- le partage des responsabilités entre nous; 7- le nombre de personnes impliquées dans ce comité; 8l'animation des rencontres; 9- l'accompagnement et la collaboration des membres de l'équipe pastorale.

B- Mon engagement au comité

1- Comment j'évalue ma présence et ma participation au comité....; 2- Mon engagement dans ce comité est-il une occasion de mettre à contribution mes talents et mes aptitudes personnelles?; 3- Estce que cet engagement permet de me ressourcer au niveau de ma foi?; 4- Mon engagement me permet-il de mieux connaitre ma paroisse?; 5 - Si oui, est-ce que je me sens plus responsable de ma paroisse?; 6- Ai-je le sentiment que ma communauté apprécie ma contribution à la vie de la paroisse?; 7- Suis-je intéressé (e) à poursuivre cet engagement l'an prochain?; 8- Autres commentaires ou suggestions...

31 Évaluation diocésaine

"A.-La santé de votre paroisse.

1- Les points forts de la pastorale dans votre paroisse...

2- Les points faibles...

3- Quel est le degré d'implication des membres de votre communauté? 
prendre des moments particuliers pour évaluer plus profondément une vie paroissiale. J'ai fait une synthèse des réponses concernant la santé de la paroisse dans le but de relancer les membres du C.P.P. à la première réunion de la nouvelle année pastorale. Voici ce résumé qui prouve la richesse d'une évaluation communautaire.

\section{Synthèse de l'évaluation}

\section{1- LA SANTE DE LA PAROISSE}

1- LES POINS FORTS de la pastorale dans la paroisse

- Les paroissiens ont un sentiment d'appartenance à la paroisse.

- Plusieurs personnes sont impliquées dans les comités paroissiaux.

Au dernier souper des bénévoles, on comptait 230 personnes.

- Il y a plus de 30 comités actifs à l'intérieur de la paroisse.

- Le C.P.P. existe depuis 12 ans. C'est un signe de vitalité communautaire.

- Rassemblement liturgique de bonne qualité. Célébrations priantes.

- Les jeunes ne sont pas délaissés: animation pastorale, initiation

sacramentelle, liturgie pour enfants, les amis de Jude, etc.

- La paroisse est vivante.

- L'accueil des pasteurs est chaleureux.

\section{2- LES POINTS FAIBLES....}

- Certains comités ont de la difficulté à trouver une relève: comité missionnaire, de liturgie, S.P.M., des malades.

Un certain souffle leur serait nécessaire.

- Le comité d'accueil des nouveaux arrivants fonctionne difficilement.

- Difficulté des pasteurs d'être présents dans tous les comités.

4- Participation à la pastorale d'ensemble du secteur ou de la zone:

Quels gestes concrets posez-vous ou êtes-vous prêts à poser, comme communauté, pour B. - Votre pasteur.-

un meilleur partage des services avec d'autres communautés?...

1- Comment le voyez-vous comme pasteur et animateur?

a) est-il à l'aise dans le travail d'équipe?

b) fait-il confiance aux autres?

c) aime-t-il travailler avec les laïcs?

d) avec quelles catégories de personnes est-il plus à l'aise?

Autres observations...

2- Recommanderiez-vous un autre mandat de 6 ans? Oui .... Non ...

Si non, pourquoi....

$\mathrm{Si}$ oui, quelles améliorations pourriez-vous suggérer?" (CONSEIL DES NOMINATIONS, Formulaire d'évaluation à la fin d'un mandat, Diocèse de Chicoutimi, p.2 ) 
- Il manque de relations entre les différents comités.

- Les bénévoles: nous aurions besoin d'une plus grande formation.

- Ce sont toujours les mêmes paroissiens qui s'impliquent.

- Nous aurions besoin d'un service d'education de la foi des adultes.

- Nous sommes pauvres dans quatre pastorales:

-la pastorale pour ceux qu'on appelle les 'marginaux'

-la pastorale pour les divorcés

-la pastorale sociale

-la pastorale auprès des 18-25 ans

- Nous avons encore un peu un esprit de clocher. Nous pourrions

améliorer notre ouverture aux autres paroisses de la ville.

3- Le DEGRE D'TMPLICATION des membres de la paroisse.

- Plusieurs paroissiens sont impliqués à 200\% d'autres à $0 \%$.

- Nos gens sont généreux et s'impliquent: brunch, foire de la pâtisserie, capitation, etc.

- Nos pasteurs nous motivent à nous engager.

- L'absence de relève de nouveaux bénévoles nous inquiète.

- Place à l'amélioration.

4- PARTICIPATION A LA PASTORALE D'ENSEMBLE du secteur, de la zone.

- Notre curé est président de la zone. Nous sommes donc bien sensibilisés au partage et à l'ouverture auprès des autres paroisses.

- Nous collaborons déjà avec d'autres paroisses dans certaines pastorales sacramentelles [surtout avec la paroisse St -Joseph...]

+ [A.F.E. A.S.; Tiers-Ordres; comité missionnaire]

- Nous sommes prêts à partager les services de notre paroisse avec d'autres communautes.

- Nous suggérons un comité qui ferait le lien entre les paroisses pour savoir leurs besoins, leurs préoccupations, leurs défis.

- Nous désirons une implication plus marquée dans les grands problèmes de l'heure.

\subsection{La formation et l'accompagnement}

Étant donné les responsabilités que nécessite l'animation de divers comités, un certain nombre de bénévoles dans la majorité des paroisses de l'Église locale de Chicoutimi ont senti le besoin de se donner une formation adaptée. Plusieurs sont allés participer à des journées de formation ou à des sessions prolongées offertes dans leur 
zone pastorale ou au plan diocésain. Par ailleurs, quelques-uns ont poussé davantage leur formation en s'engageant dans des programmes de formation théologique et pastorale universitaire. 32 Depuis quelques années, nous sommes donc en présence d'un phénomène assez nouveau au coeur de la vie des paroisses: elles peuvent compter sur des petits noyaux de bénévoles ayant une formation pertinente et capables d'une pensée articulée au niveau de la vie de foi et de la pratique pastorale. En regard d'un passé encore récent, c'est là un saut qualitatif remarquable qui manifeste le tournant dans lequel les paroisses se sont engagées. Davantage, cette émergence de bénévoles formés et assumant des responsabilités pastorales diverses montre à elle seule que le modèle traditionnel de la paroisse a changé.

Cependant, même si les bénévoles ont suivi quelques sessions de formation, il demeure que ceux-ci réclament régulièrement, à juste titre, un accompagnement de la part des permanents pour assumer avec plus de facilité leurs responsabilités. La formation que les bénévoles reçoivent ne suffit pas. Ceux-ci vivent parfois des moments difficiles dans leur engagement. Seul un accompagnement suivi leur permet alors de passer à travers ces périodes plus souffrantes. Les nombreux témoignages sur l'accompagnement offert confirment l'importance pour les permanents de consacrer du temps aux personnes impliquées en paroisse. En voici quelques-uns:

32

"En tout cas, le nombre de laïques formés en sciences religieuses ne cesse de s'accroître. Les universités produisent chaque année une moisson de 12 à 20 diplômés en théologie originaires de notre région. À l'Université du Québec à Chicoutimi, de 1971 à 1985, 587 personnes ont obtenu un diplôme de certificat ou de baccalauréat en sciences religieuses. Ce total inclut 188 baccalauréats en sciences religieuses, 83 baccalauréats d'enseignement en sciences religieuses et 316 certificats en sciences religieuses, ces derniers conférés pour la plupart à des adultes de tout âge provenant souvent des divers mouvements"( SERVICE DIOCÉSAIN DES MINISTERES, Face à l'avenir, Les ressources humaines en pastorale, Diocèse de Chicoutimi, 1988, p.23). Un nouveau certificat en animation pastorale a été offert par l'UQAC en 1988. Jusqu'à aujourd'hui, plus d'une centaine de personnes ont obtenu ce diplôme. J'ai enseigné à plusieurs d'entre eux comme chargé de cours. 
"Ta confiance envers moi et ton accompagnement m'a permis de poursuivre la route de mon engagement" (Une femme de 51 ans).

"Merci de m'avoir fait confiance et m'avoir consacré du temps lorsque je vivais des difficultés dans mon engagement au comité..."(Une femme de 54 ans).

"Tu me montres tellement d'égards comme responsable du comité..... Jamais, je me sens jugé par toi. J'aime ta compassion dans les difficultés vécues au comité.... Je suis monté d'un cran dans l'estime de moi et je te le dois. La valorisation que tu as fait grandir en moi est un cadeau d'or" (Un homme de 49 ans).

"Si tu n'avais pas pris le temps pour m'accompagner dans la responsabilité que la communauté m'a confiée, jamais j'aurais été capable de l'assumer " (Une femme de 43 ans).

Dans la structure pastorale actuelle, il est de plus en plus difficile pour les permanents d'avoir de la disponibilité dans leur horaire pour l'accompagnement désiré par plusieurs bénévoles de la communauté. Le fait que les ministres ordonnés se voient de plus en plus confier deux ou trois paroisses, complique encore davantage la situation. Les permanents ne peuvent pas donner beaucoup de temps pour accompagner les bénévoles dans leur engagement. Pourtant, ceux-ci demandent de plus en plus d'être mieux guidés dans les nouvelles responsabilités qui leur sont confiées.

"Mon plus grand besoin comme responsable du comité...., c'est de pouvoir compter sur un accompagnateur, un guide spirituel. Ils sont rares. Plus j'approfondis ma foi et plus j'assume des responsabilités dans la paroisse, plus je ressens le désir de partager ce que je vis. Mais les prêtres de la paroisse sont tellement occupés que je n'ose pas leur demander de m'accompagner" (une femme de 49 ans).

"Avant, nous n'avions pas beaucoup de choses à faire en Église nous les laïcs. Aujourd'hui, les prêtres nous courent après.... C'est tout un changement! Mais nous ne pouvons pas être compétents du jour au lendemain. Nous avons besoin d'être soutenus"(Une femme d'une soixantaine d'années).

"Nous avons besoin des pasteurs présents à nos vies. Dans nos engagements, nous aimerions que nos permanents nous offrent une présence au fil des jours" (membres du comité de ......, juin 1990).

"L'an passé, notre curé a pris sa retraite. Il était avec nous depuis plusieurs années. Il était à temps plein dans notre paroisse. Lorsqu'il a quitté, l'évêque a demandé au curé de la paroisse voisine, de devenir également le curé de notre paroisse. Il a accepté. Il est très gentil et bien dynamique mais quand il vient dans notre paroisse, il est toujours à la course. Il m'a confié de nombreuses responsabilités. Je me sens tellement démunie. J'aurais besoin de lui partager mes préoccupations et d'échanger avec lui sur certaines orientations pastorales. Mais, il n'a pas le temps. Des fois, je me demande si nous n'aurions pas dû demander à notre vieux curé de rester avec nous. Il était peut-être dépassé avec la nouvelle pastorale mais au moins nous le sentions avec nous et il avait du temps pour nous écouter" (une femme très engagée en paroisse). 
Quels choix pastoraux devons-nous établir pour répondre à ces besoins d'accompagnement des bénévoles? Pouvons-nous faire surgir des paroisses dynamiques si nous ne sommes pas attentifs à ces paroissiens engagés? 


\section{CHAPITRE 5}

\section{LE TRAVAIL DES PERMANENTS}

Pendant mes six années d'expériences pastorales, j'ai connu plusieurs permanents ecclésiaux. Lors de mon premier stage pastoral de deux ans à la paroisse Saint-Dominique de Jonquière, j'ai collaboré étroitement avec quatre ministres ordonnés. Mon travail à la paroisse Saint-Jude d'Alma, à Saint-Léon et mes responsabilités au niveau de la pastorale d'ensemble du secteur ou de la zone pastorale m'ont alors permis de faire route avec divers permanents (agents pastoraux laïques, religieux, diacres permanents et prêtres). Mes fonctions à l'Office du clergé m'ont aussi donné la chance de connaître plus profondément le vécu des prêtres de mon Église locale. Enfin, ma participation mensuelle au groupe de réflexion des jeunes prêtres de mon diocèse m'offre encore aujourd'hui la chance d'approfondir les défis ecclésiaux auxquels nous sommes confrontés constamment.

\subsection{Les agents et agentes de pastorale laïques}

À la fin de l'année 1993, le diocèse de Chicoutimi comptait 123 agents et agentes de pastorale laïques. C'est un nombre important si l'on considère qu'il y a dix ans cette catégorie d'agents de pastorale était inexistante.

\section{"Les agents et agentes de pastorale laïques}

Nombre

* dans les paroisses et les écoles primaires

* dans les zones pastorales

* dans les services diocésains
1978

0 $\frac{1988}{85}$

85

16

6

16 $\underline{1993}$

123

58

9

14 
* dans les services diocésains

$*$ dans les mouvements et projets particuliers

* dans les écoles secondaires, collège et UQAC

32

14

9

$33 " 1$

Ce nouveau groupe de personnes joue ainsi de plus en plus un rôle de leadership dans l'Église locale et dans d'autres diocèses du Québec. Ces personnes accomplissent un service important à l'intérieur de l'Église. Déjà en 1985, les permanents du Service de formation pastorale du diocèse de Chicoutimi ont vu la nécessité de regrouper ces agents afin qu'ils puissent approfondir leurs nouvelles expériences en Église. C'est alors qu'a été mise en place la "table des agents pastoraux laïques". Dans le compterendu de leur première rencontre du 19 septembre 1985, ces agents ont clarifié les objectifs de cette table de réflexion:

"1. Permettre aux agents pastoraux laïques de trouver un lieu de réflexion où ils puissent confronter leur expérience et approfondir les enjeux que soustend leur pratique;

2. Donner à ces mêmes agents la possibilité d'une prise en charge de leur devenir et les moyens de trouver les compléments de formation pastorale et spirituelle jugés nécessaires." 2

Le 6 juin 1989, l'Association des agents et agentes de pastorale laïques (AAPL) du diocèse de Chicoutimi a été légalement constituée. En 1993, cette association a publié un document de réflexion intitulé: "Identité et insertion des agents et agentes de

1 COMITÉ DIOCÉSAIN SUR L'AVENIR DES COMMUNAUTÉS, Bâtir ensemble... Collaborer pour l'avenir, Document d'accompagnement pour les communautés paroissiales sur la route d'une plus grande prise en charge communautaire, Diocèse de Chicoutimi, p. 1.4.3.3, suite 2. "Depuis quelques années, un phénomène nouveau s'affirme avec plus d'ampleur, celui de la présence de plus en plus nombreuse d'agents de pastorale laïques. La diminution du nombre de prêtres fut souvent l'occasion de voir émerger ces nouvelles vocations; on retrouve maintenant des agents, hommes et femmes, au service des paroisses ou des écoles, dans l'animation diocésaine ou auprès des mouvements" (COMITÉ DES MINISTÈRES DE L'AEQ, Les nouvelles pratiques ministérielles, document de réflexion, Montréal, Fides, 1993, p. 97.). DU DIOCESE DE CHICOUTIMI, Identité et insertion des agents et agentes de pastorale lä̈ques dans le diocèse de Chicoutimi, Chicoutimi, Document de réflexion diocésaine, 1993, p. 1. 
pastorale lä̈ques dans le diocèse de Chicoutimi". Ce document nomme bien les défis vécus par ces nouveaux permanents dans le contexte ecclésial actuel.

\subsubsection{Une présence révélatrice d'une transformation ecclésiale}

L'arrivée des agents de pastorale, entre autres dans les différentes paroisses du diocèse, a fait prendre conscience à plusieurs croyants des transformations majeures vécues par l'Église. Alors qu'autrefois la vie interne des paroisses était maintenue presqu'exclusivemnt par les membres du clergé, voilà qu'aujourd'hui des "laïques" prennent part à son organisation et à son animation.

"Notre Église a été tellement longtemps à ne voir que des prêtres, des religieux et des religieuses consacrer leur personne et leur temps au service de la communauté chrétienne qu'elle n'a pas une longue expérience en regard de la présence du travail pastoral des agents et agentes laïcs. /.../ Nous sommes tous et toutes appelés à travailler ensemble et à bâtir une Eglise de communion et il est de très grande importance que nous ayons la même théologie des ministères et que nous puissions bien les identifier et les situer dans leur diversité et leur complémentarité." 3

Pourquoi ces personnes laïques occupent-elles aujourd'hui un champ d'activité qui leur était jusque-là interdit ou du moins inaccessible? Est-ce uniquement afin de remédier à la baisse de la vocation presbytérale ce qui, par le fait même, entraîne un manque de personnel pour répondre aux besoins pastoraux des différentes communautés paroissiales? Ou serait-ce plutôt une nouvelle réponse à l'appel lancé par l'Esprit qui cherche à former davantage une Église Peuple de Dieu, tout entière responsable? Le but premier de l'engagement des "laïques" exerçant une fonction pastorale n'est-il pas de "contribuer à la vie et à l'édification de la communauté auprès pastorales laïques...., p. i.

COUTURE Jean-Guy, évêque de Chicoutimi, Identité et insertion des agents et agentes de 
de laquelle ils sont mandatés"? 4 Des convictions profondes animent ces agents et agentes de pastorale laïques impliqués depuis quelques années dans diverses paroisses du diocèse.

\begin{abstract}
$" / . . /$ quelles sont les convictions qui nous animent? Notre foi en Jésus le Christ engage toute notre vie. Dans l'Église, nous avons trouvé une famille d'appartenance. Nous nous donnons à cette Église au nom même de cette foi chrétienne qui nous construit. Nous nous sentons appelé-es à être pasteur à la suite de Jésus. C'est le sens que nous donnons à notre vocation. Â cause de la foi qui nous porte, nous désirons rendre service de multiples façons. Au sein de l'Église diocésaine, en union avec les ministres ordonnés, nous sommes une ressource humaine disponible. Nous faisons confiance à l'Esprit-Saint. Depuis le jour de la première Pentecôte, il souffle sans arrêt dans l'Église de Jésus-Christ: le concile Vatican II, la réforme liturgique, l'émergence de nouveaux ministères, etc. Que notre présence en Église questionne, cela est inévitable. L'émergence d'un nouveau ministère demande des ajustements dans le vivre ensemble ecclésial. Mais nous reconnaîtrons qu'il s'agit bien d'une volonté de l'Esprit à la manière dont se feront ces ajustements. "Et par-dessus tout, revêtez l'amour: c'est le lien parfait" (Col. 3,14). C'est lui qui unit les uns les autres, les membres du corps, c'est-à-dire l'Église. 5
\end{abstract}

\title{
5.1.2. Des richesses humaines pour les paroisses
}

Les agents de pastorale laïques engagés en paroisse ont le plus souvent comme tâche principale le dossier de l'initiation sacramentelle et de la pastorale scolaire. 6 Les autres tâches qui leur sont généralement confiées pour compléter leur charge de travail sont la pastorale du baptême, la pastorale du mariage et la pastorale jeunesse. L'expérience paroissiale m'a permis de connaître plusieurs agents de pastorale laïques. En collaborant avec plusieurs d'entre eux, j'ai découvert la richesse

4

COMITÉ DES MINISTÈRES DE L'AEQ, Nature et exigences des liens entre l'Église diocésaine et les agents de pastorale lä̈ques, document de travail présenté le 23 août 1989 , p.5.

$5 \quad$ AAPL, Identité et insertion des agents et ....., p.18.

$6 \quad$ "L'inventaire des tâches pastorales révèle que plus de $60 \%$ des interventions concernent le secteur de la pastorale sacramentelle soit par des activités relatives aux rencontres et aux catéchèses préparatoires, soit par l'organisation et l'animation des célébrations" (CHARRON, JeanMarc, "Entre le vrai et le faux, Le discours des intervenants sur leurs pratiques, in Entre l'arbre et l'écorce, Un monde pastoral en tension, Montréal, Fides, 1993, p. 156. [Cahiers d'études pastorales \# 14] ). 
de leur présence dans l'animation communautaire. Même si les bénévoles constituent des ressources précieuses pour le dynamisme d'une paroisse, cette institution ecclésiale a besoin de "ministres permanents" engagés à son service. Une prise en charge communautaire ne peut se faire sans s'appuyer sur un service d'accompagnenent permanent. Les différents agents pastoraux laïques deviennent ainsi de plus en plus des ressources humaines importantes et appréciées par les paroissiens. Les témoignages entendus par plusieurs croyants le confirment. Écoutons-en un très significatif.

\begin{abstract}
"Au comité de...., nous apprécions beaucoup travailler avec notre nouvelle agente de pastorale. Elle nous accompagne dans les nombreux défis paroissiaux auxquels nous sommes confrontés. Elle est pour nous une soeur dans la foi. Nous sentons qu'elle prend à coeur le devenir de notre paroisse. Elle met sa compétence théologique et son expérience spirituelle au service de notre communauté. Nous accueillons sa présence permanente dans notre paroisse comme un cadeau de l'Esprit-Saint. Nous avons une autre preuve que le Seigneur continue de prendre soin du devenir de notre communauté. Nous ne pouvons pas assumer seuls la prise en charge de notre paroisse. Nous avons besoin d'être accompagnés et soutenus par des permanents compétents" (Une responsable d'un comité paroissial accompagné par une agente de pastorale laïque depuis quatre années).
\end{abstract}

La vie paroissiale a été dynamisée par l'arrivée de ces nouvelles ressources humaines. La multiplication d'agents de pastorale laïques apparaitt alors comme une richesse et un espoir pour les paroisses. Ces agents apportent manifestement une note de jeunesse au sein d'un personnel où les jeunes ne sont pas nombreux et où les prêtres ont une moyenne d'âge d'environ de soixante ans.

"Notons que $65 \%$ des permanents laïques dans les paroisses, les zones ou les organismes diocésains ont entre 20-30 ans, et 29\% entre 30-40 ans. Plus des deux tiers (70\%) détiennent une formation universitaire en théologie (baccalauréat ou certificat)." 7

7

SERVICE DIOCÉSAIN DES MINISTÈRES, Face à l'avenir, les ressources humaines en pastorale, Diocèse de Chicoutimi, document de travail, 1988, p.21. 
La présence des agents et des agentes de pastorale laïques a donc été un facteur important de rajeunissement des effectifs dans mon Église locale.

\subsubsection{De nombreuses souffrances}

Plusieurs des agents de pastorale vivent difficilement leur engagement paroissial. Certains parce qu'ils se sentent isolés. D'autres parce qu'ils sont dépassés par l'ampleur de la tâche. De plus, certains se sentent parfois davantage considérés comme des exécutants plutôt que comme des personnes exerçant un réel ministère à l'intérieur de la communauté paroissiale. Tenus parfois à l'écart dans des décisions concernant l'avenir et la prise en charge de la paroisse, ceux-ci sont conscients du risque d'être ni plus ni moins que de simples employés de la Fabrique. C'est pour cette raison que dans le document publié en 1993, les membres de l'exécutif de l'AAPL ont formulé des souhaits pour résoudre les difficultés vécues.

"Pour être partie prenante de la prise en charge concrète du devenir de notre communauté, nous nous attendons à ce que la communauté nous assure une place au sein des différentes instances responsables de son animation, de son ressourcement et de sa présence dans le monde (C.P.P., équipe pastorale, équipe de secteur, etc.) afin que nous puissions exercer la part du ministère qui nous revient." 8

La multiplication rapide des agents de pastorale laïques ne peut manquer de poser de manière inédite la question des rapports entre les ministères ordonnés et les autres ministères. Le diocèse de Chicoutimi a fait beaucoup pour assurer une bonne intégration de ces nouveaux agents pastoraux. Mais il reste que nous sommes en pleine période d'ajustement et que des tensions sont toujours présentes. Comment gérer ces tensions qui surgissent dans les milieux peu habitués à un réel partage de fonctions, à une telle collaboration entre prêtres et permanents laïques, ces derniers 
étant de plus en plus associés au leadership et détenteurs d'une formation souvent plus récente?

Les conditions d'emploi des agents de pastorale laïques sont précaires en paroisse. Le salaire offert à ces agents est un revenu qui les maintient près ou sous le seuil de la pauvreté. Celui-ci leur permet difficilement "d'envisager l'avenir avec sérénité, d'envisager la possibilité de fonder une famille et d'accéder à la propriété."9 C'est pour cette raison qu'un bon nombre de ces agents "libres" exercent leur profession sur une assez brève période de temps. Ces dernières années, j'ai constaté le départ de quelques agents de pastorale en paroisse vers des postes mieux rémunérés dans les institutions scolaires. L'animation pastorale en paroisse est alors aux prises avec les problèmes reliés à un changement régulier de personnel. Avec les nombreux défis pastoraux actuels, la paroisse ne peut se permettre de perdre ces personnes prêtes à mettre leur savoir, leur savoir-faire, leur savoir-être, en somme leur compétence à son service. Également, j'ai remarqué un ralentissement quant au nombre de jeunes terminant leurs études théologiques qui postulent les emplois disponibles en pastorale paroissiale. Ils hésitent à s'aventurer dans un travail qui risque, à plus ou moins long terme, de les conduire dans un cul-de-sac. La question financière de certaines paroisses règle parfois davantage leur avenir que les besoins même de celles-ci. Paradoxalement, ceux qui demeurent en pastorale paroissiale pour une longue période de temps font face à un autre problème: celui d'être dans une paroisse depuis de longues années et de ne pouvoir en sortir. Actuellement, les agents pastoraux ne sont pas considérés comme des ressources humaines disponibles pour l'ensemble du diocèse. Ils sont rattachés à telle fabrique, à telle zone pastorale, à tel service diocésain. La mobilité des agents de pastorale laïques est presqu'inexistante. Pourtant, il n'est souhaitable, autant pour la 
paroisse que pour l'agent pastoral lui-même, d'être trop longtemps au service de la même communauté. Les dangers sont évidents: routine, perte graduelle de motivation, risque de devenir une institution à l'intérieur de la paroisse. Les autorités du diocèse sont toutefois éveillés à ces défis.

"Les communautés sont-elles en mesure d'assumer les coûts financiers que peut représenter la rémunération de ce personnel laïque? Quelle est à leur égard la responsabilité des autorités ecclésiales dans des matières aussi concrètes que la sécurité d'emploi, le lien d'emploi, l'accompagnement et la formation continue à assurer, le niveau de rémunération décent pour des personnes qui ont pour la plupart des charges familiales?"10

Plusieurs autres souffrances vécues par ces nouveaux intervenants pastoraux pourraient être ajoutées. Il semble cependant que celles nommées suffisent pour décrire globalement la situation des agents de pastorale laïques nouvellement engagés en paroisse.

\subsection{Les religieux et les religieuses}

Les religieux et les religieuses ont traditionnellement constitué une des ressources majeures pour la mission ecclésiale dans les écoles, dans les hôpitaux et dans les services sociaux. Ces personnes ont été, dans l'Église, les chargés de service pour le monde, les diacres sans le nom ou avant le temps. C'est une des catégories dans les ressources humaines du diocèse de Chicoutimi (et ailleurs aussi) qui a le plus diminué ces dernières années. Il importe de se rendre compte de cette réduction et d'en mesurer les conséquences. Les statistiques indiquent que le nombre des religieux dans le diocèse de Chicoutimi a chuté plus de moitié de 1967 à 1993, passant de 1813 à 854. Voici le tableau des effectifs en 1967, 1977, 1987 et 1993. 
Effectifs des religieuses et des religieux

\begin{tabular}{lrrrr} 
& 1967 & 1977 & 1987 & 1993 \\
\hline Anné & 1470 & 1058 & 838 & 759 \\
Religieuses & 317 & 132 & 98 & 68 \\
Frères & 26 & 21 & 28 & 27 \\
Institut séculier & 1813 & 1211 & 964 & 854
\end{tabular}

La moyenne d'âge générale pour l'ensemble du diocèse de Chicoutimi est de 64,7 ans pour les religieuses et 62,4 ans pour les religieux. Naguère consacrés principalement à l'éducation et aux soins hospitaliers, les religieuses et les religieux sont aujourd'hui présents dans divers champs pastoraux, notamment dans les paroisses à titre d'animatrices ou d'animateurs. Même si leur apport est très précieux actuellement dans quelques paroisses du diocèse, on peut prévoir que de moins en moins de religieuses et de religieux pourront oeuvrer en pastorale paroissiale. Le vieillissement de ce groupe de permanents et le nombre restreint de jeunes novices ( 2 en 1994) portent à croire à cette dernière affirmation.

"En l'an 2000, on prévoit dans le ministère actif 120 religieuses et 35 religieux- frères $(-60 \%)$. Leur travail ne se situe habituellement pas en paroisse. Leur moyenne d'âge sera également très élevée. Leur collaboration suffira-t-elle pour suppléer au manque de prêtres et pour répondre aux besoins des paroisses?"12

11 SERVICE DIOCÉSAIN DES MINISTÈRES, Face à l'avenir...p.p.23 et ÉVÊCHÉ DE CHICOUTIMI, L'annuaire diocésain 1994, p. 13.

12 COMITÉ DIOCÉSAIN SUR L'AVENIR DES COMMUNAUTÉS, Bâtir ensemble... Collaborer pour l'avenir, p. 1.4.3.3, suite 1. 


\subsection{Les diacres permanents}

Le diaconat permanent a été établi dans le diocèse de Chicoutimi en 1977. La première ordination a eut lieu en 1978. Quinze ans plus tard, cette Église locale compte 31 diacres permanents.

\begin{tabular}{lccc} 
& \multicolumn{3}{c}{ "Les diacres permanents } \\
Nombre & $\frac{1978}{2}$ & $\frac{1988}{18}$ & $\frac{1993}{31}$ \\
Moyenne d'âge & 46 & 54 & $50 " 13$
\end{tabular}

Ils s'agit d'hommes mariés, poursuivant leur travail professionnel ou leur métier. L'âge moyen pour l'ordination tend toutefois à baisser avec les nouveaux candidats.

\subsubsection{Des collaborateurs précieux}

J'ai eu la chance de travailler avec plusieurs diacres permanents. La paroisse Saint-Jude d'Alma est même la communauté qui a le plus 'donné' de diacres permanents au diocèse. Quatre de ces 29 diacres ont été accompagnés par la communauté Saint-Jude durant leur formation. Leur collaboration dans la paroisse a toujours été appréciée. Ils sont d'un grand soutien dans les responsabilités pastorales. Ils ont à coeur le devenir de leur communauté paroissiale. Ils ne ménagent aucun effort pour être au service de leurs frères et soeurs dans la foi, pour accepter les responsabilités confiées et pour se soucier de l'avenir de la paroisse. À cause de la qualité de leurs interventions pastorales, les paroissiens de Saint-Jude ont fait confiance rapidement à leurs frères ordonnés diacres permanents. La réaction positive de la majorité des paroissiens envers ces ministres m'a motivé à leur confier de plus en plus

13 COMITÉ DIOCÉSAIN SUR L'AVENIR DES COMMUNAUTÉS, Bâtir ensemble... Collaborer pour l'avenir, p. 1.4.3.3, suite 2. 
de responsabilités pastorales: la présidence des célébrations de la parole, de baptême, de mariage et de funérailles, la présidence de certains comités paroissiaux (pastoralejeunesse, pastorale auprès des divorcés-réengagés, pastorale des malades), la prédication dominicale.

\subsubsection{De réelles tensions avec les autres intervenants pastoraux}

L'insertion des diacres permanents dans l'Église locale ne s'est pas faite sans heurt. La nouveauté fait toujours peur et bouscule les mentalités des gens. Parfois les réticences les plus vives sont venues davantage de la part des permanents que des paroissiens eux-mêmes. Il est bien évident que certains paroissiens ont eu des réactions parfois négatives lorsqu'il leur a été proposé de faire baptiser leur enfant par un homme marié ordonné ou de "se faire marier" par un diacre permanent. Je me rappelle des commentaires de paroissiens qui exprimaient leur désaccord par cette affirmation: "Si tu penses que c'est un homme marié, qui couche avec sa femme, qui va baptiser mon bébé ou me marier, je refuse....." Une preuve que le sacré et le sexuel ne font pas toujours bon ménage en Église. La doctrine de l'Église catholique a bien meublé l'inconscient des gens. Cependant, vu parfois l'impossibilité de trouver un prêtre pour présider ces célébrations sacramentelles, bien de ces paroissiens ont été obligés d'accepter le service du diacre permanent. À plusieurs reprises, ces mêmes paroissiens sont revenus me voir pour s'excuser de leur agressivité et me dire combien ils avaient apprécié l'intervention pastorale de l'homme marié ordonné... "Nous avons vécu une belle célébration personnalisée." Leurs commentaires prouvent que la qualité de l'accompagnement est plus importante pour bien des paroissiens que le "dégré hiérarchique" du ministre. Par le moyen des diacres permanents, l'Esprit-Saint n'est-il pas en train de travailler subtilement la mentalité des paroissiens et des permanents 
ecclésiaux dans le but de faire changer la politique concernant l'accession au ministère presbytéral (l'ordination des femmes et des hommes mariés $\left.{ }^{14}\right)$ ?

Des diacres permanents vivent bien des incompréhensions de la part de prêtres diocésains. Ils ne se sentent pas acceptés par eux. Je me souviens du commentaire d'un prêtre qui venait d'être nommé dans une paroisse où un diacre permanent exerçait un ministère. Il m'avait dit: "Ce n'est pas moi qui lui confierai de plus grandes responsabilités. Toute ma vie, j'ai fait des sacrifices comme célibataire pour être prêtre, je ne laisserai pas un homme marié prendre ma place." Nous sommes assez loin de l'évangile! Quelques diacres permanents vivent également du rejet de la part de certains agents pastoraux laïques. Les remarques à leur égard sont parfois même méchantes. En voici quelques-unes que j'ai déjà entendues à plusieurs reprises: "L'arrivée des diacres permanents dans l'Église bloque l'avenir d'une Église moins cléricale." "Ils jouent aux prêtres." "Ils nous enlèvent nos jobs." La mission de l'Église est tellement grande qu'il ne serait pas nécessaire de perdre autant d'énergie pour lutter entre nous. Nous serions mieux, me semble-t-il, investir ces énergies au service de l'avènement du Royaume et nous réjouir plutôt de la richesse des différents ministères ecclésiaux. Cependant, il ne faut pas généraliser et dramatiser la situation. Les efforts constants à la table des Service des Ministères du diocèse de Chicoutimi (où siègent les responsables des agents pastoraux laïques, des religieux et des religieuses, des diacres permanents, des futurs prêtres et des prêtres) pour harmoniser les relations démontrent une évolution réelle dans ce désir de communion entre les différents permanents ecclésiaux.

14 "Selon le dernier sondage Gallup, publié dans le quotidien USA Today du 11 août, /.../ $76 \%$ des catholiques américains se disent partisans du mariage des prêtres et $63 \%$ de l'ordination sacerdotale des femmes. Toute forme de discrimination sexuelle est récusée" (TINCQ, Henri, "Dans l'Ouest américain, Jean-Paul II fouettera les fidèles trop tièdes", in Le Devoir-Le Monde, 12 août 1993, p.7). 


\subsubsection{Une remise en question de la politique diocésaine sur le diaconat}

Selon l'option prise par le comité diocésain du diaconat permanent en 1978, il était préférable que le diacre ne reçoive pas de mandat pastoral pour une paroisse en particulier mais plutôt pour une zone pastorale. En se laissant instruire par ces quinze dernières années d'expériences diaconales dans l'Église locale, il semble que nous devons remettre particulièrement en question cette orientation. D'une part, de nouveaux besoins ecclésiaux sont apparus relativement à la situation des paroisses sans prêtres résidants et à la mise sur pied d'équipes pastorales en paroisse. Mon expérience enrichissante vécue avec plusieurs diacres permanents m'a convaincu qu'ils sont et peuvent continuer à être des ressources humaines de plus en plus précieuses dans les paroisses, particulièrement dans les futurs équipes pastorales. D'autre part, le rattachement nécessaire du diacre à une zone pastorale a pour effet de laisser celui-ci sans communauté d'appartenance véritable. La zone pastorale apparaît souvent comme une unité plutôt administrative qui est loin de procurer l'enracinement communautaire d'une paroisse. 15

\subsubsection{Une appropriation du diaconat encore insuffisante}

Même après ces quinze dernières années 'd'histoire diaconale' dans l'Église locale de Chicoutimi, je constate, pour avoir accompagné plusieurs diacres permanents et travaillé avec eux, que le diocèse doit encore voir à s'approprier ce ministère, c'est-àdire à mieux l'intégrer au coeur de sa propre vie. C'est encore trop souvent un évolution du comité diocésain du diaconat permanent. Il reste à officialiser cette manière de faire dans les politiques diocésaines du comité des nominations. 
ministère "de plus", qui vient s'ajouter aux autres "on ne sait trop pourquoi". Cette articulation du diaconat avec les autres ministères et services dans l'Église de Chicoutimi reste à faire. 16 Cependant, ne nous surprenons pas qu'elle ne soit pas encore pleinement accomplie: quinze ans pour limplantation d'un ministère (nouveau ou ancien?), c'est bien peu. Il va sans dire que l'émergence du diaconat permanent a créé des relations nouvelles de même que des conflits. Cette émergence oblige à une répartition différente des tâches entre les divers ministères, en tenant compte de la condition propre du diacre permanent: homme marié, bénévole, à temps partiel. On ne saurait penser son ministère sur le modèle de celui du prêtre, qui connaît une autre condition, mais on peut estimer qu'une part du champ d'action du prêtre pourrait être désormais assumée par un diacre permanent.

\subsection{Les prêtres}

Dans l'ensemble des ressources humaines en pastorale paroissiale, les prêtres occupent une place importante. Le paysage décrit jusqu'à présent montre cependant que cette place n'est plus exclusive comme elle l'était autrefois. Le ministère presbytéral s'inscrit aujourd'hui dans une symphonie de ministères. 


\subsubsection{Un vieillissement significatif du presbyterium}

Une étude a été faite sur le presbytérium du diocèse de Chicoutimi en 1987.17 Ces données ont été mises à jour en 1993. Le presbytérium de cette Église locale comptait 225 prêtres en 1993. La moyenne d'âge se situait alors à 60,3 ans. $66,6 \%$ des prêtres étaient en deça de l'âge de la retraite (un total de 150, pour une moyenne d'âge de 56,2 ans) et $33,3 \%$ au delà (un total de 75 ). Cette étude révèle un vieillissement significatif du presbytérium et une diminution importante de ses membres de 1972 à 1993 ( de 319 à 225). Ces données indiquent que la moyenne d'âge chez les prêtres augmente avec une constance remarquable et que la courbe du presbyterium se déplace comme un bloc monolithique, si bien que les responsables de la recherche prévoient qu'en l'an 2000, il y aura deux fois moins de prêtres dans le diocèse de Chicoutimi, soit \pm 98 en deça de l'âge de la retraite.

\begin{tabular}{|c|c|c|c|c|}
\hline Année & 1972 & 1987 & 1993 & 2000 \\
\hline $\begin{array}{l}\text { Nombre total de prêtres } \\
\text { Moyenne d'âge }\end{array}$ & $\begin{array}{l}319 \\
50 \text { ans }\end{array}$ & $\begin{array}{l}252 \\
59,5\end{array}$ & $\begin{array}{l}225 \\
60,3\end{array}$ & $\begin{array}{l} \pm 200 \\
\pm 64\end{array}$ \\
\hline $\begin{array}{l}\text { Nombre de prêtres en deça } \\
\text { de l'âge de la retraite } \\
\text { Moyenne d'âge }\end{array}$ & $\begin{array}{l}284 \\
46 \text { ans }\end{array}$ & $\begin{array}{c}188 \\
54,3\end{array}$ & $\begin{array}{l}150 \\
56,2\end{array}$ & $\begin{array}{l} \pm 98 \\
\pm 57\end{array}$ \\
\hline
\end{tabular}

Cette prévision de \pm 98 prêtres en deça de l'âge de la retraite a été faite à partir d'un scénario fortement optimiste. Les responsables de cette recherche pour le Service des Ministères ont compté deux nouveaux prêtres par an pendant les quinze prochaines années au diocèse de Chicoutimi. À moins d'une remontée spectaculaire par une 
révision des critères actuels d'accession au presbytérat, il semble irréaliste d'envisager deux ordinations par année d'ici l'an 2000 au diocèse de Chicoutimi. Au cours des quinze dernières années, la moyenne s'est maintenue à environ 1,5 par année. Depuis 1987, un candidat au presbytérat a été ordonné annuellement. Il serait plus sage de prédire qu'environ \pm 75 prêtres en deça de l'âge de la retraite travailleront en permanence en l'an 2000 dans cette Église locale. Mais ce ne sont pas tous ces prêtres qui oeuvreront en pastorale paroissiale. N'y aurait-il qu'une cinquantaine de ministres ordonnés disponibles à l'aube de l'an 2000 pour les 97 paroisses de notre Église locale? J'ai bien peur que oui.

Cependant, pour juger de la situation des effectifs presbytéraux, il est important de tenir compte du nombre de prêtres par rapport à la population catholique totale. Pour le diocèse de Chicoutimi, cela donne un prêtre pour 1053 catholiques. Cet indice est particulièrement significatif lorsqu'on le compare à celui des autres diocèses. En ce qui concerne le rapport du nombre de catholiques par prêtre, le diocèse de Chicoutimi ne connaissait pas une situation plus difficile que les autres diocèses $\mathrm{du}$ Québec en 1987.

"Ste-Anne de la Pocatière: 1 prêtre/ 516 catholiques; Nicolet: 1/817; Rimouski 1/860; Sherbrooke: 1/931; Trois-Rivières: 1/1374; Québec: 1/1411; St-Hyacinthe: 1/1479; BaieComeau: 1/ 1616; Longueuil 1/3325."19 de la Commission épiscopale pour les relations avec les associations de prêtres, de religieux et laïques vient de publier ses plus récentes données dans un document intitulé "Statistiques de l'Église catholique au Canada. Rapport 1991-1992." En comparant les chiffres avec ceux des rapports précédents (de 1987 à 1990), on peut vite repérer les indices les plus parlants. Et que disent-ils? L'ensemble du pays compte actuellement 6502 prêtres ou diacres, dont près de la moitié au Québec (3572). À l'échelle nationale, on note une diminution d'une centaine de prêtres diocésains et d'une trentaine de religieux prêtres par rapport à l'étude de 1990-1991. Depuis 1977, le Québec a perdu 1091 prêtres diocésains et 691 religieux-prêtres. Le Québec n'a ordonné que 19 prêtres diocésains en 1991. Le nombre est largement insuffisant, ne serait-ce que pour remplacer les 93 prêtres qui sont morts en 1991 et les trois qui ont quitté le presbytérat au cours cette année. Pendant la même période, 176 Québécois étaient candidats au presbytérat pour le presbytérium diocésain. 20 de moins que l'année d'avant, 45 de moins qu'en 1987-1988" (BAILLARGEON, Stéphane, L'Église des stats, Les 
Donc, en ce qui concerne le nombre de prêtres relativement à la population catholique, l'Église locale de Chicoutimi n'est pas la plus mal prise ni non plus la mieux nantie des diocèses au Québec.

\subsubsection{Une situation du presbytérium précaire}

Comme la moyenne d'âge des prêtres augmente en même temps que leur nombre diminue, il est évident que l'ordre actuel des choses en paroisse ne pourra subsister longtemps. Les communautés paroissiales ont vu leur nombre de prêtres chargés de l'animation pastorale diminuer régulièrement entre 1970 et 1990 . Habituées qu'elles étaient à pouvoir compter chacune sur 'son' prêtre ou 'ses' prêtres, plusieurs paroisses se sont vues dans l'obligation de partager avec la paroisse voisine ou les paroisses environnantes le ou les prêtres disponible(s). Une telle situation nous presse d'envisager l'avenir autrement. Non pas un avenir lointain, mais un avenir proche, c'est-à-dire dans cinq ans, dans dix ans. Déjà, en 1993, 31 paroisses du diocèse de Chicoutimi n'ont pas de prêtres résidants, soit $32 \%$ des communautés. ${ }^{20}$ Face à l'avenir des paroisses, le nombre d'autres collaborateurs à la mission pastorale tend à

catholiques dressent leur portrait statistique, Bilan? L'hémorragie des troupes se poursuit, in Le Devoir, 10 mai 1993, p. B. 2). "En nombre moyen de fidèles par prêtres, les continents manifestent des disparités là aussi importantes: en Amérique du Nord, on compte un prêtre pour 1030 catholiques; en Europe, un pour 1270; en Océanie, un pour 1290; en Asie un pour 2460; en Afrique un pour 4260 et en Amérique latine un pour 7600 (chiffre 1990)"(GUETNY, Jean-Paul, Dossier: "Les clercs", in $A R M, \mathrm{n}^{\circ} 144,5$ septembre 1993, p.25).

20 La recherche Risquer l'Avenir montre que cette réalité est présente dans l'ensemble des Églises diocésaines du Québec. "Sur les 38 communautés qui ont participé à la recherche, huit n'ont plus de prêtre résidant: sept paroisses rurales et une paroisse urbaine. Celles qui ont conservé un ou des prêtres ont souvent connu une réduction du temps accordé à l'animation pastorale, lorsqu'il s'agissait d'un seul prêtre, ou d'une coupure du nombre de prêtres engagés dans la paroisse. Entre 1970 et 1990, la diminution du nombre des prêtres disponibles a souvent été de 50\% et parfois davantage, même si la population des baptisés vivant sur le territoire était en croissance" ( Risquer l'avenir, pp.19-20). 
s'accroître, mais il faudra apprendre à composer avec des prêtres de moins en moins nombreux et plutôt âgés. Cette situation soulève immédiatement plusieurs questions incontournables. Pourrons-nous fonctionner longtemps avec le modèle pastoral actuel? Pourrons-nous encore longtemps conserver en paroisse l'héritage de structures et de façons de faire qui nous a été transmis? Autant de questions inéluctables qui se posent régulièrement entre les différents permanents.

\title{
5.4.3. La croissance humaine du ministre ordonné au coeur de la paroisse
}

Je ne suis plus le même homme et le même croyant depuis que j'ai vécu six années de travail pastoral en paroisse. Des paroissiens m'ont fait croître humainement et spirituellement. À travers eux, le Dieu Vivant a continué à me façonner "fils du Père". Lorsque j'ai quitté la paroisse Saint-Jude d'Alma et celle de Saint-Léon pour retourner aux études à la demande du Conseil des nominations, j'ai prononcé les paroles suivantes dans ma dernière homélie aux célébrations eucharistiques soulignant mon départ:

\begin{abstract}
"Je pars faire mon doctorat en théologie. Sachez que grâce à vous, chers frères et soeurs dans la foi, vous m'avez aidé à faire mon doctorat de la vie. À vos contacts, vous m'avez appris beaucoup sur le mystère de la vie et celui de la foi. J'ai toujours été touché par votre confiance. Merci pour toutes les confidences que vous m'avez faites. Plusieurs parmi vous m'ont partagé, dans différents contextes, le trésor de leur expérience de vie et de leur cheminement de foi. Merci de m'avoir accueilli avec mes limites et mes capacités. Ce n'est plus le même Éric qui vous quitte. Je repars aux études pétri par vos présences. Ces quatre années m'ont rendu plus sage... J'ai fait de bons coups mais j'ai aussi commis des erreurs. J'aimerais publiquement vous demander pardon si j'ai blessé des paroissiens./.../ Du plus profond de mon coeur, merci beaucoup. Je vous demande de prier pour moi. Mon futur défi m'insécurise. Je pars incertain de moi mais sûr de Lui. "21
\end{abstract}

La pastorale paroissiale nous offre "la chance" de pouvoir accompagner plusieurs personnes: des paroissiens lors des demandes sacramentelles, des bénévoles au coeur 
de leur engagement, des gens qui souffrent physiquement et moralement, des personnes mourantes et leurs familles éprouvées, etc. Toutes ces expériences humaines nous changent intérieurement. Nous sommes confrontés rapidement à nos propres limites dans le ministère. Les personnes brisées et blessées par la vie nous révèlent nos propres brisures et blessures.

"Oui, le cri et l'angoisse du pauvre déclenchent notre propre cri et notre propre angoisse; c'est comme si la blessure de notre être s'ouvrait, nous laissant dans un état de vulnérabilité totale, mais aussi tout ouverts à la présence aimante de Dieu. /.../ C'est une joie tellement extraordinaire de savoir que nous sommes aimés d'un amour inconditionnel. C'est à travers nos blessures mêmes que cet amour surgit en nous. Peutêtre sommes-nous venus à la communauté pour servir le pauvre; et que Jésus est venu annoncer la bonne nouvelle non pas à ceux qui servent les pauvres mais à ceux qui sont pauvres! Ce sont les personnes brisées qui nous révèlent nos propres brisures et notre besoin d'un sauveur. C'est ainsi qu'elles nous conduisent vers Jésus, vers la guérison, vers l'unité intérieure, vers la résurrection. Cette double expérience - de communion, de souffrance et de ténèbres - nous introduit peu à peu dans une alliance: alliance avec Jésus, et avec le pauvre." 22

Lors de nos rencontres mensuelles des jeunes prêtres du diocèse, il nous arrive souvent de nous redire entre confrères tout ce que les gens nous font découvrir. Cette prise de conscience nous motive à une qualité d'attention aux personnes rencontrées dans notre ministère.

"Le prêtre se met à l'école de la communauté. Son intention première n'est pas de "faire passer" sa doctrine à l'aide d'une nouvelle rhétorique, ni d'ajouter à la théologie classique un appendice sur les rites et les mythes locaux. Il cherche à comprendre des hommes, parce qu'il croit Dieu déjà présent chez eux. Et puisque son bagage religieux est encore extérieur à leur vie, il les rejoint là où ils sont, tels qu'ils sont, dans la terre que Dieu habite à leur insu. Cette réalité humaine qui résiste au langage de sa foi est le lieu où il doit réapprendre à lire Dieu - Dieu écrit en caractères encore inconnus du prêtre /.../ Il faut que le prêtre se laisse comme "engendrer" par eux et qu'il le leur dise ouvertement et sincèrement, pour qu'ils connaissent la joie de se savoir source de vie pour lui. /.../ "Vous 
m'avèz aidé à me comprendre", peut-il leur dire à son tour; vous m'avez fait mieux comprendre la présence de celui qui nous appelle tous à la vie." 23

Avec le manque de prêtres, les jeunes ministres ordonnés des Église locales deviennent rapidement curé d'une, deux ou même de trois paroisses. Avec le peu d'expérience pastorale, nous découvrons que sans le soutien de quelques soeurs et frères de la communauté et parfois un accompagnement plus spécialisé, il nous serait impossible de pouvoir bien assumer les responsabilités confiées. ${ }^{24}$ Ces relations humaines qui se tissent au coeur des années dans une paroisse permettent alors à un prêtre de devenir plus humain et d'expérimenter la richesse de la communion fraternelle.

\begin{abstract}
"Nous [les prêtres] ne sommes pas ceux qui guérissent, nous ne sommes pas ceux qui réconcilient, nous ne sommes pas ceux qui donnent la vie. Nous sommes pécheurs, des êtres vulnérables qui avons autant besoin de soins que ceux dont nous avons soin. Le mystère de notre ministère est que nous avons été appelés à faire en sorte que notre amour limité et bien conditionnel serve de porte d'entrée à l'amour inconditionnel et illimité de Dieu. Par conséquent, le vrai ministère se doit d'être mutuel. Lorsque les membres d'une communauté de foi ne peuvent pas vraiment connaître et aimer leur berger, la présidence de la communauté devient alors un moyen subtil d'exercer un pouvoir sur les autres et laisse apparaître des attitudes dictatoriales et autoritaires. /.../ C'est un ministère de service, par lequel le pasteur se fait serviteur vulnérable ayant besoin de son peuple autant que son peuple a besoin de lui ou d'elle. /.../ Rien, si ce n'est la pauvreté nous permet d'être un pasteur tout en nous laissant diriger. /.../ S'il y a de l'espoir pour l'Église de demain, ce sera l'espoir d'une Église pauvre dont les pasteurs accepteront de se laisser mener. /.../ Jésus nous demande finalement, non d'être des leaders avides de pouvoir, mais des guides qui peuvent discerner où Dieu est en train de nous mener, avec ceux et celles qui nous entourent /.../ Mais lorsque je pense au leadership chrétien de
\end{abstract}

23 p. $73 ;$ pp.82-83.

24 Dans l'Église actuellement, il y a un manque considérable de guides spirituels compétents et disponibles pour les jeunes agents pastoraux laïques ou prêtres. Nous aurions besoin d'être davantage accompagnés dans les nombreuses responsabilités confiées par les autorités diocésaines dès le commencement de notre ministère. Depuis quelques années, je bénéficie d'un accompagnement de qualité par un conseiller spirituel. Mes rencontres avec ce guide m'aident à mieux nommer les questions que ma pratique pastorale soulève et à les intégrer davantage dans mon expérience spirituelle. 
l'avenir, je crois que les personnes de qui je pensais n'avoir rien à apprendre sont vraiment celles qui me montrent le chemin à emprunter." 25

Pour que l'expérience communautaire paroissiale puisse permettre à un ministre ordonné de croître humainement et spirituellement ${ }^{26}$, elle exige que celui-ci s'ouvre aux autres membres de la communauté, qu'il vive comme un frère dans la foi et se donne du temps de silence pour analyser ce qu'il vit en paroisse dans un climat d'intimité avec le Vivant. "Patience, patience dans l'Azur, chaque atome de silence est la chance d'un fruit mûr"(Paul Valéry).

\begin{abstract}
"Un prêtre nous semble aujourd'hui plus convaincant comme homme, avec toutes ses contradictions, et dans ses contradictions mêmes, parce que sa proximité des hommes le fait paraître plus proche de Dieu que celui qui plane dans les nuages en se gardant de se salir les pieds dans la poussière du monde. /.../ seulement, il n'est plus nécessaire que nous considérions ces êtres admirables et rares comme des êtres divins et infaillibles, situés en dehors de toute caducité terrestre, mais au contraire, nous aimons ces "essayeurs" grandioses, ces esprits audacieux précisément dans leurs crises et leurs combats, et là où nous les aimons le plus, c'est non pas en dépit de leur faillibilité, mais à cause d'elle. Car notre génération ne veut plus vénérer ses saints comme des envoyés de Dieu venus d'un au-delà supra-terrestre, mais comme les plus terrestres des humains." 27
\end{abstract}

NOUWEN, Henri J.M., Au nom de Jésus, Réflexions sur le leadership chrétien, Ottawa, Novalis, 1991, p.28, p.38, pp. 42-43.

Y-a-t-il véritablement une différence entre l'humain et le spirituel? Pour moi, la spiritualité chrétienne aide un être humain à maximiser sa qualité d'humanité. Maurice Bellet exprime bien cela dans un de ces derniers volumes où il réfléchit sur la vieillesse et la mort. "Qu'est-ce qui nous reste quand il ne reste rien? Ceci: que nous soyons humains envers les humains, qu'entre nous demeure l'entre nous qui nous fait hommes"(BELLET, Maurice, Incipit ou le commencement, Paris, Desclée de Brouwer, 1992, p.8.).

27 ZWEIG, S., Trois poètes de leur vie, Paris, Belfond, 1983, pp.273-274. in DREWERMANN, Eugen, Les fonctionnaires de Dieu, Paris, Albin Michel, p.20 


\subsubsection{Dépassés par la situation paroissiale actuelle}

L'expérience acquise à l'Office du clergé m'a permis de constater qu'un bon nombre de prêtres se sentent dépassés par les exigences nouvelles de la pastorale paroissiale d'aujourd'hui.

"Je ne sais plus quoi faire. L'Église a tellement changé ces dernières années que même si je me donne des moyens pour me tenir à jour, je me sens vite dépassé" (Un prêtre de 58 ans).

"De toute façon, pourquoi se recycler, quand ça va mal dans une paroisse, c'est toujours la faute du curé" (Un prêtre de 64 ans).

D'autres, en raison de leur âge, sont venus à la conclusion qu'ils n'étaient plus capables de suivre l'évolution théologique et pastorale. Ils ont hâte de prendre leur retraite.

Les autorités diocésaines de Chicoutimi ont été soucieuses d'offrir des sessions pour aider à la formation permanente des agents pastoraux (laïques, religieux, diacres et prêtres). La participation à plusieurs sessions m'a permis de constater que ce sont les prêtres qui viennent le moins à ces journées de formation pastorale. Il est plus normal de se sentir dépassé par la tâche paroissiale lorsqu'on se donne peu ou pas de moyens pour mettre à jour sa formation. ${ }^{28}$ C'est un sérieux problème pour l'Église

28

Le 30 octobre 1991, le Service de recherche du diocèse de Saint-Jean-Longueuil a publié, dans un document de travail, une première lecture des réponses et des commentaires faits par les prêtres et les futurs prêtres diocésains et religieux qui ont accepté de participer à l'enquête sur la vie et le ministère des prêtres. 157 ministres ordonnés ont répondu aux 120 questions de l'enquête. Plus des deux tiers des répondants (104) sont des prêtres séculiers. Un peu plus du quart sont des prêtres membres d'une communauté religieuse. Huit sont des futurs prêtres. Plus des deux tiers des répondants sont engagés en ministère paroissial. Dans cette étude, les résultats concernant la vie intellectuelle des prêtres sont intéressants et reflètent, me semble-t-il, l'ensemble du presbytérium du Québec. Ces résultats quantitatifs confirment mes observations sur le peu de temps consacré par les prêtres à leur formation permanente. "Plus de la moitié des prêtres $(52,7 \%)$ n'ont pas participé à des journées ou sessions de formation autres que les journées presbytérales et pastorales au cours des derniers douze mois. /.../ Près des deux tiers des participants (62,9\%) n'ont jamais suivi, pendant les cinq dernières années, de cours d'une durée d'au moins 30 heures. /.../ Une majorité de $57 \%$ ne souhaitent pas participer à une activité de recyclage de quelques semaines./.../ Les prêtres font en moyenne neuf heures de lecture par semaine. Les lectures en théologie, pastorale et spiritualité 
actuelle. Comment pouvons-nous surmonter les nombreux défis paroissiaux actuels sans un renouvellement continuel de nos conceptions théologiques et pastorales? Des sessions de formation ne deviennent-elles pas de plus en plus importantes dans un contexte social, culturel et religieux comme celui du Québec qui évolue si rapidement.

"J'ai toujours hâte aux sessions de formation offertes annuellement par le Service des ministères. Les exposés des personnes-ressources et les partages communs me stimulent et rajeunissent mes conceptions théologiques et pastorales. Ces sessions sont indispensables pour quelqu'un qui travaille encore à temps plein en Église" (Un prêtre de 67 ans).

Ceci confirme la pertinence de l'affirmation de $M$. André Charron au congrès de l'AEQ à l'Automne 1992 sur les voies d'avenir des communautés chrétiennes locales:

\begin{abstract}
"J'insisterai sur la nécessité aussi d'une éducation permanente, chez les prêtres et chez les autres agents pastoraux. Les agents permanents sont des professionnels et les auxiliaires bénévoles doivent tendre aussi à la qualité professionnelle de leurs interventions. Or il n'y a pas un corps professionnel qui ne soit pas obligé de se recycler aujourd'hui, s'il veut rester compétent, crédible, et conserver sa clientèle. Peut-être les agents pastoraux en restent-ils trop aux acquis de la formation initiale. Le recyclage fait partie des conditions de notre profession." 29
\end{abstract}

prennent quatre heures; les lectures d'actualité deux heures 30; les lectures de détente deux heures; et les autres lectures 30 minutes" (SERVICE DE RECHERCHE, ROY, Gilles, dir., Analyse des résultats des l'enquête sur la vie et le ministère des prêtres du diocèse de Saint-Jean-Longueuil, 30 octobre 1991, pp.58-59.). Les chercheurs de l'Université du Québec à Trois-Rivières arrivent dans leur étude aux résultats suivants concernant la formation des prêtres. "La formation théologique de près de $30 \%$ des curés s'est faite exclusivement au Grand Séminaire, tandis que $70 \%$ ont obtenu un diplôme universitaire en théologie. Pour l'ensemble du Québec, le niveau de formation théologique se répartit comme suit: -Grand Séminaire seulement: 29,6\%; -Baccalauréat en théologie: 33,6\%; Maîtrise en théologie: 34,3\%; Doctorat en théologie: $2,5 \%$ /../ In faut noter, enfin, que la plupart des curés disent avoir continué leur formation pastorale en participant, au cours des cinq dernières années, à des activités comme des stages, sessions, congrès, journées d'études, etc. Dans notre échantillon, $34,9 \%$ l'ont fait de 1 à 5 fois, $31,7 \%$ de 6 à 10 fois, $15,6 \%$ de 11 à 20 fois et 17,8\%, plus de 20 fois" (LEVASSEUR et TURMEL, L'évaluation pastorale au Québec, pp. 53-54; p.56).

29 CHARRON, André, Réactions au rapport de recherche..., in L'avenir des communautés chrétiennes, Rapport du congrès provincial tenu à Montréal en octobre 1992, p.111. 
Les services diocésains de formation permanente doivent continuer à offrir des sessions aux permanents ecclésiaux. Cependant, ils doivent se soucier que le contenu proposé soit ajusté aux défis du terrain pastoral.

"J'ai déjà participé à des sessions de formation. Mais, après quelques-unes, j'ai décroché... Le contenu donné était trop 'universitaire'. Les réflexions offertes n'éclairaient pas suffisamment les défis pastoraux auxquels nous sommes confrontés au quotidien. C'est trop théorique et idéologique. La vie pastorale est plus complexe que les grilles 'miraculeuses' suggérées par certains 'spécialistes' " (Un prêtre de 49 ans).

Connaissant assez bien le milieu universitaire, je peux dire que les théologiens qui n'ont pas un contact régulier avec les défis de la pratique pastorale concrète ont tendance facilement à "flyer". Je comprends les permanents ecclésiaux qui trouvent difficile de suivre ces conférenciers dans leur 'jet-set théologique".

\subsubsection{Un travail d'équipe souvent difficile}

Les défis paroissiaux ont amené les différents agents permanents à travailler davantage en équipe. Depuis quelques années, les agents pastoraux, entre autres les prêtres, se réunissent de plus en plus régulièrement en paroisse, en secteur, à la table de la zone (région) pastorale pour porter plus solidairement les différents enjeux ecclésiaux. Il n'est plus rare maintenant de voir en paroisse des équipes de permanents se rassembler tous les lundis matins pour planifier le travail pastoral de la semaine. J'ai beaucoup investi personnellement de mon temps à ces rencontres d'équipes, convaincus que les énormes défis de la pratique ne peuvent plus nous permettre de travailler et de réfléchir seuls. J'ai pu, à maintes reprises, découvrir la fécondité pastorale d'un travail d'équipe malgré les difficultés vécues. 
La recherche-action dans différentes paroisses de l'Église locale m'a fait constater que les rencontres d'équipe des permanents consistent plus à faire un partage de tâches entre les agents qu'à soutenir un questionnement approfondi sur les interventions pastorales et leurs incidences dans le devenir de la communauté paroissiale. L'analyse de plusieurs ordres du jour de quelques équipes de permanents permet de découvrir que les points discutés touchent presqu'exclusivement des questions de planification. Qui va dire la messe du matin et celle du soir? Qui va prêcher aux messes de la prochaine fin de semaine? Qui va présider les funérailles au cours de la semaine? ${ }^{30}$ Qui peut rencontrer tel couple désirant se marier? Qui va faire l'enquête prénuptiale de tel autre couple? 31 Une personne malade de telle rue aimerait 'recevoir la communion'. Qui a du temps pour y aller? Il existe un problème de recrutement de bénévoles dans tels comités paroissiaux. Quels paroissiens pourrionsnous interpeller? Lors de ces réunions d'équipe, les permanents prennent donc

Il y avait en moyenne une à deux cérémonies de funérailles par semaine dans la paroisse où j'ai fait mon stage. C'est encore vrai aujourd'hui. Un de mes confrères travaille actuellement dans cette paroisse. À lui seul, il a présidé 93 funérailles en deux ans. Il doit consacrer un temps important par semaine uniquement à ce service pastoral. Une cérémonie de funérailles prend en moyenne une journée et demie de travail: une ou quelques visites au salon funéraire selon le président de la célébration-, la préparation de l'homélie, la célébration, etc. La réunion hebdomadaire dans cette paroisse permet alors aux prêtres de planifier leur horaire de la semaine en fonction des célébrations à présider. En somme, ils ne peuvent pas tellement faire autrement avec en moyenne par année, rappelons-le, 100 funérailles, 60-75 mariages et 150-175 baptêmes à présider. Cette situation n'est pas rare dans les paroisses urbaines. Les prêtres doivent consacrer un temps considérable à la sacramentalisation. Je crois beaucoup à cette pastorale mais ne pourrions-nous pas trouver d'autres solutions? Pourquoi faut-il que ce soit uniquement les ministres ordonnés qui puissent présider ces célébrations?

31 Avec en moyenne 60-75 mariages par année dans la paroisse de mon stage, il y avait toujours un à deux couples par semaine à rencontrer. Déjà au commencement de février, la secrétaire faisait un horaire pour les enquêtes prénuptiales. Durant les mois de mai et de juin, les permanents rencontraient deux à trois couples par semaine pour faire ces enquêtres et pour préparer avec eux la célébration de leur mariage. Et durant les mois de juin, juillet et août, trois, quatre et parfois même 5 mariages étaient célébrés par fin de semaine. De plus, étant donné les vacances estivales respectives de chacun des prêtres, il est arrivé quelques fois que durant une seule fin de semaine, le curé ou le vicaire ait présidé une dizaine de célébrations. Lorsque j'ai été ordonné, j'ai vécu cette situation inhumaine d'avoir à présider plusieurs célébrations par fin de semaine. Je me sentais considéré comme un 'guichet automatique'! Je me disais: "Si ça continue comme ça, je n'aurais plus de fonds. Je serai 'dans le rouge' dans mon compte d'énergie!" 
rarement le temps de faire un retour sur leur vécu et de vérifier les priorités pastorales. Même si la planification du travail entre les permanents est essentielle, il demeure qu'un nombre de minutes considérable est consacré uniquement à ce sujet au détriment d'une réflexion plus approfondie sur les enjeux pastoraux présents dans la communauté.

Dans l'ensemble, lorsque les permanents ont répondu aux besoins de chacun des comités, 'assisté' aux nombreuses réunions (paroissiales, de secteur, de zone, diocésaines) et animé les célébrations sacramentelles et quelques-unes de la parole, leur emploi du temps est complet. C'est pour cette raison que plusieurs prêtres considérent leur travail 'accompli' lorsque les baptêmes, les mariages et les funérailles sont célébrés, les messes 'dites' et les réunions paroissiales ou de secteurs pastoraux vécues. Ils ont raison puisqu'ils ont déjà dépassé les 40 heures de travail.

Dans plusieurs paroisses du diocèse, certains prêtres ont été nommés solidairement responsables de l'animation de quelques communautés, sous l'appellation "in solidum". 32 Peut-être employons-nous trop facilement l'expression "travail d'équipe" en Église. C'est comme si en utilisant l'expression, la réalité est automatiquement déjà vécue. La recherche-action permet de constater que c'est plus complexe dans la pratique. En général, les prêtres (et les autres agents pastoraux) travaillent plutôt 'ensemble individuellement'. Chacun a ses comités dont il doit

Cette manière de fonctionner en paroisse est tout à fait nouvelle puisque, pour la première fois, on la trouve proposée dans le Code de Droit canonique promulgué en 1984. Au canon 517 paragraphe 1, il est écrit: "Là où les circonstances l'exigent, la charge pastorale d'une paroisse ou de plusieurs paroisses ensemble peut être confiée solidairement à plusieurs prêtres, à la condition cependant que l'un d'eux soit modérateur de l'exercice de la charge pastorale, c'est-à-dire qu'il dirigera l'activité commune et en répondra devant l'Évêque" (Code de droit canonique, Paris, CenturionCerf,Tardy, 1984, p.95). 
s'occuper, ses célébrations à animer, ses paroissiens à rencontrer et sa journée hebdomadaire et demie de congé à prendre.

Travailler en équipe demeure toujours un défi pour n'importe quelle personne. Mais en tenant compte d'un passé ecclésial récent et de la formation donnée aux ministres ordonnés, on en vient à se demander si le travail d'équipe n'est pas une réalité plus difficile à vivre pour les prêtres. L'expérience pastorale permet de le croire pour différentes raisons. Dans la pratique paroissiale, nous sommes souvent confrontés à des conceptions théologiques et pastorales fort diverses chez les ministres ordonnés de même que chez les autres agents pastoraux. Les prêtres ont reçu une formation tellement différente les uns les autres qu'il nous arrive de nous demander si nous parlons du même Seigneur et de la même foi. "Comment est-il possible de travailler avec des confrères qui n'ont pas la même vision pastorale, la même conception des sacrements, la même....?" me demandait un jour un confrère. Plusieurs prêtres ont été également davantage habitués à travailler seuls. De plus, les besoins pastoraux sont tellement nombreux qu'il est facile de se laisser prendre par les engagements et le court terme et de consacrer moins de temps à la réflexion commune. Finalement, j'ai constaté dans certaines paroisses que le travail d'équipe était difficile puisqu'une lutte de pouvoir était présente entre les différents permanents ( les agents pastoraux laïques, les religieux, les diacres permanents et les prêtres) et entre les permanents et les bénévoles. La racine de cette lutte ne serait-elle pas le besoin disproportionné de valorisation et de reconnaissance?

Plusieurs présidences de Fabrique sont maintenant confiées à des paroissiens. Cette orientation pastorale est intéressante mais elle n'est pas sans toutefois causer certaines difficultés. Quelques présidents de Fabrique "laïques" [c'est ainsi que l'Église officielle les appelle] sont souvent plus "clercs" que bien des ministres 
ordonnés. Ils gèrent la paroisse comme une P.M.E.. Ils ont parfois peu de connaissances pastorales. Ils prennent des décisions qui ont des conséquences malheureuses dans le dynamisme paroissial. Ils ne veulent pas engager de nouvelles ressources humaines en pastorale. Ils coupent sur les services offerts aux prêtres dans les presbytères. 33 Cette réduction de services affecte l'équilibre humain des pasteurs. Pour augmenter les revenus, certains Conseils de Fabrique demandent aux prêtres de présider plus d'eucharisties. Ces options administratives révèlent des conceptions théologiques et pastorales assez particulières. Il est inquiétant de voir que des prêtres se désintéressent facilement de la dimension économique de la communauté en confiant rapidement la présidence de Fabrique à un paroissien sans toutefois vérifier suffisamment si ce dernier a non seulement une compétence administrative mais également une vision pastorale? Nous mésestimons parfois les enjeux économiques d'une paroisse dans leurs conséquences sur son dynamisme.

\subsubsection{Le pouvoir du prêtre en paroisse}

Les ministres ordonnés ont encore beaucoup de pouvoir en paroisse. Une présidente de C.P.P. d'une paroisse de mon diocèse décrit 'savoureusement' cette réalité:

"Ça fait plusieurs années que je suis impliquée dans la paroisse. Qu'on le veuille ou pas, le curé donne encore beaucoup de la couleur à une communauté. J'aime comparer un curé à un cuisinier. Il doit veiller pour que la paroisse ne cesse pas de mijoter l'évangile dans le psychologiquement de travailler et d'habiter dans le même milieu. Un de mes confrères m'a déjà dit: "Ce n'est pas sain de travailler et de dormir dans la même 'shop' ! Il est difficile de se sauvegarder un endroit d'intimité. Cela constitue pourtant un besoin fondamental pour l'équilibre humain. N'y a-t-il pas derrière ce désir de l'Église que ces ministres couchent même à l'intérieur de ses murs un subtil pouvoir institutionnel ? "Le curé est tenu de résider au presbytère près de l'église" (canon 533,1). Ne devrions-nous pas permettre plutôt à un prêtre séculier de choisir librement son milieu de vie? Mais cela ne peut se faire sans reviser en profondeur les conditions actuelles de salaire et de travail des ministres ordonnés. 
milieu. Mais encore aujourd'hui, le prêtre a tellement de pouvoir qu'il peut, par son attitude, éteindre le feu de la communauté ou brûler le souffle des bénévoles qui collaborent avec lui. N'y-a-t-il pas en chacun de nous un 'cuisinier-dictateur' qui bout davantage dans certaines situations insécurisantes....?

"Dans le système actuel, le curé a pratiquement le contrôle de tout. Son orientation d'esprit commande le reste de la vie paroissiale" (Une femme d'une cinquantaine d'années).

L'amabilité du prêtre liée à sa fonction ne manque pas parfois de se muer instantanément en dirigisme impérieux, dès qu'il se sent personnellement mis en cause dans son rôle. Le nouveau code de droit canonique accorde encore beaucoup de pouvoir aux prêtres en paroisse. 34 De plus, étant donné un passé ecclésial récent, plusieurs paroissiens ont facilement tendance à remettre 'gratuitement' ce pouvoir aux mains des ministres ordonnés. "M. le curé, êtes-vous d'accord? Si ce n'est pas à votre goût, nous allons changer notre décision", ai-je entendu à quelques reprises de la bouche de bénévoles de différents comités paroissiaux. À force de nous faire considérer comme des chrétiens supérieurs aux autres, nous sommes venus à y croire sérieusement. À force de nous passer toujours la rondelle, nous en venons parfois à jouer seuls sur la patinoire paroissiale, surtout dans les moments de décisions stratégiques pour le devenir de la communauté. Ceci me fait dire que lorsqu'un prêtre n'est pas confronté à des partenaires égaux que sont ces frères et soeurs dans la foi, il en vient à monopoliser le pouvoir ou la 'game ecclésiale'. Il est également facile de camoufler sa fragilité et ses insécurités personnelles dans le pouvoir institutionnel. L'insécurité ontologique et l'angoisse foncière poussent parfois certains ministres ordonnés à vouloir tout contrôler. 35 Cette attitude "empoisonne" la vie paroissiale et Paris, Tardy, 1989, pp.119-168. [Le nouveau droit ecclésial, Commentaire du Code de Droit Canonique - Le Peuple de Dieu]. assumer qu'en luttant en toute liberté pour chercher la vérité provoque chez le clerc une telle insécurité que rien ne peut plus le rassurer, sinon la définition par decret des vérités chrétiennes, l'anathématisation des hérétiques, et la remise dans le droit chemin de tous ceux qui doutent. Mais, psychologiquement, on assiste alors à une dégénérescence de l'essence et des contenus de la religion 
détruit le prêtre lui-même. Chaque être humain (le prêtre n'en est pas exempt) peut être atteint un jour ou l'autre par le virus 'clérical', dont le symptôme se développe en une soif toujours plus grande de pouvoir, afin de calmer l'angoisse causée par les responsabilités. Ce 'virus', tout comme le SIDA, se propage rapidement si nous ne sommes pas vigilants. Parfois, seuls des éléments de croissance humaine et une continuelle confrontation fraternelle, peuvent nous protéger contre les ravages de ce 'virus, naturellement présent dans l'organisme humain. 36

Le pouvoir en Église est encore trop concentré entre les mains des ministres ordonnés. Les structures ecclésiales actuelles, particulièrement en paroisse, n'aident pas le prêtre à passer d'une "autorité paternelle cléricale" à une "autorité fraternelle". Le ministre ordonné est un humain trop fragile pour que nous lui remettions tous les pouvoirs. Il a besoin des autres joueurs (baptisés) pour éviter de monopoliser la rondelle (le pouvoir). J'ai constaté à quel point un dynamisme communautaire pouvait surgir lorsque le prêtre est associé à d'autres croyants dans l'exercice du pouvoir.

\subsubsection{L'équilibre humain du prêtre}

Actuellement, il est facile pour un prêtre qui travaille en paroisse de faire un burn-out . Comme curé de la paroisse Saint-Jude d'Alma, j'ai déjà calculé le nombre d'heures de travail nécessaire dans une semaine pour offrir uniquement "les services

en affaire humaine relevant de la pure administration, à la mort de la pensée au profit de fausses garanties qu'on impose. /.../ Le prêtre s'identifie à l'Église, à la hiérarchie et à Dieu, dans la mesure où il se sent dépassé par sa tâche et manque d'assurance dans sa communauté" (DREWERMANN, Eugen, Les fonctionnaires de Dieu, p. 131, p. 674.).

36 "En vérité, dans la vie de beaucoup de clercs, il n'y a qu'un élément capable de constituer un véritable élixir de vie: la relation pastorale avec des personnes réelles. Là seulement les concepts théologiques peuvent recouvrer leur véritable contenu, la profondeur de leur substance humaine. C'est là ou jamais qu'on peut parler en tant que personne et que lui a la possibilité de répondre comme tel, et non plus à travers son surmoi"(DREWERMANN, Eugen, Les fonctionnaires de Dieu, p. 116). 
dits essentiels". Avant même d'ouvrir mon agenda personnel, 35 heures était déjà retenues pour les célébrations à présider, les comités paroissiaux à 'coacher', les homélies à préparer, l'administration générale à superviser, les réunions paroissiales et de zone pastorale à assurer. Un prêtre du diocèse, curé depuis plus de vingt ans, me disait un jour:

"Avant d'arriver dans n'importe quelle paroisse, 95\% de notre travail est déjà planifié. Nous ne pouvons pas être véritablement attentifs aux besoins des gens du milieu et à la particularité de chacune des paroisses. Le système est plus fort que nous. Je me demande si la vie d'un prêtre n'est pas devenue la vie d'une marionnette manoeuvrée de l'extérieur par les ficelles institutionnelles."

Dans le contexte pastoral d'aujourd'hui où il est difficile de remettre en question ces "services dits essentiels", un prêtre désireux d'apporter du renouveau en paroisse, doit consentir à fournir des heures supplémentaires, ce que font plusieurs prêtres. 37 En 1991, l'enquête réalisée auprès de mes confrères m'a permis de savoir que chacun consacrait en moyenne de 55 à 70 heures de travail par semaine en paroisse. Nous négligeons alors les autres dimensions de la vie pourtant essentielles pour un équilibre humain soit: l'approfondissement des liens familiaux et des relations d'amitié pour un sain équilibre affectif 38 , la participation à des activités sportives pour une meilleure hygiène physique et psychologique et l'intérêt à des activités culturelles pour une réelle insertion dans la société. Et il ne faut surtout pas oublier la grande importance de temps

Les résultats d'enquête du diocèse de Saint-Jean-Longueuil sur ce point me semblent réels pour l'ensemble du presbytérium du Québec. "La majorité des prêtres $(60 \%)$ consacrent plus de 40 heures par semaine à leur travail pastoral et parmi ceux-ci, $31 \%$ travaillent plus de 50 heures" (SERVICE DE RECHERCHE DU DIOCESE DE SAINT-JEAN-LONGUEUIL, Analyse des résultats...., p.60).

38 "Le blocage de l'affectivité suffit à barrer l'accès au monde de la peinture, de la poésie, de la musique même /.../ Mais, avec l'agenda surchargé, comment sortir voir un opéra ou une pièce de thêâtre? /.../ Ils ne sont guère sujets aux émotions artistiques. Refoulées dans le professionnel, leurs émotions sont sans sublimation possible. /.../ Le risque, c'est la vulgarisation des joies défendues, qui peut conduire à des explosions pulsionnelles et à des satisfactions primitives en tout genre, à des décompensations chroniques dont les symptômes les plus fréquents, sinon les plus visibles, sont sans doute l'abus d'alcool et de médicaments" (DREWERMANN, Eugen, Les fonctionnaires de Dieu, p. 200). 
de gratuité dans la prière pour une intégration de tout ce que la vie éveille en nous comme interpellation. Ce n'est pas pour rien que dans l'ensemble des diocèses du Québec, les Offices du clergé constatent que les jeunes prêtres deviennent rapidement épuisés et que quelques-uns d'entre eux doivent demander un congé de maladie seulement après quelques mois ou quelques années de ministère. Ce problème de l'équilibre humain ne se retrouve pas uniquement chez les jeunes prêtres. Il y a une augmentation considérable des congés de maladie ces dernières années chez les prêtres de tous âges travaillant en pastorale paroissiale. ${ }^{39}$ Le système paroissial est-il un 'tueprêtre' ou un 'gruge-monde'? Notons que les agents pastoraux laïques qui assument de plus en plus de responsabilités importantes dans les paroisses sont confrontés au même problème. Leur équilibre personnel et celui de leur famille demeurent aussi menacés présentement.

Il est facile de dire que les prêtres ont seulement à couper dans les services paroissiaux s'ils veulent conserver leur équilibre de vie. "Tout dans mon ministère semble avoir son importance. Ce qui est "tuant", c'est de sentir qu'on ne vient jamais à bout de son ouvrage" (Un prêtre de 48 ans). Quoi couper puisqu'en paroisse tout semble important? ${ }^{40}$ Les prêtres ont une certaine part de responsabilités dans le choix

C'est en assumant mes responsabilités à l'Office du clergé que j'ai mieux compris pourquoi certains curés ont décidé de ne donner que les 'services dits essentiels'. C'est le moyen qu'ils ont trouvé pour conserver leur santé et pour pouvoir survivre dans le système pastoral actuel. "La baisse alarmante du recrutement sacerdotal provoque depuis longtemps une accumulation des fonctions et des tâches telle que n'en avaient jamais connu les générations passées" (DREWERMANN, Eugen, Les fonctionnaires de Dieu, p.193).

40 Les chercheurs sur la vie et le ministère des prêtres au diocèse de Saint-JeanLongueuil ont posé la question suivante dans leur enquête: "Si vous aviez le choix, quel ordre d'importance accorderiez-vous, dans votre pratique pastorale, aux activités suivantes: Sur une échelle de 5 à 1 , indiquez l'importance que vous accordez à chacun de ces énoncés; $5=$ très important, $4=$ important; $3=$ plus ou moins important; $2=$ peu important et $1=$ pas du tout important. Voici leurs résultats: "très importantes et importantes: présider l'eucharistie (95,7\%), faire la prédication (95,6\%), concerter les personnes qui avec vous assument la vie pastorale $(86,7 \%)$, dispenser les sacrements $(86,3 \%)$, aider des agents laïques à assumer des responsabilités dans la communauté $(84,4 \%)$, être celui qui assure les liens de communion entre les personnes engagées en pastorale $(78,1 \%)$, prier personnellement au nom de l'Église par l'Office divin (73,7\%), faire de l'accompagnement ou du 
de leurs priorités pastorales mais il semble que le problème soulevé soit beaucoup plus complexe. ${ }^{41}$ C'est le système paroissial dans sa globalité qu'il faut remettre en question. Les exigences du système sont souvent plus fortes que la volonté du prêtre lui-même. Pour éviter de faire moi-même un burn-out en paroisse, je n'ai cessé d'être vigilant dans mes heures de travail. Mais même avec une attention parfois 'obsessionnelle' sur mon équilibre de vie, je réussissais rarement à travailler moins de 45 heures par semaine. Les prêtres en paroisse arrivent à peine à faire 'l'essentiel' (qu'est-ce que l'essentiel?) malgré un nombre d'heures considérable consacrées par semaine à la communauté. Également, plusieurs ministres ordonnés se retrouvent actuellement dans des paroisses dont les soucis financiers tuent toute liberté missionnaire et 'grugent' bien de leurs énergies vitales.

Il ne serait pas surprenant que ce problème d'équilibre humain des prêtres (et aussi des autres permanents) s'accentue dans les prochaines années si le système pastoral n'est pas sérieusement remis en question. Nous demandons aux ministres ordonnés d'assumer de plus en plus de responsabilités sans toutefois reviser la

counselling spirituel auprès d'individus $(71,1 \%)$, être personne-ressource des responsables des célébrations $(68,8 \%)$, organiser des projets visant à instaurer plus de justice ou de partage dans le milieu $(68,5 \%)$, animer une équipe pastorale $(68,3 \%)$, dépanner, rendre service aux confrères et aux communautés $(59,1 \%)$, participer à la vie des mouvements $(56,9 \%)$, animer ou participer à un groupe de partage évangélique $(55,8 \%)$, faire la visite de paroisse $(51,2 \%)$, animer des rencontres (49,5\%), assumer la présidence de la fabrique (17,5\%)." Ce qui fait dire à ceux qui ont interprété les données: "Presque toutes les activités de pratiques pastorales sont jugés importantes par les prêtres." (SERVICE DE RECHERCHE..., Analyse des résultats..., p. 24 ; pp.65-66).

41 Les prêtres répondent souvent aux besoins au fur et à mesure qu'ils se présentent, sans se poser la question de la hiérarchisation des tâches. Plusieurs prêtres sont à leur poste. Ils ne refusent rien, c'est là leur disponibilité. Quand la générosité l'emporte sur la réflexion et quand la charité fait fi de l'intelligence, il s'ensuit une espèce d'émiettement et d'écartèlement qui n'est guère favorable à une action pastorale pensée et suivie. Il y a une générosité pastorale qui peut dépasser les limites. Les besoins pastoraux dans une paroisse ne sont-ils pas "des barils sans fond"? Nous pourrions travailler jour et nuit si nous le voulions. Si un prêtre n'est pas vigilant, il se sent vite dissipé, éparpillé et son être intérieur spirituel en souffre. Qu'est-ce qu'il y a derrière nos incapacités à dire "non" à certaines demandes? Peur de la réaction des autres? Peur d'être jugé? Peur de pas être aimé? Peur de passer pour un paresseux? Se pourrait-il qu'il y ait une forme de générosité qui soit névrotique? 
structure paroissiale actuelle. Écoutons un curé qui décrit bien les souffrances vécues

par les prêtres dans l'aménagement paroissial actuel.

\begin{abstract}
"J'étais curé de la paroisse de ..... L'évêché m'a demandé d'être le curé de l'autre paroisse voisine. J'ai accepté. Je suis vidé seulement après quelques mois comme curé de deux paroisses. Je ne sais plus quoi faire. J'ai tout en double: deux C.P.P., deux Conseils de Fabrique, deux S.P.B., deux comités d'initiation sacramentelle, double célébration à présider, etc... Je suis toujours à la course.... entre deux messes... Je me sens éparpillé un peu partout. Rencontre dans une paroisse, rencontre dans l'autre, rencontre de secteur, rencontre de zone pastorale, rencontre diocésaine... je n'ai même plus le temps de me rencontrer! Je suis toujours en réunion. Est-ce important d'avoir tous ces comités en paroisse et de participer à toutes ces rencontres? C'est pas facile de ne pas avoir tel comité dans une paroisse ou de ne pas être présent à telle réunion. D'autres personnes se chargent rapidement de nous culpabiliser ou de nous accuser subtilement. Je suis essouflé de courir plusieurs 'lièvres à la fois'. Je dois donner la respiration artificielle aux bénévoles épuisés dans leur engagement. En plus, en paroisse, nous sommes toujours en train de devoir recruter de nouveaux bénévoles. Mais, que fait-on quand on a soi-même peur de manquer de souffle pour assumer ses propres responsabilités? /../ Je me demande si je ne changerai pas mon auto pour une ambulance... Je pourrais faire inscrire sur cette voiture "urgence pastorale". Lorsque j'arriverais dans l'une ou l'autre des paroisses, je pourrais faire crier la sirène pour avertir les paroissiens que je suis arrive. Cette ambulance pourrait peut-être servir un jour aux paroissiens pour me transporter à l'hôpital lorsque je n'aurai plus d'énergie pour servir ... /.../ Je n'ai pas le temps de bien connaître les gens. Je n'ai plus le temps d'une gratuité de présence. C'est tellement important pour une communauté et pour son dynamisme personnel. Ce sont les relations humaines qui nous font vivre. Je n'ai pas le temps d'accompagner les paroissiens sauf de déposer les dossiers diocésains sur la table et de leur demander de les lire et si possible de les réaliser tout seuls. /../ Je prépare mes homélies dans mon auto. Il faut questionner ces nouvelles nominations. Dans 10 ans, j'aurai combien de paroisses sous ma responsabilité? J'ai perdu la joie dans mon ministère. Ce qui me fait vivre, c'est de bien connaître les gens avec qui je fais route. Ce n'est plus possible dans les circonstances actuelles. Je me sens comme un fonctionnaire. Je me demande si je vais être capable de tenir le coup. J'ai peur de le dire. J'ai peur de ne pas être compris et de passer pour un 'pépère'"(Un prêtre d'une cinquantaire d'années).
\end{abstract}

Ce témoignage ne peut laisser personne indifférent, particulièrement les autorités ecclésiales. Combien sont nombreux les prêtres qui vivent sensiblement la même réalité et qui gardent toutes leurs souffrances dans le secret de leur coeur parce qu'ils ont peur de ne pas être compris. Comment gérer ses limites humaines dans un système paroissial où les besoins pastoraux sont illimités? La vie paroissiale ellemême ne s'est-elle pas industrialisée ces dernières années? N'est-elle pas évaluée qu'en 
termes de production, de rapports d'efficience? Pour pouvoir survivre dans le système paroissial, les relations pastorales ne sont-elles pas fonctionnarisées?

Depuis quelques années, plusieurs nouvelles tables de concertation pour les agents de pastorale ont été mises sur pied (rassemblement des agents pastoraux en secteur (rural et urbain), le R.A.P.P.Z [le regroupement des agents pastoraux de la zone pastorale de....], le Conseil presbytéral, le Conseil diocésain de pastorale, etc.). Il y a beaucoup de chevauchement entre tous ces différents niveaux de structures pastorales. Combien de fois ai-je réfléchi sur les mêmes sujets aux tables du secteur, de la zone pastorale et au niveau diocésain? À la longue, j'ai davantage compris pourquoi bien des permanents remettent de plus en plus en doute l'importance de toutes ces tables de concertation. Il y en a même qui n'y croient plus du tout et décident, pour survivre, de s'isoler dans 'leur(s)' paroisse(s) et de ne plus participer à aucune rencontre à l'extérieur. 42 Je les comprends puisqu'il m'est arrivé comme curé de passer plus d'heures à l'extérieur de la paroisse qu'à l'intérieur pour assumer mes responsabilités dans une semaine. De plus, ces rencontres épuisent puisqu'elles sont généralement centrées sur la tâche et pas suffisamment sur l'être-ensemble. 43

42

Mes responsabilités à l'Office du clergé m'ont permis de découvrir à quel point un bon nombre de prêtres sont grugés par le cancer de la solitude. Je ne parle pas de la "solitude habitée", source de revitalisation et essentielle pour la croissance spirituelle de tout croyant, mais de l'isolement. 43

Pendant les années pastorales de 1989-1991, j'ai été l'animateur des agents pastoraux (majoritairement des prêtres) du secteur de la ville d'Alma. Dans le questionnaire d'evaluation à la fin d'une de ces années, j'ai posé une question pour vérifier la satisfaction des agents pastoraux concernant les rencontres de secteur. Voici ce qui est ressorti: "Plusieurs aimeraient que la table du secteur des agents pastoraux soit davantage un lieu où on peut partager les experiences pastorales qui font vivre et font souffrir. Partir plus du vécu des agents pastoraux. Pour vivre une plus grande solidarité, il faut se connaître comme personne" (TREMBLAY, Eric, Compte-rendu de l'évaluation du travail en secteur, juin 1990, p.1). C'est à partir de ce moment que j'ai pris conscience que nous étions beaucoup trop préoccupés par les tâches pastorales. N'oublions-nous pas trop facilement la communion fraternelle dans la mission? Ce lien de fraternité n'est-il pas un élément d'une grande importance pour une fécondité personnelle et une réelle solidarité? Peut-il y avoir des liens de mission significatifs s'il n'y a pas de liens d'appréciation entre les permanents? 


\title{
5.4.8 Des tensions entre les ministres ordonnés eux-mêmes
}

On ne peut passer sous silence les réelles tensions vécues entre les ministres ordonnés. J'ai été témoin de plusieurs d'entre elles. Le témoignage entendu d'un jeune presbytre dans un atelier lors d'un congrès annuel des prêtres du diocèse de Chicoutimi en mai 1991 est révélateur à ce sujet.

\begin{abstract}
"Vous, les prêtres plus âgés, vous vous préoccupez beaucoup de la relève 'sacerdotale'. Dans le contexte d'aujourd'hui, je ne suis pas sûr si je suis désireux d'interpeller moi-même un jeune pour qu'il devienne un prêtre en lui disant: "si la vie t'intéresse, viens te joindre à nous". Pourquoi? Eh bien, vous êtes dans les paroisses actuellement à plein temps et vous ne préparez pas les paroissiens aux futurs changements. Vous vous dites: "À nos retraites, ceux qui assumeront notre relève feront le changement." C'est nous les jeunes prêtres qui prenons votre relève. Étant donné la baisse du nombre de prêtres, il n'est pratiquement plus possible d'être à temps plein dans une seule paroisse. La preuve: les jeunes prêtres du diocèse sont presque tous nommés curés de deux paroisses actuellement. Qui va être nommé à vos places lorsque vous allez quitter ces paroisses? C'est nous à demi ou à tiers temps. Vous ne préparez pas les paroissiens à ces changements. Présentement, nous ne pouvons pas offrir tous les services comme avant. Les paroissiens qui n'ont pas été préparés aux changements sont frustrés. Ils se déragent sur nous.... Je n'ai pas le goût que des jeunes deviennent prêtres dans de telles circonstances... à moins d'être 'masochiste'. Avant de vous soucier de la relève, ne pourriez-vous pas plutôt vous soucier de nous en préparant ces paroisses aux changements? J'adore faire de la pastorale mais je suis en train de perdre ma passion..." (Un jeune prêtre d'une trentaine d'années).
\end{abstract}

Que dire de plus... Boucher des trous au fur et à mesure qu'ils se présentent en confiant deux ou trois paroisses à un prêtre parce qu'elles sont devenus vacantes et qu'il n'est plus possible d'y mettre un curé, confier à certains prêtres toutes sortes d'activités disparates au point qu'ils ne sachent plus s'occuper sérieusement d'aucune..., c'est peut-être un nécessité du moment, mais ce n'est pas une politique saine et constructive de remembrement des paroisses et de répartition des énergies presbytérales. 


\section{DEUXIÈME PARTIE}

\section{HERMÉNEUTIQUE DU TEMPS PRÉSENT ET DE LA TRADITION}


"Il n'y a pas de réponse

à ce qui ne fait pas question..."

( Jean-Luc CHRÉTIEN).

La démarche méthodologique proposée en praxéologie pastorale prévoit une étape de problématisation de la situation observée (essai de modélisation). Elle constituera le contenu du sixième chapître (la première section de la deuxième partie de la thèse: herméneutique du temps présent et de la Tradition). Les chapitres sept à treize feront une relecture de mes défis pastoraux explorés à partir de quelques disciplines des sciences humaines et de certaines pratiques de la Tradition chrétienne (partie II.2: des clés de compréhension éclairantes). C'est la partie de la thèse que je développerai davantage. Elle me permettra de vérifier mon hypothèse de sens. Avant d'analyser l'évolution historique de la paroisse canadienne française, je replacerai cette institution dans l'ensemble de l'histoire de l'Église au chapitre septième. La révolution industrielle et l'urbanisation qui s'en est suivie ont amené des bouleversements profonds et durables dans la société. Le chapitre huitième se proposera d'analyser plus en profondeur le phénomène de l'urbanisation et ses conséquences sur la structure paroissiale. Nous disons que les paroissiens ont été influencés par les valeurs de la modernité. Derrière le débat de l'acceptation ou non du paroissien "moderne" en luimême se joue l'enjeu fondamental du rapport entre l'Église et le monde. Le chapitre neuvième tâchera d'analyser l'évolution du rapport entre l'Église catholique et la société moderne, particulièrement durant la période du concile Vatican II et celle postconciliaire. Les responsabilités pastorales sont tellement nombreuses en paroisse qu'il nous arrive souvent d'oublier le but de notre travail. Dans ces circonstances, il sera à propos de nous rappeler au chapitre dixième ce qu'a été la passion de Jésus: 
l'avènement du Règne de Dieu. La situation actuelle des paroisses exige aussi de faire advenir de plus en plus de ministères nouveaux. Toutefois, la version officielle de l'Église concernant cette problématique ne nous aide guère à la créativité mais plutôt à demeurer dans le statu quo. Pour sortir de ce cul-de-sac, il sera essentiel dans ce même chapitre de retourner consulter les textes du Nouveau Testament pour analyser plus profondément l'héritage que les premières communautés chrétiennes ont légué à l'Église dans la manière d'organiser leur vie fraternelle. Le chapitre onzième permettra de réfléchir plus spécifiquement sur les forces et les lacunes ecclésiologiques du Concile Vatican II. Même si les Pères Conciliaires n'ont pas beaucoup réfléchi sur l'institution paroissiale, le chapitre douzième cherchera à connaitre quelle a été la conception de la paroisse à Vatican II. Il sera également important de réfléchir dans la deuxième partie de ce chapitre les innovations canoniques touchant la paroisse dans le Code de 1983. Je compléterai enfin celui-ci en donnant certains axes théologiques pour renouveler la paroisse selon l'ecclésiologie de communion et en nommant les possibilités paroissiales actuelles porteuses d'avenir. Les années d'expériences pastorales m'ont fait découvrir que les demandes de services pouvait être un lieu propice d'évangélisation dépendamment de la qualité du dialogue entre les intervenants pastoraux et les paroissiens et de la qualité de la célébration. Dans le chapitre treizième, je proposerai un nouveau paradigme de pédagogie pastorale en paroisse. 


\section{II.1 ESSAI DE MODÉLISATION \\ DE LA DYNAMIQUE PASTORALE PAROISSIALE}

\section{CHAPITRE 6}

\section{ÉLÉMENTS-CLÉS D'OBSERVATION}

Au fil des chapitres d'observation, ma perception et ma compréhension de la réalité paroissiale ont évolué. Des intuitions sont apparues et se sont précisées. Des images d'apparence banale au premier chef ont pris tout-à-coup une envergure inattendue. Au fur et à mesure que mon expérience a été discutée, réfléchie et confrontée, la masse imposante de données recueillies s'est articulée différemment. Bref, il me semble qu'ont surgi des "poignées" nouvelles, grâce auxquelles je crois pouvoir mieux comprendre le sujet retenu en articulant des propositions . Voilà la tâche qui sera mienne au cours de ce chapitre sixième. Je "revisionnerai" mon observation des paroissiens, des bénévoles et des permanents en tentant d'opérer une forme de recoupement progressif. Non seulement, me faudra-t-il assembler et raccorder de nombreuses données d'observation; mais l'ensemble de l'opération devrait me permettre d'appliquer un "effet entonnoir" au sujet traité, en vue d'en canaliser les éléments significatifs et éclairants pour la pratique paroissiale.

Grâce à certaines notions empruntées au monde des sciences humaines, à certains champs de la théologie et fort d'un certain recul établi avec l'expérience acquise, je suis parvenu à résumer en cinq propositions les résultats fournis jusqu'à présent par la recherche-action. Ces propositions ne couvrent pas tout le champ d'investigation de la paroisse actuelle. Elles n'ont rien d'exhaustif. Ce sont plus des interrogations, des pistes de recherche, des terrains de prospection. Je me défends de 
toute attitude dogmatique en un domaine aussi complexe et lié à bien des contingences humaines.

\subsection{Une méconnaissance des paroissiens actuels et de leurs déplacements}

\subsubsection{Les paroissiens influencés par plusieurs phénomènes}

La lecture de l'ensemble des données d'observation recueillies m'a permis de faire le même constat qu'André CHARRON: en Église, nous ne connaissons pas vraiment les paroissiens d'aujourd'hui ni leurs déplacements. Comme lui, je pense que "les croyants sont "ailleurs" et "autrement" 1.

"Or, il y a des questions à se poser en Église pour comprendre ce qui s'est passé, pourquoi plusieurs sont partis, pourquoi plusieurs demeurent déçus ou encore étrangers au vécu des communautés,... qui leur paraît souvent étranger. Il y a certes des causes propres au milieu ecclésial. Et cela il faut se le dire." 2

Plusieurs facteurs ont profondément modifié le style de vie des paroissiens et ont eu des conséquences sur leur mentalité. Les paroissiens actuels ont été influencés par le processus de la modernité. Ces valeurs sont apparues au confluent de divers phénomènes: l'urbanisation, la sécularisation, la révolution technologique, le pluralisme, la mobilité par l'accesssibilité du transport, le développement des moyens de communication, etc. Ces facteurs ont façonné les paroissiens d'aujourd'hui.

1

CHARRON, André, "Réaction au rapport de recherche et aux politiques retenues", in L'Avenir des communautés chrétiennes, Montréal, Fides, 1992, p. 99. Je m'inspire beaucoup de cet article dans les prochaines lignes puisque je suis arrivé aux mêmes constatations que ce chercheur dans plusieurs analyses de mes données d'observation.

2

Ibidem. "On discute encore de la bonne manière de comprendre le sacerdoce, les sacrements, la tradition et le primat romain, mais sans se rendre compte qu'on laisse constamment hors de la discussion le point décisif: la signification du sujet, avec ses expériences et son affectivité, ses misères et ses angoisses, ses tragédies et ses espoirs" (DREWERMANN, Eugen, Les fonctionnaires de Dieu, Paris, Albin Michel, 1993, pp. 148-149.). 


\subsubsection{Une Église qui résiste encore à la modernité}

Au lieu de vouloir comprendre les déplacements des paroissiens, l'Église est davantage préoccupée de dénoncer les valeurs modernes qu'ils portent en eux. On semble avoir peur ainsi de l'altérité du monde. De sorte que j'ai décelé dans mes données d'observation auprès de plusieurs permanents, comme Guy LAPOINTE l'a lui-même constaté dans le document Risquer l'Avenir, "une suspicion des êtres humains et de leurs possibilités de croire, en somme, un doute sur la possibilité d'une relation entre les communautés chrétiennes et la modernité"3.

Le concile Vatican II avait paru introduire un changement remarquable dans le rapport du catholicisme à la modernité, grâce aux perspectives positives qui commandaient la Constitution pastorale sur l'Église dans le monde de ce temps, mais plus généralement par un ton, un style, une allure, bref un esprit qui traversait la plupart des textes adoptés par les Pères. Mais, depuis quelques années, un ton nouveau fait de critique, de mises en garde, voire de condamnation de la société moderne prend le dessus.

La pertinence du christianisme aujourd'hui est qu'il aide l'être humain, comme Jésus l'a fait, à se tenir debout, à ne pas désespérer, à se mettre positivement en état de créer librement son avenir par-delà les difficultés de la vie, à entendre l'appel de Dieu sur lui. Cependant, les observations m'ont démontré que pour beaucoup de nos paroissiens contemporains, l'Église est perçue comme une immense machine prête à leur mettre le grappin dessus ou à leur imposer un catalogue d'invraisemblables

3 octobre 1992.

LAPOINTE, Guy, Analyse du document Risquer l'Avenir, Notes personnelles, p. 1, 
dogmes et de pratiques invivables. ${ }^{4}$ Voilà pourquoi un énorme travail de remise en place des justes perspectives est à faire qui conduit à l'inverse des restaurations de façade.

\subsection{L'inadaptation structurelle de la paroisse territoriale causée par l'urbanisation}

\subsubsection{La paroisse, une plaine balayée par tous les vents urbains}

Les observations réalisées m'ont permis de constater que le territoire de la paroisse n'est plus tellement représentatif, surtout dans le milieu urbain. Nous l'avons vu, beaucoup de chrétiens ne savent même pas à quel territoire paroissial ils se rattachent: les moments du mariage, du baptême d'un enfant ou des funérailles sont très révélateurs de cet état de fait. Le territoire paroissial n'est plus considéré par plusieurs d'entre eux comme un lieu d'identification. Le phénomène de l'urbanisation au Saguenay-Lac-Jean comme ailleurs au Québec et dans le monde a profondément marqué les assises de la vie paroissiale, particulièrement dans les villes. Alors que le monde s'est urbanisé de plus en plus dans les régions, nous nous trouvons dans les villes devant une multiplicité de paroisses organisées de façon autosuffisante sur le modèle rural.

4 "Selon le dernier sondage GALLUP, publié dans le quotidien USA Today du 11 août, $84 \%$ des catholiques américains - qui sont au total près de 60 millions - rejettent cet interdit sur la contraception. $58 \%$ pensent que l'Église ne devrait pas prohiber en toute circonstance l'avortement. /... / Dans une autre enquête, publiée dans le dernier numéro de Newsweek, la position de l'Église est également jugée par les catholiques américains comme "trop conservatrice" sur la contraception (62\%) et sur la place des femmes dans la société (46\%)" ( TINKQ, Henri, "La morale sexuelle", in Le Devoir - Le Monde, 12 août 1993, p. 7). Je mentionne ces statistiques récentes même si elles proviennent de nos voisins du Sud. Je crois que si l'enquête avait été faite auprès des catholiques canadiens ou québécois, les résultats auraient été sensiblement les mêmes. C'est pour cette raison qu'en fidélité à ma conscience personnelle, j'ai été un des soixante théologiens à signer la lettre envoyé à l'AEQ et à la CECC pour questionner certaines affirmations de l'encyclique Veritatis Splendor. 
Ici au Québec, plus particulièrement depuis la deuxième décennie du $\mathrm{XX}^{\circ}$ siècle et davantage après la guerre, alors que la ville a connu une recrudescence de développement qui a achevé de faire éclater la cohésion des quartiers et des institutions strictement locales, la paroisse, organisée à partir de limites territoriales, apparaît de moins en moins, aux yeux d'urbains mieux ancrés, aux yeux d'organismes civils et même à ceux des administrateurs diocésains, comme la médiation la plus adéquate entre Église et citadins, entre citadins et ville. La paroisse est devenue comme une plaine balayée par tous les vents urbains: les étroites frontières qui l'enferment ne sont plus que de simples limites administratives sans signification sociale. L'industrialisation de l'ère technique a généré l'urbanisation, comme type de civilisation même dans la plupart des milieux ruraux avec l'éclatement des communautés naturelles, y compris la paroisse, la diversification des univers sociaux, la spécialisation des services, la mobilité et l'anonymat. ${ }^{5}$ Dans une société pluraliste et post-moderne, l'être humain désire avoir la gérance de sa liberté, y compris une liberté face au territoire.

\subsubsection{La paroisse...à "l'heure de la campagne"}

La paroisse urbaine n'a pas été capable de rejoindre les rythmes de vie des citadins. Comme l'a déjà affirmé Guy LAPOINTE, on est encore à " "l'heure de la

"Bien sûr, tout cela est lié à la mutation sociologique, à l'urbanisation croissante. À la fin du siècle, il y aura sur terre près de quatre milliards de citadins, quatre cents villes ayant plus d'un million d'habitants! Le problème ne réside pas cependant seulement dans l'effondrement des structures rurales de la pastorale. Il est celui d'une réorientation spirituelle de grande envergure" (Drewermann, Eugen, Les fonctionnaires de Dieu, p.195). 
campagne". On n'a pas assez tenu compte dans les faits que le nomadisme est devenu une variable stable dans notre société"6.

"Mais cette mobilité n'est pas que spatiale; plus profondément, elle est d'ordre culturel. Ce qui se déplace, ce n'est pas seulement l'être humain physique, mais ce sont les enjeux fondamentaux humains." 7

On a souvent l'impression, à écouter des paroissiens,

"qu'ils perçoivent que les véritables enjeux humains qui commandent une lecture évangélique communautaire, enjeux qu'ils jugent importants, se jouent complètement en dehors du cadre paroissial. Un des facteurs de cette mobilité qui touche de près la paroisse est l'apparition du week-end comme temps hautement symbolique de ce nomadisme culturel. La paroisse n'a pas encore été capable de faire face convenablement à ce défi." 8

Également, parce que les paroisses sont encore des 'blocs hermétiques' non suffisamment intégrés dans une pastorale d'ensemble, elles épousent très peu les grands défis ruraux et urbains d'aujourd'hui: la manie centralisatrice des gouvernements de vouloir fusionner les petites municipalités, l'augmentation de la pauvreté dans les centre-villes, les affrontements sociaux et ethniques, l'étalement urbain, etc. Depuis Vatican II, nous avons essayé de renouveler la théologie de l'Église. Sa sociologie et sa géographie, dans le cadre de notre société industrielle sont encore balbutiantes. En outre, depuis la fin du Concile en 1965, on a assisté à une accélération de l'histoire. Des phénomènes nouveaux ont surgi qui ont influencé la vie de l'Église peut être plus que le concile Vatican II lui-même.

6 LAPOINTE, Guy, "L'avenir de la célébration liturgique dans le cadre paroissial", in Liturgie et foi chrétienne:: de l'assemblée à la communauté", $\mathrm{n}^{\circ} 99, \mathrm{p} .13$. Je m'inspire également beaucoup de cet article dans les prochains lignes vu la complicité de mes problématiques avec le Professeur Guy LAPOINTE de l'Université de Montréal.

7 DENIS, Henri, "La paroisse: déclin ou promesse? Essai de théologie pastorale", in Lumière et Vie, ${ }^{\circ} 123,1975$, p. 78.

8 LAPOINTE, Guy, "L'avenir de la célébration liturgique dans le cadre paroissial", pp. 13-14. 


\title{
6.2.3 La paroisse, un "enclos" territorial
}

L'organisation territoriale actuelle de la paroisse dans les milieux urbains ressemble parfois à un 'enclos' enfermant une portion de fidèles catholiques dans les limites d'un territoire afin de pouvoir mieux vérifier si ceux-ci n'ont pas contrevenu aux réglements ecclésiaux du 'système paroissial'.

\begin{abstract}
"Deux remarques s'imposent ici. D'une part, une telle distribution de l'espace (Rome, diocèses, paroisses) répond à un système d'emboîtement des pouvoirs, apparaissant ainsi comme la transposition spatiale du pouvoir des clercs hiérarchiquement défini. Le fait de toucher à cet espace est et sera ressenti comme une manière d'ébranler le système clérical lui-même. D'autre part, la paroisse est considérée comme un lieu où il apparaît possible de regrouper une population, quelle que soit la diversité de celle-ci, de recréer une communauté unitaire par-delà les divergences sociales. L'institution paroissiale a longtemps trouvé dans cette idéologie les éléments essentiels de sa justification."9
\end{abstract}

La ville a fait éclater le voisinage comme lieu privilégié de socialisation. L'univers urbain a dissocié les deux pôles "résidence" et "travail" mais la pastorale paroissiale n'a pas tellement assumé cette mutation. Le principe de la territorialité de la paroisse ne devrait-il pas être obligatoirement étudié en Église puisqu'il n'est plus applicable dans nos sociétés post-industrielles et modernes? Depuis plusieurs années, nous nous efforçons de résoudre les problèmes pastoraux selon les cadres anciens. Nous essayons de sauver la paroisse née de la société rurale pour n'avoir pas à repenser la pastorale urbaine sur de nouvelles bases. De plus, même le monde rural s'est régionalisé. La "cura animarum", les structures paroissiales sont encore tellement enveloppantes qu'elles empêchent parfois plusieurs permanents de s'ouvrir à des préoccupations qui traversent les frontières paroissiales. Tout cela dépasse les rôles assignés par le droit canon qui limite le curé à ses paroissiens, à son territoire. Des français", in Prêtres, Pasteurs et Rabbins dans la société contemporaine, VIe Colloque du Centre de sociologie du protestantisme, Paris, Cerf, 1982. p.61. 
influences très profondes débordent le quadrillage territorial. Les méconnaître ou les négliger, c'est se mettre en porte à faux au coeur même de la pastorale paroissiale. Le principe absolu de la résidence rend impossible la rencontre des éléments les plus actifs qui n'opèrent pas sur une base territoriale, mais sur d'autres espaces humains d'ordre économique, professionnel, culturel, récréatif ou autres. Se pourrait-il que la paroisse n'ait un avenir que si elle devient un réseau de communautés diversifiées? En ville, devrions-nous continuer à promouvoir comme structure pastorale le modèle de la fédération de paroisses ou concevoir plutôt l'agglomération urbaine comme structure de base pastorale et faire advenir une "super-paroisse" ou donner de réels pouvoirs juridiques à la zone (région) pastorale?

\subsection{Les interpellations de Vatican II sur l'organisation paroissiale}

\subsubsection{L'Église-communion: un voeu pieux}

Il n'y a pas seulement le phénomène de l'urbanisation qui remet en question la vie paroissiale et sa structure. Vatican II a opéré un grand tournant dans la vie ecclésiale pour amener tous les baptisés à devenir des sujets chrétiennement plus libres et responsables. Grâce à ce concile, nous étions invités à passer d'une Église pyramidale à une Église communionnelle. Cependant, dans ma pratique pastorale, j'ai observé que ce passage se fait très lentement et parfois difficilement surtout dans l'exercice de la coresponsabilité. Ces résistances sont peut-être normales, tant l'Église a été invitée à un changement profond. Ce passage d'une Église de sujets-objets (clercslaïcs) à une Église de sujets (tous frères et soeurs) s'avère malgré tout très long et laborieux puisque l'ecclésiologie de communion dont Lumen Gentium a posé les assises à Vatican II n'a pas été traduite en une organisation structurelle juridique adéquate. Une analyse plus approfondie de l'observation me pousse à croire que la 
paroisse est une 'cellule' de base de tout un système institutionnel ecclésial qui engendre dans la pratique des sujets (les clercs) et des objets (les laïcs). La manière dont l'Église catholique est structurée crée deux catégories de personnes dans l'Église: les clercs qui répondent aux besoins institutionnels et les laïcs qui aident ceux-ci à les combler. La dynamique ecclésiale actuelle enfante deux 'peuples de Dieu': le 'hautpeuple' (la hiérarchie ecclésiale [pape-évêques-prêtres-diacres] ) et le 'bas-peuple' (les "fidèles" catholiques). Le 'haut-peuple' dirige le 'bas-peuple'. Un 'haut-peuple' qui répond presqu'exclusivement aux besoins des gens tel que définis par les clercs. Les gens du 'bas-peuple' ne sont pas définisseurs de leurs besoins et n'ont aucun poids ecclésial. Les bénévoles sont en fait des agents qui favorisent une exécution plus large, en bas, de décisions qui se prennent en 'haut lieu'. Ils ne peuvent prendre aucune décision sans que celle-ci ait été passée au crible par les clercs. La collaboration des laïcs? Certes! Mais à condition qu'ils n'aient pas voix au chapitre, qu'ils n'aient pas part aux décisions importantes. Des services de consultation? Le 'hiérarchisme' de l'Église, qui, dans le concret, continue d'ignorer les responsabilités des laïcs. La rechercheaction m'a fait découvrir que la paroisse est une partie du corps ecclésial atteint par le 'SCL' ('Syndrome Clerc-Laïc') qui met sérieusement en danger la vitalité de toute l'Église catholique. Syndrome qui procure sur le 'sujet-clerc' un goût plus aigü de pouvoir [l'avarice], sur 'l'objet-engagé' une diminution de l'appétit pour l'engagement paroissial [l'anorexie] et pour 'l'objet-fidèle' un goût pour la consommation [la gourmandise]. Même si les orientations conciliaires de Vatican II ont injecté dans le corps ecclésial, par "in vitro", l'anti-corps CM (communauté-ministères) pour combattre le syndrome clerc-laïc (SCL) qui met sérieusement en danger la santé de l'organisme ecclésial, celui-ci n'a pas réussi à le détruire. Cet anti-corps $\mathrm{CM}$ a été bien 'fabriqué' théoriquement en laboratoire par les Pères conciliaires mais ceux-ci ne lui ont pas fourni les conditions nécessaires pour qu'il puisse donner les effets escomptés sur toutes les cellules du corps ecclésial atteintes par le SCL. 


\subsubsection{Aucun renouveau paroissial possible sans changements institutionnels}

Quelques initiatives teintées du CM (communauté-ministères) ont émergé dans différents milieux paroissiaux mais plusieurs d'entre elles ont subi des traitements parfois assez violents de 'chimiohiérarchie' qui a minimisé leur impact. C'est pour cette raison que plus de trente ans après le Concile, la vie paroissiale et ecclésiale n'a pas changé autant qu'on l'aurait souhaité. Un regard rapide sur la paroisse peut laisser croire que ça 'fonctionne' généralement bien. Les permanents ne chôment pas. Plusieurs bénévoles y sont engagés et les paroissiens demandent abondamment les sacrements. Cependant, un "second regard" avec les lentilles d'approche du dernier concile nous amène à mettre sérieusement en question le fonctionnement actuel de cette institution paroissiale. La paroisse semble se situer plus dans la ligne d'une dynamique institutionnelle à sens unique qu'à double mouvement. Par contre, des pas significatifs ont été faits depuis ce concile pour engager davantage l'ensemble des baptisés dans le devenir de l'Église. Dans l'ensemble des paroisses, sont apparus des noyaux de chrétiens cherchant ensemble à mettre en oeuvre les orientations concilaires. Ces noyaux varient d'après les objectifs de leur rassemblement et selon le pouvoir réel qui est laissé pour un véritable travail de création d'ensemble. Mentionnons ici les Conseils Paroissiaux de Pastorale, les équipes de préparation au mariage, les équipes liturgiques, etc. Certes, dans bien des cas, on "utilise" les laïcs pour exécuter des tâches, sans aller jusqu'à les impliquer au niveau décisionnel. Mais il y a des comités paroissiaux où prêtres et "laïcs" collaborent dans une nouvelle conscience ecclésiale et un nouveau partage des tâches. Il y a là un véritable acquis. Nous pouvons également parler de l'avènement des équipes pastorales, des agents pastoraux laïques et des différents synodes paroissiaux et diocésains. Toutefois, même si la collégialité paroissiale et diocésaine a progressé, les résultats sont encore inégaux. En beaucoup 
d'endroits, nous sommes encore bien 'cléricaux'. Est-ce possible de croire que l'ecclésiologie de Vatican II a ouvert le sentier aux communautés chrétiennes mais qu'on n'a pas changé la dynamique de fonctionnement de la paroisse pour y parvenir? La paroisse est demeurée une station-service religieuse cléricale au lieu de devenir un réseau de communautés et de ministères nouveaux. Pour accéder au renouveau, des changements institutionnels ne seraient-ils pas essentiels afin de susciter des chrétienssujets et des Église-sujets, sans lesquels aucun changement paroissial véritable n'est possible?

Le renouveau ecclésial semble de plus en plus difficile avec les politiques restauratrices du pape actuel Jean-Paul II. Un vent glacial de restauration est en train de mettre en danger sérieusement le printemps conciliaire de Vatican II. La hiérarchie veut de plus en plus un catholicisme fort et conforme aux lignes tracées par le Vatican. Toute créativité doctrinale, liturgique et pastorale est suspectée de violer la nécessaire unité avec le modèle romano-catholique. Les caractéristiques de la romanité doivent être reconnaissables en tout et deviennent une garantie d'authenticité. Cependant, les expériences pastorales m'ont fait découvrir que de plus en plus de croyants espèrent en un christianisme qui aurait le courage de chercher avec cohérence à traduire le rêve de Jésus dans des institutions toujours provisoires. Une telle réalité n'est pas une utopie: elle existe déjà, comme une semence, dans certaines communautés paroissiales, comme l'anticipation joyeuse de ce qui pourra devenir une vaste réalité collective pour les prochaines générations. Mais il reste des pas énormes à franchir pour que l'expérience chrétienne puisse se dire en des pratiques communautaires variées . 


\subsubsection{La préférence de la paroisse: assurer sa survie ou promouvoir sa mission}

L'observation participative m'a fait découvrir que l'institution paroissiale prend souvent le pas sur la vie des paroissiens. Les énergies des uns et des autres sont utilisées pour le fonctionnement administratif de structures. Il arrive souvent que les énergies soient presque totalement absorbées par la mise en place et le fonctionnement de ces superstructures. ${ }^{10}$ Les tâches administratives s'accumulent et les permanents ne se rendent pas toujours compte des réalités essentielles laissées pour compte. Il est difficile de sortir des sentiers traditionnels de la paroisse. Comme toujours, c'est plus facile d'entretenir les anciens chemins que de battre de nouveaux sentiers. En somme, c'est comme si la dynamique institutionnelle de la paroisse fonctionne sans même être influencée par la densité de la vie des gens et de leurs besoins. Se pourrait-il que l'institution paroissiale a historiquement préféré assurer sa survie plutôt que de promouvoir sa mission? Aurait-elle oublié que son rôle premier est de servir le mouvement d'avènement du Royaume dans une portion du peuple de Dieu ?

\subsubsection{La nécessité de l'émergence de ministères nouveaux}

Après Vatican II, les défis de la pastorale paroissiale (marquée en particulier par la diminution du nombre des prêtres) ont donné lieu à des pratiques nouvelles quant à l'organisation des services et des ministères ecclésiaux (agents de pastorale laïques, diacres permanents, bénévoles mandatés, équipes pastorales). Ces initiatives n'ont pas pu se prendre autrement que sous le mode d'essais et de tâtonnements, d'échecs même; elles ont souvent provoqué des conflits. Tout ce bouillonnement, loin d'inviter à revenir à la théologie d'avant Vatican II, pousse à 
comprendre avec plus de cohérence encore l'Église que nous sommes maintenant invités à vivre. Mais, dans l'Église d'aujourd'hui, particulièrement concernant l'émergence des nouveaux ministères, des résistances tenaces s'opposent à la mise en place des orientations conciliaires. Pourtant, les études des dernières années en exégèse et en théologie biblique ne nous éclairent-t-elles pas suffisamment sur l'importance d'éviter une sorte de monolithisme du ministère et de favoriser plutôt l'éclosion de toutes les figures ministérielles qui sont nécessaires à la vie de l'Église? La manière de vivre et d'organiser les ministères ne constitue-t-elle pas un enjeu majeur pour la vitalité des communautés paroissiales, l'accomplissement de leur mission et l'avènement d'une Église vraiment servante du monde?

\subsection{Un dialogue paroissiens - intervenants qui fait problème}

\subsection{1 Écart grandissant entre l'offre et la demande}

Les observations ont démontré que la paroisse constitue un lieu privilégié pour les besoins saisonniers d'une vie. ${ }^{11}$ En ce sens, elle contribue à fournir aux demandeurs ce qu'il est convenu d'appeler des 'rites de passages'.12 Comme je l'ai mentionné dans le chapitre troizième de cette thèse, il est toujours étonnant de rencontrer en paroisse des demandeurs qui, malgré la distance qu'ils ont prise avec la

En portant un regard d'ensemble sur mon observation participante, je suis venu à me demander si la paroisse, telle que structurée actuellement, ne ressemblait pas plutôt à un super centre commercial religieux. Un "supermarché du Seigneur" où des services sont offerts pour répondre aux besoins mais dont les interrelations sont vagues comme les boutiques d'un centre commercial. Un grand magasin où les permanents sont les directeurs, les bénévoles des gérants de différents 'rayons' et les paroissiens demandant des services, des clients.

12 Je n'aime pas utiliser l'expression "demandeurs" pour qualifier les croyants qui veulent vivre un rite de passage. Je me demande si en Église on ne parle pas de demandeurs comme pour s'appesantir sur la distance. Toutefois, je consens à l'utiliser puisque nous l'entendons régulièrement dans le circuit ecclésial. 
pratique dominicale et l'énorme difficulté qu'ils éprouvent à dire leur foi, tiennent à recevoir tel sacrement ou tel autre service paroissial. L'offre et la demande ne correspondent pas toujours: les politiques collectivistes mises en branle par les intervenants pastoraux se heurtent à la recherche d'une démarche d'abord familiale et personnalisée du côté des demandeurs. Comme Guy LAPOINTE le note, je crois également

"qu'il y a un écart grandissant entre le sens donné et cherché par les responsables de la pastorale du baptême et de l'euchartistie et celui des personnes qui demandent l'accès à ces deux sacrements. L'écart est parfois à ce point important, qu'il génère un profond malentendu. 13

Nous nous retrouvons alors en pastorale sacramentelle devant une situation complexe et délicate à traiter. Plusieurs intervenants pastoraux prônent une politique sacramentelle qui encourage l'intransigeance vis-à-vis les "distants". L'Église ne devrait sacramentaliser que ceux qui donnent des signes d'appartenance à la communauté. Pour atteindre cet objectif, plusieurs paroisses ont organisé leur pastorale comme un 'système routier' qui permet à chaque paroissien de recevoir le service demandé après avoir répondu aux exigences des 'agents' permanents du 'poste de péage'(le presbytère)! Ainsi, dans cette pastorale sacramentelle, les formules à remplir et les rencontres obligatoires occupent le premier plan. C'est peut-être pour cette raison que la paroisse a toujours privilégié un mode de rassemblement sur le caractère territorial des adhérents afin d'avoir un contrôle sur les fidèles. Certains 'agents ' pastoraux (laïques, religieux, diacres permanents, prêtres) vont jusqu'à interdire à des catholiques de 'conduire' leur baptême. Ils inscrivent à leur dossier des "points de démérite" en les qualifiant non pas de chauffards mais de 'marginaux'! En analysant plus sérieusement le travail pastoral des permanents, je suis venu à me demander si celui-ci ne

13 LAPOINTE, Guy, "La pratique des sacrements: risquer la situation présente", in Prêtre et Pasteur, juin 1993, p.356. 
ressemblait pas de plus en plus à un travail de 'fonctionnaires' paroissiaux. Des fonctionnaires qui sont responsables chacun de quelques services (dossiers) de leur 'ministère' et, selon leur disponibilité, toujours 'de garde' au presbytère (bureau) pour répondre aux demandes des paroissiens (des clients). Des permanents qui, avec l'aide de quelques bénévoles, analysent les différentes demandes faites par des paroissiens pour savoir s'ils sont éligibles, selon les critères établis en haut lieu, au service (au bien-être) paroissial demandé. Une équipe de permanents convoqué à chaque lundi matin par le responsable de service pour planifier sommairement leur travail de la semaine et voir si tout fonctionne bien. Si oui, le travail est accompli. Ces intervenants portent un jugement extrêmement sévère sur ce que vivent certains paroissiens qui n'arrivent pas à formuler clairement leurs liens au Dieu de Jésus. Est-ce que les mots peuvent dire clairement ces réalités profondes de la vie travaillée par Dieu? Qui peut juger de la qualité de la demande des personnes qui se rattachent au catholicisme?

"Comme si le christianisme culturel de référence était peu de choses! Comme si la demande des rites de passage à plus de $90 \%$ était peu de choses! Autrement dit, on maintient à distance les distants parce qu'ils sont trop envahissants" 14

Comme si le retour à la tribu familiale comme l'a démontré le sociologue Michel MAFFESOLI était peu de choses! La relation à la tradition chrétienne ne pourrait-elle pas prendre de multiples sentiers et s'exprimer de diverses façons?

"Le christianisme a une histoire concrète dans notre milieu; il a façonné tout un imaginaire, tout un réseau de représentations. Quoi qu'on en pense, il a planté ces racines jusque dans la chair vive des croyants même si leurs rapports à l'institution Église sont forts ambigüs." 15 


\subsubsection{Des "distants"....par rapport à qui? et à quoi?}

En Église, nous parlons des distants pour qualifier un grand nombre de gens. Mais, qu'en est-il de nos propres distances par rapport à eux? N'y a t-il de résistances que chez les gens? Quels sont nos propres blocages et résistances? $\mathrm{Ne}$ sommes-nous pas autant receveurs de foi que donneurs de foi? Comme je l'ai décrit précédemment, j'ai fréquenté beaucoup de 'distants' durant mes six années de travail paroissial. Ceux-ci m'ont fait beaucoup évoluer. Ils m'ont permis de devenir autre. Ils m'ont amené à découvrir un Christ Autre et un Dieu Autre. Ils m'ont guéri de mon "Alzeihmer spirituel", maladie qui nous fait oublier que l'Esprit est à l'oeuvre bien avant nos interventions pastorales. L'expérience paroissiale et la recherche-action m'ont donc révélé que bien des réussites pastorales ont en commun une expérience de complicité. Tout ne dépend-il pas de notre approche pastorale pour la fécondité évangélique de toute intervention?

\subsubsection{Une mort nécessaire à notre imaginaire autour de l'appartenance paroissiale et de lidéologie communautaire}

Il me semble que la problématique en pastorale sacramentelle (et lors des demandes de services) se traduit en termes d'appartenance à l'institution paroissiale: telle qu'elle se vit actuellement dans les milieux paroissiaux, la sacramentalisation met en scène des intervenants pastoraux d'appartenance forte (ou "nucléique") appelés à accueillir et à accompagner des demandeurs "majoritairement périphériques" face à cette même institution. Opéré sans discernement, ce dialogue peut à la fois freiner la croissance des demandeurs et empêcher les accompagnateurs permanents ou bénévoles de s'épanouir dans leur engagement. Ici, nous sommes confrontés à la fidèle opposition historique entre des intervenants pastoraux assoiffés d'une Église idéale, 
très exigeante pour ses nouveaux adhérants et ses anciens membres convertis et d'autres intervenants pastoraux soucieux de bâtir une Église accueillante en cherchant plutôt à rassembler, à faire croître l'unité entre les diversités d'appartenance et des cheminements divers. N'est-ce pas une richesse historique de la paroisse de se définir comme une structure de service ouverte au tout-venant, quels que soient sa condition et son degré d'appartenance ou d'insertion? Le dialogue entre les intervenants pastoraux et les "distants" ne devrait-il pas demeurer ouvert au cheminement de croissance du toutvenant auquel s'adresse la pastorale sacramentelle pour répondre à la véritable catholicité de l'Église et aux défis de la nouvelle évangélisation? Ne sont-ils pas des nouvelles chances du catholicisme d'ici, ces rapports de plus en plus libres et gratuits entre le monde pastoral et les gens? Accompagner le devenir de la foi chez quelqu'un, est-ce désirer qu'il entre dans notre propre course ou ne devons-nous pas plutôt ajuster notre marche à la propre foulée de mise en marche de l'autre dans son devenir autre?

La vision d'une paroisse globale est probablement celle que portent encore beaucoup les intervenants pastoraux. Le théologien Guy LAPOINTE porte cette même interrogation. "À cet égard, un des premiers pas à franchir parmi les nombreux deuils à vivre est de revoir et de vérifier notre imaginaire de la communauté." 16 Notre imaginaire n'est-il pas lié à une nostalgie de la chrétienté? Dans un contexte moderne où toutes les institutions sont en crise, ne sera-t-il pas de plus en plus impensable de concevoir la paroisse en termes d'une expérience de globalité?

"Il faut davantage penser la communauté comme un espace transitoire, un sorte de travail permanent, qui permette de passer dans le monde avec, à certains moments significatifs de la vie, des rappels d'Évangile liés possiblement aux grands moments d'intensité et d'émotion liés à la naissance, au choix de vie, à la mort." 17 
Pouvons-nous imposer un seul modèle d'appartenance à la diversité des paroissiens d'aujourd'hui?

\subsection{Un renouveau paroissial impossible sans renouveau des pédagogies pastorales $^{18}$}

\subsubsection{Une éducation de la foi qui tienne compte des étapes de la vie}

Des changements institutionnels sont certes essentiels pour renouveler la pastorale et la paroisse en milieu urbain mais ils ne suffisent pas. Il faut obligatoirement s'intéresser de près à la pédagogie pastorale utilisée. Celle-ci constitue un élément-clé dans le développement de la communauté et de lidentité chrétienne des personnes. L'expérience d'accompagnement auprès de plusieurs paroissiens m'a révélé que la foi naît et grandit dans l'effort que chaque personne met à devenir elle-même. Et ce devenir n'est atteint que grâce à la présence des autres. De plus, le développement de la foi n'arrive pas de façon uniforme durant la vie adulte mais se produit de façon variée et à travers des événements de l'existence humaine.

La recherche-participative m'a démontré qu'un des grands défis auxquels sont confrontées les paroisses d'aujourd'hui est précisément l'accompagnement des personnes au cours de leur vie. Pour cela, je crois comme l'a mentionné André Charron au congrès Risquer l'Avenir que nous devrions

"tenir compte des lois du développement religieux de la personne selon ses stades psychologiques d'évolution. /.../ Cela a une incidence sur la formation des agents accompagnateurs: pédagogie inspirée de l'andragogie et de la psychologie religieuse."19 
N'est-il pas de plus en plus urgent de s'initier à des approches qui veulent aider les paroissiens adultes à se comprendre psychologiquement et religieusement à travers leur évolution personnelle? Ne faudrait-il pas proposer aux paroisses des suggestions concrètes pour les aider à soutenir les croyants dans leur quête spirituel en tenant compte de leur diversité?

"En ce domaine de l'éducation de la foi comme en d'autres, un délestage ou un allègement pourrait se résoudre par une pastorale de secteur, une pastorale urbaine ou régionale. Il n'est pas possible- sauf peut-être au plan des groupes-relais- que chaque paroisse d'un diocèse ait un service compétent, du dernier cri. La collaboration inter-paroissiale est ici une voie possible, avec spécialisation en tel ou tel domaine d'une paroisse à l'autre."20

N'est-ce pas une autre occasion pour constituer une pastorale urbaine mieux coordonnée?

\subsubsection{L'éducation de la foi: le "comment faire" remonte sans cesse à la surface}

Depuis quelques années, l'éducation de la foi des adultes est de plus en plus présentée comme le chantier prioritaire de l'Église du Québec. Elle a été la priorité de premier rang qui a été choisie par 600 chrétiens et chrétiennes réunis au Congrès de l'AEQ sur l'avenir des paroisses au Québec tenu à Montréal du 9 au 11 octobre 1992. On parle beaucoup de l'éducation de la foi, mais plus on en parle, moins on semble savoir précisément ce que c'est. Toutefois, le seul fait d'en faire une priorité ne résout pas tous les problèmes. On veut bien offrir des services de qualité, mais la question du "comment faire" remonte sans cesse à la surface. 
"Le problème reste de savoir comment va se faire cette éducation, dans quels termes et selon quelle pédagogie. /.../ L'éducation de la foi devra présenter le projet de vie proposé par Jésus comme pertinent au projet humain individuel et collectif." 21

Plusieurs paroissiens espèrent des services d'éducation de la foi. La plupart des paroisses offre très peu de moyens pour aider les paroissiens (périphériques et nucléïques) à cheminer spirituellement à travers les étapes de leur vie. Ne faut-il pas consentir aussi à ce que l'éducation de la foi se fasse de plusieurs façons et savoir qu'elle se déroulera souvent lors des rites de passage?

\section{$6.6 \underline{\text { Un pari }}$}

L'institution paroissiale, particulièrement dans le milieu urbain, doit être transformée rapidement car l'ensemble des autres formes de l'Église ne déboucheront pas si la paroisse urbaine ne bouge pas. C'est là, à mon avis, que se jouera pour une bonne part l'avenir de l'Église. La paroisse constitue un lieu privilégié de renouveau communautaire et de nouvelles initiatives concernant l'éducation de la foi. Les paroisses peuvent être des milieux communautaires précieux pour promouvoir une nouvelle évangélisation, pour faire naître des nouveaux ministères et pour être attentif d'une manière privilégiée aux plus démunis de la société. L'Église doit donc réviser ses aménagements sociaux et institutionnels ainsi que ses pédagogies d'accompagnement de la foi. Une théologie plus élaborée sur la paroisse s'impose ainsi d'urgence puisqu'elle a été la plus oubliée à Vatican II par les Pères conciliaires et depuis ce concile, par les théologiens. 


\subsection{Une réflexion qui arrive à point}

Je désire ouvrir un chemin d'espérance pour le renouvellement de la structure pastorale paroissiale en milieu urbain dans une ecclésiologie de communion. Un chemin que d'autres ont essayé difficilement d'ouvrir depuis Vatican II. Déjà en 1975, dans l'Église locale de Chicoutimi, Mgr Marius PARÉ, évêque titulaire à cette époque, a lancé le projet d'une commission diocésaine de recherche pastorale (la Commission PEDNEAULT). ${ }^{22}$ Cette Église diocésaine voulait ainsi entrer dans la mouvance d'une vision renouvelée de l'Église suscitée par le concile Vatican II. Quelques années plus tôt, l'Église du Québec avait entrepris une vaste consultation avec la Commission DUMONT. Le rapport de cette commission, "L'Église $d u$ Québec, un héritage, un projet", proposait des orientations pastorales dont la richesse est loin d'être épuisée. ${ }^{23}$ Depuis quelques années, les diocèses du Québec s'intéressent à cette question de la pastorale urbaine et du devenir de la paroisse. Au diocèse de Québec, une étude sur la pastorale en milieu urbain en 1977 a déclenché une réflexion intéressante dans cette Église locale. ${ }^{24}$ Dans le diocèse de Saint-Jean-Longueuil, le projet "Le Renouveau" se présente comme une démarche de renouvellement de la paroisse. ${ }^{25}$ En 1990, le diocèse de Baie-Comeau a également réfléchi sur la structure pastorale en milieu urbain. ${ }^{26}$ D'autres expériences de renouveau prennent tranquillement racine au Québec. Nous n'avons qu'à penser au projet NIP ( Nouvelle Image de la Paroisse ) qui a amorcé une pédagogie de changement plus articulé à ce

22 COMMISSION DIOCÉSAINE DE RECHERCHE PASTORALE, Mission et coresponsabilité, Chicoutimi, Secrétariat de la commission, 1977, 191p.

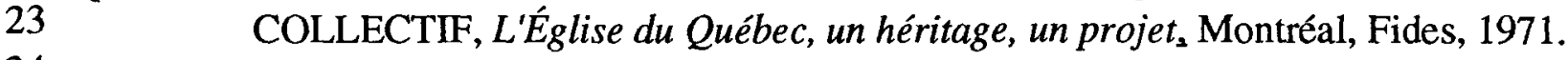

24 MORISSETTE, Pierre, La pastorale en milieu urbain, Service de la pastorale, Diocèse de Québec, 1977, 48p. [pro manuscripto]

25 FARLY, Clément, "Pratiques de renouveau communautaire", in Communauté chrétienne, vol. 25, $\mathrm{n}^{\circ} 147$, mai-juin 1986, pp. 223-233.

26 COMITÉ D'ÉTUDE SUR LA PASTORALE URBAINE, L'Église de Sept-îles $s$ 'interroge sur son avenir, Projet de pastorale urbaine, document de travail, 1990, 17p. 
niveau. 27 Les communautés de base constituent aussi pour certains un motif d'espérance pour la vie de l'Église même si au Québec elles ont de la difficulté à émerger. L'"importation" des communautés de base d'origine latino-américaine dans les paroisses québécoises fait problème. De plus, la hiérarchie romaine souhaiterait que celles-ci soient considérées comme des cellules de base de la paroisse. D'autres, en particulier des théologiens de l'Amérique Latine, sont contre cette insistance sur leur incorporation à une paroisse territoriale et dénoncent le désir des autorités ecclésiales de 'paroissialiser' les CEB. 28 Pour plusieurs d'entre eux, les communautés ecclésiales de base sont une manière autre de faire Église. Elles doivent garder leur autonomie et être plutôt incorporées à un regroupement des CEB au niveau d'une ville ou d'un secteur.

Quatre études québécoises viennent récemment d'être publiées sur la paroisse. Il s'agit premièrement de la recherche menée par deux chercheurs de l'Université du Québec à Trois-Rivières Jean-Marie LEVASSEUR et André TURMEL. Cette étude est intitulée: "L'évaluation pastorale au Québec, L'enquête sur les pratiques évaluatives en usage dans les paroisses catholiques du Québec" (TroisRivières, Pastor, 1992, 264p.). Deuxièmement, Lucia FERRETTI, a publié sa thèse intitulée: "Entre voisins, la société paroissiale en milieu urbain Saint-Pierre-Apôtre de Montréal 1848-1930" (Montréal, Boréal, 1992, 261p.). Troisièmement, les évêques du Québec, en concertation avec l'Institut de Pastorale de Montréal, ont publié leur recherche participative sur les voies d'avenir des communautés chrétiennes locales

COMEAU, Maurice. "Vers une nouvelle image de la paroisse", in Prêtre et Pasteur, vol. 86., $\mathrm{n}^{\circ}$ 7, juillet-août 1983, pp. 410-416. CAPELLARO, Juan-Bautista, La paroisse communion de communauté, Kinshasa, CEP-Centre d'études pastorales, 1982, 96p. ["Eglise demain", \#2] . CAPELLARO, J. B., LIUT , J., CANESSO, L., COSSU, F., MC NABB, J., De la masse au Peuple de Dieu, traduction établie à partir de l'édition italienne: Da massa a popolo di dio, $1984,153 \mathrm{p}$.

28 Voir CONFERENCIA GENERAL DEL EPISCOPADO LATINO AMERICANO $\left(\mathrm{IV}^{\circ}\right)$, Nueva evangelizacion promocion humana cultura cristiana , Conclusiones, Santo Domingo, 12-28 de Octubre de 1992, 86p. 
intitulée: "Risquer l'avenir" (Montréal, Fides, 1992, 227p.). Quatrièmement, la thèse de doctorat d'André CHEVALIER sur "La paroisse post-moderne - Faire Église aujourd'hui l'exemple du Québec" (Montréal, Paulines, 1992,372p.) a été publiée aux Éditions Paulines. Depuis plus d'une trentaine d'années, on n'avait presque rien écrit sur l'institution paroissiale. En une seule année, celle de 1992, quatre études sur les paroisses ont été publiées, ce qui indique que mon sujet de recherche constitue une préoccupation très actuelle dans les milieux ecclésiaux et universitaires. Cependant, aucune étude englobant les différentes problématiques de la pastorale en milieu urbain et le devenir de la paroisse n'a été faite. C'est à l'avènement de ce chantier que je désire apporter une contribution modeste dans la présente thèse.

6.8. Hypothèse d'interprétation de la situation paroissiale actuelle

\subsubsection{Hypothèse de sens}

Pour renouveler la paroisse dans le but de mieux assurer la mission de l'Église en réponse au phénomène de l'urbanisation en contexte moderne, deux défis se dégagent: -Il faut une réforme institutionnelle pour faire advenir une structure pastorale qui soit fonctionnelle par rapport à la dynamique urbaine. -Il faut un renouveau de la pédagogie pastorale pour répondre à la culture actuelle et aux exigences d'incarnation de l'Évangile.

\subsubsection{Hypothèse à vérifier}

Les orientations fondamentales de l'ecclésiologie conciliaire de Vatican II (la synodalité de l'Église, la dimension communautaire plus affirmée, le renouvellement des ministères, l'explicitation de la mission de l'Église) ne sont-elles pas une manière 
de répondre aux défis du phénomène de l'urbanisation et de la modernité? La ressaisie de la mission de l'Église, en particulier celle de la paroisse, comme service du Royaume dans la croissance des personnes et le devenir des collectivités, conduit également à une remise en question en profondeur des pédagogies pastorales d'accompagnement de la foi. Au carrefour de ces deux propositions, l'Église doit redevenir capable d'engendrer les humains à une qualité de vie spirituelle. C'est à cette condition que l'Église et la paroisse elle-même pourront retrouver une pertinence à cette fin de $\mathrm{XX}$ siècle marquée par une soif spirituelle dont le phénomène du Nouvel Âge constitue une manifestation. 


\section{II.2 DES CLÉS DE COMPRÉHENSION ÉCLAIRANTES}

\section{CHAPITRE 7}

\section{HISTORIQUE DE LA PAROISSE: "L'HISTOIRE D'UNE LENTE DÉGRADATION"1}

La paroisse, circonscription ecclésiastique, s'est maintenue jusqu'à nos jours. Presque partout elle a donné naissance à une division civile, la commune. Elle a été pendant bien des siècles le seul centre de l'activité locale. C'est autour de leur église que des générations d'êtres humains se sont regroupés: c'est près de leur autel, sous le regard de leur Dieu ou de leur saint, qu'elles ont vécu, travaillé, espéré, souffert. L'histoire des paroisses est étroitement unie à l'histoire des institutions, des croyances et des moeurs. Fait contingent, la paroisse est née et s'est développée lentement au cours des siècles. Les modalités de sa croissance ont beaucoup varié d'un pays à l'autre, d'une province à l'autre, et plus encore de la ville à la campagne. Il n'est donc pas inutile de présenter la paroisse comme un phénomène historique dont la valeur est circonscrite par les circonstances qui ont provoqué et justifié son apparition.

Avant d'analyser l'évolution historique de la paroisse canadienne-française, il est important de replacer cette institution dans l'ensemble de l'histoire de l'Église. Cette première étape n'en reste pas moins nécessaire, si l'on veut respecter et assumer les dynamismes de la tradition vivante et les processus durables de structuration

"La paroisse, comme bien d'autres structures a connu une histoire qui, malgré ses gloires, est aussi l'histoire d'une lente dégradation" (DENIS, Henri, "La paroisse: déclin ou promesse? essai de théologie pastorale", in Lumière et Vie : "Les paroisses: mort lente ou renouveau", tome XXV, $\mathrm{n}^{\circ} 123$, juin-juillet 1985 , p. 76). 
ecclésiale, qui ont eu cours dans cette expérience deux fois millénaire de l'Église. Les données établies par quelques historiens permettront de cerner l'itinéraire de cette institution. 2

\subsection{L'absence de paroisse dans l'Église apostolique}

\subsubsection{L'origine du mot "paroisse"}

Le mot "paroisse" vient du latin "parochia", lequel vient du grec "paroikia". Or ce mot, qui se retrouve uniquement dans la langue de la Bible ou de l'Église a, originairement, plutôt un sens religieux et théologique qu'un sens sociologique et canonique. En réalité, par cette expression "paroikia", les chrétiens entendaient exprimer la conscience qu'ils avaient d'être des "étrangers" sur la terre, de n'y avoir pas de demeure permanente de même que l'espérance de trouver au ciel seulement leur vraie patrie. Plus de soixante fois nous trouvons dans les Septante le verbe "paroikein". Le mot hébreu "étranger" (Ger) se traduit dans les Septante par "paroikos". Le Nouveau Testament reprend incontestablement ce sens lorsqu'il emploie "paroikein", pour signifier être étranger et "paroikos" dans le même sens. Il est intéressant de remarquer que, dans la première épître de Pierre, l'existence chrétienne est considérée comme "le temps de séjour à l'étranger". Pierre exhorte les premiers chrétiens: "Puisque vous invoquez comme Père Celui qui juge sans

Cette synthèse historique a été difficile à rédiger en raison de la pénurie de documents. Cependant, un certain nombre d'ouvrages relatifs à l'histoire de la paroisse ont été publiés ces dernières années, témoignant d'un regain d'intérêt pour celle-ci. Citons notamment LE BRAS, G., Les institutions ecclésiastiques de la chrétienté médiévale, t. XII de l'Histoire de l'Église, vol. 2, Paris, 1964, pp. 404-423; GAUDEMET, J., Le gouvernement de l'Église à l'époque classique, t. VIII, de l'Histoire de Droit et des Institutions de l'Église en Occident, vol. 2, Paris, 1979, pp. 217 304; AUBRUN, M., La paroisse en France des origines au XV siècle, Paris, Picard, 1986, 269p.; COLLECTIF, Histoire de la Paroisse, Actes de la Onzième Rencontre d'Histoire Religieuse tenue à Fontevraud les 2 et 3 octobre 1987, Angers, Presses de l'Université d'Angers, 1988, 233p. 
acception de personnes selon les oeuvres de chacun, vivez dans la crainte durant le temps de votre séjour comme étrangers (ici-bas), ton paroikias chronon" ( $1 \mathrm{P} \mathrm{1,17}$; cf 1 P 2,11). Ces expressions ont passé telles quelles dans la littérature chrétienne des premiers siècles. Ainsi, la seconde lettre de S. Clément adjure le lecteur d'abandonner "paroikia", c'est-à-dire l'exil de cette terre. L'en-tête de cette lettre de Clément de Rome aux Corinthiens, rédigée sans doute entre 92 et 101, est formulé comme suit: "L'Église de Dieu qui séjourne (en étrangère - paroikousa) à Rome, à l'Église de Dieu qui séjourne (en étrangère - paroikouse ) à Corinthe."3 Dans la lettre à l'Église de Philomenium, écrite entre 155-157, et qui raconte le martyre de Saint Polycarpe, paraît pour la première fois le substantif "paroikia" au sens de l'Église locale. La nuance profonde eschatologique impliquée dans le verbe "paroikein" et le substantif "paroikia" ne s'est pas effacée tout de suite. Même au $\mathrm{IV}^{\circ}$ siècle elle est encore vivante. Mais à partir de cette époque, l'expression perd sa saveur biblique et fait partie de la langue administrative. Cette vue sommaire sur l'origine, l'histoire et le changement de sens de "paroikia" montre que ce terme, originairement plein de sens religieux de l'existence du chrétien et de la communauté chrétienne, a pris progressivement un sens canonique et administratif. ${ }^{4}$ Alors qu'au début, il désigne une qualité de l'existence chrétienne, il signifie de plus en plus une réalité concrète, administrative qui rend visible le groupe chrétien. 50-56 DILLENSCHNEIDER, Clément, La paroisse et son curé dans le mystère de l'Église, Paris, Alsatia, 1965, pp.3-15. 


\subsubsection{Une ville, un diocèse (une paroisse), un évêque}

Pour nous, la paroisse, 'cellule' ecclésiale de base, est un donné qui va de soi. L'histoire bouscule cette évidence simpliste. Au tout début de l'Église, paroisse et diocèse coïncident. Pour les chrétiens des premiers siècles allait de soi l'indivision de la communauté dans les limites de la 'cité': la ville et ses dépendances campagnardes. Le diocèse était le rassemblement de la totalité des chrétiens qui vivaient dans une ville déterminée. On emploie paroisse comme synonyme d'Église particulière, d'Église épiscopale. Il y avait une ville, un diocèse (une paroisse), un évêque. ${ }^{5}$ La paroisse est donc l'Église d'une ville. Il y avait toujours équivalence géographique entre la ville et l'Église ou la paroisse. C'est pourquoi, d'ailleurs, les limites des Églises ou des paroisses ne sont pas déterminées. Elles s'embrassent sur l'étendue de l'influence ou du pouvoir de la cité. Que chaque ville n'ait qu'une Église ou paroisse fut ainsi la doctrine et la pratique les plus constantes de l'Église ancienne. Le principe d'une paroisse par ville est même entré dans la législation de l'Église ancienne et cette unicité de la paroisse dans chaque ville sera rigoureusement respectée. ${ }^{6} \mathrm{Ce}$ principe vise l'édification de l'Église et l'accompagnement de la mission dans l'unité.

"En termes modernes, on dirait: le diocèse n'est qu'une seule paroisse, l'évêque 'monarchique' -c'est-à-dire seul responsable ultime, cela à partir du $\mathrm{II}^{\circ}$ siècle au moinsassure et manifeste l'unité. Autour de lui, on trouve d'autres 'ministres', des 'presbytres' en

5 Voir COMBLIN, Joseph, Théologie de la ville, Paris, Ed. Universitaires, 1968, p.319. Voir aussi CROCE, P.W., Histoire de la paroisse, in La paroisse de la théologie à la pratique, Paris, Cerf, 1961, pp. 2-3."Celle-ci [la paroisse] est un institué d'importance, datant des origines du christianisme, qui prit naissance en milieu urbain, selon la structure collective de l'époque. Les chrétiens, minoritaires et dispersés, y "faisaient paroisse" pour des motifs religieux et d'entraide fraternelle, répondant à l'intention du rassemblement communautaire déjà promu par Jésus. On connaît cette salutation du pape Clément en 95: "L'Église de Dieu qui tient paroisse à Rome à l'Église de Dieu qui tient paroisse à Corinthe". On faisait d'une unique paroisse de la cité, l'instance globale de vie: il y avait donc une ville, un évêque, une paroisse" ( CHARRON, A."La paroisse évangélisatrice d'aujourd'hui", in Prêtre et Pasteur, vol. \# 94, no 10, novembre 1991, p.616.). 
particulier (mot grec signifiant 'ancien', 'homme d'âge'); mais ils exercent leur charge collegialement, donc sans partage de territoire."7

Et, à chaque fois que dans une ville secondaire, le nombre de chrétiens augmentait suffisamment, on y installait un évêque, assisté d'un clergé plus ou moins considérable. De plus, le peuple était appelé à prendre part à l'élection de l'évêque et des autres ministres. ${ }^{8}$ Également, les évêques consultaient l'assemblée dans les grandes décisions, ce qui veut dire qu'ils reconnaissaient dans l'assemblée des chrétiens d'une ville, l'expression d'une Église locale. Le droit reconnaît ce fait.

La frontière ou le territoire était une question quasi étrangère à la culture de ces croyants des premiers siècles. De toute façon, aucun problème interne ne les conduisait non plus à poser cette question d'une frontière pour leur diocèse (paroisse). "... si l'on avait demandé à un évêque des trois premiers siècles si son église avait des frontières, il aurait problablement répondu que non." 9 Ainsi, pour les chrétiens de l'Église apostolique, l'Église était d'abord le diocèse (la paroisse) ou la ville. ${ }^{10}$ C'est

7

GEREST, C. , "Aux origines de la paroisse: le peuple, les puissants et la sacralisation de l'espace", in Lumière et Vie, tome XXV, no 123 , juin-juillet 1975, p. 52.

$8 \quad$ "Jusque dans le droit médiéval l'intervention du peuple dans les élections sera mentionnée. À Rome ce fut la réforme du concile de 1059 et le décret sur l'élection du pontife romain qui porta le coup de grâce à l'élection populaire" (COMBLIN, J., Théologie de la ville, p.326).

9 LEGRAND, H., "La délimitation des diocèses", in La charge pastorales des évêques, coll.Unam Sanctam, Paris, Cerf,1969, no 74, p.181.

10 Des historiens disent qu'on emploie indifféremment Église, paroisse ou diocèse jusqu'au Moyen Âge. Selon eux, ce fut au Moyen-Âge que l'usage se forma de réserver le nom diocèse à la circonscription épiscopale, tandis que les circonscriptions inférieures recevaient le nom de paroisses. Cette évolution fut imposée par la nouvelle situation faite à l'Église locale. D'autres historiens mentionnent au contraire qu'au VI ${ }^{\circ}$ siècle, les deux termes "paroecia" et "diocesis" s'échangent comme deux synonymes. Á partir du VII siècle, dans les décisions conciliaires, le mot "parochia" signifie ordinairement la paroisse, telle que nous la concevons à présent. La "paroikia" va désigner non plus seulement, comme jusqu'alors, la communauté de la ville ayant l'évêque à sa tête mais même les petits territoires avec un prêtre comme pasteur. "Le premier mot qui la désigne est celui de dioecesis. Au commencement du $\mathrm{V}^{\circ}$ siècle, le terme parochia s'applique surtout au diocèse. Encore à l'époque de Sidoine, puis du concile d'Adge, les dioeceses sont les paroisses. C'est au $\mathrm{VI}^{\circ}$ siècle seulement que, par une interversion assez curieuse des mots, le district d'un diocèse, celui d'une église rurale ont reçu les noms qu'ils portent aujourd'hui"( DE LA TOUR, Imbart, Les 
dans l'Église de leur ville, rassemblés autour de leur évêque pour la célébration eucharistique, que les chrétiens voyaient l'épiphanie la plus plénière et la plus authentique du mystère de l'Église. L'Église locale était l'Église de telle ville. ${ }^{11}$ Il allait de soi que tous les chrétiens qui demeuraient dans une ville constituaient une seule entité. Et ce fut ainsi que dans chaque ville naquit une "Église" nouvelle. Le christianisme primitif a donc été un phénomème essentiellement urbain. La mission de l'Église était réellement subordonnée à la rédemption, à la restauration de la ville, pour que cette dernière devienne vraiment humaine.

\subsection{L'origine de nos paroisses 'rurales': aux $\mathrm{III}^{\circ}$ et IV siècles}

\subsubsection{Une décentralisation de l'unique paroisse-diocèse au profit des campagnes}

C'est au III ${ }^{\circ}$ siècle que se produisit, sur une plus vaste échelle, une certaine décentralisation de l'unique paroisse-diocèse au profit des campagnes. C'est en Gaule qu'apparurent ces premières Églises rurales. Au début, le phénomène prit plus d'ampleur en Orient qu'en Occident. Cependant dès la fin du III $^{\circ}$ siècle, le découpage du diocèse en paroisses fut plus systématiquement poussé, sans toutefois former un réseau dense de paroisses. La multiplication de ces paroisses se fit lentement et non sans résistances. Quelques communautés sont érigées par des 'presbytres' ou certains prêtres sont attachés au service de communautés rurales.

origines religieuses de la France, Les paroisses rurales $d u I V^{\circ}$ au $X I^{\circ}$ siècle, Paris, Picard, réimpression de l'édition de 1900, 1979, p.51). Voir aussi LECLERCQ, H. , "Paroisses rurales", in Dictionnaire d'archéologie chrétienne et de liturgie, tome treizième, deuxième partie, Paris, Letouzey et Ané, 1938, col. 2198-2235. À consulter l'histoire, il nous arrive souvent de voir des divergences entre les historiens eux-mêmes. Ne faut-il pas consentir à admettre qu'il n'existe jamais une histoire d'une réalité mais des histoires.....

COMBLIN, J. Théologie de la ville, p.311. 
"La paroisse, au sens restreint et actuel du mot commence à se dessiner le jour où un 'presbytre' est délégué pour exercer une charge pastorale (à l'époque, en fait surtout cultuelle) sur une part du territoire de la 'cité'. De ce 'presbytre', on peut dire qu'il devient un 'prêtre', au sens où nous l'entendons ordinairement." 12

"Le contraste est d'ailleurs saisissant entre la situation des villes et celle des campagnes. On sait que les villes ont été christianisées en premier lieu, ou plutôt il faudrait dire qu'elles ont été habitées par l'Église du fait de la présence de communautés chrétiennes et de la présidence épiscopale. Il n'y a pas de paroisses en ville. Le christianisme est un phénomène urbain, unifié autour de l'évêque. L'intuition de la paroisse rurale est donc bien celle de la démultiplication de la présence de l'Église, une présence plus proche de la réalité de la vie rurale" 13

Mais ces paroisses n'ont pas d'indépendance réelle vis-à-vis de la communauté citadine et de son évêque. Dans la ville, centre de la 'cité', l'unicité de la paroisse resta longtemps un principe. C'est pour cette raison que les baptêmes, l'eucharistie des grandes fêtes, la réconciliation des pénitents n'ont lieu que là où se trouve l'évêque. Lorsque se sont fondées les premières paroisses rurales, il n'était donc pas question de fractionner l'Église épiscopale en districts paroissiaux où le prêtre serait un petit évêque sur son territoire, mais bien plutôt de signifier l'Église universelle en ce milieu précis. Tout prêtre n'était que l'auxiliaire ou le conseiller de l'évêque dans l'unité du presbyterium.

\subsubsection{L'unité du presbytérium: une priorité}

Il aura fallu attendre la fin de ce $\mathrm{IV}^{\circ}$ siècle et l'action des grands évangélisateurs des campagnes pour voir apparaître en plus grand nombre des Églises rurales, des paroisses. Les paroisses rurales ont été ainsi des paroisses urbaines en réduction. Les évêques s'emploient à promouvoir l'évangélisation des campagnes par l'envoi de presbytres dans ces lieux qui sont encore des déserts chrétiens. Cependant, 
jamais dans l'antiquité on n'aurait conçu qu'un clerc eût à demeurer dans une ville sans faire partie du collège des ministres de l'Église du lieu, ni d'ailleurs que la juridiction sur la ville fût divisée en plusieurs collèges parallèles et indépendants, comme aujourd'hui dans nos paroisses urbaines. 14 Donc, pour l'Église ancienne, ce qui fait l'unité d'une Église locale, ce n'est pas nécessairement l'évêque. Il y eut beaucoup d'Églises sans évêque résident. L'unité de l'Église lui vient de son clergé. Il ne s'agit pas d'un ministre délégué de l'évêque, mais d'un clergé comme un collège ou un corps. L'Église locale n'est pas considérée comme une division administrative de l'Église où réside l'évêque. Non, elle a son unité propre, son principe de vie et d'organisation: c'est son collège de ministres. Il n'y a pas d'Église locale sans cette diversité de ministères réunis en un seul collège. Chaque ville n'a pas son évêque, mais chaque ville a son sénat ecclésiastique, chaque Église locale a son clergé. 15 L'image idéale de l'Église locale ou de la paroisse que nous laisse l'antiquité chrétienne, est celle de la communauté des chrétiens qui se savent responsables d'une ville et exercent leur mission sous la direction d'un collège de ministres présidé par un évêque ou en dépendance du corps épiscopal d'une manière adaptée aux circonstances. ${ }^{16}$ Quant au diocèse, il n'est qu'une création administrative réunissant un certain nombre d'Églises

14

15

COMBLIN, J. , Théologie de la ville, p.324.

Ibid, p.326. "...les pasteurs des premiers siècles ont construit des communautés ouvertes en développant d'abord un vrai presbytérium et en vivant une collégialité concrètement traduite dans les faits. Voici ce que Cyprien disait à ses prêtres et à ses fidèles: "Je me suis fait une règle, dès le début de mon épiscopat, de rien décider sans votre conseil et sans le suffrage du peuple. Comme nous sommes loin de là, dans bien des églises locales, et cela au siècle du grand éveil démocratique!"(GRAND'MAISON, JACQUES, La paroisse en concile, Ottawa, Fides, 1966, pp. 123-124.).

16 La législation canonique sur les évêques et les témoignages des Pères sur l'épiscopat confirment pleinement le principe d'une Église par ville. En effet, très tôt sans aucun doute, l'usage s'établit de constituer un évêque par ville de quelque importance. Cependant, au IV ${ }^{\circ}$ siècle, on commença à limiter la multiplication des évêques, sans doute à la suite de l'importance nouvelle que les évêques acquirent dans la structure de l'Empire. Il ne fallait pas que le titre d'évêque perdît son prestige par suite d'une multiplication excessive. C'est pourquoi les conciles du $I^{\circ}$ siècle interdisent de multiplier inconsidérément les sièges épiscopaux dans les petites villes. 
locales pour les maintenir en contact avec le collège épiscopal et avec la communion de l'Église universelle. ${ }^{17}$

Nous nous retrouvons ici encore avec certaines divergences entre les historiens eux-mêmes concernant les liens entre les prêtres et l'évêque à cette époque. Contrairement aux affirmations précédentes et suivantes sur l'unité du presbytérium, quelques historiens affirment que les prêtres sont venus rapidement à travailler plus individuellement et à présider seuls l'eucharistie. Les concélébrations, expression symbolique de l'unité d'un presbytérium, étaient beaucoup plus rares qu'on le prétendait. Certains historiens affirment que nous avons un rapport mythique avec la concélébration. Celle-ci est devenue de moins en moins populaire avec l'évangélisation des campagnes.

"L'idéale concélébration de tous les prêtres romains avec l'évêque rassemblant toute la communauté, si jamais elle avait existé à l'origine et si souhaitable qu'on l'ait toujours considérée ("une seule Eucharistie pour unir", disait saint Ignace d'Antioche, 18 tout en admettant qu'un prêtre la célébrât avec la permission de l'évêque), était déjà impossible à l'époque de saint Irénée." 19

17

L'implatation d'églises locales se fit en dehors des villes. Dès le début, de grands efforts furent tentés pour assurer cette communion ecclésiale à laquelle on tenait tant. On réussit à éviter ces groupes sociologiques paroissiaux qui apparaîtront plus tard... jusqu'à nos jours! Il s'agissait plus de relais de l'Eglise épiscopale, de carrefours d'évangélisation, privés de tout pouvoir antarcique même s'ils avaient une relative autonomie. L'évêque en restait le premier responsable. La juridiction territoriale mit du temps à faire son chemin surtout en dehors de l'Italie où chaque petite ville avait son évêque.

18 Dès les premières années du $\mathrm{II}^{\circ}$ siècle, saint Ignace d'Antioche parle de la concélébration. "Ayez soin de ne participer qu'à une seule eucharistie; car il n'y a qu'une seule chair de notre Seigneur Jésus Christ, et un seul calice pour nous unir à son sang, un seul autel, comme un seul évêque avec le presbyterium et les diacres, mes compagnons de service" (MARTIMORT, A.G., L'Église en prière, Chapitre II: La concélébration eucharistique, Paris, Desclée, 1983, p. 239. Il faut noter que le terme concelebrare n'apparaît plus précisément qu'au Moyen Âge; son correspondant grec se trouve au IX ${ }^{\circ}$ siècle chez Photius. Voir S. IGNACE D'ANTIOCHE, Lettre aux Philadelphiens, 4, éd. trad. P. T. CAMELOT, 1951, SC 10, pp. 142-145.

BOULET, Noële Maurice-Denis, Titres urbains et communauté dans la Rome chrétienne, in La Maison-Dieu, $\mathrm{n}^{\circ} 36,1953$, p.21. En Gaule, la "concélébration" est tombé en désuétude, lorsque la liturgie romaine y fut introduite; la raison première devait en être la dispersion des communautés rurales. C'est là une motivation pastorale qui, en bien d'autres régions aussi, a 
Cependant, pour d'autres historiens, la concélébration a été très populaire dans les premiers siècles et s'est poursuivie jusqu'au XIII ${ }^{\circ}$ siècle.

"La concélébration, autre usage ancien pour manifester l'unité de l'Église locale, se maintint à Rome jusqu'au XIII ${ }^{\circ}$ siècle. Ce n'est qu'à Avignon que les papes interrompirent la tradition. Les papes, loin du peuple romain, ne célébrèrent qu'une liturgie privée." 20

C'est à partir du $\mathrm{IV}^{\mathrm{o}}$ siècle, que les diocèses commenceront à prendre conscience de leurs frontières en raison de conflits. À partir du moment où des communautés rurales commencèrent à naître, il arriva qu'elles fussent réclamées par deux évêques différents. Donc, nous pouvons dire que la paroisse n'a pris naissance que vers la fin du $\mathrm{IV}^{\circ}$ siècle, avec l'indépendance donnée aux Églises rurales jusque là simples dessertes de l'Église-mère. ${ }^{21}$

"Une tentation insidieuse peut s'offrir: celle de définir une sorte de "théologie abstraite" de
la paroisse qui satisfasse, dans notre situation présente, nos besoins de rationalisation.
Cette tentation est heureusement vite apaisée. On ne pourrait décemment parler d'une
théologie un peu définitive de l'institution paroissiale. Celle-ci est née, il y a bien
longtemps, d'exigences toutes empiriques (toutes sociologiques, serait-on tenté d'écrire).
Par suite des difficultés de communications, les évêques ont dû déléguer certains de leurs
pouvoirs à des curés: c'est là résumer à peine grossièrement les origines. Mais cette

provoqué l'abandon de la règle primitive de l'unique messe. Il semble exagéré de croire que la concélébration a symbolisé longtemps la communion parfaite, la fraternité par excellence et était par le fait même à la source de l'assemblée des frères chrétiens. Selon certains historiens, c'est faux de dire que cette tradition d'une seule eucharistie locale, même avec un grand nombre de prêtres, s'est poursuivie longtemps. Au contraire, elle s'est perdue rapidement dans les particularismes des églises locales multipliées où les prêtres ne pouvaient plus être proches de la ville où résidait leur évêque.

20 COMBLIN, J., Théologie de la paroisse., p.331.

21 GEREST, C., Aux origines de la paroisse..., p. 55. "Vers la fin du IV ${ }^{o}$ siècle, on se mit à installer des prêtres à demeure, au moins dans les villages éloignés. Ainsi furent constituées, les premières paroisses au sens où nous l'entendons aujourd'hui. $\mathrm{Au} \mathrm{V}^{\circ}$ siècle, il y en avait déjà un assez grand nombre /.../ Le pape Zosime (417) protesta un jour contre le développement arbitraire des paroisses /.../ Il est important à noter qu'à cette époque, les territoires paroissiaux étaient très étendus et contenaient souvent huit à dix villages"(CROCE, P.W., Histoire de la paroisse..., p. 20). 
organisation qui fut liée d'abord à des nécessités toutes immédiates est devenue une institution permanente." 22

\subsection{La "constitution" du système paroissial à l'époque mérovingienne $\left(\mathrm{V}^{\circ} \mathrm{au} \mathrm{VIII}^{\circ}\right.$ siècle $)$}

\subsubsection{La fondation de nombreuses paroisses}

$\mathrm{Du} \mathrm{V}^{\circ}$ au VIII $^{\circ}$ siècle, le nombre des paroisses augmente considérablement. Plusieurs facteurs expliquent cette multiplication des paroisses: l'évangélisation des populations campagnardes 23 , la ruine des villes, le retour à une économie rurale, la multiplication des oratoires privés ruraux 24 , la population dispersée dans les grands domaines, l'église de la cité trop éloignée, l'insistance sur la pratique religieuse comme devoir pour tous, le désir de garder les paysans sur leurs terres, les cultes des saints et des reliques, etc. Ne fallait-il pas donner aux villae (grands domaines) une organisation paroissiale? Les évêques ont hésité. Le domaine rural était le plus souvent la propriété d'un grand seigneur laïque. L'église érigée sur une terre ne risquait-elle pas d'être considérée par lui comme une chose lui appartenant? C'est ce qui arriva. Les fondateurs à l'origine de ces nouvelles paroisses sont des personnages bien différents. On trouve parmi ces fondateurs, aussi bien des

DUMONT, Fernand, "La paroisse, une communauté", in Communauté chrétienne, vol. \#1, $\mathrm{n}^{\circ} 1$, janvier-février 1962 , p.22. La paroisse n'est donc pas une création de Jésus-Christ, ni de l'apôtre Paul! La paroisse s'est organisée peu à peu. C'est une organisation ecclésiastique qui est née en vue de satisfaire les besoins d'une époque.

23 "Mais la paroisse, comme dispositif institutionnel autonome, est venu du besoin d'évangéliser les campagnes, à compter du $\mathrm{V}^{\circ}$ siècle: elle desservait alors les communautés humaines en milieu rural. Charlemagne ordonna le quadrillage de son empire en territoires, consacrant le système des paroisses rurales comme micro-structures territoriales" ( CHARRON, A., "La paroisse évangélisatrice d'aujourd'hui", in Prêtre et Pasteur, vol. \# 94, no 10 , novembre 1991, p.616.).

$24 \quad$ "La fiction de la grande paroisse baptismale de type ancien n'allait pas résister à la multiplication des oratoires privés ruraux qui se mettent à tenir un rôle de plus en plus exclusif dans la vie religieuse des fidèles /.../ Les raisons évoquées sont toujours les mêmes: la longueur des chemins, les dangers des forêts et des eaux......"(AUBRUN, M., La paroisse en France des origines aux XV siècle, p.35). 
clercs et des moines que des rois et des grands propriétaires. Ainsi, la multiplication des paroisses durant cette période ne s'est pas toujours faite pour le seul motif pastoral. On dénote parfois de grandes fantaisies: ici des églises très rapprochées, là de grandes étendues mal desservies. De gros villages ne sont pas des centres paroissiaux alors que de misérables bourgs à demi désertés ont leur église et leur cimetière.

Néanmois, l'origine de l'institution paroissiale se trouve dans les communautés extra muros qui s'organisent à mesure que sont évangélisées les campagnes. Au lieu de ramifier le réseau épiscopal comme en Italie ou en Afrique, la Gaule multiplie depuis le $\mathrm{V}^{\circ}$ siècle des centres ruraux cultuels, dont l'érection est la plupart du temps due à l'initiative de l'évêque afin que les ouvriers du domaine puissent aisément fréquenter l'église. ${ }^{25}$ Les temples s'élèvent dans les contrées suivant les besoins du culte, le nombre et les ressources du clergé ou des "fidèles". À cette époque, la frontière diocésaine devient donc de plus en plus importante. Elle est conçue comme la traduction juridique de la notion de compétence territoriale des évêques et comme une mesure devant assurer la catholicité de l'Église. ${ }^{26}$ Les frontières diocésaines coïncident ordinairement avec les frontières de l'administration civile.

PASSICOS,J., "Paroisse", in Catholicisme, hier, aujourd'hui, demain, Paris, Le Touzey \& Ané, 1984, col. 671.

26 LEGRAND, H., "La délimitation des diocèses, p. 192. "Jusqu'à Vatican II inclusivement, on a estimé que c'est la territorialité de l'Église particulière qui lui permettait de réaliser la note de catholicité. Le principe 'une Église, un évêque, un territoire' maintenu avec constance au moins depuis Ignace d'Antioche, en passant par le concile de Nicée (can. 8) jusqu'à nos jours, traduit la conscience que l'Église a d'elle-mêmel.../ Et si le principe de la territorialité de l'Eglise particulière a été maintenu, c'est parce que seul il élimine dès l'abord tout exclusivisme"( BUSSINI, F., "Donner lieu à l'Eglise", in Lumière et vie, $\mathrm{n}^{\circ} 123$, p. 67.). 


\subsubsection{Le patronage des grands propriétaires et de celui du saint}

Le patronage des grands propriétaires a été dès le $\mathrm{V}^{\circ}$ siècle, la cause d'une décentralisation politique qui a enlevé les hommes au pouvoir de l'État et les a peu à peu soumis au pouvoir de l'aristocratie. Quant au patronage du saint, il a provoqué la décentralisation religieuse qui a brisé la communauté primitive et détaché de l'église de la cité les églises des vici (bourgs importants) ou des domaines. 27 C'est par lui que la petite église locale, créée d'abord pour les besoins du culte, érigée en souvenir d'un confesseur ou d'un martyr, est devenue un centre religieux, un organe doué de sa vie propre et de ses fonctions. C'est par lui qu'elle s'est affranchie de la tutelle étroite et exclusive de l'évêque et de son presbytérium et qu'elle a pu avoir son clergé et son patrimoine. On peut dire que c'est aussi par le culte du saint que la paroisse rurale s'est constituée. C'est par le patronage des églises que la société religieuse a perdu son caractère des premiers siècles et est entrée peu à peu dans la féodalité.

\subsubsection{La création des paroisses: l'oeuvre des évêques}

Il faut écarter l'idée que la création des paroisses se rattache à un décret de la papauté ou d'un concile. Si nous parcourons les lettres des papes ou les canons des

27

"On peut constater que c'est au même moment que se développent et le 'patronage' du puissant propriétaire sur l'institution paroissiale et le sens de la protection céleste du saint sur un territoire: double sentiment de protection, lié aux besoins d'une époque où l'on préfère la sécurité à l'indépendance; ce qui se conçoit dans les crises de l'époque. Mais on ne saurait minimiser, à l'origine de la constitution de notre réseau paroissial, le sens d'une sacralisation de l'espace autour du saint conçu comme le vrai possesseur des lieux et l'animateur de la communauté, à laquelle il confère sa personnalité propre"( GEREST, C., Aux origines de la paroisse, pp. 58-59.). "Sans doute, ce sont des idées semblables qui ont poussé les peuples à rechercher le patronage d'un grand et le patronage d'un saint. Le besoin de protection qui est au fond des âmes est toujours le même. Ici, c'est au riche, au puissant que l'on confie sa terre ou sa vie menacée: là, c'est au favori de Dieu que l'on demande secours pour son corps ou pour son âme. Ici, la protection est d'accord avec l'intérêt, là, avec l'intérêt et la croyance; mais dans la vie sociale, comme dans la vie religieuse, l'homme s'adresse à plus puissant que lui qui le fait vivre et qui le sauve"( DE LA TOUR, Imbart, Les origines religieuses, p.48). 
synodes de cette époque, nous n'y trouvons aucun texte relatif à l'institution des paroisses. Il serait faux de s'imaginer qu'à la suite d'une décision venue de Rome ou d'une entente entre les évêques, le sol de la Gaule ou d'ailleurs, ait été régulièrement découpé en diocèses et en paroisses. Ces divisions ecclésiastiques se sont établies sans ordre préconçu, sans théorie préméditée. Les paroisses ont été dans chaque cité l'oeuvre spontanée, personnelle des évêques. Elles doivent leur origine à une foule de mesures particulières, non à une décision venue de Rome ou émanée d'une assemblée de l'épiscopat. 28

Entre le $\mathrm{V}^{\mathrm{o}}$ et VIII' siècle, on pratiquait encore dans l'Église une certaine démocratie: le peuple participait à l'élection de l'évêque et avait son mot à dire dans l'ordination de ses clercs. Le clergé était choisi en son sein: normalement, on ne désignait pas d'étrangers à l'Église rurale. Mais, plus l'extension hors des villes du système paroissial était favorisée, moins cette démocratie était respectée et l'évêque était de moins en moins présent.

"L'évêque est plus un visiteur et un inspecteur de communautés que la tête unique d'une assemblée locale. Entre lui et les 'simples prêtres', il a fallu créer toute une série d'intermédiaires, comme par exemple les 'archiprêtres'. L'autonomie de la paroisse s'est accrue sur le plan financier, administratif et cultuel. Presque tous les actes se font dans l'église du village /.../ pour la desservir, il y a toujours un prêtre, le plus souvent entouré d'un clergé nombreux: lecteurs et chantres. Dès le $\mathrm{VI}^{\circ}$ siècle, ce clergé devient inamovible: il acquiert le droit au titulus de son ordination." 29

Les différentes Églises, présidées chacune par un prêtre qui recevait la 'cure' d'âmes ( la cura aimarum ), devinrent autonomes. L'autel n'était plus unique dans la ville, ni même, bientôt, dans l'église cathédrale ou paroissiale. On multipliait les messes, pour

"... la fondation des paroisses rurales a été l'oeuvre des évêques. Il ne pouvait en être autrement; seul l'évêque était qualifié pour donner des succursales à sa propre église" (GRIFFE, E., Les paroisses rurales de la Gaule, p. 36.).

GEREST, C., Aux origines de la paroisse..., pp. 55-56. 
les besoins de la population chrétienne. L'archiprêtre ${ }^{30}$, présidant sous l'autorité de l'évêque son presbytérium, devint le vrai 'curé ( curatus ) de la cathédrale', et l'évêque se détacha de ses charges immédiatement pastorales, en même temps qu'il s'élevait audessus de sa propre église cathédrale pour 'surveiller' toutes les églises de sa juridiction, maintenant 'émancipées'. 31 D'une façon générale, le district paroissial est resté très étendu jusqu'à la fin de l'époque mérovingienne. Bien des villae ont continué à n'avoir que de simples oratoires et à relever, par conséquent, d'une église baptismale voisine, église de vicus ou église de villa.

\subsection{L'organisation de la paroisse à l'époque carolingienne}

\subsubsection{Une généralisation du régime paroissial}

À partir du milieu du VIII' siècle, surtout à l'époque carolingienne, surviennent trois phénomènes bien différents l'un de l'autre, l'un en marche lente depuis longtemps: la multiplication des oratoires privés, l'autre brutal: l'intrusion autoritaire du pouvoir carolingien dans les affaires de l'Église en vue d'une christianisation de l'ensemble de la population ressentie comme un moyen indirect de contrôle efficace. Le troisième est la privatisation des institutions paroissiales avec tout

"Ceux qui avaient sous leur juridiction un certain nombre de clercs, de basiliques, d'oratoria , prirent un titre nouveau, celui d'archiprêtre /.../ Son titre est surtout honorifique. Il est le premier de ses clercs, comme l'archiprêtre urbain est le doyen du presbytérium épiscopal"(DE LA TOUR, Imbart, Les origines religieuses, p.74, p.82). L'archiprêtre rural de l'époque mérovingienne ne doit pas être confondu avec l'archiprêtre de l'époque carolingienne. Celui-ci a pour mission d'exercer la surveillance sur plusieurs paroisses qui constituent son district, et il n'est pas obligatoirement un des curés du district. L'archiprêtre mérovingien est un curé qui n'a autorité que sur sa paroisse et sur les clercs de sa paroisse: prêtres, diacres, sous-diacres.

31

"Détail intéressant: les titres épiscopaux se sont maintenus jusqu'à nos jours. Les évêques continuent à porter le titre de la ville où ils résident/.../ C'est une survivance du passé, et comme le témoignage du temps ou l'Église locale se recouvrait avec la ville"(COMBLIN, J. , Théologie de la ville, p.332.). 
le retentissement que ce changement va susciter dans la mentalité des prêtres comme des "fidèles".

$\mathrm{C}^{\prime}$ est bien du $\mathrm{VII}^{\circ}$ siècle au $\mathrm{X}^{\circ}$ siècle que le régime paroissial se généralise.

\begin{abstract}
"Ainsi, il y eut sous le règne de Charlemagne, de 768 à 814 , plus spécialement de 800 à 814 , un accroissement notable du nombre des paroisses. Ce progrès répond assurément à la politique religieuse de l'empereur, à la lutte entreprise contre les dernières pratiques du paganisme, à la réforme des institutions ecclésiastiques; il est aussi une conséquence de ses mesures économiques, la mise en valeur de terres nouvelles, l'établissement de colonies saxonnes dans la Gaule. Mais le mouvement ne s'arrêta pas à sa mort. Il fut continué, pendant le $\mathrm{IX}^{\circ}$ siècle et le $\mathrm{X}^{\circ}$ siècle, par l'initiative des fidèles, des seigneurs ou du clergé. $\mathrm{Au} \mathrm{IX} \mathrm{IX}^{\circ}$ siècle surtout, sous Louis le Pieux, pendant la première partie du règne de Charles le Chauve, une foule de paroisses nouvelles furent établies. Nous connaissons assez bien les règles formulées par l'Église pour la création de ces nouveaux districts. En principe, les canons ne l'autorisaient que dans certains cas: l'étendue trop grande du territoire, l'impossibilité pour un groupe de fidèles de se rendre à leur église." 32
\end{abstract}

Nous pouvons dire que c'est surtout vers la fin du VIII ${ }^{\circ}$ siècle que la chrétienté s'est présentée comme un réseau organisé de paroisses. Le terme même de vicus appliqué à la paroisse tend alors à disparaître. Nous le trouvons encore dans quelques documents du IX ${ }^{\circ}$ siècle. Il n'est plus d'un usage général. Le mot parochia est devenu l'appellation définitive de chaque district presbytéral. Les limites du réseau découpent tout l'ensemble du territoire diocésain. Les formes juridiques éloignent ainsi de plus en plus l'institution ecclésiastique de la structure urbaine. On assiste donc à une désintégration des Églises locales où les paroisses deviennent de plus en plus isolées les unes des autres. 


\subsubsection{Les effets de la dîme sur l'institution paroissiale}

Durant l'époque carolingienne, un étrange abus s'établit dans certains vici (bourgs importants): des laïques prennent le titre d'archiprêtre pour se donner sans doute l'apparence de protecteurs de la paroisse, en réalité, pour la mieux régenter et pour disposer plus aisément de ses revenus. Les conciles protestent à plusieurs reprises, mais que peut l'autorité des évêques? La royauté carolingienne se préoccupera de remédier à ces abus. Pour restaurer les ressources de la paroisse et par là, redonner vie à cette institution, Charlemagne prend une mesure des plus efficaces: il rend obligatoire la dîme qui devient ainsi un véritable impôt du culte. L'établissement de cet impôt a eu des conséquences incalculables. À une époque où la principale richesse était celle du sol, la perception de la dîme a favorisé la multiplication des églises de villae (grands domaines). Bien des domaines fournissaient des dîmes suffisantes pour l'entretien d'un prêtre: d'où le désir des habitants de posséder un "curé" pour eux seuls. À l'époque, quelques évêques ont senti le danger d'un morcellement excessif, mais il était difficile de résister à un mouvement qui favorisait la pratique religieuse et qui répondait aux voeux des populations rurales.

L'institution de la dîme obligatoire eut une autre conséquence que Charlemagne n'avait certainement pas prévue. 33 Dans la plupart des paroisses, la dîme était une source régulière et abondante de revenus. Sauf pour la part qui revenait à l'évêque, le curé en disposait pour lui, pour son église et pour les pauvres, si bien que la charge curiale apparut souvent, non seulement comme un office spirituel, mais aussi comme un "bénéfice". 34 Quand, à partir du $X^{\circ}$ siècle, l'Église tombera "au pouvoir

Au début, les dîmes portaient sur les produits agricoles, mais dès le $\mathrm{IX}^{\circ}$ siècle, les conciles les étendirent à tous les domaines.

34 Au plan pastoral, l'idée du beneficium prend donc peu à peu le pas sur l'idée apostolique de servitium. 
des laïques", ce bénéfice deviendra la proie des seigneurs comme l'évêché et l'abbatia. L'Église rurale connaîtra de nouveau des mauvais jours jusqu'au moment où la réforme grégorienne, produisant ses fruits, fera rendre aux laïques les dîmes usurpées. Les clercs redeviendront les maîtres, mais c'est alors que s'organisera, au sein de l'Église, ce régime bénéficial qui a duré aussi longtemps que la dîme et qui a exercé tant d'influence, en bien et en mal, sur la vie des paroisses. 35

\subsection{Au Moyen Âge: la paroisse, une affaire de seigneurs!}

\subsubsection{La propriété privée d'un grand nombre de paroisses}

Plus on avance dans le temps et plus les paroisses rurales dans l'Occident chrétien augmentent en nombre. 36

\footnotetext{
"Au Moyen Âge, la population se déplaçant vers la campagne, et la féodalité aidant, furent constitués des 'centres d'évangélisation' hors des villes, qui sont devenus des paroisses rurales avec leur clergé, et autosuffisantes. Le système paroissial fut donc imposé par les nécessités d'une société rurale et féodale." 37
}

Établies sur les terres d'un roi, d'un évêché, d'un monastère, d'un grand propriétaire, ou dans une villa composée de petits propriétaires libres, les paroisses deviennent à leur tour un centre de culte; elles ont leur desservant, leur baptistère et leur patrimoine. Mais ce qui caractérise cette période historique est la propriété privée d'un grand

35 Voir BRION, Michel, "La paroisse dans l'organisation financière de l'Église", in Lumière et Vie , tome XXV, \# 123, juin-juillet 1975, pp. 37-51.

36 "L'an mille voit, comme chacun sait, l'Occident se couvrir d'un "blanc manteau d'églises..."( AUBRUN, M., La paroisse en France des origines..., p.8).

37 CHARRON, A., "Les caractéristiques théologiques d'une communauté chrétienne vivante en paroisse", in Communauté Chrétienne : Les paroissiens, avenir de la paroisse, vol.17, no 97, janvier-février 1978, p.24. 
nombre de paroisses. De riches propriétaires (seigneurs) de terres contruisent des églises sur leur territoire et fondent leurs propres paroisses.

"La paroisse est devenue parfois le cadre de la seigneurie ou elle est entrée elle-même dans la seigneurie. Elle a cessé d'être une communauté libre pour devenir la chose d'un homme. L'église rurale a été possédée comme un domaine, vendue, léguée, inféodée: elle a eu à la fois un clerc et un maître. /.../ Il n'y a pas de différence entre la propriété d'une église et la propriété d'une terre. Le seigneur exerce sur l'église les mêmes droits que sur toute autre partie de son domaine; il en tire les mêmes profits que des tenures données à fief ou à cens. À peu près complète est l'absorption de la paroisse dans la seigneurie /.../ On peut donc dire, au $\mathrm{XI}^{\circ}$ siècle: nulle église sans seigneur."38

Le nombre des églises construites par les propriétaires augmente parallèlement au progrès de la colonisation agricole. Les patrons fondateurs calquaient les limites de la paroisse sur celles de leur propriété, ce qui aboutissait parfois à des résultats curieux. La paroisse s'étendait sur toute l'étendue de la seigneurie et jusque sur ses principaux écarts, même éloignés. Les droits paroissiaux étaient perçus dans les limites mêmes où le seigneur collectait les taxes féodales. ${ }^{39}$ Le patronage des laïcs sur les paroisses enleva donc à l'épiscopat, pour une bonne part, la liberté du choix de ses clercs. Ce sont souvent ces riches propriétaires qui présentaient à l'ordination presbytérale les candidats de leur choix. Ces candidats étaient souvent des serfs. Toutefois, le monde clérical a réagi contre la mainmise de ces 'puissances séculières' sur les choses de l'Église.

"La présence de ces deux pouvoirs, le patronal et l'épiscopal, allait naturellement créer des situations conflictuelles: on accusait les évêques de refuser les candidats proposés par les patrons et à plusieurs reprises, les conciles durent condamner l'arbitraire, ou ce qui était considéré comme tel des refus épiscopaux qui, précisent-ils, doivent reposer sur une éléments. Les jugements rationnels dont dans la majorité des cas, peu déterminants; par contre, les raisons économiques (bénéfices) ou les motifs personnels (les nobles veulent une église propre) interviennent davantage" ( BODZENTA, Erich, "Critères de planning paroissial urbain", in Paroisses urbaines - paroisses rurales, $5^{\circ}$ conférence internationale de sociologie religieuse, Paris, Caterman, 1958, p. 143.). 
raison valable. /.../ Les évêques aidés par le pouvoir civil ont réussi dans une certaine mesure à contrôler ce clergé des paroisses, mais dès que se dissipa l'autorité et au fur et à mesure que se "privatisait" l'ensemble des institutions, l'eglise ne fut plus qu'un élément générateur de revenus et de prérogatives pour les "seigneurs". C'est dans ce contexte, que les dernières églises, non point paroissiales en leur origine, allaient être bâties et devenir pour la plupart d'entre elles le centre d'une nouvelle paroisse." 40

Plus tard, le pouvoir de ces riches propriétaires (patrons) sur la nomination de leurs clercs sera réduit. C'est la réforme grégorienne qui va donner un coup de barre dans cette querelle.

"...c'est ainsi que le droit de nommer les curés deviendra pour les patrons un simple droit de présenter les candidats au choix de l'évêque. Mais on observera que cette reconquête de leurs 'libertés' par les clercs ne put se faire que dans la mesure où ils se rendirent plus puissants que les laïcs dans la société de leur temps." 41

On voit donc ce que sont devenues la plupart des paroisses au $\mathrm{XI}^{\circ}$ siècle. Possédées par des "laïques", démembrées entre le prêtre et le seigneur ou entre plusieurs seigneurs, elles ont souvent plusieurs maîtres et obéissent à plusieurs juridictions. La paroisse se divise et s'émiette à l'infini. Ainsi dépouillée, sa servitude est complète. De même que l'église rurale devient la "chose" du seigneur, par une dernière transformation, le prêtre qui le dessert devient "son homme". L'entrée du clergé dans la féodalité suit donc l'entrée de la paroisse dans la seigneurie. Le prêtre reçoit l'église ou son office presbytéral comme un bénéfice ou comme un fief. Ainsi, dans une foule de localités, à l'investiture ecclésiastique donnée par l'évêque s'ajoute l'investiture féodale donnée par le seigneur. La commendatio ecclesiae se fait à charge d'hommage et de fidélité, et le prêtre est tenu à tous les devoirs du vassal. On voit par ces transformations ce que la paroisse est devenue et quels changements elle a subis dans son histoire.

AUBRUN, M., La paroisse en France des origines..., pp.42-43; pp. 69-70. "Paroisse", col. 673. 


\subsubsection{La paroisse est convoitée par les moines}

Il est important de noter que les moines ayant été les principaux bénéficiaires de la réforme de l'Église engagée du milieu du $\mathrm{XI}^{\circ}$ siècle vont se retrouver mêlés à la vie paroissiale alors que ni leur état ni les exigences de pauvreté n'étaient compatibles avec un tel rôle. Les ressources provenant des paroisses étaient cependant à ce point appréciées par eux que les réformateurs monastiques devront prioritairement les éliminer afin de retrouver une régularité conforme à leurs idéaux. Mais l'histoire prouve la tenacité peu commune de la mainmise des moines sur une bonne partie du réseau paroissial.

\subsection{La naissance des paroisses urbaines selon le modèle rural:} $\underline{\mathrm{XI}^{\circ} \mathrm{s} .-\mathrm{XIII}}{ }^{\circ} \mathrm{s}$.

\subsubsection{L'envahissement du système rural en ville}

À partir des $\mathrm{XI}^{\circ}$ et $\mathrm{XII}^{\circ}$ siècles, les villes reprennent vie en Occident: on assiste à la création de villes nouvelles, à la renaissance de beaucoup de villes anciennes et à l'émergence du phénomène communal.

"Les plus anciennes circonscriptions urbaines datent du $\mathrm{XI}^{\circ}$ siècle, les plus récentes de la fin du XIII ${ }^{\circ}$ siècle. La grande masse des créations des paroisses urbaines se place dans la période intermédiaire de 1100 à 1250 . Elles correspondent, bien sûr, à la principale phase de l'essor urbain." 42

On commence la division des villes en paroisses: le système rural envahit la ville. C'est le signe que le modèle de l'ancienne Église locale s'efface et les structures du Moyen Age", in Histoire de la paroisse, Actes de la Onzième Rencontre..., p. 46. 
monde rural deviennent beaucoup plus déterminantes. En fait, l'Église déjà profondément engagée dans le système féodal et "bénéficial", ne remit pas en question les nouvelles structures qu'elles venait de se donner. Elle ne songea pas un instant à un retour à l'Église urbaine de l'antiquité: le modèle s'était perdu. En résumé, l'Église médiévale offre à la question des relations entre l'Église et la ville une réponse toute différente de celle de la chrétienté primitive. Les structures officielles restèrent celles de la société rurale féodale. ${ }^{43}$ On ne tenta pas d'en faire de nouvelles qui fussent adaptées au peuple des cités. Ici commence une forme de paroisse qui a ses prolongements jusqu'aujourd'hui. La perspective d'évangélisation de la paroisse change pour une perspective plus administrative et de contrôle religieux.

"L'ambition originelle qui a fait naître la paroisse comme succursale de l'Église épiscopale urbaine était bien différente de celle qui l'a animée à partir du $\mathrm{IX}^{\circ}$ siècle. Le processus de multiplication des paroisses et de quadrillage territorial, a, en réalité, infléchi l'institution primitive; il l'a bel et bien transformée. Au départ, la perspective était une perspective d'évangélisation; plus tard, la perspective sera une perspective d'administration et de contrôle des gens évangélisés ou supposés tels." 44

La société appuie sa cohésion et son unité sur les structures d'Église. Celle-ci est un facteur d'ordre et de stabilisation. ${ }^{45}$ La législation se durcit. Le facteur administratif prend donc le pas. Les relations entre le curé et l'évêque revêtent un certain caractère contractuel. Et le premier devient de plus en plus inamovible. Il est "installé" plutôt qu'envoyé en mission d'Église.

La paroisse urbaine n'est pas seulement le cadre essentiel de leur vie religieuse pour la majorité des citadins, elle est aussi et cela pour tous le lieu ordinaire de leur vie civile. Certains des avantages offerts par elle en tant que circonscription territoriale sautent aux yeux: des limites précises, stables, connues de tous, respectant les dominations seigneuriales qu'elles prennent en compte chaque fois que cela est nécessaire et avantageux.

44 1963, p. 149.

FRISQUE, J., La paroisse, centre d'évangélisation, in Paroisse et Liturgie, no \#59, 45

Un phénomène semblable s'est produit au Canada français à un tournant important de son histoire. 
À la fin du XII ${ }^{\circ}$ siècle, longtemps monopolisé par la cathédrale 46 , le culte urbain est célébré de plus en plus dans des églises de quartier indépendantes. Dans les villes comme à la campagne apparaît en outre une élite de chrétiens non nobles, ruraux, enrichis ou marchands à l'aise pour lesquels les seules réunions paroissiales ne suffisent plus. Naissent alors des associations, mi-pieuses, mi-corporatives, les confréries, qui pendant les deux derniers siècles du Moyen Âge vont à la fois animer et concurrencer les activités de la paroisse. Les nefs romanes et gothiques où les fidèles s'étaient réunis pendant des siècles ouvrent désormais leurs flancs afin d'accueillir les chapelles de style flamboyant destinées à servir de témoignage à la piété et à la vanité de telle famille patricienne, de telle corporation de métier.

\subsubsection{La paroisse: une "succursale" de l'Église}

$\mathrm{Du} \mathrm{X}^{\mathrm{o}}$ au $X \mathrm{~V}^{\mathrm{o}}$ siècle, plusieurs papes ont pris l'initiative de créer de nouveaux diocèses, et pas toujours pour des motifs pastoraux. De toute façon, à partir du début du XII ${ }^{\circ}$ siècle, de plus en plus l'Église catholique devient gouvernée par le pape. "Evêque universel, le pape peut déposer, rétablir ou déplacer les évêques, créer, diviser ou réunir les diocèses, ériger les abbayes, reconnaître les ordres religieux et les soustraire à l'Ordinaire." 47 Cet accroissement de la centralisation pontificale diminua la

Les cathédrales ne furent pas construites par les princes, ni par les rois, ni même par les évêques, mais par les villes et par les chanoines, le clergé bourgeois. En l'espace de trois siècles, de 1050 à 1350, la France a extrait plusieurs millions de tonnes de pierres pour édifier 80 cathédrales, 500 grandes églises et plusieurs dizaines de milliers d'églises paroissiales. "Les cathédrales n'auraient pu être construites si les villes n'avaient formé des communautés fortement unies et solidaires. Elles furent les monuments symboliques de l'unité des collectivités communales. D'ailleurs, les cathédrales n'étaient pas simplement des lieux de culte, mais aussi des lieux de réunion du peuple, où l'on pouvait discuter les affaires publiques. Plus tard seulement le clergé revendiquera l'usage exclusif des cathédrales et en expulsera toutes les activités profanes, ce qui ne sera pas uniquement un progrès. On ne verra pas seulement un témoignage de foi dans la cathédrale, mais principalement le témoignage d'une volonté d'inspirer par l'évangile la vie de la ville. C'est la ville qui exprime son salut" (COMBLIN, J., Théologie de la ville, pp.335-336.).

47 HENRI, M.A., et CHELINI, J., La longue marche de L'Église, Paris/Bruxelles, Elsevier/Bordas, 1981, p.115. 
dépendance des évêques face aux riches seigneurs féodaux, mais accrut leur dépendance par rapport à Rome. C'est donc vers la fin du Moyen Âge que commence à émerger une ecclésiologie d'ordre institutionnel, fortement centrée sur la hiérarchie et la papauté. La paroisse apparut à la suite de cette histoire comme un département, une section, une "cellule", une 'succursale' de l'Église universelle.

À la fin du Moyen Âge, le système paroissial était si bien adapté aux circonstances médiévales et il connut tant de succès que la chrétienté entière fut bientôt couverte d'un quadrillage de dizaines de milliers de paroisses minuscules. Le réseau des paroisses urbaines achève de se constituer. Pourtant l'étendue de la paroisse n'a jamais fait l'objet de normes précises. Les villes du Moyen Âge et de l'Ancien Régime comptaient des paroisses de toute taille dont certaines très petites car l'étendue n'avait guère d'importance. Les petites paroisses vivaient aussi bien que les autres. Mais, durant cette période, on a vu de plus en plus s'établir deux niveaux de circonscription. C'est ainsi que l'on réservera le nom de diocèse à la circonscription supérieure et celui de paroisse à la circonscription inférieure. 48 On évitera le mot Église comme étant trop vague. 


\title{
7.7 Les 'retombées' du Concile de Latran sur la paroisse (1215)
}

\subsubsection{L'obligation de se confesser à son curé et de faire ses Pâques dans sa paroisse}

Les paroisses se développent considérablement à partir du Concile de Latran IV en 1215 quand on oblige les fidèles à se confesser au moins une fois par an chez le curé de leur paroisse et à remplir leur devoir pascal dans leur église propre. 49

\begin{abstract}
"Tout fidèle parvenu à l'âge de discrétion doit confesser ses péchés au moins une fois l'an à son curé, accomplir la pénitence qui lui est imposée, recevoir au moins à Pâques le sacrement de l'Eucharistie. Sinon qu'il soit interdit ab ingressu ecclesiae de son vivant et privé de sépulture chrétienne après sa mort" (canon 21).
\end{abstract}

Cependant, "le droit coutumier accepte aussi que chaque paroissien accomplisse ces deux actes essentiels également à l'église cathédrale qui est aussi son Église." 50 Le paroissien se trouve ainsi contrôlé de plus en plus dans sa dévotion tout au long de sa vie. Également, c'est à partir du concile de Latran qu'on voit naître et s'épanouir une spiritualité propre au curé de paroisse. Le curé devient un médiateur, la paroisse un corps mystique.

\subsubsection{La naissance des fabriques}

Plusieurs historiens s'entendent pour dire que les fabriques sont en place dans l'ensemble des paroisses vers 1270-80.51 Les revenus affectés à la paroisse

49 Voir LE BRAS, G., "Paroisses urbaines -paroisses rurales", in Études de sociologie religieuse, tome I, Sociologie de la pratique religieuse dans les campagnes françaises, $\mathrm{p}$. 313.

50 LEGRAND, H., "La réalisation de l'Eglise en un lieu", in Initiation à la pratique de la théologie, tome III, Paris, Cerf, 1983, p.175.

51 Voir COLLECTIF, Histoire de la paroisse, Actes de la Onzième Rencontre d'histoire religieuse....., p. 231. 
étaient depuis fort longtemps confisqués par les patrons laïcs puis monastiques qui, en outre, ne respectaient pas toujours leurs engagements, concernant l'entretien de l'édifice notamment. À ce réel besoin s'ajoute le désir des paroissiens de gérer eux-mêmes leurs affaires, sans intermédiaires ni tutelle. Telles sont les deux causes de la naissance de la fabrique.

\subsubsection{Une querelle entre les séculiers et les religieux}

Il est intéressant de mentionner qu'à partir approximativement du milieu du XIII' ${ }^{\circ}$ siècle, les prérogatives pastorales du curé urbain à l'intérieur de "sa" paroisse sont sérieusement battues en brèche par les religieux Mendiants. Les Mendiants s'installent dans les villes entre 1220 et 1240 , donc juste après l'achèvement de la mise en place du réseau paroissial. Une nouvelle période dans l'histoire du ministère paroissial est alors inaugurée avec l'intervention des Franciscains et des Dominicains au XIII ${ }^{\circ}$ siècle .52 Leur oeuvre correspondait à un besoin, car ce que l'on appelait ministère pastoral n'y ressemblait guère jusqu'alors. Aussi les nouveaux Ordres mendiants bénéficièrent-ils d'appuis précieux de la part des papes (Grégoire IX, Innocent IV, Alexandre IV, Martin IV, Boniface VIII). 53 Ils se heurtèrent, il est vrai à quelque résistance de la part du clergé séculier qui se prévalait de ses droits paroissiaux et alla jusqu'à interdire aux fidèles d'assister aux prédications des frères et de leur donner des aumônes: on ne pouvait se rendre à leurs offices qu'après avoir pris part à

52

Les Mendiants se consacrèrent essentiellement aux villes. Ils se maintinrent en dehors des structures prétablies de l'Église, paroisses et diocèses, ce qui créa des conflits permanents avec les évêques et les curés: les lois d'exemption furent des motifs de frottement continuel. Ils fondèrent leurs couvents en pleine ville, tolérés plus que désirés par le clergé local, mais protégés par les papes. Ce furent les Franciscains et les Dominicains qui sortirent la prédication des cadres de la liturgie traditionnelle et des églises. Ils vivaient plus sur les places publiques et dans les rues que dans leur couvent et les sacristies. Ils allaient au-devant du peuple, là où le peuple urbain se trouvait réuni. Et leur message était celui que les habitants des villes attendaient et pouvaient comprendre.

Voir AUBRUN, M., La paroisse en France des origines..., p.123. 
une messe paroissiale. ${ }^{54}$ Quiconque enfreignait cette réglementation était excommunié et ne pouvait recevoir le sacrement des malades. Il n'y a pas lieu d'entrer ici dans le détail de ces querelles. Quoi qu'il en soit, celles-ci durèrent trois siècles.

"Le grand problème permanent de la paroisse a un nom dans l'histoire, c'est la querelle des séculiers et des réguliers. Ce qu'il faut voir, c'est que cette querelle n'est pas due à la faiblesse des hommes, elle n'est pas le produit des rivalités subjectives. Elle a pour cause la structure de la paroisse. /.../ S'il y eut une querelle séculaire des religieux et des séculiers, ce fut parce que la paroisse était incapable de répondre aux défis de l'histoire, aux besoins de l'apostolat, et en particulier aux besoins de la christianisation des villes. Elle se révéla un instrument très peu dynamique, jamais un facteur de renouveau ou de conversion." 55

\section{8 "Canonisation" de la ruralisation des paroisses au concile de Trente}

\subsubsection{L'obligation du morcellement du diocèse en paroisses}

La réforme de la paroisse a été une des grandes préoccupations du Concile de Trente de 1563, qui a misé sur la paroisse pour raviver la vie chrétienne. La paroisse est à ses yeux l'organe principal de la pastorale.

"Dans le monde catholique, la conclusion du Concile de Trente ouvre une phase de réforme ecclésiastique profonde inspirée par la cura animarum. Les acteurs en sont de grandes personnalités épiscopales, de Charles Borromée à Bartoloméo de Martyribus en passant par François de Sales. En dépit de leurs différences de culture et de génération, tous misent sur la paroisse comme base de la rénovation catholique. Plus que jamais, la "paroisse" signifie clergé paroissial, à l'instar du "diocèse" qui signifie évêque"56

À partir du XIII ${ }^{\circ}$ siècle, à cause d'un mécontentement à l'égard du clergé et de l'insécurité théologique, germa une sourde rebellion qui éclata avec le protestantisme. Pendant ce temps, curés et religieux discutaient pour savoir à qui revenaient les bénéfices paroissiaux.

55

56

\# 165, p.59.
COMBLIN, J., Théologie de la ville , p. 355

ALBERIGO, Giuseppe, "Du seizième siècle à Vatican II", in La Maison-Dieu, 1986, 
Un canon du concile de Trente rend obligatoire le morcellement en paroisses des cités épiscopales. 57 Ce concile consacra la désintégration médiévale des structures de l'Église ancienne en ordonnant alors la division des territoires urbains en paroisses selon le modèle rural. 58 Pourtant l'urbanisation sans précédent et parfois sauvage, caractéristique des années 1450-1550, avait rendu la structure de l'institution paroissiale de plus en plus inadéquate et dépassée. À partir de ce moment, le terme paroisse équivaut à un territoire déterminé qui fait partie d'un diocèse, et cette conception en viendra avec le temps à passer intégralement dans le code de Droit canonique. À cette époque et encore aujourd'hui, ce canon du Concile de Trente n'a cessé et ne cesse d'avoir des effets néfastes sur la vie ecclésiale.

\subsubsection{Les motifs de la promotion du morcellement paroissial}

Quels sont les motifs qui ont poussé les Pères du Concile de Trente à promouvoir la division en paroisses? En premier lieu, il s'agit de faciliter la réception des sacrements; la paroisse doit être établie très près des fidèles, pour que tous puissent avoir accès facilement aux sacrements. De plus, le curé doit pouvoir connaître personnellement tous les fidèles dont il est chargé. Lorsque cette tâche devient difficile, il faut diviser la paroisse ou faire appel à des coopérateurs. Comme on peut le constater, pas une seule fois le concile ne voit dans la paroisse une communauté. Elle est le lieu où l'on distribue les sacrements; elle est la responsabilité du curé. 59

"Le souci d'assurer le mieux possible les secours spirituels à tous les fidèles amena finalement à diviser le diocèse en territoires exactement délimités confiés à un pasteur. Constamment, depuis la Réforme, l'Église a fait un devoir aux évêques de diviser bien

57

Concile de Trente, Sess. 21, can. 4 (éd. Herder Conc. Oecum. Decr., p.705s.); sess. 24, can. 13 (Conc. Oecum. Decr., p. 743s.) 
nettement leur diocèse. Lorsque, au XVI ${ }^{\circ}$ siècle, les hommes ont voulu, plus que jamais, se soustraire à leur appartenance à l'Église, le concile de Trente, dans sa $24^{\circ}$ session, en 1563, a demandé aux évêques, même là où les limites des paroisses n'avaient pas été nettement fixées, de partager dans l'intérêt du salut des âmes qui leur sont confiées "le peuple chrétien en paroisses bien délimitées et indépendantes, d'assigner à chacune un propre curé qui puisse s'en charger et de qui les paroissiens doivent de préférence recevoir les sacrements." Ainsi les paroisses étaient juridiquement constituées."60

À partir du Concile de Trente, la paroisse commença à ne plus être un lieu de mission et devint davantage un enclos religieux. La juridiction du curé se durcit de plus en plus. Celui qui a charge d'âmes acquiert peu à peu un contrôle quasi total. Il a tendance à se refermer sur son pouvoir clérical. ${ }^{61}$ L'idéalisation du pouvoir sacré sur le territoire paroissial devint très présente. Et l'Église institution, en obligeant les fidèles à se confesser uniquement à leur curé de paroisse et non plus aussi à l'église cathédrale, renforça cette idéalisation. Cela constitua un net recul par rapport au concile de Latran (1215) .

\subsubsection{La fracture entre les catholiques et les protestants}

Il n'est certes pas exagéré de dire que la fracture intervenue entre catholiques et protestants marqua les communautés paroissiales d'une bonne partie de l'Europe occidentale et surtout dans le pays de langue allemande. Le reste de la chrétienté (pays latins et Iles britanniques) perçut non seulement l'écho de ce traumatisme mais connut également les réformes provoquées ou accélérées par la Réforme protestante. Par ailleurs, l'orientation de Luther, qui tend à valoriser l'appui des pouvoirs séculiers,

ARNOLD, F. X. , Proclamation de la foi et communauté de foi , p. 56.

61

"Le fait d'avoir surtout considéré les ecclésiastiques plutôt que la communauté chrétienne dans son entier a conduit la Contre-réforme à instaurer une certaine uniformité, en ébauchant le profit optimal de l'évêque et du prêtre (résidence, prédication, célibat, sobriété, instruction). C'est donc le clerc, ayant pour vocation de procurer le salut par la cura animarum qui se trouvait au centre de la réforme de Trente. Dans cette perspective, la communauté était plutôt considérée comme objet que comme acteur" (ALBERIGO, Giuseppe, "Du seizième siècle à Vatican II", p.57) 
introduit dans le protestantisme une "sensibilité" territoriale beaucoup plus intense que par le passé. Concrètement, de nombreuses communautés paroissiales passèrent au protestantisme par suite de la conversion de leur prêtre, d'autres se morcelant de manière irrémédiable. Les paroisses catholiques et les paroisses protestantes sont semblables en ce qui concerne le rôle central joué par le prêtre/pasteur. Dans les deux cas, ces paroisses gravitent autour de la célébration de la messe/cène, elles atribuent une grande importance à la catéchèse et impliquent les fidèles dans la subsistance de la paroisse par le biais d'offrandes. Dans le même temps toutefois, les communautés protestantes reconnaissent à la bible - lue, chantée, prêchée en langue vulgaire - une importance exceptionnelle; le repas eucharistique est caractérisé par l'utilisation du calice et du pain; la direction de la paroisse est confiée non seulement au pasteur mais également à l'autorité politique (dans la zone d'influence luthérienne) ou consistoire (dans la zone calviniste). Globalement, la caractéristique la plus marquante de la communauté protestante réside dans son sens communautaire, fondé sur la théologie du sacerdoce universel et alimenté par la participation au calice et l'absence d'une hiérarchie ecclésiastique véritablement structurée. ${ }^{62}$ Les communautés catholiques romaines semblent plutôt caractérisées par l'autorité sacrée du curé, de plus en plus souvent choisi et formé indépendamment de la communauté. La prédication, importante ici aussi, ne revêt pourtant pas le même aspect biblique et ce n'est que progressivement qu'elle sera faite en langue vernaculaire. En tout cas, la liturgie, qu'il s'agisse de la messe ou des sacrements, demeure en latin. Tout cela a pour effet le dépérissement de la conscience communautaire en alimentant plutôt une participation individualiste à la paroisse. Comme on le sait, le Concile de Trente se termina en sanctionnant la division confessionnelle du christianisme occidental. Pendant un siècle

62

"La seule vérité de foi qui soit inconditionnelle ... c'est que toute énonciation de foi se tient sous un "oui" et "non". À la lumière de ce critère, le protestantisme a condamné l'Église romaine. Ce ne sont pas les formules doctrinales qui ont divisé les Églises au moment de la Réforme mais le fait que l'on ait découvert ce principe qu'aucune Église n'a le droit de prendre la place de l'absolu" (TILLICH, P., Dynamique de la foi, Tournai, Casterman, 1968, pp. 110-111). 
environ, les différentes confessions - catholique romaine, luthérienne, réformée s'efforcèrent d'acquérir une base stable, dans un contexte d'indépendance ou plutôt d'hostilité réciproque.

La crise qui a secoué et menacé le catholicisme romain à cette époque suscite un besoin d'unité que l'on ressent, surtout à Rome, en termes d'uniformité. En quelques années, on verra ainsi l'édition de toute une série de "livres romains" catéchisme, bréviaire, missel, Vulgate sixtine - tous destinés à donner une vigueur nouvelle à l'ensemble de l'Église catholique. Il est difficile d'apprécier exactement les effets qu'eurent ces livres dans la rénovation mais aussi dans le processus d'uniformisation et partant de dépersonnalisation des traditions et des identités locales. On peut considérer qu'au cours des décennies comprises entre la fin du $\mathrm{XVI}^{\circ}$ siècle et le début du $\mathrm{XVII}^{\circ}$ siècle, le catholicisme a amorcé un tournant dans le sens d'une universalisation de son ecclésiologie pratique.

7.9 $\mathrm{XVI}^{\circ}$ s: L'influence "sulpicienne" sur l'institution paroissiale

7.9.1 Un modèle proposé: une vie commune pour les prêtres

Dans quelques pays, certains efforts concrets ont été faits pour concrétiser les orientations conciliaires de Trente. En France, des tentatives de réformes paroissiales furent effectuées vers le début du XVII ${ }^{\circ}$ siècle. La réforme paroissiale qui s'imposa le plus fut celle de Saint-Sulpice, réalisé par M. Olier.63 Dès le premier instant de son installation comme curé, M. Olier décida de constituer le clergé de paroisse (1642-1652)", in Histoire de la paroisse, Actes de la Onzième Rencontre...., pp. 71-85. 
Saint-Sulpice en communauté. Il ne voyait de progrès possible pour la paroisse que dans une vie commune authentique du clergé avec toutes les exigences de ce choix. Tous ces prêtres logeaient dans la même maison, prenaient ensemble leur repas, pendant lequel on faisait une lecture, suivaient un règlement qui se rapprochait, autant que le service paroissial le pouvait permettre, de celui du séminaire.

\title{
7.9.2 L'ampleur de la visite paroissiale, du régistre et du catéchisme
}

Le territoire paroissial de Saint-Sulpice était immense. M. Olier partage ainsi "sa" paroisse. Il plaça à la tête de chacun des huit quartiers, un prêtre qui devait s'occuper spécialement des paroissiens résidant dans cette circonscription. Il enjoignit aux prêtres du quartier de prendre des informations sur les habitants, et pour cet effet, de "dresser" un état nominatif de toutes les personnes, ou du moins de tous les chefs de famille, et de le renouveler tous les trois mois.

\begin{abstract}
"Il est indigne d'un curé, écrivait M. du Ferrier chargé par M. Olier de la rédaction de ce livre, de ne pas savoir le nombre de communiants qu'il a dans la paroisse, puisqu'il n'y a point de paysan ni de berger qui ne sache justement combien il a de moutons, de brebis et d'agneaux en son troupeau. Jacob le savait si bien qu'il en répondait et payait à Laban chaque bête que le loup lui mangeait." 64
\end{abstract}

Les prêtres désignés pour visiter les différents quartiers de la paroisse devaient considérer cette responsabilité comme une des plus importantes, parce que de là dépendaient 'le bon ordre de la paroisse' et 'le statut' de la plupart des paroissiens. À cette époque, la visite paroissiale et le régistre paroissial ont pris une importance beaucoup plus grande. Après enquête, il apparut à M. Olier qu'un des principaux problèmes paroissiaux était posé par les enfants dont l'instruction religieuse n'était pas 
assurée. À cette fin, il organisa les séances de catéchisme autour de l'église paroissiale. La méthode catéchétique qu'il a inaugurée s'est poursuivie jusqu'à nos jours. 65

\subsubsection{Les retombées internationales d'une réforme}

La réforme de la paroisse Saint-Sulpice a rapidement dépassé son berceau. En 1660, Antoine GODEAU, évêque de Grasse et Vence, pouvait écrire: les autres paroisses de Paris ont suivi l'exemple de la communauté de Saint-Sulpice, et la plupart des prêtres qu'on nomme habitués y vivent ensemble avec beaucoup d'édification. L'oeuvre de M. Olier s'est perpétuée sur un grand nombre de paroisses de France, d'Angleterre, du Canada et des États-Unis. Jusqu'à nos jours, Saint-Sulpice est restée la paroisse-type que le $\mathrm{XVII}{ }^{\circ}$ siècle français a proposée comme modèle.

Il est intéressant de noter que les exercices de piété deviennent de plus en plus nombreux dans les paroisses postridentines. Nombreux sont les saints de cette époque qui ont été canonisés. La fin du XVII siècle voit éclore la dévotion au SacréCoeur en France et en Italie ainsi que la pratique du Mois de Marie; ces deux formes de dévotion sont officiellement étendues à toute l'Église, la première en 1766, la seconde en 1815 et elles trouvent dans le milieu paroissial un terrain particulièrement favorable. essais de nouveaux catéchismes se succèdent de façon continue. Chaque évêque prend à coeur de publier son propre catéchisme. Aux XVIII ${ }^{\circ} \mathrm{XIX}^{\circ}$ s., l'habitude continuera. 


\subsection{0 $\underline{\mathrm{XVI}}{ }^{\circ}$ s. $-\mathrm{XIX}{ }^{\circ}$ s. : La poursuite de la multiplication des paroisses de type rural}

\subsubsection{L'Église vit de ses structures rurales}

Du $\mathrm{XVII}^{\circ}$ à la fin du $\mathrm{XIX}^{\circ}$ siècle, on assista encore à une multiplication des paroisses de type rural. L'autonomie des enclos paroissiaux continua ainsi à se renforcer. Nous sommes assez loin des intuitions originelles. ${ }^{66} \mathrm{Au}$ XVII ${ }^{\circ}$ siècle, les Églises européennes entrent dans une phase où elles seront très étroitement contrôlées par les pouvoirs politiques: le gallicanisme, le juridictionnalisme, le joséphisme sont tous, en dépit de leurs spécificités marquées, l'expression de projets de contrôle de la part des souverains sur les Églises et leurs sujets. Ces orientations produisent des effets considérables au niveau des communautés paroissiales. En fait, les autorités politiques s'emploient, de manière unanime, à accentuer le caractère territorial des Églises, en confiant aux paroisses des fonctions sociales de plus en plus importantes (état civil, école, contrôle social) et en exigeant corollairement une absolue fidélité de la part des ecclésiastiques. La situation de la paroisse aux $\mathrm{XVII}^{\circ}$ et $\mathrm{XIX}^{\circ}$ siècles est caractérisée par le mouvement des Lumières (Aufklärung), provenant d'Angleterre et qui a pour origine la séparation opérée à l'époque de la Renaissance entre la foi et la raison, entre la religion et la culture. Nous sommes en face d'une période agitée dans le domaine des idées, et qui se terminera en 1789 par le Révolution française. Au début de la révolution en France, un grand nombre de paroisses urbaines sont supprimées en même temps. Dans l'histoire des paroisses, la circonscription opérée par les assemblées révolutionnaires est un événement considérable. C'est la première fois que sont supprimées des paroisses. 67 Plus tard, le pouvoir civil tenta de limiter la 
multiplication des paroisses urbaines. Il établit le nombre des paroisses à une pour 6,000 habitants. Le pape Pie VI affirmera avec force que dans ces conditions la pastorale devient impossible puisque le pasteur ne peut pas connaître chacune des brebis de "son" troupeau. Cette conception prouve que l'Église vit de plus en plus de ses structures rurales.

Au début de la Renaissance, les souverains veulent de l'ordre dans l'administration de l'État et de ce fait, ils transforment les circonscriptions d'Église. Philippe II d'Espagne et spécialement Joseph II (1780-1790) en Europe Centrale et aux Pays-Bas recensent le population, mesurent les terrains, déterminent les limites des diocèses et des paroisses et favorisent la construction des églises. En 1824, le pape Léon XII fait effectuer une nouvelle répartition des paroisses de Rome. On y trouve l'exemple d'une dimension idéale de paroisse (comptant environ 3,000 âmes) et cela peu de temps avant le développement des grandes villes modernes. En fait, au $\mathrm{XIX}^{\circ}$ siècle, tant les limites fixées par les papes que celles fixées par leurs adversaires seront dépassées. À partir de ce moment la paroisse a avoué sa faillite, elle devient autre chose. "Depuis le XIX ${ }^{\circ}$ siècle, la paroisse n'est plus la paroisse."68

\subsubsection{L'Église se tient sur ses gardes: centralisation et uniformité}

La sécularisation s'étend aux divers domaines culturels qui avaient été jusqu'alors le patrimoine presque exclusif de l'Église. Dans ce climat, les Églises et en particulier les catholiques romains, adoptent une stratégie défensive, ils se sentent assiégés et conçoivent l'Église comme une citadelle dépositaire de la vérité ( "societas perfecta" ), objet de l'hostilité des hommes et de leur histoire. Le moteur de cette résistance est la papauté romaine dont on exagère la fonction, le prestige, les 
prérogatives. Dans cette perspective, les Papes intensifient leurs interventions publiques contre la société et contre tous ceux qui, au sein de l'Église, ne partagent pas la même hostilité à l'égard du monde contemporain. Il s'agit là d'une politique qui débouche sur la proclamation solennelle de la primauté et de l'infaillibilité de l'Évêque de Rome par le Concile Vatican I de 1869-1870.69 De la sorte, la papauté institutionnalise son image de rempart des libertés des catholiques et s'attribue la fonction de "Curé du Monde"! Si l'Église est une citadelle assiégée, la centralisation et l'uniformité à tous les niveaux constituent une nécessité imprescriptible. Ce profond changement d'attitude et de conception de l'Église ne pouvait être sans effet sur les communautés paroissiales. On assista ainsi à un repli généralisé des paroisses sur elles-mêmes.

\subsubsection{Le problème de la pastorale paroissiale n'a jamais été aussi aigu}

La situation de la paroisse au XIX ${ }^{\circ}$ siècle se caractérise d'un côté par la grande influence de l'état et de l'autre, par les changements d'ordre social provenant des trois grandes transformations qui dominent toute l'histoire de cette période: révolution démographique, industrialisation, concentration urbaine. Ce qui fait dire à $\mathrm{C}$. FLORISTAIN:

"le problème de la pastorale paroissiale n'a jamais été aussi aigu dans toute l'histoire de l'Église qu'à partir de la fin du XIX ${ }^{\circ}$ siècle $/ . . . /$ parce que l'Église n'a pas pris effectivement conscience de cette triple transformation en cours." 70

FLORISTAIN, C. , "La paroisse à la lumière de l'histoire", pp.61-62. "... cette rapidement trouvée en situation de "forteresse assiégée", impuissante à faire face aux défis politiques, économiques, sociaux et culturels de la modernité. Dans la phase de repli ultramondain et d'agressivité antimoderne qui a caractérisé le catholicisme français dans la seconde moitié du XIX ${ }^{\circ}$ siècle, la civilisation paroissiale a continué de cristalliser la vision, de plus en plus étrangère à la réalité vécue d'une société religieuse minée par le développement de l'industrialisation, de l'urbanisation et de la mobilité sociale, d'un recouvrement total de l'Église et de la société"(HERVIEU-LÉGER, Danièle, 
"Le processus d'industrialisation très intense qui s'opère dans tout l'Occident entraîne lui aussi son cortège de problèmes. Il provoque en fait la crise de l'ecclésiologie de la cura romana qui paraît désormais inadaptée aux exigences d'autonomie des masses laborieuses. Dans le même temps, l'assise paroissiale urbaine rencontre de très graves difficultés face à l'urbanisation massive, laquelle entraîne une extension très rapide des frontières de la cité. La difficulté qu'il y a à s'adapter aux évolutions sociales, doublée de la conviction que l'immobilisme constitue la meilleure arme défensive de l'Église, a pour effet de désorienter l'Église. L'autorité ecclésiastique tente d'y remédier dans deux grandes directions. Tout d'abord, elle s'emploie à renforcer et à unifier le clergé, en instaurant une nette distinction entre "Église enseignante" et "Église enseignée". Une distinction qui radicalise celle existant entre clercs et laïcs, en reconnaissant aux premiers une fonction active et aux seconds un rôle passif. On perçoit aisément le dépérissement du sensus fidelium et l'exaltation de l'identification entre clergé et Église qui en résultaient. Ensuite, on attribue une importance nouvelle à l'organisation juridique de l'Église. Il semble qu'un "rhabillage" juridique, calqué sur les codes civils modernes, puisse renforcer l'Église et on arrive ainsi à la promulgation en 1917 du code de droit canonique, qui contient un système juridique unitaire visant à régir de manière uniforme l'Église catholique en Occident."71

Le grand conflit mondial de 1914-18 a produit une casssure profonde dans la vie des sociétés européennes qui ne fut pas sans conséquences pour la condition ecclésiale. Le phénomène de l'urbanisation s'intensifia et s'élargit pour se doubler parallèlement d'une plus grande mobilité sociale. Face à ces mutations sociales aussi considérables, les communautés paroissiales se sont souvent trouvées dépourvues et désorientées. $\mathrm{Au}$ cours des $\mathrm{XIX}$ et $\mathrm{XX}^{\circ}$ siècles, les paroisses sont de moins en moins adaptées au développement démographique. ${ }^{72}$ C'est pour cette raison que le problème des paroisses dans les villes reste toujours difficile à résoudre, les remèdes n'ayant pas été appliqués à temps.

"De quelques recompositions culturelles du catholicisme français", in Sociologie et sociétés, vol. XXII, $\mathrm{n}^{\circ} 2$, octobre 1990, p. 197.).

71

72

ALBERIGO, Giuseppe, "Du seizième siècle à Vatican II", p. 67.

"Afin de comprendre comment les structures paroissiales ont évolué, il faut remonter jusqu'aux débuts de l'évolution urbaine de l'agglomération: 1800 environ pour les villes européennes, 1850 pour les villes nord-américaines et 1880 et 1900 pour les villes sud-américaines" (HOUTART, François, Le planning des paroisses urbaines, in Paroisses urbaines, paroisses rurales, $5^{\circ}$ conférence internationale de sociologie religieuse, 1958, p.107.). 


\subsubsection{Le code de 1917 décrète la paroisse territoriale}

La révision du droit canonique en 1917 sous Benoît XV a compilé l'ancien droit et les décisions des dicastères romains en marquant une nette préférence pour la paroisse territoriale. Le code décrète la division du territoire du diocèse en paroisses. À chaque partie territoriale est assignée une église avec son propre pasteur. Le principe de l'unité est nettement affirmé: une paroisse par curé, un curé par paroisse. La cura animarum est assurée par le prêtre nommé par l'évêque; elle est exercée sous son autorité. Le curé est bien le pivot de toute la discipline ecclésiastique du peuple chrétien; ceci apparaît tout au long du Code en particulier à propos des sacrements. 73

En 1922, Pie XI crée l'Action catholique qui a influencé l'activité paroissiale. Pie XII enfin, fait de la paroisse un de ses sujets de prédilection. Il spécifie que la paroisse est "dans l'Église du Christ la première communauté de vie chrétienne, communauté à la taille humaine, telle que le berger puisse connaître ses brebis et les brebis leur berger."74 Nous verrons plus loin que, même encore aujourd'hui dans nos sociétés industrialisées et fortement urbanisées, nous ne sommes pas encore sortis de cette conception "serre chaude" ou "enclos (troupeau)" de la paroisse. 


\subsection{La paroisse au Canada français 75}

\subsubsection{Un contexte sociologique différent}

Nous ne pouvons tirer nos orientations pastorales uniquement des expériences européennes. L'histoire et le contexte actuel en Amérique du Nord, et plus particulièrement au Canada français, ont façonné un type original de paroisse. La réflexion débutera ici par une brève rétrospective historique de la paroisse canadiennefrançaise. Cette démarche est essentielle pour comprendre certaines situations actuelles et analyser une littérature européenne parfois utilisée sans trop d'esprit critique. Au Canada français et en Amérique du Nord en général, la paroisse présente certains traits sociologiques qui diffèrent de ceux des pays latins d'Europe. Combien en sont conscients? Tout en évitant de tomber dans le complexe de dé-colonisation, il est important de tenir à distance, sans les oublier, les résultats des chercheurs européens, et cela avec le souci de "retrouver des yeux neufs" dans notre propre paysage. On a dit que beaucoup de paroisses actuelles sont restées des entités de type rural, même au coeur des grandes villes. Il est donc de grand intérêt de revoir l'institution dans son premier contexte historique rural. 76

75 "L'histoire du Canada français, comme celle du Québec qui en est l'origine, commence chronologiquement au XVI ${ }^{\circ}$ siècle, au moment où celle du Moyen-Âge s'achève. Même ce XVI ${ }^{\circ}$ siècle, dont les Canadiens francophones dépendent plus immédiatement, est plus médiéval qu'on ne le croit. Issus de familles françaises européennes, les premiers colons d'ici ont été écartés de deux événements mondiaux qui ont quelque peu brisé la ligne de l'histoire: la réforme protestante qui délaisse la papauté et la révolution française qui abolit la monarchie. Ainsi, il semble que les francophones d'Amérique seraient des héritiers du Moyen Âge français. C'est ce que confirme l'étude du floklore et des institutions du Québec traditionnel"( LACROLX, Benoît, La religion de mon père, Montréal, Bellarmin, 1986, p. 72).

76 Voir VOISINE, Nive, BEAULIEU, André et HAMELIN, Jean, Histoire de l'église catholique au Québec 1608-1970, Commission d'étude sur les laïcs et l'Église, Première annexe au rapport, Montréal, Fides, 1971, 112p. Ce rapport montre que la dépendance politique du Québec, comme colonie de la France puis de l'Angleterre et ensuite comme province du Canada, avait permis à l'Église de jouer un rôle social plus important que celui qui est généralement assumé par des institutions ecclésiastiques. Cette dépendance politique avait également poussé l'Église à se tourner de 
Au moment où la France, après d'autres pays européens, vient jeter en Amérique les bases d'une colonie permanente, l'Église catholique y connaît une véritable révolution de ferveur et elle est à la recherche de nouveaux champs d'apostolat. D'autre part, l'État, officiellement catholique, est tout disposé à l'aider à ouvrir des missions. C'est dans ce contexte particulier que naît au XVI' ${ }^{\circ}$ siècle l'Église canadienne qui vivra longtemps de ce legs historique du "vieux pays".

Il n'est pas banal de rappeler le rôle que l'Église a tenu ici après la Conquête. Certains n'y ont vu, n'y voient encore qu'un appétit du pouvoir savamment mis en oeuvre. La recherche historique nous apprend peu à peu à rouvrir le débat. En 1760 , les misérables débris canadiens de l'empire français d'Amérique se trouvent subitement insérés dans un autre empire, étranger par les institutions, la langue, la religion. Cette petite population possède des coutumes bien à elle; cependant, de sa première appartenance elle n'hérite d'à peu près aucune structure proprement politique. L'Église, avec ses paroisses, son clergé, son évêque, ses quelques institutions scolaires est susceptible d'en assurer la cohésion d'ensemble, la représentation officielle. Cette Église n'avait pas joué un rôle déterminant aux temps du régime français; des historiens ont parlé de sa "servitude". Elle ne jouira pas non plus d'une grande liberté sous le nouveau régime. Sous surveillance, l'épiscopat a dû constamment montrer sa loyauté, encouragé en cela par les idéologies d'Ancien Régime. À tout prendre, à travers des louvoiements, des petitesses et des grandeurs, l'Église a assez bien joué un rôle qu'elle n'avait pas d'abord choisi: être l'ossature d'un peuple minuscule dans un immense empire. Ce rôle s'est agrandi, on le sait, à partir du milieu du XIX ${ }^{\circ}$ siècle. Le triomphe d'alors, et qui s'étendit sur un siècle, fut à double figure. D'une part, il misère de l'Église du Québec reflétaient toutes deux cette situation historique particulière. 
correspondait à un vide des autres instances du pouvoir autochtone; d'autre part, et par voie de conséquence, il donnait à l'Église une puissance dont ses élites cléricales et laïques ont naturellement tiré avantage, plaisir et aveuglement.

\subsubsection{L'Église-Nation}

La paroisse canadienne-française est encore très marquée par ses antécédents. Ceux-ci ne remontent guère loin, puisque, sous le régime français, l'Institution n'avait pas pris grande consistance. En effet, la traite des fourrures amenait des déplacements constants et l'ensemble de la population a mis du temps avant de se stabiliser dans des localités bien structurées. La paroisse traditionnelle s'est façonnée surtout au $\mathrm{XIX} \mathrm{X}^{\circ}$ siècle dans un cadre rural. Il s'agissait de localités plutôt petites et assez isolées les unes des autres. La famille était "l'unité de base" et cumulait l'ensemble des relations sociales suscitées par les différentes activités: travail, loisirs, politiques, etc. Il en résultait une petite société homogène et autarcique. Les relations de voisinage et de parenté constituaient la grande partie des rapports sociaux. Les valeurs religieuses allaient de soi et se diffusaient dans la totalité de cette mono-culture et cela, jusque dans les détails de l'existence quotidienne. II s'agissait beaucoup plus "d'entretenir et d'administrer une communauté toute faite sociologiquement plutôt que de chercher à édifier sans cesse une communauté proprement religieuse."77

À la toute fin du $\mathrm{XIX}^{\circ}$ siècle, l'Église est devenue responsable de l'aménagement de l'espace et du temps. L'Église-Nation à la québécoise provient d'un vaste mouvement religieux qui s'impose en très peu de temps.

77 DUMONT, F., Réflexions sur l'histoire religieuse du Canada-français, in L'Église et le Québec, Montréal, Les Idées du jour, 1961, p. 62. 
"Par un curieux paradoxe, cette Église a émergé comme Église nationale et comme puissance politique, dans la seconde moitié du XIX ${ }^{\circ}$ siècle, précisément au moment où dans le monde occidental, les États prenaient leur distance avec les Églises et les laïcs délogeaient les clercs des fonctions profanes qu'ils exerçaient. Les évêques québécois ont su tirer parti de la conjoncture. /.../ Le vouloir-vivre collectif diffus dans la conscience du peuple, s'est incarné dans un Nous religieux /.../ La société est une nation et la nation une Église." 78

Vers 1860 , l'Église affirme son autonomie et sa supériorité par rapport à l'État. L'Église-Nation compte, à la fin du $\mathrm{XIX}^{\circ}$ siècle, 650 paroisses réparties en neuf diocèses. C'est la paroisse qui donne corps à l'Église-Nation; elle constitue une unité sociale fonctionnelle et autonome. 79

\begin{abstract}
"Mais le territoire paroissial demeure le point d'appui essentiel. L'action doit être paroissiale pour être sociale. La paroisse, pour Alphonse Desjardins, est "la cellule économique idéale, le cadre parfait où doit fonctionner une telle caisse" qui "greffée sur l'unité paroissiale, ne peut manquer de fortifier l'attachement de nos compatriotes pour le clocher natal (ne plus émigrer), le leur rendre plus cher puisqu'il symbolisera non seulement leurs aspirations les plus élevées, mais aussi celles de l'ordre matériel, qui ne sont pas à dédaigner après tout" (H.C.Q.., 3,1, p. 276-277). On ne trouve pas meilleur témoignage, sur l'Église-Nation. La première Caisse voit le jour en 1901 à Lévis. "80
\end{abstract}

Chacune des paroisses est essentiellement un groupe de fidèles gouvernés spirituellement par un curé qui connaît l'ensemble de ses paroissiens. Les paroisses ont un caractère familial. Elles animent toute la vie des paroissiens et, avec leurs institutions familiales, elles sont comme le conservatoire des traditions et de la religion. C'est l'époque où les liens territoriaux et les liens paroissiaux existent

HAMELIN, J., et GAGNON, N., Histoire du catholicisme québécois, Le XX ${ }^{\circ}$ siècle, tome 1, Montréal, Montréal, Boréal Express, 1984, p37; p. 48. André CHEVALIER dans son volume sur la paroisse explique bien cette conception de l'Église-nation au Québec. Voir CHEVALIER, André, La paroisse post-moderne, Faire Église aujourd'hui, l'exemple du Québec, Montréal, Paulines, 1992, 372p.

79 Voir HAMELIN, J., et GAGNON, N., Histoire du catholicisme québéçois, Le XX ${ }^{\circ}$ siècle, tome 1, p.24; p.41. p. 48.

80 CHEVALIER, André, La paroisse post-moderne, p.57. 
réellement; la paroisse géographique est conforme aux réalités de la vie quotidienne et ses structures coïncident avec l'organisation communautaire du temps. La grande majorité des habitants pratiquent leur religion. Les habitants y étaient tout à la fois citadins et paroissiens. Cette paroisse, non seulement suffit aux besoins religieux de ses habitants, mais elle leur apporte ce qui peut leur manquer au plan social et culturel. Dans l'histoire de 'notre pays', la paroisse a donc joué un rôle important. Elle a été l'institution porteuse de la genèse de plusieurs mouvements sociaux (mouvement Desjardins, coopératisme ouvrier et agricole, etc.). Elle s'est avérée un catalyseur dans la constitution du tissu social.

\begin{abstract}
"Tout n'était pas que négatif dans la réalisation québécoise du modèle de l'"Église-nation" apparu au cours des années 1840 et qui a été abandonné, à toutes fins pratiques, un peu plus d'un siècle plus tard, au cours des années 1960. Pendant toute cette période, l'Église a constitué, pour ainsi dire, l'ossature du peuple canadien-français. C'est peut-être elle qui lui a assuré la survie et qui a semé, parfois malgré elle, des germes suffisamment vigoureux pour assurer le passage de ce peuple à une autre étape de son destin, celle de son entrée dans la modernité. L'Église a rendu d'éminents services au peuple canadienfrançais en général et au peuple québécois en particulier. Sa vitalité lui a permis de donner des milliers de missionnaires à l'Église universelle." 81
\end{abstract}

\title{
7.11.3 La soudaineté des changements sociaux
}

Il y a quelques années à peine, l'Église du Québec n'avait pas devant elle une société civile pleinement constituée, une société munie d'institutions consistantes et autonomes. Une première communauté canadienne-française avait pris forme à la fin du $\mathrm{XIX}^{\circ}$ siècle et s'était épanouie jusqu'à la deuxième guerre mondiale. L'Église en était l'institution centrale et omniprésente sociologiquement. Tous les autres secteurs de la société devaient dans une certaine mesure s'appuyer sur elle. Pensons ici à l'histoire 
de nos organismes sociaux, politiques, culturels, scolaires, récréatifs, familiaux, coopératifs, etc. Voici que depuis la guerre les institutions civiles s'affermissent peu à peu, cherchent de nouvelles voies et s'émancipent de ce passé désormais considéré comme un féodalisme théocratique, comme une sorte de Moyen Âge en plein monde industriel. Plusieurs éléments dynamiques de ces institutions veulent une rupture avec cette période de stagnation culturelle et économique. À côté des institutions suscitées par l'Église, s'édifie une nouvelle société 'profane' où on ne sent plus le besoin de compter avec l'Église, où les attitudes sont très sécularisées, où l'on oppose le présent et l'avenir au passé. Une première donnée ressort de cet ensemble, c'est la tension entre une société qui se sécularise et une situation de chrétienté qui continue, entre une recherche d'autonomie des secteurs "profanes" et une volonté d'émancipation de l'influence de l'Église, entre une confessionnalité largement répandue et une laïcité qui veut réduire les frontières des institutions ecclésiastiques. Il suffit de se reporter aux affrontements qui ont eu cours dans les syndicats, les caisses populaires, les organismes de loisirs, les divers secteurs scolaires, les initiatives de promotion d'un planning familial, etc.

$\mathrm{Au}$ moment où l'économie agricole devenait industrielle et où les populations se déplaçaient et s'urbanisaient, on devait faire face à des phénomènes nouveaux. Dans le milieu rural, le phénomène se caractérise par un changement de la communauté paroissiale qui a cessé d'être homogène au point de vue des occupations et des centres d'intérêt pour devenir pluraliste. Dans le milieu urbain, la situation est beaucoup plus compliquée. Les relations d'amis ou de parents, qui constituaient un facteur puissant d'intégration dans la société rurale traditionnelle, se sont avérées moins fortes à mesure que se développait la nécessité de groupes secondaires, c'est-à-dire des groupes ayant comme fonction de centraliser les intérêts communs d'un certain nombre de personnes, que ces intérêts soient de portée professionnelle, de portée 
économique ou de portée sociale. Jusqu'ici l'Église avait été l'institution centrale de notre société. Elle opérait surtout sur une base locale, paroissiale. Elle ne cherchait pas tant à créer une communauté chrétienne originale qu'à épouser la communauté locale pré-existante. La famille et l'école étaient intimement liées à la paroisse. Des conditionnements historiques et sociologiques favorisaient cette situation. En effet, les Canadiens français, bloqués au plan des grandes institutions de la société industrielle, s'étaient repliés sur la famille et le clan de la parenté ou du voisinage. Ceci aide peutêtre à comprendre la prolongation de la paroisse de type rural en plein secteur urbain, même à Québec et à Montréal. Mais l'Église ne se situe pas de la même façon dans une société sécularisée, et ceci a un retentissement dans chacun des rôles qu'elle assume. Ces derniers ne se déduisent pas exclusivement de principes théologiques et canoniques. Il y a tout le poids sociologique de cette situation en transition. La paroisse, cellule nourricière de la vie sociale et religieuse au Canada français, ne correspond donc plus aux exigences de la vie urbaine. La carte des paroisses calque encore l'oekoumène agricole, même si 67\% des Québécois vivent dans des villes en 1951. D'ailleurs, la conception même de la paroisse ne répond plus aux réalités urbaines. Nombre de catholiques naissent, vivent et meurent hors de ce cadre paroissial. Le clocher n'est plus le centre autour duquel gravite l'activité sociale des croyants.

À partir de la deuxième guerre, les changements sociaux se sont prodigieusement accélérés: la guerre, l'élévation subite du niveau de vie, la croissance rapide des organisations dès le lendemain du conflit mondial, plus tard l'extension des responsabilités de l'État. Ces facteurs, et bien d'autres, ont mis à découvert des aspirations longtemps dissimulées, en ont fait surgir de nouvelles. Le développement des médias ( de la radio, de la télévision en particulier) ont modifié radicalement les représentations du monde, accru l'importance de l'intelligentsia, permis l'émergence de 
nouveaux pouvoirs. L'Église a essayé de bouger. Mais le lourd appareil acquis du passé, la soudaineté des changements l'ont débordée, comme ont été débordées d'autres institutions de la société. L'Église québécoise a dû affronter le changement avec des outils qui n'étaient pas de son héritage. Ceci a fait en sorte que beaucoup de croyants ont fini par s'apercevoir qu'il leur fallait dans ce pays, et à leurs risques et périls, retrouver une identité.

\title{
7.11.4 Une Révolution "tranquille"? 82
}

Nul besoin d'insister ici sur les effets de l'urbanisation et de l'industrialisation sur ce catholicisme national et la paroisse puisque j'analyserai plus profondément leurs effets dans le prochain chapitre. Toutefois, il est important de dire que les premiers signes en ont été tangibles dès l'entre-deux-guerres, dans la naissance des mouvements ouvriers, puis surtout lors de la grève de l'amiante en 1949 et à travers l'évolution du syndicalisme catholique lui-même. L'effritement du cléricalisme par la suite a été l'effet et le produit de deux événements indissociables pour le catholicisme québécois: le concile Vatican II et la Révolution tranquille.83

\begin{abstract}
"Mais il existe aujourd'hui une réponse adaptée à une situation qui n'a pas de précédent dans la longue histoire du christianisme. Les défis que doit affronter l'Église du Québec sont communs à tout l'espace culturel de ce qu'il est convenu d'appeler le monde occidental. Le Québec a ceci de particulier qu'il a vécu cette transition dans un délai extrêmement bref et sans que son héritage culturel lui permette de s'y préparer vraiment. L'Église du Québec en a subi durement les contrecoups. C'est une grâce pour elle que
\end{abstract}

82

Voir DUMONT, Fernand, "Crise d'une Église, crise d'une société", in Situation et avenir du catholicisme québécois, entre le temple et l'exil, Ottawa, Leméac, 1982, pp.11-48. VAILANCOURT, Jean-Guy, dir., " Catholicisme et société contemporaine", in Sociologie et sociétés, Vol. XXII, n², octobre 1990, 226p.; DUMONT, Fernand, dir., La société québécoise après 30 ans de changements, Québec, Institut québécois de recherche sur la culture, 1990, 358p. ROCHER, Guy, "Repères pour une société en mutation", in FORCES:Vingt-cinq ans d'évolution du québec et regard sur l'avenir, numéro 100, Hiver 1992-1993, pp.15-20.

83 Les chapitres neuvième et dixième seront consacrés uniquement à l'analyse du rapport de l'Église au monde et des conséquences du Concile Vatican II sur la vie ecclésiale. 
d'avoir vécu en ces années cruciales, avec les autres Églises du monde, en communion avec l'Église de Rome, l'événement du Concile Vatican II. Cette expérience lui a permis de prendre une nouvelle conscience d'elle-même et de sa mission dans le monde et ainsi, d'entendre de nouveau le double appel de l'Évangile à la conversion et à la mission pour y répondre de façon créatrice dans le monde nouveau qui est apparu à partir des années $1960 . " 84$

Le Québec (qu'il faut désormais distinguer du Canada français) est passé durant la Révolution tranquille directement de la religion ethnique, sauvegarde de son identité nationale minorisée, à la religion séculière, moteur de son dynamisme nouveau. L'Église a dû se départir du contrôle des secteurs principaux où son influence s'exerçait directement sur la société: l'éducation (création du ministère de l'Éducation en 1964), les affaires sociales (1966), la colonisation (abolition de l'office diocésain de colonisation en 1965). Dès lors, pour l'institution catholique, la Révolution tranquille a signifié la désappropriation de son discours socio-politique et la nécessité d'apprendre, quelquefois malgré elle, des rôles nouveaux renvoyant les catholiques eux-mêmes à leur autonomie. Ce catholicisme discret cachera alors une profonde crise d'identité.

La Révolution tranquille a été précédée par une floraison de critiques et de projets. Ce sont ces interprétations qui se sont ensuite cristallisées en institutions nouvelles; là fut la caractéristique la plus évidente des débuts des années 1960. Ces institutions ont été largement improvisées, mais comment aurait-on pu briser autrement un long gel historique? La Révolution tranquille est née d'une volonté neuve d'abattre les anciennes autocraties, d'implanter au Québec une véritable démocratie. C'est là que réside toujours sa grandeur irrécusable. Les efforts du gouvernement et d'autres instances pour moderniser le Québec ont eu donc des conséquences dramatiques sur la religion traditionnelle. En moins de trente ans, l'Église a perdu son

84

L'ASSEMBLÉE DES ÉVÊQUES DU QUÉBEC, L'Église du Québec 1988-1993 à l'occasion de la visite ad limina 1993, les évêques du Québec font le bilan de la situation, p. 26. 
contrôle sur les institutions et sur le peuple. L'Église fut "invitée" à jouer un rôle uniquement "religieux" et à se tenir en dehors des autres sphères d'activités.

\subsubsection{Une Église québécoise en recherche}

La Révolution tranquille des années 60 a entraîné la sécularisation rapide de la société québécoise. Pendant ces années, le peuple du Québec a cherché une définition collective qui ne serait plus liée à son passé catholique. Le gouvernement a assumé la responsabilité du réseau d'organismes religieux chargés de l'aide sociale, de la santé et de l'éducation. Ce processus s'est accompagné d'une diminution radicale du nombre des "fidèles". Les évêques du Québec ont voulu approfondir davantage ces nombreux changements sociaux influençant l'ensemble des Québécois. Ils ont alors chargé une commission de recherche, sous la présidence de Fernand DUMONT, d'analyser la crise moderne de l'Église et, à partir de ses constatations, de recommander des pratiques nouvelles et mieux adaptées. La Commission a tenu des audiences dans les divers régions du Québec et reçu des mémoires de groupes et d'organismes religieux; elle a commandé des études psychosociales sur les attitudes et les valeurs religieuses de la population. Finalement, elle a présenté un rapport, le rapport DUMONT, dans lequel elle analysait la situation et proposait de nouvelles pratiques pastorales. En 1971, la Commission a publié son rapport sous le titre L'Église du Québec: un héritage, un projet. 85 La Commission DUMONT a accepté le verdict de l'histoire, à savoir que la Révolution tranquille était un processus sociétal irréversible, que le Québec était devenu une société séculière et pluraliste et que l'Église ne pouvait plus parler au nom de toute la population. 
"Le rapport parut en décembre 1971./.../ Au cours de la rédaction, quelqu'un m'avait mis au défi de résumer le projet en une seule phrase! On me permettra de la reproduire ici, avec les soulignés requis: "Une Église fonctionnelle (c'est-à-dire intégrée à un système social et politique) dans une société dépassée (c'est-à-dire une société féodale attardée) et en train de devenir une secte (parce que fonctionnelle d'une société dépassée), a été, en l'espace de dix ans, débloquée à la fois de l'intérieur par le Concile et de l'extérieur par la "Révolution tranquille", si bien qu'elle s'est lancée dans l'aggiornamento (c'est-à-dire dans la refonctionnalisation en fonction d'une société capitaliste tardive) et dans $\underline{\text { la }}$ sécularisation (en se dissolvant dans le monde qu'elle a contribué à créer), et que, se sentant menacée par ces deux démarches et sans doute inspirée par l'Esprit saint, elle a institué, entre autres choses, la Commission d'étude sur les laïcs et l'Église qui, après enquête confirmant l'évolution qui vient d'être décrite (avec des rythmes de rémanence et de changement à quatre paliers: conservateurs, anxieux, novateurs, désengagés), recommande comme prioritaire, en s'appuyant sur les éléments prophétiques révélés par l'enquête, d'assurer un équilibre, difficile mais essentiel à la survie, entre l'intérioritế (expérience chrétienne dans la fraternité) et le service-engagement (y compris une politisation critique qui assure une dysfonctionnalité et permet une transfonctionnalité), pour que son témoignage spécifique de la vie continuée de Dieu en Jésus-Christ ici et actuellement puisse demeurer vécu et croyable". Je continue de croire que cela résume bien le rapport." 86

La Commission DUMONT s'est longuement demandé si la paroisse ellemême était encore une institution utile et viable. 87 Dans les villages, la paroisse a conservé sa vitalité, mais dans les villes, elle éprouve des difficultés. Ces difficultés ont pour cause en partie la sécularisation rapide de la population et en partie la tendance des catholiques "fidèles" à former des groupes restreints, plus intimes et plus actifs et à s'éloigner de leur paroisse. La Commission a finalement décidé de se porter à la défense de la paroisse.

"Pour nous résumer, quel que soit l'intérêt de spéculations sur d'éventuels rassemblements qui remplaceraient la paroisse dans l'avenir, cette institution demeure, dans les faits, la structure de base communément répandue. Elle est encore susceptible de jouer, à son niveau, des rôles décisifs, variables selon les milieux. Mais partout, en milieux urbains particulièrement, la paroisse doit assurer des fonctions nouvelles: servir de relais pour des structures territoriales plus étendues; être un milieu d'accueil et de génération de solidarités plus fondamentales. 88

\section{6}

HARVEY, Julien, "Le rapport Dumont, à court terme et à long terme", in Sociologie et sociétés, vol. XXII, pp. 128-129.

87 L'Église du Québec: un héritage, un projet, pp. 260-264.

88

Ibid., p.264. 
Par la suite, nous devons attendre les années 1989-1992 pour que les évêques québécois s'intéressent d'une manière plus particulière au devenir de la paroisse au Québec. Au printemps 1989, l'Assemblée des évêques du Québec a décidé de mener une vaste recherche participative dans l'ensemble des diocèses. Ce rapport de recherche a été publié en 1992 dans un dossier intitulé: Risquer l'avenir, Bilan d'enquête et prospectives. Le bilan des responsables de cette enquête est plutôt sombre.

\begin{abstract}
"Parce que la modernité s'est imposée, la culture de la société québécoise n'est plus religieuse. Désormais, chaque baptisé, sans trop s'en rendre compte, assimile en priorité la vision du monde et la hiérarchie des valeurs propres à la culture moderne. À ce point qu'avec le temps, s'il n'y a pas une intériorité articulée et s'il n'appartient pas à une communauté soutenante, sa vision chrétienne va se dissoudre petit à petit sans qu'il en ait une conscience claire et sans qu'une nouvelle vision chrétienne n'émerge qui sache discerner les convergences et les divergences entre la tradition chrétienne et la culture actuelle. Tout se fait si doucement, en particulier quand le processus s'étale sur une, deux ou trois décennies. Sa vie de foi court alors un danger mortel. /.../ L'Église d'ici est acculée au mur. Tout indique que la présence évangélique va se faire de moins en moins forte si on n'intervient pas pour réorienter le cours de l'histoire des communautés chrétiennes. "89
\end{abstract}

Selon cette recherche, la paroisse a de l'avenir à la condition "de voir la paroisse traditionnelle se transformer progresssivement en une communion de communautés restreintes plutôt qu'en une collectivité sans identité marquée."90

"Au terme de la démarche, il nous apparaît évident que, pour assurer leur avenir et leur
authenticité, les communautés chrétiennes locales auront à entrer dans un long processus
de transformations ou plutôt qu'elles devront demeurer dans le processus déjà enclenché
avec le concile Vatican II. Mais il s'agit dorénavant de le radicaliser, d'abandonner
plusieurs orientations pastorales héritées du monde de la chrétienté, de risquer de
nouvelles voies plus cohérentes avec le monde pluraliste et sécularisé dans lequel nous
vivons présentement. En prenant ce risque, il faudra emprunter des chemins où il n'y aura
pas que des réussites. Mais il y aura sûrement des réalisations qui ne manqueront pas de
surprendre et de stimuler. /.../ Peut-être, avant tout, avons-nous à découvrir que l'Église 
catholique au Québec est elle aussi désormais en terrain missionnaire. Elle ne peut plus fonctionner comme avant. Elle doit accepter de risquer l'avenir" 91

Mais qu'est-ce que risquer l'avenir ecclésial au Québec? La dernière partie de la présente thèse cherchera à répondre à cette question. Les propositions seront différentes de celles énoncées dans le bilan d'enquête de ce comité de l'AEQ.

\subsection{Acquis de recherche éclairants :}

Que retenir de ce parcours historique sur l'institution paroissiale?

\subsubsection{Une "ruralisation" de la paroisse au cours des siècles}

Nous avons vu qu'au début, le mot "paroikia" désigne une qualité de l'existence chrétienne. Mais il en vient à signifier de plus en plus une réalité administrative qui rend visible le groupe des chrétiens. Les croyants des premiers siècles emploient paroisse comme synonyme d'Église particulière, d'Église épiscopale. Il y a une ville, un diocèse (une paroisse), un évêque. La paroisse est l'Église d'une ville. Ce principe d'une paroisse par ville est entré dans la législation de l'Église ancienne et cette unicité de la paroisse dans chaque ville est respectée. Ce principe vise à l'édification de l'Église et à l'accomplissement de sa mission dans l'unité. C'est au III'siècle que se produisit, sur une plus vaste échelle, une certaine décentralisation de l'unique paroisse-diocèse au profit des campagnes. La paroisse a pris naissance vers la fin du $\mathrm{IV}^{\circ}$ siècle, avec l'indépendance donnée aux Églises rurales jusque là simples dessertes de l'Église-mère. $\mathrm{Du} \mathrm{V} \mathrm{V}^{\circ}$ au VIII siècle, l'évangélisation des populations campagnardes fait augmenter considérablement le nombre de paroisses. Le régime 
paroissial se généralise par la suite ( $\mathrm{du} \mathrm{VII}^{\circ}$ au $\mathrm{X}^{\circ}$ siècle). Le mot paroisse devient l'appellation définitive de chaque district rural. Les formes juridiques éloignent ainsi de plus en plus l'institution ecclésiastique de la structure urbaine.

À partir des $\mathrm{XI}^{\circ}$ et $\mathrm{XII}^{\circ}$ siècles, les villes renaissent en Occident. Mais, le système rural envahit la ville en divisant celle-ci en paroisse. L'Église déjà profondément engagée dans le système féodal et bénéficial ne remit pas en question les nouvelles structures qu'elles venaient de se donner. Elle ne songea pas un instant à un retour à l'Église urbaine de l'antiquité (une ville, un diocèse [une paroisse], un évêque). Le modèle s'était perdu. En somme, l'Église médiévale offre à la question des relations entre l'Église et la ville une réponse toute différente de celle de la chrétienté primitive. Les structures officielles restèrent celles de la société rurale féodale. On ne tenta pas d'en faire de nouvelles qui fussent adaptées au peuple des cités. Là est commencée une forme de "ruralisation" de la paroisse en contexte urbain qui a ses prolongements jusqu'à aujourd'hui. La perspective d'évangélisation de la paroisse change pour une perspective d'administration et de contrôle religieux.

\subsubsection{La problématique de la paroisse urbaine toujours irrésolue}

L'histoire et le contexte actuel en Amérique du Nord, et plus particulièrement au Canada français, ont façonné un type original de paroisse. La paroisse d'ici présente certains traits sociologiques différents de ceux des pays latins d'Europe. Elle a joué un rôle social important. L'Église catholique canadienne française a dû être l'ossature d'un peuple minuscule dans un empire. Elle devient une "Église-Nation". Les paroisses donnant corps à cette Église-Nation sont rurales et elles ont un caractère familial. La paroisse, non seulement suffit aux besoins religieux de ses habitants, mais elle leur apporte ce qui leur manque au plan social et culturel. Dans l'histoire du Québec, la 
paroisse s'est donc avérée un catalyseur dans la constitution du tissu social. Jusqu'aux années 1960, l'Église a été omniprésente socialement. Mais la révolution industrielle, la phénomène de l'urbanisation et la révolution tranquille ont provoqué des changements sociaux considérables. La paroisse, cellule nourricière de la vie sociale et religieuse, correspond de moins en moins aux exigences de la vie urbaine. Notre société québécoise s'est rapidement urbanisée. Cependant, nous avons transposé à la ville les archétypes acquis, les imageries toutes faites, les habitudes et les recettes de la paroisse rurale. De plus, ce qui est plus grave encore, on a gardé une sorte de nostalgie de la communauté rurale ancienne: c'est trop souvent elle qui paraît inspirer encore plus ou moins subtilement la mentalité de beaucoup d'intervenants pastoraux et de croyants à l'aube de l'an 2000. Les défis pastoraux de la paroisse en contexte urbain demeurent toujours irrésolus. 


\section{CHAPITRE 8}

\section{LE PHENOMÈNE DE L'URBANISATION \\ ET SES CONSÉQUENCES SUR LA STRUCTURE PAROISSIALE1}

"Le grand progrès accompli par la sociologie moderne est celui qu'il faut faire appel à diverses séries de facteurs, partiellement indépendants, pour expliquer la réalité sociale. L'ère des explications unilatérales est finie." 2

Il existe un fait social chaque fois que se créent des relations entre les humains. La paroisse est une forme sociale de la vie religieuse. Elle est en dépendance directe de la réalité sociale. La sociologie de la paroisse prend depuis quelques années une signification particulière. ${ }^{3}$ Les rapides et profondes modifications qui se manifestent à l'intérieur de la société moderne placent la paroisse en face de problèmes et de tâches tout à fait nouveaux par rapport à cette société, mais elles posent aussi un certain nombre de problèmes pour la structure même de la paroisse en tant que produit social. Le monde industriel et urbain a transformé l'environnement dans lequel

1 Dans les années soixante, quelques auteurs ont étudié les conséquences de l'urbanisation sur l'institution paroissiale. Mais depuis 1970, peu d'études se sont intéressées au rôle de la paroisse dans la ville, à la nature et à l'évolution de la vie paroissiale en milieu urbain. Nous avons délaissé la réflexion sur ce sujet. Il faut absolument relancer celle-ci. C'est ce que j'ose humblement faire dans ce chapitre en m'inspirant de ces auteurs. Ceci explique les dates peu récentes des ouvrages consultés.

CARRIER, Hervé, PIN, Émile, Essais de sociologie religieuse, Paris, SPES, 1967, p. 260.

3 Ce n'est qu'après 1945 que la sociologie commença à entrer en jeu dans la réflexion sur la paroisse. Pendant plusieurs années, sociologues et théologiens ont évolué parallèlement sans contact sérieux. Le résultat de l'ignorance de la sociologie, ce fut le ruralisme insconcient des théologies de la paroisse. Ceci explique que les théories théologiques des dernières décennies ont défini la paroisse a priori sans références suffisantes à l'observation sociologique, comme si la paroisse pouvait se définir uniquement à partir de la révélation. 
s'insère l'institution ecclésiale. Cette évolution n'est pas sans incidence sur le rôle de la paroisse.

De multiples formes sociologiques recoivent le titre de paroisses. On rencontre des paroisses rurales et des paroisses urbaines. Cependant, les choses deviennent plus complexes si l'on affine son observation. Le secteur urbain n'est pas homogène et le secteur rural est plus diversifié qu'il ne le laisse paraître. Nous pouvons identifier six profils paroissiaux que l'on retrouve plus régulièrement dans les diocèses: paroisses moyennes en milieu rural; paroisses urbaines en décroissance démographique (centre-ville); petites paroisses (moins de 1000 fidèles); métropoles régionales; paroisses de banlieue en croissance démographique; super-paroisse (plus de 20,000 fidèles). Il y a les paroisses plus particulières: nationales, ethniques ou linguistiques. Il y a aussi des paroisses de personnes à statut social particulier: universitaires, fonctionnaires, etc. Chaque type demanderait une description sociologique. Je me limiterai au type de paroisses rurales et de paroisses urbaines de la province du Québec, plus particulièrement de celles qui se retrouvent dans la région $\mathrm{du}$ Saguenay Lac-Saint-Jean.

Dans le chapitre précédent, nous avons vu rapidement comment la révolution industrielle et l'urbanisation qui s'en est suivie ont amené des bouleversements profonds et durables dans la société. D'abord en Europe, puis en Amérique, ce mouvement d'urbanisation fit en sorte que des masses de paysans ont été amenées à s'agglutiner dans les villes. Le présent chapitre analyse plus en profondeur ce mouvement. Le phénomène de l'urbanisation a eu des répercussions sur 
la vie des citoyens et, par voie de conséquence, sur la vie des paroissiens et sur la structure paroissiale. 4

\subsection{Un bref rappel historique}

Nous disons, en manière de boutade, que la paroisse classique était adaptée à une société "néolithique" et qu'elle ne l'est plus au monde actuel. En effet, depuis les débuts de l'époque néolithique jusque vers 1850 de notre ère, la structure de base de la société a peu changé. Il s'agissait d'une société dont l'agriculture était le fondement et le village, la cellule. La ville n'y était jamais très grande (Rome, puis Constantinople, ne dépassèrent pas quelques centaines de milliers d'habitants; Paris, Londres ou Venise se tinrent bien en-dessous; une ville de 30000 personnes passait pour une grande ville); elle n'était que centre politique, commercial ou religieux. À l'intérieur même de la ville nous retrouvons la structure du village: chaque quartier forme un tout bien délimité. Le quartier était le cadre de la vie. On y dormait, mais aussi on y travaillait à proximité immédiate de son domicile, on s'y amusait, on s'y connaissait. C'est dans ce monde que l'Église s'est établie, d'abord dans les villes, puis plus tard, chez les paysans, c'estlà qu'est née la paroisse. La cité constituait à l'origine une seule paroisse autour de l'évêque, puis bientôt apparurent des "églises-relais" dans les quartiers excentriques, communautés incomplètes, étroitement reliées à l'église-mère. Plus tard cette organisation fut étendue au monde rural. La paroisse rurale devint territoire, et cette conception territoriale influença en retour l'organisation ecclésiastique de la ville où l'on passa des "tituli" (ou églises-relais) à la paroisse "autonome" que nous connaissons. Les limites se fixèrent, les autonomies s'accentuèrent (en particulier sur le plan

$4 \quad$ Voir HOUTART, François, "Faut-il abandonner la paroisse dans la ville moderne?, in Nouvelle revue théologique, $\mathrm{n}^{\circ}$ XXVII, 1955, $\mathrm{n}^{\circ} 6, \mathrm{p} .602$. 
financier, la paroisse devient un "bénéfice" pour son curé) et là, le droit suivant le fait en arriva à canoniser cette conception territoriale de la paroisse qui inspira largement le code de 1917.

En résumé, dès le Moyen Âge, nous avions pour chaque village, chaque quartier, une paroisse. Or, dès le milieu du XIX siècle, cette société néolithique s'est désagrégée et ce, de façon complète dans les pays industrialisés. Au lieu de compter quatre-vingt-dix pour cent de paysans, la population comptera bientôt quatre-vingt-dix pour cent de citadins. Les dix pour cent qui restent à la terre ne sont d'ailleurs plus des paysans au sens classique; ce sont des exploitants du sol qui obéissent aux lois du marché et dont la mentalité est proche de celle des citadins. Les quelques paysans qui restent aujourd'hui dans les pays industrialisés ne sont pas moins urbanisés culturellement que les résidents de la ville.

En 1850, on comptait dans le monde 47 villes de plus de 100000 habitants; vingt ans après, en 1870, on en comptait plus de 150; en 1960, on en comptait 900 et on renonce à les compter aujourd'hui. ${ }^{5}$ Les grandes villes deviennent d'immenses agglomérations dépassant souvent les dix millions d'habitants. ${ }^{6}$ Dès la fin du XIX ${ }^{\circ}$

5 Voir CONNAN, F. et BARREAU, J-C., Demain, la paroisse, Paris, Cerf, 1966, p. 57; et aussi COMBLIN, Joseph, Théologie de la ville, Paris, éd. universitaires, 1968, p. 44. "En effet, pendant la période s'étendant de 1850 à 1900, l'accroissement des villes de 100,000 habitants et plus était de $222,2 \%$ et celui des villes de 20,000 ou plus de $193,5 \%$. Entre 1900 et 1950 , ces chiffres étaient respectivement de 254,1\% et 239,6\%" (HOUTART, F., RÉMY, J., Milieu urbain et communauté chrétienne, Paris, Mame, 1968, p. 84.). "La population mondiale a augmenté de $49 \%$ au cours de la première moitié du XX $\mathrm{XX}^{\circ}$ siècle, alors que celle des grandes villes s'est accrue de $24 \%$ durant la même période" (ROBERT, Georges, "L'explosion urbaine 1) chaos ou maîtrise", in Le Devoir, 22 avril 1992, p.B-8.).

$6 \quad$ "En 1990, 10.9\% de la population habitait dans les 100 plus grandes villes du monde, contre $8,1 \%$ il y a 40 ans. Parmi les 100 plus grandes villes du monde, 44 se trouvent en Asie, 30 en Amérique, 15 en Europe, 9 en Afrique et 2 en Océanie. $11 \%$ de la population mondiale se concentre sur 2 millièmes des terres émergées du globe. /.../ La plus grande ville du monde n'est plus Mexico (15,9 millions d'habitants), mais Tokyo, 24 millions sur une surface deux fois plus petite. La deuxième est la Mégalopis-Est des États-Unis (23,9 millions), qui s'étend sur $14150 \mathrm{Km} 2$ autour de New York et touche six États américains. Viennent ensuite les agglomérations de Sao Paulo (17 
siècle est née une nouvelle mentalité adaptée à ce cadre neuf: transports de masse, grandes usines et concentrations de bureau, éloignement entre les lieux de travail et les lieux de domicile, nouveaux loisirs (cinéma, télévision), nouveau rythme de vie affranchi des rythmes naturels du jour et de la nuit, etc. Le monde de la ville est devenu un nouveau monde et bientôt le tout du monde; une nouvelle mutation urbaine s'est accomplie sous nos yeux où les notions traditionnelles de ville et de campagne n'ont plus grand sens justement à cause du triomphe total de la mentalité urbaine.

\title{
8.2 L'urbanisation, conséquence de l'industrialisation, bouleverse la société contemporaine
}

Deux phénomènes principaux ont marqué l'évolution de la société contemporaine: la rationalisation de la vie économique et l'urbanisation. Ces deux processus sont loin d'être achevés, même dans les pays industrialisés.

\begin{abstract}
"Personne ne conteste aujourd'hui que depuis le début du dix-neuvième siècle, les conditions de vie extérieures n'aient subi une transformation radicale par suite de la révolution industrielle dont les effets ne cessent de s'étendre. Les chercheurs appartenant aux tendances les plus diverses s'accordent, de même, à penser que le passage à l'industrialisation a entraîné des changements si profonds dans la réalité intérieure de l'homme que les effets dans l'histoire des civilisations humaines ne peuvent être comparés qu'à ceux de la révolution provoquée par le passage à la civilisation agraire."7
\end{abstract}

millions d'habitants), Séoul (15,3), Los Angeles (13,5), Moscou (11,9). Calcutta, Buenos Aires et Bombay $(11,6)$, le Caire $(11,3)$, Rio de Janeiro, Djakarta et Manille (10,9). Osaka (10), Paris $(9,3)$, Shanghai $(9,2)$ et Chicago $(9,1)$. Depuis 1950, ces mégapoles ont vu leur population tripler alors que celle de la terre doublait" (AGENCE FRANCE-PRESSE, Le Palmarès des agglomérations les plus peuplés du monde en millions d'habitants en 1990, Paris.). "En l'an 2000, les plus grandes villes du monde seront localisées dans les pays en voie de développement. D'après les projections faites par les nations-unies, Mexico sera la plus grande ville du monde et atteindrait les 28 millions d'habitants, Sao Paulo les 25 millions, Calcutta les 20, Séoul, Bombay et Rio de Janeiro les 19, Djkarta les 17, le Caire et Karachi les 16, Téhéran les 14, etc. Bref, pour l'ensemble de ces régions (sans la Chine), 17 villes dépasseraient les 10 millions d'habitants. /.../ Dans les pays industrialisés, le rapport sera de $75 \%$ d'urbains pour $25 \%$ de personnes résidant en milieu rural (dont moins de la moitié seront d'authentiques ruraux)" (ROBERT, Georges, "L'explosion urbaime mondiale", p. B-8.). 7 BROCKMÖLLER, Clément, civilisation industrielle et religion, Paris, Desclée et Cie, 1968, p. 19. 
La société industrielle a été marquée par la révolution technologique qui s'est accompagnée de l'industrialisation et de l'urbanisation massives découlant du transfert de la campagne à la ville, d'énormes quantités de population et de leur concentration autour des manufactures d'abord, puis des usines plus grandes. ${ }^{8}$ Dans sa phase la plus avancée, l'industrialisation s'est continuée par l'automatisation, dont les effets se font encore sentir dans certains secteurs de travail qui avaient été en bonne partie épargnés par l'industrialisation, tel le travail dans les bureaux et dans l'enseignement.

L'urbanisation, conséquence de l'industrialisation au XIX ${ }^{\circ}$ siècle, a été et demeure un défi pour toute la société. Elle a bouleversé le mode de vie rurale et les structures sociales correspondantes: famille, travail, loisirs, etc. L'urbanisation est sans doute une des caractéristiques principales du développement de l'humanité des temps modernes.

"Le fait social le plus frappant de l'histoire contemporaine, c'est l'urbanisation, l'exode vers la ville. Cette urbanisation, qui a commencé en Europe dès le début du $\mathrm{XIX}^{\circ}$ siècle, en raison surtout de la révolution industrielle, s'est développée ensuite aux États-Unis et a pris un essor gigantesque au Canada, en Amérique Latine, en Asie et en Afrique."9

8

Dans la région du Saguenay-Lac-Saint-Jean, ce sont les industries forestières et d'aluminium qui ont amorcé le processus de l'urbanisation au début du $\mathrm{XX}^{\circ}$ siècle. "Briser l'équation spatiale et temporelle qui veut que rural aille de pair avec passé et tradition et urbain avec modernité et innovation est d'autant plus impératif lorsqu'on étudie une région périphérique comme le Saguenay qui a connu l'industrialisation dès le début du siècle, tout en maintenat des liens étroits avec le monde rural avoisinant" (FORTIN, Andrée, ROMPRÉ, David, La sociabilité urbaine au Saguenay, Vie associative, solidarités et dynamique communautaire, Québec, Centre interuniversitaire SOREP, 1993, p.8).

9 l'Église, Paris, Alsatia, 1965, p.21. "Voici quelques taux d'urbanisation en 1955 selon les NationsUnies: Angleterre: $80.8 \%$ - Allemagne Ouest: 71,1\% - États-Unis: $64 \%$ - Belgique: $62,7 \%$ Argentine: 62,5\% - Canada: 61,6\% - Espagne: 60,5\% - France: 55,9\% - U.R.S.S.: 48\%" (COMBLIN, J., Théologie de la ville, Paris, Ed. Universitaires, 1968, p.44). 


\subsubsection{Lurbanisation, un phénomène dynamique qualitatif et quantitatif d'organisation sociétale}

Le terme urbanisation se distingue du terme urbain ou du terme ville en ce qu'il désigne un phénomène dynamique de développement ou de croissance par rapport au territoire (territoire urbanisé par rapport à un territoire rural ou même par rapport à un état d'absence d'occupation humaine) et par rapport à l'espace (espace plus ou moins densément occupé). L'urbanisation concerne donc un phénomène dynamique qualitatif et quantitatif d'organisation sociétale dans une dimension physico-spatiale. Il faut insister sur la complémentarité des aspects qualitatif et quantitatif même si la dimension qualitative, plus abstraite, est plus difficile à cerner. Du point de vue quantitatif, on dira par exemple que $80 \%$ de la population habite des centres définis comme urbains sur la base d'un seuil minimum de population. ${ }^{10} \mathrm{Du}$ point de vue qualitatif, l'urbanisation en tant que phénomène dynamique est interreliée à l'établissement et au renforcement de liens et d'interactions complexes et multiples, par exemple entre les personnes (réseaux sociaux), entre les organisations et entreprises, entre les fonctions urbaines (par exemple entre la fonction industrielle et la fonction transport) ainsi qu'entre les espaces mêmes qui y sont consacrés. En ce sens, la multiplicité et la diversité sont qualitativement inhérentes à l'urbanisation.

10 Voir ANTOINE, J., Le phénomène urbain, coll. Recherches économiques et sociales, Paris, Aubier - Montaigne, 1965, 259 p. - CHARRIER, Jean-Bernard, Citadins et ruraux, coll. Que sais-je?, Paris, Presses universitaires de France, 1970, 128p. - RAMBAUD, Placide, Société rurale et urbanisation, Paris, Seuil, 1974, 348p. - LEFEBVRE, Henri, Du rural à l'urbain, Paris, Anthropos, 1977, 285p. - RÉMY, J. et VOYÉ, La ville et l'urbanisation. Modalités d'analyse sociologique, Bruxelles, Cabay, 1982, 252p., RÉMY, Jean et VOYÉ, Liliane, La ville: vers une nouvelle définition? , Coll. Ville et entreprise, Paris, L'Harmattan, 1992, 173p. 


\subsubsection{Urbanisation, urbanité, urbanisme}

Après l'urbanisation, cette "action d'urbaniser", on passe à l'urbanité, c'est-àdire à une philosophie personnelle, collective et organisationnelle qui fait de la ville un élément sociologique et psychologique. Ce qui est désigné ici urbanité, est plus que le fait de déménager en ville et d'urbaniser un milieu; c'est une façon d'être, de s'organiser et souvent même de penser. L'urbanisme, ou mieux, l'aménagement du territoire urbain, consiste plus précisément à agencer les fonctions de la vie sociale urbaine dans leur localisation spatiale pour qu'elles puissent se réaliser de façon adéquate. Une de ses tâches fondamentales est d'organiser la mobilité en d'autres termes, de faciliter d'un point de vue spatial et physique, l'intégration socio-culturelle des personnes. L'urbanisme est donc un des facteurs d'action humaine les plus fondamentaux. Du point de vue religieux, son action revêt une importance, car l'intégration socio-culturelle est particulièrement importante pour les expressions habituelles de la vie religieuse.

\subsubsection{L'urbanisation, un processus en trois étapes}

Le processus d'urbanisation s'est déroulé en trois étapes successives. Il a été d'abord caractérisé par des migrations fort importantes de populations rurales vers des centres urbains. Ces mouvements migratoires ont trouvé leur origine dans l'insuffisance des possibilités d'emploi offertes par les régions rurales à la suite de l'évolution démographique et des techniques de production agricole. Ces populations migrantes, à majorité ouvrière, se sont établies généralement dans les quartiers centraux des villes. Ceux-ci, et c'est le début de la seconde phase, ont accusé bientôt des densités démographiques excessives, tout en n'offrant aux nouveaux arrivés que des conditions de vie souvent très précaires. Dans la suite, par l'amélioration des transports collectifs (train, autobus, métro) et privés (automobile), on a assisté 
progressivement à une déconcentration de ce noyau urbain, le long des grands axes de circulation d'abord, puis dans les zones immédiatement concentriques, les faubourgs et banlieues se constituant peu à peu et la ville initiale se transformant en agglomération.

L'urbanisation d'une région, d'un pays ou du monde ne consiste pas simplement dans un phénomène démographique: l'augmentation de la population des villes, mais elle signifie une transformation très profonde de la société comme telle. Elle nous invite ainsi à vivre dans une société tout à fait nouvelle: nouvelles formes de groupes sociaux, nouvelles institutions, nouvelles mentalités, nouvelles cultures axées sur la technique. L'urbanisation est exactement cela: une manière de vivre, une manière de se situer, une manière de considérer les choses, une manière de comprendre et d'interpréter mentalement le monde devant de nouveaux types d'humains. Urbanism as a way of life.

La société actuelle se situe certainement dans la ligne d'évolution de la société industrielle mais, en même temps, elle dépasse celle-ci et va si loin qu'on peut à juste titre parler d'une nouvelle société. On a tenté de qualifier cette nouvelle société de diverses façons: on l'a appellée Société de masse faisant référence particulièrement à l'impact des techniques modernes de communication de masse; on l'a nommée Société de consommation par opposition à la Société de Production qu'était la Société industrielle: on l'a surnommée encore d'autres manières, la Société industrielle avancée, la Société programmée, la Société post-industrielle. Chacune de ces expressions fait référence à un trait particulier de la nouvelle société qu'on peut considérer comme plus ou moins dominant ou du moins comme très accentué. Quel que soit le nom qu'on donne à la nouvelle société, on s'accorde généralement à y reconnaître une bureaucratisation de plus en plus généralisée. 


\subsection{La mutation urbaine a ébranlé la "civilisation paroissiale"}

La mutation urbaine affecte la fonctionnalité du modèle traditionnel de la paroisse, car elle en modifie les composantes: le rôle structurant du territoire, la conjugaison des diverses fonctions sociales, le caractère interpersonnel des relations, la solidarité et l'identification du groupe. 11 L'énorme accroissement des villes (urbanisation) change qualitativement la structure des relations sociales. Cet accroissement n'aboutit pas seulement à multiplier les quartiers ayant une vie sociale propre et rassemblant une population hétérogène, mais encore à spécialiser les quartiers de la ville selon une dominante de services (quartiers commercial, hospitalier, administratif, scolaire, résidentiel, de petite ou de grande industrie...) . De la sorte, l'habitat et le lieu des diverses activités se trouvant scindés, l'homme évolue en des réseaux distincts d'activités et de relations, ceci mène à une parcellisation de l'existence. Si la paroisse territoriale reste proche d'une certaine vie familiale, une grande partie de l'activité lui devient étrangère, d'autre part, chaque quartier urbanisé tend à regrouper sélectivement une catégorie socio-professionnelle. En outre, le voisinage joue un rôle de moins en moins grand, car la personne humaine cherche à compenser par la sélectivité de ses relations, l'anonymat de la grande ville et les contraintes dans le choix de l'habitat. D'où une recherche de relations spontanées et la formation de groupes sélectifs indépendants du milieu professionnel et du milieu résidentiel, surtout dans les domaines plus spécialement personnels (culture, amour, loisir, religion). Ce droit au privé, jalousement défendu par les individus, peut s'exercer grâce à la dispersion statistique de la ville et des quartiers, car elle diminue la possibilité de contrôle et de visibilité ainsi que la force coercitive d'une idéologie unique. Enfin, le citadin cherche à se guérir du stress de la concentration urbaine en s'échappant dans la nature (seconde

11 Voir VOYÉ, L., La paroisse vue par le sociologue, in La paroisse dans l'Église d'aujourd'hui, Louvain-la-Neuve, 1981. 
résidence, tourisme), notamment durant le week-end. Cette grande mobilité a affecté l'assemblée dominicale qui constituait traditionnellement le relais privilégié de l'assemblée paroissiale.

"Dans le courant des années soixante, la paroisse commence à vaciller sur ses bases. Premier choc: l'urbanisation et les modifications de vie urbaine. La paroisse communautaire, fondée sur l'utopie villageoise, se révèle inadaptée au nouveau genre de vie urbaine." 12

\subsection{Le phénomène de l'industrialisation et de l'urbanisation au Québec}

La deuxième guerre provoque au Québec une forte croissance économique inégalement repartie entre les secteurs de l'économie et entre les régions. L'expansion des activités manufacturières à haute technologie et à forte intensité de capital donne au mouvement d'industrialisation un nouveau rythme et un nouveau visage. L'émergence d'une industrie pétrochimique, l'expansion de l'activité extractive, le boom dans la production du matériel de transport et des appareils électriques renforcent et diversifient la structure de l'économie québécoise.

"Une boutade populaire exprime bien la réaction canadienne devant la guerre: "la guerre nous fait du bien en nous permettant de faire de l'argent". /.../ Une observation approfondie de ce phénomène d'économie fébrile nous apprend cependant que des mutations de fond s'opèrent sur la scène de notre mode de vie. L'urgence de la productivité déplace de façon subite des millions de bras, de la campagne à la ville, du foyer à l'usine, du fonctionnariat au travail industriel, du chomâge au service militaire d'abord libre, plus tard obligatoire. /.../ Il faut parler d'ébranlement décisif de nos comportements traditionnels, pour ne pas dire de mise au banc de tabous héréditaires: la séduction du travail rémunéré rejetant le mythe de notre vocation rurale, le rythme du travail intensif ébranlant les imperméabilités de notre vie familiale, les nécessités de la productivité obligeant à l'acceptation factuelle de la "majorité" des jeunes, les valeurs

12 PERRIN, L., "La paroisse des années soixante, apogée ou déclin: l'exemple Parisien", in Histoire de la paroisse, Actes de la $11^{\circ}$ rencontre d'histoire religieuse, p.208. 
d'efficacité et de techniques lançant un défi aux valeurs classiques de toujours, la solidarité avec les autres peuples évacuant les exclusivismes d'un certain nationalisme." 13

La guerre fait plus que transformer les infrastructures économiques. Elles interrompt le cours normal des choses, remettant en question les us et coutumes, la morale et partant, les institutions qui en découlent. En ce domaine, les transformations sont si brutales qu'elles balaient complètement les efforts de restauration de "l'ordre social". La guerre facilite, de ce fait, l'émancipation des individus: les migrations internes les libèrent de l'emprise des communautés paroissiales; la séparation des ménages, qu'elle soit physique du fait qu'un membre du couple est cantonné dans un autre lieu de résidence ou psychologique du fait des milieux de travail différents, influence la vie familiale. La guerre s'est donc révélée un creuset où se sont forgées de nouvelles attitudes.

Sous une nouvelle poussée d'urbanisation, les assises écologiques d'une chrétienté de type médiéval s'effondrent. La reprise du processus d'industrialisation sécrète de nouvelles agglomérations et engraisse les villes anciennes; la population se concentre à un rythme accéléré. D'autres facteurs, l'amélioration des moyens de transport ${ }^{14}$, l'électrification rurale, l'expansion des mass media, se conjuguent pour conférer à la grande ville une position dominante qui en fait une force culturelle de plus en plus envahissante et irrésistible. Désormais, l'aménagement du territoire s'effectue tout naturellement par l'expansion d'un réseau urbain hiérarchisé et centralisé

13

14 du regard, notre ville est une incitation au déplacement et à la vitesse, et pourquoi ne pas dire qu'elle incline sourdement à inventer des moyens de transport de plus en plus rapides. /.../ On peut dire, dès lors, que la ville moderne fait naître un corps humain qui n'est plus le corps de l'homme médiéval. C'est un corps habité par le désir de se déplacer rapidement, apte à calculer avec le temps à se plier aux exigences rigoureuses d'un horaire, fait tout exprès pour se mouvoir dans le monde rationnel de l'activité technique" (JOLIF, Jean-Yves, La ville, projet humain, in Lumière et Vie, ${ }^{\circ}$ 90, p.92). 
intégrateur des campagnes. Villes et villages perdent graduellement leur autonomie et leur identité au profit des grandes villes. L'oekoumène québécois acquiert la texture d'un tissu urbain et, de Chicoutimi à Gaspé, on commence à ajuster sa montre sur Radio-Canada, heure de Montréal.

C'est tout le territoire québécois qui s'urbanise et, du coup, c'est "l'état de chrétienté" au sein duquel l'Église explicite le projet national et détient la haute main sur les mécanismes de socialisation, qui est menacé dans son existence même. L'urbanisation a comme conséquence de déplacer graduellement du village vers la ville avoisinante et même la grande ville le centre de la vie quotidienne. De communautés vivantes tirant leur cohésion et leur dynamisme de la similitude des genres de vie, des liens de sang et des relations face à face, les paroisses deviennent en moins de vingtcinq ans des créations anémiques sinon artificielles. Jusque-là confinée dans Montréal, la dissolution du tissu paroissial s'étend à tout le Québec. Dans les grandes et petites villes, le volume, la morphologie, les problèmes de la paroisse varient selon les quartiers. Ces paroisses ont en commun d'être de petites sociétés hétérogènes, composées d'éléments dont les occupations diffèrent et dont les préoccupations et les valeurs divergent. L'émergence de milieux de travail, de milieux scolaires, de milieux de loisir en dehors de leurs frontières ouvre les hommes et les femmes au vent du large, substituant au sens paroissial un sens d'appartenance à la cité ou à la région. Des univers sociaux autres que la paroisse sont source d'identité et de comportements. Même les paroisses rurales de plus en plus divisées entre des villageois qui travaillent à la ville et des agriculteurs spécialisés, sont aspirées par ce mouvement d'hétérogénisation.

Le problème est de taille pour l'Église. La solution appelle une révision en profondeur de son mode d'insertion dans le monde, de ses pratiques pastorales, du 
rôles des prêtres, des religieux, des laïcs au sein de l'institution ecclésiale. C'est à partir des anciens schèmes que la Hiérarchie québécoise s'efforce de ranimer la vie paroissiale. Elle applique la solution traditionnelle: la division des paroisses. $15 \mathrm{De}$ 1940 à 1968, l'Église du Québec érige 491 paroisses, soit 181 de 1940 à 1949, 218 de 1950 à 1959 et 92 de 1960 à 1969 . Quelque 73\% des nouvelles paroisses procèdent du mouvement de subdivision des anciennes paroisses. 16

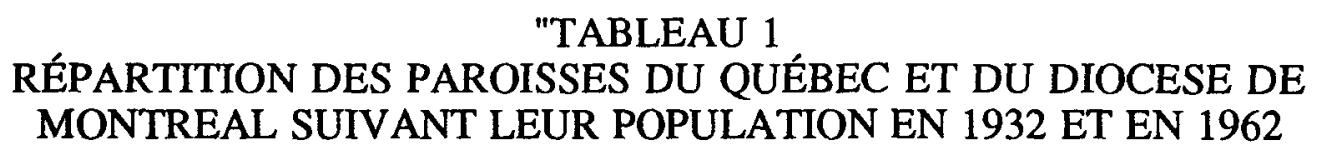

Population

de la paroisse

$1-999$

$1000-2499$

$2500-3999$

$4000-5999$

$6000-8999$

$9000+$
1932

Montréal Le Québec

$23,6 \%$

$33,9 \%$

$11,9 \%$

$9,7 \%$

$7,4 \%$

$12,9 \%$

\section{$39,9 \%$}

$41,7 \%$

$7,8 \%$

$4,1 \%$

$2,9 \%$

$3,0 \%$
1962

Montréal Le Québec

Source: Le Canada ecclésiastique.

$" 17$

Ce tableau permet de constater l'augmentation de la population dans les paroisses entre 1932 et 1962. Par exemple, à Montréal et dans l'ensemble du Québec, le pourcentage des paroisses ayant un population de 4000-5999 a plus que doublé en trente ans.

15

Cette solution est entre autre basée sur la parabole du bon pasteur: "Je connais mes brebis et mes brebis me connaissent." Le curé doit connaître tous ses paroissiens. N'y a-t-il pas derrière cette conception un désir conscient ou insconscient d'un certain contrôle de la vie des gens? Pourtant, dès cette époque, le défi était moins de connaître les "brebis" par leur nom que d'être capable de saisir leurs univers culturels.

Voir HAMELIN, Jean, "Le XX ${ }^{\circ}$ siècle", Histoire du catholicisme québécois, tome 2, De 1940 à nos jours, Montréal, Boréal Express, 1984, p.56 
Les données statistiques plus récentes sont intéressantes à analyser. Elles montrent le nombre important de paroisses au Québec et surtout l'augmentation considérable des paroisses de plus de 9,000 habitants. On compte beaucoup de paroisses au Québec. Il est vrai qu'il y a plusieurs municipalités rurales dans notre coin de pays. Mais, le nombre considérable des paroisses s'explique par le fait que les autorités ecclésiales ont divisé le milieu urbain en petites paroisses sur le modèle rural.

"TABLEAU 17

La répartition des paroisses du Québec selon le nombre de paroissiens

\begin{tabular}{llll} 
& Classes & Nombre de paroisses & Pourcentage \\
\hline 1 & {$[1-999]$} & 627 & $33,1 \%$ \\
2 & {$[1000-2999]$} & 571 & $30,2 \%$ \\
3 & {$[3000-4999]$} & 292 & $15,4 \%$ \\
4 & {$[5000-6999]$} & 192 & $10,1 \%$ \\
5 & {$[7000-8999]$} & 90 & $4,8 \%$ \\
6 & {$[9000-10999]$} & 41 & $2,2 \%$ \\
7 & {$[11000$ et plus] } & 80 & $4,2 \%$
\end{tabular}

En analysant ce tableau, nous constatons deux types de paroisses au Québec: les paroisses de petite taille (ayant une population allant de 0 à 2999 personnes) et les paroisses populeuses ( 9000 personnes et plus). Nous pouvons attacher une importance au fait que le nombre moyen de paroissiens dans chacune des 1894 paroisses du Québec est de 3103 catholiques. Mais, la considération des écarts est autrement plus intéressante que la seule observation de la moyenne. Nous constatons que 63,3\% des paroisses du Québec ont une population inférieure ou égale à 2999 catholiques. Toutefois, entre 1962 et 1990 (voir tableau \#1 et \#17), le nombre de

LEVASSEUR, Jean-Marie, TURMEL, André, L'évaluation pastorale au Québec, Les pratiques évaluatives en usage dans les paroisses catholiques du Québec, L'enquête, TroisRivières, Pastor, 1992, p. 62. Ces auteurs ont recueilli ces données dans l'Annuaire de l'Église catholique au Canada (1990). Voir aussi ROUTHIER, Gilles, La réception de Vatican II dans une Église locale, L'exemple de la pratique synodale au Diocèse de Québec (1982-1987), Université de Paris-Sorbonne (Paris IV), 1991, T.IV, pp. 1079-1080 et pp. 1095-1110. 
paroisses de plus de 9000 habitants a doublé au Québec. Nous sommes passés de $3,0 \%$ à $6,4 \%$ des paroisses québécoises. Les paroisses très populeuses (9000 et plus) se retrouvent essentiellement en banlieue: diocèse de St-Jérôme et de St-Jean Longueuil et une partie dans un secteur du diocèse de Québec et de Montréal (banlieue urbaine). À titre d'exemple, 48 des 80 paroisses (59,3\% du nombre total des paroisses de cette dimension) du Québec qui comptent une population catholique égale ou supérieure à 11000 personnes se situent dans les diocèses de St-Jean Longueuil (15), de St-Jérôme (8) ou de Montréal (33). ${ }^{19} \mathrm{Si}$ l'on ajoute à cela le fait que le diocèse de Québec compte 19 paroisses de cette taille $(23,3 \%)^{20}$, il reste 13 paroisses dans les autres Églises locales de l'ensemble du Québec comptant plus de 11000 fidèles. Dans le diocèse de Chicoutimi, deux paroisses sont de cet ordre et trois autres, de plus de 8000 habitants. 21

"TABLEAU 18

Vue d'ensemble de la répartition des paroisses du Québec selon les diocèses

\begin{tabular}{lllllll} 
Groupes & $\begin{array}{l}\text { Concentration/ } \\
\text { Classe }\end{array}$ & $\begin{array}{l}\text { Nombre de } \\
\text { paroisse }\end{array}$ & $\begin{array}{l}\text { Population } \\
\text { cath. totale }\end{array}$ & $\begin{array}{l}\% \\
\text { Pop }\end{array}$ & $\begin{array}{l}\text { Moyenne/ } \\
\text { paroisse }\end{array}$ & $\begin{array}{l}\text { Médiane/ } \\
\text { paroisse }\end{array}$ \\
\hline 11 diocèses & $1-999$ & 757 & 1336688 & 22,7 & 1766 & 890 \\
6 diocèses & $1000-2999$ & 698 & 2238570 & 38,1 & 3207 & 2088 \\
3 diocèses & & 439 & 2300876 & 39,2 & 5241 & 4400 \\
Montréal & $1000-2999$ & & & & & 4400 \\
St-Jérôme & $3000-4999$ & & & & & 4030 \\
St-Jean & $5000-6999$ & & & & & 4900
\end{tabular}

LEVASSEUR, Jean-Marie, TURMEL, André, L'évaluation pastorale au Québec, 
Ces données nous mettent en présence de ce fait significatif: dans plus de la moitié des diocèses du Québec (11 sur 20), la majorité des paroisses se situent dans la catégorie de paroisses comptant 999 personnes ou moins. À l'opposé, à eux seuls, quatre diocèses regroupent la grande majorité des paroisses très populeuses (11000 personnes ou plus). Bien plus, ces quatre diocèses (Québec, Montréal, St-Jérôme et St-Jean-Longueuil) comprennent 155 paroisses regroupant une population égale ou supérieure à 7000 catholiques, soit 73\% des paroisses de cette catégorie au Québec.

Cependant, même après plusieurs années de bouleversements occasionnés par le phénomène de l'industrialisation et de l'urbanisation au Québec, une mentalité pré-industrielle prédomine encore dans la population canadienne-française. C'est ce que croit M. Guy ROCHAIS, sociologue québécois à qui une communicatrice scientifique, Danielle OUELLET, a récemment posé la question.

-"Q:En 1976, vous remarquez la prévalence d'une mentalité préindustrielle dans une société industrielle. R:La Révolution tranquille s'est "tranquillisée" trop rapidement! C'est ce que je disais à l'époque et je le pense encore aujourd'hui. Je croyais alors que nous étions passés à la mentalité industrielle, mais je suis peut-être allé trop vite. Je me demande si la mentalité préindustrielle ne perdure pas. /.../ Au fond, le rythme d'évolution d'une mentalité n'est pas égal à celui des législations ou des structures. Les changements de mentalité sont plus lents. Ils s'échelonnent sur deux ou trois générations. /.../ Que nous en prenions trois pour sortir de la mentalité pré-industrielle n'a rien d'étonnant. Il faut laisser agir le temps." 23 society", in Forces "1967-1992: Vingt-cinq ans d'évolution du Québec", numéro 100, Hiver 19921993, p. 18. Voir aussi ROCHER, Guy, Le Québec en mutation, Montréal, Hurtubise, 1973.

"Pour la hiérarchie ecclésiastique, ce ne sont pas les individus dans la société - comme le pensait l'idéologie bourgeoise - mais la famille rurale de la société pré-industrielle de l'Ancien Régime qui est considérée comme la cellule mère de toute la sociéte" (SCHILLEBEECKX, Edward, L'histoire des hommes, récit de Dieu, Paris, Cerf, 1992, p. 307. [ Cogitatio fidei \#166] ). 


\subsection{La paroisse québécoise marquée par le milieu rural}

Quand on parlait de la paroisse canadienne-française, il y a encore quelques années, c'était pour en souligner la force et l'efficacité comme cellule d'Église et cellule de la société. On ne s'attardait pas d'ailleurs, à établir de subtiles distinctions sur le rôle de la paroisse tellement la paroisse paraissait intégrée à la société et la société à la paroisse. Il y avait réellement coexistence de la communauté humaine et de la communauté paroissiale. Dans la nomenclature des oeuvres paroissiales entraient tout aussi bien un syndicat agricole, une coopérative, qu'une association pieuse. Eh bien, ce type de paroisse aura pratiquement disparu en moins d'une génération. Le phénomène qui s'est produit et qui n'est pas absolument particulier au Canada français, est complexe: nous sommes passés d'une civilisation de type rural à une civilisation de type urbain. ${ }^{24}$ La paroisse a vu se transformer rapidement autour d'elle tout l'ensemble des conditions socio-économiques. Soumise aux déterminants d'une longue tradition rurale, elle cherche encore avec anxiété sa voie dans un univers industrialisé et urbanisé.

La campagne, c'était des villages assez semblables les uns aux autres chacun constituant une petite agglomération relativement isolée et fermée sur elle-même, coiffée d'un curé et de quelques notables et regroupant des familles d'habitants cultivateurs ou défricheurs. Ce modèle faisait de la paroisse une institution englobante qui devait circonscrire et finaliser la totalité de la vie d'un groupe donné de "fídèles". II présupposait l'homogénéité religieuse d'une population et aussi son homogénéité sociale et professionnelle. Pour qu'il y ait communication réelle entre les prêtres et les paroissiens, il fallait que non seulement ces derniers soient tous croyants mais qu'ils le 
soient de la même façon, qu'ils possèdent des attitudes et des habitudes de vie semblables. Ce modèle traditionnel est encore tout près de nous. Cette expérience a été pour nous assez longue et très intense. De fait, ce modèle continue encore aujourd'hui à inspirer la création et la gestion de nos paroisses, alors que nos milieux sont déjà, de plusieurs façons, envahis et pénétrés par la civilisation industrielle et urbaine.

La paroisse au Canada français a été profondément marquée par le milieu rural de naguère. Elle était fondée avant tout sur la similitude des conditions: les occupations étaient peu diversifiées, l'éventail même des relations sociales était restreint (se réduisant, pour la plus grande part, à des relations de voisinage et de parenté). Parmi les leaders, eux-mêmes en petit nombre, le curé occupait une place privilégiée non seulement par l'amplitude des pouvoirs qui lui étaient reconnus, mais aussi par l'importance de son rôle comme définiteur et comme gardien des modèles collectifs de conduite. Dans un pareil contexte, on peut parler d'une sorte de parenté naturelle entre la réalité sociologique et la communauté surnaturelle. Les villages sont vraiment des communautés humaines: on y naît, on s'y marie, on y loge, on y travaille et l'on y meurt. Dans les limites de son territoire se déroule la quasi-totalité des activités de ses membres: activités politiques, familiales, récréatives, éducatives, religieuses et économiques. Les habitants trouvent aussi sur place tous les services dont ils ont besoin. Le contact avec l'extérieur n'est assuré que par un petit nombre de notables. La paroisse rurale était donc le lien intégrateur de la communauté: communauté locale (village) et paroisse étaient si intimement unies que la distinction entre elles n'est souvent que de raison.

Le village qui est l'unité sociale de base est d'abord une unité territoriale de dimensions réduites, c'est-à-dire que tout le monde est capable de connaître tout le monde. La population y trouve la plupart du temps travail, résidences et loisirs. Si 
quelqu'un n'agit pas selon les normes établies, il suffit qu'une personne s'en aperçoive pour que tout le monde le sache. Dans les villages, les agriculteurs constituent la très grosse majorité de la population active. Toute l'organisation sociale de cette communauté humaine est influencée par la mentalité paysanne du temps. Or cette mentalité est autarcique. Chaque ferme pratiquant une économie de subsistance se suffit normalement à elle-même. L'unité sociale de base est la famille qui forme un groupe uni et polarisé par des tâches communes sous l'autorité de son chef. La paroisse rurale est calquée sur le même modèle. Fermée sur elle-même, elle est perçue par ses membres comme une "grande famille" (le mot d'ailleurs est largement utilisé encore aujourd'hui). L'église et son clocher sont le centre véritable de cette société où la communauté de culture et de croyances traduites par des comportements traditionnels collectifs marque un accord profond sur les valeurs fondamentales de la vie. En dépit des nuances secondaires qu'il faudrait apporter à ce tableau de la paroisse rurale d'autrefois, on est en droit d'affirmer que le milieu constituait un univers social profondément cohérent. Dans pareille situation quand un élément important de l'ensemble change, tout le reste de l'édifice socio-religieux en subit les conséquences.

\subsection{L'évolution du milieu rural au Québec}

Au Canada français, on a cru pendant longtemps que la crise de la paroisse ne concernait que le milieu urbain. Sans doute l'accroissement démographique très considérable de nos villes et les changements socio-économiques qu'elles ont connus justifiaient largement la nécessité d'une pastorale pour adapter la vie chrétienne de la communauté paroissiale à une situation nouvelle. Mais l'attention ainsi accordée à la paroisse urbaine a certainement trop fait perdre de vue que le milieu 
rural, lui aussi, était en évolution. 25 D'autant plus que l'expression "paroisse rurale" est actuellement ambigüe, tout au moins si on pense aux groupes humains auxquels elle fait référence. Dire que la paroisse rurale du Québec s'identifie territorialement à une municipalité administrative n'est plus vrai aujourd'hui dans plusieurs situations et nous conduit à devoir également tenir compte des multiples réalités culturelles et socio-économiques concrétisées par ces termes. Pour être honnête, il faut distinguer des types ou des catégories de paroisses rurales selon la dimension démographique, les fonctions économiques, la situation géographique par rapport à la ville, petite ou grande. Tout ceci n'est pas sans importance pour la compréhension des attitudes et des conduites religieuses des paroissiens résidants. Mais, au delà de ces différences, l'observation note un point commun, une caractéristique sociologique valable pour le monde rural dans sa totalité: le milieu rural connaît depuis quelques années des changements très profonds, on pourrait parler de révolution socio-économique, dans sa structure et dans sa mentalité.

Depuis plusieurs années, grâce aux facilités de communication, les ruraux ont pris l'habitude de sortir de leur milieu immédiat. Le centre de la vie quotidienne n'est plus le village mais la petite ville avoisinante et parfois même la grande ville plus éloignée. Cela est vrai à différents points de vue: plusieurs ruraux vont à la ville pour y travailler; de plus, les activités économiques et commerciales sont maintenant concentrées dans la ville. Cette dernière acquiert ainsi une force d'attraction sociale pour tous les villages situés dans un rayon de quelques milles. On pourrait enfin souligner le rôle tenu par la régionalisation scolaire dans l'élargissement, voire dans l'éclatement de la communauté paroissiale rurale.

25

Voir MONTMINY, Jean-Paul, "Repenser la pastorale des milieux ruraux", in Communauté chrétienne, $\mathrm{n}^{\circ} 24$, vol. 4 nov.- déc. 1965, pp.490-499. Voir aussi PELCHAT, Marc, "Le monde rural", in Situation et avenir du catholicisme québécois - milieux et témoignages, Ottawa, Leméac, 1982, pp.13-42. 
La continuelle circulation des ruraux entre leurs milieux d'habitation et les centres régionaux a eu pour conséquence principale de provoquer des modifications profondes dans la mentalité et les comportements tant sociaux que religieux du monde rural. Il est évident que depuis quelques années ce dernier ne présente plus le caractère de cohérence et d'homogénéité qui, autrefois, le marquait. Comme le milieu urbain, le milieu rural est maintenant devenu pluraliste. Aujourd'hui déjà, et demain davantage,

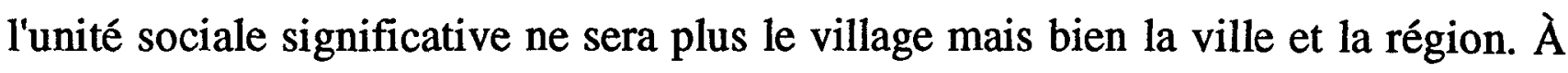
l'analyse, le visage de l'actuel monde rural nous apparaît radicalement nouveau. La cohérence sociale d'autrefois est maintenant et à jamais révolue, il faudra en rechercher une nouvelle qui tiendra compte des modifications subies par le milieu rural. Il en va de même, c'est évident pour la pastorale. Face à une situation nouvelle, il faut plutôt s'interroger et préparer des réponses pastorales, nouvelles elles aussi. 26

\subsection{La paroisse en contexte urbain}

Lieu de marché et de commerce, lieu de circulation et de concentration intense des choses et des humains, lieu d'échanges rapides des idées et de l'information, lieu de spectacles et de fêtes, lieu de proximité et de distance, la ville donne au temps et à l'espace une autre dimension. Les gens y développent une autre façon de vivre. 27 


\subsubsection{Différents types de villes}

En 1965, la population du Québec était urbaine dans une proportion de plus de soixante-quinze pour cent. ${ }^{28}$ Même s'il arrive souvent de généraliser au sujet de nos villes, il ne faudrait cependant pas oublier que celles-ci ne sont pas toutes de même type. Elles ne sont pas toutes également urbaines. Être "urbaine", pour une agglomération ou pour la population qui l'habite, n'est pas seulement une question de volume ou de densité de population. C'est aussi une question d'hétérogénéité et de complexité sociales. C'est encore davantage une question de mentalité. Nos villes diffèrent les unes des autres selon leur degré de proximité psychologique comme aussi selon la région ou le type d'industrie qui les ont fait naître. La ville de Chicoutimi est différente de celle de Québec et il en va de même pour la métropole de Montréal. Il ne faut donc jamais oublier cette grande diversité de situations existant entre les villes et qui résulte à la fois de leur évolution historique, de leur développement géographique, économique et démographique, de leur situation religieuse, etc.

\subsubsection{Diversités de paroisses urbaines}

Toute ville est un milieu dynamique. Ses fonctions économiques et industrielles ont attiré au Québec à une cadence plus ou moins vive, des populations nouvelles venant soit des milieux ruraux, soit d'autres villes, soit de l'étranger. Son espace social s'est dilaté, s'est diversifié, s'est compartimenté. Depuis la deuxième guerre mondiale surtout, plusieurs de nos villes ont absorbé des contingents successifs d'immigrants (particulièrement à Montréal) qui, reproduisant un phénomène bien demain", in Communauté chrétienne, $\mathrm{n}^{\circ}$ 24, vol. 4, nov.-déc. 1965, p. 482. Voir aussi REMY,J; HIERNAUX, J.P. et SERVAIS, E., "Le phénomène paroissial aujourd'hui-éléments pour une interrogation sociologique", in Lumière et Vie ,\#123, pp. 25-36. 
connu dans les villes d'Amérique, se sont respectivement regroupés en des îlots ethniques ou culturels. Nous avons vu, pour répondre aux besoins religieux de ces groupes, se former, au dessus des paroisses territoriales existantes, des paroisses nationales ou linguistiques. 29 Sur une même étendue de territoire urbain, se sont superposées plusieurs étages de communautés paroissiales différentes les unes des autres. À cette hétérogénéité ethnique, s'est entremêlée la compartimentation du territoire urbain en zones économico-sociales, identifiées chacune par des fonctions ou par des classes particulières de population. Les paroisses se sont inscrites dans ces zones et elles en ont acquis un certain degré ou de prestige ou de déconsidération sociale. Les paroisses urbaines sont socialement évaluées: certaines sont des paroisses huppées, des paroisses bourgeoises, des paroisses de fonctionnaires, des paroisses "ouvrières", des paroisses de déshérités... Mais aucune portion du territoire d'une ville ne conserve longtemps un unique caractère. Les populations d'aujourd'hui se déplacent, de quartier en quartier. La paroisse urbaine a désormais davantage sur son territoire de paroissiens temporaires que de paroissiens permanents.

\subsubsection{L'intérêt du citadin dépasse les limites territoriales de la paroisse}

Si l'on compare la paroisse urbaine à la paroisse rurale, la première différence est que l'unité de voisinage ou le quartier de ville auxquels correspondent plus ou moins les unités administratives paroissiales ne sont pas les communautés

La société religieuse a réussi à créer pour les citadins des enclaves protectrices, des communautés de substitution qui ont accueilli l'immigrant et l'ont ensuite encadré en lui fournissant un milieu, une protection, des coutumes. Ces communautés de substitution se sont montrées particulièrement opérantes lorsqu'elles ont su, spontanément ou sous la pression des circonstances, se muer en centres de formation à la fois culturelle et religieuse. Il semble que cela ait été largement le cas aux États-Unis où les paroisses nationales tout à la fois recevaient les immigrants, les introduisaient à la civilisation américaine et les formaient aux exigences religieuses de la vie industrielle et urbaine. Ici, au Québec, c'est surtout à Montréal, que nous retrouvons des paroisses nationales. Elles posent question à plusieurs intervenants pastoraux. Ces paroisses aident-elles vraiment les immigrants à mieux s'intégrer dans la société québécoise ou ne les encouragent-elles pas plutôt à vivre davantage en ghetto? Question complexe... 
locales. Les familles qui habitent dans un même quartier n'ont guère plus d'intérêts communs entre elles qu'entre les habitants du reste de la ville. La plupart de leurs activités se déroulent sur des théâtres géographiques divers dont le dénominateur commun spatial est la ville. Le bureau, les associations politiques ou syndicales, les cinémas ou les clubs sportifs, les écoles et les associations culturelles, les commerces spécialisés et les services publics, les connaissances ou les amis ne sont pas tous regroupés dans un seul et même quartier, mais sont établis dans les coins les plus divers de l'agglomération urbaine. L'unité de voisinage n'offre en son périmètre que quelques intérêts limités: l'école primaire, les commerces quotidiens, etc. Ces quelques intérêts communs peuvent conserver à certains quartiers un élément de vie communautaire, mais ils sont insuffisants pour constituer une communauté locale. $\mathrm{Au}$ delà du cercle familial, centre d'attraction pour des amis provenant eux-mêmes de toute la ville ou d'ailleurs, l'intérêt des citadins se porte sur la ville entière et sur les diverses organisations et services spécialisés dispersés sur son territoire. Ce n'est pas en restant chez eux mais en se déplaçant vers les divers centres de la vie citadine qu'ils peuvent s'intégrer socialement.

\subsubsection{La paroisse urbaine, plus une association qu'une communauté? 30}

Dans les zones urbaines où le sens du voisinage à base géographique a largement disparu, la paroisse est devenue une association de type secondaire,

"En sociologie, le terme "communauté" a été introduit en Allemagne au XIX ${ }^{\circ}$ siècle par Torries, qui l'oppose au terme "association". Pour lui, l'association est un groupe construit délibérément, en vue d'un objectif à atteindre qui normalement est clairement prédéterminé /.../ La communauté implique une appartenance s'imposant à cause de l'intensité affective du lieu et aboutissant à une solidarité diffuse. Dans ce sens, la communauté était la forme prédominante de vie sociale dans une société simple, tandis que les associations prennent des significations et des fonctions croissantes dans les sociétés complexes"(HOUTART, F., RÉMY, J, Milieu urbain et communauté chrétienne, p. 365). Cette distinction sociologique demeure éclairante mais nettement insuffisante pour définir le concept de communauté. Il faut obligatoirement considérer l'éclairage de d'autres sciences humaines pour enrichir la notion de communauté. 
associationnel de structure social. 31 À la totalité immédiate et affective des relations humaines se sont substituées des relations humaines impersonnelles et fonctionnelles reliant entre eux les acteurs urbains par des séries de rôles spécialisés n'interférant guère les uns avec les autres. La paroisse urbaine d'aujourd'hui tend à devenir un organisme spécialisé parmi d'autres: sa spécialisation étant nettement religieuse. L'activité religieuse devient une activité spécialisée, se réduisant aux rites hebdomadaires, annuels, ou familiaux, mais n'interférant pas, directement du moins, avec les autres activités.

La paroisse n'est plus l'agence socio-culturelle dans la vie des habitants. L'individualisation ou l'atomisation de la vie sociale urbaine s'est étendue à la paroisse urbaine de telle sorte que le concept démodé de la paroisse comme une grande et heureuse famille a disparu.

\begin{abstract}
"Dans la mesure où les responsables de la paroisse conservent devant eux l'image d'une paroisse 'grande famille', lieu d'exercice effectif de toutes les activités des 'paroissiens' , la 'fuite' de leurs paroissiens vers les multiples associations et organisations qui, situées hors du territoire paroissial sont le siège de la plupart des activités des citadins, leur cause une irritante frustration analogue à celle de la mère qui, restée au foyer, voit ses enfants devenues grands s'échapper de plus en plus souvent du domicile familial pour des activités inconnues en compagnie d'inconnus". 32
\end{abstract}

Cette individualisation fait que seuls ceux qui sont intimement convaincus s'identifient à la paroisse et participent à ses activités. Dans les grandes villes, la religion, dégagée

"Associations: elles sont des créations de la raison et de la volonté humaines. À la différence des communautés, elles ont un but défini, spécifique. Elles existent au sein des communautés. Quelqu'un sait pourquoi il appartient à une association. Il peut y entrer et en sortir. Chaque association, parce que limitée dans son but et ses moyens, ne peut étendre son contrôle sur la personne totale, mais au seul rôle spécifique que la personne joue dans l'association" (CARRIER, Henri, PIN, Émile, Essais de sociologie religieuse, p.491).

32

Ibid, pp. 465-466.

"Ceci nous démontre aussi le concept de paroisse communautaire,- la paroisse comme groupe primaire ou comme une grande famille est démodé dans la société actuelle" (FICHTER, Joseph, "La paroisse urbaine comme groupe social", in Paroisses urbaines, Paroisses rurales, $5^{\circ}$ conférence internationale de sociologie religieuse, Paris, Caterman, 1958, p.94). 
de la coutume et des pressions sociales, devient chose personnelle, affaire de conviction et de volonté propres, de liberté. La paroisse n'est plus qu'une agence privée à l'intérieur de la ville.

Un phénomène comme celui de la spécialisation a envahi aussi le monde religieux. Aucune institution d'Église ne peut prétendre à une polyvalence capable de satisfaire les principaux besoins. Comme dans la société, on assiste à une prolifération des organismes et des mouvements divers. En milieu urbain, les chrétiens les plus actifs appartiennent à des groupes religieux divers tant par leur objectif que par leur localisation géographique. Cette appartenance groupale religieuse ne se réalise plus uniquement autour de l'institution paroissiale. Des chrétiens participent à un type d'activités religieuses dans une paroisse et peut-être à un autre dans une autre paroisse ou ailleurs.

\subsubsection{La liberté, une valeur importante pour le citadin}

La ville favorise le choix, la liberté: on choisit le lieu de ses services sans égard à leur localisation territoriale. La ville fait éclater le voisinage comme lieu privilégié de socialisation. Elle favorise une multiplicité des services et une multiplication de canaux d'appartenance à l'Église. Souvent, au centre de la ville, les églises sont si proches les unes des autres que le citadin peut choisir son lieu de culte en fonction de ses commodités personnelles, parce que "l'homme de la ville refuse toute institution qui désirerait contrôler l'ensemble de sa vie."33 "Jamais les hommes n'ont eu comme aujourd'hui un sens aussi vif de la liberté." 34 La recherche de liberté, chez l'urbain, se traduira par le choix de ses relations, de ses groupes d'appartenance, vivante en paroisse",, p. 25.

$34 \quad$ Vatican II, Gaudium et Spes, $\mathrm{n}^{\circ} 4,4$ 
de sa messe dominicale 35 , de la paroisse et même de tel prêtre plutôt que de tel autre. Cette simple donnée en appelle d'autres, par exemple, celles des nouvelles formes d'influence plus attachées aux groupes choisis.

\subsubsection{Une dévalorisation des relations de voisinage causée par la mobilité}

La mobilité constitue une des caractéristiques de la vie urbaine actuelle. Elle revêt des formes très diverses: migrations rurales-urbaines, migration internes dans les villes. Il faut se garder de porter un jugement défavorable sur cette forme de mobilité car elle est une des expressions de la vie urbaine. 36 Le perfectionnement des moyens de transport a engendré aussi un autre type de mobilité urbaine: la mobilité journalière qui englobe tous les déplacements nécessaires pour se rendre à sa résidence, à son travail, à ses loisirs, etc. Finalement, une dernière forme de mobilité, la mobilité saisonnière (mobilité de vacances ou de week-end), a pris une importance de plus en plus considérable dans les villes. Ces différentes formes de mobilité n'ont pas été sans conséquences. Alors qu'autrefois le territoire représentait un des éléments constitutifs fondamentaux des groupes sociaux, il a perdu son importance pour l'ensemble de la population. Auparavant si la personne s'intégrait au niveau du village auquel elle vivait, la seule intégration maintenant possible pour une personne vraiment urbaine est une intégration à la vie urbaine dans son ensemble laquelle se fera à travers une multiplicité de groupes.

"En ville, même, la personne est constitué par un faisceau d'appartenances et non plus par une seule. L'individu n'appartient plus à la communauté directement, mais par la médiation de toutes ces associations spécialisées qui s'offrent à son choix.Un grand choix

Que l'on pense ici aux difficultés qui proviennent du fait de la mobilité de la société moderne, de l'étalement des heures de travail, des équipes de nuit, des travaux saisonniers, de la semaine de travail ininterrompu, etc..

36 Je trouve important de dire cela puisque la vie religieuse, notamment du catholicisme, a été conçue et organisée jusqu'à présent pour répondre à une situation géographique fixe, au point que parfois, encore aujourd'hui, la mobilité des gens est considérée par plusieurs intervenants pastoraux comme un mal, comme un mal social et même religieux. 
de partis politiques, un choix plus restreint, mais encore réel, de syndicats, de sociétés culturelles, de sociétés sportives, font qu'il est délié; il est devenu indépendant."37

Le quartier de résidence n'est plus l'endroit où l'on travaille ni même celui où l'on passe ses loisirs, les voisins ne sont plus les camarades de travail et généralement, non plus les compagnons de détente. La personne relève d'influences diverses qui ne se compénètrent plus. Bref, elle cesse d'être encadrée par un groupe totalisant, acquiert une autonomie nouvelle que l'être humain urbain va essayer d'accroître de diverses manières en construisant un univers social particulier.

Cette volonté de vivre dans un cadre qui préserve l'autonomie de chacun est encore renforcée par les préférences marquées vis-à-vis certaines formes de relations sociales. On constate une dévalorisation des relations de voisinage que l'on réduit à des relations rapides (se saluer, se parler dans la rue). Cette attitude n'est pas nécessairement une réaction d'individualisme, mais plutôt un réflexe d'autonomie. On désire multiplier ses relations intimes avec des personnes autres que les voisins immédiats qui pourraient devenir trop aisément des contrôleurs des allées et venues. Créer à cet endroit une zone de non attention aux autres est une garantie d'autonomie qui permet au logement de devenir un certain isoloir où se vit lintimité de la vie familiale.

"N'est-ce pas le seul endroit dans la vie moderne où on peut garder un minimum d'intimité, de primauté, d'autonomie; d'où cette crainte d'être envahi par des voisins importuns, et cela à tout moment. L'urbain doit accepter beaucoup de relations qui lui sont imposées dans les autres institutions. Quand il revient chez lui, il a soif de liberté personnelle d'autant plus que sur d'autres plans le critère "choix" est prévalent: choix de loisirs, choix de ses sources d'approfondissement, etc. Il tient à sélectionner ses amis et il ira plus facilement à ceux qui ont le même statut social, les mêmes goûts et habitudes, les mêmes modèles de comportement." 38 
Les relations personnelles ne pouvant plus jouer le même rôle qu'au village pour assurer l'unité et la continuité de la vie sociale, l'intégration de la société se fait à travers des mécanismes nouveaux qui sont compatibles avec une grande diversité interne et la sauvegarde d'un haut degré d'autonomie de l'individu. Une fois adapté à la mentalité urbaine, l'individu ne veut plus donc d'un groupe totalisant.

\subsubsection{La solution des Caisses populaires Desjardins: un exemple à suivre?}

Dans le cadre de leur congrès annuel de 1965, la Fédération des Caisses populaires Desjardins a demandé une enquête à l'échelle de la province de Québec pour remettre en question son opération majoritairement sur cette assise qu'est la base paroissiale. ${ }^{39} \mathrm{Au}$ moment où l'on cherche depuis plusieurs années la vocation de la paroisse dans le contexte urbain, il est intéressant de voir que des personnes "séculières" ont posé le questionnement bien avant plusieurs intervenants pastoraux.

Les chercheurs de la Fédération ont essayé de mieux saisir dans ses dynamismes le réseau mobile des relations entre le milieu résidentiel et le milieu de travail, entre les diverses formes d'appartenance: parenté, voisinage, paroisse, associations et endroits de travail. Ils ont accordé une attention particulière à ceux qu'ils appellent les "paroissiaux". Une caisse paroissiale a-t-elle plus de chance de rejoindre les gens qu'une caisse organisée dans un milieu de travail? Le facteur résidentiel est-il plus déterminant que celui du travail? Une première constatation de l'étude: les activités économiques se déplacent en dehors de la paroisse. Une deuxième remarque de l'enquête se formule comme suit: le milieu de travail a de plus en plus d'importance.

39 Voir FORTIN, G., Évolution de notre société, conférence aux congressistes des caisses pupulaires, juin 1965. Document non publié. 
Comme on le répète dans l'enquête, l'évolution de notre société actuelle est très liée aux changements économiques. Ceux-ci amènent la mobilité géographique, la mobilité sociale, culturelle et professionnelle. C'est dans le milieu de travail que les décisions vitales se prennent, que les éléments dynamiques des changements sociaux sont en oeuvre. Le pôle résidentiel conserve plus longtemps des résidus folkloriques et une influence religieuse. Il est plus conservateur, moins dynamique, plus attaché à la tradition. On a aussi constaté à cette époque que les activités se déplacent de plus en plus de la paroisse à la région et que les solutions commandent aussi une action de type régional. Les facteurs qui créent les pôles d'attraction de la population ont changé. Ceux-ci sont compris par une vision d'ensemble du contexte social global qui déborde les limites souvent arbitraires de la paroisse. Les secteurs homogènes se déplacent, se défont, tel quartier se prolétarise, tel autre devient de plus en plus diversifié. Parfois un plan d'habitation vient changer tout le visage de la paroisse.

La Fédération des Caisses Populaires Desjardins de l'ensemble du Québec a donné rapidement des suites tangibles à ce congrès. Elle a autorisé dans le milieu urbain la construction de caisses populaires en relativisant beaucoup l'importance territoriale des paroisses urbaines. Elle a construit des lieux de service dans les milieux de travail, dans les centres commerciaux et dans d'autres endroits où les gens s'identifiaient davantage. L'Église du Québec n'a pas été aussi rapide dans la remise en question de la territorialité de la paroisse dans le milieu urbain.

"Le pôle travail est plus dynamique que le pôle résidence. Le premier charrie des enjeux socio-économiques et politiques qui conditionnent ceux du milieu résidentiel plus conservateur, plus passif, plus dépendant. Or l'évangélisation chez les permanents de l'Église est conçue en fonction du second rôle. Dans le monde rural, résidence et travail ne font qu'un. L'univers urbain les a dissociés, mais la pastorale n'a pas tellement assumé 
cette mutation. D'où l'absence ecclésiale dans les secteurs les plus dynamiques de la vie collective. 40

\subsection{Le manichéisme urbain-rural}

La ville et la campagne sont des concepts sociologiques, mais ce sont aussi des catégories traditionnelles pour désigner une situation morale de l'être humain, le lieu de son bonheur ou de sa dégradation. La ville et la campagne ont connu des chantres qui les ont exaltées et des misanthropes qui en ont dénoncé les moindres travers. Pour les uns, la ville est une Babel, une Babylone où se développent le sensualisme, l'anarchisme, les déséquilibres familiaux, l'indifférence religieuse, alors que la campagne favorise une vie saine, naturelle et plus humaine. Pour d'autres, la cité est le foyer par excellence de culture, de progrès, de socialisation, de liberté créatrice et épanouissante et ils ont un mépris non déguisé pour cette mentalité rurale qu'ils identifient à l'étroitesse, au conservatisme, à l'esprit de clan, à la platitude, etc. En effet, beaucoup de sociologues ont centré leur observation de la société autour de deux pôles de comparaison: le milieu rural d'autrefois et le monde urbain d'aujourd'hui. Pour cette raison de nature psycho-culturelle, les concepts de ville et de campagne sont chargés d'affectivité et porteurs de valeurs. le congrès des Caisses Populaires en 1965, le sociologue Fernand DUMONT avait déjà interpellé les autorités ecclésiales sur l'importance de remettre en question l'institution paroissiale dans le contexte urbain. "Personne ne saurait le contester: l'institution paroissiale vit présentement une crise très aiguë I.../ Quoi qu'il en soit, nous vivons dorénavant dans un milieu social très diversifié, les mécanismes anonymes de communication ont remplacé pour une large part les anciennes relations personnelles. I... ... il faudra que nos pasteurs abandonnent décidément l'image de ce que j'appellerais "la paroissesynthèse". La paroisse de naguère a laissé bien des séquelles dans nos esprits." (DUMONT, Fernand, "La paroisse, une communauté", in Communauté chrétienne, vol. $1, \mathrm{n}^{\circ} 1$, janvier-février 1962, p. 21; p.27.) 
Il est important de soumettre la dichotomie ville-village à un essai de critique et d'interprétation sociologique. Deux courants typiques seront analysés tout d'abord: l'un de pessimisme, l'autre d'admiration, à l'égard de la ville; ils seront confrontés par la suite. Nous constaterons finalement que le manichéisme inhérent à l'antithèse villecampagne tend depuis quelques années à perdre de sa virulence devant le phénomène de l'urbanisation omniprésente.

\subsubsection{Le pessimisme urbain}

Les sociologues urbains estiment que la ville aurait environ cinq mille ans d'existence mais l'aversion des humains pour la vie urbaine remonte à des temps immémoriaux. La raison la plus communément avancée par les pessimistes est que la ville est une création artificielle opposée à la véritable vocation de l'homme et à son bonheur. Le poète anglais William COWPER (1731-1800) exprimait parfaitement ce réflexe par le vers suivant: "God made the country and man made the town" 41 . Le mépris et la condamnation de la ville sont vieux comme l'être humain. La première ville mentionnée dans la Bible est Hénok. La ville d'Hénok était une fondation de Caïn, le fils maudit (Gn 4:17). La bénédiction de Dieu était réservée non aux constructeurs de la ville, mais à Abel et à ses descendants, c'est-à-dire aux pasteurs fidèles, qui cultivaient les fruits de la terre ou restaient nomades et libres pour répondre à leur vocation. La ville détruit l'humain, l'exploite, le corrompt physiquement et moralement. L'agriculture au contraire conserve l'être humain sain, fait prospérer la nation dans la justice et la concorde. À la campagne, la personne respecte la nature, vit des fruits de la Terre, se sent liée à Dieu qui bénit sa famille et la protège. La ville au contraire est le règne de la concurrence féroce, de la spéculation égoïste. La technique, le commerce, l'industrie font de la ville une société immorale et dégradante. En un mot, la campagne 
espère Dieu, et la ville se fonde sur les efforts de l'homme. Entre le paysan et le citadin, la différence est d'ordre religieux. L'attraction des villes a une influence ruineuse sur la religion des ruraux. Les campagnes des pays traditionnellement catholiques sont restées pratiquantes lorsqu'elles étaient soustraites à l'influence de la grande ville ou à la rationalisation des cultures industrialisées.

\subsubsection{L'optimisme urbain}

Il me semble très significatif de noter que le premier sociologue urbain, l'Italien Jean BOTERO (1546-1617), définit la ville par son but essentiel, c'est-à-dire le bonheur. ${ }^{42}$ Déjà dans l'Antiquité gréco-romaine, Aristote dans son premier livre de la Politique affirmait que la ville a été créée en premier lieu pour rendre les hommes vraiment humains et qu'elle subsiste pour les rendre heureux. "L'homme qui trouve le début de son accomplissement dans la famille, trouve, dans la ville seulement, sa maturité. ${ }^{* 43}$ La ville est un état nouveau de liberté individuelle et sociale.

La ville rend possibles des jeux de liberté et de communication que l'on ne trouve pas dans l'environnement rural. Elle offre une grande diversité de ressources, de multiples initiatives et possibilités de rencontres signifiantes, de nombreuses formes de regroupements, un accès plus facile aux oeuvres d'art et aux milieux de création, etc. Elle se caractérise encore par la présence des étrangers: touristes et gens d'affaires, immigrants, groupes culturels divers. La ville, c'est le lieu de la diversité; c'est le lieu des Pentecôtes, des souffles nouveaux, des groupes chercheurs et militants. C'est le lieu où la Parole peut être entendue par chacun et chacune dans sa langue. 
Avouons-le, la ville nous inquiète tous un peu, elle nous fait peur, elle nous dépasse. Devant elle, nous nous sentons un peu comme les Hébreux hésitants avant d'entrer dans la terre promise. Nos espoirs et nos craintes de croyants, d'agents de pastorale influencent beaucoup le jugement que nous portons sur la ville. Ceux qui ont confiance dans la ville et dans ses habitants y trouvent des signes d'espoir. Ceux qui détestent ou craignent la ville n'y voient que des obstacles monstres qui vont les avaler. La ville, c'est le monde de la foule solitaire; c'est le lieu qui aggrave les inégalités avec ses contrastes entre la pauvreté et l'affluence. Nos villes étalent la misère: clochards, itinérants sans argent, vagabonds couchés le long des rues et aux bouches de métro. L'indifférence y est plus dure et la compassion plus urgente. L'indignation aussi y éclate plus souvent: manifestations, groupes de pression, protestations.

\subsubsection{Notre Dieu: le Dieu de la campagne et de la ville}

Nous ne pouvons pas choisir entre les deux images de la campagne et de la ville qui traversent la Bible. Il faut les tenir ensemble, même si nous sommes naturellement plus familiers avec la première image. 44 Nous ne pouvons pas non plus opposer le Dieu de la campagne et le Dieu de la ville, même si l'image du Dieu de la ville demeure moins souvent évoquée publiquement.

"Nous sommes tellement portés à penser que l'espace de la ville est une sorte de "no God's land". Dans la ville, de la place pour Dieu? La ville, un possible lieu de révélation? Autant et aussi bien que la campagne? Cela heurte nos préoccupations habituelles: la foi est plus facile à la campagne, on est plus proche du Créateur dans la nature que dans la

44

"Plus la ville devient complexe, plus différentes sont les fonctions qu'elle se propose d'accomplir, plus rigoureuse et rationnelle enfin se fait la vie urbaine, et plus en même temps cet autre pôle qu'est la banlieue ou la campagne surgit visiblement, est valorisé, apparaît souhaitable et même nécessaire"( JOLIF, J.Y., "La ville, projet humain", p. 84). 
rue, etc. Heureusement, les auteurs et témoins bibliques, eux, ont su chercher et reconnaître leur Dieu à la fois dans l'expérience de la nature et dans la silhouette et l'histoire de leur ville, Jérusalem, dont ils ont fait une image privilégiée du Royaume à venir. Nous aussi devons apprendre à chercher et nommer le Dieu de nos rues et de nos villes." 45

Il faut encore se défaire de certains schèmes hérités de notre passé et de notre culture, schèmes simplistes de la campagne ou de la ville tantôt rêvées tantôt dénoncées, sous l'effet de l'idéologie ou de la nostalgie pour dire ce rapport. Il y a plusieurs années, le Québec a connu une période de promotion de la campagne et de soupçon envers la ville, considérée comme un lieu de perdition. Dans les années 1960, avec le phénomène d'urbanisation, le mythe de la campagne s'est dégradé: la vie rurale est apparue de plus en plus comme un monde fermé, sans horizon, culturellement pauvre et étouffant en raison du contrôle social. Dès lors, habiter en ville, c'était échapper à l'enfermement rural et pouvoir enfin jouir d'une vie stimulante, ouverte sur le monde, la liberté, l'autonomie, le progrès, la culture. Ensuite est venue au cours des années 1970-80 la vague nostalgique du "retour à la campagne". Rapidement les citadins redécouvrent leurs origines campagnardes, avec le sentiment d'être déracinés. Il fallait retrouver les racines et retourner aux sources. Cette idéologie rurale est encore forte à l'aube de l'an 2000 (avec la montée des groupes "écolos"), elle entretient la nostalgie du "vivre ensemble" paysan, de fusion de l'être humain et de la nature, d'un paradis à retrouver.

La culture ambiante porte ainsi à chanter les vertus de la campagne ou de la ville, en déplorant les méfaits de la vie urbaine ou de la vie paysanne alternativement,

45

TREMBlay, Paul, "Le citadin et Dieu", in Prêtre et Pasteur, vol. 92, ${ }^{\circ} 6$, juin 1989 , p.323. Je m'inspire beaucoup de cet article de M. Tremblay dans ces lignes. Ce penseur est très significatif pour moi. Il a influencé à plusieurs reprises mon évolution intellectuelle. Voir aussi TARDIF, Francine, "La ville: attraits, peurs et défis", in Relations, octobre 1990, ${ }^{\circ}$ 564, p. 232.; BEAUCHAMP, Andre, "Trouver Dieu en ville?", in Relations, n564, pp. 240-243. 
selon les époques. Il y a trente ans, on protestait contre l'apathie et l'isolement social du monde rural. Il y a dix ans, on protestait contre le gigantisme urbain, contre la dégradation des rapports sociaux, contre la laideur et l'uniformité de l'environnement physique immédiat. Ces problèmes demeurent des défis encore bien actuels, mais aujourd'hui on parle beaucoup moins de fuir la ville que de la rendre humaine et habitable.

"C'est poétiquement que les hommes habitent" dit Holderlin. On peut habiter la campagne platement, superficiellement, avec des yeux épais, sans ouverture aux symboles, de manière toute matérialiste. Alors la campagne ne dit rien du mystère de Dieu: elle reste parfaitement opaque. De même, on peut habiter la ville platement, les yeux écarquillés et les oreilles bourdonnantes, mais sans profondeur, superficiellement. Alors la ville paraît vide de signification, vide de tout mystère. mystère de l'homme et mystère de Dieu. Tout est question de regard, de sensibilité, d'attention, d'écoute. "On n'habite finalement que soi-même" disait un jour Gilles Vigneault. Tout dépend de notre habitat intérieur. C'est lui qui importe le plus. L'environnement ou l'habitat extérieur possèdent certes leur poids et leur densité propre, mais c'est le regard humain qui leur donne sens et qui à travers eux fait du sens. C'est du dedans que vient la capacité d'habiter poétiquement la ville ou la campagne. C'est du dedans que vient la capacité de découvrir dans la ville les signes qui disent le Royaume...." 46

\subsection{L'Église et l'Urbanisation}

L'Église catholique, selon les époques et les endroits, a réagi différemment à l'égard du phénomène de l'urbanisation et ses conséquences sur l'institution ecclésiale. Voici quelques textes officiels qui démontrent les différents points de vue de l'Église.

\subsubsection{Pie XII et "l'esprit de clocher"}

Un texte de Pie XII invite les catholiques à sortir de leur esprit de clocher.

"Prenons garde que la plupart des grands problèmes sociaux auxquels les catholiques doivent désormais faire face débordent largement, dans leurs données comme dans leurs 
solutions, le cadre restreint de la paroisse; tels, parmi tant d'autres, les problèmes soulevés par la création d'une grande industrie ou la migration de populations. L'esprit de clocher nuirait ici à toute réalisation efficace; l'impulsion et la coordination doivent normalement venir de plus haut. Et la paroisse doit respecter ces conditions nouvelles de l'action sociale" 47

Cette affirmation est bien à propos encore aujourd'hui. L'expérience de six années dans deux paroisses urbaines m'a prouvé à maintes reprises la présence très forte de cet esprit de clocher particulièrement chez les paroissiens "nucléiques". Les bénévoles et les membres des équipes pastorales constituent parfois le groupe des paroissiens les moins ouverts aux autres paroisses voisines situées dans une même ville. Les paroissiens "périphériques" sont moins atteints par cet "esprit de clocher".

\subsubsection{Vatican II et sa clairvoyance}

Les Pères conciliaires à Vatican II ont nommé avec justesse l'ampleur des changements sociaux auxquels les êtres humains étaient confrontés.

"Le genre humain vit aujourd'hui un âge nouveau de son histoire, caractérisé par des changements profonds et rapides qui s'étendent peu à peu à l'ensemble du globe. Provoqués par l'homme, par son intelligence et son activitê créatrice, ils rejaillissent sur l'homme lui-même, sur ses jugements, sur ses désirs, individuels et collectifs, sur ses manières de penser et d'agir, tant à l'égard des choses qu'à l'égard de ses semblables. À tel point que l'on peut parler déjà d'une véritable métamorphose sociale et culturelle, dont les effets se répercutent sur la vie religieuse." 48

"Le mouvement même de l'histoire devient si rapide que chacun a peine à le suivre."49

"Du même coup, il se produit des changements, de jour en jour plus importants, dans les communautés locales traditionnelles (familles patriarcales, clans, tribus, villages), dans les différents groupes et les rapports sociaux." 50

"Une société de type industriel s'étend peu à peu, amenant certains pays à une économie d'opulence et transformant radicalement les conceptions et les conditions séculaires de la vie en société. De la même façon, la civilisation urbaine et l'attirance qu'elle provoque

UG II, 3020. 
s'intensifient, soit par la multiplication des villes et de leurs habitants, soit par l'expansion du mode de vie urbaine au monde rural. ${ }^{51}$

Ces textes conciliaires démontrent à quel point Vatican II a été un temps important de réflexion approfondie sur le contexte social et ecclésial.

\subsubsection{La Conférence des évêques canadiens et son réalisme}

Nos évêques canadiens ont été bien réalistes en 1985 lorsqu'ils ont écrit au sujet de la situation de l'Église canadienne dans leur rapport-synthèse en vue de la préparation du synode extraordinaire sur la réception du concile Vatican II, vingt-cinq ans après cet événement.

"En outre, depuis la fin du Concile en 1965, on a assisté à une 'accélération de l'histoire'. Des problèmes nouveaux ont surgi qui ont influencé la vie de l'Église peut-être plus que le concile Vatican II lui-même". 52

Des changements sociaux sont encore survenus depuis cette affirmation. Il est donc urgent de consacrer davantage de temps pour analyser ces bouleversements. En Église, les nombreuses tâches pastorales monopolisent tellement les énergies des intervenants pastoraux que la majorité d'entre eux négligent de consacrer du temps à une étude plus approfondie du contexte social. octobre 1985, p. A-7. 


\subsubsection{La vision pessimiste dans le document "Risquer l'Avenir"}

L'Assemblée des évêques du Québec, par l'intermédiaire de leur comité de recherche sur les communautés chrétiennes locales, ont décrit d'une manière assez sombre ces changements sociaux dans l'étude intitulée "Risquer l'Avenir".

"Des transformations profondes: Ce passage s'est opéré surtout à partir de la Deuxième Guerre mondiale. L'accumulation des connaissances scientifiques et le développement technologique ont rendu possible une transformation rapide de la structure economique /../ le phénomène de socialisation est important à considérer pour comprendre les changements de comportements de baptisés d'ici. Avec la transformation de leur société, accélérée dans les années 1960, les Québécois ont été soumis à une socialisation fort différente de celle qu'ont connue par exemple les gens qui vivaient dans des milieux ruraux au cours des années 1930. Cette socialisation nouvelle a façonné des personnes plus individualistes, qui ont progressivement reconnu comme normale une vision sécularisée de l'existence. /.../ Les Églises ont perdu leur pouvoir de faire accepter leur vision de l'existence humaine. Elles sont simplement devenues des institutions secondaires de socialisation. D'où, chez la majorité des membres de ces sociétés une forte indifférence face aux discours de l'Église."53

Il est important de réfléchir sur les changements sociaux. Il demeure toujours étonnant de constater que, quand des gens d'Église le font, c'est toujours d'une manière négative. Le prochain chapitre sur la culture moderne analysera plus en profondeur cette constatation. Nous découvrirons que ce n'est pas d'hier que le mariage entre l'institution catholique et le monde est difficile à vivre.

\subsubsection{L'analyse de quelques Églises locales du Québec}

Depuis quelques années, les diocèses du Québec s'intéressent à l'analyse des conséquences des changements sociaux dans la vie des gens et des communautés croyantes. Le diocèse de Chicoutimi a plus particulièrement réfléchi sur les 
conséquences de ces changements sociaux par rapport au devenir de l'Église en 1976

par l'intermédiaire d'une commission diocésaine de recherche pastorale nommée:

"Mission et coresponsabilité".

\begin{abstract}
"Nous ne vivons pas dans une société sans être influencés par ses modes de penser et d'agir, par les valeurs qui l'inspirent, par les traits culturels qui la différencient des autres sociétés. Notre temps, marqué par un changement brusque des structures sociales, voit naître de nouveaux schèmes culturels. Il est beaucoup plus facile de changer une structure (souvent la vie s'en charge) que d'adopter les façons de penser et d'agir qui nous permettront de trouver un nouvel équilibre, un certain confort à l'intérieur d'un système social différent. Il ne faut donc pas s'étonner des jugements négatifs portés à l'endroit d'une culture qui se cherche encore. Habitués à la stabilité des valeurs religieuses et familiales, dans une société très proche de ses structures rurales, les participants trouvent pénibles: 1. le renversement des valeurs traditionnelles - 2. l'angoisse face à l'avenir - 3 . l'influence négative des mass media - 4. le laisser-aller et la dépersonnalisation. /.../ Cette culture nouvelle qui s'élabore péniblement annonce aussi des traits fort réjouissants que les participants n'ont pas manqué de mettre en valeur: 1. un climat de liberté - 2 . les progrès de la science et de la technologie - 3 . la possibilité pour tous de s'instruire -4 . les médias d'information - 5. la revalorisation de la femme - 6. les facilités de distraction - 7. l'apparition de nouvelles valeurs. /.../ Ces aspects de notre culture viennent atténuer de beaucoup les jugements négatifs précédents." 54
\end{abstract}

Au diocèse de Québec, l'étude de Pierre MORISSETTE en 1977, a déclenché une réflexion intéressante dans cette Église locale concernant l'institution paroissiale en contexte urbain.

"Il m'est apparu de plus en plus clairement qu'on ne pouvait pas envisager le problème posé par une dizaine de paroisses sans repenser en profondeur l'organisation pastorale actuelle de la ville de Québec et de sa banlieue. Une constatation s'imposait avec force: nous avons dans une ville moderne du $\mathrm{XX}^{\circ}$ siècle, une organisation pastorale qui a été pensée d'abord pour des milieux ruraux et qui ne tient pas tellement compte de la réalité urbaine actuelle./... Or, il faut se rendre à l'évidence, les conditions de vie ont rapidement évolué depuis quelques années et le style de la vie urbaine, sous l'influence de plusieurs facteurs, s'est modifié, ce qui a eu pour effet de rendre caduque en bonne partie le modèle institutionnel. Quelques facteurs en particulier sont responsables de cette transformation; il s'agit 1) d'une mobilité plus grande à l'intérieur même de la ville; 2) d'une tendance toujours plus marquée vers une spécialisation des activités humaines; 3 ) du développement rapide des mass-média. l.../ La considération de ce qu'est une ville moderne nous invite à voir, en effet, que l'Église peut rendre le service pastoral dans des 
cadres différents de ceux que nous avons connus jusqu'à maintenant. On peut reprendre ici la parole du Seigneur en la transformant un peu et dire que la paroisse est faite pour l'homme, et non les hommes pour la paroisse. Bien sûr, cette structure a rendu à l'Église de précieux services, et il ne s'agit pas de s'en débarrasser à la légère sous prétexte que l'Église doit se renouveler. La connaissance des caractéristiques de la ville moderne nous rappelle toutefois que la réalité paroissiale ne peut plus être vécue aujourd'hui comme elle l'a été." 55

En mars 1983, par le moyen du projet Le Renouveau, le diocèse de SaintJean-Longueuil prenait conscience de l'importance du phénomène de l'urbanisation dans sa région.

"Hier, la paroisse, en général, était à taille humaine. Entre 1950 et 1960, dans le diocèse, une trentaine de paroisses ont vu le jour. Ces paroisses étaient animées par un prêtre et dotées dès le début d'un lieu de culte. À cette époque, le diocèse multipliait les paroisses. Il espérait de cette manière mieux répondre aux besoins des chrétiens. /.../ Aujourd'hui, les statistiques nous disent: Longueuil et Jacques-Cartier, en 1956, comptaient 14 paroisses pour une population totale de 52,783 personnes. En 1983, on ne compte que 15 paroisses pour une population de 133,747 personnes, donc pour une population qui a plus que doublé. Il faut ajouter à cela que 7 paroisses ont plus de 10,000 habitants. /.../ Dans la région Centre, la population a considérablement augmenté depuis le début des années '60. Brossard et Saint-Hubert sont principalement responsables de l'accroissement de la population. De 1961 à 1981, la population de ces deux villes est passée de 3,778 habitants à 52,232 pour Brossard et de 14,380 habitants à 60,573 pour Saint-Hubert. /... / Donc, les paroisses ont une population de plus en plus nombreuse et un clergé de moins en moins nombreux et plus âgé à leur service. /.../ Que faire... pour bâtir l'avenir"56

En septembre 1986, dans le diocèse de Saint-Hyacinthe, un comité d'étude sur l'animation pastorale en milieu urbain a présenté un rapport-synthèse aux autorités diocésaines. Les membres du comité sont arrivés à des constatations interpellantes. En voici une:

MORISSETTE, Pierre, La pastorale en milieu urbain, Québec, Service de la pastorale du diocèse de Québec, 1977, p.4; p.7.; pp.44-45. 56 SERVICE DE LA PASTORALE COMMUNAUTAIRE, Renouveau pour notre Église, Sensibilisation de l'équipe locale, Diocèse de Saint-Jean-Longueuil, mars 1983, pp.1-3. 
"Les agents de pastorale en milieu urbain, n'ont pas tellement réfléchi sur ce qu'est le phénomène urbain et continuent à vouloir sauvegarder malgré tout un modele rural, avec de moins en moins de résultats." 57

En 1990, au diocèse de Baie-Comeau, particulièrement dans le secteur de la ville de Sept-îles, un comité d'étude a réfléchi sur un projet de pastorale urbaine. Les membres arrivent à ces conclusions:

\begin{abstract}
"Les divisions territoriales actuelles remontent au temps où la paroisse et le village recouvraient le même terrain. Tout se correspondait et ne faisait qu'un. Ces divisions, transposées en ville,ont de quoi d'artificiel! La vie de la ville n'est pas ainsi quadrillée et elle échappe aux paroisses trop centrées sur ce qui se passe au dedans de leurs "frontières"! /.../ Les paroisses comme telles, demeurent passablement "en marge" des événements de la ville et la pastorale se tient à distance de ce qui façonne la vie des gens d'ici: l'économique, le socio-culturel, le récréatif, le professionnel, le syndical, etc. Le rôle de l'Église est moins rayonnant qu'il le devrait, en raison d'un 'morcellement' paroissial qui prive l'Église d'ici d'un témoignage d'unité et d'une qualité de présence, au coeur des réalités humaines et sociales de notre milieu. 58
\end{abstract}

Une étude récente sur une paroisse du diocèse de Montréal a été publiée en 1992. 59 L'auteure, Lucia FERRETTI, est une historienne et sa recherche sur la société paroissiale de Saint-Pierre-Apôtre de Montréal entre 1848-1930 montre comment, grâce aux liens de voisinage et aux activités religieuses, sociales ou culturelles mises sur pied par les paroisses, l'Église montréalaise a contribué à faire des Canadiens français des urbains. Par le tableau qu'elle brosse des aspirations et des attentes des Saint-Pierrais, de leurs enthousiasmes, de leurs lassitudes, des oppositions qui les séparent et des solidarités qui les lient, des difficultés qu'ils rencontrent et des moyens qu'ils se donnent pour les atténuer, cette étude de la société paroissiale apporte une

57 COMITÉ DE RÉFLEXION, Rapport synthèse du comité d'étude sur l'animation pastorale en milieu urbain, Diocèse de Saint-Hyacinthe, septembre 1986, p.8.

58 COMITÉ D'ÉTUDE, L'Église de Sept-Iles s'interroge sur son avenir, Projet de pastorale urbaine, Document de travail, mars 1990, pp.4-5.

59 FERRETTI, Lucia, Entre voisins, la société paroissiale en milieu urbain, SaintPierre-Apôtre de Montréal, Montréal, Boréal, 1992, 261p. 
dimension supplémentaire à la connaissance de la culture populaire urbaine avant 1930 en même temps qu'elle permet de rendre compte de l'acculturation réussie des Canadiens français à la société urbaine.

-"Bénéficiant de la déstabilisation des pratiques communautaires antérieures à la révolution industrielle et urbaine, l'Église montréalise du XIX ${ }^{\circ}$ siècle, par le biais justement de l'action conjuguée des pasteurs et des fidèles dans la paroisse, a su, en particulier, réorienter autour d'elle la vie sociale locale et lui insuffler pour un temps, après l'industrialisation non seulement une très nette intensification mais encore une pertinence nouvelle en milieu urbain. C'est ce qui nous fait dire qu'elle a contribué à son tour, tout comme le travail industriel, le syndicalisme, la participation à la vie politique, la presse à grand tirage et les loisirs commerciaux, à façonner l'identité urbaine des Canadiensfrançais, leurs rapports sociaux et leur rapport à la ville." 60

Saint-Pierre-Apôtre, comme paroisse d'un faubourg puis paroisse du centreville, a rempli dès le milieu du $\mathrm{XIX}^{\circ}$ siècle un rôle essentiel, particulièrement de médiation entre l'Église et les fidèles-citadins d'une part, entre eux et la ville d'autre part.

"Car, à Saint-Pierre, et ailleurs sans doute également, autorités diocésaines, pasteurs et fidèles ont su jusqu'à la Première Guerre mondiale environ, peut-être plus longtemps, dans les parties moins centrales de la ville, faire de la paroisse le cadre, le moteur et l'instrument tout à la fois d'une vie sociale en prise réelle et large sur un milieu urbain en mutation, qu'elle contribue même à façonner. Il faut réviser l'idée selon laquelle la paroisse urbaine n'aurait été dans la ville industrielle qu'une transposition de la paroisse rurale; nous espérons avoir au contraire apporté la preuve de sa capacité d'innovation et de sa pertinence durable dans son nouveau milieu. Pendant longtemps en effet, une paroisse inventive a été le moyen que l'Église s'est donné pour aborder la ville, et les citadins. Ce n'est que lorsqu'une nouvelle recrudescence de développement urbain achève de faire éclater la cohésion des quartiers et rend inadéquates les institutions strictement locales, à partir des années 1910 et plus encore après la guerre, que la paroisse perd son rôle de pivot de l'intégration sociale et devient essentiellement une communauté de foi. L'Église tente alors de se donner des outils nouveaux de compréhension du monde urbain." 61 
Dans la deuxième décennie du $X^{\circ}$ siècle et davantage encore après la guerre, la paroisse est encore plus fortement balayée par tous les vents urbains. Ce qui faire dire à Lucia FERRETTI que les autorités religieuses doivent réviser l'organisation paroissiale dans le contexte urbain d'aujourd'hui. La paroisse a été précieuse entre 1910 et 1945 pour aider les ruraux à mieux s'intégrer dans les villes. Mais l'énorme accroissement démographique après la guerre n'a pu permis à la paroisse de jouer ce rôle d'intégration. Elle a été dépassée par les bouleversements causés par le phénomène de l'urbanisation. Les étroites frontières paroissiales qui l'enferment actuellement ne sont plus que de simples limites administratives sans signification sociale.

\begin{abstract}
"Alors que la ville connaît une nouvelle recrudescence de développement qui achève de faire éclater la cohésion des quartiers et des institutions strictement locales, la paroisse, emprisonnée dans ses limites territoriales, apparaît de moins en moins, aux yeux d'urbains mieux ancrés, aux yeux d'organismes civils et même à ceux des administrateurs diocésains, comme la médiation la plus adéquate entre Église et citadins, entre citadins et métropole." 62
\end{abstract}

L'ensemble de ces quelques études de certaines Églises locales du Québec sur leur devenir dans un nouveau contexte social démontre que celles-ci sont demeurées ouvertes à un questionnement.

\title{
8.9.6. Le catholicisme américain et sa réflexion sociologique
}

Le catholicisme américain est essentiellement urbain depuis plusieurs années et cela le fait différer dans une grande mesure du catholicisme en Europe et en Amérique Latine. Déjà, en 1936, un recensement religieux indiquait que seulement $19,4 \%$ des catholiques étaient situés dans des régions rurales. 63

63 Religious Bodies, 1936, U.S. Department of Commerce. 1941, cité par HOUTARD, F. , REMY, J., Milieu urbain et communauté chrétienne, p.49 
Le P. Joseph H. FITCHER qui, avec le P. Thomas et quelques autres, a été un des pionniers de l'étude de l'aspect urbain du catholicisme aux États-Unis en publiant en 1954 un livre très important qui a marqué les études théologiques et sociologiques pendant plusieurs années. ${ }^{64}$ FICHTER a analysé d'une manière très poussée les relations sociales dans la paroisse urbaine. L'influence de la sociologie américaine est venue nous tirer de l'ornière des unités de voisinage. Selon FITCHER, nous avons eu l'illusion de croire qu'en divisant les chrétiens et les habitants d'une ville en secteur (en paroisse) de 5,000 personnes et plus, on créerait automatiquement ou favoriserait la formation de communautés. La communauté chrétienne naissait naturellement sur la base de voisinage. Cette question était considérée comme résolue implicitement. Puisque l'unité de voisinage était reconnue comme unité naturelle par les sociologues, il suffisait donc de donner à la paroisse les dimensions d'une unité de voisinage. Quelle inconscience! On a accusé et on accusera longtemps le style de vie urbaine de détruire l'Église. Déjà en 1954, FITCHER affirmait le contraire. Selon lui, c'est plutôt l'Église qui tarde à s'adapter à la nouvelle société urbaine. La tâche de l'Église est d'avoir une attitude pastorale fondée sur une connaissance de la ville, une volonté de la comprendre et d'en accepter les défis. Connaissance de la ville signifie connaissance de la civilisation urbaine, des ressorts de la vie urbaine, des communications qui la constituent et des forces qui la mettent en mouvement. Les propos de FITCHER sont encore bien pertinents... même après 40 ans! Les sociologues américains ont montré tout ce qu'il y avait de ruralisme dans les mouvements paroissiaux européens et dans leurs préoccupations de sauver la paroisse à tout prix en mettant au service de cette entreprise les armes que l'on pourrait voler à la sociologie, au lieu d'étudier la sociologie urbaine à fond.

64 Press, 1954.

FICHTER, J.H., Social Relations in the Urban Parish, The University of Chicago 
Durant l'été 1992, je suis allé faire une recherche-action dans une paroisse américaine de Boston (Our Lady Help of Christian Parish, Newton). J'en ai profité pour m'inscrire à un séminaire de recherche au Boston College sur la paroisse américaine animé par un théologien reconnu aux États-Unis William BAUCH. Les recherches et la participation à ce séminaire m'ont démontré que même si les ÉtatsUnis ont pu profiter dès le début des années 50 d'études sociologiques et théologiques approfondissant l'institution paroissiale dans le contexte urbain, les Églises locales de différents états sont encore dans une vision rurale de la pastorale urbaine. Elles ne sont pas beaucoup plus avancées que les autres Églises sur cette problématique.

\subsubsection{L'urbanisation galopante en Amérique Latine}

Le continent latino-américain connaît depuis plusieurs années une urbanisation à outrance. Le Brésil nous offre un bel exemple de l'explosion urbaine.

$\begin{array}{ccccc}\text { Annee } & \text { Pop.totale (millions) } & \text { Pop. rurale (\%) } & \text { Pop. urbaine (\%) } \\ 1940 & 41,2 & 68,8 & 31,2 \\ 1950 & 51,9 & 63,8 & 36,2 \\ 1960 & 71,0 & 54,9 & 45,1 \\ 1970 & 94,5 & 44,0 & 56,0 \\ 1980 & 121,1 & 32,3 & 67,7 & \\ 1991 & 146,2 & 25,0 & 75,0 \quad \text { "65 }\end{array}$

65

"Source: cours démographique de l'IBGE. /.../ Selon les dernières données (recensement 1991), la population brésilienne est de 146,2 millions d'habitants, parmi lesquels 32 millions sont confrontés quotidiennement au problème de la faim. /../ Il y a aujourd'hui au Brésil 232 villes dont la population dépasse les 50000 habitants et 9 régions métropolitaines ayant toutes une population supérieure à un million d'habitants"( BEZERRA, Jearson Lucas, Urbanisation et exclusion, Congrès de l'Entraide missionnaire 1993: Un monde en déplacement, CEGEP Ahuntsic de Montréal 10-11-12 sept. 1993, Textes des conférences, p.39.). 
Cette urbanisation galopante continue à prendre l'Église de l'Amérique Latine de court. En 1983, les évêques du CELAM ont publié un texte pour faire un bilan de ce phénomène en Amérique Latine, lequel bilan n'est pas uniquement négatif.

"La grande ville a des avantages. Parmi les premiers, nous pouvons noter que la ville offre la possibilité d'une vie sociale entre les hommes plus vive et plus libre, qu'elle développe de nouveaux horizons culturels et qu'elle se transforme en un moteur d'une nouvelle civilisation." 66

Ces évêques de la conférence épiscopale latino-américaine (CELAM) ont repris particulièrement la réflexion sur ce sujet lors du dernier synode tenu à Saint-Domingue en octobre 1992. Nous pouvons lire dans le texte des conclusions de la $\mathrm{IV}^{\circ}$ assemblée du CELAM:

"Il est urgent et indispendable de donner des solutions aux interrogations qui se présentent aux paroisses urbaines afin que celles-ci soient capables de répondre aux défis de la Nouvelle Évangélisation. Il y a un déphasement entre le rythme de la vie moderne et les critères qui animent d'ordinaire la paroisse /.../ Dans les paroisses urbaines on doit privilégier les "plans d'ensemble"- dans les zones homogènes- afin d'organiser certains services rapides qui facilitent la Nouvelle Évangélisation." 67

En janvier 1993, lors de son passage au Canada pour la campagne de financement de Développement et Paix, le président de la conférence épiscopale du Brésil, Mgr Luciano MENDES DE ALMEIDA déclara dans une de ces conférences : "Le défi de la culture urbaine: on doit être capable de parler aux hommes urbains mais nous avons une culture rurale dans notre pensée et dans notre approche pastorale"68

66 CELAM, "La pastorale dans les grandes villes latino-américaines", in Documentation catholique, $\mathrm{n}^{\circ} 1843,2$ janvier $1983, \mathrm{p} .59$.

67 Traduction libre à partir du texte espagnol de CONFERENCIA GENERAL DEL EPISCOPADO LATINO AMERICANO $\left(\mathrm{IV}^{\circ}\right)$, Nueva evangelizacion promocion humana cultura cristiana, Conclusiones, (\#59 et \#60 c du document espagnol final mais non officiel puisque non encore complètement "romanisé"!), Santo Domingo, 12-28 de Octubre de 1992, p.23.

68

MENDES DE ALMEIDA, Luciano, Mgr, Conférence donnée au Grand Séminaire de Montréal, 18 janvier 1992. 
Cette affirmation m'a motivé à poursuivre la présente recherche. C'est stimulant de constater que d'autres penseurs arrivent aux mêmes constats dans leurs recherches théologiques et pastorales.

\subsection{Acquis de recherche éclairants}

Que conclure de toute cette réflexion sur le phénomène de l'urbanisation et de ses conséquences sur l'institution paroissiale?

\subsubsection{Les effets néfastes de la ruralisation des paroisses à l'ère contemporaine}

À l'ère contemporaine, alors que le monde s'est urbanisé, on s'est retrouvé dans les villes devant une multiplicité de paroisses organisées de façon autosuffisante sur le modèle rural. La ville est devenue une véritable 'congestion' de paroisses. L'urbanisation a donc surpris une Église en pleine voie de ruralisation, une Église qui arrivait justement à mettre au point un apostolat rural complet grâce à un système de missions qui a atteint son sommet dans la première moitié du XIX ${ }^{\circ}$ siècle en Europe et au $\mathrm{XX}^{\circ}$ siècle au Canada français. ${ }^{69}$ Les paysans ont commencé à fuir la campagne pour former des agglomérations d'une dimension telle qu'elles remettent en question toute la problématique pastorale. Pendant plusieurs années, on s'est efforcé de contenir l'évolution et de résoudre les problèmes pastoraux selon les cadres anciens. On a essayé de sauver la paroisse territoriale née de la société rurale pour n'avoir pas à repenser la pastorale urbaine sur de nouvelles bases car tout à coup on s'est aperçu que la paroisse faite pour donner les soins spirituels à 500-1000 personnes, contenait 
jusqu'à 9000,11000 ou 50000 baptisés et plus encore dans certains pays (ex: en Amérique Latine). On a multiplié les paroisses. On a essayé de les rajeunir. Depuis quelques années, on peut dire qu'une grande part des efforts de la pastorale urbaine a été consacrée à tenter de sauver la paroisse pour n'avoir pas à remettre en question les concepts fondamentaux. On a mis sur pied toute une série d'institutions paroissiales de telle sorte que la paroisse s'est vue transformée en un centre social, une société en réduction enkystée dans la société moderne.

\begin{abstract}
"Au cours des dernières années, les sociologues ont montré que la paroisse urbaine restait en dehors du véritable milieu urbain. Ce que les sociologues ont montré et exprimé en forme technique, il y a des années que les curés de ville le savaient. Mais ils cherchaient la solution dans un mythe: ils cherchaient à refaire de la paroisse une communauté totale, à refaire le village dans leur paroisse, à refaire au fond l'Église locale dans leur paroisse. Tentative vouée à l'échec: il y a des décennies que l'on recommence toujours la même chose en rajeunissant les noms" 70
\end{abstract}

Nous l'avons vu, plusieurs autres facteurs ont marqué sérieusement la vie paroissiale dans notre société contemporaine. La sécularisation, le pluralisme, la civilisation technique qui a transformé les relations entre l'homme et la nature et les relations sociales, la rationalité, la recherche de regroupement fractionnel, le changement de la relation au temps vécu, la privatisation de l'existence personnelle, le développement des moyens de transport et de communication, etc. On peut donc dire que le monde urbain s'est développé à une allure très rapide et que la société qu'il engendre se retrouve en état de changement social continuel alors que l'Égliseinstitution a évolué à un rythme beaucoup plus lent.

En réponse au vaste mouvement d'urbanisation et d'industrialisation et devant l'émergence de la société moderne, l'Église du Québec et d'ailleurs s'est 
contentée de transplanter la paroisse rurale à la ville, ce que redisent Jean HAMELIN et Nicole GAGNON:

"Les évêques ont très peu songé à y implanter des cadres de chrétienté originaux. Leur zèle pastoral se résume à y reproduire, tant bien que mal, au rythme des mouvements de population, les cadres paroissiaux de la société rurale."71

Les Églises locales ont fait des efforts pour naviguer à travers ces grands changements sociaux créés par les phénomènes de l'industrialisation et de l'urbanisation et pour réviser leurs organisations institutionnelles. Ce mouvement d'ouverture s'est fait de deux manières: par en haut et par en bas. Les diocèses eux-mêmes ont établi de nouvelles structures en instaurant des services diocésains. Ils ont cherché à animer et à stimuler les paroisses dans leur rôle propre en leur fournissant l'instrumentation pratique. Durant toutes ces périodes, un travail s'est accompli au ras du sol. Groupées en secteurs, en zones ou en régions pastorales, les paroisses ont appris un peu plus à se connaître, à dialoguer, à échanger, à collaborer. Mais la conception de l'organisation pastorale au Québec (et ailleurs) n'a pas été capable d'intégrer tout ce qui ne venait pas de l'organisation territoriale locale. Même les efforts de pastorale d'ensemble des dernières années dans les diocèses ont été souvent axés essentiellement sur une coordination des unités géographiques polyvalentes que sont la paroisse, le secteur, la zone, la région pastorale. La conception de l'agglomération urbaine en tant qu'unité de base qui doit orienter toute la vision et l'organisation de la pastorale, est une attitude qui n'a pas encore atteint réellement les autorités ecclésiales.

71 HAMELIN, Jean et GAGNON, Nicole, Histoire du catholicisme québécois, vol. III, Le XX' ${ }^{\circ}$ siècle, tome 1, de 1898 à 1940, Montréal, Boréal Express, 1984, p. 259. 
8.10.2 Une remise en cause de la territorialité actuelle de la paroisse dans le contexte urbain

Les démonstrations des pages précédentes suffisent à prouver que l'unité territoriale ne correspond plus aujourd'hui à une unité culturelle. ${ }^{72}$ Les formes de vie jusqu'à présent unifiées dans un espace déterminé sont brisées, bousculées par de nouveaux styles de vie et de nouvelles formes de civilisation. Le concept sociologique de la paroisse est resté dans les esprits celui d'une civilisation de type rural alors que le contenu sociologique de la paroisse a complètement changé. "Depuis Vatican II, nous avons une bonne théologie de l'Église particulière. Sa sociologie et sa géographie, dans le cadre de notre société industrielle, sont encore balbutiantes".73 Dans notre société moderne post-industrielle, comme dans l'Eglise apostolique, notre civilisation est définie par les villes: tout ne se fait pas sur le territoire de la paroisse, du quartier ou du village. Le phénomène de l'urbanisation a profondément marqué les assises de la vie paroissiale dans le contexte social. Il a même 'ébranlé' la structure territoriale originelle de la société féodale. La paroisse territoriale, surtout en ville, n'englobe plus toutes les activités de l'individu. Les relations sociales l'emportent sur les liens d'appartenance à une paroisse territoriale urbaine. La ville favorise l'accroissement de la mobilité. La conséquence redoutable de cette mobilité, du nomadisme ou de l'errance des hommes du $\mathrm{XX}^{\mathrm{o}}$ siècle est que les humains relativisent d'une façon inédite l'appartenance à un territoire. Le phénomène d'urbanisation a marqué un retrait de l'emprise territoriale. Or, les paroisses sont encore caractérisées précisément par leur découpage géographique territorial. Les responsables de la pastorale n'ont pas suffisamment réfléchi sur le paradoxe qui veut que plus les gens sont entassés dans un même territoire, moins ils se trouvent définis par celui-ci.

72

Ceci est particulièrement vaia si l'on entend par culture l'ensemble des formes de vie exprimant la nature humaine, l'épanouissement de l'humain authentique.

BUSSINI, F., "Donner lieu à l'église", in Lumière et Vie, \#123, p.72. 
Les conditions socio-historiques influencent la mise en place des structures qui évoluent moins vite que la vie. Beaucoup de défis actuels apparaissent insurmontables parce qu'on ne refait pas le même chemin, parce qu'on ne retourne pas à la vie pour repenser les formes institutionnelles nouvelles à instaurer. Dans le passé, des oeuvres paroissiales ont été créées qui répondaient à des aspirations et à des besoins dans une conjoncture donnée. Aujourd'hui, on cherche à rajeunir ces oeuvres, à les adapter. On a beau changer les méthodes, les objectifs, le leadership, et même le membership, l'opération semble toujours celle de la pièce neuve sur un vieux vêtement. La paroisse est un produit de l'histoire. Elle n'a donc rien d'immuable. Il est ainsi normal que ses fonctions soient différentes actuellement de ce qu'elles étaient au cours des derniers siècles. Depuis plusieurs années, on a réussi à définir la paroisse par un schéma idéal qu'on lui impose comme étant sa vocation, faisant confiance au temps pour le réaliser. Mais une paroisse ne définit pas une réalité en projetant sur elle un schéma idéal: on ne peut donner à une communauté n'importe quelle tâche à remplir, sans voir si cette tâche est contenue dans ses possibilités historiques.

Le principe de la territorialité de la paroisse dans le milieu urbain doit donc être mis à jour en Église puisqu'il n'est plus applicable dans nos sociétés modernes et fortement urbanisées. Si non, le $\mathrm{XXI}^{\circ}$ siècle pourrait être caractérisé comme celui du dernier souffle des paroisses urbaines.

\section{10.3 La dialectique institution - fonction}

Il faut avoir le courage d'envisager en quelque sorte le problème de la paroisse urbaine dans son ensemble et de le regarder en dehors des problématiques habituelles considérées comme immuables. C'est ici qu'il faut parler de la dialectique 
de linstitution et de la fonction. Toute vie religieuse a besoin d'institutions pour s'appuyer, pour rendre réel et constant le sens d'une appartenance. Ce serait de l'angélisme que d'affirmer le contraire. Pour répondre à un besoin, l'on crée une institution et c'est nécessaire car l'action qui ne débouche pas au niveau institutionnel se condamne à n'être qu'une perpétuelle impuissance. Pendant un temps plus ou moins long, l'institution est parfaitement adaptée à la fonction qu'on lui assigne puis, vient un moment où, les conditions ayant changé et l'institution vieilli, elle ne répond plus aux besoins, elle devient un corps mort dont il faut se débarrasser, non pour revenir au néant mais pour créer de nouvelles institutions. L'institution paroissiale n'a pas à échapper à cette loi; pendant un temps, parfaitement adaptée à sa fonction, elle donne aujourd'hui de moins en moins de résultats pastoraux. Il est important que l'institution ne soit jamais une fin en soi, elle doit rester un moyen au service des besoins qui l'ont fait naître. La paroisse ne peut plus limiter son action aux frontières de son territoire ni exiger de ses membres une appartenance exclusive: ce serait marcher à contre-courant des tendances nouvelles. Les humains n'ont pas à s'adapter à la paroisse de jadis, mais c'est celle-ci qui doit évoluer; le changement continu est une condition du monde moderne. Nous sommes à l'âge des structures en mouvement et la paroisse n'y échappera pas, si elle veut être de son temps. La pastorale urbaine devra avoir autant de réalisme que la sociologie urbaine si elle veut se créer des instruments adaptés pour rejoindre les humains concrets dans leur réseau diversifié de solidarités.

\subsubsection{La structure pastorale urbaine souhaitée}

L'ensemble de la recherche-action m'a plus que jamais convaincu de l'importance de structurer la pastorale paroissiale en tenant compte du milieu humain naturel du paroissien. Le paroissien d'aujourd'hui vit dans une société moderne postindustrielle où la plupart de ses activités définissent sa vie en des appartenances 
multiples. Le paroissien ne s'identifie pas seulement à sa paroisse, il a plusieurs réseaux d'appartenance. Globalement, le paroissien urbain s'identifie beaucoup plus comme citoyen d'une ville (le type de ville du Saguenay-Lac-Saint-Jean) ou de tel quartier dans les grandes villes ou métropoles (Québec, Montréal) que comme résidant sur le territoire de telle paroisse dans le contexte urbain. Son milieu humain naturel est la ville. Il se sent davantage concerné par les enjeux humains de "sa" ville que de la paroisse territoriale. Pour cette raison, il faut obligatoirement casser le schéma simpliste d'une appartenance à l'Église qui se voudrait totalisante par le territoire paroissial actuel en milieu urbain. La structure pastorale de base souhaitée pour le paroissien urbain ne devrait-il pas être la ville ou un secteur de la ville ou un quartier d'une métropole. Le véritable 'esprit paroissial' n'est-il pas l'appartenance au milieu humain global du paroissien; n'est-ce pas l'appartenance à l'Église de la ville? ${ }^{74} \mathrm{Ne}$ devrions-nous pas briser cette indépendance des paroisses urbaines actuelles pour retrouver une structure pastorale de base pour l'ensemble de la ville? L'Église doit s'adapter à la ville dans ses structures et dans ses services. Par conséquent, il faut que les structures ecclésiales s'assouplissent et n'imposent plus une série d'actes sur la simple base d'une localisation territoriale. ${ }^{75}$ Il ne sert à rien de vouloir maintenir ou refaire l'ancienne "communauté paroissiale", une grande famille.

"Pour humaniser et pour christianiser il fallait refaire des communautés. Ce cri est à la mode depuis le début du siècle: refaire des communautés. On retrouve une continuité incontestable dans tous les essais de rénovation pastorale. Mais l'erreur consiste à croire que l'on refera des communautés urbaines sur le modèle des communautés de village. C'est l'erreur commune à toutes les théories. Elles avaient raison de vouloir former des l'autre des célébrations sacramentelles à des catholiques qui ne demeurent pas sur le territoire de la paroisse. Dans d'autres circonstances, ils acceptent après avoir demandé aux personnes concernées une autorisation de "leur" paroisse territoriale. Dans ce contexte, le presbytère devient un lieu de "douanes" sacramentelles où on est plus soucieux de vérifier le territoire des catholiques que de les accompagner dans leur cheminement lors d'une demande sacramentelle. 
communautés. Mais elles avaient tort de croire que les hommes se laisseraient réunir en communautés paroissiales qui seraient des villages restaurés" 76

L'histoire et la sociologie encouragent cette restauration de la paroisse orientée vers la ville comme phénomène total. Comme nous l'avons vu, on retrouve là une pratique séculaire de l'Église ancienne, dans la ligne de la catholicité de la paroisse originelle au service d'un christianisme qui fut au départ un phénomène urbain. ${ }^{77} \mathrm{La}$ dernière partie de cette thèse permettra de risquer certaines avenues possibles. historique. C'est faire bon marché d'une histoire de vingt siècles et du gigantesque mouvement d'urbanisation en cours. Ce que l'on doit reprocher avant tout aux théoriciens ou théologiens de la paroisse des cinquante dernières années, c'est d'avoir essayé de faire une théologie qui fit totalement abstraction des données de l'histoire et de la sociologie. Toute présence de l'Église dans la ville est impossible si elle ne prend pas d'abord en considération la nature de la ville. Pour juger la paroisse, il ne faut pas uniquement la comparer à l'Église primitive, mais surtout à la ville contemporaine. Également, il est à propos de rappeler qu'il ne faut pas non plus réduire le problème de l'institution paroissiale aux dimensions d'une inadaptation structurelle. Dans ce cas, une simple adaptation des structures ecclésiales pourrait le résoudre. Le choix d'approfondir la paroisse dans une perspective systémique a justement pour but de mettre en lumière la complexité du problème soulevé. 


\section{CHAPITRE 9}

\section{LA CULTURE MODERNE}

"La modernité a ses défenseurs autant que ses détracteurs." 1

Nous disons que les paroissiens ont été influencés par les valeurs de la modernité. Mais qu'est-ce que la modernité? Ce chapitre désire répondre à cette question. Nous savons que la modernité n'est ni un concept sociologique, ni un concept politique, ni proprement un concept historique. C'est un mode de civilisation caractéristique qui s'oppose au mode de la tradition, c'est-à-dire à toutes les autres cultures antérieures ou traditionnelles. Face à la diversité géographique et symbolique de celles-ci, la modernité s'impose comme une culture, homogène, irradiant mondialement à partir de l'Occident. Pourtant, elle demeure une notion confuse qui connote globalement toute une évolution historique et un changement de mentalité.

Comme la modernité n'est pas un concept d'analyse, elle ne possède pas de lois mais uniquement des caractéristiques. Ce chapitre montrera que l'être humain et le monde sont devenus modernes à l'issue de quatre révolutions majeures (scientifique, politique, culturelle, industrielle). La modernité n'est cependant pas seulement la réalité des bouleversements techniques, scientifiques et politiques depuis le $\mathrm{XVI}^{\circ}$ siècle, elle est aussi le jeu des signes, des moeurs et de la culture qui traduit ces changements de structure au niveau du rituel et de l'habitus social. Également, l'arrivée de la modernité s'est accompagnée d'un phénomène de sécularisation. Je démontrerai à quel point le

1 TAYLOR, Charles, Grandeurs et misères de la modernité, Montréal, Bellarmin, 1991, p. 23. L'histoire de l'adjectif "moderne" est plus longue que celle de la "modernité". Dans n'importe quel contexte culturel, l'"ancien" et le "moderne" alternent significativement. Mais il n'existe pas pour autant partout une "modernité", c'est-à-dire une structure historique et polémique de changement et de crise. Celle-ci n'est répérable qu'en Europe à partir du XVI siècle et ne prend tout son sens qu'à partir du $\mathrm{XIX}^{\circ}$ siècle. 
terme sécularité appliqué à la foi chrétienne désigne une caractéristique fondamentale de celle-ci. Il nous arrive souvent d'opposer le christianisme et la modernité. Un regard plus profond laisse voir que les caractéristiques de la modernité ont trouvé dans la foi chrétienne une matrice sans laquelle elles seraient peu intelligibles. Cependant, le "mariage" entre le catholicisme et la modernité a toujours été difficile. Ce chapitre tâchera d'analyser l'évolution du rapport entre l'Église catholique et la société moderne, particulièrement durant la période du concile Vatican II et celle post-conciliaire. De plus, les intervenants pastoraux ne cessent de répéter l'obligation d'évangéliser les paroissiens. Il m'est apparu important de réfléchir brièvement sur ce difficile concept de l'évangélisation et sur le "mystère" de l'inculturation. Cette partie interprétative sur la modernité se terminera par l'énumération de quelques conditions à respecter pour que le débat entre l'Église et la société moderne soit fécond évangéliquement et pour que l'Église soit présente d'une manière pertinente et significative dans la culture moderne du peuple où elle prend corps.

\subsection{Caractéristiques de la modernité}

La modernité est définie par les sociologues comme la civilisation qui a débuté à la fin du $\mathrm{XVIII}{ }^{\circ}$ siècle par deux phénomènes majeurs de société: la révolution industrielle et la révolution démocratique. ${ }^{2}$ Ces changements institutionnels majeurs

La civilisation moderne, définie par l'industrialisation et la démocratie, est une réalité historique complexe. Voir BAUM, Gregory, "La modernité, Perspective sociologique", in Concilium \#244: "La modernité en débat", Paris-Beauchesne, 1992, pp.15-23. JEANNIËRE, Abel, "Qu'est-ce que la modernité?", in Nouveau Dialogue, mai 1992, pp. 4-9. Voir aussi l'excellent article d'André CHARRON: "Quelques traits de la culture québécoise actuelle", in Pastorale Québec: "Le service pastoral de la foi dans le contexte culturel actuel", vol. 105, no 9, 30 juin 1993, pp. 223-245. Je me suis beaucoup inspiré de ces trois articles pour écrire les prochains paragraphes. Le monde n'est pas une réalité matérielle, sensible, aisément répérable et analysable, dissécable comme un composé chimique livrant son secret; il cache des profondeurs. C'est pour cette raison que l'analyse du monde moderne est si complexe. Notre monde n'est plus celui d'il y a deux ou trois siècles. Pour parler de ce monde-là, on parlera de modernité, ou de société moderne, ou de toute autre expression qu'on estimera plus pertinente. 
ont fait naître et se développer une nouvelle culture. La révolution industrielle engendra une plus grande richesse, accentua les effets du capitalisme sur la société et créera deux nouvelles classes sociales, celle des patrons de l'industrie, nouvelle classe dirigeante et la classe ouvrière. Elle a engendré aussi la métropole moderne. Elle a encouragé le développement de la science et de la technique et soutenu l'espoir d'un progrès indéfini. Mais l'approche sociologique reste à une description de la modernité. Si on veut déceler la racine de la dynamique spécifique de la modernité, on ne risque guère de se tromper en faisant appel aux concepts de subjectivité et de rationalité.

"Le passage à la modernité coïncide avec l'émergence d'un sujet humain conscient de son autonomie et avec la victoire d'une analyse rationnelle de tous les phénomènes de la nature et de la société (qu'il s'agisse du progrès scientifique, du processus industriel, du développement d'une économie mondiale, de la centralisation bureaucratique de l'État moderne)." 3

"Moderne" désigne ce qui est advenu après un changement radical, et s'applique aussi bien à l'être humain qu'à son environnement. Le monde moderne est celui qui succède au monde agraire; une nouvelle vision du monde est apparue, profondément différente de celle qui l'a précédée. ${ }^{4}$ Être moderne, c'est donc vivre

3

GEFFRÉ, Claude, JOSSUA, Jean-Pierre, "Pour une interprétation théologique de la modernité", in Concilium \# 244, p.7.

4 "Le début de la modernité, estime Charles TAYLOR est à chercher dans la naissance du "domaine public" ( public sphere ), au XVIII ${ }^{\circ}$ siècle. Ce milieu s'est formé dans les "salons" de la fin de l'Ancien Régime en France et dans les "cafés" des villes anglaises. S'y réunissent pour la première fois, entre eux, penseurs, artistes et hommes de lettres de nations avancées, loin du contrôle du prince et de la censure des Églises. C'est à partir de ces centres que se forme "l'opinion publique", qu'un poète allemand, Christoph Wieland, pouvait déjà décrire avec beaucoup de finesse en 1793 ["L'opinion publique, c'est à mon sens, celle qui progressivement prend racine dans tout un peuple, en particulier chez ces groupes qui, du fait de leur travail concerté, exercent une grande influence. Elle s'impose à un point tel qu'on la rencontre partout; elle s'empare, comme à leur insu, de la plupart des esprits. Dans les situations où elle ose s'exprimer tout haut. L'opinion publique se propage comme une rumeur sourde de plus en plus insistante. Il lui suffit alors de la plus petite ouverture pour s'échapper et pour éclater en force. Elle peut alors en un rien de temps bouleverser les nations et donner un visage nouveau à des portions entières de l'univers." Encyclopedia Britannica, Macropaedia, "Public Opinion", 15th edit., Chicago, 1983, vol. 15, p.211]" (LANGEVIN, Gilles, "Modernité, foi et moralité selon Charles Taylor", in Nouveau Dialogue, mai 1992, p.15). 
dans un monde qui n'est plus celui du passé et qu'il faut réfléchir avec d'autres repères. L'être humain et son monde sont devenus modernes à l'issue de quatre révolutions (traits) majeures (une révolution scientifique, une révolution politique, une révolution culturelle, une révolution technique et industrielle) qu'il nous faut approfondir avec précaution. "Après la traversée de chacune de ces révolutions, le monde a changé de configuration, on ne peut plus le lire de la même façon; l'homme pense le monde et se pense lui-même dans cette nouvelle logique." ${ }^{5}$

\title{
9.1.1 La révolution scientifique
}

Le savant Newton a inauguré la révolution scientifique et a marqué la rupture entre deux visions du monde en énonçant la loi de la gravitation universelle. D'une nature gouvernée directement par Dieu et ses anges, on passe à une nature autoréglée.

\begin{abstract}
"Avant la rupture, l'homme est médiateur entre la nature et le divin dans un monde en ordre, un monde fini, un monde hiérarchisé, un monde que Dieu a créé avec ordre et mesure. Cet ordre du monde, livré à la connaissance humaine, est essentiellement un ordre symbolique par lequel Dieu s'adresse à l'homme. Le "livre du monde" est donné à déchiffrer à l'homme. /.../ De l'image du livre du monde, on passe à celle d'un gigantesque automate cosmique. L'automate n'obéit plus qu'à des mécanismes." 6
\end{abstract}

Le monde entier est mathématisable. De nouvelles ruptures marquent les étapes de la modernité. De la mécanique et du cosmos, on passe à la relativité restreinte, puis à la relativité généralisée d'Einstein.

Le vérifiable et l'observable prennent plus d'importance que le reçu par tradition. D'où un mouvement de relativisation radicale d'une approche déductive, métaphysique, dogmatique de la réalité. Le conflit avec Galilée est symbolique de cet 
affrontement entre deux approches de la réalité (l'approche métaphysique et l'approche empirique du réel fondée sur l'observable). Ceux qui savent ne seront plus les clercs établis, mais les "scientifiques". Dans cette nouvelle approche, qu'advient-il de ce qui n'est pas immédiatement vérifiable? Il faut donc insister sur la révolution scientifique qui est fondamentale et dont toutes les autres dérivent.

\title{
9.1.2 La révolution politique
}

Dans la révolution politique la rupture sera déterminée par l'apparition de la démocratie moderne, d'abord en Angleterre, en Amérique, puis en France.

"La nouveauté tient du fait que la démocratie cesse d'être une forme de gouvernement entre autres (ce qu'elle était depuis Platon et Aristote), pour devenir la seule forme rationnelle d'un État. Désormais, un État moderne ne pourra être que démocratique."7

Ce qui important dans cette révolution, c'est le fondement du pouvoir. Un changement radical influence la nature de l'autorité et la source du pouvoir lequel ne vient plus du chef d'état, du prince, ni de Dieu mais du peuple. Le pouvoir est immanent au peuple. Il n'est justifiable que par l'accord du peuple, devenu une "nation".

\begin{abstract}
"La révolution démocratique, indépendante de l'industrialisation et pourtant liée à elle de bien des manières, a eu aussi des conséquences culturelles considérables. Elle a rejeté les hiérarchies traditionnelles, mis en avant les idéaux de liberté et suscité dans la bourgeoisie, et finalement aussi dans le peuple, un désir de participation politique. En même temps, paradoxalement, la démocratie a crée l'État moderne, caractérisé par la centralisation du pouvoir et une bureaucratie de plus en plus envahissante." 8
\end{abstract}

C'est en effet la transcendance abstraite de l'État sous le signe de la constitution et le statut formel de l'individu sous le signe de la propriété privée qui définissent la

Ibidem.

BAUM, Gregory, "La modernité, Perspective sociologique", pp. 15-16. 
structure politique de la modernité. La rationalité (bureaucratique) de l'État et celle de l'intérêt et de la conscience privés se répondent dans la même abstraction. Cette dualité marque la fin de tous les systèmes antérieurs où la vie politique se définissait comme une hiérarchie intégrée de relations personnelles.

\subsubsection{La révolution culturelle $^{9}$}

La révolution culturelle n'apparaît pas avec la même brutalité que les deux précédentes, elle prend la forme d'un mouvement de pensée très fortement enraciné dans la nouvelle vision du monde physique. "On l'appelle Aufklaerung en Allemagne, Enlightenment dans le monde anglo-saxon et les Lumières en France. Il s'agit d'une laïcisation de la pensée et d'une rationalisation de tous les critères dans tous les domaines."10 La Raison est l'instrument de la libération humaine. Nous pouvons, grâce à la raison, démontrer, comprendre et "maîtriser" la nature et la société. "La laïcisation se présente forcément comme une critique de la religion, surtout au plan de la religion telle qu'elle a été socialement vécue et instituée." 11 Ce mouvement en arrive à la conclusion radicale que les fondements de la vie sociale sont exclusivement d'ordre rationnel. La religion n'est plus considérée comme fondement du social. De fait, la culture moderne oblige à une mutation de la religion pour être crédible dans la société moderne.

9 "Il convient de voir la culture comme une réalité globale de vie, ainsi que le comprennent généralement les sciences humaines. La culture est l'ensemble organique des manières de penser, de sentir et d'agir qui caractérise une collectivité humaine déterminée. Elle est un lieu identitaire, reconnaissable à un style de vie. Et le Concile Vatican II n'a pas hésité à souligner la place éminente de la culture dans la vocation humaine, en déclarant: "C'est le propre de la personne humaine de n'accéder vraiment et pleinement à l'humanité que par la culture"( GS \# 53). La culture n'est pas que l'herritage des acquis. Elle est une réalité dynamique qui connaît des mutations" (CHARRON, André, "Quelques traits de la culture québécoise actuelle", p. 224).

JEANNIÈRE, Abel, Qu'est-ce que la modernité?, p. 6.

Ibidem. 
La réaction romantique a été de grande importance face au rationalisme, elle a produit des idées et des valeurs neuves. Une intériorité nouvelle réfléchissant sur elle-même, le prix accordé à l'expérience, la dimension cognitive des sentiments, le respect d'une sincère expression de soi, le soupçon à l'égard des vérités se prétendant universelles et l'enracinement de l'expérience font partie intégrante de la modernité. Ces idées et ces valeurs continuent de donner forme à la culture actuelle.

Dans le domaine de la culture et des moeurs, la modernité s'est traduite en opposition formelle mais en relation fondamentale avec la centralisation bureaucratique et politique et avec l'homogénéisation des formes de la vie sociale. Nous avons été témoins d'une exaltation de la subjectivité profonde, de la passion, de la singularité, de l'authenticité, de l'éphémère et de l'insaisissable, par l'éclatement des règles et l'irruption de la personnalité, consciente ou non. La modernité va donc susciter à tous les niveaux une esthétique de rupture, de créativité individuelle, d'innovation partout marquée par le phénomène sociologique de l'avant-garde (que ce soit dans le domaine de la peinture ou de la mode) et par la destruction toujours plus poussée des formes traditionnelles (les genres en littérature, les règles de l'harmonie en musique, les lois de la perspective et de la figuration en peinture et, plus généralement, l'autorité et la légitimité des modèles antérieurs en matière de mode, de sexualité et de conduites sociales).

\subsubsection{La révolution industrielle ${ }^{12}$}

Une étape révolutionnaire dans la conquête de cette nature dont l'être humain a émergé.a été marquée par l'industrialisation. 
"Cette révolution se caractérise par l'abstraction du travail. Ce qui veut dire que la technostructure, l'intermédiaire entre lui et la nature, acquiert une autonomie de plus en plus grande. Dans un premier temps, cette révolution se caractérise par le passage de l'outil à la machine-outil. Les gestes du travail ne sont plus liés directement à l'être humain producteur, mais à la machine. L'abstraction se poursuit quand les gestes du travail euxmêmes se mécanisent, en ce sens qu'ils se règlent sur la machine. /.../ L'autonomie de la technostructure est telle que l'homme peut être exclu du processus de fabrication. Et l'homme n'est plus que l'initiateur du processus qui se déroule tout entier dans une sphère intermédiaire entre lui et la nature, cette sphère qu'on peut appeler technostructure." 13

Le nouveau type de rapport à la nature tel que l'ont défini les révolutions scientifique et culturelle est accompagné et structuré par les étapes de la révolution industrielle. Comme le mentionne Abel JEANNIÈRE, au lieu de révolution industrielle, on peut encore parler de révolution technique.

"L'accent est alors mis sur la technostructure et son autonomie. Dans cette perspective, on est moins attentif aux bouleversements que le progrès technique apporte dans l'organisation du travail et, davantage au dynamisme qui permet l'autonomie croissante de la technostructure." 14

Le progrès continuel des sciences et des techniques, la division rationnelle du travail industriel ont introduit dans la vie sociale une dimension de changement permanent, de déstructuration des moeurs et de la culture traditionnelle. Simultanément, la division sociale du travail a introduit des clivages politiques profonds, une dimension de luttes sociales et de conflits qui se sont répercutés à travers le $\mathrm{XIX}^{\circ}$ siècle et le $\mathrm{XX}^{\circ}$ siècle.

L'essor prodigieux des sciences et des techniques, le développement rationnel et systématique des moyens de production et de leur gestion ont donc marqué la modernité comme l'ère de la productivité. On assiste à une intensification du travail humain et de la domination humaine sur la nature, l'un et l'autre réduits au statut de forces productives et aux schémas d'efficacité et de rendement maximal. C'est là le

Ibid., p.7.

Ibidem. 
commun dénominateur de toutes les nations modernes. Si cette "révolution" des forces productives, parce qu'elle laisse relativement inchangés les rapports de production et les rapports sociaux, n'a pas changé la vie, elle modifie du moins d'une génération à l'autre les conditions de vie. Elle instaure aujourd'hui une mutation profonde dans la modernité: le passage d'une civilisation du travail et du progrès à une civilisation de la consommation et du loisir. Mais cette mutation n'est pas radicale: elle ne change pas complètement la finalité productiviste, le découpage chronométrique du temps, les contraintes prévisionnelles et opérationnelles qui restent les coordonnées fondamentales de l'éthique moderne de la société productive.

\subsubsection{L'explosion démographique et les communications de masse}

La croissance démographique, la concentration urbaine et le développement gigantesque des moyens de communication et d'information (ex: les journaux, la radio, la télévision) ont marqué de façon décisive la modernité comme pratique sociale et mode de vie articulé sur le changement, l'innovation, mais aussi sur l'inquiétude, linstabilité, la mobilisation continuelle, la subjectivité mouvante, la tension et la crise. La libre circulation des différents courants de pensée par l'intermédiaire des média a ainsi complètement changé la mentalité des gens (des paroissiens). Il n'est plus possible à aucun sytème de pensée de contrôler la vie des humains dans toutes les dimensions de leur vie. Dans ce contexte moderne, le discours de l'Église est reçu comme un point de vue parmi d'autres. L'enseignement de l'Église est confronté à d'autres horizons de sens propagés dans différents réseaux et dans différents lieux. 


\title{
9.1.6 L'avènement de l'individu
}

Nous ne cessons de répéter que l'avènement de la modernité coïncide avec l'avènement de l'individu. Alors que dans une société traditionnelle l'individu se comprend et est compris par rapport à sa place dans l'ensemble social, dans une société marquée par la modernité (selon un processus d'ailleurs jamais achevé), l'individu est renvoyé à lui-même, élevé au rang de référence unique.

\begin{abstract}
"On parle beaucoup, ces temps-ci, d'un "retour de l'individualisme". L'expression ne me paraît pas exacte. Car l'individu qui prend forme aujourd'hui est bien différent de ce que ce mot désignait jusqu'à une date assez récente. /.../ Dans les sociétés traditionnelles, telles que les ethnologues nous les décrivent, l'individu n'existait pas: chacun s'identifiait au rôle, au statut que le groupe lui attribuait au sein de son ordre qui se reproduisait de génération en génération, organisation d'autant plus pérenne que ses fondements, religieux, lui étaient extérieurs. Le corps lui-même n'était pas individué: les marques qu'y imprimaient peintures, tatouages et scarifications, le situaient en rapport au cosmos naturel et à la société. Cette intégration était due au primat du symbolique qui fait communiquer entre elles, s'encastrer les unes dans les autres, des différentes instances de l'existence que nous avons pris l'habitude de distinguer, voire de séparer (le culturel, le politique, l'économique, etc.). ${ }^{15}$
\end{abstract}

Moins encadré socialement, il revient à l'individu de se constituer en centre de décision, à lui de trouver sa place dans la société, puisque ce n'est plus le groupe (classe ou famille) qui le marie, lui détermine son métier, l'engage dans tel système de pensée. En théorie du moins, parce que l'individu n'existe pas sans des solidarités d'où il émerge et dont l'influence le marque profondément. Il n'en reste pas moins cependant que l'emprise de ces groupes sur lui est relâchée dans des sociétés de la mobilité (mobilité des savoirs, mobilité de l'information, de la locomotive qui permet de côtoyer d'autres moeurs, d'autres idées, d'autres religions). On passe ainsi d'une

15

BLANQUART, Paul, "Nouvel individu et avenir du christianisme", in Lumière et Vie, $\mathrm{n}^{\circ} 184$, p.65, p. 67. Voir aussi WILLAIME, Jean-Paul, "L'individualisme est-il un fléau moderne?", in $A R M, \mathrm{n}^{\circ} 116,15$ novembre 1993, pp. 21-23. 
appartenance totalisante à une appartenance sociale dans laquelle l'individu est invité à faire des choix. Il y a un espace de liberté.

\begin{abstract}
"Bien sûr, l'individualisme désigne aussi ce que plusieurs considèrent comme la plus belle conquête de la modernité. Nous vivons dans un monde où les gens peuvent choisir leur mode de vie, agir conformément à leurs convictions, en somme, maîtriser leur existence d'une foule de façons dont nos ancêtres n'avaient aucune idée. /.../ Comme d'autres aspects de l'individualisme moderne - par exemple, celui qui nous demande de former nous-mêmes nos propres opinions et convictions - , l'idéal d'authenticité invite à une vie plus responsable, (potentiellement) plus pleine et plus différenciée, parce qu'elle serait mieux accordée à ce que nous sommes. Cela comporte des risques - j'en ai examiné quelques-uns. Quand nous y succombons, il se peut même que nous tombions à certains égards plus bas que si cette culture n'avait jamais existe. Mais dans ses formes les plus accomplies, l'authenticité nous appelle à une existence plus profonde. "16
\end{abstract}

Il y a là un phénomène qui peut-être corrosif du tissu social, mais aussi une chance pour l'émergence du sujet. Face au consensus magique, religieux, symbolique de la société traditionnelle, l'ère moderne a donc été marquée par l'émergence de l'individu avec son statut de conscience autonome, sa psychologie, ses conflits personnels et son intérêt privé. Cette aspiration à l'autonomie s'exprime à tous les niveaux: autonomie du savoir, dans le domaine de la connaissance et de la science; autonomie économique puisque l'individu, qui possède le droit de propriété, est l'agent de la libre entreprise et de l'échange marchand; autonomie de la sphère politique vis-à-vis du pouvoir religieux. Dans le domaine philosophique et culturel, c'est l'insistance sur la liberté de création artistique, liberté du rire, de la satire et de la critique en général. De plus, l'individualisme est l'un des éléments intrinsèque de l'affirmation démocratique. Mais condamner l'individualisme à cause de ses effets pervers, n'est-ce pas condamner l'esprit démocratique lui-même?

16

TAYLOR, Charles, Grandeurs et misères de la modernité, Montréal, Bellarmin, 1991, p. 12; p.94. Il nous arrive souvent de confondre l'individualisme et le subjectivisme. Dans une société démocratique, l'individu s'inscrit dans un cadre collectif qui n'a rien de subjectif. Le subjectivisme, c'est le refus des médiations sociales et de la recherche collective de solutions et d'orientations. Cette attitude est condamnable, à juste titre, lorsque l'authenticité de conviction devient le critère de vérité. 


\subsubsection{La modernité et le temps}

La temporalité moderne est spécifique sous ses différents aspects. L'aspect chronométrique correspond au temps qui se mesure et auquel on mesure ses activités, à celui qui scande la division du travail et la vie sociale. Ce temps abstrait qui s'est substitué au rythme des travaux et des fêtes, est celui de la contrainte productive et la temporalité bureaucratique règne même sur le temps "libre" et les loisirs. L'aspect linéaire, le temps "moderne" n'est plus cyclique, il se développe selon une ligne passéprésent-avenir, selon une origine et une fin supposées. La tradition semble axée sur le passé, la modernité sur l'avenir, mais, dans les faits, seule la modernité projette un passé (le temps du révolu) en même temps qu'un avenir, selon une dialectique qui lui est propre. Selon l'aspect historique, surtout depuis Hegel, l'histoire est devenue dominante de la modernité à la fois comme devenir réel de la société et comme référence transcendante laissant entrevoir son accomplissement final. La modernité se pense historiquement et non plus mythiquement.

Mesurable, irréversible, succession chronométrique ou devenir dialectique, de toute façon la modernité a secrété une temporalité tout à fait nouvelle, dimension cruciale, image de ses contradictions. ${ }^{17}$ Mais à l'intérieur de ce temps indéfini, et qui ne connaît plus d'éternité, une chose distingue la modernité: elle se veut toujours "contemporaine" c'est-à-dire simultanéité mondiale. Après avoir d'abord privilégié la

Comme je l'ai mentionné au chapitre premier de la présente thèse, j'interroge surtout les structures ecclésiales présentes du point de vue d'un nouvel aménagement de l'espace. Avec ce développement sur la modernité et le temps, je suis davantage conscient qu'il aurait été tout aussi important de soulever la question d'un nouvel aménagement du temps. Est-il réaliste, pour ne prendre qu'un exemple, de penser donner un certain avenir à la paroisse si celle-ci demeure le lieu de ce qu'il est convenu d'appeler "la pratique dominicale"? Le temps pose des questions aussi pressantes que l'espace. Mais il m'a semblé nécessaire de délimiter le cadre de cette recherche sans lequel ce projet doctoral n'aurait pas été viable. 
dimension du progrès et de l'avenir, elle semble se confondre aujourd'hui de plus en plus avec l'actualité, l'immédiateté, la quotidienneté, l'envers pur et simple de la durée historique.

\subsubsection{Peut-on parler de post-modernité?}

Plus souvent, ceux qui parlent de post-modernité centrent leur attention sur la révolution culturelle et la révolution industrielle. L'histoire de ces deux révolutions leur paraît comporter une rupture essentielle qui marque un avant - la modernité - et un après - la post-modernité. Pour eux, la rupture culturelle apparaît autour de 1968 lorsque la liberté individuelle est préférée aux valeurs collectives. Dans le domaine industriel, c'est la crise économique qui marque le tournant. Pour d'autres, la postmodernité serait caractérisée par l'avènement de l'informatique. Aujourd'hui, aurionsnous déjà débouché sur un autre cycle de l'histoire? Pour ma part, comme le pense Gregory BAUM, il me semble préférable de parler plutôt d'étapes de la modernité dans la suite des temps que de post-modernité. 18 Cette nouvelle phase de la modernité est caractérisée par le passage des certitudes d'une science positive triomphante à une incertitude généralisée. Elle pose un regard critique sur ses acquis et ses ambiguïtés.

"Avec la modernité se sont imposées la rationalité scientifique et sa traduction opératoire en rationalité technique avec ses impératifs de performance et d'efficacité, de production et de consommation. Cette capacité scientifique et technique du génie humain a rendu possibles le développement des connaissances, l'amélioration de la qualité de vie, la restauration de la dignité humaine et le recul des conditions de misère et de pauvreté. Mais la rationalité technique a créé une sociêté médiatisée par des objets et des échanges

Gregory, "La modernité, Perspective sociologique", p. 22). Paul BLANQUART préfère lui l'expression "néo-ancien": "Ce terme "post-moderne" est d'abord apparu dans des milieux d'architectes et de critiques d'art qui refutaient le "style international" et lui opposaient la reprise de toutes les formes du passé et d'ailleurs (c'est-à-dire non occidentales), ainsi que leur mélange /.../ Plutôt que de "postmoderne", ne vaudrait-il pas mieux parler de "néo-ancien"?"(BLANQUART, Paul, " "Postmarxisme" et "postmodernité" - Quelle présence de l'Église?", in Concilium \#244, 1992, p.154.). 
fonctionnels. On n'échappe pas au risque que les rapports sociaux deviennent fonctionnels et que prédomine la raison instrumentale: tout est vu comme instrument pour l'action, valeur de rendement dans l'action, et est mesuré à la jauge de l'efficacité et de l'utilité. Les moyens sont bien exploités, mais la fin qu'est l'homme est oubliée. Ou encore des rapports humains sont sacrifiés à la rationalité administrative et à la logique de la gestion, à la raison instrumentale qui anime une machine objective. On ne peut ignorer non plus les intérêts du marché qui entraîne le travail précaire, le chômage et la pauvreté. I... La postmodernité commence à poindre, qui assume les acquis de la modernité, mais de façon critique et pour dépasser ses ambiguïtés. Elle rétablit la primauté du sujet humain contre l'impérialisme technocratique. Elle permet le retour du religieux contre le réductionisme d'une certaine modernité rationaliste./.../ La postmodernité, face à l'impérialisme de la science et de la technique, veut garder vive l'interpellation de la conscience et l'idéal de l'authenticité de la personne. Pour rester libre dans la société de consommation, elle encourage le retour à la spiritualité, qui est exigence d'horizon, ouverture au dépassement, aspiration à la plénitude d'être, appel de transcendance." 19

En somme, tous ceux qui parlent de post-modernité constatent que le monde aujourd'hui traverse une crise grave. Le symptôme d'un changement majeur est bien la crise de l'épistémologie scientifique. Mais doit-on penser qu'une telle crise, si profonde et généralisée soit-elle, inaugure une nouvelle ère historique? Peut-être. En attendant, il me semble plus prudent de considérer la modernité comme une histoire qui continue. Une chose est sûre. La post-modernité ne peut se comprendre dans le sens du retour des certitudes.

\subsection{Sécularisation et société moderne}

En Europe, l'arrivée de la modernité s'est accompagné d'un phénomène de sécularisation. Historiens, sociologues et théologiens parlent de sécularisation pour analyser les relations complexes qu'entretiennent nos sociétés modernes avec la religion. La religion devait désormais prouver son utilité dans les catégories produites par la rationalisation de la société. 
Que désigne ce terme "sécularisation"? Il renvoie d'abord à un phénomène juridico-politique aisément observable: celui de la séparation des Églises et de l'État. 20 La sécularisation est un processus complexe qui cherche à nommer la réaffirmation de l'autonomie de fonctionnement de la société civile qui, pendant un certain temps, était théoriquement sous la tutelle du pouvoir ecclésiastique.

"La sécularisation désigne la fin du complexe mental et institutionnel de la chrétienté en ce qui concerne les relations Église-État, et l'Émergence d'une culture nouvelle dans laquelle les religions ne sont plus en position de suprématie indiscutée."21

La sécularisation désigne une mise à l'écart de plus en plus prononcée de la religion hors de la sphère publique, et sa limitation au seul domaine privé. La religion peut subsister mais dans la marge, à titre privé et à condition que ses prétendus principes moraux ne viennent pas perturber les règles de droit édictées par le gouvernement civil, ni non plus que son prosélytisme ne perturbe la paix publique. De plus, l'émergence de structures sociales laïques ne comportent plus de régulations religieuses. Un tel processus pose évidemment des défis nouveaux dans la manière de situer la dimension religieuse dans une culture et dans l'organisation de la vie collective. La sécularisation oblige à relire et à ré-interpréter radicalement la nature de la

20

"Nul problème à admettre en même temps que ce terme ne soit pas exclusif, qu'on doive mettre en série d'autres comme ceux de "société moderne", "modernité", "société industrielle, ou "société techno-scientifique". Ceux-ci, pris isolément, ont d'autres inconvénients et d'autres limites. Ils équilibrent cependant le concept de sécularisation, mais celui-ci a le mérite d'indiquer qu'en l'utilisant, c'est bien du lien religieux qu'il s'agit dans le lien social contemporain. À ce titre, on ne peut pas s'en passer" ( VALADIER, Paul, "Procès de la sécularisation - Sécularisation et société moderne", in L'Église en Procès, France, Flammarion, 1987, pp.24-25). Les réflexions de M. VALADIER ont beaucoup éclairé ma réflexion sur la culture moderne.

21 DUFOUR, Simon, BÉLISLE, Denis, BOUCHARD, Nicole, HUDON-MIOR, Jocelyne, "La sécularisation, être chrétien au coeur du monde", in Présence, vol. 1, no 7, décembre 1992, p. 13. "L'un des effets les plus bénéfiques de la sécularisation, quoi qu'il en soit par ailleurs de l'ambiguité de ce terme, est précisément de faire apparaître la juste "autonomie des réalités terrestres" (VALADIER, Paul, "Chances du message chrétien dans le monde de demain", in Concilium \#244, 1992, p. 144.). Je m'inspire largement de ces deux articles dans les prochaines lignes. 
présence de la religion chrétienne (entre autres du catholicisme paroissial) dans les structures de la société moderne.

\title{
9.2.1 La sécularité, une dimension constitutive de la foi chrétienne
}

Un christianisme authentique doit se situer dans la ligne de la sécularité ( saeculum qui fait partie du mot "séculier" signifie "monde") de la foi. Le terme sécularité appliqué à la foi constitue une caractéristique fondamentale de la foi chrétienne: c'est dans le monde, au sein d'une histoire concrète que la foi se vit avec tout ce que cela suppose.

\begin{abstract}
"C'est dans cette perspective qu'on peut saisir la sécularité comme une dimension constitutive de la foi chrétienne. C'est dans le monde et dans l'histoire, au sein de la dynamique sociale, au coeur même des défis d'humanisation, de libération et d'aménagement de la terre, que la foi nourrit son mouvement et atteste sa fécondité. En dehors de cet enracinement, elle risque fort de devenir opium -comme l'a fort à propos dénoncé le marxisme-, ou encore idolâtrie dans un processus de sacralisation aliénant pour la personne - comme l'ont dénoncé les prophètes bibliques." 22
\end{abstract}

Il est donc important de respecter la sécularité de la foi chrétienne. Il y va de son identité profonde, de son originalité dans le champ des religions. Connaître le Dieu vivant en Jésus Christ, prendre au sérieux le devenir du monde dont l'issue historique n'est pas décidée d'avance, respecter la subjectivité des personnes libres sans lesquelles aucune foi n'est possible semblent des dimensions interreliées que le concept de sécularité cherche à exprimer. Le message du salut n'est ni une gnose ni une construction intellectuelle, mais l'accueil d'un don gratuit de l'amour de Dieu qui a pris les routes de l'histoire. Les croyants ( les paroissiens) sont ainsi invités à accepter d'entrer sans réticence dans le débat constitutif de nos sociétés pour y apporter l'énergie

22 DUFOUR, Simon, BÉLISLE, Denis, BOUCHARD, Nicole, HUDON-MIOR, Jocelyne, "La sécularisation, être chrétien au coeur du monde", p.15. 
et l'espérance de la foi. La participation des croyants ( les paroissiens) au débat démocratique s'impose d'autant plus aujourd'hui que, tout le monde le sait, nos sociétés font face à des défis sans précédent. Il s'agit là d'un des lieux éminents de la présence active de l'Église (de la paroisse) à la modernité. Dès le début de son pontificat, dans sa première Encyclique le Rédempteur de l'homme (Redemptor hominis ), Jean-Paul II n'a-t-il pas martelé l'idée que l'homme concret avec tous ses problèmes "est la première route et la route fondamentale de l'Église"?23

\title{
9.3. Le christianisme: la matrice de la modernité. 24
}

La modernité est née sur le terrain géographique et culturel du christianisme. Les caractéristiques de la modernité ont trouvé dans la foi chrétienne une matrice sans laquelle elles seraient peu intelligibles. Elles sont loin de s'inscrire en opposition au christianisme ou au catholicisme.

\begin{abstract}
"C'est pourquoi le déni de reconnaissance envers la modernité dans certaines franges de l'Église nous paraît non fondé et assez catastrophique: sans fondement parce que la modernité est une des conséquences de la foi chrétienne, et à ce titre un chrétien peut et doit se sentir parfaitement à l'aise, de plain-pied avec un héritage dont, plus que beaucoup d'autres, il connaît et comprend les sources..."25
\end{abstract}

"Toutes les routes de l'Église conduisent à l'homme. L'Église ne peut abandonner l'homme, dont le "destin", c'est-à-dire le choix, l'appel, la naissance et la mort, le salut ou la perdition, sont liés d'une manière si étroite et indissoluble au Christ. /.../ Cet homme est la première route que l'Église doit parcourir en accomplissant sa mission: il est la première et la route fondamentale de l'Église, route tracée par le Christ lui-même, route qui, de façon immuable, passe par le mystère de l'incarnation et de la Rédemption" ( SS. JEAN-PAUL II, Le Rédempteur de l'homme, Lettre encyclique "Redemptor hominis", Montreal, Fides, 4 mars 1979, pp. 43-45. [ L'Église aux quatre vents]).

24 Dans son livre L'Église en procès, loin d'opposer christianisme et modernité, Paul VALADIER montre comment celui-ci est une des sources de celle-là, et comment les deux sont finalement compatibles, malgré la tension inévitable mais féconde qui les oppose. Nous savons que ce livre lui a valu d'être limogé par le Vatican de son poste de directeur de la célèbre revue des jésuites français Études.

25 VALADIER, Paul, L'Église en procès, p.110. "La modernité est donc l'horizon culturel de notre monde. On peut la considérer avec pessimisme, mais on ne peut sûrement pas l'ignorer ni passer à côté. S'il y a lieu d'être critique devant certains dérapages, il faut composer avec 
C'est la dynamique chrétienne qui est parvenue à remodeler l'ensemble du rapport de l'être humain à la nature (science) et de l'être humain à l'être humain (individualisme, État bureaucratique, démocratie). Jésus de Nazareth a présenté d'une manière totalement neuve, le Dieu vivant, et il a instauré une nouvelle dialectique du sacré et du profane et un nouveau rapport entre la religion et la vie dans une ligne libératrice pour la personne humaine et la société. Il a renvoyé les humains à leurs responsabilités, il a suscité leur autonomie et les a invités à s'engager au culte d'un Dieu qui appelle à l'adoration et à la charité fraternelle, et non essentiellement à l'observation des coutumes sociales et du système religieux de son temps. Plus que de fin de religion, il faudrait peut-être dire que le christianisme est l'aurore de la religion moderne. Car cette religion de la fin d'une religion englobant le social dans ses prescriptions, qui est religion d'une liberté à construire, enjoint ainsi au croyant un culte à Dieu qui s'exerce par le service d'autrui et la présence sociale.

\begin{abstract}
"Le christianisme a engendré un monde qui le conteste ou qui peut se passer de lui; mais un monde avec lequel il demeure en communion matricielle et auquel il a toutes les chances de demeurer associé, moyennant évolution et adaptation.... Probablement même, si l'on pousse l'analyse, le christianisme est-il la seule religion en état de compatible jusqu'au bout avec la modernité." 26
\end{abstract}

On ne saurait mieux dire.

La valorisation de la personne comme être unique et digne de respect n'est pas nécessairement le coup de force d'une raison dénaturée ou la rébellion d'un orgueil contre Dieu. On peut la considérer, par exemple au niveau des déclarations des droits

cette donnée de la culture occidentale et la faire aboutir à ses formes nobles. Considérée positivement, elle a d'ailleurs beaucoup de connivences avec la vision chrétienne la plus authentique de l'homme et de la société" (CHARRON, André, " Quelques traits de la culture québécoise actuelle", p. 225.).

26 GAUCHET, M., "La religion de la sortie de la religion", in Autrement, $\mathrm{n}^{\circ} 75$, décembre 1985, p. 12. 
de l'homme, comme la traduction politique et juridique (plus ou moins heureuse) d'une "donnée" chrétienne: l'être humain image de Dieu est aimé pour lui-même, au point même que Dieu en son Fils l'appelle à le connaître tel qu'il est et l'associe à sa propre vie. Religion de liberté, selon les affirmations répétées de saint Paul ${ }^{27}$ et même d'Hegel28, le christianisme nous met beaucoup moins devant des obligations légales ou morales à honorer que devant la libre décision de suivre le Christ et de vivre de son Esprit. Une telle religion n'est-elle pas à la fois la matrice de la modernité, celle qui est en cohérence avec ses principes?

\subsection{L'Église catholique et la modernité: un mariage difficile!}

L'Église catholique a condamné et refusé la modernité, avec une intransigeance parfois très forte, au moins jusqu'à Vatican II. ${ }^{29}$ Le Concile Vatican II a marqué un changement d'esprit dans le rapport de l'Église au monde moderne. Il a été

27

Romains.

28 "Hegel a montré de façon convaincante que le christianisme est la religion de la modernité, parce qu'il est aussi la religion de la liberté. Sans adopter en tant que telles les thèses hegeliennes sur la liberté et sur le christianisme, on peut toutefois en admettre la fécondité de l'analyse. Car la modernité met bien au centre de ses perspectives et des valeurs qu'elle veut honorer politiquement et culturellement la liberté personnelle et les libertés publiques. En d'autres termes encore, elle s'ordonne à partir de la promotion de la subjectivité, comprise comme l'aptitude d'un sujet à se déterminer soi-même librement et en connaissance de cause./.../ La liberté ou la subjectivité ne sont des valeurs positives que si elles sont désirées et honorées par des hommes et des femmes qui optent pour elles plutôt que pour la passivité, le caprice ou la servitude. /.../ La liberté moderne peut s'abîmer en caprice liberticide. /.../ Par rapport à ces redoutables dérives, le christianisme n'est pas trop mal placé pour offrir un sens de l'homme et de la société qui préviennent des maux dans lesquels pourraient bien sombrer nos sociétés" ( VALADIER, Paul, "Chances du message chrétien dans le monde de demain", pp. 146-147.).

29 "Pour l'Église romaine, qui n'a jamais eu le monopole de l'antimodernité, c'était une question de survie devant un bouleversement qui la prenait de court et dont elle ne pouvait mesurer ni l'ampleur, ni les développements, ni la puissance. La résistance fut longtemps sa seule ressource devant ce qu'elle percevait comme une "répudiation" et une "apostasie"...." (POULAT, Émile, "Catholicisme et modernité, un procès d'exclusion mutuelle", in Sociologie et sociétés, vol. XXII, $\mathrm{n}^{\circ}$ 2, octobre 1990, p.30.). 
"l'événement fondamental de la vie de l'Église contemporaine" selon une formule souvent reprise par Jean-Paul II. 30

\subsubsection{Jean XXIII: le promoteur du dialogue entre l'Église et le monde moderne}

À l'annonce de la convocation d'un Concile oecuménique par Jean XXIII le 25 janvier 1959, beaucoup n'attendaient pas grand-chose d'une telle assemblée, sinon la continuité par rapport à Trente et à Vatican I. Plusieurs espéraient que soient réaffirmés quelques principes fondamentaux contre les tentatives d'ouverture au monde moderne. Ainsi se dessinent des attentes diverses entre ceux qui pensent qu'on peut continuer dans une ligne bien marquée et ceux qui espèrent du Concile la solution d'un divorce devenu insupportable entre catholicisme et monde moderne. Or à l'ouverture de la première session, le 11 octobre 1962, Jean XXIII écarte à la fois la perspective de condamnation et celle du dépassement du divorce avec la modernité en demandant que la doctrine "soit approfondie et présentée de la façon qui réponde aux exigences de l'époque." 31 À ses yeux, l'Assemblée sera une stimulante expérience de communion ecclésiale dans l'Esprit et le point de départ d'un dynamisme renouvelé.

Jean XXIII n'a pas hésité, dès l'ouverture du concile, a faire des reproches sans ambigüité aux personnes ayant uniquement une vision pessimiste du monde. Il a adressé la parole en ces termes à ces "prophètes de malheur qui,

bien qu'enflammés de zèle religieux, manquent de justesse de jugement et de pondération dans leur façon de voir les choses. Dans la situation actuelle de la société, ils ne voient que ruines et calamités; ils ont coutume de dire que notre époque a profondément empiré

30 Par exemple dans son discours aux participants au colloque de L'École française de Rome (30 mai 1986), in La Documentation catholique, $\mathrm{n}^{\circ}$ 1921, 6 juillet 1986, col. 638.

31 La Documentation catholique $\mathrm{n}^{\circ} 1387,4$ novembre 1962, col. 1282. Cette option, prise par la suite par les Pères du concile, durant la première session, a "donné le ton" de l'attitude de l'Église envers le monde. Le "dialogue" devint en quelque sorte le paradigme conciliaire de l'attitude de l'Église envers le monde moderne. 
par rapport aux siècles passés, ils se conduisent comme si l'histoire, qui est maîtresse de vie, n'avait rien à leur apprendre et comme si, du temps des conciles d'autrefois, tout était parfait en ce qui concerne la doctrine chrétienne, les moeurs et la juste liberté de l'Église." 32

Jean XXIII a donc avancé un argument qui touche une attitude: celle qui, prenant prétexte des malheurs des temps ou de la triste situation de l'Église, exalte le passé comme le lieu béni où la foi vivante régne sur les esprits et où les moeurs chrétiennes ne connaissent pas l'actuelle dépravation. Ces "prophètes de malheur" ou ces ardents chevaliers de la "vraie" foi ne sont-ils pas victimes de leur imaginaire: hier était plus beau qu'aujourd'hui. 33 À supposer qu'il l'ait été, c'est aujourd'hui dans le monde tel qu'il est, que nous avons à vivre et à témoigner, et que Dieu sollicite notre foi et notre espérance. Le Dieu de Jésus Christ nous invite à vivre dans le monde qu'Il aime, qu'Il nous donne comme jardin d'existence où découvrir sa présence discrète et goûter sa joie. C'est au coeur de ce chantier historique qu'il nous convie à vivre la foi comme pratique des valeurs du royaume.

\subsection{2. $\underline{\text { A Vatican II, une confrontation profonde avec la modernité }}$}

À Vatican II, le niveau de confrontation avec la modernité a été très intense. Il ne s'agissait pas seulement d'adapter la vie de l'Église aux conditions modernes de la vie, mais de repenser globalement sa nature même, mise en confrontation avec les réalités sociologiques et culturelles devant lesquelles on ne voulait plus rester fermés.

32

Discours prononcé le 11 octobre 1962. Cf. La documentation catholique, $\mathrm{n}^{\circ} 1387,4$ novembre 1962, col. 1380.

33 Aucun être humain n'est jamais définitivement délivrée de cet imaginaire. Il faut une vigilance constante pour écarter cette attitude pessimiste que chacun porte en soi. L'acceptation de la modernité ne va nullement de soi. Cette tâche d'ouverture est rude et sans doute inachevée par nature. 
Au cours du concile Vatican II, l'attitude de l'Église envers le monde moderne a mûri. Cela correspond, tout d'abord, au passage d'une interprétation de la modernité comme catégorie idéologique - qui avait été celle de la tradition antimoderniste - à sa considération comme phénomène véritablement historique. Ce passage s'annonçait déjà de manière précise dans les intentions de Jean XXIII qui avait décidé de réunir le concile, considérant la situation particulière du monde moderne et estimant que l'histoire de l'être humain était arrivée à un point culminant. L'attitude envers le monde moderne mûrie au concile Vatican II correspond ainsi au renoncement de l'Église à fonder sa revendication de vérité sur un bagage indiscuté de tradition doctrinale et sur l'autorité de sa propre institution. Cela représentait, d'un côté, que l'on choisissait des formes de présence dans la société moderne étrangères au principe de la potestas indirecta de la tradition post-tridentine et tournées plutôt vers la solidarité avec quiconque subissait les conséquences et les injustices très graves de la société moderne; d'autre part, cela signifiait que l'on adoptait la méthode de confrontation réciproque comme instrument pour affirmer la validité du message du salut.

Dans la Constitution sur l'Église dans le monde de ce temps, l'Église est invitée à se tourner vers la société. ${ }^{34}$ Loin de se complaire à désigner les malheurs du temps, le Concile a reconnu que l'Église reçoit beaucoup du monde 35 , et même de ses ennemis. ${ }^{36}$ De plus, dans l'oeuvre centrale de Vatican II qu'est la Constitution sur l'Église ( Lumen Gentium), se trouve la définition de l'Église comme peuple de Dieu.

L'Église dans le monde ce ce temps, $\mathrm{n}^{\circ} 33, * 2$. L'expression conciliaire "les signes des temps" montre l'histoire comme véritable sujet théologique, lieu d'une incarnation et manifestation continuelle de la grâce, un lieu non pas conceptuel mais concret, saisi dans sa dynamique et aussi dans sa modernité.

L'Église dans le monde ce ce temps, $\mathrm{n}^{\circ} 44, * 1, * 2, * 3$.

$L^{\prime}$ Église dans le monde ce ce temps, $\mathrm{n}^{\circ} 44, * 3$. 
"Cette confrontation (la modernité et le concile Vatican II) a été thématisée d'une manière spécifique dans quelques schémas particuliers, mais a eu, de fait, une action profonde sur les problèmes et dans les débats les plus importants abordés par le concile. Par exemple, on peut soutenir que, dans la redéfinition de l'Église comme peuple de Dieu, se reflètent, d'une part, le principe juridique de l'égalité des individus et, de l'autre, la conscience du haut degré de responsabilité individuelle qui, dans une société sécularisée, pèse sur chaque fidèle. De même, dans la difficile discussion sur la collégialité épiscopale, ne manquèrent pas les références aux institutions parlementaires modernes et la considération de la diversité des situations nationales." 37

Par cette expression, plus peut-être que par bien d'autres traits, le Concile renouvelait son intelligence de l'Église qui, de société centrée sur soi, bien gardée aux postes frontières, se reconnaît comme rassemblement auquel Dieu appelle de manière diversifiée et par des modes d'allégeance multiformes. De plus, la Constitution sur l'Église en substituant à une Église statufiée dans une forme juridique éternisée, l'approche d'une Église "sacrement", vivant fondamentalement dans un rapport à une altérité qui la constitue, ouvrait des questions nouvelles sans pouvoir donner par avance la solution.

La juste appréciation des conséquences d'un Concile ne dépend pas de la seule étude de ses textes ni de l'examen des effets immédiats de son "application". La question est de savoir quel ébranlement il a provoqué dans la vie de l'Église et quelles transformations spirituelles et intellectuelles de longue portée il entraîne. Or il ne fait guère de doute que par un ensemble de dispositions théologiques et par son orientation globale, Vatican II a marqué la fin de l'ère tridentine. Il a inauguré sur tous les points examinés (références aux sources, à la société, à l'Église même) un autre rapport que celui qui prévalait. Il a engagé les catholiques (les paroissiens) à retrouver une relation beaucoup plus cohérente avec la grande tradition que le rapport crispé des siècles passés l'avaient fait. Là est l'originalité du Concile: il a rompu avec les conceptions d'un concile et dans les indications de Jean XXIII", in Concilium \#224, 1992, p.121. 
catholicisme assiégé et il a ouvert la voie à une relation sans peur ni timidité avec le monde moderne. Cependant, la réforme véritable d'une institution comme l'Église n'a de chances de s'opérer avec fruit et sans fracture grave que par une lente germination qui fait descendre les intuitions nouvelles dans les profondeurs de la sensibilité commune. Les plus beaux textes resteront sans effets ou seront appliqués de travers tant que les intelligences, les coeurs et les volontés de tous n'auront pas été atteints. Celui qui croit que l'Esprit-Saint est l'inspirateur de cette oeuvre, comprend aussi que c'est seulement dans la durée et à travers de difficiles conversions, que tous et chacun parviendront à "s'approprier" ce don spirituel.

\subsubsection{Une relation difficile entre Paul VI et la modernité}

Vatican II s'est terminé par une série de messages adressés à diverses catégories sociales, message qui, dans le style et les intentions, rappelaient le message initial d'octobre 1962 de Jean XXIII. On voulait que le "dialogue" avec le monde moderne commencé au concile continue et s'approfondisse au cours des années suivantes, que soit inaugurée une nouvelle période de "pastoralité" dans l'Église. Cependant, les difficultés que comportait un tel dialogue se manifestèrent vite (les problèmes du développement des pays du Tiers-monde, la nouvelle société de masse des pays occidentaux produite par la société de consommation, la crise progressive des valeurs culturelles qui explosa dans la contestation des jeunes à la fin des années soixante, etc.) Durant le pontificat de Paul VI, l'Église dut alors faire face à la tâche de définir en termes nouveaux son rôle et sa position dans la société moderne et elle dut aussi affronter les conséquences d'un processus de sécularisation et de modernisation ayant de profondes répercussions sur les structures elles-mêmes. De l'interprétation discordante des documents conciliaires sortirent les tensions les plus radicales. Si, d'une part, les évêques de la minorité trouvèrent en Mgr Lefebvre leur point de 
référence pour une lecture minimaliste des documents manifestant une attitude conservatrice à la modernité, d'autre part, diverses expériences, comme celle des communautés de base nées en Amérique Latine après la Conférence de Medellin, tirèrent de la relecture de la constitution pastorale Gaudium et Spes et de l'encyclique Populorum progressio de Paul VI les motivations d'un profond engagement dans les mouvements de libération de leurs pays. Devant ces développements, le Magistère de Paul VI fut assez circonspect. Le dialogue et la confrontation devaient rester les critères guidant l'attitude de l'Église. Paul VI avait lui-même consacré au terme du "dialogue" une partie très importante de son encyclique-programme de 1963. Toutefois, ce fut Paul VI qui souligna avec toujours plus d'insistance dans les années postconciliaires que dialoguer ne voulait pas dire perdre l'utile distinction entre l'Église et le monde. Plusieurs fois, il précisa que l'Église, de toute façon, devrait rester elle-même, que les promesses baptismales demandaient certains renoncements à l'esprit du monde, que l'aggiornamento ne signifiait pas l'abandon de la tradition, des dogmes, des structures ecclésiales. La difficulté de trouver un prudent équilibre entre les choix opposés conduisit finalement Paul VI à un repliement progressif vers une dimension plus spirituelle de la mission de l'Église. Dans l'encyclique Humanae Vitae qui abordait le sérieux problème du contrôle des naissances resté en suspens depuis le concile, la distinction voulue entre la doctrine ecclésiastique et les valeurs du monde moderne fut plus évidente.

\subsubsection{La mode "post-conciliaire" est "au rétro"}

Peu après le Concile, et presque sans discontinuer depuis, Vatican II a été l'objet d'un procès en règle. On dit par exemple: ce Concile a été prolixe, bavard, tout n'est pas égal dans cette production hâtive, approximative, on ne peut donc guère se fier à (tous) ses documents, il faut interpréter ce Concile strictement en fonction de la 
Tradition 38 , et c'est au Magistère de Pierre de donner cette interprétation. On estime donc à nouveau nécessaire de recourir à la bonne interprétation soit celle des anciens experts souvent déconcertés par des audaces qui leur ont échappé, soit celle du Magistère ecclésiastique. Si l'on ne peut attaquer le Concile, on s'en prend alors aux gens d'Église, laïcs, prêtres, évêques, qui ensuite l'ont, ou bien mal "appliqué" (quel mot étrange!39), ou bien ont profité de lui pour introduire des réformes hâtives, piétiner un héritage séculaire, innover sans retenue.

"Le concile Vatican II avait paru introduire un changement remarquable dans le rapport du catholicisme à la modernité. Certes d'abord, et même essentiellement, grâce

38

Le concept de tradition est à clarifier. Il faut sans cesse rappeler que l'Église n'a qu'une annonce à proclamer, celle de Jésus-Christ, sauveur des hommes, et que toutes les traditions (passé) n'ont de sens que si elles ouvrent (présent) à une intelligence concrète plus juste et plus profonde du Christ, en vue de l'avènement du Royaume (avenir). C'est même cet avenir qui doit primer dans l'ouverture à celui qui est présent, et écarter du passé tout ce qui surcharge inutilement. Aussi la tradition chrétienne est-elle essentiellement cet enracinement qui permet d'aller de l'avant, la mémoire qui permet d'anticiper sans laquelle nous n'aurions pas d'avenir parce que nous n'aurions aucune présence lestée de passé. Mais mémoire et tradition ne sont que les conditions de l'ouverture à Celui qui vient et qu'aucune tradition ne retient. L'Église doit donc être une communauté en attente active. Fernand DUMONT nous invite à cette vigilance constante lorsqu'il déclare dans une entrevue à la revue $R N D$ : "On touche là un problème bien réel pour une religion qui a 20 siècles d'existence: c'est celui de la tradition. Que faut-il entendre par tradition? Est-ce simplement l'accumulation, au cours des siècles, de tous les héritages du passé dans une espèce de bric-à-brac? La tradition vivante, n'estelle pas plutôt le tri que l'on fait dans ce que l'histoire à tendance à accumuler? Autrement dit, la tradition est-elle un dépôt pour reprendre une expression qui a été bien à la mode, mais qui est aussi bien ambiguë? N'est-pas plutôt un discriminant pour faire le tri dans ce qui nous est légué et aussi dans ce que le présent nous offre? Dans cette perspective, la tradition devient une lumière et une force pour se débarrasser de ce qui encombre. Ce n'est pas facile d'en arriver à cette idée vivante de la tradition. /../ Est-ce que nous serons capables de retrouver le sens de la vraie tradition, celle qui sert à démêler ce qui est important de ce qui ne l'est pas? À dégager ce qui est authentique dans ce qui nous vient du passé et aussi ce qui est valable dans la nouveauté qui s'offre à nous? De ce point de vue, nous sommes à un moment décisif, au Québec et ailleurs dans le monde. Un grand ménage s'impose, parce qu'il faut revenir à l'essentiel ou du moins départager l'essentiel de l'accessoire" (DUMONT, Fernand, "La crise actuelle est celle d'une dissociation entre l'Église et la croyance au Christ", in $R N D, \mathrm{n}^{\circ} 3$, mars 1993, p.20).

39 Je n'aime pas l'expression "appliquer" le Concile, car celle-ci laisse entendre que Vatican II constitue une totalité de décisions achevées qu'il s'agit maintenant de mettre en oeuvre. Le risque est d'ailleurs grand à l'heure actuelle, soit de surévaluer, soit de dévaloriser cet "événement fondamental". On le surévalue quand on l'identifie à une sorte de stade indépassable comme si avec lui le terme de l'histoire de l'Église est atteint. On le dévalorise quand on nie la rupture qu'il marque à beaucoup d'égards entre un avant et un après. En réalité la fidélité au Concile oblige à prendre acte des changements de mentalités et des conversions exigés pour regarder vers l'avenir. 
aux perspectives positives qui commandaient la Constitution pastorale sur l'Église dans

le monde de ce temps, mais plus généralement par un ton, un style, une allure, bref un esprit qui traversait la plupart des textes adoptés par les Pères. /../ Or, vingt-cinq ans après, on est presque tenté de ne voir dans l'éclaircie conciliaire qu'une brève parenthèse, presque une anomalie. Même si personne (hormis les schismatiques qui ont suivi Mgr Lefebvre) ne remet officiellement en cause les orientations du Concile, et ne peut ouvertement le faire, des relectures restrictives se développent à peu près sur tous les points. Surtout un ton nouveau de critique, de mises en garde, voire de condamnations de la société moderne prend le dessus. Qu'il s'agisse peut-être d'un conformisme assez inconscient de la part des autorités qui adoptent cet esprit, à l'égard des doutes qui traversent un monde en proie à l'inquiétude après l'optimisme des années soixante qu'on retrouve dans l'église chez ceux-là mêmes qui se croient prophétiques, un écho et une orchestration assez directs des inquiétudes de l'opinion, n'est après tout pas étrange. Mais on peut se demander si cette humeur négative, toute modelée qu'elle soit par les humeurs du "monde", n'indique pas la permanence d'un contentieux non liquidé entre catholicisme et modernité." 40

Le fait est cependant que près de trente ans après le Concile, l'Église connaît plutôt une période où dominent les interrogations et les doutes sur les "ouvertures" récentes. Tout se passe comme si, après une grande période de créativité, qui va toujours de pair avec quelques désordres, se manifestait assez largement, ou plus particulièrement chez certains responsables un souci de serrer les freins. Même sans directives précises, qui cependant ne manquent pas (qu'on pense à la glaciation liturgique actuelle, à la suspicion sourcilleuse à l'égard de la recherche théologique, 41

40

41

VALADIER, Paul, "Catholicisme et modernité, un procès permanent", p.13.

L'affaire Léonardo BOFF (ou Eugen DREWERMANN ou....) montre que les impulsions du Concile ont du mal à être acceptées par ceux qui se sentent dépouillés d'une part de leur pouvoir de contrôle. Plutôt que la discussion dont elle se méfie, l'autorité requiert l'obéissance, ou du moins "une soumission religieuse de l'intelligence et de la volonté à une doctrine que le Pontife suprême ou le Collège des évêques énonce en matière de foi et de moeurs, même s'ils n'ont pas l'intention de la proclamer, par un acte décisif; les fidèles veilleront donc à éviter ce qui ne concorde pas avec cette doctrine" (Code de Droit Canon, $\mathrm{n}^{\circ}$ 752). "Il n'en paraît que plus effrayant de voir que, de tous les groupes à activité culturelle ou spirituelle, l'Église catholique est le seul à n'avoir pas renoncé à sa vision de la sainteté de l'obéissance évangélique, comprise comme une soumission sans condition de la personne à la volonté des supérieurs ecclésiastiques, et à n'avoir pas cherché à mettre en accord son style de vie avec le principe fondamental de l'époque contemporaine: la liberté humaine, et en particulier, la "liberté chrétienne". /.../ Le personnage suprême auquel s'adresse cette soumission de l'individu à la volonté de l'Église, c'est le "père des Pères", le Saint-Père, le pape. La divinisation de son pouvoir de commandement apparaît comme le pendant logique de la volonté absolutisée de ne-pas-pouvoir-être-soi-même"( DREWERMANN, Eugen, Les fonctionnaires de Dieu, p. 385). 
etc.), des tendances se font sentir qui vont dans le sens d'une orthodoxie plus affirmée, d'une visibilité plus nette. Les rencontres et les escarmouches successives entre la religion et la modernité ont donné lieu à toutes sortes de réponses, allant du retour à l'autoritarisme et à l'intransigeance des intégrismes d'une part, à l'implication radicale des progressistes religieux dans les luttes pour la justice sociale d'autre part. Bref, ici comme ailleurs, la mode est "au rétro" dans l'Église.

\begin{abstract}
"Plus la conscience moderne, qui apparaît déjà au $\mathrm{XV}^{\circ}$ siècle dans les mouvements annonciateurs de la Réforme et se poursuit au $\mathrm{XVI}^{\circ}$ dans cette Réforme elle-même, affirme l'individu, le sujet, avec sa liberté et sa vérité propres, avec le droit à son originalité et à sa dignité, plus la forme cléricale de la pastorale catholique semble, de par toute sa structure, prendre psychologiquement du retard sur les exigences humaines, courant ainsi le risque de se transformer en appareil qui tourne à vide parce que clos sur lui-même. L'Église devient comme une citerne dans le désert: elle continue à attirer des gens pleins d'espoir d'y puiser l'eau et la fraîcheur, mais elle est asséchée depuis longtemps et ne fait plus qu'induire en erreur, sinon conduire à la mort, ceux qui se laissent appâter par son apparence. /.../ Aux défis que l'esprit moderne lance à la religion, ceux que le protestantisme a su affronter valablement et courageusement: la découverte de la subjectivité, le surgissement de la personne, l'angoisse individuelle, le postulat de la liberté, la transmission de la foi par le témoignage, et non plus par l'endoctrinement, le catholicisme n'a su répondre que par un durcissement de l'institutionnel, de l'objectivité, de la fonctionnalité, de la ritualisation. Nous sommes donc obligés de constater les effets désastreux que cet unilatérisme forcé a provoqués dans la psychologie de ceux qui en sont les plus marqués: les fonctionnaires porteurs du système eux-mêmes." 42
\end{abstract}

Les discussions autour du Concile et de l'évolution de l'Église catholique, on le voit, ne manquent pas. Il faut ajouter que les années qui ont suivi Vatican II ont été particulièrement tumultueuses au plan de l'évolution des sociétés occidentales: impressionnant remue-ménage des moeurs, des idées, des mentalités, une progression ignorée par le passé dans le confort matériel entraînant un bouleversement des modes de vie, des relations entre générations, entre l'homme et la femme, une mise en doute systématique des traditions, des croyances et des institutions. 
Un organisme comme celui de l'Église catholique obéit à des mouvements d'ouverture et de repli sur soi comme tout organisme vivant. Après une phase qui connut de nombreuses initiatives transformatrices, après une période où, dans l'urgence et l'ampleur de la tâche, s'est mêlé le meilleur au moins bon, il est peut-être normal que le besoin apparaisse d'un approfondissement de soi, d'un retour à ses racines, d'une vérification de son identité. Cette période que nous vivons actuellement est, j'ose l'espérer, moins celle d'une pause (car la vie de l'Esprit ne s'arrête pas) que celle d'une possible maturation: de nouveaux équilibres sont à trouver; surtout peutêtre les perspectives ouvertes par le Concile étaient-elles si étrangères à beaucoup de fidèles (et d'abord à bien des prêtres) qu'un temps d'assimilation, de rumination s'impose.

\subsubsection{Jean-Paul II, l'initiateur d'un nouveau divorce entre le catholicisme et la modernité?}

En janvier 1985, Jean-Paul II a convoqué un Synode extraordinaire. Contrairement à ce qui s'était fait précédemment, il proclama immédiatement à l'issue du Synode le document final qui réaffirmait les grandes options prises à Vatican II, ratifiant donc le travail synodal. Et pour que nul n'en doute, Jean-Paul II a réaffirmé avec force qu'il voit "dans ce Concile la continuation de l'oeuvre de l'Esprit-Saint" qui "a accompagné leur travail [des Pères Conciliaires] sur un chemin souvent imprévu, et ce même Esprit leur a confié aussi l'application du Concile." 43 Mais entre cette déclaration et ses nombreux autres discours, nous pouvons constater de grandes contradictions. Il est facile de reconnaître dans plusieurs déclarations officielles de Jean-Paul II l'idéal d'une "chrétienté" qui veut redonner à l'Église catholique son rôle traditionnel de garante des principes fondamentaux, non seulement dans le sens 
religieux mais aussi civil. Devant les défis que la modernité propose aujourd'hui d'une façon urgente, le Magistère de Jean-Paul II se montre disponible à la confrontation, mais toujours à partir du présupposé que l'Église est dépositaire de principes doctrinaux et moraux à valeur universelle et propres à toute la nature humaine. $\mathrm{La}$ modernité dans ce magistère est donc jugée selon un schéma rigide qui ne le reconnaît uniquement lorsqu'elle peut s'adapter et permettre l'affirmation de la nouvelle chrétienté. Son histoire personnelle en Pologne explique fort bien tout cela ayant été éduqué et ayant vécu dans un catholicisme pré-conciliaire. Et c'est fort compréhensible. Confronté à un communisme totalitaire, le catholicisme polonais n'a survécu au communisme qu'en resserrant les rangs autour de ses chefs, la hiérarchie, sans remettre en cause ses certitudes. Le processus de modernisation l'a peu atteint. D'où une difficulté majeure du pape à être cohérent dans une culture moderne. Marquée par le totalitarisme du communisme contre lequel il a lutté toute sa vie, la modernité a pour lui uniquement visage d'athéisme pratique, de violation des droits humains, etc. Le drame vient de la structure du pouvoir en catholicisme: en ayant un pouvoir monarchique, l'élection de ce pape polonais allait marquer l'évolution du catholicisme dans une ligne régressive par rapport à la société moderne. Son élection s'explique par la prédominance de l'aile conservatrice dans l'Église. 44

Le pontificat de Jean-Paul II est également marqué ces dernières années par un certain dogmatisme manifesté par la nomination d'évêques beaucoup plus conservateurs que ceux choisis sous Paul VI, par une mise au pas des épiscopats nationaux et des théologiens plus radicaux, et par des concessions du Vatican aux traditionalistes et aux intégristes. L'échec du Synode de 1987 sur les laïcs, l'imposition d'un serment de fidélité obligatoire qui est une version contemporaine du serment

44 Voir l'excellent volume sur ce sujet de GROOTAERS, Jan, De Vatican II à Jean-Paul II, Le grand tournant de l'Église catholique, Paris, Centurion, 1981. 
antimoderniste, sont quelques-unes des expressions de cette tendance. Par ailleurs, il faut être honnête, au plan socio-économique, dans le domaine de la paix et des droits humains et dans certains secteurs du champ de la culture, Jean-Paul II maintient quand même des positions plutôt ouvertes, voire parfois progressistes.

"C'est trop global comme jugement. Il y a des éléments de la modernité chez Jean-Paul II, par exemple sa défense des droits de l'homme. Mais on peut très bien comprendre ses limitations. L'emphase sur les droits de l'homme vient de la lutte contre le communisme et c'est également son origine d'un pays de l'Est qui permet de comprendre son incapacité à reconnaître la théologie de la libération. En un sens, il vient d'un monde moderne mais dont l'expérience très particulière l'empêche de comprendre le reste de la modernité. C'est pourquoi il y a des facettes de la modernité contre lesquelles il mène une lutte très dure. Mais c'est un phénomène particulier qui ne survivra pas à son pontificat." 45

Jean-Paul II est incontestablement hanté par les drames de l'époque (agrandissement du fossé entre riches et pauvres, surarmement) et par les menaces qu'ils font planer sur l'avenir de l'humanité. Mais la pièce centrale du raisonnement par lequel il justifie son entreprise tient donc en l'attribution de tous les malheurs récents (totalitarisme politique, scientisme, libéralisme économique) à la volonté moderne de s'affranchir de Dieu: la modernité étant ainsi identifiée aux tragiques effets des "grands récits" du XIX ${ }^{\circ}$ siècle, s'attaquer à ceuX-ci (ce qui doit être fait) revient à s'opposer à celle-là, c'est-à-dire au processus même de déliaison. Faire société réclame dès lors qu'on retourne en arrière, jusqu'à l'époque d'avant les temps modernes. Et l'on peut comprendre que, pour un Polonais, société=culture=religion: souvent privée d'État, c'est comme nation par sa culture, le catholicisme, que son pays a pu survivre. Mais il faut alors avoir claire conscience de ce qu'implique cette conception ignorant l'autonomie tant des individus que des diverses instances de la vie sociale.

"La tentation devient forte alors pour l'Église de se retirer d'un social où l'on a échoué après avoir mal investi, de se replier sur l'étroitesse du système religieux pour le renforcer 
en affirmant des certitudes là où il y avait recherche, ou d'investir en position de force un autre système, en l'occurence le système culturel. C'est semble-t-il la base de la nouvelle évangélisation vue d'Europe, une Europe où Rome se trouve. /.../ Ensuite, le déplacement vers le culturel procède d'un constat terrifiant établi dans les deux chapitres de Centesimus annus. Le monde moderne est détestable, y est-il dit, et court à la barberie parce que la culture s'est éloignée du christianisme. La Réforme - non citée, sinon par allusion - et les Lumières ont sécularisé la culture. Elle n'engendre plus dès lors que des oeuvres de mort: nazisme, stalinisme, avortement et contraception, etc... Il faut donc reprendre l'évangélisation de la culture pour l'amener au point où elle en était avant la dérive des quatre siècles. Sinon, si les hommes n'écoutent pas l'Église, le monde est à sa perte. Comment peut-on évangéliser un monde que l'on n'aime pas?"46

Le mariage devient ainsi de plus en plus difficile entre le catholicisme et la modernité sous le pontificat de Jean-Paul II. Va-t-il nous faire vivre un divorce officiel entre l'Église et le monde moderne. Va-t-il proclamer prochainement la "nullité" de ce mariage? Rien ne me rassure actuellement même si d'autres analystes me disent que bien loin d'être traditionnaliste, Jean-Paul II propose au contraire une alternative "postmoderne" à une modernité qui s'est révélée incapable de tenir ses promesses: il n'est donc pas d'avant, mais d'après! Je ne suis pas convaincu. Je continue à croire le contraire surtout depuis la parution de l'encyclique "Veritatis Splendor " qui reflète une très forte inquiétude par rapport à la modernité et à la perte d'emprise de l'Église au niveau des comportements moraux.

\subsubsection{L'Épiscopat québécois et la culture moderne}

En 1992, deux comités de recherche de l'Assemblée des évêques du Québec ont publié un document de réflexion approfondissant les défis ecclésiaux dans le contexte culturel québécois. 47 En analysant ces deux documents, nous sommes

MARC, Gabriel, "L'Évangile face aux enjeux de la prochaine décennie", in "D'un 'nouvel' ordre mondial à une 'nouvelle' évangélisation", Congrès de l'Entraide missionnaire 1992, Montréal, 11-12-13 septembre 1992, p.87.

47

1) COMITÉ DE THÉOLOGIE DE L'ASSEMBLÉE DES ÉVÊQUES DU QUÉBREC, Mission de l'Église et culture québécoise, Réflexion sur les liens entre foi et culture, 
étonnés de constater la divergence des points de vue concernant le rapport entre l'Église catholique québécoise et la culture moderne ou entre la foi et la culture. Il nous arrive même de noter des visions totalement opposées sur certains points. Le premier document du comité de théologie de l'AEQ propose des liens étroits entre foi et culture.

"-Pour mesurer le défi posé à la foi chrétienne - et à l'Église qui vit et propose cette foi -, il importe tout d'abord de reconnaître les mutations profondes qui marquent l'environnement culturel où notre foi est appelée à naître, à se développer et à s'exprimer. /.../ nous annoncerons quelques-unes des tâches qui s'offrent à nous pour que la mission d'évangéliser de l'Église s'accomplisse dans un dialogue fructueux avec la culture qui se fait. /.../ Il nous semble cependant que ces quelques points de repère suffisent pour engager un dialogue, comme croyants, avec la culture de notre temps. /... ... il importe tellement que nous établissions un dialogue entre foi et culture. /... $\mathrm{Si}$, comme nous l'avons proposé dans le préambule, la mission de l'Église est d'évangéliser et que l'évangélisation s'opère par le processus de l'inculturation, on reconnaîtra que non seulement la culture peut interroger la foi et opérer un discernement critique face à l'Église qui transmet la foi, mais que la foi aussi est appelée à opérer son propre discernement critique de la culture dans laquelle elle est appelée à s'incarner. /.../ Dans les deux premières parties de ce document, nous avons déjà relevé des germes d'Évangile dans les mutations culturelles en cours et dans les requêtes de la culture, de même que des appels pour qu'elle soit davantage fidèle à l'Évangile. /.../ Notre mission d'évangélisation devra donc favoriser un nouveau dialogue entre la foi et la culture et favoriser l'incarnation de l'Évangile dans un langage, des symboles, des rites, des témoignages et des signes reliés à la culture présente et comprise d'elle, et d'autres part miser sur les forces, les possibilités et les valeurs de cette culture qui est la nôtre." 48

Le deuxième document de l'AEQ intitulé "Risquer l'Avenir" et rédigé par son comité de recherche sur les communautés chrétiennes locales, présente plutôt un rapport d'opposition entre la foi et la culture, ou plus précisément entre le catholicisme québécois et la culture moderne. La modernité et la sécularisation sont souvent présentées d'une façon très négative et, à certains moments, comme une contre-valeur. Voici quelques citations qui prouvent la manière négative des auteurs de considérer la

Montréal, Fides, 1992, 51p. 2) COMITÉ DE RECHERCHE DE L'AEQ sur les communautés chrétiennes locales, Risquer l'avenir, bilan d'enquête et de prospectives, Montréal, Fides, 1992, 227p. 48 $\mathrm{AEQ}$, Mission de l'Église et culture québécoise, p.15; pp. 23-24; p. 27; p. 37; pp. 47-

48 . 
culture actuelle et les changements sociaux qui ont eu lieu au Québec ces dernières années:

\begin{abstract}
"Mais le sentiment qui se dégage, c'est celui d'une impuissance profonde face aux grands courants sociaux et culturels qui modifient avec force les attitudes des gens et qui, du même coup, bouleversent la vie des communautés chrétiennes. Pourtant, malgré ce sentiment d'avoir été largement le jouet des forces historiques au cours des dernières décennies, les membres actifs des communautés locales n'ont pas été écrasés. /.../ Les mutations socio-culturelles qui ont affecté le Québec depuis la fin des années 1940 ont eu de profondes répercussions sur la vie de l'Église et des communautés locales./.../ Cette socialisation nouvelle a façonné des personnes plus individualistes, qui ont progressivement reconnu comme normale une vision sécularisée de l'existence. I.../ Quand on regarde l'histoire du Québec des 40 dernières années, on constate que cette société est bel et bien entrée dans la modernité. Non seulement ses structures politiques et sociales ont changé, mais le processus de sécularisation a pleinement joué chez ses membres. /../ ce sont là des facteurs qui facilitent le processus de sécularisation et qui amènent les gens à opter sans réticence pour une vision non religieuse de l'existence humaine. /.../ Du même coup, leur capacité d'évaluation des idées séculières et de résistance face à elles est faible. /.../ Faute d'un encadrement leur permettant de se donner des racines, bien des baptisés ont été incapables de se situer face au mouvement de sécularisation et encore moins d'y résister. "49
\end{abstract}

Je ne suis pas le seul qui constate cette vision tout à fait négative de la modernité et de la sécularisation dans ce document. André CHARRON arrive aux mêmes conclusions dans ses réactions à l'étude sur les voies d'avenir des communautés locales.

\begin{abstract}
"La vision exclusivement négative de la modernité et de la sécularisation - qu'on rend responsable de bien des maux - paraît entraîner une certaine crainte des mutations de notre culture. On semble avoir peur ainsi de l'altérité du monde. Pourtant n'y a-t-il pas là l'énorme et difficile enjeu de l'acculturation, de la traduction des représentations, symboliques et contenus du discours chrétien dans les catégories anthropologiques et selon les états de conscience de la culture actuelle pour les rendre recevables et crédibles à nos concitoyens?"50
\end{abstract}

50 CHARRON, André, "Réaction au rapport de recherche et aux politiques retenues", in L'avenir des communautés chrétiennes - Rapport du congrès provincial tenu à Montréal en octobre 1992, p.100. 
Ce document continue donc à entretenir un conflit entre les communautés chrétiennes locales et la modernité, en somme entre Dieu et l'aventure humaine. Charles TAYLOR avait bien raison de dire que la modernité a ses défenseurs autant que ses détracteurs. Nous trouvons ces tensions au sein même de l'épiscopat québécois et de ses conseillers théologiques et pastoraux. L'AEQ a bien noté toutes ces tensions dans son dernier bilan de la situation de l'Église du Québec 1988-1993 à l'occasion de la visite ad limina 1993 à Rome. En lisant les pages de ce document qui approfondissent davantage le lien entre la foi et la culture québécoise, nous pouvons affirmer que nos évêques ont pris davantage l'option du dialogue entre ces deux réalités.

"Ces perspectives variées et complémentaires sur les transformations culturelles du Québec incitent l'Église à ne pas relâcher sa vigilance pour affiner sa connaissance du monde qu'elle est appelée à évangéliser et à servir. Dans le contexte culturel d'aujourd'hui, la pastorale de l'Évangélisation doit favoriser chez les chrétiens le discernement, le dialogue, l'approfondissement de l'intelligence de la foi et de l'expérience chrétienne authentique." 51

\subsection{Inculturer la foi: un dialogue toujours essentiel}

Comme je viens de le démontrer précédemment, depuis la fin du deuxième concile du Vatican, l'Église a pris vivement conscience du rapport dynamique entre la foi chrétienne et la culture (il serait plus juste de dire les cultures). En quelques années seulement, l'évangélisation des cultures est devenue le centre des préoccupations missionnaires de l'Église. Depuis l'exhortation apostolique Evangelii Nuntiandi (1975) de Paul VI, jusqu'aux nombreux discours de Jean-Paul II qui traite explicitement des problèmes de la culture, l'Église tout entière est invitée à développer une sensibilité nouvelle à propos de sa propre situation culturelle à l'intérieur d'un monde qui est en évolution constante. La Bonne Nouvelle de Jésus peut encore rejoindre au coeur de 
leur vie, les paroissiens qui l'écoutent. Sommes-nous capables d'accueillir, à l'intérieur de la grande communion catholique du peuple de Dieu, les diverses expériences paroissiales qui résultent de cette rencontre intime de l'Évangile avec les gens d'univers culturels différents? Sommes-nous prêts à nous laisser éclairer et enrichir par la réponse de foi de ceux et celles qui vivent dans des milieux culturels variés?

\begin{abstract}
"Les transformations que l'Église connaît depuis Vatican II conduisent directement vers la problématique centrale, celle du rapport toujours actuel entre le message central de Jésus et la vie concrète des peuples ou des personnes qui l'accueillent. C'est la mission de l'Église de se mettre au service de ce mystère. /.../ Ici, nous sommes d'abord renvoyés à la situation concrète des gens à qui l'Évangile est proposé. Certains ont accueilli l'Évangile et sont devenus membres de l'Église. D'autres continuent à poursuivre leur propre chemin. D'autres encore croient en Jésus mais tournent le dos à l'Église. L'évangélisation concerne les uns et les autres. /.../ Face à toutes ces situations très variées, l'Église "missionnaire" doit se poser les questions: est-ce que l'Évangile a réussi à rejoindre les gens au coeur de leur vie? Quels sont les aspects de notre expérience humaine qui n'ont pas encore été évangélisés? Comment l'Évangile peut-il interpeller davantage notre société? En même temps nous savons que l'Église va à la rencontre d'un monde où le Dieu Vivant, le Père de Jésus, est déjà présent. Il continue à se manisfester dans ce monde de diverses façons. Qu'est-ce que peut nous offrir ce monde en vue de l'approfondissement de notre expérience chrétienne?" 52
\end{abstract}

Nous sommes donc invités à faire valoir un pluralisme réel dans notre façon d'annoncer, d'accueillir et d'intégrer l'Évangile du Christ au coeur de nos diverses communautés chrétiennes, entre autres, des paroisses, en ce qui nous concerne.

\title{
9.5.1. Évangéliser, qu'est-ce-à-dire?
}

Nous entendons souvent en paroisse les intervenants pastoraux dire qu'il faut évangéliser les paroissiens. Mais qu'est-ce qu'évangéliser en respectant profondément les multiples univers culturels des paroissiens d'aujourd'hui? Mgr Samuel RUIZ a

52 PEELMAN, Achiel, L'inculturation, l'Église et les cultures, Paris-Canada, DescléNovalis, 1989, pp. 38-39. 
bien répondu à cette question en approfondissant le lien entre l'évangélisation et les cultures.

"Évangéliser- la tâche missionnaire implique:

1) un processus d'investigation anthropologique des cultures pour découvrir avec grand respect l'action millénaire de Dieu dans la culture d'un peuple donné;

2) un processus de réflexion théologique sur les valeurs ainsi découvertes;

3) l'exigence de témoignage d'une Eglise qui se purifie de tout contre-témoignage;

4) la présence d'un messager qui n'est pas un étranger, parce qu'il s'incarnera au sein même de la culture (comme le Christ dans l'humanité, comme Paul qui se fait grec avec les Grecs et juif avec les Juifs) - (Ad Gentes, 9 b; 11; 12; 22 b; 3 c; 10; 13, 11 a; Lumen Gentium, 23);

5) une manifestation de la présence du Christ dans la culture.

Parfois l'action missionnaire sera d'inviter l'homme à vivre consciemment et en plénitude sa religiosité, où il trouvera son propre chemin salvifique." 53

L'Église n'a donc pas comme fin la création d'une mono-culture universelle. Son message n'est pas une morale ou un ensemble de dogmes, mais un histoire de salut. Envoyée au monde, l'Église doit posséder la capacité et la conscience de pouvoir s'incarner dans chaque époque historique et dans n'importe quelle situation culturelle. Cependant, la majorité des paroissiens de notre pays ont été "endoctrinés" dans une seule façon d'être chrétien. Nous continuons souvent à imposer notre culture comme norme aux autres. La majorité des paroissiens n'attendent pas de l'Église qu'elle leur apporte des réponses toutes faites, mais qu'elle participe humblement à la recherche d'une plus grande qualité d'humanité et de justice.

\section{5. 2 Le processus mystérieux de l'inculturation}

Il n'est pas possible de parler de la genèse ou de l'implantation de l'Église dans un milieu sans approfondir une donnée fondamentale: l'inculturation de l'Évangile. Mais le processus d'inculturation concerne à la fois l'Église et l'Évangile. 
Car le travail réalisé par l'Évangile dans une culture a nécessairement un impact sur la manière de vivre l'Église.

Il est difficile de bien comprendre le mystère de l'inculturation. Achiel PEELMAN a judicieusement fait appel au langage symbolique de la parabole du grain (Mc 4, 26-29) pour aider à mieux saisir ce mystère.

\begin{abstract}
"La parabole nous montre que l'inculturation, ou sens propre que nous voulons donner à ce terme, est une action mystérieuse entre la semence (Évangile) et la terre (la culture). La semence est accueillie par la terre qui commence à la travailler de l'intérieur, lentement et d'abord invisiblement. D'elle-même, dit la parabole, la terre produit d'abord l'herbe, puis l'épi, puis plein de blé dans l'épi. Tout cela se passe tandis que le semeur dort. De fait, il s'agit d'une action mystérieuse qui échappe au regard du semeur. Qu'il dorme ou qu'il soit éveillé, la nuit ou le jour, il ne sait pas comment la semence germe et pousse. Mais arrive enfin le jour où le semeur se relève de son sommeil profond et voit le résultat. Le blé est mûr et la récolte est prête. Le semeur peut contempler les fruits de la rencontre mystérieuse de la semence avec la terre. Il peut évaluer la récolte. D'une façon très simple, cette parabole montre le rôle de chaque intervenant pastoral dans le processus de l'inculturation de l'Évangile." 54
\end{abstract}

Le semeur ou l'Église a un rôle dans ce processus. L'inculturation présuppose l'expérience de l'Évangile avec des implications bien précises pour les intervenants pastoraux et l'Église qui se fait proche des gens. Cette expérience de l'Évangile nécessite la mise en oeuvre des grandes fonctions pastorales qui ouvrent le coeur humain à la bonne nouvelle du renouvellement dans le Christ: fonction prophétique, fonction sacerdotale, fonction royale. ${ }^{55}$ C'est à la croisée de l'interrelation de ces fonctions que l'Évangile s'inculture et fait du neuf dans la vie des personnes et des groupes. et parcours, Tome III, Montréal, Fides, 1987, pp.153-184. [ Cahier d'études pastorales \#5 ]. 
L'Évangile opère un travail de renouveau en profondeur. Il suscite chez les personnes et les groupes qui en font l'expérience un dynamisme créateur de nouveauté. Il donne lieu à un avènement tel un ferment dans la pâte où le mystérieux travail de Dieu fait surgir des fruits d'humanisation et de libération au creuset de la liberté réceptive des humains. Les évangélisateurs ou les intervenants pastoraux ne maîtrisent pas ce processus complexe. Ils le fécondent dans la mise en oeuvre pertinente des fonctions pastorales. Mais le travail de l'Esprit et la réponse de foi des récepteurs constituent un facteur essentiel dans ce processus de tradition complexe et délicat. La parabole de PEELMAN, en mettant en lumière le mystérieux processus de germination de la semence en terre, attire notre attention sur l'interrelation dynamique des serviteurs de l'Évangile et des personnes et des groupes récepteurs.

Les personnes qui accueillent le message évangélique ou plus profondément qui en font l'expérience ont un rôle majeur dans la production des fruits de l'inculturation. L'inculturation apparât ainsi comme une interrelation féconde entre le dynamisme de l'Évangile (action du Dieu vivant), le rôle des intervenants pastoraux, témoins de l'Évangile et les récepteurs, ceux et celles qui accueillent et accouchent de leur réponse fidèle. L'inculturation est ainsi la rencontre intime entre une culture donnée et l'Évangile. Cette rencontre procure une réponse inventive et bien souvent elle réserve des surprises à l'intervenant pastoral. Les fruits donnés peuvent émerger par ou sans l'intermédiaire du semeur. Celui qui évangélise ne doit jamais oublier qu'il est un serviteur inutile. Il doit se faire discret. Sa seule vigilance étant le désir de créer des conditions pour que les personnes aient le goût de créer de l'espace pour s'ouvrir au travail de Dieu dans leur coeur.

Le théologien PEELMAN a donc bien raison de définir l'évangélisation "comme une affaire mystérieuse qui se passe entre la Parole vivante de Dieu et la 
culture qui l'accueille"56. Ce mystère s'accomplissant chaque fois que la culture d'accueil suscite une réponse originale à l'action évangélisatrice. Cette réponse fidèle enrichit le trésor ecclésial et permet de réaliser plus pleinement la catholicité de l'Église. L'Église doit être au service de tous les humains et elle doit offrir plusieurs alternatives afin que les richesses diverses des rencontres des personnes avec Dieu puissent être partagées. L'Église vit sa mission universelle lorsque celle-ci accepte la diversité des réponses originales des cultures à l'Évangile. Le Dieu de Jésus-Christ, c'est le Dieu Emmanuel qui désire habiter dans le coeur de chaque personne et chaque peuple. Les quatre traditions évangéliques, fruits de la réponse de foi des premières générations de disciples ouvrent l'espace de la grande Tradition de foi. Elles constituent des multiples réponses de foi d'hommes et de femmes de cultures et de milieux divers. Le dynamisme de la Tradition réside en cette fidélité créatrice suscitée par l'Esprit dans les réponses de foi si diverses et pourtant si profondément en communion dans leur enracinement dans le travail patient et amoureux du Dieu trinitaire révélé en Jésus le Christ.

Le semeur doit garder les yeux bien ouverts pour s'émerveiller de l'impact de l'expérience évangélique chez l'autre. Il est témoin de l'oeuvre de l'Esprit qui travaille le coeur de chaque personne et de chaque peuple. Le semeur doit devenir capable d'accueillir les réponses autres qu'il attendait. Il ne doit pas avoir peur de la diversité des fruits. Les fruits de l'inculturation de l'Évangile sont toujours attendus et inattendus. Cela exige de la part du semeur beaucoup de liberté intérieure et de l'humilité. Il doit mourir à ses attentes pour entrer dans le monde de l'autre et se réjouir avec lui de la puissance libératrice du Ressuscité qui le fait advenir autre. 


\subsection{Acquis de recherche éclairants}

Il est toujours important de resaissir les pointes majeures qui ressortent d'une réflexion pour éclairer avec plus d'acuité la problématique d'ensemble d'une recherche. Le paroissien porte en lui-même les valeurs de la modernité. Approfondir celles-ci offre la chance aux intervenants pastoraux d'accompagner leur devenir avec plus de respect et de fécondité évangélique. Le mariage entre la foi et la culture, entre l'Église et le monde peut se poursuivre si l'Église consent à mourir à sa prétention de posséder la vérité et si elle se vit comme partenaire du dialogue avec la société moderne.

\subsubsection{Une Église appelé à mourir à "sa prétention"}

L'Église doit accepter de devenir interlocutrice et partenaire du dialogue dans une société moderne. Conséquence qui suppose que l'Église cesse de revendiquer une position de maîtrise du social, comme si la société ne pouvait que dégénérer et comme si celle-ci ne retrouvait sa santé qu'en appliquant les remèdes proposés par elle. L'Église doit plutôt proposer son message comme source de sens pour celui qui veut bien le prendre au sérieux. "Si tu veux" est une formule qui scande beaucoup plus les discours de Jésus que d'impérieux "tu dois, sinon..." En proposant, l'Église suscite d'ailleurs le désir d'une quête spirituelle, met en route un processus de recherche qui est plus évangélique que l'imposition catégorique d'une vérité. En somme, elle doit aider des libertés à devenir responsables.

L'Église doit ainsi consentir à être une voix parmi d'autres. Même si elle pense que son message vient d'une longue sagesse spirituelle, elle se doit de le faire accepter d'abord comme un message crédible et bienfaisant parmi d'autres. En Entrant 
dans le débat de la société moderne, l'Église doit aussi découvrir la fragilité de ses positions et la nécessité de réfléchir sérieusement avant de parler.

\begin{abstract}
"Cette crise permanente des légitimités politiques et morales fixe une tâche précise à l'Église. Elle a à accepter d'entrer sans réticence dans le débat, y apportant la ressource de ses traditions morales, de sa sagesse séculaire, de son sens de l'homme. Elle a à le faire non point en prétendant écarter le débat par l'apport de solutions élaborées comme par avance, mais en s'engageant avec tous pour découvrir les enjeux réels et les risques des solutions proposées. On doit même dire que ce sont les traditions morales, appuyées sur la logique de la gratuité révélée, qui peuvent relancer le débat quand il s'éteint, parce que la vigilance morale peut faire voler en éclats les unanismes paresseux et trompeurs. /.../ l'Eglise doit jouer le jeu du pluralisme; ce faisant elle provoque aussi d'autres traditions religieuses, éthiques, philosophiques, idéologiques à intervenir dans le débat et à déclarer ce qui fait sens pour elles." 57
\end{abstract}

Il me semble qu'il vaut mieux des interventions discrètes mais bien fondées que des déclarations catégoriques que plus personne n'écoute. ${ }^{58}$ L'inflammation du discours moral en matière de morale sexuelle dans l'encyclique "Veritatis Splendor" pourrait servir ici de très éclairant contre-exemple. Ä trop parler, on se discrédite.

\begin{abstract}
"Mais il est des façons "d'enfoncer le pécheur", d'insister non sans complaisance sur les maux de nos sociétés modernes, d'accumuler sur les épaules de nos contemporains des charges insupportables qui relèvent plus du pharisaïsme de la mauvaise conscience que d'une attitude d'espérance. L'Église n'aurait-elle rien d'autre à dire que d'accabler nos sociétés par un discours obsessionnel de la culpabilisation?"59
\end{abstract}

VALADIER, Paul, L'Église en procès, pp. 139-140. Vatican II a ouvert la porte à une reconnaissance officielle du pluralisme des options politiques, économiques et sociales . Après un premier mouvement d'acquiescement au pluralisme, remarque-t-on une réserve certaine, particulièrement de la part de Jean-Paul II. (voir son discours publié dans La Documentation catholique, $\mathrm{n}^{\circ} 1906,17$ novembre 1985, col. 1087. Discours prononcé aux évêques européens réunis à Rome le 11 octobre 1985 en Symposium.) Je sens que la peur du pluralisme domine dans l'Église actuellement, comme si l'affirmation des différences préludait à la dissolution. En réalité, l'éclatement (ou la disertion latente) menace si aucune communication n'est favorisée entre positions diverses. Seule une Église capable d'instituer le débat en son sein sera crédible. Entrer dans cette voie n'est pas sans risque, mais n'est-ce pas une condition pour sortir de la stérilité?

$58 \quad$ Une longue et minutieuse préparation des dossiers est nécessaire pour tenir une parole crédible. 
Son rôle n'est-il pas plutôt d'ouvrir des chemins d'espérance? Rôle d'alerte plus que de condamnation, d'éveil plus que de propositions immédiatement applicables.

\begin{abstract}
"La culpabilisation est stérile; seul l'appel à l'espérance peut susciter des énergies neuves et la volonté d'entreprendre. /.../ Ils appartient à ceux qui croient à la Résurrection d'attester qu'en toute nuit si obscure soit-elle, peut percer une lumière. Ils peuvent le faire sans optimisme béat puisqu'ils savent bien aussi la présence du négatif et la possibilité que même le meilleur soit retourné en son contraire. Par là ils annoncent le salut en acte qui est de croire qu'il est toujours donné à l'être humain qui le veut de se remettre debout. On étouffe vraiment les forces de mort en donnant leurs chances aux forces de vie, non en amplifiant les premières." 60
\end{abstract}

\title{
9.6.2 Le rapport au monde de l'Église: une tâche permanente
}

Le concile Vatican II qui s'est terminé il y a déjà plus de 25 ans a opéré des changements considérables à divers niveaux. La reconceptualisation de l'Église comme peuple de Dieu plutôt que comme structure pyramidale, la reconnaissance de la valeur des autres traditions religieuses, les renouveaux théologique, pastoral, liturgique, biblique et charismatique ont eu des conséquences considérables sur le catholicisme dans plusieurs pays. L'émergence d'une foi plus expérientielle et plus personnelle, la contestation des femmes, la crispation des autorités vaticanes montrent toutefois que le catholicisme est en train d'opérer sa difficile mutation dans la modernité par un mélange complexe de neuf et de vieux.

"...il est impossible de penser en termes simples et univoques le rapport du catholicisme à la modernité. Une tension est inévitable et souhaitable: c'est elle qui permettrait le vrai procès, celui de partenaires, conscients de tout ce qui les tient ensemble, de ce qui les a façonnés l'un et l'autre, en quête l'un et l'autre d'une vérité plus totale sur l'homme, donc ouverts tous deux au processus (procès) de l'histoire. Ici encore, une convergence étonnante apparaît entre une modernité incertaine par définition de son avenir, mais convaincue qu'il dépend d'elle, et le christianisme qui éduque à la vigilance (attitude active) dans l'incertitude de l'Heure. Le passé d'hostilité laisse des traces dans l'Église et conduit aux hoquets conservateurs que nous connaissons aujourd'hui. Un regard plus global et moins timide laisse apparaître que, sans s'agenouiller devant une modernité 
d'ailleurs critique à l'égard d'elle-même, le catholicisme peut tenir un rôle de partenaire conscient des enjeux d'une modernité qu'il n'a pas peu contribué à instaurer. Et que, quoi qu'il veuille, il instaure encore." 61

N'est-ce pas une tâche permanente et toujours à renouveler que celle du rapport au monde de l'Église? Il n'y a pas de bon état des relations en ce domaine, comme si un jour le parfait statut du rapport à la raison commune, à l'État, à la société, aux moeurs était atteint. Cela vient de ce que nous sommes dans des sociétés en continuelle transformation d'elles-mêmes au moins à un certain nombre de plans. Cela vient aussi de ce que la raison n'est pas une réalité achevée. La raison considérée comme l'effort de l'être humain pour se comprendre dans le monde et vouloir une vie commune sensée est une tâche ouverte dont personne, pas même le croyant, n'est dispensé. À ce titre le travail de raison s'offre comme une entreprise à faire avec tous dans des conditions sociales renouvelées. Ces perspectives coupent à la racine les possibles tentations de l'Église de triomphalisme ou des recherches d'un statut définitif dans le rapport aux sociétés.

Le croyant d'aujourd'hui (le paroissien actuel) n'est pas plus mal équipé qu'un autre pour vivre la modernité sans verser dans les illusions idôlatriques qu'elle suscite. ${ }^{62}$ La conversion dans la foi l'équipe aussi des moyens pour ne pas verser dans les délires collectifs; elle le met également en état de trouver les moyens intellectuels

VALADIER, Paul, "Catholicisme et modernité, un procès permanent", p.18.

"Mais pour s'engager efficacement dans ce débat multiforme, il faut comprendre ce que la culture moderne a de grand, aussi bien que ce qu'elle a de dangereux et de superficiel. Ainsi que Pascal l'a dit des êtres humains, la modernité se caractérise autant par sa grandeur que par sa misère. Seul un point de vue qui embrasse l'une et l'autre pourrait nous donner cette vision juste de notre époque dont nous avons besoin pour relever ses plus grands défis"(TAYLOR, Charles, Grandeurs et misères de la modernité, Montréal, Bellarmin, 1991, p. 150)". J'ai participé au colloque "Identité et Modernité au Québec" tenu au Musée de la civilisation de Québec du 20 au 22 octobre 1993 et organisé par la Faculté des sciences sociales de l'Université Laval. Dans la conférence inaugurale intitulé "Critique de la modernité", le Professeur Alain TOURAINE a parlé en ce sens en nommant les grandeurs et les misères de cette culture moderne. 
pour faire le procès des processus idôlatriques pervers, donc de dénoncer les maux qui prennent l'apparence des biens, sous la pression des volontés de puissance ou des désirs de jouissance sans freins. Mais sans doute le croyant a-t-il moins de nos jours, un rôle dénonciateur qu'une tâche d'incitation, d'encouragement, de provocation à aller de l'avant malgré tout.

\begin{abstract}
"Par la pédagogie religieuse et morale qu'il met en avant, il (le christianisme) exalte la liberté dans le temps même où il lui annonce qu'elle se perd si elle ne se donne pas; il valorise la personne dans le temps même où il lui propose d'entrer dans la vie d'un Corps où il répondra à sa vocation en y trouvant sa juste place; il cultive le sens de la responsabilté en inculquant à ses fidèles que s'ils doivent légitimement chercher leur épanouissement personnel, celui-ci ne peut aller sans la promotion d'une vie collective où tous et chacun aient leur place. Par tous ces traits, le message chrétien peut se situer du dedans même de la modernité comme une force critique et de proposition, mobilisatrice pour des libertés responsables et donc féconde pour la vie sociale. Mais comment le christianisme pourrait-il manifester la vigueur de son message et apporter à la modernité les contrepoids dont elle a besoin, s'il se replie sur une agressivité méfiante envers une modernité qui lui donne pourtant ses chances? Voilà qui montre encore que la modernité n'offre un terrain favorable au message chrétien que si celui-ci accepte de relever les défis actuels et futurs, que s'il se laisse provoquer par eux au lieu de s'enfermer dans les dénonciations verbales." 63
\end{abstract}

La méfiance et la peur devant les valeurs de la modernité ont comme conséquence immédiate en contexte démocratique de dévaloriser le message chrétien. Les problèmes d'aujourd'hui et plus encore ceux de demain seront des problèmes de relation et de sens; leur traitement obligera à rouvrir une réflexion fondamentale où le message chrétien pourra exercer sa force de discernement et de jugement. À ce titre encore, loin de marginaliser le christianisme, la modernité la plus avancée lui offrira les possibilités de tirer de son héritage ancien le nouveau d'une parole éclairante. Mais, plus que tout, il faudra pour les chrétiens (pour l'Église institutionnelle aussi) une sympathie tout évangélique pour la personne humaine d'aujourd'hui telle qu'elle est (le paroissien en lui-même), dans ses limites comme dans ses forces. À une époque où le 
mépris de la société présente passe pour le dernier cri du prophétisme ecclésiastique ${ }^{64}$, on peut en effet avoir les inquiétudes les plus vives. Mais le pire n'étant pas toujours sûr, on peut espérer aussi que l'Esprit du Dieu vivant l'emportera sur le "défaitisme" des "prophètes de malheur", comme cela s'est déjà produit si souvent dans le passé.

L'Église doit proclamer l'Évangile dans les nouvelles situation culturelles de l'humanité tout en se mettant à l'écoute de ces cultures marquées par la Modernité. Les cultures s'ouvrent au message du Christ tout en contribuant à l'humanisation de l'Église. La rencontre entre l'Évangile et les cultures est sans doute un des traits les plus fascinants de l'histoire de l'humanité mais aussi de celle de l'Église elle-même. Le mystère de l'inculturation de l'Évangile comporte, rappelons-le, autant de surprises pour l'Église que pour le monde. Nous ne savons pas d'avance quelle Église renaîtra avec l'Évangile qui est allée nourrir la terre. Mais ce que nous savons, c'est que nous devons toujours être en éveil pour contempler l'action discrète de Dieu, par son Fils, au coeur des humains (paroissiens) et des communautés. Si nous demeurons attentifs, nous pouvons être étonnés de la liberté et de l'autonomie qu'il fait croître dans le coeur de tous ceux et celles qui ouvrent leur coeur à sa semence d'Amour.

64 Nous en avons eu un bel exemple dans le document de recherche sur les communautés locales de l'Assemblée des évêques du Québec intitulé: "Risquer l'Avenir, bilan d'enquêtes et prospectives". 
TOME II 


\section{CHAPITRE 10}

\section{LES RÉSEAUX D'INCARNATION DU CHRISTIANISME À L'ÉPOQUE DU NOUVEAU TESTAMENT 1}

Grâce au Nouveau Testament nous pouvons, comme dans une image réfléchie dans un miroir, percevoir historiquement dans ses traits essentiels qui fut Jésus, comment il a vécu, ce qui l'inspira. Quand on remonte aux origines de la foi chrétienne pour mieux saisir quelles images de l'Église les premiers chrétiens ont développées, un aspect ressort fortement: la diversité de leur réflexion ecclésiologique. Si cette Église vivante n'a pas d'églises visibles, elle a toutefois des ecclésiologies: non pas une seule vision d'elle-même, mais déjà plusieurs façons de concevoir et de vivre sa mission, sa cohérence interne, sa relation à la société ambiante et aux pouvoirs, son rapport au temps et à l'espace. Les premières générations de chrétiens ont compris et exprimé leur foi en Jésus à partir de ce qu'ils étaient, de leur situation sociale, de leur héritage religieux particulier, et aussi à partir des questions, défis et problèmes qu'ils ont dû affronter dans leur cheminement de foi et dans leur vie communautaire et apostolique. Les écrits du Nouveau Testament témoignent de cette diversité: de Paul à l'Apocalypse, en passant par les Évangiles, nous pouvons sentir ces courants divers et unis, qui sur la base des paroles et actions de Jésus, de sa mort et de sa résurrection,

"À notre insu, nous projetons continuellement sur le passé des choses qui sont de notre monde, et qui ne sont que de lui. L'anachronisme me semble particulièrement flagrant dans la manière dont nous parlons du "ministère", de la "prédication" de Jésus et de ses disciples immédiats. Le résultat, c'est que nous cherchons souvent dans nos origines cela précisément qu'il nous plaît d'y retrouver, et qui peut-être ne s'y rencontre pas, ou qui, s'il s'y rencontre, ne se présente pas nécessairement sous la forme où nous imaginerions volontiers qu'il s'y trouve. Pour autant, nous nous privons maladroitement d'une part des richesses de la tradition primitive, dont, faut-il le dire? les suggestions créatrices sont loin d'avoir été épuisées" (AUDET, Jean-Paul, Mariage et célibat dans le service pastoral de l'église, Paris, Oriante, 1967, p.60). Il nous faut, les textes nous y obligent, distinguer, dans le Nouveau Testament, deux périodes ou phases, qui néanmoins se recouvrent: le temps des "apôtres" et, quoique encore dans le Nouveau Testament, le temps postapostolique. 
ont développé des façons autres de comprendre et de communiquer leur foi et leur vision de l'Église. Ce chapitre désire démontrer que, ce n'est pas la rigidité, mais une certaine souplesse réaliste et féconde, qui a caractérisé, au premier moment, toute la "micro-morphologie" du service de l'évangile: service itinérant de la parole et service pastoral de l'assemblée.

Les responsabilités pastorales sont tellement nombreuses en paroisse qu'il nous arrive souvent d'oublier le but de notre travail. Dans ces circonstances, il est à propos de nous rappeler ce qu'a été la passion de Jésus: l'avènement du Règne de Dieu. La situation actuelle des paroisses exige aussi de faire advenir de plus en plus de ministères nouveaux. Toutefois, la version officielle de l'Église concernant cette problématique ne nous aide guère à la créativité mais plutôt à demeurer dans le statu quo. Pour sortir de ce cul-de-sac, il m'a semblé essentiel de retourner consulter les textes du Nouveau Testament pour analyser plus profondément l'héritage que les premières communautés chrétiennes ont légué à l'Église dans la manière d'organiser leur vie fraternelle. Ce présent chapitre tend alors de démontrer qu'à chaque étape de leur développement, les communautés ont été confrontées à des nouveaux besoins. C'est en fonction de ces besoins qu'elles ont créé des structures et des ministères, tandis que d'autres ont disparu parce qu'ils ne correspondaient plus à la situation nouvelle. Ces premières communautés croyantes ne nous invitent-elles pas à plus d'audace dans la manière de renouveler l'organisation institutionnelle de l'Église, particulièrement en ce qui concerne nos paroisses actuelles? 


\subsection{La passion de Jésus: le Règne de Dieu}

La position centrale tenue par le Règne de Dieu dans la pensée et l'agir de Jésus est une donnée qui fait l'unanimité chez les exégètes étudiant les évangiles. Le Règne de Dieu ce fut la raison d'être de Jésus, l'expression privilégiée de son espérance, le moteur de sa vie. Il faut dire que sa conception du Règne de Dieu, Jésus ne l'a pas inventée de toutes pièces; elle faisait partie de la tradition de son peuple (ex: Dt 17,18-20; Ps 72,1-4.12-13; Ps 146,3-5.7-10, etc.). Mais pour Lui, le Règne était à la fois déjà présent, proche et futur (Mc 1,15; Lc 11,2-3.20; 17,20-21; Mc 9,1; Mc 14,25). Jésus fut un artisan du Règne en redonnant le sens de la dignité à tous les fils et filles de Dieu qui l'avaient perdue ou se l'étaient fait enlever. Sa pensée et son agir n'ont cessé alors d'être l'expression humaine de l'amour privilégié de Dieu pour les pauvres (les enfants, les publicains, les prostituées, les malades, tous ceux et celles qui étaient socialement opprimés, juridiquement diminués et religieusement méprisés, etc.). "Je n'ai été envoyé qu'aux brebis perdues de la maison d'Israël"(Mt 15,24). À cette immense foule de désespérés, Jésus apporte la foi en Dieu contre la condamnation, l'amour et la compassion contre le mépris. Le Royaume de Dieu, c'est l'Amour du Père, un amour qui embrasse tout, qui libère et transforme en profondeur.

"...son message est essentiellement la proclamation du royaume de Dieu /.../ L'expression "royaume de Dieu" était à l'époque connue de tous les juifs. Il va lui donner un contenu très personnel /.../ Il en résulte clairement qu'une des données les plus solides de cette vie est le fait que, par l'annonce du règne de Dieu et sa manière correspondante d'agir, il a mis en relief la réalité Dieu telle qu'il la voyait, et qu'il l'a fait d'une manière spéciale, proprement originale. Notamment, le contenu de ce message concernant le Dieu-quiaime-les-hommes a été mis en évidence par ses paraboles, où la conversion, c'est-à-dire l'ouverture à des possibilités alternatives de vie, est proposée: une praxis du royaume de Dieu. Ce contenu est en outre manifesté par la manière de vivre et d'agir de Jésus, par sa manière de communiquer avec les gens, y compris les publicains et les pécheurs publics, par son apport à la table commune du salut venant de Dieu et son interprétation de la Loi, 
du sabbat et du temple en faveur des hommes, enfin et non moins, dans sa vie en commun avec un petit groupe de disciples." 2

Jésus n'a pas seulement annoncé la Bonne Nouvelle venue de Dieu mais, il l'a fait transparaître dans ce qu'il a été. Son "efficacité" comme évangélisateur se trouve dans son identification totale au message qu'il a proclamé. Le message et le messager ont été identiques au point où le messager a disparu littéralement derrière le message pour laisser la voie libre à la puissance créatrice du Dieu-Abba.

Les disciples se sont mis à l'école d'un "maître" dont l'"instruction" enseigne par-dessus tout la miséricorde et l'amour. ${ }^{3}$ Pour "suivre" Jésus et devenir en plénitude son "disciple", il faut d'abord être libre intérieurement. "Suivre" Jésus, en ce temps-là, ce n'est pas de quitter le "monde" pour "pratiquer les vertus évangéliques". C'est accepter d'être, avec Jésus, au coeur des villes, au coeur des villages, au coeur des maisons, au coeur des "foules", pour annoncer que le royaume de Dieu est effectivement inauguré, pour recueillir la "parole", levain déposé dans la pâte (Mt 13, 33; Lc 20-21) et, par un geste concret, témoigner que la "bonne nouvelle" d'une espérance illimitée est là, active, reconnaissable, au milieu des humains (Lc 17,21). Jésus a donc rassemblé autour de lui des personnes pour l'aider dans sa tâche d'illustrer la venue du Règne dont il espérait voir le jour très bientôt (Mt 10,6). Cependant, en Jésus le Règne futur de Dieu menaçait trop le présent pour qu'on le tolère longtemps. On lui en voulait parce qu'il fréquentait les pécheurs (Mt 18, 21-35); on était en colère parce qu'il ne rejetait pas les débauchés et les dépensiers (Lc 15,1132 ); on le maudissait parce qu'il voulait donner autant aux petits qu'aux grands (Mt

SCHILLEBEECKX, Edward, Plaidoyer pour le peuple de Dieu, Paris, Cerf, 1987, p.27; p. 31 Voir aussi MYRE, André,"Nouveau Testament et ministères", in Des ministères nouveaux?, Montréal, Paulines, 1985, p.100; PEELMAN, Achiel, "Le dynamisme des origines", in L'inculturation, l'Église et les cultures, Paris-Montréal, Desclée-Novalis, 1989, pp. 160-186.

"Montrez-vous miséricordieux, comme votre Père est miséricordieux" (Lc 6, 36). 
20,14), mais en commençant par les petits (Mt 20,8) qui sont les préférés du Père (Mt 21,31). La venue du Règne de Dieu a donc été le coeur de son activité, et non pas la fondation d'une Église. 4

"On ne fonde rien, quand on attend une fin imminente de l'histoire /.../ Selon Jésus, ce qui venait après lui, c'était Dieu lui-même. Et pas une Église. Il n'a rien fondé, institué,établi /.../ Est-ce à dire qu'il n'y a aucun lien entre lui et cette réalité que nous appelons l'Église? Si Jésus de Nazareth n'a pas fondé d'Église, le Christ, lui, l'a fait. Et comme le Christ, c'est Jésus, on peut véritablement dire, dans la foi, que l'Église a été instituée par Jésus Christ." 5

\subsection{L'Église et son origine}

"Jésus leur dit: "Et vous, qui dites-vous que je suis?" Prenant la parole, SimonPierre répondit: "Tu es le Christ, le Fils du Dieu vivant"(Mt 16,15-16). La foi vient de commencer. Mais il n'y a pas encore d'Église, de communauté; la construction de celle-ci suivra. Jésus est apparu à Pierre en particulier (Lc 22,32), ensuite à d'autres (Cf.1 Co 15,5; Mc 16,14; Mt 28,16; Lc 24, 9.33; Jn 20, 19. 24.26) et ceux-ci se sont rassemblés à Jérusalem pour former une communauté. Cette communauté "des Douze" s'est reconnue comme la communauté appelée et choisie par Dieu pour

4

"Dans les Synoptiques, on rapporte les paroles au sujet du Règne de Dieu environ cent fois; au sujet de l'Église, seulement deux fois et au futur (Mt., 16:18; 18:17). Jésus a prêché essentiellement le Règne de Dieu, qui est premier par rapport à l'Église et est à l'origine de l'Église" (CHARRON, André, "Les caractéristiques théologiques d'une communauté chrétienne vivante en paroisse", in Communauté chrétienne \#97: Les paroissiens, avenir de la paroisse, vol.17, janv.-fév. 1978, p.18.). Voir aussi GUTIERREZ, Gustavo, Praxis de libération et foi chrétienne, in Lumen Vitae, vol. XXIX, ${ }^{\circ} 2$ 2, 1974, pp. 227-254.; KEARNEY, Peter, "Trouve-t-on dans le Nouveau Testament des motifs de changer l'organisation de l'Église?", in Concilium, $\mathrm{n}^{\circ} 80,1972, \mathrm{p} .54$. 5

MYRE, André,"Nouveau Testament et ministères", in Des ministères nouveaux?, Montréal, Paulines, 1985, pp. 102-103. Voir aussi HOFFMANN, J., "L'Eglise et son origine", in Initiation à la pratique de la théologie, Dogmatique II, tome III, Paris, Cerf, 1983, pp. 83-130. Jésus a vécu une époque où les gens croyaient que le monde touchait littéralement à sa fin. Beaucoup de ses contemporains étaient convaincus que le monde se trouvait au bord d'une véritable catastrophe apocalyptique. 
préparer, annoncer et vivre le Règne de Dieu déjà présent en Jésus-Christ (Mc 3,14.6,7-8.30; Mt 10,6). ${ }^{6}$ Cette poignée d'hommes est partie ensuite partager l'espérance qui avait transformé tout leur être, l'oeuvre du Père lors de la résurrection du Fils (Ac 1, 21-22). ${ }^{7}$ Ils sont partis annoncer cette Bonne Nouvelle de Libération pour faire de tous les peuples des communautés de disciples (Mt 28,18-19) en appliquant la 'pratique jésuanite' du Règne de Dieu et non pour fonder une future Église. Mais, les Douze vont historiquement jouer le rôle de transition entre le temps de Jésus et celui de l'Église.

\subsubsection{Aucune Église sans l'expérience pascale et le don de l'Esprit ${ }^{8}$}

L'Église a été fondée par l'initiative prophétique de Jésus et par l'Esprit du Vivant à la Pentecôte. L'événement du Christ ressuscité et le don de son Esprit rendent définitivement possible l'entrée personnelle dans la relation immédiate et originelle du Fils avec le Père. Le Christ désire partager à tous les êtres humains sa propre relation à Dieu afin que tous deviennent les enfants d'une même famille. Son Esprit a touché le coeur de Pierre, des Douze, de Jacques, de Paul et de plus en plus de Juifs et de Grecs.

6

Si Jésus avait choisi un groupe de douze hommes, c'était parce que le chiffre 12 avait une signification théologique évoquant les douze tribus d'Israël. Ce groupe représentait les chefs du nouvel Israël (Cf. Mt 19,28; Lc 22,28-30). "Mise à part la mission donnée aux apôtres, les communautés chrétiennes n'ont reçu de Jésus, pendant sa vie terrestre (historique), aucun réglement ecclésial. En outre, les "Douze" étaient le symbole de la communauté eschatologique de Dieu, attendue à court terme. Au début les disciples n'étaient nullement orientés vers un long avenir historique. Cette donnée néotestamentaire doit suffire à nous rendre extrêmement prudents à l'égard de la tentation de parler avec légèreté des "lois divines" et des dispositions particulières en matière de ministère dans la communauté de foi ecclésiale [tout au moins, abstraction faite de toute médiation ecclésio-historique]" (SCHILLEBEECKX, Edward, Plaidoyer pour le peuple de Dieu, Paris, Cerf, 1987, p.84.). Je me suis beaucoup inspiré de ce volume dans ce présent chapitre.

$7 \quad$ "La mission commence par un acte de foi en Celui qui nous précède et nous envoie"(RIGAL, Jean, Le courage de la mission, Paris, Cerf, 1985, p.13.).

$8 \quad$ Voir LEGRAND, Hervé, "L'Eglise se réalise dans un lieu", in Introduction à la pratique de la théologie, tome III, pp. 159-161. VENETZ, Hermann-Joseph, C'est ainsi que l'Eglise a commencé, Paris, Cerf, 1986, pp.19-39. 
Ces hommes et ces femmes ont expérimenté à l'intérieur d'eux l'Esprit du Fils Vivant et son action transfigurante. Ils se sont senti aimés ( $R m$ 1,7), fils et filles de Dieu $(\mathrm{Rm}$

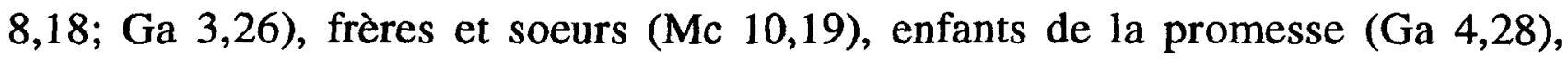
héritiers $(\mathrm{Ga} 3,29)$, élus $(\mathrm{Rm} 8,33)$, appelés ( $\mathrm{Rm} 1,6 \mathrm{~s}$.). Par le dynamisme de la Pentecôte, certains se sont regroupés pour partager et témoigner de leurs expériences. À la suite de l'activité de ces groupes et du rôle des disciples et des premiers apôtres, est née l'Église. Une Église formée de ceux qui croient au Christ ressuscité, c'est-à-dire de ceux qui croient qu'un avenir de liberté est toujours posssible sur cette terre.

"L'Église a jailli du peuple juif, grâce au ministère prophétique de Jésus de Nazareth et grâce à l'expérience pascale qui a rassemblé les disciples dispersés par la mort du Maître. Elle est toujours de nouveau recrée dans la force de l'Esprit, par l'initiative de disciples qui font mémoire du crucifié-ressuscité. I.../ On voit communément Jésus comme un "fondateur d'Église", à la manière dont la sociologie comprend la fondation des groupes religieux. Il est venu sur terre afin d'accomplir la mission reçue du Père, et cette mission inclut la fondation d'une Église. Il institue tous les sacrements et organise l'Église naissante. Il appelle les douze apôtres qui continueront son oeuvre et seront les chefs de l'Église. Il confie particulièrement son Eglise à Pierre, le chef du groupe des apôtres: "Tu es Pierre et c'est sur cette pierre que je vais fonder mon Église" (Mt 16,18). Après la mort de Jésus, les apôtres reçoivent l'Esprit qui leur donne d'être fidèles à l'héritage reçu, institutions ecclésiastiques comprises. Après la mort des apôtres, l'Église est confiée au pape, successeur de Pierre, et aux évêques, successeurs des apôtres. Dans ces perspectives, le pouvoir des évêques et du pape constitue l'élément fondamental de l'Église. Cette représentation de la naissance de l'Église est commode pour légitimer le fonctionnement d'un pouvoir autoritaire. Elles ne correspond pas aux données mises en lumière par les recherches bibliques, historiques et théologiques du XX $\mathrm{XX}^{\circ}$ siècle."

À la mort de Jésus, aucune Église n'a donc été fondée ni organisée. Il y a l'esquisse d'un mouvement de renouveau dans le judaïsme, mais ce mouvement est fragile et s'éteint presque à la mort de Jésus. Sans l'expérience pascale et le don de l'Esprit, il n'y aurait jamais eu d'Église. La mission du Fils et la mission propre au Saint-Esprit relient l'Église à l'initiative souverainement libre du Père. 
"L'origine de l'Église repose donc sur l'apport essentiel et irremplaçable du prophète galiléen mort martyr pour la cause du Royaume, et sur l'expérience de l'Esprit donné par le Ressuscité aux disciples. Dans le dynamisme de l'Esprit de Pentecôte, ces disciples organisent le mouvement issu de Jésus." 10

La reconnaissance du rôle de l'Esprit dans la constitution de l'Église est ainsi une condition indispensable si on veut faire place à l'initiative des croyants dans la constitution de l'Église. L'Église se constitue en réponse à l'appel de Dieu et dans l'attention aux situations historiques et sociales où elle s'édifie en continuant la mission que Jésus lui a confiée.

"La prise au sérieux de l'Esprit dans la vie de l'Église permet donc de valoriser la liberté et la créativité des croyants et des communautés dans le devenir de l'Église. C'est lui qui suscite des hommes et des femmes pour en faire des disciples du Seigneur Jésus, libres et responsables de donner à l'être-ensemble de l'Église des visages divers selon les contextes socio-culturels où elle prend racine. Ces hommes et ces femmes deviennent, en Esprit, les artisans des mécanismes institutionnels les plus accordés à la mission qu'ils ont vocation de servir." 11

L'Église ne prend alors son sens ultime que dans la promotion de l'avènement du Règne de Dieu- Elle n'est pas une fin en elle-même. L'Église ne monopolise pas non plus le Règne de Dieu, elle est tout entière à son service. ${ }^{12}$ Elle est un des fruits, des signes et des moyens du Règne de Dieu.

"L'Église n'est pas encore le Royaume, elle gère la distance nécessaire à la marche vers lui/.../ Elle est le lieu de la gestion risqué du quotidien ouvert sur un avenir insoupçonné."13

Ibid, p. 28.

12 KUNG,

KÜNG, Hans, Qu'est-ce que l'Église, Paris, DDB, 1972, pp.67-69.

13 DUQUOC, Christian, Des Églises provisoires, Essai d'ecclésiologie oecuménique, Paris, Cerf, 1985, pp. 66- 67. 
De ce fait, l'Église n'est à présent encore qu'en "germe et en projet" le Royaume de Dieu. Mais plus précisément, l'Église est le sacrement du Royaume de Dieu, le signe efficace de la présence de la grâce libératrice de Dieu en Jésus-Christ.

"Jésus, une fois élevé à la droite du Père, envoie son Esprit et donne à son Église la mission de proclamer le Royaume de Dieu et, du même élan, de se proclamer elle-même germe et prémices, en voie d'accomplissement eschatologique." 14

Une telle vision de l'Église comme communauté des fils de Dieu dans l'unique Fils grâce à l'Esprit est la base de tout le discours conciliaire de Vatican II: "L'Église est le sacrement, c'est-à-dire le signe et le moyen, de la communion des hommes avec Dieu et entre eux" ( Lumen Gentium \# 1). L'Église est donc cette partie de l'humanité où s'ébauche de façon privilégiée le Règne de Dieu en mal de réussir. Elle est pour le large monde comme un ferment, une convocation, une interpellation. Il est important théologiquement de ne pas durcir l'opposition Église et Royaume de Dieu. En considérant l'Église comme "sacrement du Royaume de Dieu", cette conception permet alors d'unir ces deux réalités. L'existence de la filiation divine, de la fraternité et de l'unité au coeur de l'Église révèlent que le Royaume de Dieu est déjà à l'oeuvre dans cette institution.

"Une intuition biblique: Faire la mission, tout en faisant l'Église, c'est là une oeuvre qui
ne saurait être accomplie sans fidélité à l'inspiration chrétienne fondamentale. Nous
aimerions trouver cette inspiration dans l'usage même du mot 'paroisse'. Or, il se trouve
que ce mot a une signification très particulière. Il est fait du préfixe par, qui veut dire en
quelque sorte 'ailleurs', 'à côté', 'pas ici'; et du mot oikos qui évoque maison. La paroisse
(ou le 'paroissial') a donc un sens biblique originel de nature essentiellement pascale.
Etre paroissial, c'est être citoyen de la maison de Dieu, alors que l'on vit encore en ce
monde. Etre paroissial, c'est faire le passage incessant de ce monde au Père, par le
Christ:"Vous êtes des étrangers et des voyageurs". Avec Bonhoeffer, on pourrait avancer

14 Schema Constitutionis de Ecclesia, Cité du Vatican, 1964, chap. 1, nº5, pp. 9-10. "Aussi l'Église, pourvue des dons de son fondateur, et fidèlement appliquée à garder ses préceptes de charité, d'humilité et d'abnégation, reçoit mission d'annoncer le royaume du Christ et de Dieu et de l'instaurer dans toutes les nations, formant de ce royaume le germe et le commencement sur la terre" ( $L G 5,17$ ). Voir aussi $L G 3,15$. 
que la 'paroisse' est le lieu où toutes les réalités humaines, les réalités avant-dernières, sont appelées à se manifester et à se transmuer en réalités dernières. Une telle signification est fort intéressante, car elle est directement opposée à l'idée d'installation, ou encore à une stabilisation dans un périmètre territorial, avec tentation d'un milieu fermé. La paroisse est le lieu de l'exode chrétien." 15

La paroisse, par sa signification "biblique" toute particulière, rappelle aux intervenants pastoraux qu'ils sont appelés à servir le Royaume de Dieu là où ils sont. En accompagnant les paroissiens dans un approfondissement de leur relation à Jésus Christ, Celui-ci s'occupe par la suite d'opérer des "déplacements" dans leur coeur, lieu de la maison de Dieu. À Son contact, les intervenants et les paroissiens deviennent autres. Ils ont davantage le goût de voyager, c'est-à-dire d'aller vers l'autre que l'on considère comme un étranger pour s'enrichir de son expérience "autre". Dans ce contexte, le paroissien est toujours en exode, en passage incessant de son monde à lui au monde de l'autre et de l'Autre, en continuelle route vers une plus grande libération personnelle et communautaire grâce à ce qui est différent de lui. "Dans un texte difficile à dater mais qui représente une pensée des premiers siècles chrétiens, on trouve des affirmations assez étonnantes, à la fois assurées et stimulantes: "Les chrétiens ne se distinguent des autres hommes ni par le pays, ni par le langage, ni par les vêtements. Ils n'habitent pas des villes qui leur soient propres, ils ne se servent pas de quelque dialecte extraordinaire, leur genre de vie n'a rien de singulier. Ils se répartissent dans les cités grecques et barbares le lot échu à chacun; ils se confondent aux usages locaux... Ils résident chacun dans sa propre patrie, mais comme des étrangers domiciliés. Ils s'acquittent de tous leurs devoirs de citoyens, et supportent toutes les charges comme des étrangers. Toute terre étrangère leur est une patrie et toute patrie une terre étrangère... En un mot, ce que l'âme est dans le corps, les chrétiens le sont dans le monde" (Épître à Diognète, coll. "Sources chrétiennes", traduction H.L. Marrou, Cerf, 1951, p. 63-65). On aura reconnu dans ce texte une sorte d'illustration de la thèse, bien souvent développée, du chrétien "au monde, mais pas du monde" (DENIS, Henri, L'Église, Les quatre portes du Temple, Paris, DDB, 1991, p. 164.). 


\subsubsection{La première communauté 'chrétienne' naît grâce à un conflit}

Aucun groupement ne peut se maintenir longtemps sans une certaine structuration institutionnelle. C'est une loi sociologique bien connue.16 Toutes les communautés de foi paléochrétiennes, pauliniennes ou autres se sont retrouvées tôt ou tard confrontées à la question: comment résoudre les conflits dans notre communauté ou notre confrérie? Qui détient l'autorité? Un premier conflit fondamental a vu le jour à Antioche au début du travail missionnaire de Barnabé et de Paul.

En fait, la première communauté chrétienne, à part celle des premiers disciples, n'a existé que lorsqu'à partir du concile de Jérusalem (en 49-50; Ac 15; Ga 2,9) des Juifs ont accueilli des païens non circoncis dans leur groupe et sont devenus une communauté de fils de Dieu où il n'y a ni Juif ni Grec et où tous ne font qu'un par la foi dans le Christ (Ga 3,26-29). En vertu du baptême dans l'Esprit, aucun chrétien, homme ou femme, ne peut-être exclu a priori.

"Ce conflit est riche d'enseignement quant à la structure de l'Église./.../ Les discussions se résolvent grâce à des rencontres entre chrétiens, qui discutent et s'expriment au sujet des matières conflictuelles." 17

"D'après le Nouveau Testament, l'idéal de l'Église n'est pas d'être un simple conglomérat d'individus directement rattachés au Christ; l'Église doit être un peuple organisé, une communauté structurée, car c'est là une des conditions concrètes de sa vie et de sa croissance" (LEMAIRE, André, Les ministères dans l'Église, France, Le Centurion, 1974, p.24). 
Tel est le fondement de la synodalité ecclésiale: la participation de tous à la vie et à la mission de l'Église. Cette première communauté chrétienne a donc été accueillie comme un don de l'Esprit puisqu'il est le seul capable de "réunir dans l'unité les enfants de Dieu qui sont dispersés"(Jn 11,52). "Ce n'est que dans l'Esprit qu'il est possible de faire éclater les barrières nationales et sociales, les intérêts des groupes, les différences de conditions ou l'inégalité sexuelle." 18 Antioche a donc été la première communauté chrétienne. 19

\subsubsection{Les premiers chrétiens en ville}

Comment rejoindre les gens pour leur annoncer l'Évangile dans un monde urbanisé, complexe et pluraliste comme le nôtre? De quels modèles s'inspirer pour former des communautés vivantes? Quel rapport au monde développer pour vivre en chrétiens? Aux débuts de l'expérience ecclésiale, ces questions ont rapidement surgi et des pistes ont été suggérées. Vingt-cinq ans après la mort de Jésus à Jérusalem, la foi chrétienne est déjà répandue dans les grands centres urbains de l'Empire romain: Antioche, Éphèse, Rome, Corinthe, etc. Très vite, cette Bonne Nouvelle a circulé grâce à des missionnaires mobiles; et c'est dans les cités de l'Empire que des communautés se sont formées et développées. Pendant plusieurs siècles (nous l'avons vu au chapitre septième sur l'historique de la paroisse), le christianisme sera un phénomène religieux (Ac 11,26)" (LEMAIRE, André, Les ministères dans l'Eglise, p.16). "....tous les chrétiens baptisés forment ensemble un seul peuple de Dieu prophétique et pneumatique; tous sont des partenaires égaux, sans hiérarchie ni domination /.../ De là vient le nom antiochien de "chrétien": les gens qui sont dans le Christ Jésus, en Jésus, qui est lui-même plein de Pneuma. "Nul ne peut dire "Jésus est Seigneur" que sous l'action de l'Esprit Saint" (1Co 12,3)" (SCHILLEBEECHX, Edward, Plaidoyer pour le peuple de Dieu, p.44). 
avant tout urbain. Il faudra l'écroulement de l'Empire romain et les débuts d'une nouvelle culture pour que la mission se tourne vers les campagnes.

C'est en ville que les chrétiens des premiers siècles et leurs communautés vivaient. Il est essentiel de mieux connaître ces débuts de l'Église où les défis urbains ont été affrontés. 20 Les communautés pauliniennes constituent un courant parmi les nombreux courants qui ont façonné les commencements de l'aventure chrétienne. Paul, missionnaire et pasteur, a beaucoup voyagé avec ses équipes de collaborateurs et collaboratrices pour annoncer l'Évangile et fonder des communautés dans les cités de l'Empire. Paul a été intéressé par les grands centres urbains avec leurs familles, leur pluralisme, leurs centres commerciaux, leurs débats politiques, leurs écoles philosophiques et leurs mouvements religieux. ${ }^{21}$ Dans les cités, comment Paul faisaitil pour rejoindre les gens et leur proposer l'Évangile? Tout d'abord, Paul est lui-même un citadin. Il vient de Tarse (300,000 habitants), ville réputée pour son commerce, ses universités, ses textiles. Il se sent bien dans l'univers urbain, il connaît ses réseaux de relations et de communication. La preuve, Paul utilise des images qui sont urbaines, lui venant des sports (lutte, course, stade), de l'organisation de la cité (l'image du corps). Paul va utiliser les réseaux naturels de relations dans les cités et entre cités.

20

Il existe beaucoup de ressemblances entre les villes de l'ère apostolique (ex: l'Empire Romain) et celles d'aujourd'hui. J'en note quelques-unes. À l'époque des premières communautés chrétiennes, on vit le pluralisme ethnique (ex: À Rome même, on retrouve plus de 100 groupes ethniques). L'urbanisation entrâne aussi l'augmentation du volume des échanges commerciaux. On construisit tout un réseau de voies de communication (ex: routes, voyages maritimes). Paul utilisera tous ces moyens de transport. Dans les villes, la disparité entre riches et pauvres est criante; la population est vieillissante....etc. Aujourd'hui, on perçoit la mission comme quasi impossible dans le contexte urbain. Mais elle n'était pas plus facile au temps de Paul. Par exemple à Corinthe, il y avait 70 chrétiens sur 500000 habitants... pourtant le christianisme s'est propagé jusqu'à nous.

21 Voir MEEKS, Wayne A., The first Urban Christians, The Social World of the Apostle Paul, Yale University Press, New Haven and London, 1983; THEISSEN, G., The Social Setting of Pauline Christianity: Essays on Corinth, Philadelphia, Fortresse Press, 1982; BRISEBOIS, Mireille, Saint-Paul: Introduction à Saint Paul et à ses lettres, Montréal, Paulines, 1984, 173p. 
Les communautés pauliniennes reflétaient assez bien la société urbaine. Elles regroupaient des gens de différents niveaux sociaux. Ces communautés existent dans des cités marquées par la diversité, la pluralité des options morales et religieuses et le partage d'une même culture urbaine. Dans ce contexte urbain, les principaux modèles existants de communautés sont les suivants: les maisonnées, les synagogues, les associations, les écoles philosophiques. Les communautés pauliniennes ont des ressemblances avec chacun de ces modèles, ce qui indique leur enracinement social et culturel dans la réalité urbaine et leur capacité de répondre à des aspirations. Mais elles ont aussi des différences par rapport à chacun des modèles, ce qui indique l'originalité particulière de ces communautés de disciples de Jésus et la nouveauté de l'Évangile.

"Comme missionnaire, Paul a été actif et audacieux. Il a utilisé une grande diversité de réseaux et de lieux. Il a su être attentif à la vie et à l'organisation des cités, à leurs réseaux de relations pour y trouver des voies de communication de l'Évangile. Comme pasteur, il a travaillé à bâtir un nouveau réseau, celui des chrétiens, qui soit à la fois enraciné et original dans son style et ses options. Notre univers urbain actuel n'est pas sans ressembler à celui de Paul. Nous avons à annoncer l'Évangile dans un monde urbain aux réseaux variés; nous avons à y bâtir des communautés fraternelles reliées entre elles /.../ Ces défis sont nôtres et nous avons besoin d'attention, d'espérance et d'audace pour y faire face; Paul ne nous fournit pas des réponses toutes faites pour cela. Mais ses approches pastorales et missionnaires peuvent encore nous inspirer dans nos regards sur notre culture, sur la place des chrétiens dans la cité et sur les voies d'avenir de la mission." 22

\subsubsection{La structure de base de la communauté: la maisonnée}

Il est important de rappeler que la structure de base de la communauté chrétienne ancienne était la même que celle de la société civile urbaine: la maisonnée (ou le foyer). La communauté domestique ou "la maisonnée de la foi" $(\mathrm{Ga} 6,10)$ fut dans l'Église ancienne à l'origine du christianisme dans une certaine ville ou province 
de l'empire. Cette maison était le lieu où se faisaient la prédication et la catéchèse, la place aussi où l'on mangeait et buvait ensemble, célébrait l'eucharistie, etc. .

"Mais l'assemblée, en particulier, c'était l'ekklèsia elle-même, invitée et reçue dans le cadre domestique (oikos ekklèsias). À cette ekklèsia, la maison offrit donc en premier lieu l'appui actif de l'hospitalité et de ses usages. C'était, de fait, une inappréciable contribution. Car, avec l'hospitalité, la maison apportait à l'ekklèsia l'assurance d'une continuité pour le service local de la parole, en même temps qu'elle constituait un centre de rayonnement pour ceux dont la mission propre, apôtres surtout, restait de porter la parole au-delà de l'assemblée constituée. Le cadre domestique assurait donc ainsi à l'ekklèsia, comme au service itinérant de la parole, non seulement une stabilité et une sécurité, mais encore la flexibilité et la mobilité grâce auxquelles l'évangile pourrait soutenir son progrès. I.J À cet égard, il n'est pas exagéré de dire que, dans l'ordre des institutions, c'est le cadre domestique, avant tout, qui a permis alors à l'évangile et à l'ekklèsia d'être le ferment dans la pâte." 23

Pendant les premiers siècles, il y a toujours eu coïncidence entre 1"'assemblée liturgique", d'une part, et la "communauté de base", l"'église" locale, d'autre part. 24 À l'âge apostolique, dans les pays de langue grecque, c'est un même mot, ekklèsia, qui désigne à la fois et l'"assemblée liturgique" et l'"église" locale. Si 1"'église" locale s'est appelée ekklèsia, c'est d'abord parce que cette "église" locale trouvait son expression première et toute naturelle dans une "assemblée liturgique" qui pouvait s'appeler proprement une ekklèsia. Alors,il y avait non seulement coïncidence entre "église" et "assemblée liturgique", mais cette coïncidence s'inscrivait dans le cadre domestique.

"C'est donc là que notre "église" est née. C'est là aussi que, pendant assez longtemps, elle a vécu et grandi. Les noms de quelques-uns de ceux qui ont ainsi "reçu" l'"église" dans leur maison, à l'origine, nous sont connus par les lettres de Paul: à Rome, Prisca et Aquilas (Rom., 16,5); les mêmes à Éphèse (1 Cor., 16,19); à Laodicée, Nymphas (Col., 4,15); Philémon et Apphia à Colosses (Philém., 2). Ces faits sont assez familiers en histoire, même s'il est vrai qu'ils ne sont pas toujours cernés avec une suffisante

AUDET, Jean-Paul, Mariage et célibat dans le service pastoral de l'Église, pp. 8182. Je me suis beaucoup inspire de ce volume dans les prochains paragraphes.

24 Le changement s'amorce, mais s'amorce seulement, au cours du $\mathrm{IV}^{\circ}$ siècle, avec la construction des grandes églises urbaines dont les basiliques constantiniennes donnaient désormais l'exemple. 
précision. Surtout, il ne semble pas qu'on ait généralement assez réfléchi à leur portée pastorale, comme aux suggestions qu'ils pourraient offrir en regard de la situation actuelle." 25

Il est important de réfléchir sur la question du nombre de croyants par ville à cette époque. Beaucoup croient que le nombre de chrétiens par "église" de l'âge apostolique était élevé. Les exégètes sont divisés sur cette question. M. AUDET donne une réponse éclairante:

"Naturellement, nous ignorons, et nous ignorerons toujours, par exemple, quel pouvait être, vers les années 60 , le nombre total des chrétiens de la ville d'Éphèse. Aussi bien n'est-ce pas cela qui importe. En revanche, le style et les dimensions de la maison commune de l'époque, dans le monde gréco-romain, nous sont assez bien connus. Par ce biais, nous pouvons nous faire une idée approximative, sans doute, mais assez juste, de l'ekklèsia qui se réunissait pour la "parole" et l'"eucharistie" chez Prisca et Aquilas (1 Cor., 16,19 ). Ceux-ci étaient des artisans; ils ne disposaient sûrement pas d'une villa aristocratique. Vraisemblablement, nous ne serons pas très loin de la vérité si nous avançons le chiffre de 50 pour cette ekklèsia. I.../ D'autres pouvaient en compter 30,40 , 50 ou 60 . Le chiffre le plus élevé qui nous soit connu est $93 . . . " 26$

$\mathrm{Si}$, dans les origines, les chrétiens de la ville se réunissaient dans les 'maisons', ils en sont venus à se réunir en assemblée dans un plus grand bâtiment vers le III $^{\circ}$ siècle.

"Au III ${ }^{\circ}$ siècle, il est vrai, le lieu de l'assemblée n'est pas plus, en règle générale, la maison de l'un ou l'autre des membres de l'ekklèsia. Ce n'est donc plus, à proprement parler, une maison familiale. Dans la plupart des cas, c'est une ancienne maison familiale déjà plus ou moins aménagée, transformée, et souvent agrandie, en vue des besoins spécifiques de l'assemblée chrétienne. En conséquence, l'"église", comme on se met à dire alors, tout en gardant la physionomie générale d'une véritable domus ecclesiae, ou oikos ekklèsias, est devenue, en fait, un lieu de rencontre fixe et, en principe à tout le moins, constamment disponible, n'appelant donc plus, de soi, les multiples attentions personnelles qui avaient fait l'hospitalité pastorale primitive. Il n'est pas sans intérêt de noter, du reste, qu'en outre de l'espace prévu pour l'assemblée, l'"église" de ce temps-là tend de plus en plus à englober divers locaux où peut habiter une partie plus ou moins 
importante des responsables du service pastoral: évêque, prêtres et diacres. Généralement, lecteurs et autres adjoints continuent, toutefois, à vivre dans la masse de la population." 27

Ce n'est qu'aux $I V^{\circ}$ et $V^{\circ}$ siècles qu'on est arrivé progressivement à la foule. Tout s'est passé comme si, à partir du $\mathrm{IV}^{\circ}$ et du $\mathrm{V}^{\circ}$ siècle, la "communauté de base" de la vie ecclésiale avait progressivement cessé de se modeler sur le prototype sociologique de la "maison" pour adopter en même temps un tout autre modèle: celui de la "foule". Le symbole historique le plus évocateur de ce passage d'un prototype sociologique à un autre nous est fourni par l'architecture, et c'est le lent et presque universel triomphe du plan basilical (avec tous ses dérivés mineurs) sur la domus ecclesiae antique. ${ }^{28}$

27 Ibid., pp. 99-100. "Dans les villes, la situation n'était d'ailleurs pas beaucoup plus favorable, faute de locaux pour les grands rassemblements de fidèles. Il n'y avait pas encore de basiliques et l'on en était réduit à se réunir dans les domiciles privés /.../ Où se rassemblaient donc les autres chrétiens? Ils se répartissaient, pour les célébrations liturgiques, en plusieurs "tituli" ou demeures privées. De fait, il y avait à Rome, dès le début du $\mathrm{III}^{\circ}$ siècle, plusieurs églises titulaires de ce genre, et Justin le Martyr reconnaît: "Nous ne pouvons pas nous réunir tous ensemble en un même lieu: chacun va où il peut et où il veut!" Très tôt donc, dans l'intérêt même du ministère, on assiste à une certaine décentralisation..." (CROCE, P.W., Histoire de la paroisse, in La paroisse de la théologie à la pratique, Paris, Cerf, 1961, pp. 18-19).

28 "... le plan basilical lui-même, dont le prototype était emprunté à l'architecture civile, malgré l'existence de "basilique" privée, - introduisait dans la "communauté de base" (évêché, puis "paroisse") un germe qui, en se développant, allait conduire insensiblement à ce que nous avons sous les yeux: la grande église, non seulement lieu de réunion, mais encore signe et symbole de la grande assemblée. /.../ Les conséquences de ce passage devaient être incalculables, d'une part, en ce qui concerne la structure interne de l"assemblée liturgique", et d'autre part, ce qui concerne les diverses fonctions pastorales. Un nouveau style de vie ecclésiale allait naitre, et dans la même mesure, un style également nouveau de vie chrétienne" (AUDET, Jean-Paul, Mariage et célibat dans le service pastoral de l'église, pp. 145-146). 
10.2.5 La communauté, une exigence de la foi personnelle 29

Dieu nous a créés personne et communauté. Cela implique nécessairement que nous ne pouvons nous réaliser pleinement comme personne que dans et par la communauté. La vie spirituelle et la foi sont des réalités éminemment personnelles que chacun vit dans la solitude de son propre mystère. La foi naît au coeur du sujet, dans la foi en soi. Quand le mouvement de foi s'élargit dans la foi aux autres et, éventuellement, dans la foi en Dieu, il garde de son origine son caractère toujours personnel. Pour faire communauté, il y a nécessairement une présence à soi. Il n'y a pas toujours du narcissisme dans cette recherche de sens et d'identité. Chacun doit commencer par parcourir le difficile chemin de la personnalisation à travers les relations humaines et de même que dans son insertion sociale. La foi naît et grandit dans l'effort que chaque personne met à devenir elle-même et ce devenir n'est atteint que grâce à la présence active des autres. "Pour devenir lui-même il (l'humain) a besoin de ce qui n'est pas lui, de ce qui se présente à lui du dehors et de ce qui provient de ses origines." 30 Parmi les réalités extérieures dont l'humain a ainsi besoin pour devenir lui-même, pour être un spirituel vivant et un croyant authentique, la relation aux autres tient une place de premier plan. L'individu ne devient vraiment "je" que face à un "tu" dans le cadre d'une communauté de vie et d'échange. La communauté est une exigence de la vie de foi personnelle. Parce que l'individu a besoin des autres dans son

"...il y a moins d'infaillibilité dans la foi là où la communion entre nous s'est affaiblie. La communion est donc une loi de notre vie de chrétiens. N'importe quel membre de l'Église qui tend à s'isoler de la vie de foi vécue par ses frères et soeurs est menacé d'erreurs. Cela vaut aussi bien pour le pape, les évêques que pour les fidèles et les théologiens" (FRANSEN, Pierre, "La communion ecclésiale, principe de vie", in Les Eglises après Vatican II, dynamisme et prospectives, Actes du Colloque international de Bologne, Paris, Beauchesne, 1981, p.201. [Théologie historique \# 61]). "La conversion et la communion sont deux exigences qui découlent de la vie chrétienne"( RIGAL, Jean, Le courage de la mission, Paris, Cerf, 1985, p. 30.).

30 LÉGAUT, Marcel, Devenir soi et rechercher le sens de sa propre vie, Paris, AubierMontaigne, 1981, p.27. 
devenir qui l'amène à la foi authentique, il a besoin d'une communauté de foi Et, "le Nouveau Testament confirme, amplifie, renouvelle cette dimension communautaire (1 Co 12,13; Tt 2,14; He 9,15;12,24)."31 Les sources chrétiennes expriment l'originalité de cette communauté par le thème très riche: "Koinônia", communion qui n'est pas faite d'abord de mains d'hommes mais de l'action même du Seigneur rassemblant par sa Parole et son Corps ses fils dispersés .

Nous ne pouvons découvrir la vérité et les valeurs de notre vie chrétienne qu'en communauté. La vie est toujours plus riche que nos notions 'computérisées'. En tant que chrétiens, nous sommes invités à nous unir pour former des groupes humains où s'établissent des relations personnalisées (petits groupes - relations courtes) et où se vivent des rapports de solidarité (grands groupes - relations longues). Seule la communion peut nous permettre de découvrir davantage la présence de Dieu dans notre vie personnelle et communautaire ${ }^{32}$ puis, de trouver comment exprimer fidèlement par nos paroles et nos actes ce que Dieu attend de nous. 33 Chaque croyant et chaque communauté sont invités à obéir aux poussées de l'Esprit, comme l'eau obéit aux poussées jaillissantes d'une source, dans le désir commun de reconnaître 'les signes des temps'. Egalement, ce n'est qu'ensemble que nous pouvons nous laisser façonner disciples par le Ressuscité présent dans nos frères et soeurs dans la foi et en retournant en communauté aux sources de cette foi chrétienne.

RIGAL, Jean, Le courage de la mission, p.65.

"Toujours une conviction nous habite: chaque personne et chaque communauté est objet de la tendresse du Seigneur, et il est essentiel que chacun révèle de plus en plus, selon sa manière propre, le trop-plein de cette tendresse"(PARENT, Rémi, L'Eglise, c'est vous!, Montréal, Paulines, 1982, p.76.).

33 "Dans la communauté qui naît de la foi, il y a un moment pour écouter et un moment pour parler, un temps pour se former à la révélation et un temps pour témoigner de la révélation"(BOFF, Léonardo, L'Église charisme et pouvoir, Paris, Lieu Commun, 1985, p.245.). 
La communauté est une famille de croyants dont la loi d'existence doit être l'amour fraternel (1 Th 5,11; 1 Co 12,25; Rm 12,16.;15,14; Jc 5,15; Mc 10,19). Elle est une densité de fraternité. Parce que nous nous savons aimés par Dieu qui a fait le premier pas vers les pécheurs que nous sommes, nous devenons capables d'aimer à notre tour gratuitement ce frère pour lui-même et nous rassembler devant Dieu. Cette famille réunit des enfants d'un même Père, tous prévenus par un amour qui les a remis debout, et motivés par un trop-plein d'amour qui les visite fidèlement, ils décident de s'engager dans un travail de libération. De plus, ce n'est que communautairement que nous pouvons porter cette mission qu'est le Règne de Dieu. ${ }^{34}$ La mission ne consiste pas toujours à partir ailleurs mais à exister autrement, c'est-à-dire à vivre authentiquement ce que nous sommes. Cette mission exige une écoute et une contemplation du Christ déjà en germe dans le coeur de tout humain. Elle oblige à susciter l'éclosion de toutes les potentialités de vie enfouies dans le terrain où arrive la Parole. Elle demande en plus de promouvoir la vie contre tout ce qui diminue l'humain dans sa dignité. La communion est donc une loi primordiale dans la vie chrétienne parce qu'elle est une attitude d'ouverture en face de Dieu dans l'histoire et une disponibilité profonde de tous les membres du Peuple de Dieu à se laisser rassembler par l'Esprit Saint autour du Christ en face du Père.

\begin{abstract}
"Nous sommes communion pour nous apprendre les uns aux autres que personne ne possède Jésus-Christ.C'est lui qui nous possède par le don gratuit de sa vie./.../Une telle communion interdit à chacun de vivre le Christ comme une réponse toute faite, une fois pour toutes. Elle nous ouvre la route et nous invite à la quête: le salut est trop donné pour que, devant nos pauvres façons de le vivre, nous ne recherchions des manières toujours neuves de l'incarner ici et maintenant." 35
\end{abstract}

34

"La communauté chrétienne ne saurait être considérée uniquement comme le peuple que Dieu rassemble, elle est aussi le peuple que Dieu envoie pour annoncer Jésus-Christ comme une Bonne Nouvelle pour le monde, comme une Lumière et une Espérance à travers les questions qu'il se pose, comme le Sens nouveau qui donne une clé pour sa recherche, une cohésion pour son action, une finalité pour son devenir"(RIGAL, Jean, Le courage de la mission, p.187-188).

PARENT, Rémi, L'Eglise, c'est vous!, pp. 62-63. 


\subsection{Le ministère dans le Nouveau Testament}

Identifier les liens entre Christ et Église laisse quelques insatisfactions quant à l'articulation entre le fondement et les ministères. C'est pourquoi il nous faut à nouveau porter un regard sur les premières Églises et leur organisation des ministères en rapport avec les charismes suscités par l'Esprit. Que dit le Nouveau Testament sur les relations entre Église et ministères? Les recherches bibliques des trente dernières années ont apporté un nouvel éclairage sur l'organisation des ministères dans l'Église de la période apostolique. Une conception courante, en effet, veut figer leur organisation sous prétexte qu'ils ont été institués par Jésus lui-même. Une analyse approfondie nous fera découvrir que chaque communauté locale face à un nouveau besoin, résolvait les principaux problèmes concrets concernant la vie des ministres en se montrant souple et inventive dans l'adaptation aux diverses situations.

\subsubsection{Face à un nouveau besoin de la communauté, les Douze font advenir une nouvelle structure ministérielle}

Le premier ministère attesté dans la communauté chrétienne naissante est celui des "Douze". Ces Douze étaient tous des Juifs originaires de Palestine. Leur ministère a été de témoigner de la résurrection (Ac 1,22), c'est-à-dire l'annonce de la Bonne Nouvelle auprès des hommes d'Israël (Ac 2,22; 3,12; 5,35), aussi bien aux foules juives (Ac 2,14s; 3,12) qu'aux disciples réunis dans les maisons (Ac 5,42). 36 Les "Hellénistes" appartenaient souvent à des milieux plus aisés et culturellement plus ouverts que les Juifs. Or, les Douze étaient tous des "Hébreux". Responsables de la gestion de la caisse de secours de la communauté, ils avaient naturellement tendance à 
aider davantage ceux qui parlaient la même langue qu'eux et les veuves des "Hellénistes" étaient plus ou moins délaissées. Pour résoudre ce problème qui risquait de déchirer la communauté chrétienne naissante, les Douze convoquent l'assemblée générale des disciples et proposent une solution qui va au fond du problème: puisqu'il y a deux groupes culturels différents, il est préférable que chaque groupe s'organise en communauté autonome avec ses propres ministres. Ils choisissent donc, parmi les Hellénistes un groupe de "sept hommes de bonne réputation, remplis de l'Esprit et de sagesse"(Ac 6,3).

"...face à un nouveau besoin de l'Église, les Douze n'hésitent pas à créer une nouvelle structure ministérielle et ne se sentent pas limités par le fait que Jésus n'ait institué que le ministère des Douze"37

Les Sept vont assurer chez les Hellénistes le service de la parole(Ac 6,9-10). Étienne est choisi comme leur leader (Ac 6,5). Cependant, par sa prédication audacieuse, Étienne s'attire la haine des juifs hellénistes de Jérusalem. Il est rapidement arrêté, jugé et lapidé (Ac 6-7) et une violente persécution se déchaîne contre la communauté chrétienne des Hellénistes qui sont obligés de se disperser (Ac 8,1). Dès lors, le groupe des Sept n'a plus de raison d'être et disparaît en tant que groupe constitué. Le groupe des Douze et Jacques ont subi bientôt le même sort que celui des Sept (Ac 12,2-3.17).

"À cette époque, un événement important marque un tournant dans la vie de la communauté chrétienne: les premiers païens sont admis dans l'Église(Ac 10-11); la structure ministérielle des Douze qui se référait à Israël des douze tribus perd donc sa raison d'être et, comme lors de l'institution des Sept, l'extension de l'Évangile à un nouveau groupe humain va entraîner la création de nouveaux ministères". 38 


\subsubsection{La préoccupation de Paul: les besoins des communautés}

Paul s'est engagé résolument dans l'annonce de la Bonne Nouvelle. "Car annoncer l'évangile n'est pas un motif d'orgueil pour moi; c'est une nécessité qui s'impose à moi. Oui, malheur à moi si je n'annonce pas l'Évangile!"(1 Co 9,16). Paul a cherché avant tout à édifier l'Église. Paul s'est même donné le titre privilégié d'apôtre, c'est-à-dire celui qui est envoyé.

"Historiens et théologiens sont d'accord pour admettre que le terme "apôtre", au temps de Paul, ne renvoie à aucune fonction particulière. Le concept d'apôtre appartient à la première phase constitutive des communautés ecclésiales. Les apôtres étaient bien l'instance incontestée dans tout travail missionnaire ecclésial. Apôtre, en grec, signifie à peu près "ambassadeur", un envoyé de Dieu (cf. 2 Co 5, 20)."39

Par son pouvoir apostolique, Paul a été le fondateur de nombreuses communautés chrétiennes. Cependant, il n'a jamais été le leader des Églises locales qu'il a fondées. Comme les épîtres de Paul en témoignent, ce dernier s'est toujours associé des collaborateurs pour l'aider dans sa tâche (1 Co 3,9). Et ces collaborateurs, il ne les a jamais traités comme de simples aides, mais comme des partenaires majeurs et indépendants. Parmi ses collaborateurs, il choisissait des leaders là où ils fondaient une communauté. Paul, envoyé par la communauté d'Antioche, a commencé à Corinthe à donner des titres à ses leaders. Il classait ceux-ci en trois catégories de serviteurs : apôtres (Cf. Ac13,1-3; 14,27; 15,27,18,22), prophètes (Cf. 1Co 14,15-17; 29-32; Ac 13,2; 21,11) et docteurs (Ac 13,1; 18,24; 22,3). "Et ceux que Dieu a établis dans l'Église sont premièrement les apôtres, deuxièmement les prophètes, long de l'histoire, Paul a été reconnu et honoré comme l'apôtre par excellence, celui qui a ouvert la mission universelle de l'Église. Paul occupe une place énorme dans le Nouveau Testament. Deux tiers des écrits lui appartiennent. 
troisièmement les docteurs..."(1 Co 12,28). "L'apôtre fondait la communauté, le prophète lui révélait la volonté immédiate du Christ, l'enseignant situait son vécu sur le fond de scène de la révélation passée/.../Un christianisme en vie."40 Et lorsque Paul écrivait à l'une ou l'autre des communautés chrétiennes, il ne s'adressait jamais uniquement à ces trois catégories de leaders. Il écrivait pour tous les membres de la communauté. Chez Paul, tous les services qui pouvaient s'exercer dans une communauté venaient de l'Esprit que Jésus Christ a reçu de Dieu. Paul mettait en parallèle les dons ( charismata) et les services (diakoniai). Chaque membre de la communauté a son charisme bien précis à faire fructifier (1 Co 12). Tous les dons servent à l'accomplissement de l'unité dans le Christ (cf. Ep 4,11-13). Tous sont au service d'une communauté qui appartient au Christ (cf. 1 Co 3, 21-23).

\begin{abstract}
"Chaque croyant, pour Paul, jouit d'une autorité à la fois dans et sur la communauté, à la mesure de la foi qui lui a été donnée. Comme en $1 \mathrm{Co} 12$, il situe le fait d'être à la tête de la communauté à l'avant-dernière place /.../ Ce n'est pas la structure qui domine mais la souveraine liberté du souffle de Dieu."41
\end{abstract}

Cependant, Paul demandait aux membres de chacune des communautés d'avoir des égards pour les apôtres, les prophètes et les docteurs (1 Th 5,12-13). Ceux-ci assuraient un service spécialisé qui était un véritable 'travail' et leur Église locale devait subvenir à leurs besoins ( 1 Co 9,4-6.14; 2 Co 11,8; 1 Th 2,7; 1 Tm 5, 17-18). Toutefois, l'exemple de Paul montre que le ministre, quand il le jugeait pastoralement utile, pouvait refuser cette prise en charge par la communauté et travailler de ses mains pour subvenir à ses besoins (Cf. 1 Th 2,9; 2 Th 3,7-9; 1 Co 9, 1-18). Dans ce cas, le ministre reprenait le métier qu'il avait exercé avant d'être appelé au ministère. Au total,

LEMAIRE, André,"Des services aux ministères: Les services ecclésiaux dans les premiers siècles", p.136.

41 MYRE, André, "Nouveau Testament et ministères", p. 132; LEMAIRE, André, "Des services aux ministères...., pp. 41-46. 
il semble donc que le problème de la rémunération des ministres ait été résolu en tenant compte de la diversité des situations concrètes.

Dans la communauté de Philippes, Paul reconnaît deux fonctions qui vont avoir une longue histoire: surveillant (episkopos ) et serviteur (diaconos) ( $\mathrm{Ph} \mathrm{1,1).42} \mathrm{Cette}$ association de fonctions peut avoir été créée à partir de l'initiative de l'Église locale ellemême, car on ne trouve ces fonctions dans aucune autre épître paulinienne authentique. Au sein de cette communauté, un surveillant avait certaines responsabilités à exercer (ex: encourager ses frères et soeurs, accueillir des frères et soeurs de passage, témoigner, enseigner, présider, etc.) et un diakonos était au service des autres sans en être toutefois l'esclave. Ces surveillants et serviteurs, originaires de la communauté, assuraient, comme les prophètes et les docteurs, le service de la prédication et de la proclamation de l'action de grâce. Mais plus tard dans d'autres communautés, on passera progressivement de la triade apôtres-prophètes-enseignants à une autre triade, celle des surveillants-anciens-serviteurs qui va prendre beaucoup d'importance par la suite dans l'histoire de l'Église.

Paul parle de plusieurs charismes: celui de prophétie, d'enseignement, d'exhortation morale, de sollicitude (pour les misères diverses incluant le soutien aux pauvres) et de celui du ministère. Toutes ces fonctions sociales des communautés locales ont ceci en commun qu'elles sont toutes appelées charismes - ou dons - et nommément "dons de Dieu, du Christ ou de l'Esprit." La variété des services montre la grande liberté qui existait dans l'ordre structurel du service des églises, ainsi que l'introduction d'une certaine organisation ecclésiale. Ce qui est mis ici en relief (surtout dans les listes des lettres aux Corinthiens), c'est moins la personne et son statut dans 
l'Église, que la tâche qu'elle assume de fait pour la formation chrétienne de la communauté, et donc en vue de son fonctionnement concret. Face à cette foisonnante variété qui pourrait entraîner l'établissement d'un statut personnel de pouvoir, Paul a cherché à neutraliser la différenciation hiérarchique; il veut assurer avant tout l'unité du groupe chrétien par le biais de services nombreux et variés. C'est pourquoi justement il dresse ces listes de services divers dans les communautés. Il accepte la diversification des services, tout en mettant l'accent sur la contribution de tous à l'édification collective de la communauté.

L'apôtre Paul a été très discret sur l'organisation concrète des communautés chrétiennes dans ses lettres pastorales. Ce qui le préoccupait surtout, ce n'était pas la structure mais les besoins des communautés. Et Paul n'a cessé d'expérimenter que ces besoins étaient toujours comblés par le dynamisme de l'Esprit qui faisait surgir les charismes. On ne peut tirer de ces épîtres pastorales aucune organisation préétablie remontant à Jésus Christ. Les membres de chacune des communautés prenaient les décisions qui leur semblaient les meilleures en tenant compte du milieu ambiant. Chaque communauté locale résolvait les principaux problèmes concernant la vie des ministres en se montrant souple et inventive dans l'adaptation aux diverses situations concrètes. C'est la vie de la communauté, toujours elle, qui leur faisait dire que tel ministère devait être remplacé et à quel moment, que tel autre devait être modifié et de quelle manière. Les membres de la communauté cherchaient ainsi à discerner l'Esprit de Jésus-Christ à mesure que les événements se déroulaient. Il n'y avait aussi aucune ordination. ${ }^{43}$ Il y avait seulement l'imposition des mains (1 Tm 1,$\left.18 ; 6 ; 4,14 ; 6,12\right)$ qui d'investiture des ministres. De fait, l'ordination ne semble clairement attestée que pour les presbytres, les églises de tradition juive ayant adopté le modèle de l'ordination rabbinique dont l'archétype se trouvait dans l'Ancien Testament (Dt 34,9); pour les églises pagano-chrétiennes qui n'étaient pas dirigées par des presbytres, nous n'avons aucune attestation d'ordination"( LEMAIRE, André, Les ministères..., p.38). 
était considérée comme un geste de reconnaissance publique authentifiant les charismes du frère ou de la soeur choisi(e) (1 Co 11,15; Ga 3,28; Rm 16,1-2; Col 4,15, $1 \mathrm{Tm}$ 2, 11-12; Phm 1-2; Ac 18,26-27; 21,9; etc.) pour rendre sa tâche possible dans la communauté. Il n'y avait donc pas de passation de pouvoirs d'individus à d'autres mais uniquement une reconnaissance d'autorité en communauté, et la communauté s'articulait autour du 'noyau ministériel'(1 Co 16, 15-16; $\mathrm{Ph} 2,25$; Col 4,12; Tt 1,5; 2 Tm 1,12; 2,2.8; Ac 14,23; 16,2; etc.).44 On peut sans crainte de se tromper parler d'une équipe apostolique à direction collégiale, en dépit de la place centrale (aussi psychologique) que Paul y prend. 45 Une équipe compte alors en général cinq à sept membres. Elle assume en outre souvent la direction d'une communauté urbaine de croyants à partir de laquelle les cités environnantes sont évangélisées. Paul parle (non de "frère" ou "soeur" mais) de "notre frère" ou "notre soeur", il désigne un collaborateur ou une collaboratrice personnel(le) et non simplement un(e) cochrétien(ne). Ce sont là des frères et des soeurs dans la direction collégiale des communautés pauliniennes. 46

44

"Chez Paul, l'exercice du ministère ecclésiastique dépend davantage des qualités personnelles du ministre que du fait qu'il occupe une position socialement reconnue, conférant l'autorité par sa nature même"( KEARNEY, Peter, "Trouve-t-on dans le Nouveau Testament des motifs de changer l'organisation de l'Église", p.59.).

45

46

Voir Rm 16, 21-23; 16, 6-12; Col. 4,7 ss.; Phm 23,24; Tt 3, 12-13; 2 Tm 4,10 ss. .

Paul a été entouré de beaucoup de collaborateurs et de collaboratrices. Les lettres authentiques de Paul en citent environ 80 , dont on ne peut dire, d'une façon ou d'une autre, qu'ils assument des charges communautaires, qu'ils soient (hommes comme femmes) didascales, à la tête de communautés domestiques, évangélistes, prophètes, diacres, ou dans d'autres fonctions, ou qu'ils soient au service des communautés locales, ou encore dans la prédication itinérante de l'évangile. Des responsables locaux sont envoyés dans des villes voisines, administrativement dépendantes d'autres cités, pour y fonder de nouvelles communautés. 


\subsubsection{La place importante des femmes dans l'Évangile de Marc}

Suivre Jésus pour l'évangéliste Marc signifie avant tout: le suivre dans sa passion, pour une juste cause. Souffrir pour l'évangile, pour la bonne cause des humains (non souffrir pour souffrir), voilà le coeur de cet Évangile; et ceci, dans la rédaction de Marc, n'est apparemment pas saisi par les disciples de Jésus, par les Douze. Comme plusieurs exégètes l'ont remarqué il y a, dans l'évangile de Marc, une certaine critique des Douze. Non seulement ces derniers semblent mal interpréter Jésus, mais aussi leur propre ministère apostolique. Lorsque l'heure se fait grave, tous les Douze fuient et laissent Jésus seul. Ce n'est pas sans aucune intention que Marc fasse accompagner Jésus (à quelque distance) par quelques disciples féminins jusqu'auprès de la croix $(15,40-41)$, tandis que les disciples masculins prennent la fuite. Ces femmes sont les vrais disciples de Jésus; elles ont suivi (akolouthien: 15,41) Jésus de la Galilée jusqu'à Jérusalem et elles l'ont suivi ( diakonein ), et cela jusqu'à la croix. Les femmes sont d'ailleurs dans l'Évangile de Marc les seules porteuses du message de la résurrection $(16,1-8)$, tout comme c'est une femme qui la première a reconnu la "nécessité messianique" de la mort de Jésus, et donc aussi la vraie nature du messianisme de Jésus $(14,1-9)$, et non pas Pierre, dont le témoignage messianique s'est avéré hérétique et rejeté par Jésus comme une déclaration de Satan. Les exégètes féminins ne devraient cesser d'ouvrir davantage les yeux masculins sur ces aspects de l'évangile.

Marc se situe nettement dans la ligne des communautés paléochrétiennes, où les fonctions dirigeantes et l'autorité existaient mais où il n'y avait pas de statut de puissance ministérielle, exigeant la soumission. Marc n'attribue pas d'importance aux formes structurelles, et même pas à une théologie du ministère, mais bien à l'éthique et à la spiritualité des ministres. 
" C'est pourquoi le ministre n'est pas le simple porte-parole de ce qui se vit dans la communauté, mais aussi, à l'occasion, son mentor et son "correcteur", tout comme par ailleurs les communautés elles-mêmes peuvent rappeler leurs ministres à l'ordre. Précisément parce que les ministres sont les chefs et les meneurs de la communauté, ils doivent en tant que "grands" être les plus petits: les premiers serviteurs de tous (Mc 10, 43-44). Le propre du ministere se situe, dans le Nouveau Testament, au sein de tous les autres services dans l'église." 47

Comme il ne s'agit pas, dans l'église, de fonctions civiles, mais d'un service rendu à la "communauté de Dieu", le ministère ecclésial exige des ministres un comportement exemplaire, impliquant toute la spiritualité qui se dégage dans le Nouveau Testament, du choix de suivre Jésus.

Il n'y a pas seulement Marc qui accorde une place importante aux femmes. D'après les Actes des Apôtres, des femmes ont joué un rôle important dans certaines communautés chrétiennes, spécialement dans celles des Hellénistes et celles issues du paganisme: ainsi les quatre filles de l'évangéliste Philippe prophétisent-elles à Césarée (Ac 21,9) tandis qu'à Philippes, Lydie se révèle très active et qu'à Éphèse, avant l'arrivée de Paul, Priscille et Aquilas semblent assumer ensemble la direction de la communauté (Ac 18, 26-27). Paul admet, comme allant se soi, le ministère des femmes. De manière très précise, en 1 Co $11,2-16$, il reconnaît explicitement que les femmes peuvent "prier" et "prophétiser" (1 Co 11,5), c'est-à-dire qu'elles peuvent assumer le ministère le plus important d'une église locale à cette époque, celui des "prophètes". Ce principe est confirmé par plusieurs allusions concrètes: ainsi, en Rm 16, 1-2, Paul recommande avec insistance Phoebé comme "ministre" ( le mot "diakonos" n'a pas encore le sens technique de diacre) de l'Église de Cenchrées...". De plus, les salutations personnelles de $\mathrm{Rm} \mathrm{16;} \mathrm{Col} \mathrm{4,} 15$ et $\mathrm{Phm} \mathrm{1-2} \mathrm{attestent} \mathrm{la} \mathrm{place}$ 
importante que les femmes, souvent avec leurs maris, tenaient dans les églises pauliniennes. 48 Cependant le ministère des femmes ne semble pas avoir été accepté sans restriction dans toutes les églises. Au contraire, dans les épîtres pastorales, l'auteur, très marqué par la tradition juive, interdit nettement l'enseignement des femmes et donc l'exercice du ministère presbytéral. Mais dans l'ensemble du Nouveau Testament, l'exercice du ministère ecclésial par des femmes ne semble pas avoir posé de problème de doctrine. La réflexion de l'évangéliste Marc et de d'autres, en particulier de celle de Paul, sur l'Église admet clairement cette possibilité, mais plus simplement, les adaptations pastorales au contexte culturel des différentes communautés. Le Nouveau Testament constitue donc une interpellation permanente adressée à l'Église quant à la place accordée aux femmes dans son organisation ministérielle.

\subsubsection{L'option de Matthieu:"Tous frères et un seul Maître...le Christ"}

"Pour vous, ne vous faites pas appeler 'Rabbi'; car vous n'avez qu'un Maître et tous vous êtes frères"(Mt 23,8). Derrière cette affirmation, on trouve la pratique concrète des premières communautés chrétiennes. On s'adresse la parole en s'appelant 'frère' et 'soeur'. "Ce qui aujourd'hui est réservé à des sectes, à des communautés religieuses ou aux 'confrères dans le ministère', était dans l'Église primitive la manière tout à fait normale de s'appeler dans le cadre de la communauté. Le 'frère' et la 'soeur' sont "compagnons dans la foi." 49 La conscience d'être fils et filles aimés de Dieu fait que l'on se trouve réciproquement frères et soeurs. $8 ; 9,5-6 ; \mathrm{Tt} 1,6 ;$ Ac 21,9). "...nous voyons apparaitre des prophètes et des docteurs, qui, sous des modalités diverses, se mettent à leur tour au "service de la parole". Parmi eux, il y eut des itinérants et des sédentaires. Il y eut des hommes, bien sûr, mais n'oublions-nous pas un peu trop qu'il y eut aussi des femmes?" ( AUDET, Jean-Paul, Mariage et célibat dans le service pastoral de l'église, p.62).

49 LOHFINF, Gerhard, L'Eglise que voulais Jésus, p.115. "Communauté chrétienne signifie communauté en Jésus-Christ et par Jésus-Christ. Elle ne saurait être ni plus ni moins que cela. C'est vrai pour toutes les formes de communauté qui peuvent rassembler des croyants; de celle 
"Le jeune christianisme était en effet une fraternité de frères et de soeurs égaux entre eux, théologiquement sur la base du baptême en Esprit, socialement sur le modèle romano-hellénistique des associations libres, appelés "collegia", qui se réunissent elles aussi au domicile d'un tel ou d'une telle. Ce ne sont donc pas les règles qui régissent l'oikos" greco-romaine mais bien plutôt celle de l'organisation des "collegia" (religieux ou non), bien plus "démocratiques" ou égalitaires, qui se prêtait comme modèle pour les communautés domestiques paléochrétiennes." 50

L'évangéliste Matthieu désire montrer que Jésus n'a eu qu'un seul pouvoir: celui de saisir les humains de l'intérieur pour les rendre semblables à lui, en faire des frères et des soeurs, des fils et des filles en qui se reconnaît le Dieu vivant, tout comme dans le Fils. Ainsi, Jésus a très clairement refusé le pouvoir et les structures de pouvoirs tels que la société de son temps en usait habituellement. "Si quelqu'un veut être le premier, qu'il soit le dernier de tous et le serviteur de tous" (Mt 20, 25-28). Dans le peuple de Dieu, l'exercice de l'autorité doit donc toujours garder un caractère fraternel. "Dans une communauté de frères, les pères doivent cesser de régner." 51 Chacun est maître et disciple de l'autre et tous suivent l'évangile sinon, c'est la vocation ontologique de chaque homme qui est niée, et surtout celle du chrétien, appelé à participer et non à assister en simple spectateur à l'histoire du salut. De plus, l'expérience spirituelle de tout humain risque d'être compromise car "le 'sacrement $d u$ frère' est un lieu privilégié de la rencontre de Dieu (Mt 25, 31-46)"52. Matthieu veut une communauté de "petits" ( "mikroï " est un mot clef pour tout son Évangile), ce qui

qui naît d'une simple et brêve rencontre, jusqu'à celle qui résulte d'une longue communion de tous les jours. Si nous pouvons être des frères, c'est uniquement par Jésus-Christ et en Jésus-Christ" BONHOEFFER, Dietrich, De la vie communautaire, Paris, Cerf, 1983, p.15).

50 SCHILLEBEECKX, Edward, Plaidoyer pour le peuple de Dieu, pp. 56-57.

51 LOHFINF, Gerhard, L'Église que voulait Jésus, p.123; "...que personne ne se fasse appeler maître, père ou directeur spirituel, car nous sommes tous frères [cf. Mt XXXIII, 8-10]"( BOFF, Léonardo, L'Église, charisme et pouvoir, Paris, Lieu Commun, 1985, p.245.). Voir aussi VENETZ, Hermann-Joseph, C'est ainsi que l'Église a commencé, p .128. 
soumet la pratique réelle des dirigeants de communautés surtout "à la façon du monde", à une lourde critique.

"Nulle part dans le Nouveau Testament le ministère n'est conçu comme une structure calquée sur le modèle profane de la "direction", dans le sens d'un rapport de maître à surbordonné. Au contraire; ainsi (de la façon dont cela se passe dans le monde) cela ne se fera pas parmi vous", disent les trois synoptiques (Mc 10, 42-43; Lc 22,25; Mt 20, 2526). Dans tout le Nouveau Testament, la direction est un service ou une diaconie" ( 1 Co 16, 15-16; 12, 28; 2 Co 3, 7-9; 4,1; 5,18; 6,3; Tm 4,5; Ep 4, 11-12 et Col 4,17)." 53

C'est un défi permanent, surtout pour les ministres ordonnés, de continuer à vivre comme des frères au sein des communautés paroissiales. L'expérience vécue comme curé m'a fait découvrir que même si j'étais vigilant pour vivre fraternellement mon ministère, plusieurs paroissiens ne cessaient malgré tout de me considérer comme leur "Père". La réflexion de Eugen DREWERMANN est éclairante pour mieux saisir cette problématique.

"Ce n'est pas le moindre paradoxe de la pastorale catholique qu'en aucune autre institution religieuse au monde les fonctionnaires ne sont entourés d'une aura patriarcale semblable à celle qui enveloppe la figure du prêtre. En opposition évidente avec l'interdiction formelle de Jésus: "N'appelez personne sur la terre votre "Père", car vous n'en avez qu'un seul, le Père céleste" (Mt 22,9), le prêtre, le curé, le religieux sont appelés "Pères" sans plus de façons. En contrepartie, fort logiquement, en pays germanophones, on désigne les fidèles comme les "enfants de la paroisse" (Pfarrkinder), les "enfants" du confesseur" (Beichtkinder), etc. De par sa profession, le clerc doit incarner les aspects moraux qu'un enfant peut généralement souhaiter trouver chez un père: il doit être toujours abordable, gentil, sociable, compatissant, protecteur, équitable, un modèle en tout - bref, ce que beaucoup de personnes attendent de tout coeur de leur père et que très souvent elles n'ont pas connu. Comment s'étonner dès lors de voir comment elles s'adressent au prêtre qui, par son rôle paternel, incarne à leurs yeux une figure dont elles ont rêvé toute leur vie? Elles lui témoignent vraiment la même confiance que des enfants; elles placent en lui des espoirs irréalistes, comme s'il pouvait véritablement remplacer pour elles, et leur rendre, tout ce dont elles ont dû se priver des décennies durant. Ce faisant, elles n'oublient que trop facilement qu'une telle somme de sentiments et d'espoirs s'adresse, au fond, non à la personne mais à la persona, non au moi mais au rôle de surmoi du prêtre. En termes psychanalytiques, on peut dire que le personnage du prêtre évoque comme une figure représentant le Père divin du Ciel au milieu des humains. Tout au moins suscite-t-il chez les croyants une énorme disposition à accepter des transferts paternels en tout genre. On 
accorde fréquemment à un prêtre comme une chose qui va de soi le crédit de confiance qu'un médecin ou un psychothérapeute ne peuvent souvent gagner que péniblement au bout de mois ou d'années. C'est surtout la surestimation religieuse de la figure paternelle du prêtre, sa proximité de la sphère du sacré et du pardon, son pouvoir de lier ou de délier sur Terre au nom de Dieu, tel que les lui reconnaît la doctrine de l'Église (MT 18,18), qui nimbent ses traits de mana et vont presque jusqu'à en faire l'archétype du "médecin divin". Ce n'est pas là le moindre des fondements du pouvoir psychologique que la mère Église exerce sur les âmes de ses "enfants".54

Cette analyse psychanalytique est lumineuse. Ce théologien nomme avec justesse les nombreux transferts paternels de tout genre qui peuvent être faits par chaque être humain selon la genèse de son développement psycho-affectif. Le prêtre n'est jamais exempt de ces transferts psychologiques. Il peut lui aussi vivre ses relations avec l'évêque diocésain dans un rapport de père-fils (consciemment et insconciemment). Même un évêque doit être vigilant. Sans cela, il peut avoir la tentation de s'adresser au Pape en l'appellant "Saint-Père".

\subsubsection{Les Actes présentent la direction ecclésiale comme une grâce}

En Ac 20, 17-38, lors de l'adieu définitif de Paul à sa communauté d'Éphèse, Luc lui fait rassembler les chefs de la communauté (appelés ici presbytres). Dans le testament de l'apôtre destiné aux chefs de la communauté locale, Luc donne un aperçu intéressant de la conception du ministère en fin de période néotestamentaire. Après la mort des apôtres et des autres fondateurs de communautés, le ministère de la direction ecclésiale est une grâce ministérielle reçue du Seigneur ( Ac 20.28: "le troupeau dont l'Esprit Saint vous a constitués intendants pour paître l'Église de Dieu"). Ce service consiste alors en un témoignage de l'"évangile de la grâce de Dieu" (Ac 20,24). De plus, le ministre est, comme Paul, "prédicateur du Royaume" (Ac 20,25): 
il doit s'engager pour la mission que Jésus avait à coeur afin que le Royaume de Dieu se manifeste dans la vie et l'agir de la communauté ainsi qu'il fut inauguré par le message et l'agir de Jésus grâce auxquels le Royaume de Dieu est devenu expérience historique concrète.

Aux communautés chrétiennes, déjà éloignées de l'événement fondateur du Christ, Luc rappelle par la bouche de l'apôtre Paul quelques éléments dont l'Église de tous les temps a besoin: le lien vital avec l'événement du Christ et la tradition apostolique, le ministère comme "service" (diakonia) du Seigneur et comme témoignage de sa Bonne Nouvelle; l'Église comme communion (koinonia) dans l'Esprit; la conviction que "l'affaire Jésus" (le mystère de l'inculturation de l'Évangile) peut se continuer dans le monde, grâce au dévouement inlassable de tous les chrétiens sous le leadership dynamique des ministres.

Luc parle lui-même à plusieurs reprises de la "joie chrétienne". De plus, selon la conception paulinienne du ministère, le ministre est finalement quelqu'un qui contribue à la joie de la communauté ( 2 Co 1,24). Tous ceux qui sont engagés dans le "labeur pour la communauté" proclament d'ailleurs le message de la réconciliation ( 2 Co 5, 18 ss.): la joyeuse nouvelle de la libération, la nouvelle d'un Dieu soucieux des humains et soucieux d'humanité. Les ministres, jusque dans la souffrance, sont des porteurs de joie.

\subsubsection{Tous les croyants ont l'Esprit selon la tradition johannique}

L'évangéliste Jean limite ses instructions à un cercle étroit de disciples (voir Jn 13 - 17). Contrairement à Marc, Jean ne met pas complètement l'accent sur la 
souffrance à la suite de Jésus, mais sur l'amour-service. Sans l'amour qui sert, nul n'a part au service de Jésus; ainsi parle le Jésus johannique. L'opposition haine-service domine tout cet Évangile. Les disciples ne peuvent prendre part à la haine ni à la puissance de ce monde. C'est surtout dans le récit du lavement des pieds que Jean indique la spiritualité désirée par Jésus pour ses disciples, pour ceux qui veulent vivre et agir selon leur foi. Jésus, le Maître, lave les pieds de ses disciples et nie par là les règles de la bienséance (Jn 13, 1-17). Tout comme dans l'Évangile de Marc, en d'autres contextes, c'est de nouveau Pierre qui, chez Jean, n'y comprend guère (Jn 13, 6-8).

\begin{abstract}
"Selon le johannisme, tous les croyants ont l'Esprit. En tant que renés (Jn 3, 3-9), ils sont dotés de force pneumatique. Le Ressuscité apparaît donc aussi à tous les disciples et non seulement aux seuls Douze (voir aussi 20, 21-22). /.../ Les communautés croyantes rassemblent des partenaires égaux, pour qui seul l'Esprit de Dieu, l'Esprit du Christ, exerce l'autorité et indique la voie/.../La communauté johannique naît "sous la croix", en l'absence de Pierre, et le disciple bien-aimé précède Pierre comme témoin de la résurrection de Jésus $(20,2-10 ; 21,7)$ /.../Le Quatrième Évangile connaît, il est vrai, le groupe des Douze (Jn 6,70) mais il est frappant qu'à l'encontre des synoptiques, aucune liste des Douze n'y figure; cet Évangile ne connaît pas non plus de récit de la vocation des Douze. 55
\end{abstract}

La succession des maillons de la chaîne est claire: Jésus a vu Dieu; le disciple bienaimé a vu Jésus, l'École johannique participe à cette tradition. Après la mort du disciple bien-aimé, cette École a compris que l'oeuvre du Paraclet doit être continuée par les disciples du bien-aimé qui leur avait transmis la tradition. Dans le témoignage des croyants johanniques, c'est l'Esprit lui-même qui témoigne (15, 25-26). C'est là une conception typiquement johannique. Le chrême ou l'onction de 1 Jn 2,20-27, don du Christ à chaque croyant, n'est pas un charisme de possession et d'extase, mais un pouvoir orienté par l'Esprit, accordé à tous les croyants, afin qu'ils interprètent 
fidèlement la tradition (johannique). Le Paraclet est le seul docteur détenteur de l'autorité et il est donné à tous les croyants sans exception.

\begin{abstract}
"Il existe donc bien, dans le johannisme, une structure du ministère, mais à l'origine il ne s'agissait nullement d'une autorité magistérielle. Ce n'est que progressivement que le johannisme a fait l'expérience que le seul appel à l'onction de chaque croyant par l'Esprit (1 Jn 2,27) ne suffit pas à maintenir la communauté dans la fidélité évangélique. Jn 21 témoigne du fait que finalement le johannisme accepte l'autorité ministérielle en matière de doctrine et de disciple, mais relativise cependant ces structures ecclésiales: l'image du cep et des sarments, c'est-à-dire du lien immédiat et personnel à Jésus (thème qui caractérise tout le Quatrième Évangile) demeure le fondement de toute autorité ecclésiastique. Pour le johannisme il y va avant tout de la présence vivante de Jésus, le Ressuscité, en chaque chrétien, grâce à l'inhabitation du Paraclet. Les écrits johanniques, en tant qu'écritures canoniques (comme déjà auparavant l'Évangile de Marc), sont ainsi un avertissement biblique au sujet de toute surenchère juridique de l'autorité ecclésiastique. 56
\end{abstract}

\title{
10.3.7 L'institutionalisation du ministère dans les épîtres pastorales
}

Certains contours de l'institutionalisation du ministère ecclésiastique ont été tracés par les épîtres pastorales, particulièrement la première lettre de Pierre et celle de Jacques. Pour les épîtres pastorales, Paul est le grand "transmetteur" de la tradition dans la ligne de qui la communauté veut s'affirmer. Le ministère ecclésiastique y est même présenté dans un verset comme une institution de Paul lui-même qui imposa les mains à des presbytres ( $2 \mathrm{Tm} \mathrm{1,6).} \mathrm{Dans} \mathrm{les} \mathrm{églises} \mathrm{pauliniennes,} \mathrm{certains}$ chrétiens, en qui la communauté reconnaît un don du Seigneur, sont intégrés au ministère, par l'imposition des mains des presbytres et une invocation d'un prophète (ce qui deviendra l'épiclèse de chaque consécration) et ce, après avoir été accueillis dans leurs rangs par les presbytres présents et les chefs locaux. 57 Plus tardivement

56

57

Ibid, pp. 110-111.

Rappelons que l'"ordinatio" ou insertion, appeléc plus tard consécration, est un adaptation chrétienne de l'"ordinatio" judaïque du rabbin. Sa formation achevée, le candidat-rabbin reçoit l'imposition des mains de son maître-rabbin, assisté pour cela de deux autres rabbins (selon le modèle de l'installation de Josué par Moïse, $\mathrm{Nb} 27,21$ ss.; bien que cette consécration rabbinique ne 
dans les communautés pauliniennes, on a donc pris progressivement conscience du fait qu'il faut, pour le bien de la communauté apostolique ou de l'église, assurer la direction ministérielle aussi de manière institutionnelle.

Les épîtres pastorales montrent ainsi un intérêt particulier pour la continuité de la tradition apostolique. Le ministère, et même le ministère spécifique ( $\mathrm{Tt}$ 1, 5-9), est nécesssaire afin de garder la communauté dans la ligne de l'apostolicité: "communauté de Jésus". Quels sont donc les ministères nécessaires? Il y a des diacres ( $1 \mathrm{Tm} 3,8-13$ ) mais on ne dit nulle part quelle était leur fonction. Ils sont exhortés à bien se conduire et à être des hommes probes: éprouvés par la communauté (1 Tm $3,10$ ). Il y a en outre un collège de "presbyteroï" ( $1 \mathrm{Tm} 4,14)$ qui préside ou dirige la communauté (1 Tm 5,17; Tt 1,5). Parmi ses membres, certains sont surtout actifs "par la parole et l'enseignement" (1 Tm 5,17), ce sont les docteurs et les catéchètes de naguère. Enfin, deux textes parlent d'un "surveillant" ou "episkopos" (1 Tm 3,2; Tt 1,7) dont il est dit également qu'il "enseigne et dirige" (Tt 1,9; $1 \mathrm{Tm} 3$,2). L'episkopos est-il un presbuteros, chef de l'équipe presbyterale? Quelle est sa fonction spécifique? Ces lettres n'en disent rien. Elles ne s'intéressent manifestement guère à cette organisation concrète du ministère.

\begin{abstract}
"Les Épîtres Pastorales, elles, ne nous fournissent aucune norme selon laquelle le ministère devrait être en fait différencié, elles disent simplement que le ministère est nécessaire pour conserver vivante l'apostolicité de la tradition de la communauté. Seul ce dernier point est théologiquement d'importance; sa concrétisation relève de la pastorale et l'Église doit chaque fois la revoir." 58
\end{abstract}

soit attestée dans la littérature qu'en 75 après J.-C., en tout cas bien avant la rédaction des Lettres pastorales chrétiennes). Par ce geste de consécration rabbinique, le passage de la sagesse du maître au candidat-rabbin était symbolisé; ce dernier pouvait, à partir de ce moment, porter le titre de rabbin et garantir la continuité de l'enseignement de la législation mosaïque, avec cependant le droit de l'interpréter de manière autonome. Voir KRUBY, K., "La notion d'ordination dans la tradition juive", in La Maison-Dieu, $\mathrm{n}^{\circ}$ 102, Paris, 1970, pp. 52-72.

58 SCHILLEBEECKX, Edward, Plaidoyer pour le peuple de Dieu, p.115. En ecclésiologie, il existe une polémique entre Edward SCHILLEBEECHX et Pierre GRELOT 
Les épîtres pastorales ont nettement donné la préférence au magistère doctrinal comme moyen unique de préserver l'identité chrétienne. La confiance de Paul en l'Esprit qui est présent dans la communauté (confiance il est vrai souvent ébranlée par cette dernière) n'est plus que marginalement présente dans les Épîtres Pastorales.

\subsection{8 Évolution du ministère à partir de l'édification de la communauté et. non autour de l'eucharistie}

Comme le mentionne le grand théologien Edward SCHILLEBEECKX, "il est frappant de constater dans le Nouveau Testament que le ministère n'a pas évolué à partir et autour de l'eucharistie ou de la liturgie, mais bien à partir de l'édification apostolique de la communauté par la prédication, l'exhortation et la direction. Le ministère est concerné par la conduite de toute la communauté dans ses formes

concernant la conception de l'apostolicité. "Selon Grelot, je réduirais l'apostolicité à la "sequela Jesu", la praxis du royaume de Dieu à la suite de Jésus (comme si un concept aussi riche pouvait être une réduction). J'aurais négligé d'autres aspects essentiels de ce concept. Rien n'est moins vrai. C'est pourquoi j'énumère pour commencer les quatre aspects ou dimensions de ce que, déjà dans $L e$ Ministère dans l'Église, j'entends pas "apostolicité". -a) La dimension fondamentale de l'apostolicité tient au fait que les églises ont été fondées par les "apôtres et prophètes", qui les ont organisées (Ep 2,20 et 4, 7-16). -b) Il s'agit avant tout du caractère apostolique du "dépôt" transmis de la "parathèkè" ou dépôt à garder, en d'autres mots de la tradition apostolique. Les écrits néotestamentaires en font partie comme document témoin des origines. -c) Il y a aussi apostolicité de la communauté chrétienne de foi elle-même, en tant qu'appelée à la vie par les apôtres et prophètes et en tant que normée par le contenu de la foi apostolique, le dépôt à garder (voir a et b). La "sequela Jesu" ou la praxis du royaume de Dieu - suivre l'exemple de Jésus dans son message, sa doctrine et son comportement - en fait essentiellement partie. -d) Il y a enfin apostolicité des ministères ecclésiaux, ce qu'on appelle la "successio apostolica" (SCHILLEBEECKX, Edward, Plaidoyer pour le peuple de Dieu, p.128.). GRELOT n'attache de l'importance qu'au quatrième aspect de ce concept de l'apostolicité (d). J'ai parfois l'impression que GRELOT défend plus un "système" que l'évangile. (Voir de cet auteur: Église et ministères, Pour un dialogue critique avec Edward SCILLEBEECKX, Paris, Cerf, 1983, 282p.) On ne peut pas réduire l'apostolicité de l'Église à la seule dimension de la "succession apostolique". Les quatre dimensions de l'apostolicité sont d'ailleurs en interaction constante. On ne peut isoler la "successio apostolica" d'une réalité richement nuancée, ni l'idéologiser, avec toutes les conséquences oecuméniques qu'entraîne un tel comportement. Voir aussi DENIS, Henri, L'Église, les quatre portes du Temple, Paris, DDB, 1991, p.120. 
variées." 59 Les ministres sont des témoins importants, auxquelles tous les membres de la communauté peuvent s'identifier. De plus, savoir qui doit présider l'eucharistie ne pose pas de sérieuses interrogations dans le Nouveau Testament: rien ne nous en est dit.

"L'eucharistie est un héritage laissé par Jésus à toute la communauté, qui y a donc droit de par le baptême, 60 indépendamment de tous les problèmes complexes autour du ministère: "Faites ceci en mémoire de moi." Un lien direct entre ministère ecclésial et présidence dans la liturgie n'est établi nulle part dans le Nouveau Testament (sauf peutêtre en Ac 13, 1-2). Ceci ne signifie pas encore que n'importe quel croyant pourrait présider. /.../ ...on ne peut trouver nulle part de fondements bibliques pour une base sacro-mystique du ministère dans l'eucharistie. Si nous nous rappelons que l'eucharistie ancienne est structurée selon le modèle de la prière de table juive - le "birkat hamazon" où ce n'était certes pas n'importe qui qui pouvait présider, il devient évident que les chefs de communautés domestiques présidaient, ipso facto, l'eucharistie, comme il appert d'écrits contemporains de la partie la plus récente du Nouveau Testament. Dans les couches les plus anciennes de la Didachè, ce sont les "prophètes et docteurs" qui président l'eucharistie, et dans une couche plus récente, les épiscopes et les diacres, et cela en raison de leur ministère. /.../ L'opinion commune est donc: celui qui, d'une façon ou d'une autre, est mandaté pour diriger la communauté, est du fait même aussi président de l'eucharistie (et en ce sens il ne lui faut pas de mandat spécial pour le faire). Le Nouveau Testament n'a rien d'autre à nous apprendre en la matière." 61

Dans le Nouveau Testament même, il n'est donc précisé nulle part qui remplit cette fonction de la présidence de l'eucharistie (sauf peut-être en Ac 13, 1-2). Il ressort d'écrits anciens non canoniques que cette fonction a été traditionnellement exercée par les prophètes et les docteurs. On ne peut perdre de vue que, dans les communautés domestiques, il n'existait pas à l'origine, de distinction entre la diaconie de la Parole et celle de la Table (manger et boire ensemble, avec une conclusion eucharistique). Servir aux tables (Ac 6,2; voir 16,34; Lc 10,40;12, 37; 17,8) comportait la présidence de

Ibid., p.131. "ont droit à l'eucharistie" [ce n'est pas moi qui le dis!: habent ius ad mensam Domini accedendi" Thomas, Summa theologiae III, Q. 67, a.2.] "(SCHILLEBEECKX, Edward, Plaidoyer pour le peuple de Dieu, p.130). 
l'eucharistie. Plus tard les deux services seront dissociés et confiés à des personnes différentes: "le labeur de la prédication et de l'enseignement" ( 1 Tm 5,17) et "ceux qui servent [à table]" ( 1 Tm 3,8 ss.). Originellement, la présidence de l'eucharistie est seconde par rapport au don de la personne du président à la communauté en vue de son édification.

\subsubsection{Le ministère et la période post apostolique}

Ce n'est qu'après la disparition de la première génération des apôtres que le problème théologigue des ministères s'est posé tout naturellement à toutes les communautés et cela surtout après la Guerre juive. En ce temps post apostolique, non seulement le ministère prend plus concrètement quoique diversement forme, mais il fait aussi, en tant que tel, l'objet d'une réflexion; en d'autres termes, il naît une théologie du ministère, encore que l'intérêt n'aille guère aux structures. En un temps où les chefs locaux perdaient les initiateurs de la tradition: Paul, Pierre, Jacques, un certain Jean et d'autres, ils ne pouvaient mieux "légitimer" leur propre direction de leur église à l'égard de leurs confrères qu'en insistant sur le fait qu'ils ne faisaient que poursuivre le travail, l'évangile des apôtres et des prophètes fondateurs et animateurs de la communauté.

Après la mort des "apôtres et prophètes", appelés à présent le fondement de l'Église (Ep 2, 20), les chefs de communautés, appelés ici "évangélistes, pasteurs et docteurs" (Ep 4,11; voir 2,20 et 3,6) poursuivent l'oeuvre d'édification sur le fondement déjà posé: les pasteurs et les docteurs semblent désigner les chefs locaux, tandis que les évangélistes étaient les missionnaires envoyés pour fonder de nouvelles communautés dans la province. 
Le ministère à présent ministère ecclésial, en est éprouvé comme un charisme ministériel spécial au service de la communauté en tant que concrétisation ministérielle de ce qu'est la tâche de quiconque a été "baptisé dans l'Esprit". Au début de cette période de transition, le ministère ecclésial n'est en aucune façon séparé de la communauté ou situé au-dessus d'elle; le ministère fait clairement partie d'un ensemble de services divers, nécessaires à la vie de la communauté (Ep 4,11). Le propre de ce charisme ministériel tient dans le fait que les ministres portent, ensemble avec toute la communauté, la responsabilté du maintien de la communauté dans son apostolicité ou dans son origine et son orientation apostoliques, c'est-à-dire évangéliques: l'évangile de Jésus-Christ. Ils reçoivent la charge de coordonner et de structurer tous les services dans la communauté. En tout cas, tous les services, ministériels ou non, doivent viser à "construire le Corps du Christ"(Ep 4,12b): l'Église.

"Au surplus, ni presbutéros, ni épiskopos ne furent donc à l'origine, des titres spécifiques de l'organisation intérieure de l'ekklèsia chrétienne. Ils existaient auparavant, aussi bien dans le monde juif que dans le monde grec. L'un et l'autre furent ainsi simplement adaptés aux réalités nouvelles de l'ekklèsia. Nous devons être vigilants, cependant, que presbutéros et épiskopos n'apportaient pas pour autant dans cette adaptation, le même capital d'évocations dans l'ordre des réalités humaines./.../ Avant tout emploi religieux du terme, le presbutèros est, en effet, un ancien. Collectivement, les presbuteroi sont donc "les anciens" qu'il faut entendre en premier lieu par opposition aux néôtéroi et aux néaniskoi , qui sont les "jeunes" de la génération montante./.../ nous oublions trop souvent, en effet, que la qualité et la fonction de "presbytre" avaient alors une très puissante racine sociologique dans la famille elle-même./.../ En règle générale, on peut dire que cette image commune et ce climat de pensée portaient à voir tout naturellement dans le "presbytre" un "père" qui avait d'abord fait preuve de ses qualités humaines et sociales dans le gouvernement de sa propre "maison". À cet égard, la remarque de Paul semble tout à fait caractéristique. Il faut, écrit-il à Timothée, que l'"épiscope", et donc aussi bien, le "presbytre" (Tit., 1, 5-9), - sache bien gouverner sa propre maison et tenir ses enfants dans la soumission d'une manière parfaitement digne. Car celui qui ne sait pas gouverner sa propre maison, comment pourrait-il prendre soin de l'Église de Dieu? (Tim., 3, 4-5). À la base, la qualité d'"ancien", conduisant éventuellement à la fonction de "presbytre", se présente donc tout ensemble comme un âge chronologique et un âge social. C'est d'abord le temps de la vie où l'on est censé posséder, du fait même d'un long exercice de ses responsabilités domestiques, le recul de l'expérience et de la sagesse par rapport à la génération montante. Mais c'est aussi le moment de l'intégration sociale où l'on devient susceptible de prendre la parole dans les conseils, où l'on peut être appelé à 
participer au gouvernement d'un groupe extra-familial, tel que l'était, en fait, l'ekklèsia issue du message évangélique."62

Le glissement que l'on constate à la fin de la période néo-testamentaire, mais plus encore au cours de la première moitié du $\Pi^{\circ}$ siècle, n'est pas tant le passage d'un gouvernement charismatique à une direction institutionnelle qu'un raidissement et un renforcement du gouvernement local qui vont s'emparer de l'autorité doctrinale des prophètes et des docteurs. L'enjeu reste le même: qui détient l'autorité dans la communauté? À la fin du premier siècle nous constatons que le conflit de compétence dans les communautés est tranché en faveur de croyants qui reçoivent le titre d"episkopos" (presbytre) et de diacre. La tendance à leur réserver l'entièreté de l'autorité devient manifeste. Les chrétiens ont à se soumettre à cette forme d'autorité. Le "presbyterion" ou "conseil presbyteral" apparaît comme une assemblée administrative composée des chefs de ménage. "Episkopos" apparaît toujours au singulier, ce qui pourrait indiquer une fonction assumée à tour de rôle par l'un des presbytres; en cette fonction, il préside le conseil des presbytres. En 2 Tm 5, 17 il est fait une distinction entre les presbytres et le presbytre-président, c'est-à-dire le presbytre qualifié pour assumer la direction, et recevant de ce fait double salaire. Les fonctions de ce presbytre coïncident avec celles attribuées à l'épiscope en d'autres endroits des épîtres: prêcher et enseigner. L'"episkopos" est donc un presbytre, mais tous les presbytres ne sont pas (nécessairement) "épiscope". Le ministère à trois degrés - évêques, presbytres et diacres - quoique inconnu du Nouveau Testament, est devenu une réalité historique, dès avant la canonisation officielle du Nouveau Testament, mais sans légitimation néotestamentaire. Il relève de décisions historiques.

"Qu'il existât à la fin du $\mathrm{I}^{\circ}$ siècle un ordre ecclésial selon lequel un groupe de "presbytres" était responsable de la direction et de la pastorale des communautés ecclésiales locales est historiquement indéniable (voir Ac 14, 23; 20, 17. 20-30; 1 P 5,1; 
$1 \mathrm{Tm} 3,1-7 ; 5,17-22 ; \mathrm{Tt} 1,5-11 ; \mathrm{Jc} 5,14 ; 2 \mathrm{Jn} 1,1 ; 3 \mathrm{Jn} 1,1$; aussi dans la littérature non canonique: 1 Clem. 44; Did. 15,1). Les presbytres sont également appelés épiscopes, sans différence notable de fonction, parce qu'ils avaient, entre autres une fonction de contrôle et de garde (episkopè). En outre la différence entre prêcheurs prophétiques et docteurs est très minime. En $1 \mathrm{Tm} 5,17$ il est fait doublement honneur aux presbytres qui non seulement prêchent mais aussi enseignent." 63

\subsubsection{L'Église apostolique plus préoccupée des services que des styles de vie ${ }^{64}$}

Nous nous sommes fort préoccupés, au niveau supérieur, du partage des fonctions, des pouvoirs et de l'autorité. Nous nous sommes beaucoup moins souciés d'observer de près les multiples conditions concrètes qui ont fait, pour une grande part, l'efficacité et la continuité du service pastoral de l'église ancienne. Quelle attention sérieuse avons-nous accordée, par exemple, au cadre domestique de l'ekklèsia originelle? Détournés de certaines valeurs par les prestiges authentiques ou surfaits des institutions que l'Église s'est données dans la suite des siècles, n'avons-nous pas regardé sous un angle trop souvent négatif le mariage de tous ces chefs d'"assemblée" dont nous ne nous faisons jamais faute de nous réclamer par ailleurs? Soyons justes. Ce sera peut-être pour nous un excellent moyen de rester lucides par surcroît.

Dans le Nouveau Testament, nous l'avons vu précédemment, le ministère est exercé aussi bien par des gens mariés, comme Pierre, que par des gens non-

63

64 SCHILLEBEECKX, Edward, Plaidoyer pour le peuple de Dieu, p.96.

"À prendre les choses dans leur ensemble, on peut dire que la tradition pastorale de l'Église, jusque vers le milieu du IV ${ }^{\circ}$ siècle, s'est bien davantage préoccupée des services eux-mêmes que des styles de vie qui les accompagnaient" (AUDET, Jean-Paul, Mariage et célibat dans le service pastoral de l'église, p.8). "La question mariage ou célibat semble avoir si peu d'importance dans la vie de Jésus que le Nouveau Testament n'éprouve absolument pas le besoin de nous renseigner sur sa situation sociale, sa biographie, sa profession, sa famille. Avait-il femme et enfant? Pas un mot là-dessus, comme si tout cela n'avait aucune importance et aucune valeur exemplaire aux yeux de Dieu, mais n'était que simple détail accessoire. On ne peut non plus rien tirer des paroles de Jésus lui-même, ni dans un sens ni dans l'autre"(DREWERMANN, Eugen, Les fonctionnaires de Dieu, p.613.). 
mariés, célibataires ou veufs, comme Paul... À part les apôtres Paul et Barnabé

Co 9, 5-6) et les filles de l'évangéliste Philippe (Ac 21,9), les ministres de l'Église primitive semblent avoir été généralement des gens mariés. Ce sont les épîtres pastorales, dans un contexte de tradition juive, qui sont les plus explicites sur ce point: l'auteur insiste pour que le candidat au ministère soit "un mari d'une seule femme" (1 $\operatorname{Tm} 3,3,12$; Tt 1,6) et un bon père de famille s'occupant bien de l'éducation de ses enfants (1 Tm 3,4-5, 12; Tt 1,6). Ainsi, tout en reconnaisssant la valeur du charisme du célibat de certains ministres (1 Co 7,7-8), il est clair que de manière générale, les ministres de l'Église primitive étaient plutôt des gens mariés. 65

"Les Douze, et Paul lui-même, ont-ils "tout quitté": maisons, propriétés, père, mère, soeurs, femmes et enfants, comme cela, simplement, brusquement, et sans plus de soucis? Même avant tout examen, il paraît peu vraisemblable que les choses se soient passées de cette façon. Les documents nous obligent-ils à le penser? /.../ Ni le "départ" des Douze, ni celui de Paul ne furent subits. Il y eut des délais, et même de longs délais, inspirés sans doute par toutes sortes de considérations de nécessité et d'utilité, mais aussi, pourquoi pas? - au moins une fois ou l'autre, par des motifs de simple convenance. /.../ Or, parmi ces considérations de nécessité et ces motifs de convenance, il y avait sûrement place pour une juste attention à des situations familiales déjà acquises. Tout porte à croire que, de fait, une telle attention n'a pas manqué. Nos récits n'en ont pas parlé parce que, à l'époque et dans le milieu, on se comprenait fort bien, et que, pour ainsi dire, cela allait de soi. Voilà tout. /.../ En définitive, je crois donc beaucoup plus vraisemblable que la "femme soeur" soit ici, en réalité, l'épouse chrétienne, et que, de fait, la plupart des apôtres, à partir des années 50, ont simplement trouvé convenable, s'ils étaient mariés, de prendre leur femme avec eux lorsqu'ils en vinrent à s'éloigner de leur premier champ d'action. Cette interprétation et cet usage me semblent, au surplus, entièrement conformes

65

"La question n'est pas nouvelle. Elle paraît aujourd'hui quelque peu futile. Mais, puisque certains mythes s'accrochent encore à elle, posons-la à notre tour: les apôtres furent-ils mariés? Du silence, presque total de la tradition primitive à ce sujet, Tertullien prétendit tirer un jour cette audacieuse conclusion: à l'exception de Pierre, dont nous apprenons que la belle-mère fut guérie par Jésus, les apôtres, ou bien restèrent dans le célibat, ou bien vécurent dans la continence. /.../ Pour sa part, Basile, esprit modéré, nullement suspect de facilités par ailleurs, admettait tranquillement que tous les apôtres avaient été engagés dans le mariage. /.../ La vérité historique se situe problablement entre ces deux extrêmes. Car si le hasard d'une fièvre n'avait pas amené Jésus auprès de la belle-mère de Pierre, la tradition évangélique se serait trouvée garder le silence le plus complet sur le mariage des premiers disciples. Pourrions-nous en conclure qu'aucun d'eux n'avait été marié? Sûrement pas. Ce qui reste à dire revient donc simplement à ceci: les idées et les usages du milieu suffisent à rendre probable le fait que la plupart des apôtres aient été mariés; il est même fort possible qu'ils l'aient tous été, sans exception" (AUDET, Jean-Paul, Mariage et célibat dans le service pastoral de l'église, p.70.). 
à l'intention de Jésus en ce qui regarde le service de la parole. Quand il disait: "quitter", il ne voulait pas dire: abandonner, encore moins abandonner pour toujours." 66

Paul a perçu au coeur de son ministère que sa vision des réalités lui créait une responsabilité avant de lui conférer un titre d'honneur (1 Cor., 9, 15-23). Sans lien conjugal, il s'est donné entièrement au service de l'évangile. À sa manière, il mit donc ainsi à profit une situation déjà faite, et que, personnellement, il estimait bonne par ailleurs ( 1 Cor.,7,1; 7, 7-8; 7, 26-35). Mais Paul ne semble pas avoir songé, même un instant, à imposer aux autres son style de vie, fût-ce sous le voile d'une critique indirecte qu'il aurait pu leur adresser (1 Cor 9,5). Ainsi chacun pouvait-il, sans mauvaise conscience, apporter sa contribution à l'oeuvre commune. Paul avait expérimenté que les dons de Dieu sont multiples et divers ( 1 Cor 7,7 ). II les respectait, rendant ainsi hommage à la liberté divine. Une analyse des textes néotestamentaires nous fait également découvrir, au surplus, combien les valeurs positives du mariage se sont retrouvées liées, concrètement, dans les structures du service pastoral de l'Église ancienne, aux valeurs également positives de la "maison", qui fournissait alors son cadre le plus habituel et le plus normal au double service de la parole et de l'assemblée.

"A ce propos, ce qu'il faut remarquer, en premier lieu, c'est qu'on s'est orienté sans hésitation, dès le départ, vers des styles de vie, déterminés dans leurs grandes lignes par les nécessités spécifiques de chacune des fonctions, plutôt que vers des états de vie, commandés d'en haut, et fixés une fois pour toutes, par une hiérarchie des degrés de perfection dans les relations de l'homme avec Dieu et avec le prochain. Il y eut ainsi, pourrait-on dire, autant de styles de vie qu'il y avait de fonctions distinctes, et il y eut autant de fonctions distinctes que de besoins ressentis et de dons pour les satisfaire, soit du côté du service de la parole, soit du côté du service de l'ekklèsia. En définitive, c'étaient donc les besoins reconnus et les dons disponibles qui portaient, chaque fois, le style de vie à la mesure de la fonction et du service." 67 donc le mariage, plutôt que la continence ou le célibat, qui, pour le style de vie, semble avoir été un peu partout la réalité dominante dans le service pastoral de l'Église. C'est de cette situation que nous 
Les conditions générales ont donné naissance, comme il était naturel, à une rapide et très riche diversification dans les styles d'action autant que dans les styles de vie à l'intérieur du service commun de l'espérance de l'évangile, qui rassemblait tout dans la poursuite d'une même fin. On se sentait, et l'on était, de fait, en régime de flexibilité. Évidemment, on ne cherchait pas cette flexibilité pour elle-même comme un régime idéal qu'on aurait envisagé avec faveur dans une théorie abstraite de l'action évangélique. Cette flexibilité résultait plutôt en premier lieu, de la soumission commune aux situations concrètes, et, en dernier lieu, de la persuasion spontanée que le dessein de Dieu était vaste, autant que ses dons multiples et divers. Mais nous savons qu'à peine deux siècles plus tard,

\begin{abstract}
"la réflexion de l'Église sur les structures de son service pastoral a passé de plus en plus d'une considération des styles de vie, commandés, au niveau même des réalités, par les conditions mouvantes des divers services, à une considération préférentielle des états de vie, commandés d'en-haut par les conditions idéalement immuables de la "perfection chrétienne". L'histoire nous instruit longuement sur le reste. Car ce double déplacement dont nous pouvons maintenant mesurer la nouveauté par rapport à l'état de choses qui avait prévalu à la génération apostolique, devait avoir pour des siècles, et jusqu'à nos jours, des conséquences incalculables." 68
\end{abstract}

C'est seulement au début du $\mathrm{II}^{\circ}$ siècle que les premiers signes, encore sporadiques, d'une certaine tension entre mariage et célibat des "clercs" commencent à se faire jour dans l'Église. Cette lutte pour la "chasteté parfaite" des clercs s'est trouvée coïncider chronologiquement avec l'apparition dans le langage chrétien, des premiers signes manifestes d'un processus de sacralisation du service pastoral de l'Église. L'histoire nous montre que c'est le service direct de l'eucharistie qui commandera la règle de la continence conjugale pour l'évêque, le prêtre et le diacre déjà mariés. C'est

devons partir. Quoi qu'on ait dit, l'histoire ne nous paraît pas pouvoir se prêter, dans l'ensemble, à une autre interprétation"( Ibid, p.26). 
donc une perception du "sacré" qui est à l'origine de l'abstention sexuelle à l'intérieur du mariage. Osons le dire. Ce n'est pas le mariage qui faisait problème mais l'exercice de la sexualité dans le mariage lui-même, et cela seul. Le désir pastoral d'honorer les sacramenta en arriva donc un jour au point où il ne pouvait plus inspirer qu'une chose: l'exclusion totale de l'exercice de cette sexualité dont on ne voyait plus trop bien, par ailleurs, comment il pouvait jamais s'affranchir de la honte d'une certaine souillure. Une véritable loi de continence conjugale imposée à tous les clercs engagés dans le service direct des sacramenta, parut donc offrir seule une disposition convenable. Le "ministère sacré" entraîne alors comme conséquence la règle de l'abstention sexuelle, c'est-à-dire, de la continence sous toutes ses formes, y compris, éventuellement le célibat. Le cercle est bouclé.

"En réalité, la perception d'une "pureté" et d'une "impureté" sexuelles, de même que les valorisations très variables que cette perception a connues à travers l'histoire, appartiennent au fond le plus archaïque de la conscience humaine, où elles sont liées aux structures les plus élémentaires de la crainte. Est-il désirable que nous maintenions indéfiniment ces structures et que nous cultivions cet archaïsme? La loi du célibat des clercs avec les grandeurs authentiques qu'elle a suscitées, continuera-t-elle à servir indirectement de caution à l'un des éléments régressifs les plus avérés de tout notre héritage humain? La sexualité, celle des clercs comme celles des laïcs, sera toujours mieux servie par la justice, l'espérance et l'amour que par toutes les surenchères du "pur" et de l'"impur" qui, en fait, ne peuvent que la parasiter, la déséquilibrer et l'avilir."69

Je pose la même question que M. AUDET: "accepterons-nous donc, un jour prochain, de reconsidérer franchement notre loi du célibat ecclésiastique? Il me semble qu'il faut le souhaiter. Si nous l'acceptions, l'exemple particulièrement riche du service pastoral de l'Église primitive, avec son intégration du mariage au cadre domestique de l'ekklèsia, reprendrait aussitôt toute sa valeur de suggestion créatrice pour le monde de demain. Nous verrions naître alors un service pastoral dont la première intention serait, non de se conformer à un idéal sacral fixé une fois pour toutes, mais de pourvoir dans 
une juste et vigilante liberté aux nécessités concrètes de l'évangile."70 J'espère de tout coeur que cette question sera considérée comme urgente à répondre dans toutes les conférences épiscopales du monde entier.

\begin{abstract}
"Nous estimons, cependant, que le temps presse. Car, fondamentalement, ce n'est pas nous qui posons le problème du célibat et du mariage dans le service pastoral de l'Église: c'est le problème qui s'impose à lui-même à nous. Pour une large part, il naît de deux phénomènes majeurs de notre époque dont l'action pastorale n'a pas de contrôle: l'accroissement démographique et l'urbanisation générale de la planète. Ces deux phénomènes se développent sous nos yeux avec une force et une rapidité qui ne nous permettent plus guère de compter sur de longs délais. Il nous reste peut-être, en fait, une génération pour trouver une solution convenable aux problèmes dont nous nous occupons ici. Après, l'immensité de la tâche ne pourra que multiplier aveuglément les difficultés."71
\end{abstract}

Plus d'une génération sépare ce texte de Jean-Paul AUDET et le contexte d'aujourd'hui. Pourtant, aucune solution n'a été apportée et nous sommes confrontés à ce qu'il avait prédit en 1967..." à l'immensité de la tâche qui multiplie aveuglément les difficultés".

\title{
10.4. L'héritage légué par le Nouveau Testament: la liberté et l'audace
}

Avant et pendant la période d'élaboration des livres du Nouveau Testament, les communautés de foi sont encore en quête des structures les mieux adaptées, structures qu'elles ne créent pas de toutes pièces, mais qu'elles élaborent à l'intérieur d'un contexte socio-historique déterminé. Dans ces situations diverses, des formes concrètes d'organisation ecclésiale apparaissent de différentes façons, d'abord divergentes ensuite, les Églises une fois établies, dans le sens d'une uniformité croissante. Mais on ne peut absolument pas projeter sur le Nouveau Testament l'ordre

Ibid., p.160.

Ibid, p.13 
ecclésial tel qu'il a surgi par la suite. Très souple à l'origine, l'organisation de la vie communautaire et surtout des ministères s'est de plus en plus fixée, institutionnalisée, uniformisée dans l'Église au cours des siècles. Cette 'uniformalisation' s'accompagnant toujours d'une accentuation de l'autorité pastorale au détriment du service de la Parole (cf. Ac 6,4 et 1 Co 1,17).

"Le Nouveau Testament est un livre ouvert. Il n'impose rien. Il présente un visage de Dieu et des façons dont les hommes et femmes se sont organisées pour le révéler. Ce sont leurs modes de discernement qu'ils nous lèguent, leur passion pour la liberté qu'ils nous transmettent, leur amour des pauvres qu'ils nous offrent, et non les moyens qu'ils ont pris pour en vivre. Ils nous disent qu'une communauté a besoin de leadership, ils n'avaient aucune idée de celui dont nous avons besoin. A les lire d'ailleurs, on pourrait leur faire justifier à peu près n'importe quelle forme de gouvernement: leadership collectif (surveillants-anciens, Sept), triumvirat (les trois colonnes de Jérusalem), leadership partagé en diverses zones d'influence (Jacques, Céphas et Jean d'un côté, Paul de l'autre), équilibre de charismes (communautés pauliniennes), etc.. Il faut un leadership. Toutes les formes sont possibles. Toutes ne sont pas concrètement souhaitables. Que veut le Christ? Qu'en pensent les croyants et croyantes? La réponse viendra quand l'Église verra que c'est le Christ qui pose la question/.../Bien sûr que ce n'est pas le Nouveau Testament qui tient la clef des réponses,(ce ne peut être, faut-il le répéter, que le Christ [l'Esprit de Jésus Christ vivant aujourd'hui] )/.../."72

L'organisation de l'Église n'est généralement pas un sujet d'importance capitale dans le Nouveau Testament. Le Nouveau Testament assigne à l'Église les tâches essentielles de prêcher le Règne de Dieu et de vivre en union avec le Christ. Il exige aussi que l'organisation de l'Église serve ces deux missions pour édifier l'unité de l'Église.

Les premières communautés chrétiennes avaient déjà compris qu'elles ne pouvaient vivre leur fidélité à la mission évangélique sans se renouveler sans cesse à partir de sa source, la personne et l'oeuvre de Jésus, tout en se lançant sans crainte sur tous les chemins ouverts par l'Esprit du Christ ressuscité. L'Église d'aujourd'hui doit disciples immédiats ne font l'effet d'avoir été des théoriciens de l'action. En pastorale aussi bien qu'en histoire, il serait donc périlleux de systématiser à outrance leurs paroles et leurs gestes." (AUDET, Jean-Paul, Mariage et célibat dans le service pastoral de l'église, p.81.). 
retrouver la liberté et l'audace de ces premières communautés. Comme l'a si bien dit Gerhard LOHFINK, "l'Eglise doit sans cesse décider entre la sécurité de la servitude et le risque de la liberté."73 Il me semble que ce qui met le plus en danger notre Église catholique à la veille de l'an 2000, ce n'est pas l'affaiblissement de ses institutions mais le poids de ses peurs et l'affadissement de son élan missionnaire. Ce qui est encore plus dramatique c'est que, parfois certaines autorités ecclésiales confondent leur peur et leur absence d'imagination avec la volonté de Dieu....

"Il y a des gens qui utilisent la Bible comme un livre de cuisine et qui pensent en plus faire preuve d'esprit 'biblique'. Je pense que le Nouveau Testament et les premières communautés chrétiennes réagiraient ainsi: 'Pourquoi n'acceptez-vous pas d'avoir vousmêmes des idées? Vous ne devez pas regarder nos propres institutions, mais la foi à partir de laquelle nous avons cherché les structures adaptées à notre temps. C'est l'Esprit qui fait vivre. La lettre tue (cf. 2 Co 3,6). Si vous confondez nos institutions et notre foi, la lettre et l'esprit, vous ne vous comprenez pas"74

\subsection{Acquis de recherche éclairants}

Que retenir de tout ce parcours de théologie biblique? Quelles lumières ces pages d'approfondissement sur les réseaux d'incarnation du christianisme à l'époque du Nouveau Testament, projettent-elles sur le devenir de la paroisse en contexte urbain?

\subsubsection{La paroisse, servante du Royaume de Dieu au coeur du monde}

L'ensemble de ce chapitre a démontré que le Nouveau Testament n'est pas un livre de recettes qui nous fournit des solutions toutes faites pour les situations 
inédites dans lesquelles l'Église (entre autres les paroisses) se trouve aujourd'hui. On doit plutôt le considérer comme une mémoire inspiratrice de l'événement Jésus. Les écrits néo-testamentaires veulent montrer l'insistance de Jésus à dire que nous n'avons qu'un Père, celui qui est dans les cieux. Tel est bien, en effet, pour Paul, le dessein merveilleux de Dieu à l'égard de l'humanité et réalisé en Église (en paroisse): faire de nous des fils adoptifs dans l'unique Fils; devenir les enfants de Celui que nous pouvons appeler familièrement $A b b a$; et pour cela être animés par l'Esprit qui se joint à notre esprit pour prier et pour dire Père. Jésus est véritablement l'expression humaine de l'amour de Dieu qui libère de la misère et fait "être" la personne socialement opprimée, juridiquement diminuée et religieusement méprisée. L'objectif des différents auteurs des livres du Nouveau Testament est de montrer que le désir le plus profond de Jésus est de faire participer l'homme et l'humanité à l'amour du Père. Le Règne de Dieu est la passion et le moteur de la vie de Jésus. Le Nazaréen prêche le Royaume, le Royaume qui vient, qui est au milieu de nous, mais qui est aussi à attendre, car il viendra soudainement comme l'éclair. En Jésus, le monde devient alors le lieu de la recherche et de l'attente de Dieu-Abba, le lieu où s'avive un désir, où se creuse une Espérance, où nous sommes invités à vivre un Royaume de communion des hommes avec le Père et des hommes entre eux. C'est pour cette raison que le Royaume a une place tout à fait privilégiée dans les Évangiles.

Dire que Jésus est l'Envoyé, c'est équivalemment dire son identité. L'Église sera marquée à jamais par cette relation à l'Envoyé, relation qui va s'épanouir grâce à l'Esprit. C'est l'Esprit qui "fait l'Église" puisqu'elle a été fondée par l'initiative des disciples fidèles au Paraclet qui les a aidés à se souvenir des inspirations de Jésus pour poursuivre son Oeuvre. Il continue à "faire l'Église" à chaque fois que celle-ci se met au service du Royaume de Dieu de manière audacieuse. 
"Décidément, il y a ici un fort courant d'air! Il y a le souffle de l'Esprit. Cette manière nouvelle de découvrir l'Église comporte moins le souci des bagages que celui de voiles capables de gonfler aux vents de Pentecôte. Notre Église est l'Église de Pentecôte. Une Église qui sort sans cesse d'elle-même."75

L'Église est envoyée pour annoncer la Nouvelle du Ressuscité. Jusqu'à la fin des temps, elle entend avec les Apôtres cet "Allez!" qui clôture, si l'on peut dire, l'Évangile de Matthieu $(28,19)$. Il va falloir sans cesse se demander ce que cela exige d'elle, car rien de l'avenir de l'Église n'a été écrit dans le Nouveau Testament, ni dans le ciel! II n'y a que cet "Allez" sans cesse répété en son coeur. L'Église en mission, c'est une Église créatrice de son avenir. Toute l'Église est ainsi envoyée par la grâce du Christ. Elle ne serait plus l'Église si elle n'était établie pour cet exode, cette sortie hors d'ellemême par fidélité à l'Amour qui l'habite. L'Église tente de faire grandir le Royaume dans les coeurs et dans le monde. La paroisse, comme cellule de l'Église, constitue donc un lieu privilégié pour servir cette croissance du Règne au coeur d'une portion du peuple de Dieu.

Si l'on veut amener à comprendre que l'Église a pour tâche de détecter les signes du Royaume et d'en montrer la source en Jésus-Christ, sans pour autant se prendre elle-même pour le Royaume, on dira qu'elle en est le "sacrement" ou le signe au milieu du monde. La formule est heureuse parce qu'elle dit que l'Église ne serait rien sans le Royaume, mais qu'elle n'est pas tout le Royaume. L'Église est composée de ceux et celles qui croient au coeur du monde, à la promesse du Royaume inauguré par le Christ. L'Église est dans le monde le signe visible de la tension irréductible entre le monde et le Règne de Dieu. Elle est là pour dévoiler et dire cette réalité dernière, dans l'attente où Dieu sera tout en tous. L'Église c'est cela, c'est la communauté de ceux favoriser la libération des sacralisations institutionnelles, source du conservatisme enfermant l'avenir dans le passé. 
qui, ayant les pieds bien plantés dans la terre et leurs mains tendues s'écrient dans une même confiance: "Père, que ton Règne vienne!" L'Église c'est cette communauté se tenant là debout! La paroisse n'a ainsi aucune raison d'exister si elle ne se vit pas comme servante du Royaume au coeur du monde. Il nous arrive facilement d'oublier cette mission fondamentale au coeur de l'action pastorale, particulièrement dans les comités paroissiaux. Nous sommes tellement préoccupés par les tâches à remplir que nous portons rarement un regard plus critique pour vérifier si les activités offertes aident les paroissiens à être davantage saisis par le Christ afin de pouvoir faire advenir solidairement un monde plus juste et fraternel.

\subsubsection{S'inspirer de la souplesse et de la malléabilité de l'organisation structurelle des premières communautés}

La situation actuelle des paroisses en contexte urbain exige de faire advenir des structures et des pratiques ministérielles nouvelles. Que nous inspire la première génération de chrétiens? Ce chapitre a démontré qu'à chaque étape de leur développement, les premières communautés ont été confrontées à des besoins nouveaux. C'est en fonction de ces besoins qu'elles ont créé des structures et des ministères, tandis que d'autres ont disparu parce qu'ils ne correspondaient plus à la situation nouvelle (ex: Les Douze, les Sept, les communautés pauliniennes). Chaque communauté locale a résolu les principaux problèmes concrets concernant la vie des ministres en se montrant souple et inventive dans l'adaptation aux diverses situations. Les premiers chrétiens ont expérimenté que le dessein de Dieu était vaste autant que ses dons divers et multiples. De plus, les leaders des différentes communautés apostoliques ont eu cette vigilance constante de faire en sorte que les responsabilités de quelques-uns ne confisquent jamais la consistance du corps ecclésial où tous les disciples sont égaux en dignité et en droit. Nous devons nous laisser interpeller par leur créativité et la malléabilité de leurs structures communautaires. De plus, il est 
important de rappeler que l'Église apostolique a été plus préoccupée des services que des styles de vie. Les textes du Nouveau Testament constituent également une interpellation permanente à l'Église quant à la place accordée aux femmes dans son organisation ministérielle.

Déjà des progrès en paroisse ont été réalisés au niveau d'une réorganisation ministérielle. Pour s'en convaincre, il suffit de rappeler l'augmentation du nombre des "laïcs" en responsabilité pastorale au Québec entre 1980 et aujourd'hui, passant de quelques unités à plusieurs centaines et bientôt quelques milliers. Les nouvelles expériences d'équipes pastorales et de ministère partagé se sont aussi multipliées de même que les mandats confiés à des laïcs pour participer à la charge pastorale des communautés, en même temps que ceux confiés à des prêtres pour le service de plusieurs paroisses. Nous devons poursuivre ce réaménagement afin que chaque communauté paroissiale puisse avoir les ministères indispensables à sa vitalité évangélique: des ministères qui amènent les paroissiens à devenir les premiers responsables de leur vie communautaire afin que la vie et la mission de l'Église ne reposent plus principalement sur les épaules de quelques-uns mais sur l'ensemble des paroissiens. Pour atteindre cet objectif, des changements institutionnels sont encore nécessaires. Une Église soucieuse de son témoignage évangélique doit alors se demander sans cesse si son organisation est elle-même compatible avec l'Évangile qu'elle proclame? La place importante accordée aux femmes dans plusieurs des premières communautés chrétiennes devrait interpeller plus vivement l'Église officielle dans son organisation ministérielle. Pour assumer les défis pastoraux causés par l'accroissement démographique et le phénomène de l'urbanisation, il n'est pas sans importance de "faire mémoire" de l'Église apostolique qui a été plus préoccupée des services que des styles de vie. Les situations pastorales dans le contexte urbain d'aujourd'hui, comme au temps des apôtres et au temps post apostolique, exigent de 
créer un service pastoral dont la première intention soit, non de se conformer à un idéal sacral fixé une fois pour toutes, mais de pourvoir dans une juste et vigilante liberté aux nécessités concrètes de l'Évangile. L'Église ne devrait-elle pas alors mourir à son désir constant d'une uniformité croissante dans ses formes structurelles et ministérielles et tendre plutôt vers une diversité de structures et de ministères comme celles et ceux qui sont apparus dans l'organisation ecclésiale des communautés néo-testamentaires? Les évêques du Québec ont été sensibilisés par ce questionnement par leur comité des ministères.

"L'exigence pour des ministères dans l'Église provient tout autant de sa réalité sociohistorique dans laquelle se réalise son mystère propre. Les écrits néo-testamentaires et l'histoire de l'Église nous montrent un froisonnement de ministères divers, témoins de la variété des situations et de la diversité des charismes. S'il y a danger, aujourd'hui, de voiler la distinction entre les ministères ordonnés et les ministères confiés ou reconnus ainsi que les divers services de l'Évangile, il faut admettre que le Nouveau Testament ne connaît pas ce danger. On y voit parfois une tâche accomplie tantôt par une personne ayant reçu l'imposition des mains et tantôt par une personne qui ne semble posséder d'autre titre que sa foi baptismale. Nombre de responsabilités nécessaires à la vie des communautés néo-testamentaires sont assumées par des chrétiennes ou des chrétiens sans que cela implique un titre ou un statut particulier qui les distingue des autres baptisés ( $R m$ 16, 3-16; Ac 18,18-19.26). L'oeuvre de Dieu à accomplir semble primer sur l'organisation ministérielle, mais il faut admettre que les Épîtres pastorales, en mettant l'accent sur la responsabilité des dirigeants et sur leur conduite ( 1 Tim 3, 1-5), témoignent d'un début d'organisation que la Tradition précisera par la suite. On ne peut qu'être frappé par la pluralité étonnante des services et des ministères dans le Nouveau Testament. Une telle diversité exprime à merveille la créativité de la communauté et son accueil des charismes ministériels suscités par l'Esprit."76

Une question a toujours été bien présente dès le début de l'institutionalisation des ministères: qui détient l'autorité dans la communauté? La tendance a été de placer l'entièreté de l'autorité entre les mains des ministres ordonnés dès la fin du premier siècle. Cette situation demeure un défi "politique" majeur dans les

76 Comité des ministères de l'Assemblée des évêques du Québec, Les nouvelles pratiques ministérielles, Document de réflexion, Montréal, Fides, 1993, p.144. 
paroisses d'aujourd'hui. Comment redonner cette autorité'à la communauté comme au temps des apôtres?

Plusieurs ministres reconnus, mandatés et ordonnés sont angoissés devant les défis à assumer en pastorale urbaine. Notre univers urbain actuel n'est pas sans ressembler à celui de l'apôtre Paul. N'est-ce pas dans le milieu urbain que le christianisme a pris forme? Paul peut être pour nous aujourd'hui une figure inspiratrice. Il a annoncé l'Évangile dans un monde urbain aux réseaux variés. Il a édifié des communautés fraternelles reliées entre elles. Ces défis sont nôtres et nous avons besoin d'attention, d'espérance et d'audace pour y faire face. Paul ne nous fournit pas des réponses toutes faites pour cela. Mais ses approches pastorales et missionnaires peuvent inspirer nos regards sur notre culture, sur la place des chrétiens dans la cité et sur les voies d'avenir de la paroisse au service du Royaume de Dieu. Nous avons appris que la maisonnée a été le premier lieu d'incarnation du christianisme. Cette source du ferment communautaire ne serait-elle pas à conserver dans les logiques de masses et de grandes foules de nos sociétés modernes?

La paroisse est précieuse à la condition qu'elle permette aux personnes d'approfondir leur relation d'intimité avec le Christ afin qu'elles puissent devenir agentes du Royaume au coeur du monde. La paroisse ne peut donc être un lieu figé ni un espace clos mais elle doit servir au mouvement de transfiguration dans le Christ. Elle doit offrir des lieux pour que le paroissien puisse investir dans des relations personnalisées (petits groupes- relations courtes) et des réseaux de solidarité (grands groupes - relations longues) afin de pouvoir parcourir le difficile chemin de la personnalisation de son expérience spirituelle. Seule la communion (vécue en communauté; non pas le grégarisme ni le collectivisme), peut nous permettre de découvrir davantage la présence de Dieu dans notre vie personnelle et communautaire 
et de trouver comment exprimer fidèlement par nos paroles et nos actes ce que le Dieu de Jésus-Christ attend de nous après nous avoir remis debout par son Amour libérateur. Mais cela ne peut se faire automatiquement. La paroisse a besoin de trouver de meilleurs outils pédagogiques qui aideront à mieux accueillir ce mouvement de transfiguration promis à tout humain et à toute communauté se laissant façonner par le Vivant. 



\section{CHAPITRE 11}

\section{FORCES ET LACUNES DE L'ECCLÉSIOLOGIE DE VATICAN II}

Le concile Vatican II a été un événement historique important dans la vie de l'Église. Le jeudi 11 octobre 1962, le XXI ${ }^{\circ}$ concile oecuménique commence. Soixante-dix-neuf nations sont représentées. Deux mille cinq cents pères conciliaires sont présents. ${ }^{1}$ Pour cinq cents millions de catholiques qui ont les yeux fixés sur Rome, c'est le plus grand événement du siècle. Ce concile s'est achevé le 8 décembre 1965. On doit à Vatican II seize documents, quatre constitutions, neuf décrets, trois déclarations. Mais on ne peut réduire un événement de cette ampleur à un volumineux recueil de textes. Le Concile a été une expérience, une vie, un esprit, un dynamisme. Les évêques canadiens ont même déjà dit à un Synode extraordinaire qui s'est tenu à Rome, du 25 novembre au 8 décembre 1985, que le Concile Vatican II fut "la plus grande grâce de ce siècle". 2 Encore aujourd'hui, il demeure pour nous un point de

1

80 cardinaux, sept patriarches, 1134 archevêques et évêques résidentiels, 53 nonces et délégués apostoliques, 54 prélats et abbés nullius des territoires ne relevant d'aucun diocèse, 29 administrateurs apostoliques, etc. Sur 2778 "pères" convoqués (êvêques et supérieurs religieux), quelque 2500 avaient fait le déplacement pour la cérémonie inaugurale. On en compta cent de moins pour l'apothéose finale. Au cours des quatre sessions, tenues à l'automne de chaque année, la participation s'échelonna entre 2100 et 2300 personnes munies d'un droit de vote (sans compter, donc, experts, théologiens, observateurs laïcs ou représentants des autres confessions religieuses). Vatican II s'est imposé par sa "massivité mondiale": un tiers des pères venait d'Europe de l'Ouest, $22 \%$ d'Amérique Latine, $13 \%$ d'Amérique du Nord, $10 \%$ d'Afrique noire, $10 \%$ d'Asie, 3,5\% du monde arabe, 2,5\% d'Océanie. Voir à ce sujet l'excellent dossier paru en l'honneur du quarantième anniversaire de la revue ARM, GUERTNY, Jean-Paul, dir., Église, qu'as-tu fait de ton Concile?, in $A R M, \mathrm{n}^{\circ} 117,15$ décembre 1993, pp. 19-41.

2 CECC, "Synthèse des travaux du Synode extraordinaire des évêques", in Église Canadienne, vol. 19, no 9, 2 janvier 1986, p.268. "Vingt spécialistes du fait religieux, théologiens, historiens ou journalistes, ont été choisis, parmi d'autres, pour constituer le jury du concours organisé par l'Actualité Religieuse dans le Monde (ARM) à l'occasion de ses quarante ans. Dix-sept ont répondu à notre invitation. Leur mission: faire, chacun, son marché dans la liste des événements qui ont changé la face du christianisme au cours des quatre décennies écoulées, pour établir un top tem de ces événements. /.../ La palme d'or a été décernée au concile Vatican II. À l'unanimité? Presque. Seule 
repère et une lumière. Mais comme l'a si bien dit Jean-Marie TILLARD lors du colloque international de théologie de 1980 qui s'est déroulé à Bologne sous le thème: "L'ecclésiologie de Vatican II: dynamisme et prospective", l'Église post-concilaire a été marquée, vis-à-vis de Vatican II, par trois tendances maîtresses.

"On peut, en les classant par ordre d'importance, les décrire ainsi: la volonté d'appliquer strictement le Concile et d'en suivre l'esprit, le désir d'aller au-delà des décisions conciliaires en s'ouvrant déjà à l'avenir dans un monde en pleine évolution, la nostalgie du passé et l'effort pour bloquer les dynamismes mis en branle au Concile dans la crainte qu'ils compromettent l'identité catholique romaine /.../ La première tendance elle-même -celle de la fidélité stricte- s'appuie souvent sur une lecture myope des textes, faisant l'économie d'une recherche de leur intention, ce qui en gauchit gravement l'application."3

Plus de vingt-cinq ans après le Concile, je perçois que la tâche n'est pas seulement d'appliquer et de prolonger Vatican II. Elle est surtout d'approfondir et de mener à leur pleine cohérence les intuitions fondamentales de ce concile. Pour ce faire, nous devons porter un jugement: un jugement sur les structures actuelles de l'Église et leur signification, non sur les personnes et sur leur bonne ou mauvaise volonté.

Le présent chapitre permettra de réfléchir plus précisément sur les forces et les lacunes ecclésiologiques du dernier Concile. En premier lieu, j'ai essayé de démontrer à quel point la nouvelle conception de l'Église diocésaine et la revalorisation du sacerdoce baptismal constituent un grand tournant en ecclésiologie, qualifié même par bien des théologiens de "révolution copernicienne". Toutefois, une analyse critique de plusieurs décrets concilaires mettra en lumière des lacunes sérieuses concernant la théologie du laïcat, du presbytérat et de l'institution paroissiale. Plusieurs lignes seront

voix discordante...."(KAREH TAGER, Djénane, "40 ans magiques", in $A R M, \mathrm{n}^{\circ} 117,15$ décembre 1993, p.38.). 3 Eglises après Vatican II, Dynamisme et Prospectives, Actes du Colloque international de Bologne 1980, Paris, Beauchesne, 1981, p. 347. Voir du même auteur, Église d'Églises, l'ecclésiologie de communion, Paris, Cerf, 1987. [Cogitatio fidei, \# 143]. ; Chair de l'Église, Chair du Christ, Aux sources de l'ecclésiologie de communion, Paris, Cerf, 1992, 168p. [Cogitatio fidei, ${ }^{\circ}{ }^{\circ}$ 168]. 
consacrées à démontrer que l'ecclésiologie de communion dont Lumen Gentium a posé les assises au Concile n'a pas été traduite en une organisation structurelle juridique adéquate. Les derniers paragraphes feront finalement ressortir les pointes lumineuses de ce parcours théologique touchant plus directement l'ecclésiologie de Vatican II et ses conséquences sur la structure paroissiale.

\subsection{La promotion de l'Église locale comme une Église-Sujet et de sujets}

Aujourd'hui encore, il n'y a pas à vrai dire de théologie de la paroisse, mais seulement une théologie de l'Église locale qui seule situe la paroisse selon sa médiation ecclésiale propre. Il est alors important d'analyser premièrement les déplacements ecclésiologiques opérés à Vatican II concernant l'Église locale.

\subsubsection{L'acquis le plus déterminant}

Le concile Vatican II a reconnu que

"le diocèse lié à son pasteur et par lui rassemblé dans le Saint-Esprit grâce à l'Évangile et à l'Eucharistie, constitue une Église particulière en laquelle est vraiment présente et agissante l'Église du Christ, une, sainte, catholique et apostolique"(CD 11).

Plus d'un théologien s'entend pour dire que cette conception de l'Église locale (particulière ou diocésaine) comme présence et actualisation de l'unique Église de Dieu constitue, à tous les plans, l'une des visions ecclésiologiques les plus déterminantes de ce Concile. ${ }^{4}$ La possibilité de comprendre l'Église à partir de l'Église locale se révèle l'un des plus grands acquis de l'ecclésiologie de Vatican II.

4

Les textes conciliaires s'expriment selon une terminologie diversifiée qui laisse toutefois prévaloir l'expression "Ecclesia particularis" pour désigner le diocèse. L'expression a des 
"La rupture de l'Église catholique romaine avec son passé féodal se situe indéniablement au cours de la période de 1962 à 1965, au temps de Vatican II /.../ Vatican II, c'est, dans l'Église, la consécration des acquis de la Révolution française, cent cinquante ans après! /.../ On trouve en effet dans la constitution pastorale Gaudium et Spes des formules voisines du cri de guerre de cette Révolution: "Liberté, égalité, fraternité"."5

\section{Hervé LEGRAND affirme que de la vision théologique de l'Église locale} au Concile Vatican II, découle un double dynamisme:

"...en elle-même, l'Église locale est composée de groupes actifs de sujets; dans sa relation avec l'Église de Dieu ensuite, elle cesse d'être conçue comme une partie subordonnée et incomplète, de l'Église entière, mais elle est le sujet actif de la manifestation de cette Église en un lieu donné. Bref, l'Église locale a vocation d'être une Église de sujets en même temps qu'une Église-sujet dans sa relation avec les autres Églises."6

significations plurielles. Le document Ad Gentes utilise côte à côte les expressions "Ecclesia particularis" et "Ecclesia localis" pour parler du diocèse (AG 6, 22, 45; 19, 27; 32). Mais globalement je pourrais dire que le mot "Église particulière" est majoritairement utilisé dans une terminologie juridique et l'expression "Église locale" comme une terminologie théologique. "Le code de 1983 a opté en faveur de l'expression 'Église particulière' plutôt que 'Église locale' dont on ne retrouve aucune mention. Évidemment, c'est encore 'diocèse' que l'on emploie le plus souvent" ( PAGÉ, Roch, Les Églises particulières, tome 1, Montréal, Paulines, 1985, p.14.). Voir aussi GHIRLANDA, G., "Eglise universelle, particulière et locale au Concile Vatican II et dans le nouveau Code de droit canonique", in Vatican II, bilan et prospectives: vingt-cinq ans après (19621987), LATOURELlE, R., dir., Paris-Montréal, Cerf-Bellarmin, 1988, pp. 274-280; CHOUINARD, P., "Les expressions "Église locale" et "Église particulière" dans Vatican II", in Studia canonica, \#6, 1972, pp. 115-161.; LANNE, É., "L'Église locale et l'Église universelle: actualité et portée du thème", in Irenikon, \#43, 1970, p. 490. ; DEJAIVE, G., "L'Eglise particulière dans le mystère de l'Église", in Un tournant décisif de l'ecclésiologie de Vatican II, Paris, Beauchesne, 1978, pp. 13-22. [Le point théologique, \#31].; ROUTHIER, Gilles, "'Église locale" ou "Église particulière", querelle sémantique ou option théologique?", in Studia canonica, \#25, 1991, pp. 277-334. La paroisse est-elle une Église locale et l'expression "Église locale" doit-elle être réservée à la paroisse? Je reviendrai plus loin sur ce questionnement dans les deux prochains chapitres concernant l'approche conciliaire et canonique de la paroisse.

SCHILLEBEECKX, Edward, L'histoire des hommes, récit de Dieu, Paris, Cerf, 1992, p. 312. [ Cogitatio fidei, \# 166].

6 LEGRAND, Hervé, "Le développement d'Églises-Sujets. Une Requête de Vatican II", in Les Églises après Vatican II, Dynamisme et Prospective, p.149. Notons que l'expression 'Eglisesujet et de sujets' est absente du vocabulaire de Vatican II. Le Concile parle plutôt de 'communion'. LEGRAND refuse d'employer cette expression parce que selon lui le terme de communion est trop large. Je ne partage pas son point de vue à ce sujet. 
L'angle d'approche de cette recherche me pousse à creuser davantage le premier dynamisme qui tend à faire des Églises locales des Églises de sujets. Il aurait été intéressant d'approfondir le deuxième dynamisme. Plusieurs théologiens continuent à approfondir la théologie conciliaire de l'Église locale. Ils admettent que cette théologie est encore bien incomplète. ${ }^{7}$ Quoi qu'il en soit de ces critiques, le bilan de Vatican II sur ce plan est capital et déterminant. Il renverse en effet le courant sociétaire qui, en ecclésiologie, fondait à se représenter l'Église comme une société transnationale qui, sous l'autorité du pape, établissait par toutes ses filiales ( les diocèses étant des succursales "Macdonald's romaines") une conception uniforme de la Révélation. Paul VI a été ferme sur ce point en déclarant quelques années après le Concile que l'Église locale ne devait pas être considérée comme une "fraction d'Église" mais comme une "expression authentique de l'Église unique et catholique".

"On devra donc parler de l'Église locale non pas comme d'une "fraction d'Église" qui s'additionne arithmétiquement à d'autres "fractions" pour constituer l'Église universelle: non pas d'une Église autonome et autarcique, juridiquement refermée sur elle-même, ou, pis encore, en opposition avec l'Église universelle et ayant des prérogatives propres à celle-ci, mais bien comme d'une expression authentique (même si souvent elle revêt des caractères originaux) de l'Église unique et catholique, tirant son autorité et sa garantie de son rapport organique et hiérarchique, ainsi que du souffle de l'Esprit-Saint dont vit l'Église tout entière. C'est de cette notion authentique que devra partir toute discussion en vue d'une pastorale valable et c'est là que devra être trouvée la solution des problèmes liés au renouveau authentique des structures et des actions." 8

Mais les évêques canadiens sont conscients que nous ne sommes pas encore parvenus à vivre pleinement cette nouvelle conception de l'Église locale. "On véhicule encore beaucoup trop l'image d'une Église universelle gouvernée par le pape et que les

7

Voir LEGRAND, H.M., "Inverser Babel: mission de l'Église", in Spiritus, \# 43, 1970, p. 323.; KOMONCHAK, J.A., "L'Église universelle, communion d'Églises locales", in Concilium, \# 166, juin 1981, p.60.; NOCENT, A., "L'Église locale, réalisation de l'Église dans les documents conciliaires", in La réception de Vatican II, ALBERIGO, G. et JOSSUA, J.P., dir., Paris, Cerf, 1985, p. 290.[ Cogitatio fidei, \# 134].

$8 \quad$ PAUL VI, "Diocèse, Paroisse et Communauté de base", Allocution adressée aux participants de la XXI ${ }^{\circ}$ semaine italienne d'aggiornamento pastoral, 9 septembre 1971, in La Documentation Catholique, 3 octobre 1971, pp. 857-858. 
diocèses ne sont que des régions administratives gouvernées par les évêques"9 Cependant, sans être complet, l'enseignement de Vatican II sur l'Église locale est déjà riche; il ouvre des horizons nouveaux et offre d'intéressantes perspectives. Grâce à ce Concile, toutes les Églises locales sont "Églises" dans la mesure où elles sont ouvertes à la communio, à la communication avec les autres Églises et où elles la favorisent.

\subsubsection{La revalorisation du sacerdoce baptismal}

Promouvoir des Églises de sujets, c'est prendre en compte en ecclésiologie, la solidarité de tous dans la responsabilité de l'Église et de sa mission au sein d'une diversité de ministères. ${ }^{10}$ Et cette orientation concilaire vers des Églises de sujets (Église Peuple de Dieu [ $L G 2]$ ) est très différente de l'ecclésiologie des derniers siècles qui distinguait soigneusement, parmi les chrétiens, les gouvernants et les gouvernés, les enseignants et les enseignés, les célébrants et les assistants. En 1885, dans sa lettre Epistola tua au Cardinal GUILBERT, archevêque de Paris, Léon XIII écrivait:

"Aux seuls pasteurs, il a été donné tout pouvoir d'enseigner, de juger, de diriger; aux fidèles, il a été imposé le devoir de suivre leurs enseignements, de se soumettre avec

CECC, "Diagnostic sur la réception du concile Vatican II par l'Eglise canadienne", in Le Devoir, 17 octobre 1985, p. A.5. Les conférences épiscopales doivent demeurer vigilantes pour être fidèles à la conception conciliaire de l'Église locale. Actuellement, il faut même qu'elles contrebalancent le pouvoir central de Rome qui, "sous le pontificat de Jean-Paul II", semble vouloir contrôler l'ensemble des Églises particulières. "Le tableau s'impose de lui-même: le pape considère les évêques comme des fonctionnaires de haut-niveau. Ils ne font pas la politique, ils l'éxécutent seulement. Peu importe leur opinion personnelle; ils n'ont qu'à la garder pour eux. Le pape seul parle pour l'Église." (DREWERMANN, E., Les fonctionnaires de Dieu, p. 391). Nous en avons eu une belle preuve lors de la parution de l'encyclique "Veritatis Splendor ". Nous savons que plusieurs evêques n'étaient pas en accord avec l'ensemble du texte. Mais devant les caméras, plusieurs d'entre eux ont défendu Jean-Paul II au détriment de leurs opinions personnelles au nom de la communion! La fidélité évangélique n'exige-t-elle pas plus de transparence que de splendeur?

10 "Etre sujet, c'est être auteur de transformations dans la structure même"(DUQUOC, Christian, Des Églises provisoires, Essai d'ecclésiologie oecuménique, Paris, Cerf, 1985. pp. 4950.). 
fidélité à leur jugement et de se laisser par eux gouverner, corriger, conduire au salut. C'est dans cette subordination et dépendance que gisent l'ordre et la vie de l'Église."11

Pie X proclamera cette même vision en 1906:

\begin{abstract}
"L'Église est par essence une société inégale, c'est-à-dire comprenant deux catégories de personnes, les pasteurs et le troupeau, ceux qui occupent un rang dans les différents degrés de la hiérarchie et la multitude des fídeles. Et ces catégories sont tellement distinctes entre elles que dans le corps pastoral seul résident le droit et l'autorité nécessaires pour promouvoir et diriger tous les membres vers la fin de la société. Quant à la multitude, elle n'a pas d'autre droit que celui de se laisser conduire et, troupeau fidèle, de suivre ses Pasteurs." 12
\end{abstract}

Pie X écrira un an plus tard dans l'encyclique Pascendi : "Voici, vénérables frères, que nous voyons déjà se manifester cette doctrine funeste qui présente les laïcs dans l'Église comme un élément de progrès."

L'une des redécouvertes du concile Vatican II, dans Lumen Gentium, a été vraiment de revaloriser le baptême comme fondement d'activités et de responsabilités ecclésiales. C'est par le baptême qui nous incorpore à l'Église ( $L G 11$ et 14) que les chrétiens participent à la triple charge royale, sacerdotale et prophétique du Christ dans l'Église ( $L G 10 ; 11 ; 12 ; 34 ; 35 ; 36) .{ }^{13}$ Par le baptême tous les chrétiens ont une même dignité ecclésiale.

"Il n'y a donc qu'un peuple de Dieu choisi par lui: "Il n'y a qu'un Seigneur, une foi, un baptême"(Eph. 4,5). Commune est la dignité des membres du fait de leur regénération p.61). "Si tous les membres de l'Église sont "prêtres", s'ils forment un peuple sacerdotal, alors la vieille distinction entre prêtres et laïcs devrait être abolie, parce qu'accomplie dans le Christ" (DENIS, Henri, L'Église, les quatre portes du Temple, Paris, Desclée de Brouwer, 1991, p.36.). Le sacerdoce est donc une habilitation radicale pour tous les baptisés à vivre toute la vie humaine personnelle et collective comme un culte qui plaît au Dieu de Jésus Christ. Voir aussi RIGAL, Jean, Le courage de la mission, Paris, Cerf, 1985, pp.65-70. 
dans le Christ; commune la grâce d'adoption filiale; commune la vocation à la perfection; il n'y a qu'un salut, une espérance, une charité sans division. Il n'y a donc, dans le Christ et dans l'Église, aucune inégalité qui viendrait de la race ou de la nation, de la condition sociale ou du sexe, car "il n'y a ni Juif ni Grec, il n'y a ni esclave ni homme libre, il n'y a ni homme ni femme, vous n'êtes tous qu'un dans le Christ Jésus"[Gal. 3,28 grec; cf. Col; $3,11]$ " ( $L G 32$ ).

Une telle conception n'autorise ainsi aucune relation maître-esclave dans l'Église. Aucune structure de domination n'y est acceptable: "Vous savez que les chefs des nations leur commandent en maîtres et que les grands leur font sentir le pouvoir. Il n'en doit pas être ainsi parmi vous" (Mt 20, 25-26; Mc 10, 42-43; Lc 22-25). En un mot, à Vatican II, la pyramide a été renversée. Nous sommes passés d'une Église "Societas Perfecta" à une Église "Peuple de Dieu". Des théologiens utilisent d'autres expressions pour qualifier ce changement. Léonardo BOFF utilise l'expression "la hiérarchiologie" pour qualifier l'ecclésiologie d'avant Vatican II. Il entend par cette expression une Église pour laquelle seule compte la hiérarchie.

"Dans cette conception, le fidèle n'a rien si ce n'est le droit de recevoir. Les évêques et le prêtre ont tout reçu: ils produisent les valeurs religieuses et le peuple consomme. Il s'agit d'un véritable capitalisme dont la structure politique est de type monarchique et pyramidal". 14

Hervé LEGRAND parle plutôt d'un modèle d'Église pré-conciliaire "christomoniste". 15

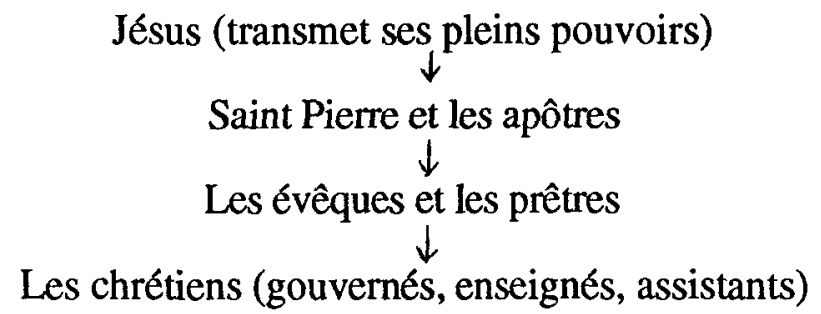


Pour lui, ce modèle n'est évidemment pas fidèle à une Église-sujets car il ne part pas de la Koinonia [communion-communauté]. Il part d'une scission initiale entre un groupe de chrétiens actifs et un groupe passif. Ce modèle favorise la scission entre le clergé, responsable de l'Église, et les laïcs responsables du monde. L'ordination y est abstraite de l'ecclesia pour devenir transmission verticale de pouvoirs d'individu à individu. Ce modèle recouvre donc une conception réductrice de l'origine de l'Église. Au lieu de partir du Christ, l'envoyé du Père et donnant l'Esprit, on en reste au Jésus de l'histoire. De ce fait, on utilise spontanément le modèle social d'un fondateur de groupe dont la fonction fondamentale se continue dans la chaîne historique des détenteurs du pouvoir apostolique. L'identité des ministres se fonde en termes de supériorité et d'extériorité par rapport au peuple chrétien. Leurs relations s'établissent à sens unique: un pape pour une Église, un évêque pour un diocèse, un curé pour une paroisse.... Les prêtres (clercs) sont actifs: ils possèdent le monopole du savoir et du pouvoir. Les laïcs sont passifs: leur rôle consiste à se laisser enseigner, à obéir aux directives reçues, au mieux à devenir les "auxiliaires du clergé". Edward SCHILLEBEECKX explique bien l'origine de cette Église sous forme de pyramide hiérarchique.

"Une conception hiérarchique néo-platonicienne de l'Église la voit comme une pyramide, comme un système échelonné: "Dieu, le Christ, le pape, les évêques, les prêtres et diacres, suivis des religieux et, enfin, au bas de l'échelle, les laïcs", d'abord les hommes, ensuite les femmes et les enfants. Cette conception de l'Église s'est imposée au cours de la seconde moitié du $\mathrm{I}^{\circ}$ millénaire et elle conduisit, à partir du $\mathrm{I}^{\circ}$ siècle, à une centralisation intensive du pouvoir ecclésiastique à Rome. Après Trente, cette conception de l'Église prit forme juridique, surtout dans les ouvrages du jésuite Bellarmin et du dominicain Torquemada. Elle fut ensuite universellement accepté, et au cours du combat contre le monde moderne qui se déchaîna au XIX ${ }^{\circ}$ siècle elle fut encore renforcée. L'Église est décrite comme une société organisée autour du pape de Rome, de qui les évêques, dans leurs diocèses, sont les préfets; ceux-ci sont représentés à leur tour par les prêtres, leurs lieutenants locaux, chargés de paître le troupeau. La légitimation de ce système repose sur deux paliers: 1. celui d'une christologie, lourde de conséquences; l'Esprit qui souffle au pied de la pyramide est ignoré pour être intégralement récupéré par la seule hiérarchie, à travers la succession apostolique; 2 . le pilier de l'interprétation 
sociologique de l'infaillibilité pontificale. De cette perspective, le pape devient le "vicaire du Christ" en ce monde, à la manière des gouverneurs fondés de pouvoir de l'empereur de Rome dans les provinces lointaines. Le don de l'Esprit se limite, pour le niveau inférieur de la pyramide, en une acceptation obéissante de ce qui a été décidé et promulgué au niveau hiérarchique supérieur. Une telle conception de l'Église exclut complètement la majorité des fidèles de toute participation aux activités dirigeantes où se prennent les décisions. Les laïcs, surtout les femmes, ne sont plus des sujets, porteurs et acteurs de la démarche ecclésiale, mais les objets des décisions hiérarchiques et des activités masculines de prédication et de monition pastorale. L'effet le plus funeste de cet état de choses est que l'autorité reconnue à certains actes pontificaux dans des circonstances bien définies et juridiquement contrôlées se concentre dans la seule personne du pape, qui devient ainsi infaillible dans l'exercice de son pouvoir personnel." 16

L'expression signifiant l'édification pyramidale du pouvoir ecclésiastique s'est donc introduite sous l'influence des formes symboliques empruntées au statut social dans l'Empire gréco-romain décadent (reprises par l'Église postconstantinienne au moment où la concurrence s'atténue). À partir du VI ${ }^{\circ}$ siècle, l'Église est sous l'influence néoplatonicienne du pseudo-Denys qui fournit une légitimation philosophique et théologique. Ce principe de substitution pseudo-dionysien fut à l'origine d'une dévaluation de nombreux ministères spécialisés, nés des besoins pastoraux de l'Église au fur et à mesure de son développement historique. Les laïcs, à la base de la pyramide, sont dévalués par rapport aux niveaux hiérarchiques supérieurs jusqu'à n'être plus qu'objets du souci pastoral des évêques et des prêtres. Dans une telle situation, le souci des âmes, lorsque le pouvoir était en question, se transformait aisément en moyen de contrôle. En principe dans le clergé (où l'épiscopat est revêtu du plus haut état de perfection) se réalisaient pleinement un mode de vie religieux et une union religieuse à Dieu que les fidèles "ordinaires" ne pouvaient vivre qu'indirectement et imparfaitement par leur obéissance aux prélats dans l'Église.

16

SCHILLEBEECKX, E., L'histoire des hommes, récit de Dieu, pp. 301-302. "Cela dit, cette même Église a adopté, sans la moindre hésitation, les formes civiles du régime impérial et féodal, régimes autoritaires, et plus tard celles de la monarchie absolue. Elle l'a fait comme allant de soi, comme parfaitement légitime" (Ibid., p. 329.). 
Vatican II a parlé très différemment de l'Église en la définissant comme Peuple de Dieu. Ce Concile a renversé la pyramide en redonnant l'Église à tous les baptisés.

"Tous les services sont au peuple de Dieu, dans le peuple de Dieu, au profit du peuple de Dieu. C'est la communauté qui les fonde et les services n'apparaissent qu'en fonction des nécessités, dans une structure souple, où s'établissent des relations fraternelles et communautaires" 17

Le sacerdoce baptismal est pleinement remis en valeur.

Hervé LEGRAND, comme d'autres théologiens l'ont noté, qualifie ce nouveau modèle ecclésiologique de trinitaire. 18

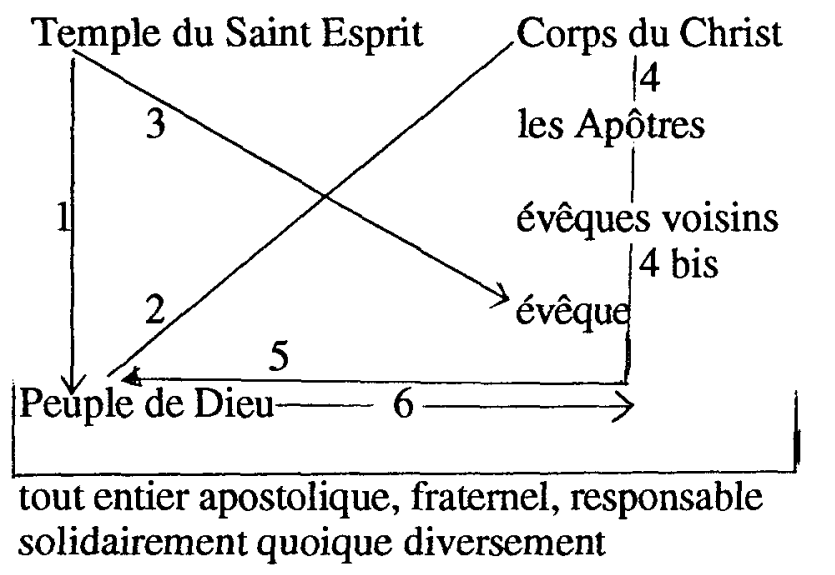

17

BOFF, Léonardo, Église, charisme et pouvoir, p. 235. Voir aussi COLLECTIF, Un peuple ensemble, PELCHAT, Marc et VIAU, Marcel, dir., Montreal, Paulines, 1990, 133p.; RIGAL, Jean, Le mystère de l'Église, Fondements théologiques et perspectives pastorales, Paris, Cerf, 1992, pp. 111-154.

18 LEGRAND, H. "Le développement d'Églises-Sujets. Une Requête de Vatican II", in Les Églises après Vatican II, Dynamisme et Prospective, pp. 171-172. 
L'ecclesia est manifestement le peuple de Dieu le Père, le Temple du Saint-Esprit, le Corps du Christ (flèches 1,2,3,4). L'ecclesia est Église de sujets et Église-Sujet: -tous sont des sujets appelés, à la mesure de leurs charismes à participer à la construction de l'Église une, sainte, catholique et apostolique (ainsi flèches 1,6), -les ministres y sont les partenaires des chrétiens: c'est le sens de la double flèche 5 et 6 indiquant que l'évêque est autant dans l'Église que face à elle, -les églises sont toutes ensemble responsables de la tradition apostolique manifestée par le témoignage et la réception de la même tradition des Apôtres (4 et 4bis). Elles sont sujet à l'égard les unes des autres. Dans ce modèle trinitaire, l'Église est remise à tous les croyants et à toutes les communautés croyantes et

\footnotetext{
"tout ce qui naît spontanément de la base est essentiellement, et à juste titre, expérimenté spontanément et interprété explicitement comme 'don de Dieu' [Ep 4,8-11; 1 Tm 4,14; 2 Tm 1,6]"19

"Le mouvement part de la base là d'où jaillissent les charismes ministériels /.../ La communauté ecclésiale intervient afin d'interpréter explicitement ce qui doit être accueilli comme un don de Dieu, un charisme. S'amorce ainsi une dynamique qui garde les ministères en relation constante avec la communauté ecclésiale." 20
}

Le Père CONGAR, parle dans les mêmes termes du déplacement théologique ainsi opéré à Vatican II. "À une vision principalement juridique, et de ce fait à dominante purement christologique, on a substitué une vision d'Église comme communion de sens de la foi qui habite le "dernier" des chrétiens jusqu'aux évêques et au pape. Vous imaginez ce que cela supposerait, si l'on devait mettre en forme et mettre en oeuvre concrète cette possibilité pour tout chrétien d'avoir l'intelligence de sa foi, de dire ce qu'il pense, de chercher évangéliquement de nouvelles façons de l'expérimenter,etc."(DENIS, Henri, L'Église, les quatre portes du Temple, p.40). 
personnes et communion d'Églises locales dans une perspective trinitaire." 21 Une pneumatologie véritable articule ainsi les différences dans une communion.

C'est seulement à Vatican II que s'est véritablement amorcé un processus de 'décléricalisation' de l'Église. Cette nouvelle manière d'être Église, caractérisée par le passage d'un modèle clérical (Église de sujets-objets; dynamique institutionnelle à sens unique) à un modèle communionnel (Église de sujets; dynamique institutionnelle à double mouvement), met ainsi en valeur l'appel de tous les croyants, à la mesure de leurs moyens et de leurs charismes, à participer activement à la construction de l'Église et à assumer sa mission dans le devenir du monde. L'Église est devenue "le sacrement du 'nous' chrétien.

"L'Église est "la communauté des hommes et des femmes qui disent: j'accepte et je décide que le sens de ma vie c'est Jésus Christ. Du même coup, ils se reconnaissent une commune dignité, celle d'être fils et filles de Dieu. Du même coup aussi, ils se consacrent à nouer entre eux des rapports fraternels. Car ces rapports sont chargés de révéler, dans I'histoire, le 'nous' que nous recevons comme une grâce de Jésus Christ"22

Vatican II n'a pas seulement introduit des réformes. Il a changé l'image que l'Église se faisait d'elle-même. Ce n'est qu'après avoir établi l'existence et la vie du peuple de Dieu qu'il a parlé par la suite de la hiérarchie et des ministères ordonnés. La communion de tous les chrétiens devenait préalable à la distinction de fonctions. 23 Ainsi reconnaissaitil la priorité du peuple de Dieu sur ses ministres quels qu'ils soient, et celle de l'être chrétien baptismal sur quelque autre statut ecclésial. Vatican II a orienté le devenir de Père CONGAR a eu une influence considérable dans cette nouvelle conception ecclésiologique de Vatican II. Plusieurs théologiens se sont inspirés de lui dans leur réflexion sur l'Église. de l'Église et de sa structure institutionnelle: condition de possibilité de ministères nouveaux", in Des ministères nouveaux?, p.197. 
l'Église dans une perspective trinitaire et donc communionnelle. Il a pris ses distances par rapport à une conception christomoniste du peuple chrétien, trop limitée à la hiérarchie et trop absorbée par son organisation. Prenant appui sur le fondement trinitaire de l'Église, la communion devenait la manifestation d'un peuple où tous sont égaux quant à l'activité commune et solidaire dans la mission, d'un corps où tous sont différents et complémentaires, d'un Temple où tous bénéficient des dons multiples de l'Esprit. Aucune norme juridique humaine devrait avoir une force supérieure à la norme de la communion ecclésiale. Les prochaines lignes démontreront malheureusement le contraire.

\title{
11.2. Une organisation structurelle juridique inadéquate à l'ecclésiologie conciliaire
}

Vatican II a ouvert les chemins par où pourrait se vivre le passage d'une Église de sujets-objets à une Église de sujets . Mais ce passage s'avère long et laborieux puisque l'ecclésiologie de communion dont Lumen Gentium a posé les assises au Concile n'a pas été traduite en une organisation structurelle juridique adéquate.

\begin{abstract}
"Une ecclésiologie doit se traduire dans des institutions en pleine harmonie avec elle. C'est ici surtout que, peut-être à cause de la permanence de forces puissantes pas encore converties à l'esprit du Vatican II, des problèmes se posent, des inquiétudes sérieuses se manifestent. Le concile pourrait être mis en échec /.../ Le problème est grave. Il traduit une hésitation et une ambiguïté qui pourraient même, lentement, aboutir à stériliser l'intuition du Concile, à fausser son intention." 24
\end{abstract}

En d'autres mots, Vatican II a accepté des orientations appelées à transformer cette 'hiérarchiologie', mais ces nouvelles orientations n'ont pas trouvé une traduction concrète opérationnelle, au niveau organisationnel. 
"On a beaucoup célébré l'ecclésiologie renouvelée de Vatican II; on n'a pas assez pris en compte la distorsion entre cet idéal et le fonctionnement institutionnel. Proposer une essence de l'Église ne suffit pas: il faut rester attentif à sa concrétisation dans la vie réelle des hommes. Les plus belles ecclésiologies se révèlent stériles aussi longtemps qu'elles ne sont pas traduites en une organisation structurelle adéquate. Si l'inspiration ecclésiologique est absente, les réformes institutionnelles ne sont que du vent, mais, inversement, sans réformes concrètes, l'inspiration ecclésiologique s'étiole et se meurt." 25

Cette impuissance de l'ecclésiologie conciliaire face aux questions juridiques prend origine dans l'incompréhension mutuelle des dogmaticiens et des canonistes à Vatican II. Knurt WALF affirme que c'est cette incompréhension qui a contribué aux incohérences verbales des textes conciliaires.

"L'impuissance de l'ecclésiologie contemporaine en face des structures juridiques se montrait pour la première fois, mais aussi très clairement, dans les textes de Vatican II lui-même. Ce fait a eu déjà jusqu'à présent des conséquences fatales pour l'Église catholique. Et la fin de cette évolution inquiétante n'est pas en vue. Pendant et aussi après le Concile, il se manisfesta des conséquences fâcheuses, c'est-à-dire que les dogmaticiens -relativement rares- qui s'occupaient spécialement de questions ecclésiologiques, firent preuve d'une attitude méprisante souvent inconvenante à l'égard du droit canon et de ses représentants. Les canonistes au contraire voulaient -d'une manière déplacée- se comporter comme des professeurs à l'égard des dogmaticiens. Je suis sûr qu'en définitive ces difficultés d'entente entre dogmaticiens et les canonistes ont contribué aux incohérences verbales des textes concilaires /.../ L'attente sans doute la plus illusoire au sujet du Concile et de ses conséquences fut certainement ce qu'on a appelé la démocratisation de l'Église. Que cette démocratisation ne soit ecclésiologiquement pas possible, en tout cas pas dans l'Église catholique. C'est ce qui fut et est sans cesse souligné par la hiérarchie et aussi par les canonistes /.../Vatican II a mené tout au plus à donner un caractère collégial à l'aristocratie ministérielle, ou disons-le d'une manière encore plus concise: un caractère aristocratique à la hiérarchie" 26

Hervé LEGRAND abonde dans le même sens. Il croit que l'absence d'une théologie du droit à Vatican II est l'une des plus graves lacunes de ce Concile. 
"Il faut signaler ici d'abord la difficulté d'articuler le langage théologique et le langage canonique. Il est vraisemblable que les ecclésiologues ont généralement sous-évalué l'importance du droit canonique pour leur discipline, si même dans la bouche de nombre d'entre eux le terme 'juridique' à lui seul, n'est pas connoté péjorativement! Aujourd'hui ils découvrent, un peu tard, que les beaux textes conciliaires passent dans la vie de l'Église par la médiation du droit /.../ L'une des lacunes les plus graves de Vatican II pour notre sujet est l'absence d'une théologie du droit /.../ car non seulement le concept de koinonia n'y est pas structurant, il en est même absent." 27

\title{
Christian DUQUOC croit également qu'on a beaucoup célébré Vatican II sans lui
} donner les conditions nécessaires pour son application.

\begin{abstract}
"Le passage d'une image pyramidale à celle d'un pouvoir disséminé n'a pas été acccompagné, jusqu'à présent, d'un droit qui assure les rapports de ces institutions entre elles et un fonctionnement interne /.../ je constate un manque de réflexion théologique sur le fonctionnement de l'Église catholique: on a beaucoup célébré l'ecclésiologie nouvelle de Vatican II, on a peu pris en compte la distorsion entre l'idéal, le droit et l'application. Pour ma part, je considère comme essentielle en ecclésiologie la réflexion sur la distance entre l'idée de l'Église scripturairement ou conciliairement promulguée et sa transcription dans le fonctionnement repérable /.../ Les mutations désirées et esquissées dans tant de domaines par Vatican II, mais ni reprises dans le droit, ni assumées en théologie (il n'existe guère d'ecclésiologie depuis Vatican II), témoignent de la nécessité d'articuler dans une pensée de l'Église la promesse du Royaume qu'elle confesse et le provisoire qu'elle représente institutionnellement /.../ L'émergence de la contestation après Vatican II était inscrite dans la contradiction entre les proclamations et l'élaboration d'une théologie de compromis ["La formule de compromis consiste en ceci: trouver une formule qui satisfasse à toutes les exigences contradictoires et, grâce à une tournure ambigüe, laisse indécis les véritables points litigieux" (Définition du professeur de droit allemand Carl SCHMITT dans son volume Verfassungslehre cité dans WALF, K. , Lacunes et ambiguités... p.211).] qui laisse finalement la domination à la hiérarchie." 28
\end{abstract}

C'est donc pour cette raison que plus de vingt-cinq ans après le Concile, rien de décisif n'a véritablement changé dans le fonctionnement interne de l'Église. Les espérances nées du Concile ont été sans cesse étouffées par le fonctionnement institutionnel de l'Église. En fait, Vatican II n'a brisé que théoriquement cette 'hiérarchiologie'. Le modèle christomoniste d'Église est encore omniprésent aujourd'hui. L'Église 'Peuple $158 ;$ p. 177. 
de Dieu' est restée un voeu pieu, j'oserai même dire une 'idéologie' au lieu de devenir 'historique'. 29 Le problème institutionnel demeure donc 'douloureux' dans l'Église catholique. Et ce problème pourtant débattu par Vatican II, restera toujours difficile à aborder notamment parce que l'histoire récente, marquée par un excès de centralisation romaine et de bureaucratie, a exacerbé la sensibilité à l'égard de tout ce qui est juridique, formel, en un mot, institué. En plus, plusieurs théologiens croient que c'est l'hypertrophie de la fonction papale qui empêche le réglement du problème institutionnel dans l'Église. Le rapport entre l'évêque de Rome et les autres évêques ne représente qu'un cas d'une situation plus large qui vaut aussi dans l'Église locale par exemple pour la relation entre évêques et presbytérium et entre clercs et laïcs dans les paroisses. Christian DUQUOC est un de ces théologiens:

"Ni le problème institutionnel de l'Église catholique qu'avait espéré régler Vatican II par la création de la collégialité ni le lien organique avec les autres Églises ne pourront trouver une solution tant que l'usage de la fonction papale sacrifiera à la connotation symbolique du leader saint et infaillible. Il faut que la fonction de l'unité redevienne un ministère parmi d'autres et non le ministère unique, c'est-à-dire qu'il soit conforme au dessein

29

Même le Pape actuel, Jean-Paul II, n'emploie presque plus l'expression "Peuple de Dieu" pour décrire l'Église. Il met plutôt l'accent sur la notion de "Mystère". Mais cette insistance ne va pas sans problème. Elle risque en effet de désarticuler une approche qui tentait de prendre en compte l'historicité de l'Église sans rien négliger de son origine transcendante. En exaltant le Mystère, on risque de dissocier Mystère et institution (simplement humaine), économie du salut et historicité, contre le voeu même des Pères conciliaires de Vatican II ( Voir $L G$ 1,8). "Ces derniers temps il a été fait un large usage de la vision de l'Église en tant que mystère. On en a même abusé! /./ L'Église en tant que Mystère ne doit pas se chercher derrière ou au-dessus de la réalité concrète, visible. La communauté ecclésiale est cette réalité ici présente et clairement assignable. Nous tous, le vulgum pecus à la base, nous sommes ce Mystère. Ce qui se passe au niveau le plus humble fait partie du mystère de l'Église. Chercher en tâtonnant, errer dans l'obscurité, trouver parfois, tout cela fait partie intégrante du mode d'être et d'apparaître de la Catholica, au sens large, présente dans beaucoup de communautés de croyants, avec plus ou moins de vitalité, avec chaleur ou avec tiédeur, mais toujours vraiment catholique. On la rencontre dans les réunions des communautés de base, dans certaines "maisonnées" chrétiennes, partout où des hommes et des femmes se réunissent au nom de Jésus qu'ils confessent être le Christ. Parmi eux beaucoup souffrent dans ce monde et de ce monde, dans leur Église et de leur Église, et ils se dressent contre toute souffrance-que-Dieu-n'a-pas-pu-vouloir. Ils font partie du mystère de l'Église; ils le célèbrent, ils en témoignent. Ils ne sont pas prêts à accepter qu'une décision hiérarchique, pour des motifs de politique ecclésiastique à courte vue, les en bannisse"( SCHILLEBEECKX, E., L'histoire des hommes, récit de Dieu, pp. 317-318, p. 322.). 
évoqué par Vatican II. Trop idéalement, malheureusement. Cet idéalement est-il inévitable pour une institution qui prétend gérer le don de l'Esprit?"30

Edward SCHILLEBEECKX est également convaincu de cette hypothèse concernant les effets néfastes en ecclésiologie du culte de la personnalité du "Souverain Pontife".

"Transférer sans plus cette infaillibilité canoniquement définie et limitée à la personne du pape prive en fait toutes les autres instances institutionnelles dans l'Église - les évêques et les communautés ecclésiales - de leur autorité chrétienne propre et originale. Le culte de la personnalité du souverain pontife, qui résulte d'une mystique de l'infaillibilité, oublie que la fonction de Pierre, ou fonction pétrinienne d'unité et de communion, n'est, dans l'Église, qu'une fonction et donc un ministère parmi d'autres. "31

Yves CONGAR a bien démontré dans son volume "Ministères et communion ecclésiale" l'origine de cette idéologie papale. C'est à la suite de la réforme grégorienne et grâce à la science canonique et aux théologiens du XII ${ }^{\circ}$ siècle que s'est davantage développée cette idéologie papale autour de deux termes: plenitudo potestatis et vicarius Christi. Le développement triomphal de cette idéologie dont des retombées sont encore présentes dans l'Église actuellement a eu d'immenses conséquences dans les siècles suivants. À la réforme grégorienne, la compréhension du ministère de l'évêque de Rome a été sortie de son ordre sacramentel pour la situer davantage dans l'ordre juridique. Également on a sorti la relation et le lien entre pape et évêques des domaines de l'apostolicité. Ces problématiques demeurent encore présentes dans les débats eccésiologiques même vint-cinq années après Vatican II. 
"Si les évêques, ou plutôt les cardinaux, sont les Apôtres, le pape, lui, est le Christ. Le rapport classique, repris par Vatican II,

$\begin{array}{ccc}\text { Pierre } & = & \text { pape } \\ \text { autres Apôtres } & \text { l'ensemble des évêques }\end{array}$

tend à être remplacé, chez les plus curialistes (il y a de nombreux textes de ce genre) par le rapport

\begin{tabular}{ccc} 
Christ & $=$ & pape \\
\hline les Apôtres & les évêques
\end{tabular}

Une telle doctrine ne laisse guère de place à une authentique collégialité puisque c'est une théologie de monarchie pontificale. De plus, mettre en oeuvre comme titre du pape, celui de "vicaire du Christ" porte aussi à reconnaître à l'évêque de Rome un titre à être chef de l'Église indépendant et différent de son titre de chef du collège des pasteurs. Cette notion donne une ecclésiologie de l'Église universelle conçue comme "un unique peuple sous une unique tête" et contraire à celle de Vatican II. Dans la conception "grégorienne", le pape a une position venant d'une institution divine et il n'est plus un fidèle, un membre et donc une partie de l'ecclesia, soumis de droit évangélique à la correction de l'ecclesia (cf. Mt 18,18). À Vatican II, le pape a été remis dans l'ordre épiscopal, non au-dessus comme "vicaire du Christ" mais comme "le président du collège des évêques". Les évêques sont membres du collège dont le pape est le chef.

"Vatican II, nous l'avons vu, a lié la succession apostolique à la permanence de la mission donnée aux Douze, et pas à Pierre seul; il a situé la consécration épiscopale dans cette perspective, de telle sorte qu'en constituant chef d'une Église locale, elle fait entrer dans le corps qui a hérité de la mission totale du collège auquel Pierre préside. Dans la perspective de Vatican II, on ne peut pas dire que les évêques succèdent aux Apôtres sous 
la raison formelle de chefs d'Églises locales, à l'exclusion de celle du collège. On ne peut ni opposer, ni même séparer les deux. 33

Les évêques canadiens sont conscients des enjeux ecclésiologiques autour de la collégialité épiscopale:

"La façon dont sont vécues la collégialité et la communion au niveau suprême de l'Église déteint sur les modes de fonctionnement des Églises diocésaines et des communautés paroissiales et vice-versa." 34

"Il y a une analogie très profonde, entre la co-responsabilité dans l'Église et la collégialité des évêques avec le Pape." 35

Les bonnes volontés et les accusations mutuelles ne servent donc à rien tant qu'une nouvelle structure ne sera pas mise en place dans la ligne du modèle d'Église de sujets annoncé par Vatican II. Comment affirmer une égalité absolue dans l'Église sans en préciser les formes institutionnelles?

\subsection{La théologie conciliaire du laïcat est lacunaire}

Le Concile a beaucoup valorisé le rôle des laïcs dans l'Église. Les évêques québécois l'ont fait aussi abondamment.

"Une des suites les plus remarquables du Concile, en effet a été l'engagement de nombreux laïcs dans l'action pastorale de l'Église et dans le service du monde. Des hommes et des femmes ont reçu, comme un nouveau souffle, la réaffirmation par le Concile que l'Église est le Peuple de Dieu. Ils ont pris conscience de la grandeur de leur

Ibid, p. 140.

34 Rapport-synthèse de la CECC en vue de la préparation du Synode extraordinaire: "Diagnoctic sur la réception du concile Vatican II par l'Eglise canadienne", in Le Devoir, le 17 octobre 1985, p. A-5.

35 Mgr Bernard HUBERT a fait cette déclaration à un journaliste du journal Le Devoir. APRIL, Pierre, "Mgr Hubert se rend au Synode avec mandat de faire triompher la collégialité", in Le Devoir, 26 octobre 1985, p. A-7. 
baptême qui les rend participants de la fonction sacerdotale, prophétique et royale du Christ"36

\subsection{Aux clercs l'Église, aux laïcs le monde}

Quand le Concile parle des laïcs, il esquisse plus explicitement leur 'caractère séculier'.

"La caractère séculier est le caractère propre et particulier des laïcs /.../ La vocation propre des laïcs consiste à chercher le règne de Dieu précisément à travers la gérance des choses temporelles qu'ils ordonnent selon Dieu. Ils vivent au milieu du siècle, c'est-à-dire engagés dans les divers devoirs et travaux du monde, dans les conditions ordinaires de la vie familiale et sociale dont leur existence est comme tissée" $\left(L G \mathrm{n}^{\circ} 31\right)$.

La vocation des laïcs, dans la constitution dogmatique sur l'Église (Lumen Gentium) et également dans le décret sur l'apostolat des laïcs (Apostolicam Actuositatem) est la gérance des choses temporelles ("l'ad extra ") qu'ils ordonnent selon Dieu, mais non la gérance de l'Église (" l'ad intra "). Cette conception s'est malheureusement répandue dans les Églises locales.

"Curieusement, le Concile, et ce n'était sûrement pas son objectif, surtout si l'on pense à Gaudium et Spes, était surtout lu comme une invitation à donner une plus grande

HUBERT, Bernard Mgr, "Les ministères dans une Eglise-communion", in Église Canadienne, vol. 19, $\mathrm{n}^{\circ} 8,19$ décembre 1985, p.231. Je le répète. J'emploie l'expression "läic" parce qu'elle est employée dans les documents conciliaires. Par ailleurs, en fidélité aux profondes intuitions de Vatican II et du message du Nouveau Testament, il ne faut plus utiliser ce terme pour qualifier les croyants non-ordonnés. "Le Nouveau Testament ne connaît pas de laïcat mais un peuple, un peuple saint, un peuple élu, un peuple mis à part, un Kléros qui exerce tout entier un sacerdoce royal, appelant chacun de ses membres à rendre à Dieu un culte véritable en esprit /.../ le peuple vit collectivement sa vocation de croyant ..." (FAIVRE, Alexandre, Les laïcs aux origines de l'Église, Paris, Centurion, 1984, pp. 18-19.). "Le terme laïc vient du grec "laos" qui veut dire peuple /.../ I faut noter que, à l'origine, laïc est un terme emprunté au grec extra-biblique et même au langage cultuel grec pour classifier une partie du peuple par rapport à une autre..."(CHARRON, André, "Laïcs et clercs: des catégories à dépasser, voire à supprimer", in Cahiers d'Études Pastorales: Relations clercs-laïcs, Analyse d'une crise, ${ }^{\circ}{ }^{1}$, Montréal, Fides, 1985, pp. 148-150.). 
participation au laïcat dans la vie de l'Église, souvent au détriment de leur vocation première qui est d'être à l'oeuvre dans le monde."37

Un synode a été convoqué en 1989 pour réfléchir sur la vocation et la mission des laïcs dans l'Église et dans le monde. Dans l'exhortation apostolique post-synodale Christifideles Laici, Jean-Paul II réaffirme la spécificité du caractère séculier des laïcs.

\begin{abstract}
"En vertu de cette dignité baptismale commune, le fidèle laïc est co-responsable, avec tous les ministres ordonnés et avec les religieux et les religieuses, de la mission de l'Église. Mais cette dignité ecclésiale commune revêt chez le fidèle laïc une modalité qui le distingue, sans toutefois le séparer, du prêtre, du religieux, de la religieuse. Le Concile Vatican $I$ a indiqué que cette modalité se trouve dans le caractère séculier: "Le caractère séculier est le caractère propre et particulier des laïcs"( $L G 31)$ ". I.../ Ainsi, l'être et l'agir dans le monde sont pour les fidèles laïcs une réalité non seulement anthropologique et sociologique, mais encore et spécifiquement théologique et ecclésiale. Dans leur situation au milieu du monde, en effet, Dieu manifeste son dessein et leur communique leur vocation particulière de "chercher le règne de Dieu précisément à travers la gérance des choses temporelles qu'ils ordonnent selon Dieu." 38
\end{abstract}

Derrière cette conception, n'y-a-t-il pas cette idée: plus les laïcs sont présents au monde et moins ils sont encombrants dans la vie de l'Église, au niveau de la réflexion et des décisions ? "Les perspectives séduisantes de la transformation de l'ordre temporel comme charisme propre au laïcat ne doivent pas nous empêcher de voir les racines cléricales de ce modèle de réflexion: aux clercs l'Église, aux laïcs le monde."39 Dans

37

Le secrétariat de la CECC,"Vingt ans de promotion du laïcat en Église - synthèse des rapports des diocèses-", in Église Canadienne, vol.20, n8 ,18 décembre 1986, p. 237.

38 JEAN-PAUL II, Exhortation apostolique post-synodale Christifideles Laici (Les fidèles laïcs), Montréal, Fides, 1989, p.34; p.37. [L'Église aux quatre vents].

39 DUFOUR, Simon, PARENT, Rémi,"Structure institutionnelle de l'Église d'après Vatican II", in Des ministères nouveaux?, p.185. Voir aussi RIGAL, Jean, Le courage de la mission, pp.89-102. "Les mouvements d"'action catholique" ne furent pas tellement lancés pour promouvoir l'apostolat ou l'émancipation des laïcs, mais eurent pour but de redonner à la hiérarchie, grâce aux laïcs, une emprise sur tous les secteurs de la société, que la démocratie libérale avait abrogée. Dans cette intention, les laïcs reçurent de la hiérarchie un "mandat", une sorte de "missio canonica", ce qui suffit à montrer qu'il s'agissait bien du pouvoir du clergé: on concédait une participation active aux laïcs, afin de compenser les pertes d'influence subies par la hiérarchie du fait de la neutralisation libérale. La séparation de l'Église et de l'État avait en effet privé la hiérarchie de son pouvoir sur la société, en violent contraste avec sa puissance dans le passé"( SCHILLEBEECKX, E., L'histoire des hommes, récit de Dieu, p.311.). 
ce dualisme subtil où deux catégories de baptisés se font face, le "nous" des chrétiens ne peut émerger. Ce dualisme définit la spécificité des vocations et des ministères par une simple subdivision des tâches ou répartition des responsabilités. Les risques de ce bipartisme sont nombreux. Il fait passer les différences avant la priorité du peuple de Dieu en tant que tel. Il situe les chrétiens dans un "face-à-face" agressif et stérile. Il favorise une attitude de franc-tireur, en dehors d'une responsabilité ecclésiale. En effet, ce schéma binaire conduit à définir les deux termes (clerc-laïc) l'un par rapport à l'autre, et comme mode de répartition des tâches, voire d'exclusivité. C'est une perspective étroite et à saveur concurrentielle. De plus, le couple "clerc-laïc" contribue à entretenir une sorte de dichotomie entre vocation spirituelle et ecclésiale et vocation séculière. Mais nous l'avons vu au chapitre neuvième de la présente thèse sur la culture moderne, la vocation séculière, au coeur du monde, constitue la vocation globale du peuple de Dieu tout entier, soit de tous les baptisés, ministres ordonnés compris. La sécularité n'est pas d'abord le fait de ceux qu'on appelle malheureusement les "laïcs", elle constitue une dimension essentielle de la vocation baptismale. Vatican II n'a t-il pas souligné que la mission des prêtres appelle à "n'être séparés d'aucun homme quel qu'il soit.... et à vivre dans ce monde au milieu des hommes" ( $\left.\begin{array}{lll}P O & 3\end{array}\right)$ ? Avons-nous oublié cette affirmation conciliaire?

L'exhortation apostolique sur les fidèles laïcs va jusqu'à affirmer que les laïcs ne peuvent pas être appelés "pasteurs". Ils sont précieux par l'aide qu'ils peuvent offrir aux ministres ordonnés, véritables pasteurs de l'Église.

"En outre, lorsque la nécessité ou l'utilité de l'Église l'exigent, les pasteurs peuvent, selon les normes établies par le droit universel, confier aux fidèles laïcs certains offices et certaines fonctions qui, tout en étant liés à leur propre ministère de pasteurs, n'exigent pas cependant le caractère de l'Ordre (canon 230,3). Il faut remarquer toutefois que l'exercice d'une telle fonction ne fait pas du fidele laic un pasteur: en réalité, ce qui constitue le ministère, ce n'est pas l'activité en elle-même, mais l'ordination sacramentelle. Seul le sacrement de l'Ordre confère au ministère ordonné une participation particulière à la fonction du Christ Chef et Pasteur et à son sacerdoce éternel ( $P O 2$ et 5). La fonction 
exercée en tant que suppléant tire sa légitimité formellement et immédiatement de la délégation officielle reçue des pasteurs et, dans l'exercice concret de cette fonction, le suppléant est soumis à la direction de l'autorité ecclésiastique $\left(\begin{array}{lll}A A & 24\end{array}\right)$. /.../ Voyons de plus près la communion et la participation des fidèles laïcs à la vie des paroisses. Il faut rappeler à l'attention de tous les fidèles laïcs, hommes et femmes, une parole si vraie, si pleine de sens et stimulante, du Concile: "Dans les communautés ecclésiales, leur action est si nécessaire que, sans elle, l'apostolat des pasteurs ne peut la plupart du temps, obtenir son plein effet $(A A 10) . " 40$

Ceci est une preuve tangible des effets néfastes à long terme du fait que la participation du laïcat au triple ministère du Christ n'ait pas été décrite concrètement dans les textes conciliaires de Vatican II. L'activité apostolique éventuelle des laïcs est vue ainsi plutôt comme une aide en cas de nécessité qui peut être apportée quand les prêtres manquent.

\begin{abstract}
"Ainsi non seulement le laïc, dans la vue du Concile, apparaît comme un bouche-trou dans le domaine des tâches ecclésiales, mais c'est plutôt la théologie elle-même des laïcs dans les textes concilaires qui est lacunaire, en tout cas pour autant qu'il s'agit de la position ecclésiologique du laïc. Une Église, une communio, dans laquelle les laïcs sont vus uniquement comme des 'gardiens' passifs, se bouche son propre avenir. La communauté ecclésiale aussi, et elle précisément, ne peut pas prospérer sans la coopération active de tous les membres de l'Église. Le Concile n'a donc pas vu que la doctrine ecclésiale comme la structure ecclésiale sont des grandeurs correspondantes qui, sans l'accord et la coopération du 'nouveau peuple de Dieu', sont condamnés à une anémie silencieuse. Le concile n'a pas vu, ou du moins n'a vu qu'insuffisamment, la solidarité et même l'action réciproque entre le magisterium et le sensus fidelium ".41

"Les charismes des 'fidèles' ne sont pas seulement des charismes auxiliaires du ministère épiscopal, et l'intervention des laïcs ne peut se réduire à donner une aide à l'évêque (curé) pour qu'il remplisse mieux son ministère". 42
\end{abstract}

C'est donc pour cette raison que plusieurs laïcs engagés qui avaient ressenti une stimulation pour une activité paroissiale, par la valorisation de tous les membres de

60, p. 75.

Exhortation apostolique post-synodale Christifideles Laici (Les fidèles laïcs), pp. 59-

41

WALF, Knurt, "Lacunes et ambiguittés dans l'ecclésiologie de Vatican II", p.217. Il est évident que la théologie du laïcat est lacunaire dans les documents conciliaires. Cette insuffisance théologique ne doit pas toutefois nous empêcher de reconnaître le tournant majeur qu'a constitué Vatican II dans l'Église. Jamais dans l'histoire de l'Église un concile s'est intéressé autant à préciser la situation et la mission du laïc. Mais ce progrès ne doit pas non plus nous aveugler et nous faire croire qu'il n'y a plus de pas à faire pour une réelle responsabilité de tous les baptisés dans l'Église.

42 ACERBI, Antonio, "L'ecclésiologie à la base des institutions post-concilaires", in Les Eglises après Vatican II. Dynamisme et prospectives, p. 251. 
l'Église telle qu'elle fut affirmée au Concile, se sont depuis lors pour une bonne majorité sentis frustrés. 43 Ils se sont aperçus qu'un des problèmes les plus cruciaux dans l'Église était celui de la reconnaissance des charismes. Et cette reconnaissance touche directement leur dignité personnelle.

\begin{abstract}
"L'épiscopat français, après avoir identifié le sujet de la vie ecclésiale (chaque personne et chaque communauté), pouvait-il faire autrement que de confier à ce sujet la responsabilité de l'Église? En cela, il respecte simplement la logique d'un petit principe (dont la limpidité semble pourtant se brouiller assez vite quand il s'agit d'organiser l'Église d'une manière qui le respecte pleinement): on n'est pas le sujet de cela dont on n'est pas responsable. Il n'est pas vrai que chacun est Église si chacun n'est pas responsable de l'Église. Dès qu'on lance aux personnes et aux communautés: "L'Église, c'est vous" 44 , il faut aussitôt ajouter qu'elles sont responsables de l'Église, sinon, en leur enlevant leur responsabilité, c'est de leur être même qu'on les spolie." 45
\end{abstract}

L'organisation institutionnelle a privé de participation au gouvernement de l'Église ceux qui sont aussi l'Église: les laïcs. Beaucoup de laïcs se sont sentis appelés ces dernières années à innover, à créer de nouveaux modes de vivre-ensemble ecclésial. Presque toujours, ils se sont heurtés à un système en place... qui a la tête plus dure que la vie. Il existe donc une contradiction institutionnelle entre cet appel fondé sur la radicale dignité de tous dans l'Esprit $(L G 32)$ et la barrière mise à la participation à l'élaboration des décisions par l'appartenance à un 'ordre sacré' ( $L G 37$ ). Les laïcs peuvent être consultés mais ils ne peuvent prendre part au gouvernement. 46

43

De nombreuses données d'observation prouvent cette affirmation. Voir chapitre 4: Écoute des bénévoles et chapitre 5.1: Agents de pastorale laïques. La participation à quelques séminaires de recherche sur la paroisse en contexte américain à l'été 1992 au BOSTON COLLEGE m'a permis de constater que cette même problématique se retrouvait dans d'autres Églises diocésaines. Voir BAUSCH, William J., Ministry, traditions, tensions, transitions, Connecticut, Twenty-third publications, 1990, 176p.; RADEMACHER, William J., Lay ministry, a theological, spiritual and pastoral handbook, New York, Crossroad, 1991, 274p. 44

45 PARENT, Rémi, Prêtres et évêq
Paulines, 1992, p. 166. [Brèches théologiques].

Jean-Paul II, au stade olympique de Montréal, lors de sa visite de 1984.

46 La plus belle preuve est que même le Conseil pontifical pour les laïcs demeure très largement aux mains des clercs qui détiennent les postes clés du secrétariat et appellent au Conseil les 
"Les "laïcs" sont fort bien capables de comprendre qu'il existe des conflits qui ne sont pas de nature peccamineuse mais qui proviennent de différences de vue et d'une autre manière de "peser" l'histoire du salut, par exemple lorsqu'il s'agit, d'une part, des besoins pastoraux du peuple et, d'autre part, des intérêts propres des organismes hiérarchiques. Il n'en est pas tenu compte dans la pratique. Cette manière de bagatelliser ou de ramener au péché tout conflit dans l'Église situe la hiérarchie dans une zone d'intouchabilité, à l'abri des tempêtes. L'Église est perçue comme une societas perfecta, accomplissement du Royaume de Dieu sous la houlette du vicaire du Christ, tandis que du côté des fidèles la seule attitude qui convienne est celle d'une obeissance docile. Vue dans cette perspective hiérarchique, tant que le peuple obéit, l'Église est sans histoire. Si conflit il y a, il ne peut que faire partie de l'histoire de l'humanité pécheresse des croyants. Une telle conception de l'Église n'est pas un simple point de vue; dans maint diocèse elle est pratiquée par la hiérarchie, avec pour conséquence que beaucoup de fidèles ont "mal à leur Église". /.../ Quand la hiérarchie et les fidèles prennent des chemins divergents, les dirigeants oublient fréquemment que ces fideles n'agissent ainsi, le plus souvent, que mus par un profond souci évangélique et pour le bien de l'Église." 47

\subsubsection{Un scandale évangélique: la place réservée aux femmes dans l'Église}

Le scandale le plus visible est que la moitié des chrétiens, les femmes, n'ont aucun droit à participer au gouvernement de l'Église: elles sont exilées du 'pouvoir' par la non-possibilité pour elles d'être ministres en vertu de leur sexe !

Pourtant, ce sont elles qui dans une proportion de plus de $80 \%$ exercent le bénévolat dans les paroisses. À cet égard, l'AEQ (l'Assemblée des Évêques du Québec) semble plus sensibilisée sur cette problématique que d'autres épiscopats. Les membres de leur comité des ministères ont bien nommé cet enjeu ecclésial dans un document de réflexion sur les nouvelles pratiques ministérielles:

"Parmi les laïcs qui se voient confier des responsabilités croissantes dans la vie ecclésiale, il y a une majorité de femmes. Elles sont dans tous les secteurs d'activités: catéchèse d'initiation, animation liturgique, pastorale des malades, conseil paroissial,

membres de leurs choix, entre autres ces dernières années, plusieurs sont recrutés au sein de l'Opus Dei. Voir MONNOT, Patrice, "Les laïcs et le pouvoir de gouvernement au sein de la curie romaine", in Praxis juridique et religion, $\mathrm{n}^{\circ} 3$, Cerdic, 1986, pp.173-184. 
conseils et cadres diocésains, etc. Certes, la pleine reconnaissance du rôle des femmes est loin d'être acquise. Mais leur participation en nombre fait surgir une question déterminante pour l'avenir des ministères: ne marchons-nous pas vers une nouvelle division d'Église, une Église exclusivement masculine dans sa hiérarchie et de plus en plus féminine dans ses services quotidiens? Dans un temps où les femmes prennent une part de plus en plus active à toute la vie sociale, les ministères ecclésiaux risquent de perdre beaucoup de visibilité et de crédibilité si l'on ne recherche pas un meilleur équilibre dans la représentation homme/femme." 48

\section{Les membres de ce comité invitent ainsi l'autorité pastorale québécoise à poursuivre} ardemment son questionnement concernant la présence des femmes au coeur de l'Église.

"Mais, plusieurs questions, posées plus ou moins largement dans l'Église, piétinent sans trouver d'issue. Il en va ainsi de domaines comme l'ordination au presbytérat d'hommes mariés, coexistant avec des prêtres célibataires, l'ordination des femmes au diaconat et au presbytérat éventuellement, la véritable reconnaissance de ministères laïques conférés à des femmes et à des hommes. L'autorité pastorale peut difficilement refuser de se poser ces questions alors qu'elles sont présentes à l'esprit des croyants et dans de larges secteurs de la société contemporaine." 49

À l'occasion de la visite ad limina 1993, les évêques du Québec ont fait part à la curie romaine de leurs efforts pour promouvoir le partenariat hommes-femmes en Église. Ces efforts ont été concrétisés par leur Comité des affaires sociales qui ont organisé des forums diocésains sur ce sujet.

"Comme contribution à l'apprentissage de la collaboration entre hommes et femmes dans l'Église, le Comité des affaires sociales a fait la promotion de forums sur le partenariat hommes-femmes en Église. Hommes et femmes, prêtres et laïcs, y sont invités à se

Comité des ministères de l'Assemblée des évêques du Québec, Les nouvelles pratiques ministérielles, document de réflexion, Montréal, Fides, 1993, p. 92.

49 Comité des ministères de l'Assemblée des évêques du Québec, Communautés et ministères au Québec: Situation, questions, défis, Montréal, Fides, 1993, p. 33. "Plus de trois quarts (77 p. cent) des Québécois sont en faveur de l'ordination des femmes à la prêtrise /.../ Selon un sondage réalisé par la maison de recherche SOM pour le compte de La Presse et de TVA, l'appui de la population québécoise à l'ordination des femmes est aussi prononcé chez les hommes que chez les femmes" (BÉLIVEAU, Jules, "Oui massif des Québécois au sacerdoce des femmes", in La Presse, 3 avril 1993, p. A.1). 
sensibiliser aux obstacles qui se dressent pour vivre un partenariat véritable, à identifier ce qu'il y a de positif dans cette nouvelle façon de réaliser la communion et la coresponsabilité et à ouvrir de nouvelles voies pour rendre plus fructueuse la collaboration hommes-femmes en Église. Un bilan établi à la fin de l'année 1989-1990 permet de constater que 26 de ces forums se sont tenus dans 17 diocèses au bénéfice de quelque 1000 participants et participantes." 50

Il est intéressant que les évêques québécois aient trouvé important de partager aux "confrères" romains leur désir d'encourager le partenariat hommes-femmes en Église. Mais comme le rappelle Yvonne BERGERON, ces forums ont été précieux mais la condition des femmes dans l'Église demeure encore inchangée dans sa traduction institutionnelle.

\begin{abstract}
"N'est-ce pas d'ailleurs cette problématique de flottement qui ressort du vécu exprimé lors des Forums diocésains sur le partenariat hommes-femmes? Oui, en nombre croissant, les femmes s'engagent dans leur communauté chrétienne et plusieurs occupent des postes d'animation ou de responsabilité soit au plan paroissial ou diocésain, soit dans les zones ou en région, dans les écoles ou les mouvements. Oui, elles peuvent influencer des décisions et compter sur la solidarité de certains hommes, clercs et laïcs, qui cherchent à vivre les rapports de partenariat. Oui, l'Église elle aussi a été influencée par le mouvement des femmes dans la société et questionnée par son analyse. Bref, oui, la réflexion est amorcée et il y a des acquis. Mais la condition ecclésiale des femmes demeure inchangée dans sa traduction institutionnelle. Quant à la reconnaissance concrète du partenariat au coeur des pratiques quotidiennes, on en est encore loin. Comme on est loin aussi d'une égalité à tous les plans et d'un réel partage des responsabilités. La plupart des femmes oeuvrent dans des tâches de service et elles sont souvent considérées comme des suppléantes aux prêtres - sans les avantages ni la reconnaissance - ou comme des aides précieuses et discrètes par surcrôit." 51
\end{abstract}

50

L'ASSEMBLÉE DES ÉVÊQUES DU QUÉBEC, L'Église du Québec 1988-1993, à l'occasion de la visite ad limina 1993, les évêques du Québec font le bilan de la situation, Montréal, Fides, 1993, p. 73.

51 BERGERON, Yvonne, Partenaires en Église, femmes et hommes à part égale, Montréal, Paulines, 1991, pp. 19-20. "Les décisions importantes dans l'Église ont toujours été le monopole des hommes /.../ la question de la présence des femmes est souvent liée à la question de la sexualité et il y a encore une peur des femmes au niveau du fonctionnement. Il y a des résistances à trois niveaux: le fonctionnement, le niveau structurel (le droit canon, la réglementation) et le troisième, la justification théologique. On ne se défait pas du jour au lendemain d'un système patriarcal"(BERGERON, Yvonne, "Les prêtres craignent de perdre le pouvoir", entrevue à CHARETTE, Donald, in Le Soleil, 15 novembre 1992, p. A-9.). "Selon moi, il existe un lien étroit entre la sexualité enserrée dans le seule fécondité, réglementée, et un type d'institution patriarcal" (DE LOCHT, Pierre, entrevue avec GUETNY, Jean-Pierre, in L'Actualité Religieuse dans le Monde, $\mathrm{n}^{\circ}$ 115,15 octobre 1993 , p. 44.). 
Il demeure inquiétant de ne pas retrouver dans le rapport de la visite ad limina 1993 le questionnement plus explicite de l'épiscopat québécois sur l'accession des femmes au ministère presbytéral. Mais Jean-Paul II sait bien que la question de l'ordination des femmes est toujours présente dans l'Église du Québec. Ce n'est pas par hasard que, dans son discours adressé aux évêques québécois lors de cette visite "ad limina Apostolorum", il a abordé directement le sujet.

\begin{abstract}
"En particulier, je pense aux questions posées sur l'état de vie et la personne des ministres ordonnés: L'Église-Épouse est fidèle à son Seigneur en appelant au sacerdoce des hommes destinés à être personnellement, par un don total et plénier, des signes du Fils de Dieu incarné. Elle n'éprouve pas pour autant, vous le savez bien, aucune réticence à l'égard des femmes; même si elle "ne se considère pas autorisée à admettre les femmes à l'ordination sacerdotale", elle reconnaît la grande importance de leur participation à la vie de la communauté, notamment par l'exercice de responsabilités significatives, comme celles dont vous les chargez de plus en plus fréquemment, avec une confiance bien normale et dans le respect de "la mission respective de l'homme et de la femme" (Déclaration Inter insigniores, 15 octobre 1976)." 52
\end{abstract}

\title{
52
}

JEAN-PAUL II, "Le Pape reçoit les Évêques du Québec", in L'Osservatore Romano, $\mathrm{n}^{\circ}$ 19, 11 mai 1993, p.2. Les assemblées épiscopales ne doivent pas négliger de rappeler constamment à la curie romaine la question de l'accession des femmes et des hommes mariés au presbytérat. Il devient de plus en plus urgent de le faire dans un contexte ecclésial où le pape JeanPaul II durcit ses positions sur ce sujet. Nous en avons eu une autre preuve lors du synode de 1989 sur les "fidèles laïcs" lorsque celui-ci a déclaré: "Sans être appelées à l'apostolat propre aux Douze, et donc au sacerdoce ministériel, beaucoup de femmes accompagnent Jésus dans son ministère et assistent le groupe des Apôtres (cf. Lc 8,23)... /.../ Dans le participation à la vie et à la mission de l'Église, la femme ne peut recevoir le sacrement de l'Ordre, et donc ne peut remplir les fonctions propres du sacerdoce ministériel. C'est là une disposition que l'Église a toujours reconnu dans la volonté précise, totalement libre et souveraine, de Jésus-Christ qui a appelé des hommes seulement à être ses Apôtres; c'est une disposition qui peut s'éclairer par le rapport entre le Christ Époux et l'Église son Épouse. Nous sommes dans le concept de la fonction, non de la dignité et de la sainteté. On doit, en fait, affirmer: Même si l'Église possède une structure "hiérarchique", cette structure est cependant totalement ordonnée à la sainteté des membres du Christ" (JEAN-PAUL II, Exhortation apostolique post-synodale Christifideles Laici (Les fidèles laïcs), p.148; pp. 154-155. [L'Église aux quatre vents]); Voir aussi CONGRÉGATION POUR LA DOCTRINE DE LA FOI, Déclaration sur la question de l'admission des femmes au sacerdoce ministériel Inter insigniores, 15 octobre 1976: AAS 69 (1977), pp. 98-116. ; JEAN-PAUL II, Lettre Ap. Mulieris dignitatem, 26-27. Dans le récent catéchisme de l'Eglise catholique, c'est encore cette même conception qui a été proclamée encore avec plus de fermeté. "Qui peut recevoir ce sacrement? Seul un homme (vir) baptisé reçoit validement l'ordination sacrée. Le Seigneur Jésus a choisi des hommes (viri) pour former le collège des douze apôtres, et les apôtres ont fait de même lorsqu'ils ont choisi les collaborateurs qui les succéderaient dans leur tâche. Le collège des évêques, avec qui les prêtres sont unis dans le sacerdoce 
Le 30 mai 1994, pour une énième fois, mais de façon plus catégorique, sur un ton sans appel, Jean-Paul II a redit non, non et non à l'ordination presbytérale des femmes. "Je déclare, en vertu de ma mission de confirmer mes frères, que l'Église n'a en aucune manière le pouvoir de conférer l'ordination sacerdotale à des femmes et que cette position doit être définitivement tenue par tous les fidèles de l'Église" 53 souligne le pape dans une courte lettre apostolique intitulée "Ordinatio sacerdotalis " (L'ordination sacerdotale ). Selon lui, cette position est définitive mais je crois que la question de l'ordination des femmes ressurgira prochainement dans l'Église. La problématique sera soulevée sans aucun doute lors du synode à Rome sur le thème de la vie religieuse en octobre 1994.

Le précédent chapitre sur les réseaux d'incarnation du christianisme dans le Nouveau Testament a démontré qu'il n'est plus possible d'accepter cette conception traditionnelle. Plusieurs recherches théologiques et exégétiques actuelles encouragent l'ordination des personnes mariées et des femmes en fidélité au message évangélique. ${ }^{54}$ Henri DENIS croit que rien ne s'oppose doctrinalement à l'accession au presbytérat pour les femmes et les hommes mariés. Il mentionne de plus que l'Église

rend présent et actualise jusqu'au retour du Christ le collège des douze. L'Église se reconnaît liée par ce choix du Seigneur lui-même. C'est pourquoi l'ordination des femmes n'est pas possible. ( ${ }^{\circ}$ 1577)" (JEAN-PAUL II, Catéchisme de l'Église Catholique, Paris, Mame/Plon, 1992, p.336.). Pour Jean-Paul II, l'Église est l'incarnation directe de la volonté du Christ. À tel point que lui-même ne se sent pas autorisé de modifier les formes voulues par son fondateur.

53 CITÉ DU VATICAN (Reuter), "Les femmes et le sacerdoce", in Le Quotidien, 31 mai 1994, p. 5.

$54 \quad$ Je crois de plus en plus que les résistances à l'accession des femmes et des hommes mariés au presbytérat sont moins d'ordre théologique que d'ordre de la dimension psycho-affective des individus. Si nous désirons que l'ordination des femmes et des hommes mariés deviennent possible dans l'Église, va-t-il falloir que des évêques s'autorisent à en ordonner même sans l'approbation du Pape? Celui-ci pourrait peut-être par la suite les accepter comme il l'a fait pour les prêtres de l'Armée de Marie... C'est la seule solution que je trouve pour l'instant pour vaincre les peurs de certains "ecclésiastiques" envers les femmes. Suis-je trop naîf? Peut-être! Mais la foi est impossible sans une bonne dose de naïveté... 
ne peut défendre socialement les valeurs de la démocratie ("liberté, égalité, fraternité") sans que celles-ci atteignent l'institution ecclésiale dans son organisation interne.

\begin{abstract}
"À propos des ministères, nous devons aborder la question de l'ordination des personnes mariés et des femmes. Au milieu de toutes les recherches et réflexions de ces dernières années, on peut dire que rien ne s'oppose doctrinalement à ces deux éventualités. /... on peut affirmer que les Églises (comme certaines l'ont déjà fait) seront amenées à prendre de telles décisions, en raison des impératifs de la Mission. /.../ La liberté, le droit à la recherche, la dignité de la femme, la nécessité de pratiques démocratiques ne pourront pas rester des obligations proclamées par l'Église pour la cité des hommes, sans provoquer aussi une réforme au-dedans d'elle." 55
\end{abstract}

Edward SCHILLEBEECKX demande à l'Église officielle de permettre aux femmes, sujettes actives de la foi et du devenir ecclésial, d'accéder aux fonctions ministérielles. L'Église doit demeurer ouverte pour entendre la voix des femmes qui désirent collaborer à la mission du Royaume de Dieu par le moyen d'une plus grande symphonie ministérielle dans l'Église.

"... je veux aussi citer la plainte (mesurée) des femmes, qui, s'achève dans une prise de conscience croyante d'être elles aussi sujettes actives de la foi et du devenir de l'Église. /.../ Elles luttent contre le patriarcalisme en tant que système socio-culturel de domination qui s'exerce à des degrés divers, à tous les niveaux, et qui a rendu la femme soumise et sans voix. Cette femme "sans voix" parvient à présent (tout au moins dans les pays developpés) à faire entendre sa propre voix; le silence est rompu, définitivement. /../ Les femmes revendiquent leur droit de naissance chrétien ( en vertu du baptême de l'Esprit): leur droit d'être, en tant que femmes, l'Église, c'est-à-dire des sujets capables, responsables de la foi, de l'expression de la foi. L'accès à une fonction dirigeante dans l'Église, y compris aux fonctions ministérielles, doit leur être alors logiquement reconnu." 56

Le "théologien-bombe" Eugen DREWERMANN est sévère envers l'Église officielle qui refuse l'ordination presbytérale aux femmes. Il croit que cela constitue une double

DENIS, Henri, L'Église, Les quatre portes du Temple, p. 120; p. 88. SCHILLEBEECKX, E., Plaidoyer pour le peuple de Dieu, p.263; p. 265. 
injustice. Il qualifie d'absurde la position théologique sur laquelle on fonde la nonpossibilité des femmes d'accéder à une fonction dirigeante dans l'Église.

"L'Église commet une double injustice, tout d'abord en refusant aux femmes le droit d'exercer le ministère sacerdotal, et ensuite en faisant croire qu'elles sont psychiquement trop différentes des prêtres pour assurer une telle fonction. /.../ L'idée qu'il y aurait dans l'Église ou la société des tâches qui ne pourraient être accomplies que par des hommes ou que par des femmes (mis à part l'enfantement) devient de plus en plus absurde: que l'Église se cramponne au principe selon lequel seuls des hommes peuvent être prêtres est dejà aujourd'hui un anachronisme manifeste." 57

La théologienne québécoise Yvonne BERGERON nous invite à garder une espérance "têtue" en continuant les luttes pour dénoncer un système de pensée considéré comme voulu par Dieu et pour révéler aux communautés croyantes les nouvelles perspectives théologiques et exégétiques sur cette question.

\begin{abstract}
"À ce niveau, les changements risquent d'être lents à venir mais ils sont fondamentaux. Pour y arriver, nous devrons à la fois "révéler" (à ceux et celles qui l'ignorent) et dénoncer un système qui est encore considéré par plusieurs comme immuable, inattaquable, sacré car, prétend-on, sa légitimité serait fondée sur le bon vouloir de Dieu. Système à désarticuler au plus tôt en référence à la liberté de l'Esprit. Beaucoup de chemin reste à parcourir et il n'existe pas de voies d'accès permettant aux femmes de porter leur questionnement, leur expérience et leur discours là où se formule la doctrine et où se prennent les décisions. Mais l'expérience est forte. Et têtue." 58
\end{abstract}

Nous devons nous laisser interpeller par l'admission des femmes à la prêtrise par l'Église anglicane. En 1991, la revue Oecuménisme a publié une déclaration du comité du Dialogue anglican-catholique romain du Canada sur l'expérience des femmes au Canada. ${ }^{59}$ Quatre éléments caractérisent cette déclaration. D'abord, elle jette un regard

57 DREWERMANN, Eugen, Les fonctionnaires de Dieu, p.83; p. 639.

58 BERGERON, Yvonne, Partenaires en Églises....., pp. 92-93. Voir aussi PARENT, R., Prêtres et évêques, pp. 231-246. Rémi PARENT réfléchit avec rigueur sur cette problématique concernant les femmes et le ministère ordonné dans le présent volume.

59 Voir LE CENTRE CANADIEN D'OECUMÉNISME, "Déclaration du Dialogue anglican-catholique romain du Canada sur l'expérience du ministère des femmes au Canada", in Oecuménisme, $\mathrm{n}^{\circ} 103$, septembre 1991, pp. 4-25. 
généreux sur la situation des femmes au Canada et sur les contributions riches et variées de leurs ministères faites aux Églises à travers l'histoire canadienne. Deuxièmement, elle cerne la question de l'ordination des femmes dans un très large cadre de travail. Troisièmement, la déclaration pose d'importantes et difficiles questions auxquelles doivent répondre à la fois, les promoteurs de l'ordination des femmes tout comme ses opposants: aucune des deux pratiques n'échappe à la critique. Finalement, la Déclaration soutient que la "question de l'ordination des femmes doit être traitée comme une question disputée au sujet de l'inculturation de l'Évangile"60.

"Les chrétiens du Canada ressentent comme étranger ou injuste tout manquement perçu dans l'Église à célébrer et à favoriser l'égalité des femmes dans le Christ. L'archevêque de Québec, Louis-Albert Vachon (maintenant retraité) a reflété le point de vue prévalant dans nos Églises quand il a dit, à titre de délégué des évêques catholiques romains au Synode des évêques de 1983: "les appels de l'Église au monde pour la promotion des femmes n'auront bientôt plus d'impact, si ne se réalise parallèlement à l'intérieur de l'Église la reconnaissance effective des femmes comme membres à part entière"[VACHON, Louis-Albert, "La réconciliation hommes et femmes dans l'Église", in L'Église canadienne, 20 octobre 1983, p. 101.]."61

Plusieurs catholiques romains et anglicans voient donc dans le refus d'ordonner des femmes, une négation de la pleine égalité des femmes et des hommes dans le Christ. Ils craignent que ce refus ne soit basé sur des stéréotypes culturels tirés de la culture gréco-romaine au sujet des hommes et des femmes. La tradition chrétienne en aurait hérité en quelque sorte sans y réfléchir plutôt qu'après un réel discernement sur les exigences de l'Évangile. savons que ce Synode sur le laïcat n'est pas le lieu de traiter expressément de la question de l'ordination des femmes. Mais nous ne pouvons pas ne pas souligner dans cette assemblée, que les arguments utilisés jusqu'ici pour réserver le ministère ordonnés aux hommes arrivent mal à convaincre les jeunes notamment"(HAMELIN, Jean-Guy, "La participation des femmes à la vie de l'Église", Synode des évêques, Rome, 9 octobre 1987.). 
"Quand les femmes assument un nombre croissant de ministères au sein de notre Communion, pour l'amour de l'Évangile, il devient difficile d'expliquer pourquoi elles devraient être tenues en dehors de ce seul ministère - surtout quand la pénurie de ministres ordonnés, la sensibilité culturelle à l'égalité des femmes, les discussions théologiques au sujet des femmes, l'expérience positive des anglicans et des autres Églises qui ordonnent des femmes, et l'impression de faire scandale en n'ordonnant pas les femmes - tout cela questionne et demande si l'Esprit-Saint peut nous mener à une nouvelle inculturation de l'Évangile en ce milieu. L'urgence avec laquelle la question est perçue au Canada nous amène à penser que cette question peut être un signe des temps ayant une signification pour tout l'Église, qui reconnaît que la "diversité de moeurs et de coutumes ajoute seulement à la beauté de l'Église et contribue grandement à l'accomplissement de sa mission"[ CECC, "Réponse de la Conférence des évêques catholiques du Canada au Rapport final d'ARCIC I", in Oecuménisme, n88, décembre 1987, p.15]."62

À celui ou celle qui se permet une critique contre l'Église, on répond que l'Église, c'est lui ou elle, que "nous" sommes "tous et toutes" l'Église, et qu'il n'y a pas d'autre Église. Excellente intention que celle d'encourager tout le monde à prendre ainsi en charge la vie de la communauté. Depuis le deuxième concile du Vatican, on a mis l'accent sur la "participation des laïcs". Mais ce terme même traduit déjà un courant de pensée sous-jacent, celui qui s'est imposé au cours de l'histoire: les véritables acteurs, les "ouvriers" de la moisson du Seigneur (Jn 4,35-38), ce ne sont pas les laïcs, ce sont les non-laïcs, autrement dit les clercs. C'est chez eux qu'il faut chercher les "spécialistes" du message chrétien, les dispensateurs de la parole et des sacrements. Nous constatons donc que l'aménagement du vivre-ensemble des chrétiens selon le modèle de la communion implique encore aujourd'hui des changements majeurs dans l'organisation de l'Église. Nous ne sommes pas encore arrivés à cette ecclésiologie trinitaire. Celle-ci appelant les Églises particulières à agir en partenaires responsables les unes et les autres, et toutes ensemble de l'Église et de sa mission dans le monde. L'ecclésiologie de communion étant aussi une invitation à mieux articuler la responsabilité globale du peuple chrétien. L'avènement de l'Église-communion ne peut se faire sans une diversification de la structure ministérielle. Cela exige que l'on passe 
concrètement d'une concentration des responsabilités entre les mains de quelques-uns à une multiplicité de services assumés par des chrétiens. Cette évolution n'est possible que si, dans la réflexion comme dans la pratique, on substitue au modèle pyramidal ou dualiste, le modèle de communion où le peuple de Dieu apparaît comme la réalité enveloppante à l'intérieur et au service de laquelle se situent les différents ministères. À la lumière de cette ecclésiologie trinitaire qui met en relief le "nous" des chrétiens, le binôme "communauté -charismes et ministères" ne se réduit pas à un simple déplacement d'accent ou, à plus forte raison, à une question de vocabulaire. Il reflète, au contraire, un tournant radical qu'il faut opérer dans la conception et la vie de l'Église. Tout cela constitue encore tout un programme! La paroisse sera toujours un lieu privilégié pour vérifier les avancés ou les reculs d'une réforme institutionnelle. Même Jean-Paul II l'a reconnu en déclarant: "Les paroisses sont des points de repères indispensables, des signes de l'action du Seigneur dans son peuple."63 Et n'a-t-il pas déjà lui-même déclaré aux représentants des paroisses à Utrecht:

"...tous sont appelés lorsqu'ils s'agit de construire la vie d'une paroisse. Les laïcs ne sont pas de simples récepteurs, l'objet de soins pastoraux. Sur la base de leur vocation de chrétiens, ils doivent être les co-auteurs de l'Église. Tous sont appelés à témoigner de l'Esprit qui leur a été accordé selon leurs talents et leurs capacités." 64

J'ai encore de la difficulté à comprendre pourquoi Jean-Paul II considère les laïcs comme étant des "co-auteurs" de l'Église et en même temps, il ne cesse de rappeler leur vocation plus particulière dans le monde vu leur caractère séculier. Jean-Paul II est paradoxal dans sa pensée. Plusieurs aspects différents dans sa conception de l'Église ne sont pas toujours bien conjugués. Ce n'est pas étonnant que nous retrouvions le

63 JEAN-PAUL II, "Vie diocésaine et vie paroissiale, discours aux évêques français de la région sud-ouest", in La Documentation catholique, \#2046, 15 mars 1992, p. 259.

64 JEAN-PAUL II, "Construisez la maison de tous les disciples du Christ", Allocution aux représentants des paroisses à Utrecht, in La Documentation Catholique, $\mathrm{n}^{\circ} 1898,16$ juin 1985, p. 632 . 
paradoxe chez lui puisque la vision paradoxale de la réalité est présente chez tout être humain "faillible".

\title{
11.4. Le prêtre. un frère (une soeur!) dans la foi
}

L'ecclésiologie trinitaire définie au dernier Concile nous a permis de passer lentement à une conception renouvelée du ministère ordonné. De toute façon, pouvons-nous aller d'une Église de sujets-objets à une Église de sujets sans remettre en cause la conception du ministère ordonné?

\begin{abstract}
"C'est peut-être ce que Mgr Damert BELLIDO (Pérou) a pressenti lorsqu'au cours d'une session plénière il s'exprima comme suit au sujet de la prêtrise: "Toute tentative de transformer une infrastructure (il s'agit de la prêtrise) au sein d'une structure plus vaste (l'Église), sans changer cette dernière est une utopie." Il aurait pu préciser: c'est une idéologie." 65
\end{abstract}

Des mécanismes se sont mis en place qui ont changé petit à petit la représentation du rôle des ministres ordonnés et la manière de vivre leur ministère. À Vatican II, la théologie du presbytérat a évolué de celle du pouvoir à celle du service. Mais "quelles implications une telle substitution suggère-t-elle? Cette interrogation doit nous poursuivre, car on peut avoir un vocabulaire de service et des comportements de pouvoir." 66

\subsubsection{La théologie du presbytérat de Trente à Vatican II}

De la comparaison entre les perspectives du Concile de Trente et de Vatican II concernant la théologie du presbytérat, Henri DENIS, dans un excellent article, 
dégage plusieurs aspects. $67 \mathrm{~J}$ 'en reprends quelques-uns en les enrichissant toutefois de la réflexion théologique d'autres penseurs sur ce sujet. Le point commun fondamental entre les deux Conciles est l'affirmation du presbytérat comme sacrement. On constate que Trente comme Vatican II présentent le sacrement du presbytérat comme le don d'une grâce. La primauté du don de Dieu domine ainsi dans l'enseignement des deux Conciles.

\begin{abstract}
"Ce n'est pas en raison d'un vouloir personnel, mais par la grâce de la communauté croyante et d'un don charismatique de Dieu qui tous deux dépassent sa personne, que le prêtre est effectivement tenu à servir ses frères et soeurs, au sein de la communauté chrétienne, en raison de sa mission dans le monde. "68
\end{abstract}

Il est important d'observer le vocabulaire employé par les deux Conciles pour parler du prêtre. Le Concile de Trente a intitulé le document de la session XXFI: Doctrina de sacramento Ordinis. Le Concile de Vatican II donne comme titre au chapitre 1 du Décret: Presbyteratus in missione ecclesiae. Quand on sait, en outre, que le point de vue du Concile de Trente imposera le plus souvent l'usage du mot sacerdos plutôt que presbyter, ou celui du mot sacerdotium plutôt que presbyteratus, on comprendra qu'il s'agit là d'autre chose que d'une question de pur vocabulaire.

Le point de départ de Trente concernant la finalité du ministère ordonné est eucharistique et sacrificiel.

"Il y a un sacrifice unique du Christ; ce sacrifice est rendu visible dans l'Église; or, comme il y a un lien intime et voulu par Dieu entre sacerdoce et sacrifice, il faut qu'il existe un sacerdoce visible et externe: c'est le sacerdoce des prêtres de la Nouvelle Alliance." 69 II, Les prêtres, Formation, Ministères et Vie, Paris, Cerf, 1968, pp. 206-232. [Unam Sanctam \#68]. 
L'insistance est mise sur la visibilité du sacrifice de la messe, les autres aspects du ministère passent au second plan. Le point de vue de Vatican II est nettement renouvelé par rapport à celui de Trente. Au lieu de se baser premièrement sur l'Eucharistie, le Décret conciliaire prend son point de départ dans la mission du Peuple de Dieu tout entier. Vatican II choisit de partir du Peuple de Dieu, c'est-à-dire de l'Église, et non pas d'une relation entre le Christ et le prêtre définie par un pouvoir. Ce Concile reconnaît implicitement que le sacerdoce baptismal est premier dans l'ordre ontologique et que l'on doit présenter l'oeuvre des ministres ordonnés à l'intérieur de ce peuple sacerdotal. C'est la réalité de la mission qui sera la base de l'intelligence du ministère dans l'Église.

"À Trente, les fonctions sacerdotales sont déterminées par leur aspect cultuel et il n'est pas dit un trâtre mot de la prédication et de l'enseignement, tâches qui, tant dans l'Écriture que dans l'Église ancienne, marquaient si fortement l'image ecclésiale des ministères. De même le sacerdoce collectif des croyants, dont les théologiens et les évêques avaient si abondamment parlé pendant les deux premières sessions, est passé sous silence dans la version finale des canons /.../ Sous la pression de circonstances politiques, le chapitre concernant le sacrement de l'Ordre fut hâtivement rédigé au Concile de Trente /... Ainsi, tout l'accent est mis sur le pouvoir qu'a le prêtre de consacrer et d'absoudre; sa fonction de prédication disparait à l'arrière-plan /.../ Une conception théologique étroite du prêtre va ainsi se perpétuer durant les générations suivantes." 70

À Trente, on ne pose donc pas la question du sens de l'institution du presbytérat à partir du Peuple de Dieu. La justification théologique du sacrement de l'Ordre est purement eucharistique. Le prêtre est celui qui a reçu le pouvoir (sous-entendu: que n'ont pas les laïcs) de célébrer l'Eucharistie et de remettre les péchés. Son pouvoir clérical mettait alors en oeuvre une logique du besoin. Les laïcs avaient besoin des clercs parce que ceux-ci possédaient quelque chose que les premiers n'avaient pas. l'image tridentine du prêtre sera nourrie par la spiritualité sacerdotale de l'École française (XVI ${ }^{\circ} \mathrm{s}$.). L'École française fait du prêtre un "médiateur entre Dieu et les hommes", un "alter Christus" ( un autre Christ). 
L'ordination sacerdotale rendait les clercs capables de donner aux laïcs une réalité qui leur manquait.

À Vatican II, la raison d'être de l'Institution du presbytérat est à chercher à l'intérieur du sacerdoce commun des fidèles ou encore à l'intérieur d'un unique Corps diversifié dans ses membres. Pour que toute l'Église puisse participer en corps à la mission de son chef (Jésus le Christ), il faut que des humains soient à leur tour envoyés et consacrés. De plus, la perspective est beaucoup plus large et, du même coup, elle se trouve rectifiée. Les fonctions du prêtre ne sont pas limitées à la célébration de la messe et à l'absolution des péchés. La fonction de l'annonce de la Parole sera présentée en premier. En second lieu, vient la fonction sacramentelle. Enfin, la troisième est la fonction du gouvernement.

"Vatican II a fait une première tentative, encore bien hésitante de compromis entre les deux conceptions en soulignant d'une part la riche plénitude du charisme spirituel reçu au baptême, en décrivant d'autre part le ministère ecclésial non seulement en termes sacerdotaux mais aussi en termes pastoraux et prophétiques: direction de la communauté (fonction pastorale), office divin (fonction sacerdotale), prédication évangélique (fonction prophétique) [LG 31 et 36]. /.../ À Vatican II, un déplacement complet de la problématique du sacerdoce s'est manifesté. Au deuxième Concile du Vatican il s'agissait de revaloriser le prêtre en tant que héraut de la Parole et stimulateur-dirigeant de l'édification de la communauté face, à l'accent exclusif par Trente sur l'activité cultuelle sacrale du prêtre." 71

À Vatican II, le presbytérat est ainsi conçu moins comme un pouvoir sur le corps physique du Christ qu'une autorité ministérielle sur l'Église elle-même. Dans Lumen Gentium, le concile a évité le terme "potestas" (pouvoir) pour parler de "ministeria" et de "munera" (les services). Le souci de Vatican II a été également de ne pas isoler le sacrement du presbytérat des sacrements de l'initiation chrétienne (baptême, confirmation, eucharistie). Le presbytérat n'absorbe pas le baptême et il n'est pas non 
plus un super-baptême. L'ordination foncière du presbytérat est à la construction du Corps du Christ. C'est sur ce point que Vatican II a le plus innové. À vrai dire, le prêtre n'est pas séparé par le culte (c'est une idée de religion païenne), mais il est mis à part pour le service de l'Évangile.

À Trente, l'évêque est défini par rapport au prêtre tandis qu'à Vatican II, le prêtre est défini par rapport à l'Ordre épiscopal, dans une unique mission. Le dernier concile réintroduit ainsi le ministère presbytéral dans l'organicité de l'ensemble du sacrement de l'Ordre. Trente ne dit rien sur la pluralité presbytérale: le prêtre reçoit le sacrement de l'Ordre. Vatican II ne parle jamais du prêtre au singulier, mais toujours au pluriel. Devenir prêtre, c'est entrer dans l'Ordo presbyterorum ou presbyteratus. La nature du presbytérat est donc originellement communautaire. Cette fraternité sacramentelle des prêtres entre eux est le ciment du presbyterium diocésain. C'est ce tout organiquement unifié qui constitue le sacrement du Ministère ordonné. ${ }^{72} \mathrm{La}$ pyramide des pouvoirs très affirmée jusqu'au Concile Vatican II (pape-évêque; évêque-prêtre; curé-vicaire) a été renversée pour suivre la ligne d'un partenariat responsable. Tous les ministres ordonnés deviennent des membres d'un collège qui porte dans la responsabilité la charge de pasteur d'une portion du peuple de Dieu.

À Trente, les croyants (appelés laïcs) se sont trouvés réduits, de sujets inspirés de la foi qu'ils étaient, à n'être plus que l'objet du souci pastoral des prêtres. Cette conception conduira à la concentration de tous les charismes de l'Esprit dans l'unique charisme spirituel spécifique du "ministère sacerdotal". Vatican II a, au

72

"La "collégialité" ou la "synodalité", sont des options importantes, mais plus importante encore est la façon dont les dirigeants, en tant que personnes et en tant que collège, se situent au sein de la communauté, c'est-à-dire de la communion ecclésiale. Sinon l'on retombe dans l'opposition entre ce qui vient d'en-haut et ce qui se vit à la base ecclésiale, vrai temple du SaintEsprit, au service de laquelle (toujours sous la guidance du même Esprit) s'exerce le ministère" (SCHILLEBEECKX, E., Plaidoyer pour le peuple de Dieu, p. 290). 
contraire, proclamé l'Église comme Peuple de Dieu. Alors, le presbytérat n'est plus la synthèse du ministère ecclésial mais il devient inséré dans une diversité de ministères. Le prêtre est désormais un ministre ordonné qui, avec les autres ministres reconnus et mandatés, met ses charismes au service de la croissance évangélique de la communauté croyante.

"Les ministres ordonnés "sont placés d'une certaine façon face à l'Église comme instance décisionnelle responsable de présider à sa croissance, en faisant en sorte que les dons multiples suscités par l'Esprit servent à la construction du corps du Christ et à l'accomplissement de sa mission dans le monde: le service de l'Évangile". ${ }^{73}$

J'ai relevé à grand trait la progression de la théologie du presbytérat de Trente à Vatican II. Je suis bien conscient que cela exigerait un plus grand développement pour chaque aspect de comparaison. Chaque élément aurait pu constituer en lui-même un sujet de thèse doctorale. Mais j'ai voulu surtout montrer à quel point la progression opérée depuis Trente sur la conception du prêtre a été considérable. À Trente, nous n'avons pas une théologie du presbytérat, mais une théologie du sacerdoce établie en fonction du pouvoir de célébrer l'Eucharistie. Or, à Vatican II, le presbytérat a été replacé dans une ecclésiologie plus large. Dans les prochains paragraphes, j'explicite quelques traits de cette nouvelle théologie ayant des conséquences concrètes sur la manière de vivre le ministère presbytéral dans le contexte paroissial.

73

DUFOUR, Simon et PARENT, RÉMI,"Le renouveau de la configuration sociale de l'Eglise et de sa structure institutionnelle: condition de possibilité de ministères nouveaux", in Des ministères nouveaux? , pp.200-201. Il n'y a aucune différence ontologique entre un baptisé et un prêtre, entre un ministre mandaté ou reconnu (agent pastoral, bénévole-membre d'une équipe pastorale) et un ministre ordonné. Je ne viens pas de déclarer une grande découverte. Mais je suis toujours surpris de constater que nous oublions rapidement cette même dignité pour tous les croyants. Les relations entre le ministère ordonné et les autres ministères constituent un réel défi auquel l'Église sera de plus en plus confrontée. Nous pouvons relever ce défi avec sagesse que si nous nous vivons en égalité entre nous. 


\title{
11.4.2 Le presbytérat, le service de la croissance de l'unité
}

Depuis plusieurs années, nous sommes à la recherche du spécifique du ministère ordonné. 74 Plusieurs théologiens, éclairés par le Décret conciliaire Presbyterorum Ordinis, s'entendent pour dire aujourd'hui en quoi la tâche de prêtre est originale par rapport à celle de ses autres frères et soeurs baptisés. Sa responsabilité se situe plus particulièrement au service de la croissance de l'unité dans l'Église.

\begin{abstract}
"Il est possible de comprendre le ministère ordonné comme service de l'unité catholique de la communion des croyants et des croyantes, et comme service de la vigilance sur l'apostolicité de la foi au coeur d'un agir collégial qui renvoie au Seigneur glorifié comme à la tête de l'Église, sans renier la responsabilité fondamentale du peuple de Dieu."75

"Il existe un office tout spécial: celui qui donne l'unité à tous les services, afin que l'ensemble puisse se développer harmonieusement: c'est la fonction du prêtre dans la communauté locale, et celle de l'évêque dans la communauté régionale. Leur mission spécifique n'est pas de consacrer, mais d'être l'unité dans le culte, dans l'organisation, dans la transmission de la foi". 76
\end{abstract}

Avant d'aller plus loin, il est important de clarifier certains thèmes. Il ne faut pas confondre unité, uniformité, pluralité et communion.

"...l'unité de l'Église est le lieu même où se rencontrent pluralité et communion. /.../ Quand l'unité ecclésiale, en effet, prétend ne se définir que par la communion, elle risque

74 Depuis deux décennies, nous investissons beaucoup d'énergie dans les milieux théologiques et pastoraux pour trouver les tâches plus spécifiques des prêtres. Il faut surtout apprendre à situer ecclésialement le sacrement du ministre ordonné autrement qu'en termes de choses à faire, d'utilité et d'efficacité. C'est à l'intérieur du tout ministériel objectivement organisé le plus adéquatement possible qu'on doit situer le ministère ordonné. Il est également toujours bon de nous rappeller qu'un ministère n'est pas nécessaire en lui-même. Il l'est à la condition qu'il soit au service de la vitalité évangélique de la communauté croyante et de la libération chrétienne du monde.

75 DUFOUR, Simon, "Le presbytérat dans la mission de l'Église", in Prêtre et Pasteur vol. $90, \mathrm{n}^{\circ} 4$, avril 1987, p. 235.

76 BOFF, Léonardo, Église, charisme et pouvoir, p.235. Voir aussi RIGAL, Jean, Le courage de la mission, pp.143-166. Léonardo BOFF aurait dû éviter d'utiliser les expressions "donner l'unité" et "être l'unité". Les prochaines lignes vous permettront de comprendre le pourquoi d'une telle remarque. 
de se défigurer historiquement en uni-formité. Quand on prétend, à l'inverse que l'unité va s'épuiser dans la pluralité, elle cède à la division."77

L'unité est la communion de l'originalité irréductible des différentes personnes et des différentes communautés. Chaque personne et chaque communauté vivent un contexte historique qui leur est propre et qui, justement, les particularise. L'uniformité étouffe la vie et ne crée qu'un semblant d'unité alors que l'unité véritable différencie. Ce qui ne veut pas dire qu'il soit toujours facile de vivre l'unité dans la différence. 78 L'uniformité, elle, impose un modèle. Elle sait toujours d'avance ce que les personnes et les communautés doivent être et faire pour vivre. Celle-ci n'est pas touchée par l'inédit qui surgit à tel moment du temps ou en tel lieu de l'espace. L'unité dans l'Esprit est échange entre les charismes dans lesquels se déploie, comme en un prisme, la grâce plurielle de Dieu. Les charismes, les spiritualités, les théologies ne sont sources de vie que grâce à l'échange et l'appréciation réciproque. Sans ce souci de convergence, d'écoute et d'étonnement mutuels, pas d'édification de l'Église.

PARENT, Rémi, Prêtres et Evêques, pp. 150-151. La réflexion sur le concept de l'unité est abondante dans l'Église. Plusieurs conceptions different. Le cardinal Joseph RATZINGER intervient souvent pour clarifier ce thème. "La promotion d'une unité qui ne soit pas un obstacle à la diversité, tout comme la reconnaissance et la promotion d'une diversité qui ne soit pas un obstacle à l'unité, mais l'enrichisse..." (RATZINGER, Joseph, "Aux évêques de l'Église catholique, sur certains aspects de l'Église comprise comme communion", Lettre de la Congrégation pour la Doctrine de la foi, in La Documentation Catholique, $\mathrm{n}^{\circ} 2055,2$ et 16 août 1992, p. 732). Cette déclaration est intéressante mais en analysant d'autres textes de ce Préfet de Congrégation Romaine, nous notons que celui-ci a davantage une vision de type juridique du concept d'unité au lieu d'une vision sacramentelle et communionnelle de l'Église. "En même temps l'humanité glorifiée du Christ, Tête de l'Église, se substitue au Saint Esprit comme agent de l'unité du corps ecclésial. Ainsi à une vision sacramentelle et communionnelle de l'Église tend à se substituer une vision de type juridique: l'unité est pensée désormais beaucoup plus comme soumission à la même tête que comme animation par un même Esprit, dans la diversité de ses dons"(HOFFMAN, J., "L'Église et son origine", in Initiation à la pratique de la théologie, Dogmatique II, tome III, p. 69.).

78 C'est un défi constant de vivre l'unité dans la différence. Humainement, la tentation demeure toujours forte de chercher à tout prix l'unification par une seule langue comme à Babel plutôt que de vivre la diversité comme à la Pentecôte. 
"Et pour l'Église, être catholique, c'est à la fois "accueillir les dons de Dieu dans leur plénitude et "présenter" une diversité de réponses vivantes à l'unique bonne nouvelle annoncée dans toutes les langues."79

Pour un presbytre, être au service de la croissance de l'unité est donc se mettre à l'écoute des personnes et des communautés. C'est analyser par la suite les conditions concrètes de leur existence en tel lieu de l'espace et déterminer avec d'autres frères et soeurs de la communauté, les enjeux historiques qui doivent être trouvés dans l'unité et la solidarité. Ce service exige une vigilance constante pour reconnaître la présence de Dieu dans la nouveauté de ce que les autres sont et font.

Ce n'est pas le prêtre qui crée, donne ou "est" l'unité. Sans cela, le prêtre rend présent quelque chose d'absent. Si Jésus Christ a déjà tout réconcilié, le prêtre n'a pas besoin de créer l'unité. Cette unité, Jésus Christ l'a déjà mise dans le coeur des croyants et des communautés croyantes. Le ministre ordonné n'a qu'à accompagner la croissance de cette unité. Nous sommes au service de Quelqu'un qui est déjà là. C'est si facile d'oublier que Jésus Christ nous précède toujours dans notre service. L'unité est la responsabilité de tous les membres du peuple de Dieu, dans leur docilité à l'Esprit.

\begin{abstract}
"Mais ce souci d'élargissement ne garantit pas automatiquement qu'on a enfin évité les pièges du cléricalisme. Il est en effet possible de remettre encore toute la responsabilité de l'Église aux prêtres et aux évêques en leur confiant, cette fois, la responsabilité d'être le sacrement de l'unité ecclésiale." 80
\end{abstract}

Il n'y a qu'un seul répondant de l'unité chrétienne: Jésus Christ. Les chrétiens (incluant les ministres ordonnés) ne peuvent pas se donner leur propre unité. Ils ne peuvent non plus la construire par la seule force tendue de leurs bras, de leur volonté et de leur intelligence. Ils la reçoivent comme un don toujours neuf. Toutes les personnes et lente ou renouveau", tome XXV, $\mathrm{n}^{\circ} 123$, juin-juillet 1975, p. 66. 
toutes les communautés sont donc responsables de prendre en charge l'unité ecclésiale et sa croissance. Personne ne peut échapper à cet engagement. "C'est une unité toujours en train de se faire, en croissance, c'est un mouvement, un rassemblement qui est aussi une tâche." 81 Le ministre ordonné doit ainsi favoriser une responsabilisation maximale des personnes et des groupes dans l'Église. Pour prendre une image de l'univers du spectacle, il doit passer du 'one man show' à un animateur d'un spectacle réalisé grâce à l'apport de plusieurs participants. Son ministère doit être axé sur le service de la communauté et de ses besoins. Le presbytre est appelé à servir l'établissement de liens à l'intérieur des communautés. Sa présence devient précieuse dans une communauté locale pour que tous les baptisés puissent grandir dans l'unité d'un seul Corps (MVP 6; MVP 9).

\subsubsection{Une tentation du prêtre: se prendre pour la tête de l'Église}

Pour préciser davantage le service spécifique des prêtres et des évêques, Presbyterorum Ordinis dirige l'attention vers l'unité de l'Église, plus précisément vers l'image du Christ-Tête et les relations que le Corps entretient avec sa Tête.

"Si l'on cherche, en effet, en quoi la tâche du prêtre est originale par rapport à celle du chrétien, on est renvoyé à ce signe essentiel à l'Église: le signe du Christ-tête, pour son Corps. Autrement dit, il y a un ministère dans l'Église, pour que soit signifiée l'oeuvre du Christ dans l'oeuvre de l'Église." 82

Quel est le sens chrétien et ecclésial de cette image? Il est important de réfléchir à cette question puisque plusieurs prêtres se définissent depuis lors comme la tête de l'Église.

81 DUFOUR, Simon, PARENT, Rémi, Les Ministères, Paris-Montréal, La CroixL'Évenement, 1993, p.71.

82 DENIS, Henri, "La théologie du presbytérat de Trente à Vatican II", p.216. 
Dans le texte conciliaire $P O 2$, il y a une différence théologique très nette entre le "in nomine" et le "in personna Christi Capitis".

"PO 2 ne dit pas pas que les prêtres agissent "au nom du" (in nomine) Christ-Tête, mais "in persona Christi Capitis". Cette distinction pourrait conduire à des précisions tout à fait décisives. /... L'expression "in nomine" laisse entendre que les prêtres et les évêques agissent en fonction d'un mandat qu'ils ont reçu: c'est le Christ lui-même qui les mandate et détermine, en cela, leur situation ecclésiale et ecclésiologique. Ils sont gratifiés d'une délégation de pouvoir et peuvent agir à la place de Jésus Christ. /.../ L'expression "in personna Christi Capitis" interdit que la présidence des prêtres et des évêques soit ecclésialement située à partir d'un mandat qui leur donnerait d'agir "à la place" du ChristTête. Au contraire, le Ministère ordonné n'a sens chrétien et ecclésial que lorsquil rappelle que "c'est le Christ qui agit" et, plus précisément encore, dans son renvoi même à la seule Tête de l'Église, Jésus Christ." 83

Cette distinction est excessivement importante puisque c'est sur la formule "ut in persona Christi Capitis agere valeant" que reposent la spécificité du ministère hiérarchique en général et celle du ministère presbytéral en particulier. Si l'on cherche, en effet, en quoi la tâche du prêtre est originale par rapport à celle du chrétien, on est renvoyé à ce signe essentiel à l'Église: le signe du Christ-Tête, pour son Corps. Avec cette clarification, il n'est pas permis à un ministre ordonné de succomber à la tentation de se prendre pour la tête de l'Église ou de se définir comme un "représentant" du Christ-tête. Cette conception donne des maux de tête et parfois même de douloureuses migraines à plusieurs baptisés dans différentes communautés paroissiales.

\subsubsection{Une exigence du ministère ordonné: le décentrement}

L'expression "in persona" exige une désappropriation constante qui entre dans la définition sacramentelle des ministres ordonnés. Le sacrement est à l'oeuvre quand le ministre ordonné vit la désappropriation, c'est-à-dire un décentrement. Les 
personnes et les communautés se décentrent de la personne du ministre ordonné vers le Christ-Tête qui est le seul à agir. Cette désappropriation au profit de l'Autre (ChristTête) doit se faire constamment au profit des personnes et des communautés qui sont le sacrement de l'Autre.

"In nomine" centrerait la vie ecclésiale sur la personne des prêtres et des évêques, tandis que "in persona" manifeste comme une exigence la nécessité pour ceux-ci de se décentrer au profit de Jésus Christ. Les ministres ordonnés accomplissent leur service sacramentel dans le mouvement où, loin de monopoliser sur eux l'attention des personnes et des communautés, ils les invitent à ne pas chercher le principe de leur cohésion ailleurs que dans le Christ-Tête." 84

Quel défi permanent ce dé-centrement du ministre ordonné au profit des personnes et des communautés croyantes? J'ai toujours trouvé ce décentrement exigeant. Naturellement, on a besoin d'être aimé et d'être reconnu. On cherche alors à centrer les gens sur nous pour combler ces besoins fondamentaux. C'est seulement après un long cheminement spirituel et une vigilance constante que nous pouvons devenir capables de vivre ce décentrement. C'est possible lorsque les croyants de la communauté découvrent que le ministre ordonné est une personne avec des qualités mais aussi avec des limites bien réelles. Le prêtre devient capable de se décentrer de lui lorsqu'il reconnaît ses propres limites. Il le devient encore davantage capable lorsqu'il reçoit la grâce de pouvoir demander pardon à des frères et à des soeurs de la communauté croyante qu'il a offensés "par action ou par omission" dans certaines situations pastorales .

"Un service réellement fécond ne peut résulter que de l'expérience du pardon. Tant que je n'ai pas fait cette expérience évangélique fondamentale, mon service sera, le plus souvent insconsciemment, trop centré sur moi-même." 85

"Plus je sers le devenir des autres, plus ceux-ci libèrent concrètement l'Amour qui visite leurs vies, et plus ils me renvoient à la nécessité de devenir moi-même".86 
Il me semble impossible pour un ministre ordonné de vivre ce dé-centrement si celuici ne se donne pas également des moyens pour analyser la dimension psycho-affective de sa vie et laisser Jésus Christ transfigurer son besoin d'être aimé et reconnu. "Cet aveu de pauvreté n'est pas masochisme. Il ouvre plutôt, dans l'existence responsable des croyants, l'espace à l'intérieur duquel pourra se manifester l'initiative fidèlement prévenante du Christ-Tête." 87

\section{Le prêtre est sans cesse appelé à "disparaître" pour que se lèvent des} personnes chrétiennement plus libres et responsables et qu'émergent des communautés révélatrices de la fraternité chrétienne. Il doit constamment être vigilant pour vivre son ministère au service et à l'intérieur du sacerdoce baptismal. Il est appelé à s'effacer au profit du sacerdoce saint et royal de tous les baptisés.

"....la nature du presbytérat exige que celui-ci soit compris sur le fond du sacerdoce qui est commun à tous les baptisés /.../ Tous les chrétiens deviennent un sacerdoce saint et royal pour une raison fondamentale: le Seigneur Jésus les fait lui-même participer à "l'onction de l'Esprit qu'il a reçu." Oint n'est pas un titre parmi d'autres attribué à Jésus Christ; il "récapitule tous les autres titres" et il "est devenu comme le nom propre" de Jésus, celui-là même qui renvoie au mystère de sa personne toute entière. Par leur participation "à l'onction de l'Esprit que le Christ a reçue", grâce est ainsi donnée à tous les baptisés d'un sacerdoce, qui n'est pas qu'une fonction parmi d'autres possibles, ou qui ne dirait qu'une dimension de leur être chrétien. Ils deviennent "un sacerdoce saint et royal" par leur entrée dans la totalité du mystère christologique. D'où le nom propre de tous ceux et celles qui confessent Jéus Christ comme Sauveur: "chrétiens", c'est-à-dire oints. /.../ ce qui doit être exigé d'un ministre, d'abord et avant tout, c'est une foi en la présence de Jésus Christ dans la vie des croyants et des communautés, une certitude que le Seigneur l'attend là où son service l'appelle. En toute rigueur, le ministre ne va pas y mettre quelqu'un qui n'y serait pas déjà, il ne va pas le "donner" ou le "faire venir"; il va toujours à la rencontre de Jésus Christ qui, dans l'Esprit le précède dans la vie des personnes et des communautés. S'effacer pour qu'adviennent des personnes et des communautés libres, chrétiennement libres et responsables: prêtres et évêques ne peuvent entendre autrement l'exercice du service pour lequel ils sont ordonnés." 88 
Ce décentrement change donc le type de présidence du ministre ordonné. "Vatican II, au minimum, interdit que les prêtres, les évêques et le pape comprennent leur agir comme une présidence de type totalitaire qui unifie en uniformisant, qui force au silence les innombrables originalités personnelles et communautaires." $89 \mathrm{Au}$ contraire, cette présidence veille à ce que chaque personne atteigne sa pleine mesure et elle invite chaque communauté à relever chrétiennement les défis qui lui sont propres, particuliers. La communion et la pluralité peuvent advenir dans ces conditions. De plus, ce type de présidence a la mission de renvoyer toujours les personnes et les communautés à leur responsabilité inaliénable. Ne sommes-nous pas sujets de ce dont nous sommes responsables? Si la communauté ne se tient pas responsable d'ellemême, aucun prêtre, le plus dynamique soit-il, ne réussira à rendre les membres responsables de leur communauté.

"Prêtres et évêques servent donc l'Église quand ils recentrent l'attention sur quelqu'un qui est devenu le Passeur, Seigneur qui ne se lasse pas d'offrir à l'histoire humaine la possibilité d'écrire une histoire qui soit celle d'une filiation divine et d'une fraternité universelle." 90

11.4.5 Le prêtre, un capitaine d'équipe et un membre d'une ligue: la LOP

J'aime comparer un curé à un 'capitaine' d'une équipe de hockey. Étant donné mon contexte culturel, cette analogie m'est signifiante même si je suis conscient de sa limite. Elle permet d'imager ma conception du ministère ordonné. Le prêtre est un baptisé qui accompagne d'autres croyants afin que l'unité puisse continuer de croître en communauté. Comme un capitaine d'une équipe de hockey, il rassemble l'équipe des baptisés, pour qu'ensemble ils puissent se laisser instruire par l'enseignement du 
'coach' Jésus Christ et se confronter mutuellement, afin de mieux agir sur la 'patinoire' du monde et compter davantage de points dans l'édification de la communauté et dans la construction d'une humanité plus juste et plus fraternelle. Ce capitaine a besoin des autres joueurs (baptisés) pour éviter de monopoliser la rondelle. Il doit même 'viser' à devenir un joueur de plus en plus discret sur la patinoire ecclésiale au profit des autres joueurs afin que ceux-ci puissent devenir chrétiennement plus libres et responsables. Le capitaine de l'équipe (le prêtre) n'est donc pas plus important qu'un autre joueur (baptisé) même s'il a une responsabilité différente.

Lorsque quelqu'un en autorité n'est pas confronté à des partenaires égaux, il en vient à monopoliser le pouvoir ou la "game" ecclésiale. Demeurer frère exige une conversion permanente du ministre ordonné. Il est facile de camoufler sa fragilité dans la sécurité institutionnelle. Les structures actuelles n'aident pas suffisamment à passer d'une autorité paternelle cléricale à une autorité fraternelle, pleine de sollicitude pour les autres. Le ministre ordonné, comme tous les êtres humains, est trop fragile pour qu'on lui remette entre les mains tous les pouvoirs sans confrontation fraternelle. Dans tout système politique, la concentration du pouvoir est toujours dangereuse quelles que soient la vertu d'une personne et sa force de personnalité. En concentrant le pouvoir entre les mains d'une seule personne, on place cet individu en situation prochaine de pécher par abus de pouvoir. L'histoire de l'Église et plusieurs situations pastorales actuelles nous le confirment trop souvent. Pour aider le ministre ordonné, il me semble que dans l'avenir, nous ne devrions jamais le nommer juridiquement seul responsable d'une paroisse. Quelques frères et soeurs dans la foi devraient être mandatés avec lui et avoir les mêmes pouvoirs que lui, afin que chaque membre de l'équipe pastorale puisse s'interpeller fraternellement. De plus, il est possible de favoriser le processus d'authentification des signes des temps uniquement en communauté de frères et soeurs égaux en dignité. Le danger est grand de monopoliser 
le pouvoir et d'éteindre l'Esprit lorsque le ministre ordonné est canoniquement reconnu seul responsable de la communauté. 91

Comme nous l'avons vu précédement, la nature du presbytérat est originellement communautaire puisque son oeuvre vise la croissance dans l'Unité d'un seul Corps du Christ.

"Le ministère ordonné, de par sa nature même, ne peut être accompli que pour autant que le prêtre soit uni au Christ par l'insertion sacramentelle dans l'ordre presbytéral et donc pour autant qu'il est en communion hiérarchique avec son évêque. Le ministère ordonné est radicalement de "nature communautaire" et ne peut être rempli que comme "oeuvre collective". 92

Le prêtre n'est donc pas seulement un capitaine d'une équipe de baptisés mais également membre d'une ligue de capitaines d'équipe, la LOP (la ligue de l'Ordre Presbytéral). ${ }^{93}$ La participation fidèle à cette ligue demeure un énorme défi. Quelques paroissiens font beaucoup de "pression" pour garder "leur" curé sur "leur" territoire. Plusieurs d'entre eux n'apprécient guère que "leur" prêtre collabore avec d'autres ministres ordonnés au sein des paroisses avoisinantes et assument des responsabilités à l'échelle régionale ou diocésaine. Si un prêtre n'est pas vigilant, il se laisse "bouffer" par les désirs de possession de certains membres de la communauté paroissiale et il oublie facilement de vivre une exigence de son ministère qu'est l'appartenance à un presbytérium. Pour un prêtre,

"son appartenance à un presbytérium doit être concrètement vécue, comme une double exigence. Plutôt que de se prétendre seul répondant du service de présidence qu'il assume dans une communauté, il a comme première responsabilité de partager avec les autres membres du presbytérium les particularités de son propre service /../ Mais une deuxième exigence doit être respectée, et justement parce qu'il s'agit d'une dépendance réciproque: chaque membre d'un presbytérium doit accueillir l'apport des autres membres, même si

91 La dernière partie de cette thèse développera davantage les différentes formes de nomination possibles, plus fidèles aux intuitions conciliaires. 
cet apport, précisément parce qu'il est autre et révèle du différent, dérange et inquiète /.../ aucun prêtre ne respecte son 'être' lorsqu'il se retire du mouvement."94

Les lettres des nominations actuelles formulent uniquement comme un souhait l'exigence de la fraternité sacramentelle pour le prêtre.

"L'inarticulation en cause a d'abord conduit à éloigner les prêtres de l'évêque. Une fois conféré le pouvoir de célébrer la messe, en effet, en vertu de quoi un prêtre serait-il tenu d'entretenir avec l'évêque des relations soutenues? Rien, dans le pouvoir que donne l'ordination, ne fonde la nécessité de ces relations. Chacun peut ainsi partir dans son coin, riche de son pouvoir sur l'eucharistie et, plus largement, maître de la communauté qui "assistera" à "sa" messe. Un premier individualisme brise donc les liens des prêtres avec leur évêque. Un second en dépend probablement, qui, cette fois, rompt les relations des prêtres entre eux: une fois reçu le pouvoir de dire la messe, chaque prêtre peut aller à sa guise, vaquant à son affaire indépendamment des autres." 95

Il faut juridiquement codifier cette fraternité sacramentelle dans les lettres de nomination. Les implications ecclésiologiques et pastorales sont trop importantes pour que cela tienne uniquement à la bonne volonté du ministre ordonné lui-même. En nommant les prêtres de la sorte, nous pourrions plus facilement interpeller les communautés à s'ouvrir entre elles.

"En même temps, la fraternité presbytérale, en ouvrant chaque prêtre aux autres membres de son presbytérium, constitue une invitation sacramentelle qui est lancée à chaque communauté particulière; elle doit garder ouverte la communication avec les autres communautés, s'offrir à elles et les accueillir. Elle n'a pas digéré le Christ, ne le possède pas, et n'en sera le sacrement que dans la communication avec d'autres communautés qu'une même filiation/fraternité prévient elles aussi." 96

JEAN-PAUL II, Pasteurs selon mon coeur, Exhortation post-apostolique sur la formation des prêtres dans les circonstances actuelles, Montréal, Paulines, 1992, pp. 43-44.

93 Être membre d'une ligue sans toutefois être obligé de défendre une ligne de parti!

94 PARENT, Rémi, Prêtres et Évêques, pp. 295-296. La recherche-action m'a fait constater que souvent ce sont les prêtres insistant le plus sur la pratique dominicale auprès de "leurs" paroissiens qui sont les "moins pratiquants" aux rencontres de secteur, de zone ou de région pastorale... 


\subsubsection{Réflexion insuffisante sur le presbytérat}

Il n'est presque nullement question du ministère de la présidence ecclésiale de la communauté paroissiale dans les documents conciliaires de Vatican II. Peut-être avons-nous là une des causes importantes de la crise d'identité presbytérale. Les prêtres sont situés par rapport à l'évêque, un peu comme les évêques étaient reliés par rapport au pape à Vatican I. Il importera sans doute de rééquilibrer ce rapport pour qu'il ne soit pas à sens unique.

"Un certain nombre de Pères conciliaires souhaitaient que le ministère paroissial soit considéré pour lui-même. La Commission responsable du schéma répondit que celui-ci faisait déjà l'objet de considérations particulières dans le schéma sur la charge pastorale des évêques." 97

La constitution dogmatique sur l'Église a traité du pape et des évêques, tandis qu'elle s'est faite beaucoup plus discrète sur le service de la présidence ecclésiale dans le contexte paroissial. Il y a eu un rapatriement du cléricalisme à ce niveau. Le presbytérat est défini uniquement par rapport à l'Ordre épiscopal. À cet égard, nous avons encore des bouts de chemin à franchir et nous devons de nouveau clarifier certaines conceptions conciliaires de Vatican II sur le presbytérat. Selon Hervé LEGRAND,

"Presbyterorum Ordinis réduit le presbytérat à une participation à l'épiscopat, au lieu d'y voir un charisme spécifique, bien que pour une charge subordonnée à celle de l'évêque; l'ensemble du document manque d'ailleurs de cette articulation". 98

97 PÉRISSET, Jean-Claude, La Paroisse, Commentaires des Canons 515-572, Paris, Tardy, 1989, p.181. [Le Nouveau Droit Ecclésial].

98 LEGRAND, Hervé, "Le développement d'Églises-Sujets", p. 160. 
Certains affirment que la vision du presbytérat à Vatican II fut, "pour les prêtres, une cause d'irritation. Car si au Concile les évêques se sont approprié de larges pouvoirs, les prêtres se sont sentis victimes et laissés pour compte". 99 Les prêtres n'ont pas fini de 's'irriter' car cette conception du presbytérat a été très présente au Synode extraordinaire des évêques de 1985 où Jean-Paul II a déclaré: de sociologie du prostestantisme, Paris, Cerf, 1982 , p. 62 
"...c'est la tâche des évêques comme pasteurs des âmes, en union avec les prêtres qui sont leurs auxiliaires, d'enseigner aux fidèles ce que le Synode a proposé de salutaire et de les exhorter à puiser, avec une ferveur renouvelée dans les trésors du Concile, un stimulant à une vie chrétienne de plus en plus conforme aux principes de la foi...". 100

Que doit être le prêtre aujourd'hui? Pour le savoir, il n'est pas seulement nécessaire de connaître ce qu'il doit être théologiquement. Une Église, Peuple de Dieu en marche, doit constamment être à l'écoute de ce que l'Esprit révèle au coeur des défis actuels et particuliers de chaque Église locale. Si nous l'écoutons en communauté, le Paraclet nous aidera à lire les "signes des temps" afin que les pratiques ministérielles aident davantage à faire advenir le Royaume de Dieu d'une manière plus fructueuse.

"Ce n'est qu'à partir des "signes des temps", c'est-à-dire des questions et des problèmes concrets du prêtre, et à partir de leur réflexion et de leur praxis qu'on peut ouvrir une perspective pastorale sur ce que le ministère ecclésial doit être à notre époque pour être fidèle à la tradition évangélique et apostolique. Il s'agit d'ailleurs là, selon moi, d'une nécessité herméneutique: il n'est pas possible de définir a priori ce qu'un prêtre doit être "en soi", le rapport à l'actualité doit faire partie de "l'essence" même de la prêtrise. Le passé est ici nécessaire en tant qu'avertissement capable de nous garder d'une fascination exclusive par le seul présent. Le présent de l'homme est en effet le lieu où le passé ouvre et détermine à la fois les possibilités futures." 101

\subsubsection{La crise d'identité du prêtre}

Les responsabilités assumées à l'Office du clergé du diocèse de Chicoutimi m'ont confirmé les nombreuses angoisses vécues par les prêtres concernant l'avenir du presbytérat et la conception théologique de ce ministère. Dans l'Église, il y a une crise 1986, p. 270. 
d'identité du ministère ordonné. Les prêtres cherchent encore plus leur spécificité depuis l'arrivée massive des agents pastoraux laïques. Pour tenter d'affiner ce constat, on peut qualifier la crise pastorale contemporaine de crise d'identité. "S'il existe vraiment une crise d'identité du ministère presbytéral, il n'existe pas moins une crise d'identité du ministère laïque ainsi que du ministère diaconal."102 Les prêtres sont actuellement dans une crise d'identité dont deux traits sont particulièrement saillants: le modèle pastoral véhiculé par la tradition ne tient plus; les individus qui en assument les fonctions sont par là soumis à des tensions extraordinaires. Contrairement au passé, le ministère ne porte aujourd'hui plus la personne: c'est la personne qui est appelée à porter le ministère. Rémi PARENT croit que le crise d'identité du ministère ordonné tient surtout au fait qu'on a perdu les justifications théologiques au nom desquelles on a ordonné et sur lesquelles les prêtres et les évêques ont misé le sens de leur existence. 103

Il est important de dire quelques mots sur cette recherche existentielle de l'identité personnelle. Y réfléchir pour tout simplement dire que celle-ci ne peut pas connaître d'achèvement. J'aime l'image utilisée par un de mes amis parlant de cette quête d'identité. Selon lui, elle est comme le travail du chien qui court après sa queue, il ne réussit jamais à l'atteindre.... L'identité n'est jamais acquise une fois pour toutes: la quête de l'identité détermine l'existence pastorale comme un devenir dans lequel l'existence personnelle et professionnelle se rencontrent, se répondent et s'influencent continuellement de façon intense. Mais il convient particulièrement de ne pas tout confondre dans ce processus et de rêver d'un moi totalement intégré dans lequel tous les aspects de la vie et de la personnalité seraient transparents et ordonnés à une fin

102 COMITÉ DES MINISTERES DE L'ASSEMBLÉE DES ÉVEQUES DU QUÉBEC, Communautés et ministères au Québec: Situation, questions, défis, Montréal, Fides, 1993, p. 20. 
d'avance déterminée. Pour le prêtre, comme pour tout autre humain, l'identité personnelle reste une énigme dont la solution est à conquérir dans les combats quotidiens. La vie du ministre ordonné est ouverte à l'imprévisible comme toute existence humaine. L'identité ne peut être la somme d'identités fragmentaires. Elle est un pouvoir de totalisation et d'intégration des identités partielles, au-delà de leurs contradictions éventuelles. Il est vain de rêver d'une identité compacte, parfaite et définitivement stable. Les contradictions font intrinsèquement partie de la quête de lidentité.

"Un prêtre nous semble aujourd'hui plus convaincant comme homme, avec toutes ses contradictions, et dans ses contradictions mêmes, parce que sa proximité des hommes le fait paraître plus proche de Dieu que celui qui plane dans les nuages en se gardant de se salir les pieds dans la poussière du monde. I.../ ... nous aimons ces "essayeurs" grandioses, ces esprits audacieux, précisément dans leurs crises et leurs combats, et là où nous les aimons le plus, c'est non pas en dépit de leur faillibilité, mais à cause d'elle. Car notre génération ne veut plus vénérer ses saints comme des envoyés de Dieu venus audelà supra-terrestre, mais comme les plus terrestres des humains. Autrement dit, on ne croit plus au "témoignage chrétien" d'ecclésiastiques qui s'épargnent l'existence humaine et terrestre, la vie semée d'embûches et "tributaire du péché", en traçant une frontière hermétique autour du clerc. Un témoin ne restera crédible que si, animé d'une force confiante, il ne craint pas de s'exposer corps et âme au doute, au besoin, au désespoir, à la boue, à la laideur, au danger du mépris et de l'incompréhension, au tragique de l'erreur et au désastre de l'échec, aux aléas funestes des meilleures intentions et aux hasards déshonnorants des sentiments, même de l'amour. /.../ Jésus n'a pas choisi pour apôtres des icônes dorées, mais bien des êtres de chair, faibles, vulnérables, parfois complètement perdus. 104

La vigilance la plus importante pour un prêtre est celle d'éviter que son identité presbytérale devienne plus forte que son identité personnelle. Il doit éviter que sa fonction soit tout pour lui et que sans elle, il ne soit rien.

"Dans ce sens, est chef celui qui, en raison d'une insécurité ontologique ou de l'angoisse profonde qu'il ressent face à son néant, a foncièrement besoin d'avoir une fonction particulière et une mission officielle pour se sentir vivre comme personne. La singularité lui donne le sentiment de sa valeur et la normalité le droit à l'existence. /.../ La personne 
est si profondément et si désespérément vidée et effritée que seuls un rôle extérieur, une mission objective plaquée, semble pouvoir lui garantir une identité. La "fonction" devient ainsi la vérité du moi, sa défense et sa preuve; c'est la seule valeur à laquelle le moi puisse se mesurer. La forme essentielle de l'existence, ce n'est plus d'être une personne, mais d'être un clerc." 105

Pour éviter de vivre seulement au niveau de la fonction, le prêtre doit se constituer un réseau d'amis où il peut être lui-même et se nourrir affectivement. Il doit créer des liens de fraternité non seulement avec des prêtres mais aussi avec d'autres hommes et femmes avec qui il peut partager en toute gratuité. Nous pouvons devenir nousmêmes si quelques personnes nous aiment pour ce que nous sommes et non pas uniquement pour ce que nous faisons. L'identité personnelle du ministre ordonné se solidifie à la condition que celui-ci ait la grâce d'être aimé inconditionnellement par des êtres humains remplis de tendresse à son égard.

\subsubsection{Le prêtre, un interprète dans son service de la Parole}

On peut préciser la compétence théologique du prêtre en reconnaissant d'emblée que dans la communauté chrétienne tous sont des interprètes, mais que le prêtre, grâce à ses années d'études universitaires en théologie et parfois en d'autres disciplines, a eu la chance d'être formé aux méthodes de l'interprétation et a acquis par le fait même des connaissances permettant d'accompagner le processus. 106 Il doit être

Ibid., pp. 75-76.

donne son savoir pour dominer les autres en imposant son point de vue pour faire la communaté son image. Le prêtre dispose bien d'un certain savoir: mais il n'a pas à prétendre à un monopole du savoir théologique; ce qu'il sait autant en méthodes qu'en contenu, il doit le mettre à disposition au moment voulu pour aider chacun et tous dans leur recherche de sens. Ses compétences ne sont pas l'indice d'une supériorité dans la foi. Sa formation l'aide à proposer des éclairages sur le réel à partir de l'Évangile. Il n'a pas le monopole de l'interprétation et, a fortiori, de l'interprétation juste. Il dispose de quelques instruments qui lui permettent de faire des distinctions entre les interprétations et d'en montrer les divergences et les convergences. Il doit également toujours vivre dans la conscience que 
à même, par là, d'encourager et de stimuler le travail permanent du sens. C'est dire qu'à l'origine, par formation, le prêtre est un théologien, par conséquent un intellectuel, qu'il le veuille ou non. Il doit inviter constamment à l'échange continu entre l'expérience et la réflexion, à l'expression de ces échanges. Les prêtres en exercice aujourd'hui tendent à renoncer à cette conception du ministère comme oeuvre théologique. Ce repli me paraît symptomatique d'autre chose: il indique une réticence quant à la responsabilité d'interprète au sein de la communauté croyante. Pourtant cette responsabilité est de plus en plus importante dans un contexte ecclésial où les interprétations que l'Église officielle propose sont devenues dans plusieurs situations désuètes. Dans bien des situations pastorales, elles n'éclairent plus le questionnement suscité par les nouvelles expériences communautaires. Alors, devant l'échec des interprétations officielles et de leurs discours, les prêtres préfèrent parfois garder l'intégralité de leurs pensées pour eux et en eux, ou pour le petit cercle des "fidèles" déjà convaincus, plutôt que de les soumettre aux risques de démentis cruels. Ils renoncent ainsi au travail fatigant et constant de l'interprétation: celui-ci consisterait précisément à revoir l'interprétation à laquelle on était attaché, donc à réviser aussi le système des convictions dont on vivait jusque-là. Une telle perspective peut paraître si angoissante que beaucoup préfêrent la masquer et masquer ainsi par leur repli une crise des convictions liée à une déficience de l'interprétation, donc du travail théologique. ${ }^{107}$ Le presbytre est un accompagnateur du travail d'interprétation de la communauté. Si le prêtre est important comme interprète, ce n'est pas pour donner le sens mais pour accompagner la recherche de sens de la communauté. Il ne peut jamais se considérer comme le seul artisan de sens

ses convictions personnelles sont elles-mêmes provisoires donc révisables. Il ne détient pas le sens, la "splendeur de la vérité" mais il risque des propositions à son propos.

107 "C'est un des rôles de la théologie, en utilisant les outils de l'histoire et des sciences de l'interprétation (herméneutique), de critiquer constamment l'institution de l'Église en retournant sans cesse à ce que voulait Jésus et aux visages que l'Église prend à chaque époque. Les premières communautés sont déjà une interprétation, dans le cercle apostolique, de ce que voulait Jésus comme rassemblement du nouveau peuple d'Israël" ( Comité des ministères de l'AEQ, Communautés et ministères au Québec: situation, questions, défis, p. 30.). 
ni le seul interprète dans la communauté. Il aide à l'articulation du sensus fidéi et du magistère, à la condition de ne pas rapatrier le magistère au seul échelon supérieur de la hiérarchie catholique.

L'intellectuel, le théologien paraît souvent mal "coté" par plusieurs prêtres. 108 Le prêtre en question a l'impression que par sa présence au coeur d'une paroisse, il est beaucoup plus proche du concret que ne saurait l'être un intellectuel ou un théologien. Et il oublie vite que cette appréhension du concret peut aussi constituer le piège de l'immédiat. Accepter d'être aussi un intellectuel paraît à certains le comble de l'abomination: on dira volontiers que Jésus ne l'a pas été! Comme si le prêtre pouvait se prétendre un Jésus, et comme si la distance des siècles n'impliquait pas un profond travail herméneutique de la part de celui qui veut être un témoin plus fécond du Christ. Pourtant cet interprète, cet intellectuel, ce théologien, le prêtre, cet être humain de communication est proche du vécu puisqu'il a vocation de le comprendre et de l'exprimer sous un sens nouveau. Il est placé au carrefour où se croisent et se rencontrent le message de l'Évangile et la vie, le monde, le réel. Il a pour tâche d'aménager ce croisement et cette rencontre. Son travail herméneutique le met en rapport aussi bien avec l'un qu'avec l'autre. Il est donc entre écoute et affirmation, au point d'impact de l'un et de l'autre, non pas pour décider seul des effets de ce choc, mais pour, si possible, permettre à chacun de s'y confronter. Il fait des propositions pour aider les personnes et les communautés chacune à comprendre et à se comprendre. Il ne connaît pas le sens de la vie de chacune: il accompagne (et se laisse aussi accompagner!) tous ceux et celles qui recourent à lui pour poursuivre leur quête

108

Le chapitre cinquième a démontré que plusieurs prêtres sont intéressés à la réflexion intellectuelle. Ils qualifient de passionnante toute recherche théologique qui part des enjeux de la pratique pastorale. Cependant, ils ne sont pas intéressés à une théologie uniquement fabriquée en laboratoire universitaire. Pour éviter ce piège, le théologien "professionnel" doit se tenir proche du vécu des communautés croyantes et non seulement "courir" les congrès des grandes sociétés savantes de théologie, parfois très "idéologiques". 
de sens. Même quant à sa propre vie, il n'est pas en possession du sens: la quête est ouverte, l'imprévisible est encore devant lui, rien n'est jamais acquis. Il propose et écoute, révise et reconquiert ses propres convictions et renvoie ainsi toujours au-delà de lui-même. Être interprète, c'est accepter d'être en devenir dans la condition humaine qui implique doutes et certitudes, angoisses et sérénité. Le mieux auquel le ministre ordonné puisse prétendre, c'est d'apparaître un chemin de plausibilité du devenir chrétien en tant que processus d'interprétation.

Où trouver la force de s'accepter ainsi interprète, donc intellectuel et théologien? L'opposition triviale de l'action et de la réflexion n'est plus possible dans cette manière de concevoir le "ministère de l'interprétation" que doit vivre le prêtre au sein d'une communauté. Assez de paroles, assez de théories: des actes! Quels actes? Interpréter et communiquer, n'est-ce pas agir?

\subsubsection{Le prêtre, un "humoriste"}

"Quand il est véritable, le rire est la voix de la foi"(Harvey COX).

Pour garder l'équilibre dans la situation pastorale contemporaine, le prêtre est invité à devenir une personne remplie d'humour. Il ne faut pas confondre l'humour et la rigolade, ni l'assimiler à l'ironie. L'humour est la distance enjouée à l'égard de soi: pouvoir et compétence de faire et de refaire l'intégration de son être. Car, "l'humour marque le moment où notre moi regagne du terrain sur une conscience oppressive"109 S'il n'est pas une exclusivité de la foi chrétienne, l'humour en fait partie intégrante et il 
l'accompagne: "l'humour est une grâce qui doit nous être donnée sans cesse, sans quoi nous succombons à notre désespoir."110 L'humour est le garde-fou contre toutes les tensions. L'humour est ainsi le vrai sérieux de la foi et donc aussi de la vie pastorale. J'oserais même dire que le prêtre doit avoir en lui quelque chose du bouffon. Il renvoie les êtres humains à eux-mêmes dans le miroir qu'il constitue pour eux; il les renvoie à un au-delà de lui-même et d'eux-mêmes par l'interstice des contradictions dont il est porteur. Dans le cours du temps, l'humour assure le prêtre contre le rêve malsain de nier ses propres contradictions.

Le prêtre doit aider les membres de la communauté à tomber en humour par amour. L'humour est une qualité de l'amour. Un tel humour est sagesse. La sagesse de faire confiance en dépit des règles, des convenances et des normes établies. L'humour vient faire la différence qui nous empêche de trop jouer les vierges offensées, de nous prendre trop au sérieux et de nous installer sur des piédestaux, pour ne pas dire des trônes, au-dessus de ceux-là et de celles-là qui sont comme ceci ou comme cela!

Notre Dieu n'est-il pas le Dieu de l'humour qui nous apprend à rire de nos lenteurs pour vivre le bonheur? L'humour fou de Dieu se manifeste tout au long de l'histoire du salut. Il a fallu à Dieu beaucoup d'humour pour faire alliance avec l'humanité, pour choisir un peuple sans influence politique, un peuple insignifiant en nombre. Il a fallu à Dieu beaucoup d'humour pour choisir comme chef de son peuple un homme handicapé par le bégaiement. Il a fallu à Dieu un humour fou pour choisir un Fils appelé à révéler son amour à l'humanité après le sort réservé à tous les autres prophètes qu'Il a envoyés avant Jésus. Il a fallu au Fils de Dieu beaucoup d'humour pour canoniser de son vivant un brigand: "Aujourd'hui même, tu seras avec moi en

110 BÜHLER, Pierre, "Foi et humour", Une petite dramatique de la foi chrétienne d'après DÜRRENMATT, in Bulletin du Centre Protestant d'Études, $28^{\circ}$ année, $\mathrm{n}^{\circ} 3$, Genève, juin 1976, p. 37. J'ai constaté que de manière générale les intégristes n'ont pas beaucoup d'humour.... 
paradis"; pour donner aux ouvriers de la dernière heure le même salaire qu'à ceux qui ont besogné tout le jour; pour attester que Dieu "fait lever son soleil sur les méchants et sur les bons et tomber la pluie sur les justes et les injustes" (Mt 5, 45); pour provoquer son auditoire: "les publicains et les prostitués arrivent avant vous dans le Royaume de Dieu"(Mt 21,31). Il faut que Dieu ait beaucoup d'humour pour laisser les catholiques, surtout le Pape et la curie romaine, croire qu'ils ont le monopole de la "splendeur de la vérité", qu'il n'y a pas de salut possible hors de l'Église. Il a fallu à Dieu beaucoup d'humour pour laisser l'Église ne canoniser presque exclusivement que des prêtres et des religieux. On peut donc présumer que Dieu doit souvent "rire dans sa barbe" qu'elle soit longue ou courte! Notre Dieu doit avoir régulièrement le "sourire en coin". La démesure du pardon de Dieu et la puissance de son humour sont une merveilleuse révélation du visage de Dieu. Un visage à contempler, à aimer et à laisser transparaître à travers les nôtres. Il y a ainsi l'humour fou de Dieu et l'humour des fous de Dieu!

Dans la vie, on ne peut pas s'en sortir sans un certain humour. L'humour, n'est-ce pas une sorte d'hygiène spirituelle? L'humour devrait être même élevé au rang des vertus cardinales! L'humour est une forme de l'esprit d'enfance étant à la fois étonnement et lucidité, détente et authenticité. Un humour sans lequel le nouveau départ n'est pas possible. Nos communautés chrétiennes ont besoin de ces "fous de l'humour", de ces "jongleurs" de Dieu. Sans cette folie de l'humour, que la vie serait triste! Car la gratuité n'aurait plus de place. Notre sérieux en pastorale paroisiale manque quelquefois d'éclats de rire et nous ne savons pas suffisamment perdre la tête dans certaines circonstances pour retrouver notre coeur. Un tel humour, n'est-il pas une forme d'amour de soi, des autres et de Dieu? L'humour et la sagesse, ne sont-ils pas deux conjoints de route qui permettent à un être humain de poursuivre son chemin avec plus de sérénité et de liberté? 
"C'est facile de reconnaître le Sage: on le reconnaît à son rire. /..J/L'humour des sages est le signe extérieur de leur richesse intérieure. /.../ Un homme libre, intérieurement libre, libéré des pièges de l'ego, du moi haïssable, ne peut être qu'un homme joyeux. /.../ Finalement, le secret de cet humour des sages ne serait-il pas qu'avant d'aborder les grands principes, il faut connaître son insignifiance? Quelle est belle la prière de Saint Thomas More, chancelier d'Angleterre canonisé en 1935: "Seigneur, ne permet pas que je fasse trop de soucis pour cette chose incombrante qui s'appelle moi et, surtout, donnemoi l'humour"."111

Je suis certain que Dieu s'amuse de nos efforts désespérés à paraître "quelqu'un". Il faut beaucoup d'humour pour rire et surtout rire avec ce qu'il y a de plus sérieux dans la vie... Un célèbre humoriste anglais ne disait-il pas: si vous prenez la vie au tragique, vous n'en sortirez pas vivant?

\subsection{Acquis de recherche éclairants}

Ce chapitre a soulevé plusieurs questions importantes. Essayons dans quelques lignes de les "ramasser" dans le but de mieux illuminer les différentes problématiques de la présente thèse doctorale.

\subsubsection{La plus belle ecclésiologie sans droit correspondant est une idéologie}

C'est à Vatican II que s'est opérée une révolution ecclésiologique "copernicienne": l'Église est passée de la "Société Parfaite" pour devenir "Peuple de Dieu" ( $L G$ 2). Ce foisonnement ecclésiologique a produit des acquis. Il a permis un meilleur partage de la responsabilité pastorale, une atténuation de la dichotomie clercs/ laïcs, un partenariat hommes/femmes un peu plus équilibré, la montée de la 
participation dans les instances où se décide la vie des Églises. Toutefois, Vatican II a posé les germes pour faire naître une Église plus communionnelle, mais n'en a pas dégagé toutes les implications. Le Concile a cherché à convertir des mentalités mais a oublié de convertir les structures de l'Église.

\begin{abstract}
"Vatican II a manifesté un autre visage de l'Église. Il a soumis la figure antérieure de l'Église à une révision drastique. Hélas, le Concile ne put donner à son oeuvre la confirmation nécessaire au plan juridique et institutionnel. Une révision du Codex devait, selon le voeu de Jean XXIII, y pourvoir. (Cette révision se fera beaucoup plus tard et dans un sens qui, sur quelques points fondamentaux se révélera infidèle aux inspirations majeures de Vatican II.) /.../ Or, la façon dont l'Église organise de fait les ministères rend impossible ou extrêmement difficile l'établissement d'une base institutionnellement et juridiquement assurée afin que l'Esprit-Saint, présent dans le laïcat chrétien, remplisse librement son rôle." 112
\end{abstract}

Un des principaux problèmes en paroisse est vraiment celui de la dynamique ecclésiale. Cette dynamique institutionnelle de l'Église est à sens unique. Elle engendre encore aujourd'hui des sujets (les clercs) et des objets (les laïcs et les clercs situés aux échelons inférieurs de la hiérarchie et quelques-uns aux échelons supérieurs). Le type de relations ecclésiales fait des ministres ordonnés le seul sujet véritable de l'Église. De plus, le Nouveau Code remet dans les mains du clergé tout le pouvoir. Les laïcs sont inévitablement condamnés à la condition d'objet. Le seul droit ecclésial du laïcat est un droit à la passivité.

\footnotetext{
"Nous n'avons pas porté dans les années qui ont suivi Vatican II, une attention suffisante à ces impératifs d'ordre institutionnel /.../ Le prêtre qui lutte pour que, dans sa paroisse et au-delà, dans le diocèse, la notion de ministère comme service ne demeure pas un voeu pieux, constate que les structures institutionnelles actuelles ne favorisent pas la mise en pratique du discours."113
} 
"Ce qu'il importe de modifier, c'est le rapport de l'homme à ses institutions, plutôt que le contenu des institutions /.../ Entre l'homme et son monde, le rapport doit être un rapport de circularité, ou autrement dit, un rapport dialectique." 114

Les sciences politiques nous ont appris que les libertés qui ne se concrétisent pas par des droits sont abstraites et irréelles. La capacité juridique permet d'agir. Elle est certes insuffisante, mais sans elle on ne fera rien ou on ne nous laissera rien faire d'important.

\begin{abstract}
"Nous sortons d'une époque marquée dans le catholicisme par une polémique contre le juridisme, d'une époque de mépris, d'ignorance du droit. Demeure en nos esprits quelque chose de l'esprit de 1968, de l'utopie d'une liberté au-delà du droit et des institutions. Nous voyons mal qu'une effervescence de l'Esprit inattentive aux formes du droit nous réduit vite à l'impuissance./.../ On croit souvent vivre dans un "univers spirituel toujours évangélique" dans l'Église. Un jour vient où une décision d'autorité nous concerne (à l'occasion d'une demande de baptême, d'un mariage mixte), on s'aperçoit assez rapidement qu'on dépend d'une société visible où un droit nous est opposé. Par contre, si nous sommes sujets de droit, nous pouvons faire reconnaître notre droit." 115
\end{abstract}

C'est que, s'il est vrai que les plus belles organisations sont des codes vides quand elles ne sont pas animées par l'Esprit, il est vrai aussi que les meilleures intentions sont inefficaces quand elles sont paralysées par des structures inadaptées.

\title{
11.5.2 Une nécesssaire "dépapelisation" de l'Église
}

La réflexion théologique est excessivement importante dans le contexte ecclésial d'aujourd'hui. Les pratiques pastorales actuelles démontrent les nombreux enjeux ecclésiologiques à affronter avec intelligence. La manière dont Jean-Paul II assume sa responsabilité ministérielle et l'organisation structurelle actuelle avec un

114

JOLIF, Y., Humanité, Foi et Institution, Notes philosophiques, document de travail de R. PARENT présenté au cours sur le Ministère ordonné du 14 avril 1992 à l'UM.

115 ESLIN, Jean-Claude, "Citoyen de la république chrétienne?, Manifeste d'un catholique français", in Esprit, mars-avril 1993, n90, p.116. 
partage inégal du pouvoir mettent en péril bien des acquis conciliaires concernant entre autres l'Église diocésaine comme Église-Sujet, expression authentique de l'Église catholique. La forte personnalité de ce pape polonais a augmenté les effets ecclésiologiques néfastes du culte au "Souverain Pontife". Nous ne sommes pas encore arrivés à vivre concrètement cette ecclésiologie trinitaire prônée à Vatican II. Celle-ci appelant particulièrement les Églises locales à agir en partenaires responsables les unes et les autres, et toutes ensemble de l'Église et de sa mission dans le monde. L'évêque qui préside l'Église particulière, peut et doit parler de plus en plus fort. S'il ne le fait pas, s'il se laisse intimider à Rome, réduire au mutisme, s'il se laisse interroger, il ne remplit déjà plus sa fonction plénière: car chez lui et à Rome, il est l'égal de l'évêque de Rome, c'est à lui d'interroger la curie, de mettre en valeur les besoins du peuple et des communautés paroissiales, de renvoyer les questions à l'interlocuteur, de résister au pouvoir central.

Pourquoi la faiblesse d'influence de l'Église locale par rapport à l'Église de Rome, malgré sa redécouverte et sa mise en valeur à Vatican II? Quels sont les obstacles majeurs au développement des pouvoirs dans l'Église et en particulier dans les diocèses? Pourquoi cette nouvelle ecclésiologie ne parvient-elle pas à fonctionner dans le catholicisme? Je dirais entre autres que c'est parce que le pouvoir effectif des évêques n'a pas été clairement défini par Vatican II. C'est le point décisif. Ce qui fait ombre à l'Église locale est l'illimité du pouvoir papal voulu par Vatican I et l'ambiguïté de Vatican II qui dit deux choses à la fois. Le retournement ecclésiologique opéré par Vatican II n'a pas été suivi dans ses conséquences. Partir des évêques, c'est aussi partir des Églises locales et de la communion des Églises locales. Lumen Gentium \#27 dit bien: "....il ne faut pas voir en eux des vicaires des pontifes romains, car ils exercent un pouvoir qui leur est propre et c'est en toute vérité qu'on les appelle chefs du peuple qu'ils dirigent." Mais le texte conciliaire, à la suite de tant d'autres, affirme tellement à 
la fois le pouvoir plein et entier de l'évêque dans son diocèse et le pouvoir plein et entier de l'évêque de Rome sur l'Église universelle qu'en pratique deux ecclésiologies coexistent potentiellement dans la constitution Lumen Gentium, avec pour effet une ambivalence, la possibilité de tirer de ce document deux représentations de l'Église, une plus épiscopale, et une autre dominée par le pape. ${ }^{116}$

\begin{abstract}
"Dans la pratique et la conception romaine actuelle s'est instaurée une répartition des rôles: aux évêques la gestion pastorale; cela suffit largement à les occuper; au pape le magistère doctrinal. Cette répartition des tâches est contraire au fondement théologique. Les évêques sont par définition docteurs et gardiens de la foi. /.../ Quelle est la liberté des éêques en regard de l'enseignement du pape? Les évêques sont coincés dans l'exercice de leur magistère entre deux fidélités: celle qu'ils doivent à la vérité et qui réclamerait une grande liberté, celle qu'ils doivent au pape, président du collège des évêques dont ils sont membres, et qui réclame une attitude de solidarité." 117
\end{abstract}

Il faut une décentralisation du magistère au niveau des ministres diversifiés en relation avec les communautés. Un des problèmes majeurs en Église est la concentration du magistère au seul niveau du pape. Il faut le descendre au niveau des évêques mais aussi au niveau des baptisés. Cette manière de concevoir le magistère permet de faire éclore la diversité qui constitue une richesse permettant de contempler la grâce plurielle du Dieu Vivant dans le coeur des personnes et des communautés croyantes. Le pouvoir de dire "la splendeur de la vérité" dans l'Église catholique se trouve monopolisé actuellement. Ce pouvoir doit être redonné à l'universalité de l'Église. La fausse unanimité épiscopale provoque des effets de rejet de la part des paroissiens ayant des esprits lucides et des effets d'aveuglement de la part des esprits timides. Elle élimine la dialectique des opinions contraires, nécessaires à tout progrès dans la pensée. La démocratie exige le pluralisme, surtout le débat!

\footnotetext{
$116 \quad$ Voir à ce sujet: ALBERIGO, G., Irenikon, 51, 1978, p. 475.

117 ESLIN, Jean-Claude, "Citoyen de la république chrétienne?, Manifeste d'un catholique français", p.124. "Si les évêques ont un devoir d'enseigner et de le faire de façon responsable, ils ont un droit corrélatif d'avoir des avis personnels, dans la compatibilité avec la foi chrétienne /.../ La liberté des évêques est plus nécessaire à l'Église qu'aux évêques euxmêmes."NAUD, André, Le Magistère incertain, Montréal, Fides, 1987, p. 123; p. 169.
} 
Nous sommes loin de la paroisse me direz-vous? Au contraire.... Si nous sommes attentifs aux besoins des communautés paroissiales, nous découvrons qu'il faut accéder, entre autres, à de nouvelles pratiques ministérielles. Ces nouveaux ministères ne peuvent pas émerger actuellement. Pourquoi? Ce pouvoir de décider appartient exclusivement aux évêques et surtout au Pape dans l'Église. Si nous ne le remettons pas en question, il ne sera jamais possible de renouveler l'institution paroissiale et la pastorale en milieu urbain en conformité avec les besoins de la pratique communautaire et de "décléricaliser" les ministères. Le pouvoir dit H. ARENDT correspond à la faculté humaine non seulement d'agir et de faire quelque chose, mais de s'associer à d'autres et d'agir en accord avec eux. 118 Être une personne en droit romain, c'est avoir une capacité juridique, une responsabilité. L'esclave n'a pas de personnalité civile. La personne, le citoyen, le paroissien, le catholique existe dans la mesure où il exerce une potestas, des pouvoirs, des responsabilités. C'est ce qui m'amène à croire comme Jean-Claude ESLIN que

"les questions aujourd'hui capitales dans l'Église sont des questions de pouvoir, de droit et pas uniquement de théologie. Des procédures de pouvoir se sont cristallisées dans l'Église romaine./.../ Aussi longtemps que l'autocritique de cette cristallisation ne sera pas menée, aucun espoir d'unité des chrétiens, aucune liberté dans l'Église ne seront sérieux. Un droit a donné visage à l'Église, un droit devra modifier son visage. De ce point de vue, la théologie risque souvent de n'être qu'idéologie." 119

Derrière les obstacles actuels dans l'Église sont en jeu des manières de concevoir la liberté, la pluralité, l'unité, la vérité et tous les autres concepts doctrinaux et finalement le visage qu'a pris l'Église romaine. Mais il est également naïf d'envisager une

118 Voir ARENDT, H., Condition de l'homme moderne, Traduction de: The Human Condition, Paris, Cerf, Paris, Calmann-Lévy, 1988, 406p.

119 ESLIN, Jean-Claude, "Citoyen de la république chrétienne?, Manifeste d'un catholique français", p. 117. 
redistribution du pouvoir dans le catholicisme sans une sorte de révolution mentale et surtout spirituelle.

\subsubsection{Un nouveau Concile: Vatican III et un Code renouvelé?}

La mise en oeuvre d'un concile est en un sens, plus importante que le concile lui-même. Elle en donne le visage concret, effectif. Après Vatican II, comme après le concile de Trente, une vingtaine d'années sont nécessaires pour que l'on puisse prendre la mesure des tenants et aboutissants de l'événement et pour que se dessinent les lignes de force de sa mise en oeuvre. L'avenir du concile de Trente s'est joué vingt ans après sa conclusion quand des décrets en fixèrent un type d'interprétation et de mise en pratique, très en retrait sur les décisions conciliaires. Quelques années après le concile Vatican II, au demeurant convoqué d'en haut plus que demandé par la base, dans les années 1970, il apparut que des choix décisifs devaient être faits au niveau des moyens et relais à mettre en oeuvre: ou bien s'orienter vers la mise en place d'un réseau de communautés et de ministères "pauliniens", dans le sens d'une diversification des ministères, repenser le ministère du prêtre dans le contexte paroissial, donner une place institutionnelle aux femmes; ou bien donner la priorité au maintien et à la sécurité de l'appareil, de la hiérarchie catholique traditionnelle. L'autorité "suprême" a finalement privilégié l'appareil clérical. La stratégie adoptée par Jean-Paul II renforçant l'image traditionnelle du prêtre ${ }^{120}$, refusant l'ordination d'hommes mariés et de femmes, laisse voir, vingt ans après, ses conséquences. Dès maintenant et à terme, elle ruine la vie des paroisses. Que faudrait-il faire pour s'en sortir? L'organisation d'un synode diocésain dans les Églises locales sur les sujets les plus controversés en Église et la remontée des débats jusqu'à la curie romaine? La convocation d'un nouveau concile, Vatican III

$120 \quad$ Nous avons eu une autre belle preuve dans le document romain paru en avril 1994 qui demande aux prêtres de porter la soutane. 
et un travail commun entre dogmaticiens et les canonistes pour la rédaction d'un nouveau Code fidèle aux décisions conciliaires? Pourquoi pas?

"Un concile en appelle un autre. Beaucoup de questions restent en suspens. Les textes conciliaires contiennent tant de choses différentes, et parfois contradictoires, qu'il faudra bien trancher un jour! Va-t-on enfin donner aux Églises locales la chance d'être ellesmêmes? Va-t-on développer une véritable inculturation qui tienne compte de la diversité des peuples et des cultures? Comment l'Église peut-elle continuer à légiférer pour le monde entier? II faudrait un Vatican III pour mettre en oeuvre Vatican II." 121

Il faut penser à toutes ces solutions. Le dynamisme de l'Église catholique et surtout l'avènement du Royaume de Dieu en dépendent. 


\section{CHAPITRE 12}

\section{L'APPROCHE CONCILIAIRE ET CANONIQUE DE LA PAROISSE}

Même si les Pères Conciliaires n'ont pas beaucoup réfléchi sur l'institution paroissiale, il est important de connaître quelle a été la conception de la paroisse à Vatican II. La paroisse est le cadre dans lequel les chrétiens rencontrent l'Église et c'est aussi le cadre à travers lequel la majorité des ministres ordonnés, reconnus et mandatés exercent leur action pastorale. Le pape Jean XXIII, avant le début des travaux conciliaires, avait déclaré que le prochain concile devait se concentrer avant tout sur la paroisse. Mais les Pères conciliaires ont privilégié la réflexion sur l'Église diocésaine. Ceci explique pourquoi la paroisse a été définie comme une "cellule" du diocèse. Nous avons noté dans le chapitre précédent l'importance d'une organisation structurelle juridique adéquate à l'ecclésiologie conciliaire. J'ai alors trouvé essentiel d'approfondir dans la deuxième partie du présent chapitre les innovations canoniques touchant la paroisse dans le Code de 1983. Nous constaterons une fois de plus que le Nouveau Code est encore actuellement un frein plus qu'un accélérateur dans l'Église. L'analyse de l'approche canonique de la paroisse nous prouvera d'une manière plus explicite à quel point les orientations ecclésiologiques de Vatican II n'ont pas véritablement trouvé une traduction juridique opérationnelle au niveau organisationnel, même dans ce nouveau Code publié presque vingt ans après ce Concile. Ce chapitre se terminera par la validation d'une partie de mon hypothèse de recherche: la paroisse est réellement une "cellule" de l'Église locale atteinte, comme tout l'organisme ecclésial, par le syndrome Clerc-laïc ("SCL"). Je compléterai enfin en donnant certains axes théologiques pour renouveler la paroisse selon l'ecclésiologie de communion et en nommant les possibilités paroissiales actuelles porteuses d'avenir. 


\subsection{La paroisse dans les Actes du Concile Vatican II}

Cette première partie du chapitre est consacrée à l'analyse de quelques textes du dernier Concile abordant plus explicitement la paroisse. Nous verrons que les Pères conciliaires l'ont définie comme une "communauté localement organisée sous un pasteur qui tient la place de l'évêque". Également, pour eux, la paroisse ne peut être considérée comme une réalité autonome mais comme une portion de l'Église diocésaine. Nous noterons finalement les dommages ecclésiologiques du fait que le Concile ne lui ait pas prêté suffisamment attention.

\subsubsection{Une communauté locale, organisée sous un pasteur}

Le Concile Vatican II a parlé de la paroisse principalement dans trois textes, l'un dans la constitution sur la liturgie et deux dans la constitution sur l'Église. Ces trois textes pourraient être lus en parallèle. Citons les passages essentiels:

\footnotetext{
"Comme l'évêque dans son Église ne peut présider en personne à tout son troupeau, ni toujours, ni partout, il doit nécessairement constituer des assemblées de fidèles, parmi lesquelles les paroisses, organisées localement sous un pasteur qui tient la place de l'évêque. Car d'une certaine manière, elles représentent l'Église visible établie dans l'univers. C'est pourquoi il faut favoriser dans l'esprit et dans la pratique des fidèles et du clergé, la vie liturgique de la paroisse et son rattachement à l'évêque; et il faut travailler à ce que le sens de la communauté paroissiale s'épanouisse, surtout dans la célébration communautaire de la messe dominicale" (SL 42).

"(les prêtres) dans chacune des communautés locales de fidèles, rendent pour ainsi dire présent, par leur fidèle et généreuse collaboration, l'évêque dont ils assument, chacun pour sa part, les devoirs et les préoccupations en faisant l'objet de leur constante sollicitude. Sous l'autorité de l'évêque, ils sanctifient et gouvernent cette portion du troupeau qui leur est confiée; là où ils se trouvent, ils rendent visible l'Église universelle et contribuent à l'édification de tout le corps mystique du Christ" $(L G 28,2)$.
}

"Cette Église du Christ est vraiment présente dans toutes les communautés locales des fideles légitimement réunies autour de leurs pasteurs et que le Nouveau Testament luimême appelle Églises. En effet, là où elles se trouvent, se trouve aussi le Peuple nouveau 
appele par Dieu dans le Saint-Esprit... Dans ces assemblées souvent petites, pauvres et éloignées les unes des autres, le Christ est présent de qui par sa puissance rassemble l'Église une, sainte, catholique et apostolique" $(L G 26,1)$.

La constitution sur la liturgie n'entendait pas donner directement un enseignement sur la paroisse, un concept de paroisse. Cela est clair. La communauté de fidèles, qu'est le diocèse, l'Église particulière, est subdivisée en diverses communautés et parmi cellesci précisément existent les paroisses. De là on doit conclure que la paroisse pour les Pères conciliaires doit être considérée comme un "groupe de fidèles", une "communauté de personnes". Plus loin la Constitution parle de "communauté paroissiale". Ce texte ne précise pas directement les éléments spécifiques qui identifient la paroisse, mais on retrouve quelques éléments: "localement organisée sous un pasteur qui tient la place de l'évêque".

$\Delta$ "localement": la communauté paroissiale est une communauté locale, même si la notion de territoire n'est plus première pour définir la paroisse. Ici territoire est un moyen concret pour délimiter ou identifier une communauté particulière. 1

$\Delta$ "organisée sous un pasteur": la communauté paroissiale doit avoir un pasteur comme chef. La présence du pasteur est essentielle au concept de communauté en général et à celui de communauté paroissiale en particulier. ${ }^{2}$

$\Delta$ "qui tient la place de l'évêque": le pasteur, chef de la communauté paroissiale, tient la place de l'évêque; ce que l'évêque est pour le diocèse, le curé l'est pour la paroisse. La communauté paroissiale est donc en lien essentiel avec la communauté diocésaine, ce qui est fortement souligné au n ${ }^{\circ} 2$ de $S L 42 .{ }^{3}$ Les textes de

1

Le territoire n'est ici qu'un moyen, un instrument pour identifier à l'intérieur du diocèse une communauté concrète de personnes (Voir aussi $C D 11 ; 22 ; 24 ; 30,1 ; 38,1 ; 39 ; 40,3 \ldots$ ).

2 Pour les Pères du Concile Vatican II, la présence du prêtre en qualité de pasteur est essentielle à l'existence et à l'être de la communauté. Que la communauté soit diocésaine ou qu'elle soit paroissiale, la présence du ministère pastoral est requise. Une communauté ecclésiale ne peut pas se concevoir si elle n'est pas hiérarchiquement structurée. C'est l'élément pastoral qui rassemble dans l'unité la pluralité des personnes.

3 Le prêtre, pasteur, chef de la communauté, est considéré dans sa relation essentielle avec l'évêque diocésain. Cette relation hiérarchique du curé vis-à-vis de l'évêque est constamment 
Lumen Gentium font référence à des éléments très proches de ceux étudiés précédemment. La paroisse est considérée comme une "assemblée de fidèles", "une "portion du troupeau du Seigneur". Les communautés paroissiales sont multiples et locales. À la tête de chacune des communautés spécifiées localement, il y a un prêtre en qualité de pasteur: la communauté ne se concevrait pas sans lui. Le prêtre rend présent l'évêque et il est sous son autorité.

Le texte de $L G$ 26,1 contient les mêmes éléments: le diocèse et la paroisse sont essentiellement "rassemblement de fidèles", "peuple nouveau", ("fidelium congregationes, populus novus "). Ce sont des ensembles de personnes, des communautés. Elles sont légitimes en "adhérant à leurs pasteurs". L'élément hiérarchique, la fonction du pasteur, est de ce fait au concept de communauté ecclésiale et donc de communauté paroissiale. Il est affirmé que "l'Église du Christ est vraiment présente" dans de telles portions et qu'elles "sont aussi appelées Églises dans le Nouveau Testament". Nous avons vu comme Sacrosanctum Concilium s'exprimait: "Elles représentent d'une certaine manière l'Église visible établie sur toute la terre" et $L G$ 28,2: "Dans leur lieu, elles rendent visible l'Église universelle". Ici l'expression est plus prégnante: "l'Église du Christ est vraiment présente"; les communautés locales hiérarchiquement structurées sont donc l'Église en cet endroit. Le Concile parle d'abord de l'Église diocésaine, mais l'analogie est extensible aux communautés paroissiales. La suite a une expression très forte: "Dans ces communautés le Christ est présent". Cette présence du Christ semble se situer en parallèle avec l'autre expression vue ci-dessus: "L'Église du Christ est vraiment présente". Non seulement l'Église du Christ, mais le Christ lui-même est présent dans ces communautés locales. Notons que le lieu où le Christ se rend présent, c'est la communauté en tant que telle, la communauté des Il est impossible de concevoir un curé sans nomination de l'évêque, cela serait absolument illégitime. 
fidèles. Nous devons admettre que le Concile ne définit pas ceci avec de nets contours conceptuels, mais la substance y est, même s'il n'est pas facile de préciser en quoi consiste cette présence du Christ et ce qui en découle pour la communauté ecclésiale.

\subsubsection{Une "cellule" de l'Église}

La paroisse est en relation avec l'Église diocésaine. Elle est une portion de l'Église particulière. Elle ne peut pas se considérer comme une réalité autonome. On a employé cette expression: l'image de la paroisse est une "cellule" de l'Église particulière ( $A L 10, \# 3$ ). La paroisse est cellule au sens biologique en tant qu'elle provient de la division et de la différenciation de la cellule primaire qu'est le diocèse. C'est pourquoi elle est engendrée par l'organisme dont elle fait partie et elle ne trouve sa nature profonde et sa raison d'être que dans cet organisme et en référence à lui. C'est à partir de la théologie de l'Église particulière qu'il faut alors considérer la paroisse, comme moyen privilégié pour elle d'accomplir sa mission de salut. Cette mission s'articule dans les trois fonctions d'enseigner, de sanctifier et de servir les hommes pour faire d'eux les fils du Père, dans le Fils, par l'Esprit-Saint. À la lumière de la théologie de l'Église-communion, la paroisse devient compréhensible comme structure ecclésiale, car elle actualise l'Église localement bien que de façon non plénière comme le diocèse. L'élément déterminant, théologiquement, de la paroisse comme communauté ecclésiale est d'être, dans sa relation à l'Église particulière, un moyen stable, précis, universel dans sa composition, multiple dans ses réalisations, en vue de réaliser pour et avec des personnes déterminées la mission de salut confiée par le Christ. 


\subsubsection{La "communauté" paroissiale}

D'autres textes du Concile parlent de la paroisse, de sa vie, de ses activités et de ses buts. Je me contente d'en citer quelques-uns:

"Il faut travailler à ce que le sens de la communauté paroissiale s'épanouisse surtout dans la célébration communautaire de la messe dominicale" ( SC 42,2).

"Les curés favoriseront la croissance de la vie chrétienne dans toute la communauté paroissiale"( SC 30,7).

"La paroisse offre un exemple remarquable d'apostolat communautaire, car elle rassemble dans l'unité tout ce qui se trouve en elle de diversités humaines et elle les insère dans l'universalité de l'Église" $(A L 10,2)$.

"... des assemblées de fidèles qui, menant une vie digne de l'appel qu'elles ont reçu, soient telles qu'elles puissent exercer les fonctions à elles confiées par Dieu: sacerdotale, prophétique, royale. C'est de cette manière qu'une communauté chrétienne devient signe de la présence de Dieu dans le monde" ( $A G$ 15,2).

"Puisque le peuple de Dieu vit dans des communautés, diocésaines et paroissiales surtout, et que c'est dans ces communautés que d'une certaine manière il se montre visible, c'est aussi aux communautés qu'il appartient de rendre témoignage au Christ devant les nations" ( $A G 37,1)$

"Mais il est par ailleurs nécessaire de former les enfants de telle manière que, dépassant le cadre familial, ils ouvrent leur esprit à la vie des communautés, aussi bien ecclésiales que temporelles. Leur intégration à la communauté paroissiale locale doit être faite de telle manière qu'ils y prennent conscience d'être membres vivants et agissants du peuple de Dieu" $(A L 30,3)$.

Ces textes contiennent une série d'éléments intéressants. La paroisse est considérée comme une communauté, une unité, un sujet communautaire, plus précisément, un sujet agissant communautairement. Tous les textes évoquent les activités typiques de la paroisse, qu'il s'agisse de la vie à l'intérieur de la paroisse ou de ses activités externes. En premier, le Concile souligne d'une manière particulière l'activité liturgique de la paroisse: la célébration eucharistique en est le point culminant. L'activité caritative et la vie chrétienne font grandir la vie spirituelle et c'est ainsi que la communauté 
paroissiale se construit. Le témoignage de la communauté rend visible pour le monde la présence salvifique de Dieu et du Christ. La communauté paroissiale doit devenir signe de salut et attirer tous ceux qui sont au loin, dans la mesure où elle saura traduire dans sa vie la parole et les préceptes du Seigneur.

\subsubsection{La grande oubliée à Vatican II: la paroisse}

Même si je viens de noter plusieurs textes conciliaires sur la paroisse, il demeure que, si on considère l'ensemble des déclarations de Vatican II, nous retrouvons peu de documents sur cette institution. Le Concile a privilégié la réflexion sur l'Église particulière, le diocèse. "La paroisse est le cadre dans lequel les chrétiens rencontrent en fait l'Église et c'est aussi le cadre à travers lequel la majorité des prêtres exercent leur action pastorale. À ce double titre, pratique, la paroisse est plus importante que le diocèse...". ${ }^{4}$ Cependant, historiquement et théologiquement, la paroisse a toujours été une donnée seconde par rapport à l'Église locale. Le dernier Concile ne lui a pas prêté une attention vraiment spécifique. Vatican II a tout axé sur le diocèse et sur les évêques. Lorsque le Pape Jean XXIII, à l'aube du deuxième concile de Vatican s'est adressé aux paroissiens de Castel Gandolfo (le 15 août 1962), il a spontanément souligné que le travail conciliaire devait se concentrer sur la paroisse.

"La lumière vive du concile oecuménique éclairera en particulier les paroisses et préparera ainsi un renouvellement de l'activité pastorale. /.../ Le travail préparatoire ainsi que l'abondante littérature déjà édictée par le concile ont placé la paroisse, en évidence, au centre du débat, suivie par les diocèses et par les problèmes de la vie sociale au sein de l'Église." 5

LEGRAND, Hervé, "La réalisation de l'Eglise en un lieu", in Initiation à la pratique de la théologie, tome III, Paris, Cerf, 1983, p.175.

5 HUTSMANS, R., Tussen Concilie en Synode, Hilversum, 1981, p. 9 cité par KERKHOFS, Jan, "L'Église locale de Vatican II jusqu'à nos jours", in La Maison-Dieu, $\mathrm{n}^{\circ} 165$, 1986, p. 74. 
Parmi les 70 études préparatoires, cinq études étaient principalement consacrées à la paroisse et de nombreuses autres abordaient ce sujet dans leur thématique. Cependant, dès 1963, la paroisse avait déjà cessé de constituer un sujet prioritaire dans les débats, et l'intérêt porté à la paroisse a diminué de session en session.

La lacune grave de Vatican II est donc qu'aucune attention n'est vraiment accordée en fait à la base pastorale, aux communautés paroissiales. Toutefois, Hervé LEGRAND croit que la théologie de l'Église locale élaborée au dernier Concile assure à la paroisse une base doctrinale satisfaisante. Pour lui, le véritable problème n'est pas uniquement celui de l'attention insuffisante des Pères du Concile à l'institution paroissiale mais également, du nouveau rôle de la paroisse dans l'espace urbain industrialisé. C'est précisément ce défi de l'adaptation de la paroisse au milieu urbain qui constitue le coeur de la présente thèse doctorale.

"Les perplexités exprimées de-ci de-là au sujet de l'avenir de la paroisse, traduisent moins des incertitudes théologiques que les difficultés de cette institution à passer d'un rôle globalisant, qui était le sien pour les chrétiens de l'espace rural, aux multiples rôles qu'elle doit remplir dans l'espace urbain industrialisé."6 


\subsection{L'approche canonique de la paroisse ${ }^{7}$}

Le 27 novembre 1983 est entré en vigueur dans l'Église latine le Nouveau Code de Droit canonique promulgué par le Pape Jean-Paul II le 25 janvier 1983. Ce jour-là, les dispositions du Code de 1917 ont été abrogées. Ceux qui attendaient du sensationnel ont été fatalement déçus; le nouveau droit n'est pas révolutionnaire. Mais il demeure intéressant d'analyser un peu plus profondément les innovations canoniques entre le Code de 1917 et celui de 1983 concernant l'institution paroissiale.8

\subsubsection{Les innovations canoniques}

Dans l'ancien Code, les éléments constitutifs de la paroisse étaient par ordre de priorité les suivants:

$\Delta$ Le territoire;

$\Delta$ L'église;

$\Delta$ La communauté des fidèles;

$\Delta$ Le curé comme pasteur propre;

$\Delta$ Le bénéfice du curé, à savoir l'office avec les revenus qui y sont attachés.

7

Je me suis limité à utiliser les expressions canoniques pour écrire les prochaines lignes même si plusieurs d'entre elles sont incompatibles avec ma vision ecclésiologique et théologique de la paroisse. Ce choix a été fait pour éviter toute polémique avec les canonistes. Les échanges avec plusieurs d'entre eux m'ont invité à une plus grande prudence dans le choix des expressions utilisées. C'est pour cette raison que je me suis tenu très proche du texte du volume d'un canoniste réputé dans le but d'être plus fidèle aux nombreuses nuances juridiques importantes. Voir PÉRISSET, JeanClaude, La Paroisse, Commentaires des Canons 515-572, Paris, Tardy, 1989, 278p. [Le Nouveau Droit Ecclésial]

Notons que les premiers éléments de l'histoire du statut canonique de la paroisse remontent au IV ${ }^{\circ}$ siècle; elle s'est forgée par la suite autour du statut du curé et de la fonction curiale d'une part, de celui du bénéfice d'autre part. C'est au Concile de Trente que la paroisse comme telle reçoit un statut dans le droit de l'Église.

$8 \quad$ Le Code 1983 traite au chapitre VI du titre III de la deuxième partie du livre II, soit 38 canons, des "paroisses, curés et vicaires paroissiaux". Notons tout de suite que le Code de 1917 n'étudiait pas directement les paroisses; 28 canons en deux chapitres parlaient des curés et des vicaires paroissiaux. 
Le territoire apparaissait comme l'élément déterminant. L'église et la communauté des fidèles confiés au curé comme pasteur propre venant au second, comme pour meubler ce territoire.

La définition de la paroisse donnée par le Code de 1983 met en valeur au contraire la communauté des fidèles constituée de façon stable (c. 515,\#1), ainsi que la charge pastorale du curé comme office, la formule bénéficiale étant appelée à disparaître. ${ }^{9}$ Il n'est plus fait mention de l'église ni du territoire, sinon indirectement (cc. 374, \#1 ; 516 et 518). ${ }^{10}$ Le Nouveau Code reconnaît comme éléments canoniques constitutifs de la paroisse les suivants:

9

"La paroisse est une communauté précise de fidèles constituée de façon stable dans l'Église particulière, dont la charge, sous l'autorité de l'évêque diocésain, est confiée au curé comme à son pasteur propre " (c. 515,\#1). "Dans le projet de 1977, la paroisse était définie comme "portion déterminée du peuple de Dieu qui est constituée dans l'Église particulière". Un consulteur propose de dire: "communauté de fidèles", avec l'assentiment du secrétaire de la Commission, parce que la parole "portion" exprime davantage un fait physique statique que l'interaction dynamique entre plusieurs personnes sous la conduite du même pasteur. Tout en souhaitant le maintien de "portion" pour le diocèse, un second consulteur estime que "communauté" convient bien à la paroisse, dans laquelle l'aspect communautaire est plus manifeste. Au rapporteur qui voudrait juxtaposer les deux notions, le secrétaire répond: "la caractéristique de la paroisse n'est certainement ni le territoire ni la communauté, mais bien qu'une certaine partie de l'Église soit confiée au curé comme à son pasteur propre, muni de droits et devoirs précis" (cf. Comm, 13 (1981), p.148)" ( PÉRISSET, Jean-Claude, La Paroisse, Commentaires des Canons 515-572, Paris, Tardy, 1989, p. 29. [Le Nouveau Droit Ecclésial].Je me suis beaucoup inspiré de ce volume pour rédiger ce chapitre). Le Nouveau Code clôt ainsi la vieille querelle doctrinale relative au concept de paroisse, tel qu'il était exprimé dans le Code de 1917 au canon 216. En fait, les auteurs considéraient la paroisse comme un simple territoire ou comme un territoire pourvu d'une église, de fidèles ou de pasteurs, ou comme un office de curé et seulement quelques-uns considéraient la paroisse comme une communauté.

10 "La norme de ce canon 374,\#1 rend obligatoire la division du diocèse en paroisses, obligation tempérée cependant par les dispositions du canon 516. Curieusement, ces deux canons n'explicitent pas le pourquoi ou le fondement de cette division./... / Vu la nature de la paroisse comme partie du diocèse, toute intervention relative à son existence dépend de l'êvêque diocésain avec le concours du conseil presbytéral (c. 515,\#2), conformément à la norme du canon 114,\#1. C'est du diocèse que la paroisse tire non seulement son existence, comme "partie distincte" (c. 374, \#1), mais encore sa structure fondamentale./../ Tout comme le canon 216 de l'Ancien Code, le canon 374 part du diocèse pour dire qu'il doit être divisé en parties distinctes, sans préciser davantage. La dimension territoriale est donc absente des canons 374 et 515,\#1, pour laisser intacte la notion d'Église particulière non territoriale (cc. 368-372). La territorialité affleure pourtant au canon 374,\#2 dans l'expression "paroisses voisines" pour des regroupements comme les vicariats forains. Elle est explicite par contre au canon 518: "En règle générale, la paroisse sera territoriale." /.../ L'érection de 
$\Delta$ La communauté des fidèles;

$\Delta$ L'office du curé en tant que pasteur propre. Le territoire n'est qu'élément extrinsèque de détermination de la communauté des fídèles.

Également, l'église ne conserve sa nature canonique de personne juridique, en tant que chose ou fondation autonome, qu'à condition d'être gérée par un conseil de fabrique distinct de la paroisse. Par conséquent, c'est la paroisse comme un tout, telle que définie au canon 515, \#1, qui possède de droit la personnalité juridique (c. 515,\#3).

"La paroisse telle que définie au canon 515, \#1 du Nouveau Code apparaît comme le rassemblement local le plus immédiat de l'Église dont elle possède tous les éléments. Seul le diocèse est Église particulière dans laquelle et à partir de laquelle, existe l'Église catholique dans ses multiples réalisations concrètes (c. 368). La paroisse est dans l'Église particulière, comme une partie distincte ou une cellule, pour son actualisation effective. C'est à partir de l'Église particulière par conséquent qu'il faut considérer la paroisse et les éléments qui font d'elle une communauté ecclésiale."11

La paroisse est donc dans l'Église particulière. Elle n'a pas d'existence autonome, comme division du diocèse, soit sous l'aspect de communauté comme partie distincte, soit sous l'aspect de l'exercice du ministère, le curé étant d'abord membre du

paroisses personnelles était auparavant réservée au Siège apostolique (c. 216,\#4) dans l'Ancien Code. Il n'y a plus aujourd'hui de limites à la responsabilité de l'évêque diocésain en ces questions, ni pour les paroisses territoriales, ni pour les paroisses personnelles (c. 518). Cette compétence pleine et entière de l'évêque dans tout ce qui concerne la paroisse, comme aussi pour la nomination du curé (c. 523), est l'un des acquis essentiels du Concile Vatican II dans le domaine pastoral (Christus Dominus, 31; 32)."( PÉRISSET, Jean-Claude, La Paroisse, Commentaires des Canons 515-572, p.26, p.30, p.33, pp.35-36). Rappelons que ce n'est qu'avec le Code de 1917 que la division du diocèse en paroisses a été rendue obligatoire (c. 216,\#1 a.C.)., le Concile de Trente ayant seulement souhaité l'érection des paroisses pour un meilleur exercice du ministère pastoral (sess. XIV, c.9 de réf. ), surtout quant au mariage (sess. XXIV, c. 13, de ref.).

11 PÉRISSET, Jean-Claude, La Paroisse, Commentaires des Canons 515-572, Paris, Tardy, 1989, p. 15. "Notons cependant qu'il serait canoniquement faux de dire que la paroisse est au diocèse ce que le diocèse est à l'Église universelle; il n'y a pas de proportionnalité propre entre ces deux termes, car "l'Église catholique existe et subsiste dans les Églises particulières", en un rapport essentiel (c. 368); tandis qu'il serait faux d'affirmer que le diocèse existe et subsiste dans la paroisse. Au contraire, comme "cellule", c'est la paroisse qui n'existe et ne subsiste que dans le diocèse; non pas en un rapport essentiel, mais existentiel" ( Ibid., p.35 ). 
presbytérium diocésain, ayant comme charge l'office de pasteur propre d'une communauté. Cette conception canonique de la paroisse comme partie distincte d'un diocèse est ici assez fidèle aux textes conciliaires.

Le diocèse est défini comme "portion du peuple de Dieu confiée à un évêque pour qu'il en soit le pasteur, avec la coopération du presbytérium, de sorte que, dans l'adhésion à son pasteur et rassemblée par lui dans l'Esprit Saint par le moyen de l'Évangile et de l'Eucharistie, elle constitue une Église particulière" (c. 369). Rappelons que l'expression "portion du peuple de Dieu" est réservée uniquement à l'Église particulière (cc. 368-372). Les éléments nécessaires au diocèse sont les suivants:

$\Delta$ La communauté des fidèles rassemblée par l'évêque qui en a la charge;

$\Delta$ L'Évêque proclamant l'Évangile et célébrant l'Eucharistie;

$\Delta$ Avec la coopération des prêtres formant un presbytérium;

$\Delta$ Dans la communion hiérarchique avec le chef et les membres du collège des évêques (cc. 336 et 337 ,\#2).

C'est pourquoi, dans le rapport nécessaire de la paroisse à l'Église particulière, les éléments constitutifs de la paroisse sont:

$\Delta$ La communauté précise de fidèles dans l'Église particulière;

$\Delta$ Le curé exerçant la charge pastorale sous l'autorité de l'évêque;

$\Delta E n$ union avec les prêtres membres du presbytérium, en particulier par une action commune dans le vicariat forain, ou tout autre regroupement.

"Il faut noter ici, les limites de l'analogie entre la paroisse et le diocèse, car canoniquement le curé membre du presbytérium ne partage pas la charge pastorale de l'évêque comme celui-ci partage celle du pape, chef du collège des evêques, qui est sujet du pouvoir suprême et plénier sur toute l'Église ( c.336). Canoniquement, le curé ne partage pas le pouvoir de gouvernement de l'évêque /.../ mais y coopère, n'ayant aucun pouvoir législatif; aucun pouvoir exécutif, sinon des facultés habituelles de droit ou déléguées pour l'accomplissement de certains actes; aucun pouvoir judiciaire (cc. 391 et 519). C'est surtout en raison de l'office du curé comme participation à la charge pastorale de l'évêque, 
que la paroisse acquiert sa nature ecclésiale propre, sa référence à l'Église particulière étant nécessaire à son existence." 12

D'autres innovations canoniques concernant la paroisse dans le Code de 1983 sont intéressantes même si elles sont nettement insuffisantes. Du point de vue systématique, les déterminations relatives à la paroisse sont contenues dans quatre canons (515-519) qui précèdent les normes pour le curé et le vicaire paroissial (cc. 519-552). Quant aux normes elles-mêmes, l'innovation majeure est celle des canons 517 ,\#1 et 542-544, qui permet de confier la charge pastorale d'une ou de plusieurs paroisses ensemble solidairement à plusieurs prêtres; et celles du canon 517,\#2, de confier l'exercice de cette charge à des non-prêtres, pour les tâches qui n'exigent pas "l'intervention immédiate du prêtre". D'autres innovations sont importantes à mentionner: l'institution du conseil pastoral paroissial (c. 536) qui n'est cependant pas obligatoire; l'abolition de l'inamovibilité du curé, tout en lui maintenant une stabilité relative dans sa charge; la possibilité de confier la charge de curé pour un temps déterminé (c. 522); la description de la charge propre du curé selon les trois fonctions de la mission de l'Église, d'enseigner, de sanctifier et de servir (cc. 528-529); la nouvelle figure juridique du vicaire forain qui met en valeur sa charge de coordonnateur du ministère des curés, conformément à la définition du vicariat forain (c. 374,\#2), charge éminemment pastorale, plutôt qu'administrative (c. 555). Il est utile de spécifier également les points suivants: la convenance d'être consultée pour la nomination, le transfert ou la révocation du curé (c. 524), le devoir des fidèles de participer aux initiatives pastorales et de s'en faire les promoteurs dans la paroisse, en collaboration avec le curé, en application des canons 519; 529, \#2; 215; 216; 225; 211 et 228 ,\#1 et la place des laïcs assumant un office ecclésiastique dans la paroisse comme assistants ou agents pastoraux, en application du canon 231. 


\subsubsection{Une conception juridique paroissiale toute centrée sur le curé}

Même si la nouvelle définition de la paroisse parle premièrement de la communauté des fidèles, il demeure que canoniquement, c'est la charge pastorale du curé qui est si l'on peut dire, l'élément constitutif formel de la paroisse. Les fidèles n'ont pas de poids juridique. 13 De fait, les normes concernent en priorité le curé, pour l'exercice convenable de sa charge. La relation du curé à la communauté dont il reçoit la charge de l'évêque diocésain comme pasteur propre, détermine non seulement la paroisse comme personne juridique (cc. 515,\#3; 115,\#1; 116), mais lui donne encore sa structure interne et sa mission. Lorsqu'il est question de la communauté des fidèles, elle est toujours en relation à la charge pastorale, conformément à la définition donnée au canon 515,\#1. Le curé est d'abord le pasteur qui met à la disposition des fidèles les biens du salut à travers la prédication, la célébration du culte et les actes du gouvernement (can. 519). Même un canoniste déplore cette conception juridique tout axée sur le curé:

"Il faut regretter que la communauté précise de fidèles n'ait pas été davantage considérée pour elle-même, bien qu'elle n'ait pas d'existence comme paroisse en dehors de sa relation au curé. Le législateur aurait pu cependant dire quelque chose du droit des fidèles, en tant que communauté paroissiale, comme par exemple, d'avoir un pasteur apte à remplir sa charge convenablement (cela n'est dit qu'indirectement aux canons 539, $545, \# 1 ; 1740$ ). De plus, le Code devrait faire droit davantage à la dimension charismatique de la paroisse, tant de la part du curé que de la communauté elle-même. I.../ Le pasteur propre qui décide les entreprises pastorales paroissiales et qui est l'animateur premier est le curé /../ De fait, la définition de la paroisse (c. 515,\#1) exprime cette inégalité dans le fait que la communauté des fidèles est l'objet de la charge pastorale confiée au curé." 14

13

Les baptisés, appelés canoniquement les "fidèles", ne sont donc pas des sujets. Comme nous l'avons noté dans le précédent chapitre, en droit romain, être une personne, c'est avoir une capacité juridique. La personne, le citoyen, le paroissien existe dans la mesure où il exerce une potestas, des pouvoirs, des responsabilités.

14 PÉRISSET, Jean-Claude, La Paroisse, Commentaires des Canons 515-572, p. 19; p. $170 ;$ pp. 172-173. 
Ce n'est donc pas la communauté des fidèles qui donne à la paroisse son être ecclésial mais le curé, comme membre du presbytérium coopérant à la mission pastorale de l'évêque. 15 Nous sommes encore loin de l'Église communionnelle de Vatican II qui nous centrait sur l'ensemble du peuple de Dieu tout en ne faisant pas l'économie des instances de représentativité. Si large que soit la participation du peuple de Dieu, les ministres ordonnés sont les porte-parole officiels du peuple et sont les centres de coordination de l'ensemble. Le défi étant de ne pas faire des courts-circuits entre ces instances de représentativité et les autres baptisés du peuple de Dieu.

"Le ministère du curé est principalement l'exercice de la "cura pastoralis", sollicitude ou soin pastoral qui est l'une des charges principales de l'Église comme "sacrement universel de salut" ( $L G 1$ ). I.../ L'expression "cura pastoralis" revient quinze fois dans les canons 515 à 552. /.../ Dans les normes concernant la paroisse, "cura pastoralis" est traduit par "charge pastorale" aux canons 539 et 541,\#1, et par "fonction(s) pastorale(s)" aux canons 544 et 550,\#1; donc toujours sous l'aspect de la sollicitude pastorale assumée par un pasteur d'âmes." 16

Cette nuance est importante puisque l'expression "sollicitude pastorale" met l'accent sur la communauté; tandis que "charge pastorale" le met sur son pasteur. ${ }^{17}$ Le nouveau Code de droit canonique de 1983 emploie le terme 'pastoral', ce qui ne se voyait à peu près pas dans le Code de 1917.

15

Le Code de 1983 ne donne aucune définition du presbytérium diocésain, mais en affirme seulement l'existence (cc. 245,\#2; 400,\#2; 495,\#1; 499; 529,\#2; 713,\#3; 757). Le Code de 1917, dans sa formulation du rapport à l'évêque, se contentait d'affirmer que le curé exerce sa charge "sous l'autorité de l'évêque". Le nouveau Code exprime la relation hiérarchique du curé à l'évêque, en ajoutant: "dont il partage le ministère du Christ." En définitive, le curé, comme pasteur propre, exerce sa charge non pas au nom de l'évêque,mais en relation à l'évêque. Dans le Code de 1917, on ne trouve pas l'expression "pasteur", ni pour l'évêque (c. 329 a.C.) ni pour le curé (c. 451 a.C.) ni même pour le Pape (c. 218 a.C.).

16

17 Dans la vision renouvelée du Code de 1983, c'est la charge pastorale qui est confié à un prêtre membre du presbytérium et non plus une paroisse comme un titre de "propriété". 
"Maintenant, le 'soin pastoral' a presque supplanté la cura animarum ; on parle de 'fonctions pastorales', 'd'action pastorale', de 'bien pastoral', 'd'oeuvres pastorales' . I.../ la paroisse elle-même est devenue une 'communauté précise de fidèles [...] dans l'Église particulière (can. $515 \mathrm{n}^{\circ} 1$ ); et le diocèse, qui est une portion du peuple de Dieu (can. 369)'. Et pour tout dire, la personne, membre de ce peuple, est dans l'ensemble privilégiée par rapport à l'institution" 18

Sur ce point, le Code de 1983 a fait des progrès mais, comme nous l'avons vu précédemment, il lui en reste encore beaucoup à faire.

Le curé peut devenir modérateur d'une équipe pastorale. Mais, dans ce cas, c'est lui qui reçoit la charge pastorale et non les laïcs. Canoniquement, ceux-ci sont appelés à être des aides précieux et même pas des collaborateurs.

\begin{abstract}
"(c. 517,\#2) Il s'agit ici soit d'un fidèle non-prêtre pris isolément (diacre, religieux, religieuse, laïcs), soit d'une équipe pastorale (dont la composition peut être variée), dont l'activité doit obligatoirement être dirigée par un prêtre doté de tous les pouvoirs et facultés du curé. C'est ce prêtre qui "a la haute main sur", qui "est maître de" - c'est le premier sens du verbe "moderari" - la charge pastorale paroissiale, parce que lui seul est apte, en raison de son état sacerdotal, à exercer pleinement le ministère nécessaire pour la communauté (cc. 150, 519, 528 et 529). Toutefois, il ne peut le remplir convenablement seul (c. 545,\#1), et n'ayant pas d'autres prêtres pour l'aider, ni comme vicaire (ibidem), ni comme collaborateurs (c. 519), il a besoin d'aide sûre et stable. /.../ Quoi qu'il en soit de la possibilité pour les laïcs d'être sujets du pouvoir de gouvernement ou de juridiction, le droit actuel exprimé au canon 517,\#2 stipule que les fidèles non-prêtres peuvent participer seulement à l'exercice de la charge pastorale du curé."19
\end{abstract}

La première optique du Code de 1983 dans cette situation est bien celle de l'aide des laïcs à la charge du curé. L'activité propre des laïcs est donc réduite à un simple soutien à la mission du curé et non pas à un partage de la présidence ecclésiale. Les perspectives plus ouvertes à Vatican II allaient davantage pour les laïcs mandatés vers une participation à la présidence. En fidélité aux profondes intuitions conciliaires, nous

\footnotetext{
18 PAGÉ, Roch, Les Églises particulières, Montréal, Paulines, 1985, pp.11-12.

19 PÉRISSET, Jean-Claude, La Paroisse, Commentaires des Canons 515-572, p.199;

p. 204.
} 
pouvons affirmer que comme les prêtres sont coopérateurs de l'Ordre épiscopal, les laïcs doivent être les coopérateurs des prêtres dans la mission en un rapport d'égalité.

\subsubsection{Peut-on comparer le Code de 1983 et le Concile Vatican II ?}

\section{Le Code de 1983 s'est inspiré du Concile Vatican II mais il n'en a pas repris}

l'ensemble des grandes intuitions, entre autres en ce qui concerne l'institution paroissiale. Il n'est pas parvenu à une organisation structurelle de cette participation de tous pour qu'advienne l'Église-Sujet et de sujets. Sa structure ne reflète pas parfaitement les changements intervenus à Vatican II. ${ }^{20} \mathrm{Il}$ existe donc une distorsion entre les promesses conciliaires et les décrets d'application. La défaillance du droit perçue après le Concile demeure même avec ce nouveau Code.

"Mais il subsiste toujours un écart entre les représentations de l'Église et les pratiques ecclésiales. On peut même parler de certaines impasses dans la mise en oeuvre de cette ecclésiologie théologique. Plusieurs attribuent cette difficulté à la co-existence d'ecclésiologies concurrentes. Ainsi, dans les documents conciliaires de Vatican II, et dans la pratique de l'Église post-conciliaire, une ecclésiologie de la communion voisine l'idée de société hiérarchique. La communion ecclésiale, parce qu'elle fait participer des personnes différentes aux mêmes réalités, fonde l'aspiration à une responsabilité partagée. Une ecclésiologie plus hiérarchique insiste sur la diversité des dons et des charges confiées pour le bien de tous, mais concentre la responsabilité de l'Église entière entre les mains de quelques-uns. Tout le problème consiste à traduire dans les institutions et les pratiques une représentation théologique. Le code de droit canonique de 1983 n'est pas vraiment parvenue à traduire le nouveau visage de l'Église inspiré de Vatican II. Des pratiques cléricales ou autoritaires chevauchent encore avec des pratiques communautaires. Certains discours officiels semblent parfois se situer en deça de l'esprit manifesté à Vatican II, tout en utilisant le vocabulaire conciliaire. Une ecclésiologie strictement théologique risque donc de "spiritualiser" une définition de l'institution qui ne parvient pas à prendre forme dans la pratique. Il est facile d'utiliser les notions théologiques de communion et de mystère tout en maintenant une vision proche de la rationalité juridique et légitimant le statu quo ecclésial. Tout en ne cessant pas d'être

20

Nous avons vécu une "révolution copernicienne" ecclésiologique au deuxième Concile. Cependant, il est important de noter qur les Pères conciliaires ont à quelques reprises ménagé la chèvre et le chou. Ils ont, dans certains documents du Concile, exposé encore parfois une vision pyramidale de l'Église, même si ce n'était pas leur intention. Nous ne devons pas être surpris alors que les "Pères" canoniques aient succombé aussi à ces fortes tentations! 
théologique, l'ecclésiologie doit donc s'engager sur un terrain plus pratique au nom même de la vérité de sa réflexion sur l'Église."21

Vatican II avait insisté non seulement sur la dignité du laïcat mais aussi sur la responsabilité à l'endroit de l'ensemble de la vie ecclésiale. La fonction de conseiller, de consulté, d'aide sûre et stable n'épuise pas cette responsabilité. Les canons 208-231 concernant les droits et les devoirs des laïcs chrétiens excluent les laïcs de toute participation au pouvoir législatif.

\begin{abstract}
"La période que nous vivons connaît de grandes difficultés à articuler des concepts théologiques nouveaux, ou traditionnels mais oubliés, avec leur implication juridique. Par exemple, les notions de peuple de Dieu, d'Églises particulières, de sens de la foi des fidèles, de collégialité, de synodalité, de coresponsabilité, de "ministère" ou charges de laïcs ont-ils trouvé un contenu juridique concret susceptible de modifier la configuration structurelle de l'Église? Un point chaud de cette articulation se situe dans l'avènement des divers conseils de la vie ecclésiale: synodes et conseils diocésains, conseils presbytéraux et, plus largement, les conseils de pastorale de paroisses ou de secteurs. Ces institutions ont une compétence seulement "consultative". Ce qualitatif, "consultatif", pourrait donner à penser que leurs membres sont appelés à y exercer un rôle d'approbation ou d'exécution, ou au mieux de conseiller en vue de décisions, qui, de toute façon, seront prises en haut. Une telle perspective s'opposerait à la dynamique ecclésiale d'une Églisecommunion préconisée par Vatican II. Il importe de l'affirmer face à une pratique qui ne respecte pas la participation responsable des baptisés ou rappelle, de manière obsessionnelle, le caractère consultatif de ces instances. Dans ce cas, on ne ferait qu'augmenter le nombre de chrétiens requis pour faire fonctionner un système déjà établi et solliciter le pouvoir discrétionnaire des ministres." 22
\end{abstract}

Les chrétiens les plus conscients refusent de rester de simples exécutants dociles et irresponsables. Ils veulent participer à la vie de l'Église. Joseph RATZINGER, n'avaitil pas déjà déclaré en 1972: "Il est insensé et naïf de penser que l'Église... puisse s'enfermer paisiblement dans le passé. Comme les autres âges, celui de la démocratie est un appel qui s'adresse directement à l'Église. Elle doit s'y rendre avec l'esprit à la

PELCHAT, Marc, "Ecclésiologie théologique et ecclésiologie contextuelle, L'ecclésiologie dans les études pastorales", in VISSCHER, A.-M., dir., Les études pastorales à l'université, Perspectives, méthodes et praxis, Ottawa, Les Presses de l'Université d'Ottawa, 1990, p. 162. 
foi ouvert et critique." 23 De nombreux documents démontrent malheureusement que celui-ci a changé d'idée depuis qu'il est le Préfet de la Congrégation de la Doctrine de la foi. Il semble maintenant plus proche d'une conception monarchique que démocratique de l'Église.

\begin{abstract}
"Quoi d'étonnant que l'Église, lorsque les structures démocratiques de l'État moderne se généralisent, Eprouva les plus grandes difficultés à adapter ses structures à l'exigence d'écoute et de participation aux délibérations de tous les fidèles en matière de gouvernement ecclesiastique (quelle que soit la forme concrète qu'il serait possible de donner à une telle adaptation). Lorsque cette Église exprime ses réticences à ce sujet, elle le fait toujours en faisant appel à ce qu'elle déclare être la "structure hiérarchique, voulue par Dieu". Cet ordre hiérarchique, conforme au plan divin, ne pourrait s'accommoder de structures démocratiques. Ce malentendu historique est devenu, à notre époque démocratique, un des points de friction les plus douloureux entre le "troupeau" des catholiques fidèles et ses bergers. Notre époque est particulièrement soupçonneuse à l'égard de toute forme de monarchisme absolu, où le pouvoir se concentre en un seul chef, et/ou dans une oligarchie élitaire, car elle en a reconnu les abus et l'arbitraire. En conséquence, le monarchisme ecclésial est éprouvé aujourd'hui comme proprement intolérable." 24
\end{abstract}

Les Actes du Siège apostolique nous permettent régulièrement de constater que pour le moment, l'Église officielle présente le mode démocratique de gouvernement comme une sorte d'idéal à préférer pour toute "société civile". Cette même Église catholique romaine s'y présente, au contraire, et par principe, comme une structure sociale non démocratique. Or c'est bien là la clef de l'argumentation que l'on retrouve dans quantité de documents officiels des dicastères de l'Église catholique romaine: un mode de gouvernement démocratique serait incompatible avec la soumission à la révélation divine. Pourquoi donc? Elle est le produit d'une idéologie cachée: le pouvoir en place (conduit par l'Esprit) a toujours raison; tout partage de pouvoir avec les subordonnés ne serait que nuisible à son bon fonctionnement. Prétendre que l'Église ne peut s'accommoder de l'esprit démocratique parce qu'elle est hiérarchique n'est donc rien

RATZINGER, J., et MAIER, H., Démocratisation dans l'Église, Paris, Apostolat des éditions, 1971, p. 54.

24 SCHILLEBEECKX, E., L'histoire des hommes, récit de Dieu, p. 286 
d'autre qu'un "trompe-l'oeil", qui tire son apparence d'argument d'un usage magique et idéologique du mot "hiérarchie".

Il faut être honnête. Le nouveau Code a fait un progrès sur la place des laïcs comparativement au Codex de 1917. La perspective de ce Codex était individualiste et reproduisait une scission plus grande entre hiérarchie et fidèles. L'unique canon positif consacré était le c.682 qui leur assurait le droit de recevoir les sacrements et les secours spirituels de la part des clercs. 25 Ces derniers, pour leur part, se voyaient consacrer 379 canons! Mais malgré ses avancées par rapport à celui de 1917, le Code de 1983 continue de maintenir les laïcs, particulièrement les femmes, dans une situation d'infériorité. Elles sont exclues de tous les domaines qui concernent la juridiction ordinaire de l'ensemble de la vie ecclésiale: enseignement doctrinal et moral, organisation et gestion, vie sacramentelle, etc. Le lectorat et l'acolytat, pourtant ouverts aux laïcs, sont encore réservés aux hommes (canon 230, \#1). Quant à "l'ordination sacrée", seul un homme (vir ), baptisé peut la recevoir validement (canon 1024). Les femmes ne peuvent même pas bénéficier de toutes les prérogatives du statut de laïque (lectorat, acolytat). Il n'est donc pas vrai de penser que le Nouveau Code correspond pleinement aux déclarations conciliaires de Vatican II. C'est ce que croit pourtant JeanPaul II....

" .... cet instrument qu'est le Code correspond pleinement à la nature de l'Église, spécialement comme la décrit le magistère du Concile Vatican II en général, et en particulier dans son enseignement ecclésiologique.Et en un certain sens, on pourrait même voir dans ce Code un grand effort pour traduire en langage canonique cette doctrine même de l'ecclésiologie conciliaire." 26 
Jean-Paul II va même jusqu'à affirmer dans son discours aux Auditeurs de la Rote le 26 avril 1984 que le Code "pourrait même être considéré comme le dernier document conciliaire".27 Je crois au contraire, comme le pense également Edward SCHILLEBEECKX, que le Nouveau Code est actuellement plus un frein qu'un accélérateur dans l'Église. "Le droit ecclésiastique actuellement en vigueur au sujet de la place des ministères dans l'édification évangélique de l'Église est davantage un frein qu'un accélérateur." 28 Et ce théologien, qui constitue une figure inspiratrice pour moi, va même jusqu'à souhaiter qu'on impose les mains aux nombreux croyants engagés au service des Églises. Cela permettrait de pouvoir redonner aux communautés croyantes l'eucharistie et éviter d'en être privé en raison de l'absence structurelle de prêtres.

"...je cherche une solution à un problème poignant puisque l'absence de prêtres prive beaucoup de communautés croyantes de la célébration eucharistique. Constatant que cette pénurie de ministres est une situation ecclésialement impossible qui n'a pas lieu d'être, je demande que l'on impose les mains aux nombreux croyants engagés au service des Églises, au cours d'une épiclèse adéquatement formulée, créant ainsi une nouvelle différenciation des ministères qualifiés. Il y a de nombreux candidats. L'obstacle est donc ailleurs." 29

Je formule ce même souhait, cette même intention de prière.

La Documentation Catholique, $\mathrm{n}^{\circ} 1869$, p. 260 . Il est dangereux de donner la même valeur ecclésiologique au travail de quelques canonistes et à celui de l'ensemble des évêques du monde entier réunis en collégialité au concile. Le Pape aurait dû être plus prudent et éviter de faire une telle déclaration qui a de graves conséquences théologiques. Toutefois, un canoniste m'a rassuré en me disant que Jean-Paul II aurait demandé aux juristes de poursuivre leur travail dès maintenant pour que le prochain Code de droit canonique soit encore plus fidele aux intuitions conciliaires de Vatican II. 


\subsection{Acquis de recherche éclairants}

Fidèle à "ma tradition", je complète ce chapitre en resaississant certains éléments pour en faire des pointes lumineuses en vue d'éclairer les problématiques d'ensemble de cette thèse doctorale écrite sous l'angle de l'approche systémique.

\subsubsection{La paroisse, une "cellule" ecclésiale réellement atteinte du SCL}

Ce chapitre consacré à l'approfondissement de l'approche conciliaire et canonique de la paroisse et le précédent touchant plus explicitement l'ecclésiologie de Vatican II valident une partie de mon hypothèse de recherche. La paroisse est véritablement une "cellule" de l'Église locale atteinte, comme tout l'organisme ecclésial, du Syndrôme Clerc-Laïc (SCL; Église de sujets et d'objets). Même si les orientations conciliaires de Vatican II ont injecté dans le corps ecclésial, par "in vitro", l'anti-corps "CM" (Communauté-Ministères; dynamique institutionnelle à double mouvement; valorisation du sacerdoce baptismal ${ }^{30}$, sacrement du "nous" chrétien) pour combattre le "SCL" qui met sérieusement en danger la santé de l'organisme ecclésial (entre autres une de ces cellules: la paroisse), celui-ci n'est pas encore parvenu à le détruire. Cet anticorps "CM" a été bien "fabriqué théoriquement en "laboratoire conciliaire" par les Pères de Vatican II mais ceux-ci ne lui ont pas donné les conditions nécessaires (ex: traduction juridique insuffisante de l'organisation structurelle de l'Église en conformité aux intuitions conciliaires, une théologie du laïcat lacunaire, une réflexion quasi inexistante sur le service de la présidence ecclésiale dans le contexte paroissial, un

$30 \quad$ ".... trois propositions sur le sacerdoce baptismal: 1) Leur sacerdoce permet à tous les baptisés de vivre ici et maintenant (hic et nunc) la plénitude du salut /.../2) Le sacerdoce baptismal vit la plénitude du salut dans l'histoire humaine, y compris dans ses limites et son péché /.../3) Le sacerdoce baptismal doit être compris comme un horizon indépassable de vie, d'agir et d'intelligibilité "(Dufour, Simon, PARENT, Rémi, Les Ministères, pp. 17-18.). 
pauvre approfondissement sur l'institution paroissiale, etc.) pour qu'il puisse donner les effets escomptés sur toutes les cellules du corps ecclésial atteintes depuis de nombreuses années du "SCL". Également, depuis plus de 25 ans, particulièrement "sous" le pontificat de Jean-Paul II, certains membres de l'Église ont maintes fois contribué à faire avorter les effets novateurs du "CM".31 Le "SCL" continue ainsi à se proliférer dans toutes les différentes parties du corps ecclésial. Ceci explique que de nombreux efforts de "laïcs" depuis plusieurs années pour devenir des sujets actifs dans le devenir des communautés ecclésiales et pas seulement dans les "affaires du monde", ont à quelques reprises subi des traitements assez violents de "chimiohiérarchie" par l'autorité compétente, les "spécialistes cléricaux". Il devient donc de plus en plus urgent de poursuivre notre lutte communautaire contre ce cancer ecclésial afin que les dynamismes concilaires les plus novateurs à Vatican II puissent définitivement constituer les principes de structuration ecclésiale.

\subsubsection{Les axes théologiques pour renouveler la paroisse selon l'ecclésiologie de communion}

Une des lacunes graves à Vatican II est qu'aucune attention n'est véritablement accordée à la base pastorale, c'est-à-dire aux communautés paroissiales. Jean XXIII espérait que la réflexion conciliaire se situe prioritairement au niveau de la paroisse et par la suite au niveau du diocèse. Mais nous avons vu que les Pères $d u$ Concile ont fait le cheminement inverse. Le défi actuel est donc de retourner aux "premières inspirations" du bon pape Jean XXIII et d'investir dans la réflexion

31

Le champ de bataille de Jean-Paul II semble bien être la lutte contre l'avortement. Ses proches conseillers affirment que l'encyclique récente "Veritatis Splendor" en constitue l'objectif principal poursuivi... indirectement. Il demeure étonnant que c'est ce même pape (lui et certains membres de la curie romaine) qui est en train de faire avorter les embryons de vie "communionnelle" les plus vigoureux, autonomes et responsables dans l'Église. Sa vision ecclésiale inspirée davantage de Vatican I que de Vatican II est la méthode "contraceptive" ecclésiale la plus "naturelle" et la plus "efficace" pour tuer tous les foetus ecclésiaux produits à Vatican II. Quel paradoxe! 
théologique sur l'institution paroissiale. Cependant, nous n'avons pas besoin de partir à zéro. Il me semble que la théologie de l'Église locale élaborée à Vatican II peut constituer une base doctrinale intéressante pour approfondir ecclésiologiquement la paroisse. La piste théologique ne serait-elle pas de poursuivre la logique ecclésiologique du dernier concile jusqu'au bout, c'est-à-dire jusqu'au niveau de la paroisse en considérant celle-ci comme une "Église en laquelle est vraiment présente et agissante l'Église du Christ, une, sainte, catholique et apostolique" ( $C D$ 11) ?

Si nous désirons mener à leur pleine cohérence les intuitions fondamentales du concile Vatican II, nous devons aller jusqu'à concevoir la paroisse comme présence et actualisation de l'unique Église de Dieu. La paroisse ne devrait alors plus être considérée comme une "cellule" du diocèse mais comme une expression authentique de l'Église unique et catholique où le Christ est lui-même présent comme l'ont si admirablement déclaré les Pères dans $L G$ 26,1.

"Cette Église du Christ est vraiment présente dans toutes les communautés locales des fidèles légitimement réunies autour de leurs pasteurs et que le Nouveau Testament luimême appelle Églises. En effet, là où elles se trouvent, se trouve aussi le Peuple nouveau appelé par Dieu dans le Saint-Esprit... Dans ces assemblées souvent petites, pauvres et éloignées les unes des autres, le Christ est présent de qui par sa puissance rassemble l'Église une, sainte, catholique et apostolique" $(L G 26,1)$.

Nous savons que dans ce texte le Concile parle d'abord de l'Église diocésaine mais l'analogie peut et doit être extensible aux communautés paroissiales. La paroisse devrait être reconnue comme une structure ecclésiale actualisant l'Église localement et cela de façon plénière comme le diocèse. Dans cette conception, on ne pourrait plus parler de paroisse comme d'une "fraction" d'Église s'additionnant arithmétiquement à d'autres fractions pour constituer l'Église diocésaine ni non plus d'une Église autonome et autarcique, juridiquement refermée sur elle-même mais bien comme d'une expression authentique de l'Église unique et catholique, tirant son autorité et sa garantie 
de son rapport organique avec l'Église diocésaine et l'Église tout entière. Elle ne serait plus conçue comme une partie subordonnée et incomplète de l'Église diocésaine mais elle deviendrait un sujet actif de la manifestation de l'Église en un lieu donné. En bref, la paroisse serait une Église-Sujet dans sa relation avec les autres paroisses du diocèse, également Églises-Sujets. La mission de l'Église diocésaine (elle-même Église-Sujet) serait entre autres de favoriser la concorde, la cohésion et la synodalité des communautés paroissiales présidées par l'ensemble des divers ministres sous la présidence de l'évêque.

Il est important de préciser les conséquences théologiques et juridiques qui découlent de cette conception de la paroisse comme d'une Église authentique. Cette manière de considérer la paroisse comme une véritable Église en un lieu amènerait à approfondir le ministère de la présidence ecclésiale en lui-même et non plus en dépendance à l'Ordre épiscopal. À Vatican II, on a traité du pape et des évêques tandis qu'on s'est fait beaucoup plus discret sur le service de la présidence ecclésiale dans le contexte paroissial. Le presbytérat a été réduit à une participation à l'épiscopat au lieu d'y voir un charisme spécifique. Alors, de la même manière que nous avons voulu au Concile réaffirmer le ministère épiscopal comme partenaire du ministère de l'évêque de Rome, il faudrait resituer les prêtres comme des coopérateurs de l'Ordre épiscopal en les considérant comme des partenaires authentiques dans le travail d'animation, de coordination et de présidence des communautés. Le curé (ou le modérateur) comme membre du presbytérium devrait partager la charge pastorale de l'évêque comme celuici partage celle du pape, chef du collège des évêques. Il devrait avoir les mêmes pouvoirs de gouvernement que l'évêque dans la portion du peuple de Dieu confiée (pouvoir législatif et exécutif et non pas uniquement des facultés habituelles). Comme dans l'Église ancienne, il faudrait que l'évêque redevienne curé de la cathédrale (tout en étant président du presbytérium) pour avoir un enracinement concret sans cela il 
devient facilement un administrateur et un touriste pastoral dans les différentes communautés. Il n'y aurait plus de différence ontologique entre un prêtre, un évêque et le pape. Ils sont tous des baptisés et des ministres égaux en dignité. Ils ont tous un bâton pastoral pour accompagner la marche (croissance) évangélique des communautés chrétiennes. C'est seulement la longueur de leur bâton pastoral (i.e. la juridiction du territoire) qui diffère. Dans cette conception théologique, le pape n'est pas le pasteur de l'Église universelle mais le pasteur de l'Église de Rome et président du collège des évêques. Il est un évêque parmi d'autres qui préside le collège épiscopal. L'Église locale n'est pas une partie de l'Église universelle mais l'Église universelle en un lieu. L'évêque n'est plus le pasteur de toute l'Église diocésaine mais le pasteur de l'Église cathédrale, président du presbytérium. Il est un prêtre parmi d'autres qui préside le collège des presbytres. La paroisse n'est plus une partie incomplète du diocèse mais l'Église diocésaine se réalisant en un lieu. ${ }^{32}$ Le prêtre n'est pas un "sousévêque" mais un coopérateur à part entière avec les mêmes droits et pouvoirs que l'évêque titulaire pour une portion du peuple de Dieu. Le curé (ou le modérateur) n'est pas le seul pasteur de la communauté mais devient, avec la coopération des divers ministres, le président de l'équipe pastorale. ${ }^{33}$ L'appartenance à un presbytérium devrait continuer à être vécue comme une double exigence pour le ministre ordonné. La première étant de partager avec les autres membres les particularités de son propre service. La deuxième étant l'accueil de l'apport des autres ministres, même si cet apport dérange et inquiète.

32

J'élaborerai un peu plus sur ce sujet dans la dernière partie de cette thèse. Je trouve important malgré tout de dire brièvement que la paroisse doit aspirer à devenir une communion de communautés. Chaque communauté, qu'importe le nombre de ses membres $(50,100,1,000,20,000$, etc.) doit être considérée comme une authentique Église. Au niveau théologal, il y a Église en un lieu dès que nous avons un groupe ecclésial constitué. Au niveau institutionnel, il faut une organisation juridique (comme exemple la paroisse, le diocèse) pour aider à faire crôtre l'unité entre les diverses communautés. Le ministre ordonné a justement cette mission de promouvoir le lien entre le niveau théologal et celui institutionnel.

33 Les membres de l'équipe pastorale devront posséder de réels pouvoirs pour qu'ils puissent avoir un poids juridique dans l'Église. 
Ce travail proprement théologique de donner une base doctrinale à l'institution paroissiale en fidélité aux intuitions conciliaires de Vatican II ouvre des voies intéressantes. Il nous fait sortir réellement de l'ecclésiologie à étages (pyramidale) et permet de vivre concrètement l'Église communionnelle. L'Église "Peuple de Dieu" ne serait plus une idéologie mais deviendrait une donnée historique. J'ai dit dans le précédent chapitre que les questions aujourd'hui capitales dans l'Église sont des questions de pouvoir, de droit et non uniquement de théologie. ${ }^{34}$ En proposant cette conception de la paroisse comme Église unique et authentique, nous sommes obligés d'aborder directement ces questions dans leurs principaux enjeux.

\subsubsection{Les possibilités paroissiales actuelles porteuses d'avenir ${ }^{35}$}

Nous ne pouvons pas attendre Vatican III et un autre Code de droit canonique pour renouveller la paroisse. En attendant le Grand Soir, il y a des possibles porteurs d'avenir déjà présents dans différentes communautés paroissiales. Il est vrai que nous retrouvons plusieurs lacunes dans l'ecclésiologie de Vatican II et dans le Code de 1983. Toutefois, grâce à ce même concile et à certaines innovations canoniques, nous avons franchi en Église des étapes importantes dans la mise en

34

Voir CESARI, Constance Colonna, Urbi et Orbi, Enquête sur la géopolitique vaticane, Paris, Ed. de la découverte, 1992, 279p.

35 Voir Comité des ministères de l'Assemblée des évêques du Québec, Communautés et ministères au Québec: situation, questions, défis, Montréal, Fides, 1993, 35 p.;Voir aussi BAUSCH, William J., The hands-on parish, Reflections and suggestions for Fostering Community, Connecticut, twenty-third publications, 1991, 220p.; SWEETSER, Thomas, Successful Parishes, How they meet the challenge of change, San Francisco, Harper and Row, 1983, 254 p.; SWEETSER, Thomas, WISNIEWSKI HOLDEN, Carol, Leadership in a successful parish, San Francisco, Harper and Row, 1987, 204p.; FOSTER M. Patricia, SWEETSER, P. Thomas, Transforming the parish, Models for the future, Kansas City, Sheed and Ward, 1993, 241p.; DOLAN, P. Jay, APPLEBY, R. Scott, BYRNE, Patricia, CAMPBELL, Debra, Transforming Parish, The changing roles of catholic clergy, laity, and women religious, New York, Crossroad, 1990, 336p. 
oeuvre d'une Église-communion. Il faut faire mémoire de ces pas pour éviter de ne plus croire en un avenir possible et de tomber dans le découragement. Les prochains défis ne sont pas insurmontables. Déjà, depuis 1965, des petites semences ecclésiologiques "communionnelles" ont éclos et permis de vivre plus concrètement cette Église "Peuple de Dieu". Il y a encore des mauvaises herbes. Il y en aura toujours. Mais cela ne doit pas nous empêcher de poursuivre le jardinage ecclésial pour faire pousser cette nouvelle Église définie à Vatican II dans la terre du Royaume de Dieu. Le dernier Code nous a donné quelques "marges" de liberté pour inventer de nouveaux réaménagements pastoraux. Il faut utiliser au maximum ces marges permises pour jardiner la terre paroissiale avec les engrais de l'ecclésiologie du dernier Concile. Il importe donc de faire connaître et de reconnaître les expériences pastorales réussies, en particulier celles des équipes pastorales où des prêtres, des diacres et des laïcs travaillent de concert à l'animation de la vie ecclésiale. Cette diffusion des meilleures expériences devrait s'étendre d'une paroisse à une autre, d'un diocèse à un autre et même au niveau de l'Église universelle. Il sera toujours profitable d'apprendre de situations ecclésiales à la fois proches et lointaines.

Comme l'ont fait les membres du Comité des Ministères de l'Assemblée des évêques du Québec dans leur document "Communautés et Ministères au Québec: situations, questions défis", "il est important de souligner les domaines où les mentalités ont évolué au cours des dernières années, favorisant l'acquisition progressive d'un certain nombre de convictions sur lesquelles nous pouvons nous appuyer dans l'avenir" 36 pour renouveler la paroisse et l'Église. Je reprends quelquesuns des acquis qui ont retenu leur attention. Nous devons demeurer vigilants pour ne pas perdre ces acquis et nous en servir pour aller encore plus loin dans de nouvelles ministères au Québec: situation, questions, défis, p.14. 
solutions audacieuses et les accompagner d'une recherche théologique suffisante. Il ne faut pas demander à la théologie des solutions toutes faites, mais réfléchir théologiquement aux choix qui se présentent à nous aujourd'hui pour inventer l'avenir. Il faut susciter des recherches et des échanges plus ouvertes entre les spécialistes du "dire" et les experts du "faire", en somme, entre tous les interprètes des différents terrains théologiques et pastoraux.

Il est primordial d'avoir une vigilance sur le "hiérarchique" en poursuivant la valorisation du sacerdoce baptismal et la responsabilisation des différents conseils paroissiaux. Il faut continuer à promouvoir la participation la plus large possible des chrétiens à tous les niveaux organiques de l'Église. C'est un des seuls moyens pour combattre le syndrome ecclésial "SCL" et ainsi faire naître l'anti-corps "CM" (communauté-ministères). Déjà, de nombreuses fonctions ecclésiales ont été ouvertes aux laïcs. Des femmes et des hommes accèdent à des ministères précédemment occupés par des prêtres. Nous devons poursuivre en ce sens.

\footnotetext{
" Au cours des dernières années, le mot d'ordre a porté sur la coresponsabilité en Église. La fortune du mot n'a eu d'égale que son ambiguïté pratique, il demeure qu'on a commencé à mieux saisir que la responsabilité pastorale devrait être partagée, collégiale. /.../ Ainsi a-t-on commencé à prendre davantage pour acquis un principe ecclésial de base voulant que personne dans l'Église n'agisse seul, mais qu'on s'acquitte de sa responsabilité en respectant sa dimension profondément communautaire, à travers les conseils pastoraux, les équipes d'animation, les assemblées et comités qui sont autant d'expressions de la réalité ecclésiale."37
}

On voit maintenant comme une orientation particulièrement urgente, surtout depuis une quinzaine d'années, la promotion et le développement de la participation, influencée et soutenue par tout un courant de démocratisation qui marque de plus en plus la société et l'Église. 
Un aspect de la réalité important à noter est l'accession des femmes à des ministères. Il n'est plus rare de voir des femmes assumer un poste de direction administrative ou de coordination pastorale même dans le cadre théologique et juridique actuel. Nous devons nous réjouir de l'audace des autorités pastorales du Québec et les encourager à aller encore plus loin dans les responsabilités confiées aux femmes. De plus, des efforts ont été faits pour comprendre le ministère autrement que par opposition et séparation. Nous sommes en train de redécouvrir la différence et la diversité, sans continuellement retomber dans l'opposition prêtre et non-prêtre. Il faut continuer à élargir la conception du ministère au-delà de ce qui est conféré par l'ordination. Il faut rappeler également que le ministère est important mais, qu'il soit ordonné ou non ordonné, il n'a rien réussi tant et aussi longtemps qu'il n'a pas suscité l'éveil des baptisés à la responsabilité de l'Évangile.

Il faut noter l'effort pour mettre en place des équipes pastorales formées de prêtres et d'agents pastoraux laïques parmi les pratiques ministérielles qui ont été privilégiées à l'occasion de réaménagements pastoraux au cours de la dernière décennie. Dans les prochaines nominations, il faut privilégier la structure de l'équipe pastorale. Grâce à ce type de nomination, on assiste au développement d'un "pastorat" auquel plusieurs baptisés sont associés. Il faut donc favoriser les équipes de ministères diversifiés sous la modération d'un prêtre qui vit son ministère comme un service. Nous devons aussi promouvoir la présidence "extraordinaire" des célébrations de baptême, de mariage et de funérailles par des baptisés mandatés par la communauté. Cette modalité permettrait de vivre concrètement le partage du service du sens. L'expérience pastorale m'a fait prendre conscience à plusieurs reprises que la fécondité sacramentelle d'une célébration dépend de la qualité de l'accompagnement offert et de la qualité du climat de la célébration. S'il y a davantage de personnes qui peuvent 
présider des célébrations, nous allons pouvoir offrir une plus grande qualité de présence dans notre approche pastorale et recueillir plus de retombées spirituelles chez les personnes et dans les communautés croyantes. Le prêtre ne peut pas tout faire. Il y a des risques réels actuellement pour les ministres ordonnés de s'enfermer dans le cultuel.

La société démocratique a engendré une importante bureaucratisation. L'Église a été influencée par ce phénomène. L'Église organisationnelle a parfois géré les ministères sur le modèle d'une fonction publique. Il est bien évident qu'une certaine conception du ministère presbytéral centrée sur les tâches, aussi bien que la multiplication des services et des fonctions confiés à des laïcs, ont fortement contribué à réduire le ministère, sinon toute la vie de l'Église, à une pure fonctionnalité. C'est une tendance de la culture technocratique de tout envisager en termes d'utilité, d'efficacité et d'activité. Il faudra être vigilant sur ce point pour éviter que cette tendance se répande encore trop longtemps dans l'Église institutionnelle.

La reprise de la réflexion intensive sur le ministère presbytéral a permis de déployer sa signification en le situant dans la totalité du Corps du Christ, relié à l'ensemble du Peuple de Dieu dans sa plénitude et sa catholicité. C'est un progrès significatif. Mais les ajustements pastoraux ont eu parfois pour effet de cantonner de plus en plus les prêtres dans l'univers des sacrements en faisant d'eux des commisvoyageurs du rite. Il faut poursuivre nos efforts de réflexion afin de centrer le ministère ordonné plus sur le "faire signe" que sur le "pouvoir faire". Également, nous savons que les attentes institutionnelles et celles des personnes et des communautés croyantes envers les presbytres sont illimitées. Si le prêtre n'est pas vigilant pour se donner un équilibre de vie et un espace où il peut refaire ses forces, il devient facilement un "fonctionnaire" de Dieu et un candidat à un burn-out prochain. Il vient rapidement à 
donner à la communauté non pas ce qui déborde de sa vie spirituelle mais seulement les miettes qui restent. La sollicitude pastorale doit nous inviter à garder les yeux bien ouverts pour dénoncer les exigences inhumaines demandées aux ministres ordonnés dans certaines circonstances ecclésiales.

"La situation actuelle des paroisses et l'évolution des pratiques ministérielles provoquent des réactions diverses: crainte face à l'avenir des communautés, enthousiasme devant le dynamisme de nombreux laïcs, inquiétude devant la crise du ministère ordonné, désillusion devant les blocages institutionnels, agressivité à cause des relations de pouvoir ou d'inégalité, espoirs nourris à propos d'un nouveau visage de l'Église. Quoi qu'il en soit, les faits nouveaux qui appellent des changements d'attitude et des restaurations sont incontournables. Le défi consistera à gérer le changement de manière responsable, conscients de l'urgence sans nous replier continuellement sur les solutions de remplacement qui ne font pas appel à la créativité chrétienne ou qui portent atteinte au véritable sens de l'Église."38

Il ne faudra jamais oublier que dans nos recherches pour inventer un nouveau visage de la paroisse et de l'Église, c'est la communauté baptismale et sa mission d'évangélisation qui doivent toujours passer au premier plan et non la défense d'un système institutionnel. 


\title{
CHAPITRE 13
}

\section{UN NOUVEAU PARAdigMe De PÉDAgogie PASTORALE}

\begin{abstract}
"Une religion qui veut contribuer à la liberation des hommes a besoin d'images et de sacrements de ce genre, parce qu'ils sont profondément ancrés dans la psyché humaine." 1
\end{abstract}

Il nous arrive souvent d'entendre de la bouche de plusieurs intervenants pastoraux que l'Église est trop investie dans les tâches de sacramentalisation et que ce fait paralyse sa présence au monde et le plein accomplissement de sa mission. Ce diagnostic un peu court relève davantage d'un slogan facile que d'une réflexion à partir de la réalité. Des années d'expériences pastorales m'ont fait découvrir que la sacramentalisation pouvait être un lieu propice d'évangélisation selon la richesse du dialogue entre les intervenants pastoraux et les paroissiens et la qualité de la célébration.

$\mathrm{Au}$ coeur des responsabilités paroissiales, j'ai été constamment interpellé par cette question: comment établir avec les demandeurs de l'un ou l'autre des sacrements (majoritairement distants de l'institution paroissiale) des relations qui permettent à ceux-ci de croître humainement et spirituellement et aux intervenants pastoraux de s'épanouir dans leur engagement ? En d'autres mots, quelles attitudes doivent présider aux relations entre les demandeurs et ceux et celles qui reçoivent la demande pour instaurer une dynamique pastorale plus fructueuse? Comment être un meilleur p.635. 
'passeur' de la foi comme intervenant pastoral lors des demandes sacramentelles, spécialement avec ceux qu'on appelle les 'distants'?

\begin{abstract}
"Nous parlons souvent des "distants" pour qualifier un grand nombre de gens. Qu'en estil de nos propres distances par rapport à eux?/.../ N'y-a-t-il de résistances que chez les gens? Quels sont nos propres blocages et resistances?"2
\end{abstract}

Dans ce chapitre, je m'intéresse plus spécialement aux personnes que nous qualifions malheureusement de distants. J'évolue à leurs contacts. ${ }^{3}$ Ils m'aident constamment à apprivoiser et à analyser mes propres distances, mes perceptions et mes présupposés par rapport à eux. Ils me permettent constamment de devenir autre. Ils m'amènent à découvrir toujours un Christ Autre et un Dieu Autre. Ils me guérissent tranquillement de mon "Alzeihmer spirituel", maladie qui nous fait oublier que l'Esprit est à l'oeuvre bien avant nos interventions pastorales.

La première partie de ce chapitre analyse l'écart du sens cherché et donné entre la demande (sacrement ou autre service) et l'offre des intervenants (des accueillants). Cette analyse permet de découvrir dans la deuxième partie deux visions différentes dans le monde pastoral concernant l'approche sacramentelle. La troisième partie résume globalement une tranche d'histoire qui nous montre en Hippolyte de Rome et dans le Pape Calixte deux attitudes opposées face aux distants de leur époque. Par la suite, nous nous laissons instruire par les "attitudes pastorales" de Jésus dans différents contextes, particulièrement, celui de son dialogue avec la Cananéenne. La

2 $1992,1^{\circ}$ atelier, p.1-1.

GRAND'MAISON, Jacques, Notes de cours PTR 6400, Université de Montréal, 3 "...en foi chrétienne, on est toujours libéré par ceux et celles qu'à priori on pense plus pauvres que soi" (PARENT, Rémi, Chemin faisant...en quête d'Église, Montréal, Paulines, 1991, p. 126.). "Je dois reconnaitre que ma mise au rancart m'a amené, depuis un certain nombre d'annés, à des contacts passionnants avec le monde agnostique. J'y ai découvert que quantité de valeurs que je croyais spécifiquement chrétiennes sont tout simplement des valeurs humaines. Cela permet de vivre entre humains de profondes solidarités"(DE LOCHT, Pierre, entrevue accordée à Jean-Pierre GUETNY, in L'Actualité Religieuse dans le monde, \# 115, 15 octobre 1993, p. 45). 
cinquième partie démontre la fécondité d'une approche pastorale axée sur l'accueil et une écoute 'amoureuse' du paroissien. Nous savons que la dimension spirituelle est située au sein de multiples composantes de la personne. Il existe un lien étroit entre le développement humain et celui de la foi. Ce lien m'a incité à consulter certaines études sur le développement psychosocial de l'adulte selon la perspective du cycle de vie avec ses périodes de transition, de changement et de crise. Ce chapitre se termine par une réflexion sur des malentendus à dissiper concernant la conception de la communauté et celle de l'identité chrétienne. On y retrouve également une invitation aux intervenants pastoraux à concevoir la paroisse comme un lieu de "passage" pour le "tout-venant" et à accueillir les demandes sacramentelles comme des "clins d'oeil" du Dieu Vivant. Cette manière de concevoir la paroisse exige alors un nouveau paradigme de pédagogie pastorale.

\subsection{L'offre et la demande sacramentelle ${ }^{4}$}

Nous entendons dire régulièrement que la paroisse joue trop souvent le rôle d'une station-service pour les besoins saisonniers d'une vie en fournissant aux

"Les difficultés de départ proviennent par ailleurs du décalage qui existe entre l'offre et la demande. Ces derniers termes demandent cependant quelque précision. En effet, parler d'"offre" et de "demande", c'est adopter le langage du marketing. Un tel langage a ici sa valeur pour autant que, qu'on le veuille ou non, le baptême et le mariage religieux constituent des biens symboliques que l'institution ecclésiale offre sur le marché public et qu'elle cherche à négocier dans les meilleurs termes: ils obéissent donc, à certains égards, à une stratégie commerciale. Cependant, ces termes d"'offre" et de "demande" ne sont pas sans inconvénients du point de vue pastoral. /.../ C'est donc la nature même de l'Église, sa nature de "mystère" ou de "sacrement" du Royaume qui vient, qui requiert une distance critique par rapport au vocabulaire de l"'offre" et de la "demande". On adopte ici ce vocabulaire qu'en raison de sa commodité et de sa part de pertinence; mais on ne le fait qu'avec prudence"(CHAUVET, Louis-Marie, Les sacrements, Parole de Dieu au risque du corps, Paris, Éd. Ouvrières, p. 204.). 
demandeurs ce qu'il est convenu d'appeler des "rites de passage"5. Il est toujours étonnant de rencontrer des paroissiens qui, malgré la distance prise avec la pratique dominicale, tiennent à faire baptiser leur enfant, à se marier à l'église, à demander une célébration des funérailles pour une membre de leur famille. L'offre et la demande ne correspondent donc pas toujours: les politiques "collectivistes" mises en branle par les intervenants pastoraux se heurtent inexorablement à la recherche d'une démarche d'abord familiale du côté des demandeurs.

"La demande de ces parents est extrêmement diversifiée: motivations de la demande, profession, expérience religieuse, milieu d'appartenance, etc... Un premier fait saute aux yeux: l'écart entre les responsables institutionnels et ces parents qui demandent le baptême, entre le langage de ces personnes et celui des agents pastoraux. On ne peut accentuer cet écart en optant pour une attitude de discrimination et d'exclusion ou tenter de le combler par le dialogue et la rencontre. De plus, une attitude trop rigide peut facilement conduire au conformisme ou au jeu de rôle pour obtenir le rite en répondant aux autres attentes institutionnelles." 6

Oublier l'intérêt concret des demandeurs pour les sommer de s'aligner sur l'intérêt de l'Église, c'est donc parasiter d'emblée la communication entre eux et les accueillants.

$5 \quad$ "L'expression elle-même de "rite de passage" nous vient d'un folkloriste français du début du siècle, Arnold Van Gennep (Les rites de passage, Paris, 1909). /.../ Une telle célébration aux quatre moments nodaux de la vie humaine (la naissance, l'adolescence, le mariage, la mort) semble être universelle. Ce fait, qui ne saurait être l'effet du hasard, permet de présumer que ce type de ritualisation est lourd de signification au plan anthropologique. /.../ Les divers rites de passage cherchent donc à intégrer symboliquement dans la culture ce qui, laissé à l'état brut de nature, demeurerait lourd de menaces, parce que trop étranger au corps social. /.../ On devine également que les rites de passage (l'initiation notamment, on le verra) sont de prodigieux systèmes d'intégration au groupe social et de reproduction de son système culturel de valeurs"(CHAUVET, Louis-Marie, Les sacrements, Parole de Dieu au risque du corps, pp. 189-190.).

6 DUFOUR, Simon, TREMBLAY, Éric, "Lieu de mission et de présence au monde", in Liturgie, Foi et Culture, volume 27, Printemps 1993, p.17. J'ai déjà écrit un article sur le sujet de ce chapitre en collaboration avec Simon DUFOUR dans une revue de la CECC. 


\subsubsection{Un écart grandissant entre le sens donné et cherché}

Nous nous retrouvons en pastorale sacramentelle devant une situation complexe et délicate à traiter. D'un côté, les intervenants pastoraux sont des personnes pour qui l'institution paroissiale revêt une grande importance dans la façon d'aménager leur vie chrétienne. Ces personnes peuvent être considérées comme des 'nucléiques', puisqu'elles constituent en quelques sorte le 'noyau' de l'institution paroissiale. En contrepartie, la grande majorité des demandeurs de sacrement peut être vue comme 'périphérique' face à la même institution paroissiale. La majorité des demandeurs sont donc des 'distants' face à la pratique dominicale. Pour la plupart d'entre eux l'institution paroissiale a une faible importance dans leur façon d'aménager leur vie chrétienne: ils réduisent en général leurs contacts aux rites de passage, à une pratique dominicale occasionnelle (Noël, Pâques,...) ou quasi inexistante. Les demandeurs rencontrés donnent ainsi plusieurs signes de la distance qu'ils ont prise avec la paroisse à laquelle ils demeurent rattachés. Pourtant, ils persistent à demander des services. Pour eux, les gestes de passage (baptême, première eucharistie, confirmation, mariage, funérailles) ont acquis une force symbolique significative de leur expression de la foi et de leur enracinement dans une Tradition. L'obtention du baptême ou du mariage leur tient symboliquement au corps: au corps individuel de leur désir, au corps culturel de leur appartenance sociale et de leur tradition.

"Je reprendrai ici une réflexion faite par André CHARRON: "La liturgie est pourtant la voie d'accès encore la plus fréquente pour les chrétiens de toutes appartenances. Elle demeure un enjeu important, vu dans cette perspective de la qualité et de la pertinence de notre service, notamment en regard des défis de l'acculturation en termes de langage et de symbolique." 7 C'est, à sa façon, rappeler que les langages de la foi sont symboliques et que les espaces rituels restent des lieux d'enracinement et de "transmission" privilégiés avec toutes les ambiguités qu'ils charrient. /.../ Mais il faudrait peut-être se rappeler que, dans une société comme la nôtre, c'est encore dans les rites que les personnes identifient 
le plus clairement la dimension religieuse de la vie. Sur ce point, une réflexion sérieuse est à initier." 8

La paroisse se voit ainsi exposée à se définir comme une structure de service ouverte au tout-venant, quels que soient sa condition et son degré d'appartenance ou d'insertion. Mais les expériences vécues dans les comités d'initiation sacramentelle m'ont permis de découvrir que nos interventions pastorales tournent facilement au jugement de valeur. J'ai entendu à plusieurs reprises et j'entends encore ce commentaire: "Il faut cesser de sacramentaliser des païens." Dans certaines rencontres de préparation aux sacrements, il m'a été donné de constater à quel point bon nombre de demandeurs (surtout ceux qui sont distants face à l'institution paroissiale) se sentent jugés, créant par le fait même un climat stérile et moralisateur. Du côté des intervenants pastoraux, la non-pratique religieuse est bien souvent perçue comme une sorte de maladie à combattre. "Une trop grande préoccupation de la pratique religieuse et du langage de foi conduit parfois à ignorer une pratique chrétienne en ses éléments humains les plus essentiels." 9 Combien de demandeurs en recherche sont sortis brisés de ce genre de relations pastorales. Plusieurs d'entre eux m'ont confié combien ils étaient déçus d'une telle expérience. Réparer les pots cassés, en pareils cas, constitue à n'en pas douter une manoeuvre délicate, et pour laquelle les occasions et les moyens ne se font pas toujours accessibles à court terme. L'Église a parfois blessé des gens et ceux-ci ont fermé leurs portes. Quand ils reviennent vers nous, il faut aller par "leur cheminée

8 LAPOINTE, Guy, "La pratique des sacrements: risquer la situation présente", in Prêtre et pasteur, juin 1993, p.359; p. 362.

9 DUFOUR, Simon, TREMBLAY, Éric, "Lieu de mission et de présence au monde", p.17. Au moment du jugement dernier, le Dieu de Jésus-Christ portera-t-il un regard sur le nombre de fois que nous sommes allés à la messe ou sur la qualité de notre présence humaine au coeur de la vie. En méditant la vie de Jésus par le moyen des textes de l'évangile, il me semble que Celui-ci nous apprend que le seul étalon pour mesurer la vie des personnes, c'est la mesure dans laquelle nous avons voulu rassasier les affamés, délivrer les prisonniers et vêtir ceux qui étaient nus (Mt 25, 35s.). 
intérieure" pour rejoindre leur profondeur, pour nous laisser réchauffer par le "buisson ardent" de leur coeur à coeur intime et secret avec le Dieu Abba.

\title{
13.1.2 L'importance "d'entretenir la foi"
}

Nous avons été témoins récemment de plusieurs jugements de valeur concernant les "distants" dans une étude d'un comité de l'AEQ intitulé "Risquer l'Avenir". Voici quelques extraits démontrant parfois même la méchanceté des propos de certains "nucléiques" ecclésiaux.

\begin{abstract}
"N'importe quel non-pratiquant, ou presque, peut se dire chrétien et exiger des services de la communauté sans donner de signes d'appartenance à la communauté et sans se préoccuper d'offrir en retour une quelconque contribution. D'où le sentiment chez certains d'encourager le parasitisme des non-pratiquants. Ce problème renvoie à la faiblesse de l'éducation de la foi des membres des communautés ainsi qu'aux politiques pastorales ambiguës en ce qui a trait à l'accès aux sacrements. /.../ Cette pratique des parents distants est pleine d'ambiguittés. Ils se tiennent à la périphérie du champ institutionnel et symbolique de l'Eglise. Ils se contentent d'emprunter certains éléments de la vision chrétienne du monde et de faire appel à l'Église pour des célébrations rituelles qu'elle est seule à dispenser. Un tel comportement entraîne une méconnaissance de ce qu'est la vie chrétienne. Il n'est pas surprenant qu'ils ne soient guère intéressés à s'engager dans une démarche de foi chrétienne, puisqu'ils ignorent ce qu'elle pourrait impliquer. /.../ Par ailleurs, certains de ces groupes semblent viser davantage l'entretien de la foi que son éducation." 10
\end{abstract}

Je ne peux rester indifférent à ces affirmations. Comme plusieurs autres, je suis critique envers ce diagnostic.

"Jugement extrêmement sévère sur ce que vivent certains croyants qui n'arrivent pas à formuler clairement leurs liens au Dieu de Jésus. /.../ La relation à la mémoire chrétienne peut prendre de multiples chemins et se manifester de diverses façons. /.../ Qui peut juger de la qualité de la demande des personnes qui se rattachent à la tradition chrétienne et pour lesquelles il est probable que le style de regroupements chrétiens qu'ils voient ne semble plus attirant?"11

10

11

Risquer l'Avenir, p. 59; p. 84; p.37.

pp.357-358

LAPOINTE, Guy, "La pratique des sacrements: risquer la situation présente", 
Il me semble dangereux de qualifier péjorativement "d'entretien de la foi" l'accompagnement des personnes lors des demandes sacramentelles. Il est essentiel de "faire de l'entretien" dans le domaine de l'éducation de la foi. Et j'irai même plus loin en disant qu'éduquer à la foi, n'est-ce pas "entretenir la croissance spirituelle"? Nous avons beau planter des graines dans un jardin, si on ne l'entretient pas, les mauvaises herbes vont prendre le dessus. La foi à l'état pur n'existe pas. Il y a seulement une vision "non réaliste" ou "idéaliste" qui peut nous faire croire à une croissance spirituelle sans vigilance ou sans "entretien ". La logique de lincarnation exige de consentir à la présence "de livraie et du bon grain" dans le coeur de chaque personne, cette terre féconde pour le jardinage de Dieu. De plus, les Pères de Vatican II n'ont-ils pas invité les intervenants pastoraux dans le décret conciliaire Ad Gentes à être attentifs dans la relation pastorale pour découvrir les semences du Verbe secrètement cachées dans le coeur de chaque personne humaine.

"...ils doivent être familiers avec leurs traditions nationales et religieuses, découvrir avec joie les semences du Verbe qui s'y trouvent cachées" /.../ "La semence, qui est la parole de Dieu, venant à germer dans une bonne terre arrosée de la rosée divine, puise la sève, la transforme et l'assimile pour porter enfin un fruit abondant" (Ad Gentes 11, 14-16;22, $1-3)$.

Au chapitre neuvième, pour comprendre quelque chose du mystère de l'inculturation, j'ai fait appel au langage symbolique de la parabole du grain (Mc 4, 26-29). Je rappelle brièvement certains de mes propos. La parabole nous montre que l'inculturation (nous pourrions parler également de l'évangélisation ou de l'éducation à la foi) est une action mystérieuse entre la semence (Évangile, la présence secrète du Dieu Vivant dans chaque humain) et la terre (la culture, le coeur de l'être humain). La semence est accueillie par la terre qui commence à la travailler de l'intérieur, lentement et d'abord invisiblement. D'elle-même, dit la parabole, la terre produit d'abord l'herbe, puis l'épi, 
puis plein de blé dans l'épi. Tout cela se passe tandis que le semeur dort. De fait, il s'agit d'une action mystérieuse qui échappe au regard du semeur. Qu'il dorme ou qu'il soit éveillé, la nuit ou le jour, il ne sait pas comment la semence germe et pousse. Mais arrive enfin le jour où le semeur se relève de son sommeil profond et voit le résultat. Le blé est mûr et la récolte est prête. Le semeur peut contempler les fruits de la rencontre mystérieuse de la semence avec la terre. D'une façon très simple, cette parabole montre le rôle de chaque intervenant pastoral dans le domaine de l'éducation de la foi par le moyen des rites de passage. La croissance spirituelle d'une personne peut se faire par l'intermédiaire de l'agent pastoral ou sans lui. C'est un mystère en présence duquel il est comme un serviteur inutile. Cette parabole permet de remettre en question la vision de certains permanents ecclésiaux qui croient que c'est à coup de rencontres initiatiques que nous éduquons à la foi. Dans une certaine "vision catéchuménale", c'est le nombre de rencontres qui permet d'évaluer la qualité d'un programme d'éducation de la foi. Tout accompagnement spirituel exige une certaine discrétion de la part de celui qui chemine avec un croyant. Cette attitude évite à l'intervenant pastoral de se prendre pour un autre et par le fait même, il laisse toute la liberté à l'autre d'accueillir la parole de l'Autre, de la faire fructifier et d'y répondre. Sa réponse unique et originale enrichit le trésor spirituel, théologique et pastoral de l'Église et contribue à la véritable catholicité de l'Église. Nous ne savons pas d'avance quelle personne renaîtra après une demande sacramentelle. Mais ce que nous savons, c'est que nous devons toujours être en éveil pour contempler l'action discrète de Dieu, par son Fils, au coeur des humains.

"Le Père que Jésus nous invite à rencontrer est le Dieu de l'amour gratuit, qui aime toutes les personnes, sans distinction de race, de nation, de religion. C'est le Dieu qui fait lever son soleil sur les bons et les méchants, tomber la pluie sur les justes et les injustes, celui qui invite aux noces de l'alliance des estropiés, des aveugles, des prostituées, celui qui embauche à son chantier à toute heure au grand scandale de ceux qui pensent avoir des 
droits sur lui, de tous ceux qui pensent être les grands patrons de son projet de salut, des pharisiens de toutes les époques." 12

Si nous demeurons attentifs, nous pouvons être étonnés de la liberté intérieure et de l'autonomie que Dieu fait croître dans le coeur de tous ceux et celles qui ouvrent leur être à sa semence d'Amour. C'est donc important pour les intervenants pastoraux de consacrer du temps pour aider un paroissien à "entretenir" sa foi.

\begin{abstract}
"Les responsables pastoraux auraient tort de considérer ces entretiens pastoraux comme un simple appendice à leur mission, dont le "sérieux" serait ailleurs; ils auraient encore plus grand tort de les traîner comme une sorte de boulet, "puisque l'on ne peut pas faire autrement".... En fait, il s'agit là - la majorité d'entre eux l'ont d'ailleurs (peu à peu) compris - d'une plate-forme missionnaire importante, vraisemblablement appelée à se développer de manière assez considérable dans les décennies qui viennent. Dans notre société "post-moderne" en effet, la perte de points de repère est telle chez les catholiques qu'un nombre croissant d'entre eux, semble-t-il, éprouve le besoin de se repositionner à un moment donné: la préparation du baptême ou du mariage leur en fournit l'occasion. I.../ Cela peut être vécu, ainsi que l'atteste fréquemment l'expérience, comme un "temps de grâce". Quant aux responsables pastoraux, pourquoi rechigneraient-ils par principe face à une responsabilité qui, au plan humain aussi bien qu'évangélique, est sans doute l'une des plus nobles qui soit, puisqu'il s'agit d'aider des personnes à accoucher, fût-ce de manière très partielle, de leur propre vérité, à s'interroger sur le poids qu'elles accordent aux choses élémentaires de la vie, à se demander où elles ont mis leur "trésor", donc aussi leur "coeur" (Lc 12,34)."13
\end{abstract}

\title{
13.2. Deux visions différentes concernant l'approche sacramentelle.
}

"Notre action pastorale est bien souvent le reflet de nos orientations spirituelles" (Jean-Claude BRETON).

J'ai découvert dans le monde pastoral deux visions différentes concernant l'approche sacramentelle: la vision "miséricorde-compréhension" et l'autre volet 
"vérité-exigence" du sacrement. La deuxième vision est beaucoup plus répandue dans l'Église. 14 Nous proposons plus souvent une vision des sacrements teintés d'exigences et de radicalisme, surtout face aux 'distants'. Plusieurs intervenants pastoraux sont reconnus comme partisans de la 'ligne dure'. J'ai expérimenté à quel point une telle attitude, qui frise souvent l'intransigeance, peut être source d'une foule de malaises. Dans les plus récentes années d'expériences pastorales, je me suis senti progressivement mal à l'aise de fonctionner dans des équipes d'initiation sacramentelle où le règlement, le contenu, les formes établies, passent bien avant les personnes. Un tel discours teinté d'intransigeance vient paralyser les relations avec les demandeurs et les intervenants pastoraux. Il est plus fructueux dans l'intervention pastorale de "mourir" à l'idéalisme à visage de vertu et par le fait même à consentir au réel humain toujours ambigu mais sans cesse prometteur.

\subsubsection{Les nucléiques Vs les périphériques}

Le dialogue pastoral pose problème dans la pratique sacramentelle. L'établissement d'un dialogue pastoral dans le contexte actuel, parvient difficilement à honorer la vérité du sacrement et le respect du tout-venant auquel s'adressent les intervenants pastoraux. La difficulté d'établir un dialogue pastoral fructueux est réelle. Comment concilier la vérité du sacrement et le respect des personnes, en évitant l'intolérance tout autant que le laisser-aller, tout en tenant compte de la mentalité contemporaine? Cette problématique se traduit ainsi en termes d'appartenance à l'institution paroissiale: telle qu'elle se vit actuellement dans les milieux paroissiaux, la pastorale sacramentelle met en scène des intervenants pastoraux d'appartenance forte

14 "Je pense que l'Église rend les gens névrosés en exigeant trop d'eux" (DREWERMANN, Eugen, La parole qui guérit, Paris, Cerf, 1991, p. 318). 
(ou "nucléique"), appelés à accueillir et à accompagner des demandeurs 'majoritairement "périphériques" face à cette même institution.

"....on peut remarquer qu'il y a un écart grandissant entre le sens donné et cherché par les responsables de la pastorale du baptême ou de l'eucharistie et celui des personnes qui demandent l'accès à un de ces deux sacrements. L'écart est parfois à ce point important, qu'il génère un profond malentendu. On convoque les chrétiens, comme un appel à se mobiliser, a se refaire une identité claire qui serait circonscrite dans une appartenance ferme à une communauté chrétienne. ${ }^{15}$

Opéré sans discernement, ce dialogue peut à la fois freiner la croissance des demandeurs et empêcher les acccompagnateurs permanents ou bénévoles de s'épanouir dans leur engagement.

"Le véritable défi peut s'exprimer ainsi: comment nos manières de faire servent-elles la dimension communautaire et le devenir des personnes dans leur croissance, leur quête de sens, leur recherche de foi? Seules la souplesse et la diversité des démarches peuvent permettre de répondre aux défis du pluralisme culturel." 16

De tout temps, les sacrements ont constitué une 'frontière' pour l'institution ecclésiale: en accueillant la demande sacramentelle qui lui est adressée, l'Église est également amenée à se définir face au monde dans lequel elle se trouve insérée et à évaluer constamment son action pastorale. Depuis Jésus jusqu'aujourd'hui, les moindres gestes des intervenants pastoraux ont une importance indéniable. L'expérience pastorale m'a maintes fois permis de constater avec étonnement à quel point un simple geste d'accueil peut se révéler important pour le tout-venant qui sollicite un service pastoral. Dans la pratique sacramentelle, les échanges qui ont lieu, si anodins soientils, se révèlent garants de la fécondité de l'ensemble des efforts consentis. 
"Sur une base plus large, nous avons noté que bien des réussites pastorales ont en commun une expérience de complicité/../ Des complicités naissent ainsi quand le discours chrétien ou pastoral se fait modeste, non exclusif, non monopolistique mais surtout attentif à la diversité des chemins de vie et de foi, à la fragilité humaine avec ses blessures et ses ruptures." 17

\subsubsection{Les puissants véhicules symboliques des sacrements}

Le dialogue entre les intervenants pastoraux et les paroissiens (qu'ils soient "nucléiques" ou "périphériques") doit demeurer ouvert au cheminement de croissance du tout-venant auquel s'adresse la pastorale sacramentelle pour répondre à la véritable catholicité de l'Église et aux défis de la nouvelle évangélisation. "Signes des temps, nouvelle chance historique du catholicisme d'ici que ces rapports de plus en plus libres et gratuits entre l'Église et la société, entre le monde pastoral et les gens." 18 Cela implique en outre chez les intervenants pastoraux, une conversion de mentalité devant se traduire en attitudes: saisir que la vérité des sacrements se réalise dans l'accueil du paroissien et la mise en valeur de l'action de Dieu le Père dans la vie. Les sacrements ne sont pas des réalités objectives dont la vérité existerait indépendamment des relations humaines. La qualité des relations entre disciples vécue dans les expériences sacramentelles fait partie de la vérité des sacrements. Ils sont un mystère de relations entre personnes et avec Dieu.

"À mon avis, ces attitudes qui restent de l'ordre du permettre me paraissent rester trop près d'une norme encore liée à l'arbitraire de ceux et celles qui doivent accueillir les demandes. Or la question de la vérité ne se pose pas d'abord à ce niveau. Le véritable enjeu porte sur la vérité de la signification du christianisme dans notre société et sur le sens que prennent certaines situations fondamentales pour les personnes qui demandent à vivre un sacrement à l'occasion d'une naissance, d'un mariage ou d'une cérémonie de funérailles. Le christianisme a une histoire concrète dans notre milieu; il a façonné tout un imaginaire, tout un réseau de représentations. Quoi qu'on en pense, il a planté ces racines chrétienne, Les passeurs de la foi, L'enjeu d'une nouvelle évangélisation, vol. $2, \mathrm{n}^{\circ} 16$, décembre 1991, p.18. 
jusque dans la chair vive des croyants même si leurs rapports à l'institution Église sont fort ambigus. Leurs liens à la mémoire chrétienne, si confus soient-ils, s'expriment dans certains moments plus ponctuels de la vie. Ils ne désirent peut-être plus vivre le type de communauté qui a marqué, pour le meilleur comme pour le pire, leur conscience. Mais, une majoritê souhaite, dans les situations fondamentales de la vie, trouver des lieux, des moments significatifs, où la plupart du temps avec la famille élargie (la tribu), ils prendront conscience du besoin d'ouverture de leur vie à une altérité, du besoin d'une certaine profondeur à leurs désirs. Or pour la majorité des gens d'ici le christianisme, qui fait partie de leur histoire, reste encore le lieu pour exprimer une relation à Dieu (avec toutes les ambiguittés de ce nom) et pour tenter de retrouver, pour un moment, un morceau d'Évangile." 19

Les sacrements représentent des puissants véhicules symboliques. ${ }^{20}$ Les symboles remplissent une fonction unifiante à l'intérieur de notre être permettant la mise en circulation du désir de notre profondeur mystérieuse à notre existence la plus quotidienne. De même ils permettent une replongée dans l'être profond à partir de ce qu'offre la vie de tous les jours.

"C'est dans cet ensemble que se situe le système symbolique religieux dont l'objectif est d'aider les gens à faire du sens, à donner sens à leur vie. Il aide à faire du sens en permettant de relire la vie pour mettre en lumière la dimension de profondeur et pour la relier, l'unifier. Dans cette perspective, les hommes et les femmes utilisent le système symbolique pour donner sens aux grands événements de leur vie par des rites de passage. Des gens font appel à l'Église pour célébrer la naissance d'un enfant, pour approfondir l'expérience d'aimer dans le mariage, pour accompagner la perte d'un être cher, etc. L'art pastoral consiste à faire fonctionner le système symbolique d'une manière féconde pour les personnes dans leur recherche de sens." 21

Les fonctions symboliques, en unifiant l'être à l'intérieur de lui-même, permettent ainsi une communication entre les personnes à un niveau particulièrement profond.

LAPOINTE, Guy, "La pratique des sacrements: risquer la situation présente", p.360.

20 Voir CHAUVET, Louis-Marie, Symboles et sacrement: une relecture sacramentelle de l'existence chrétienne, Paris, Cerf, 1987, 582p. [ Cogitatio fidei ,\#144]

21 DUFOUR, Simon, TREMBLAY, Eric, "Pour un sens à la vie", in RND: L'Église d'ici a-t-elle un avenir?, ${ }^{\circ} 1$, janvier 1994, p.9. 


\section{3. À la lumière de l'histoire: Hippolyte (235) et Calixte (222) ${ }^{22}$}

Une tranche d'histoire éclaire le défi concernant la pastorale sacramentelle au sein de l'institution paroissiale. On relate qu'Hippolyte, presbytre de Rome $(+235)$, et le pape Calixte $(+222)$ avaient eu des attitudes opposées face aux distants de leur époque. La réflexion sur cette période historique a influencé ma manière d'intervenir en pastorale et elle met bien en lumière les axes de fond de deux pédagogies pastorales. Vers le $\mathrm{III}^{\circ}$ siècle, sous l'empereur Septime-Sévère, la persécution fait alors place à une période de paix avec les autorités de l'Empire. Ceci "eut comme résultat de faire apparaître au grand jour les oppositions entre les intellectuels rigoristes assoiffés d'une Église idéale et les pasteurs soucieux de bâtir une Église accueillante pour tous, même pour les pécheurs." 23 La communauté de Rome doit en effet prendre position sur le sort de ceux qui ont apostasié leur foi (ou rejeté la morale chrétienne) pendant la dernière période de persécutions. Plusieurs parmi ces périphériques du temps cherchent en effet à réintégrer le groupe des chrétiens.

À en croire Hippolyte, Calixte remettait les péchés à tout le monde, y compris les péchés réputés irrémissibles. La même pratique avait été inaugurée à Carthage. En fait, il s'agissait de savoir si apostats, homicides et adultères pouvaient être admis à la réconciliation sacramentelle après une pénitence appropriée. Calixte à Rome, Agrippinus à Carthage avaient relâché la sévérité ancienne en faveur des adultères repentis, avant qu'on fasse la même chose pour les apostats en 250-251.

Je me suis inspiré d'un mémoire de maîtrise d'un de mes confrères pour rédiger ces pages d'histoire. GIRARD, Irénée, Pour un dialogue plus fécond en pastorale baptismale, Mémoire de maîtrise, Montréal, Université de Montréal, 1989, 201p.. Irénée GIRARD a obtenu le Prix Centenaire de l'Université de Montréal pour son mémoire.

23 CHRISTOPHE, Paul, L'Église dans l'histoire des hommes: Des origines au XV siècle, Limoges, Droguet et Ardant, 1983, p. 67. 
Hyppolyte et Tertullien, partisans attardés de la sévérité, se déchaînèrent contre ce prétendu laxisme qui était en réalité la pastorale miséricordieuse de l'avenir. ${ }^{24}$

Un bien grave problème se pose alors à la jeune Église. Les options se dessinent donc entre deux clans opposés, représentés par leurs leaders: d'un côté, le prêtre Hippolyte rêve d'une Église de purs, une communauté de martyrs (nostalgiques face à son passé), qui se replie et craint le monde, une Église à tendance sectaire, très exigeante pour ses nouveaux adhérents et anciens membres repentis. Hippolyte pose de grandes conditions au retour de ces pénitents et va même jusqu'à les rejeter. De l'autre côté, le diacre Calixte, devenu évêque de Rome, prône une attitude plus accueillante. Il accepte de réintégrer les exclus d'hier. Il cherche plutôt à rassembler, à créer l'unité dans l'Église et réserve le jugement final à Dieu seul.

Le débat est dur, la comparaison l'est aussi. Cependant, au-delà des conclusions et des rapprochements simplistes auxquels pourrait conduire ce recours à l'histoire, force nous est de reconnaître que l'on retrouve dans cette opposition, des éléments dialectiques bien actuels. Je ne peux pour ma part m'empêcher de noter une ressemblance significative entre les attitudes qui dominent actuellement la scène pastorale et certaines facettes de cette antique opposition. À observer cette dernière de plus près, on peut constater à quel point les options de fond s'y trouvent littéralement stigmatisées et donnent l'impression de rendre impossible tout dialogue, tout rapprochement. Irénée GIRARD a bien synthétisé dans un tableau les enjeux théologiques de chacune de ces deux approches. sainteté chrétiennee, Tome II: La semence des martyrs, 33-313", Paris, Hachette, 1987, p.170. 
"VISION 'HIPPOLYTE'

VISION 'CALIXTE'

\section{DIALOGUE AVEC LES DISTANTS:}

Vu comme un risque, une menace:

Vu comme une chance, un défi:

Il suscite peur, crainte et crispation;

Il vise la conversion des autres

Il révèle la qualité de l'action pastorale;

Il invite à une constante conversion de l'agent

\section{2- ECCLESIOLOGIE SOUS-JACENTE À CETTE ATTITUDE;}

Tendance idéaliste et sectaire, $\underline{\mathrm{OU}}$

Catholicisme quantitatif et totalisant

Tendance réaliste et ecclésiale ET

Catholicisme qualitatif et ouvert

\section{3- PERCEPTION DU ROYAUME ET DU SALUT:}

Repose entièrement sur l'action pastorale de lintervenant:

L'Esprit du Ressuscité nous devance...

C'est d'abord lui qui travaille. Au delà des apparences, il fait toutes choses nouvelles

L'intervenant donne tout L'intervenant donne et reçoit

Tourné vers les autres:

lois, règlements, politiques de tous genres

OU:

vers soi: culpabilité, découragement,...

\section{4- MISE EN PLACE DES EXIGENCES:}

Tournée vers la formation des agents pastoraux Croissance dans l'amour-service, selon l'horizon évangélique (Jn 13)

Dépassement de la culpabilisation stérile
Vision à tendance manichéiste:

"Au commencement, était le mal..."

\section{5- VISION DU MONDE:}

Vision chrétienne:

"Au commencement, il y a l'Amour de Dieu.

6- ROLE DE L'ÉOUIPE S.P.B (comme cercle de "nucléiques"):

Tendance à l'exclusivisme, menant soit

au zèle intempestif ou au retrait

Vise à tout donner, dans le minimum de temps

Aversion à voir les distants se contenter

de simples "fragments" de croyances

et d'appartenance
Quverture dialogale et réciproque

Nouvelle "table" qui répand en abondance les "miettes" du bon pain de la foi, de façon adaptée aux destinataires, selon la mesure qu'ils peuvent prendre

7- FACE À LA RÉACTION DES DEMANDEURS (agressivité ou indifférence...)

Preuve formelle de leur distance ecclésiale

Obligation: Durcir les politiques existantes,

OU: Fuir les décisions pastorales engageantes
Occasion de rendre témoignage

Invitation pressante à revoir notre approche

pastorale, nos stratégies d'animation

La vision d'Hippolyte a été celle qui a été majoritairement privilégiée dans les équipes d'intiation sacramentelle des différentes paroisses du Québec. Cette page d'histoire 
nous fait également découvrir que le "magasinage" des pratiques religieuses ne date pas d'hier.

"D'abord il n'y a rien de moins certain que les chretiens, même aux plus forts moments de la chrétienté n'aient perçu les services offerts par l'institution d'Église comme des services à la carte. On a toujours "magasiné" ses pratiques et ses dévotions. De plus, je ne suis pas convaincu que de taxer de "simples consommateurs" les personnes qui vivent une sacramentalité soit la trouvaille du siècle. Bien avant notre société de consommation, les chrétiens ont passablement "consommé" des sacrements. Un peu de mémoire ferait du bien! " 26

\subsection{Les attitudes "pastorales" de Jésus}

Jésus a été "pasteur" dans ses paroles et ses gestes, non pas en défendant la religion de ses pères, mais en se mettant à l'écoute des besoins des personnes rencontrées. Je crois que c'est particulièrement l'épisode de la Cananéenne qui révèle le mieux comment Jésus lui-même a été converti, ouvert à de nouvelles dimensions de sa mission dans la rencontre avec l'Autre dans l'autre.

"Tout au long de l'Évangile, on trouve de ces tiers passeurs qui vont marquer des tournants dans le projet évangélique de Jésus: la Cananéenne, la Samaritaine, le Centurion romain/.../ Souvent ce sera l'autre qu'on n'attend pas, l'étranger et même l'ennemi, l'inclassable."27

\subsubsection{Jésus "converti" par la Cananéenne}

Dans son comportement et sa manière de répondre à la Cananéenne en premier lieu, Jésus paraît indifférent et semble vouloir poursuivre son chemin. Et comme il arrive à bon nombre d'intervenants pastoraux, Jésus semble hésiter devant le 'cas' qui se présente à lui. Le texte révèle chez lui une sorte d'évolution progressive: de taciturne

LAPOINTE, Guy, "La pratique des sacrements: risquer la situation présente",

GRAND'MAISON, Jacques, "Sur les terrains des complicités..., p.14. 
qu'il est au début, c'est comme si Jésus, plus loin, commence à fléchir, et plutôt que de se débarrasser de cette femme, comme le lui suggèrent ses disciples (les "nucléiques"!), il lui donne au moins ce qu'il peut lui offrir: la gentillesse d'un dialogue. À relire le texte, on développe l'impression que Jésus passe d'une attitude d'indifférence apparente à une attitude de compréhension et de reconnaissance, voire même d'admiration envers cette périphérique. Il connaît sûrement la tentation facile d'un certain obscurantisme étroit qui mène au rejet, mais Jésus ne s'y attarde pas: il accorde à la Cananéenne le dialogue d'argumentation que présente le texte. Contrairement à la coutume de ses compatriotes, Jésus ne se ferme pas. Il prend le temps de s'arrêter pour considérer la demande de cette femme et lui accorder un dialogue intéressé. Le silence du début, sous des dehors de refus ou d'indifférence, devient ainsi espace de liberté et de révélation: par ce moyen, Jésus permet à la femme d'exprimer sa demande avec plus d'insistance. Au début de la rencontre, Jésus semble comme ébranlé, embarrassé. Il vit pleinement son incarnation. Il ose se laisser déranger par la persistance de cette "paroissienne obstinée". On sent que la conscience de son identité et de sa mission prend ici un véritable tournant. Et il est étonnant que, même dans une société aussi misogyne que la sienne, Jésus fasse fi des coutumes établies, cède à la femme et aille même jusqu'à la louanger publiquement. Une autre preuve que Jésus est le "grand passeur-transgresseur par excellence. Le Christ délie ce qui est lié à l'héritage culturel de la foi pour une alliance libre, personnelle et communautaire qui ne peut se vivre que dans un nouveau rapport de sujet à sujet."28 Bien davantage, quelle modestie lui faut-il pour accepter qu'un pareil tournant survienne dans sa mission et ce, par le concours d'une étrangère. Oui, cela est vrai: faut-il l'admettre, ce sont souvent les plus lointains et les plus entêtés parmi nos 'nonpratiquants' qui nous (intervenants pastoraux) font franchir des pas en termes de croissance humaine et spirituelle. "Reconnaissons-nous que nous pouvons être 
enseignés nous aussi de l'Esprit qui nous parle et nous convertit à travers les Cananéennes, les Corneilles, les Marie-Madeleine, les Samaritains, les pauvres de tous ordres, les dits pécheurs de notre temps." 29 Le vent (de l'Esprit) souffle où il veut...(Jn 3,8). Dieu sait déjouer nos visions théologiques et pastorales à courte vue. L'action imprévisible de son Esprit nous oblige constamment à réviser nos approches pastorales.

\title{
13.4.2 La qualité du dialogue de Jésus
}

J'aurais pu approfondir d'autres scènes évangéliques pour analyser dans chacune d'elles les attitudes pastorales de Jésus. Mais globalement je pourrais dire que Jésus répond toujours à la demande de la personne rencontrée au-delà de ses attentes les plus légitimes, au coeur d'un dialogue franc, simple, imagé et évocateur.

\begin{abstract}
""Le Christ lui-même a scruté le coeur des hommes et les a amenés par un dialogue vraiment humain à la lumière divine; de même ses disciples, profondément pénétrés de l'Esprit du Christ, doivent connaître les hommes au milieu desquels ils vivent, engager conversation avec eux, afin qu'eux aussi apprennent dans un dialogue sincère et patient, quelles richesses Dieu, dans sa munificence, a dispersées aux nations" (Ad Gentes 11, 22-28).
\end{abstract}

Par son comportement Jésus se manifeste comme un véritable pédagogue de l'éveil à la foi. Il sait attendre, laisser une marge d'initiative et accorder un dialogue face à face. Il trouve le moyen de permettre à la personne rencontrée d'exprimer le meilleur d'ellemême. Chose certaine, Jésus sait adapter son discours à son interlocuteur. N'est-ce pas une condition de réussite pour toute stratégie pastorale? Il demeure fascinant de constater dans plusieurs scènes évangéliques que Jésus sait en quelque sorte 'doser' son enseignement. Tenant sans doute compte du fait que les périphériques ont en horreur les solutions totalisantes, Jésus renonce à imposer d'un seul coup le pain 
complet de l'héritage religieux. Bien au contraire, en reconnaissant la foi chez l'autre, il consent à lui donner les miettes qu'il espère. Mais ces miettes lui font prendre part au même pain, dont elles proviennent. Chez une personne rendue accueillante à la suite d'un dialogue fructueux avec un (ou des) témoin(s) de la foi, ces quelques miettes suffisent à nourrir même la vie chrétienne la plus endémique, criarde et obstinée en apparence. Combien, nous intervenants pastoraux, tirerons profit de ces expériences 'pastorales' de Jésus, nous qui cèdons souvent à la tentation de vouloir donner tout l'héritage chrétien (et d'un seul coup) aux "périphériques" que nous rencontrons?30 Les gestes salvifiques de Jésus dans l'Évangile sont parfois réponse à la demande confiante des malades et parfois geste gratuit et inconditionnel de Jésus (pensons à l'aveugle-né). Une chose est certaine: dans chaque cas, la personne "bouge" et se trouve ainsi appelée à venir à la foi consciente. Ce ne sont pas toujours des gestes qui ont des suites: pensons à la guérison des dix lépreux, dont un seul vient "reconnaître" l'auteur de sa guérison.

Jésus ne s'est inquiété que des êtres humains et de la façon dont ils pourraient vivre sous le regard de Dieu. Un Dieu qui ne se perçoit que dans l'intimité du coeur.

"Ce que Jésus voulait, ce n'était aucunement une théologie ou une idéologie destinées à fonder une nouvelle religion, tout au contraire. C'est avec des images simples qu'il parlait de confiance en la bonté de Dieu et c'était bien là une marque de son style: au lieu de parler de catégories juridiques, éthiques ou philosophiques, il décrivait des scènes de la vie humaine de façon à ouvrir notre existence sur le ciel. Du point de vue de la psychologie religieuse, on peut affirmer que ses enseignements, sa pensée imagée, concrète, liée à une situation donnée, représentent la seule manière de permettre une compréhension intime, sans contraintes ni aliénation, des vérités religieuses, tandis qu'une

30

"Cela signifie seulement qu'il faut doser en quelque sorte le volume de ce qu'ils semblent en mesure d'en supporter, afin d'éviter soit les effets "euphoriques" d'un enthousiasme qui sera sans suite, soit les effets "dysphoriques" de l'écoeurement. Si tous doivent sentir ou pressentir le goût étonnamment nouveau de la Bonne Nouvelle, en revanche la capacité d'absorption, c'est clair, n'est pas la même pour tous"(CHAUVET, Louis-Marie, Les sacrements, Parole de Dieu au risque du corps, pp. 212-213.). 
doctrine ne fait que favoriser la tendance à se fabriquer un surmoi intellectuel qui se retourne contre le moi./../ Il n'y a qu'une théologie qui soit conciliable avec l'attitude de Jésus: celle qui tente de communiquer par des images et des symboles des expériences sur Dieu en faisant preuve de tant d'ouverture, de tant d'humanité, de tant de douceur que celles-ci en deviendrait universelles et qu'on pourrait les comprendre et les assimiler partout, dans chaque culture et à chaque époque. /.../ Jésus, ce fut d'abord quelqu'un qui voulait apprendre aux hommes à faire confiance à Dieu; quelqu'un capable de chasser la peur des gens en leur caressant le front; quelqu'un qui, rien qu'à la façon de toucher un paralysé, lui redonnait le courage de se mettre debout et de partir dans le monde." 31

Avant de parler, Jésus s'est donc inscrit profondément dans le terreau humain. Il a vécu à fond les expériences humaines ordinaires de son milieu. La dernière Cène est l'aboutissement d'un long cheminement en pleine pâte humaine. Et au lendemain de la Résurrection, avant de rompre le pain avec les siens, il apparaissait comme un passant, un jardinier, et un riverain pour marquer sa présence discrète derrière tout visage humain. En rencontrant des paroissiens, l'intervenant pastoral ne va pas porter le Christ. Il va le chercher, le rencontrer au creux de leur existence. Devant tout être humain, il faut savoir que le Christ est dèjà là, qu'il nous a précédés, qu'il chemine "incognito" avec cette personne, comme avec les pèlerins d'Emmaüs. Nous ne savons ni le jour ni l'heure où celle-ci reconnaîtra que cet inconnu qui lui brûle le coeur par son Amour est le Seigneur. Cela exige patience, vigilance, pauvreté et recherche du coeur.

\subsubsection{Le Seigneur part avec ce qu'il a en main}

"Il y a des aspects essentiels du mystère chrétien qu'on ne comprend qu'en pleine vie, au moment où les questions se posent. L'événement est ici l'heure de grâces, du passage du Seigneur" (Jacques GRAND'MAISON).

On ne le répétera jamais assez: l'action divine première est souterraine. Dieu ne s'est pas d'abord révélé dans la nature (le premier chapitre de la Genèse remonte au

31

DREWERMANN, Eugen, Les fonctionnaires de Dieu, pp. 150-151.; La parole qui guérit, p.99. 
$\mathrm{V}^{\circ}$ siècle). Il a cheminé longtemps dans la vie des êtres humains (Abraham et Moïse), dans l'histoire d'un peuple (Israël), avant de révéler explicitement son message et son identité en la personne de Jésus. Nous allons toujours trop vite. On n'a peut-être pas encore saisi toutes les conséquences concrètes du mystère de l'Incarnation et de son réalisme qui prend corps dans le terreau le plus humain. Rejoindre un travailleur sur son propre terrain, s'intéresser à ce qu'il fait, avec une foi et une charité authentiques, c'est déjà rejoindre le Christ qui continue sa création, sa Rédemption et sa Pâque. Le Seigneur part toujours de ce qu'il a en main. Partir de la situation réelle, de ce qu'on a; accepter les moyens pauvres, risquer en s'appuyant sur la force du Seigneur. Chacune des situations est unique, irréversible. Elle est un passage du Seigneur qui interroge, appelle et engage. Mais aussi, elle est là, à la merci de la fidélité ou de la négligence des serviteurs, de la mise en oeuvre de leurs talents. Cette force de l'Esprit éclate dans la fragilité humaine pour mieux manifester sa présence gratuite. Refuser d'avancer avec ce qu'on a c'est donc endiguer le courant le plus authentique de la tradition judéochrétienne. Bref, le Seigneur nous demande d'avancer non pas en partant de ce qu'on souhaiterait avoir, mais de ce qu'il place sur notre chemin. Les humains ne se mettent pas en marche si on ne le leur fait pas confiance. La victoire du Christ est venue donner aux personnes ce pouvoir de reprendre en mains leurs responsabilités et leur destinée individuelle et communautaire. "Lève-toi et marche". L'amour du Christ est un amour qui fait voir, entendre, parler et marcher. C'est un amour qui guérit et fait vivre l'être humain en le libérant des servitudes les plus profondes. Il est également un amour qui recrée, dynamise et ouvre à un dépassement. En somme, c'est un amour qui assume tous les dynamismes naturels pour les élever au-delà des possibilités, des ruptures et des limites humaines. 


\subsection{Une pédagogie axée sur l'accueil et une écoute "amoureuse"}

L'approche pastorale des bénévoles et des permanents ecclésiaux lors des rencontres préparatoires aux sacrements est souvent abstraite, déconnectée de la vie. Certaines activités proposées conservent une sorte d'effet d"'éteignoir" face au vécu. Nous l'avons vu au chapitre troisième de la présente thèse, les paroissiens qui participent aux rencontres de préparation sacramentelle trouvent souvent les propos abstraits, arides. Ils ne se sentent pas rejoints.

"Le trait essentiel de cette pensée en surmoi, c'est l'impossibilité de partir de l'expérience vivante et foisonnante pour s'appuyer sur elle et comprendre ce que peuvent signifier Dieu et la Révélation. On part de Dieu ou d'idées figées touchant à une révélation donnée une fois pour toutes, et on les plaque sur la réalité humaine. Dans ce discours du clerc en fonction, aucune surprise: tout reste formel, froid, ennuyeux." 32

L'expérience me révèle que toute personne grandit et se sent valorisée lorsqu'elle peut partager ses préoccupations, ses réalisations, son vécu et ses projets. Notre rôle d'intervenants pastoraux consiste alors à devenir "sourciers" des intérêts de nos interlocuteurs. En ce sens, l'indifférence apparente de certains demandeurs peut devenir creuset au sein duquel peut s'opérer l'éveil à une expérience de foi vivante et intensément personnalisée. Qu'on le veuille ou non, les discours abstraits ou dogmatiques répugnent à la foi des gens car cette dernière se nourrit dans la trame des événements de la vie. Les interventions pastorales m'ont convaincu que lorsqu'on procède à partir du vécu des personnes, les rencontres sont plus intéressantes et fécondes. Paul VI nous a déjà interpellés sur cette vigilance.

"Il faut, avant même de parler, écouter la voix et plus encore le coeur de l'homme; le comprendre et autant que possible le respecter et, là où il le mérite, aller dans son sens. Il 
faut se faire les frères des hommes du fait même qu'on veut être leurs pasteurs, leurs pères et leurs maîtres." 33

\title{
13.5.1 La vie, le lieu de la Révélation du Dieu Vivant
}

C'est au coeur de l'expérience humaine des gens que le Dieu Vivant les travaille à partir de leur effort pour donner sens à ce qu'ils vivent.

\begin{abstract}
"Nous avons appris aussi comment présentement bien des gens de tout âge rejettent ces discours et ces comportements où l'autre prétend les connaître avant qu'eux-mêmes aient pu dire la moindre parole sur eux-mêmes/.../ Je savais déjà tout ça, ce dont j'ai besoin c'est comment faire passer le message..(mon message? mes affaires à moi?). C'est précisément ce qui révulse bien des gens face à ce genre de communicateur de la foi qui semble pouvoir se passer de l'expérience et de la parole de l'autre pour comprendre ou faire comprendre la Parole neuve du Christ aujourd'hui. Ce Dieu de la Bible et de Jésus en nous risquant à sa ressemblence, c'est-à-dire libres,'s'engageait dans une aventure qui ne pouvait être toute tracée à l'avance'. Dieu ne sait pas l'autre, Il est en attente de ce que l'autre va dire (Marie Balmary). Cela heurte la théologie de base de bien du monde en pastorale." 34
\end{abstract}

Accueillir avec attention les demandes de service et les rites de passage peut devenir un lieu de conversion et de cheminement. Cela suppose le désir réel de dialoguer et de prendre le risque de la rencontre vraie de l'autre, de la part des deux parties. Dans cette rencontre, un mouvement de renouvellement et de conversion peut surgir. L'autre accueilli peut devenir chemin de rencontre de l'Autre. Actuellement la logique institutionnelle risque parfois d'aboutir à une pastorale "industrielle" dans laquelle il y a peu de place pour une présence attentive à chaque situation. Heureusement que dans bien des situations, quelles que soient les politiques, les intervenants pastoraux ont été plus soucieux d'ouvrir des chemins divers pour répondre aux situations particulières, alors que d'autres agents ecclésiaux "mercenaires" se sont contentés d'appliquer la

33

34 GRAND'MAISON, Jacques, Notes de cours PTR 6400, Dossier 1-Rapport de Recherche, Université de Montréal, 1992, pp. 11-12. 
mécanique des règlements. Si l'Évangile a pu se propager dans les premières communautés chrétiennes et par la suite, de génération en génération, c'est grâce à l'attitude d'accueil des chrétiens.

\begin{abstract}
"L'accueil pastoral revêtait du même coup une très appréciable valeur "apostolique". De l'intérieur de l'assemblée, il préparait les voies au message lui-même. Pour une part certainement considérable, c'est en fait, à l'accueil pastoral auquel l'assemblée donnait occasion, que l'évangile a été redevable, de sa rapide et extraordinaire percée dans la masse des populations urbaines de l'époque." 35
\end{abstract}

Au cours des siècles, l'accueil a heureusement dominé en Église sur l'attitude de l'intervenant "douanier" qui vérifie la "légalité" de la demande d'un croyant désirant franchir une "frontière" dans son cheminement au coeur du "monde intérieur". L'attitude des accueillants doit donc être celle de la "gracieuseté". L'attitude "gracieuse" est fondamentalement respect de l'autre comme autre. Ceci signifie qu'elle s'interdit éthiquement de chercher à "avoir" l'autre. Elle est ainsi faite d'abord d'écoute attentive de l'autre: de ce qu'il dit, mais aussi de ce qui, pour lui, demeure de l'ordre de l'indicible. Elle est constituée ensuite d'une parole qui veut, autant que faire se peut, libérer celle de l'autre afin d'aboutir à une authentique communication. Il s'agit moins, dans cette perspective, de tenir des discours que de s'engager soi-même dans une parole qui dit en quoi l'Évangile donne à vivre personnellement et fait vivre d'autres, une parole qui enseigne en quoi miser sa vie sur l'Évangile est effectivement pour soimême et pour d'autres, chemin de liberté et de bonheur.

AUDET, Jean-Paul, Mariage et célibat dans le service pastoral de l'église, p. 98. Cet auteur a démontré dans ce même volume que la qualité de l'accueil et de l'hospitalité d'une personne constituait des critères de discernement pour appeler un(e) croyant(e) à un service particulier dans une communauté chrétienne. 


\subsubsection{Suivre le rythme de cheminement du paroissien}

Il est important de faire confiance à l'Esprit qui travaille le coeur des personnes. Cela exige beaucoup de souplesse de l'action pastorale au niveau de la préparation. Non pas une pastorale de "fast food" apprêtée d'avance mais plutôt une préparation adaptée à la situation en faisant ce qui est possible dans le temps disponible. Cette préparation doit être axée non pas uniquement sur le message mais sur l'expérience de rencontre de quelqu'un. Dans de telles circonstances, il est facile de préparer soigneusement une célébration en relation avec ce qui a été vécu en faisant appel à des symboliques diverses adaptées aux univers culturels des gens. Expérience riche et simple à la fois qui montre bien qu'en acceptant de cheminer avec des personnes au gré des événements de la vie, le Dieu Vivant peut se révéler comme partenaire d'alliance.

"....l'enjeu n'est pas d'abord de préparer une liturgie ou d'aménager des rites, mais de faire naître quelqu'un à la foi, de favoriser l'éclosion d'un sujet croyant. Ce défi fait ressortir l'importance d'un espace symbolique où s'intégrent les divers apprentissages de la foi. Le devenir chrétien implique une clarification de l'espace intérieur, un enracinement humain dans lequel s'interpénètrent la quête de sens au sein des diverses situations de vie, la soif de Dieu, l'émergence de la foi."36

DUFOUR, Simon, TREMBLAY, Éric, "Lieu de mission et de présence au monde", p.18. "En premier lieu, l'incapacité de penser symboliquement, déjà mentionnée: elle oblige sans cesse à chercher la réalité du religieux là où elle ne peut pas être, à l'extérieur, dans l'espace et le temps, et non pas à l'intérieur, dans l'affectivité et l'expérience du coeur humain. Que d'énergie la théologie de l'Eglise catholique n'a-t-elle pas gaspillée jusqu'à aujourd'hui pour contraindre les gens à penser que les symboles de la foi chrétienne doivent être compris comme des réalités historiques objectives /.../ Une des grandes tragédies de l'Église catholique, c'est d'avoir toujours préféré répondre aux défis spirituels de la modernité avec les moyens du pouvoir plutôt qu'avec ceux de l'esprit, en essayant de discipliner et d'homogénéiser la pensée au lieu de faire confiance à la force convaincante de ses enseignements, en utilisant un système raffiné de censure et de sanctions au lieu de faire fond sur l'amour des fidèles pour la vérité et leur désir de la chercher."(DREWERMANN, Eugen, Les fonctionnaires de Dieu, p.151; p.155). 
Dans le contexte actuel, il est urgent de développer une meilleure pédagogie pastorale qui accepte le rythme de cheminement des paroissiens. Nous prenons trop facilement les chemins les plus courts: une administration centralisée et nous négligeons les médiations humaines de la recherche en commun, les processus de participation et d'auto-éducation si importants dans l'éducation des adultes. Le paroissien s'attend à ce qu'on le rejoigne là où il est, à ce qu'on réponde aux questions réelles qu'il se pose hic et nunc. Pourquoi avons-nous autant de difficulté à accepter que pour certains paroissiens le questionnement spirituel soit en quelque sorte "parachuté" dans sa vie par intervalles? De plus, pour être fidèle à la catholicité ecclésiale, Vatican II n'a-t-il pas renouvelé son intelligence de l'Église qui, de société centrée sur elle, bien gardée aux postes frontières, doit se reconnaître maintenant comme rassemblement auquel Dieu appelle de manière diversifiée et par modes d'allégeance multiformes? On sait bien que c'est une conception eclésiologique nouvelle toujours à reprendre, une manière tout à fait autre de concevoir l'Église qui exige une grande pauvreté du coeur, un retour sur ses préjugés, ses "positions blindées". Il n'y a rien de plus préjudiciable pour l'Église et sa mission que ces attitudes "toquées", parfois trop fréquentes chez les intervenants pastoraux.

"Les évêques italiens s'exprimaient ainsi (communio e communità, intruduzione al piano pastorale, 43-44): "L'ambition pastorale de la paroisse est au contraire de rassembler dans l'unité des personnes les plus diverses entre elles par l'âge, l'origine sociale, les mentalités et les expériences spirituelles. Insérée normalement dans un territoire, la paroisse est la communauté chrétienne qui en assure la responsabilité. Elle a le devoir de porter l'annonce de la foi à ceux qui y résident et sont loin d'elle, et elle doit prendre en charge tous les problèmes humains qui accompagnent la vie d'un peuple, pour assurer la part que l'Église peut et doit porter. Ainsi elle est dans la société non seulement le lieu de communion des croyants mais aussi le signe de l'instrument de communion de tous ceux qui croient aux valeurs de l'homme: semblable à la fontaine du village, comme aimait à dire le pape Jean, à laquelle tous ont recours pour leur soif." 37 


\subsubsection{Sortir de la forteresse supérieure}

En deça du paroissien qu'on rencontre en vue du baptême ou de la première communion de son enfant, il y a un homme, une femme, une personne, un travailleur, un citoyen inséré dans plusieurs institutions. Voilà autant de terrains de rencontre, autant d'appels d'évangélisation. Et si l'on passe facilement à côté, c'est peut-être qu'on a l'esprit préoccupé trop uniquement par l'institution à faire fonctionner. L'adulte ne peut nous prendre au sérieux s'il ne nous sent pas intéressés à ce qui constitue l'ensemble de sa vie. Nous faisons si facilement de notre institution un but en soi. Et nous cherchons trop exclusivement à utiliser les uns et les autres pour des cadres qui resteront toujours secondaires, alors qu'il faut surtout construire le Royaume dans la vraie vie des humains.

"Il faudrait instituer une pédagogie de la gratuité dans ce monde de l'utilité et de la nécessité." 38

"La redécouverte de la personne derrière la persona suppose la renonciation à la volonté de planifier, de manipuler, de ranger, de diriger les gens. Il n'est possible de laisser s'exprimer le toi de l'autre que si nous le rencontrons sans conditions, donc en laissant tomber la question de son utilité possible, pour nous ou pour quelque institution que ce soit, fût-ce l'Église, et en ne nous souciant que de la vérité qui réside en lui. C'est alors que nous pourrons découvrir en lui la vie enfouie en attente de son éveil. Nous aurons à nous confronter avec une tendre patience aux angoisses, aux blocages mécanisés, aux obsessions morales de l'autre, jusqu'à ce que nous sentions progressivement mûrir son être tel que Dieu le veut vraiment. C'est un chemin long ..."39

Entre humains, on ne peut prétendre connaître l'autre en le réduisant à un objet qu'on pourrait fixer de façon neutre. La connaissance de la personne est toujours liée à un échange entre un "moi" et un "tu". Il ne saurait en être autrement dans la religion alors qu'il suffit d'un peu de compréhension, d'ouverture et d'acceptation pour tout faire bouger, tout comme il suffit d'un vent du sud pour faire fondre tout d'un coup des blocs de glace. Cette force incroyable, capable de dégeler ce que ni pic ni explosifs ne 
pouvaient dégager, c'est la puissance de la douceur, de l'écoute amoureuse des gens. La façon dont Dieu s'adresse à nous est similaire à la révélation du soleil aux fleurs: c'est sa chaleur et sa clarté qui les font s'ouvrir à sa lumière. De même, c'est en trouvant autour de nous présence, bonté, confiance, que nous percevons Dieu; à l'arrière-plan de chacune de ces attitudes humaines positives, il se révèle comme personne. Nous ne voyons jamais Dieu qu'à travers l'humanité des autres. Si nous sortons de la forteresse de notre supériorité, nous trouverons les mèches fumantes de la foi que nous avions tendance à négliger.

"...en chaque homme, le visage de Dieu attend de briller; en chaque homme, il vaut la peine de retrouver l'oeuvre d'art de la forme divine, et chaque homme, que ce soit Léonard de Vinci, Mozart, Shakespeare, toi ou moi, porte au fond de lui-même une image, une musique, une parole d'éternité qui ne pourra s'exprimer qu'en lui, ne se chanter qu'en lui, ne se jouer qu'en lui./.../ Ce n'est ni l'"action", ni la "rigueur", ni la "violence", ni la "volonté"- ce n'est pas le Michel-Ange du bloc de marbre, mais bien plutôt l'art de la contemplation patiente, de l'écoute pleine de compréhension, de l'unité dans la tendresse et de la résonance spontanée du coeur qui suscite dans le "jardin" de l'humanité sa plus belle floraison. Il ne s'agit ni de "transformer" ni de "modifier", mais de laisser mûrir et d'amener à la lumière./.../ Ce ne sont pas les "devoirs" qui soudent les humains les uns aux autres; ce qui les lie pour toujours, c'est la résonance qui peut exister entre leurs âmes, cette onde tremblante de bonheur /.../ Il n'y a ni à vouloir créer un "bateau" ni à construire un "temple" pour fonder la valeur d'une personne; il suffit d'entrer dans l'âme de l'être qu'on aime comme dans un sanctuaire où l'on est proche de Dieu. En s'inclinant vers cet être, on peut sentir la lumineuse chaleur de la divinité qui coule à flots à travers la rosace, et l'on peut voir le portail s'ouvrir tout grand sur les rives de l'éternité comme le croyaient les Égyptiens, la barque du soleil se trouve déjà prête sur le rivage, et il n'y a plus qu'à se laisser porter par le flot de l'amour jusqu'à ce monde que nous l'appelons l'"autre"." 40

Il est extrêmement important pour celui qui accompagne de comprendre qu'on ne peut aider une autre personne que si on renonce strictement à prendre la mesure de sa vie et

40

DREWERMANN, Eugen, L'essentiel est invisible, Une lecture psychanalytique du Petit Prince, Paris, Cerf, 1992, p. 132-133. L'écoute pastorale est une écoute poétique et musicale. C'est une écoute qui laisse jouer à l'autre son chant intérieur, sa plainte, sa joie, sa revendication profonde, sa subjectivité chaude, son sens du jeu des mots, avec la capacité à percevoir les harmoniques et à laisser résonner librement les multiples échos en soi de l'intériorité de l'autre, particulière et originale. 
à la juger d'après ses propres catégories et ses normes personnelles. L'essentiel est que l'accompagnateur exige de lui-même de mettre entre parenthèses les valeurs de sa vision du monde et essaie de voir ce monde avec les yeux de l'autre, il aura ainsi à coeur de s'abstenir de tout jugement. Pour lui, l'essentiel est donc de comprendre qu'il ne peut savoir ce qui est le mieux pour l'autre. Il ne peut rien faire d'autre que l'accompagner avec le plus de compréhension possible. Il lui faut se libérer des solutions et des recettes toutes faites pour s'ouvrir à l'autre. S'il veut vraiment aider l'autre dans sa croissance humaine et spirituelle, il doit littéralement devenir pauvre. Aussi longtemps qu'il s'enfermera dans un rôle de maître compétent, de spécialiste entraîné, d'expert qualifié, l'intervenant pastoral restera lui-même victime des conflits d'autorité que provoqueront ses manières.

\begin{abstract}
"Normalement la politesse exigerait que le chef vienne à la rencontre du subordonné qui vient lui rendre visite. Mais le (la) supérieur(e) reste assis(e) derrière un bureau si chargé de dossiers qu'il en ressemble à une forteresse imprenable. Toute son attitude émet un message muet: "N'approche pas trop." /.../ L'Église préfère toujours imposer comme normes ses statuts tout faits, plutôt que de s'ouvrir à la possibilité de nouvelles expériences et de nouveaux espaces de développement." I.../ En opérant ainsi, l'Église serait contrainte de faire précisément ce qu'elle a toujours le plus craint: renoncer à l'objectivisme de sa pensée administrative et mettre au premier plan de ses préoccupations le sujet, les personnes vivantes dans leur réalité, seul point de départ et seule fin valable en la matière." 41
\end{abstract}

Les paroissiens ne redeviendront personnes vivantes qu'en rencontrant des intervenants pastoraux assez audacieux pour vivre vraiment, et assez connaissants d'eux-mêmes pour cesser de transposer leurs peurs, leurs attentes ou leurs refoulements sur les autres; donc des personnes capables d'être vraiment elles-mêmes avec les autres, d'être elles-mêmes, sans retenue. La transmission de la foi peut être possible lorsqu'elle est le fruit de personne à personne et non pas lorsqu'on recherche à lier celle-ci à l'institution d'un système d'enseignement par fonction infaillible. 


\subsubsection{Comprendre le langage de l'autre et non imposer le sien}

Le défi pour l'intervenant pastoral est de découvrir la vérité cachée d'une vie à travers ce que l'autre nous en dit. Ce défi exige une écoute de l'autre ne cherchant rien d'autre qu'à le laisser être et manifester sa valeur. C'est une écoute de la parole créatrice que Dieu a prononcée sur son existence quand il l'a appelé à la vie et de la parole qu'il suscite au coeur de sa vie. Cette manière de se mettre à la disposition de l'autre constitue un véritable art de la rencontre interhumaine, proche parent des autres arts, poésie, peinture, musique. Au-delà de toute utilisation fonctionnelle, la relation pastorale se propose uniquement de tirer de l'autre le mot, l'image, la figure, la tonalité à travers laquelle il s'exprime avec le maximum de vérité, acquiert le mieux sa transparence, révèle le plus sa beauté intérieure. Devant Dieu, ce n'est pas l'extérieur qui est essentiel mais l'intérieur. Mais on ne peut rejoindre la profondeur des autres qu'à partir de la profondeur de soi. L'éducation de la foi, ce n'est pas seulement une question de "tactique" mais aussi (et peut-être surtout) de "mystique". Un éducateur ne peut conduire à la gratuité de l'Amour de Dieu que s'il en vit lui-même.

L'intervenant pastoral doit essayer de comprendre le langage de l'autre. Plusieurs agents pastoraux croient qu'une éducation de la foi est réussie lorsque l'autre utilise les mêmes mots qu'eux pour parler de Dieu, de Jésus, de l'Église,etc. Eugen DREWERMANN parle "savoureusement" de cette approche en la qualifiant d'une "pensée pastorale sur bande magnétique."

"Cependant, plus la vie des clercs se fait impersonnelle et affectivement pauvre, plus s'affirme la seconde variante de la pensée inauthentique: la pensée pastorale sur bande magnétique. C'est ainsi que, en plein milieu d'une conversation sur un problème humain ou une question religieuse, on entendra soudain une personne bien connue changer d'intonation, prendre une voix mélodramatique et une articulation posée et solennelle, 
tandis que de sa gorge montent les accents de la conviction. Bref, le grand jeu pastoral qui, malgré toute la volonté qu'on y met, ne prouve qu'une chose: qu'on cesse de parler de façon authentique et personnelle et qu'on est en train de mentir par fonction. Ce n'est plus la personne qui parle: une espèce de bande magnétique invisible se met en marche dans sa tête évoquant des thèmes et des questions déterminées, selon un programme prévu et à des occasions données. Au lieu de traiter vraiment la question posée, on fait pleuvoir des tournures visant toutes à étouffer dans l'oeuf une autre question: "Comment poser ce problème, si on voit vraiment les choses dans "la foi", comme on doit les voir?" En figeant ainsi la conversation par des lieux communs apparemment rationnels, on escamote complètement le sens subjectif qu'elle pourrait avoir pour les interlocuteurs. On ne voit plus, et on ne doit pas voir, l'intérêt qu'il pourrait y avoir à défendre certaines idées, l'importance qu'il y aurait à prêter à certaines thèses un sens différent de celui qu'on leur donnait depuis la première communion. Sur fond d'insécurité ontologique règne en permanence la peur de voir tout, vraiment tout, s'ébranler, pour peu qu'on bouge un détail dans l'édifice du surmoi. Mais on n'a pas conscience de cette peur; elle est constamment présente, mais recouverte par l'assurance de la pensée en surmoi. Dans ces conditions, le clerc ne peut s'engager subjectivement dans un débat théologique qu'avec le sentiment de défendre la vraie foi. En d'autres termes, il fait de l'étouffement des sentiments la règle: on ne se touchera pas; on ne pourra que se mettre d'accord, au nom d'une idéologie qui se fera intolérante en cas de déviation." 42

La foi chrétienne ne retrouvera dans l'Église catholique son humanité que lorsque la théologie des intervenants pastoraux se mettra à prendre en compte la vie des êtres humains, au lieu de prétendre la régir administrativement et de la détruire par des contraintes morales et intellectuelles. Nous nous construisons un langage sur Dieu qui nous permet de "doctoraliser" mais qui ne nous touche pas. Il ne nous remet pas en question. Il peut nous valoir pouvoir et prestige. Le Dieu de Jésus-Christ est le Dieu "Autre" qui refuse de se laisser cantonner dans des mots. De plus, n'est-ce pas constamment difficile de trouver des mots pour nommer sa propre expérience spirituelle?

"Il faut paradoxalement le dire en termes de rapport de proportionnalité inverse: plus une expérience est intensive religieusement, moins il est possible de la communiquer en dogmatiques, ce qui est ainsi enseigné peut être qualifié de nexus mysteriorum; c'est-à-dire que tous les mystères révélés du salut sont imbriqués entre eux de telle sorte qu'il faut ou bien croire au système tout entier et y croire comme le veut l'Église, ou bien passer pour hérétique"(Ibid., p.677). 
termes de faits objectifs, et plus le langage qui la traduit devient au contraire symboliquement riche. 43

Nous avons sans cesse à choisir d'être une Église de Babel ou une Église de Pentecôte. À Babel, le langage ne rassemble pas, il divise, il disperse. À la Pentecôte, l'Esprit crée de la communion en situant le langage au niveau de la profondeur où chaque personne peut reconnaître et entendre proclamer les merveilles de Dieu dans sa propre langue et sa propre culture. N'est-ce pas l'interpellation que les Pères de Vatican II ont lancée aux pasteurs de toute l'Église?

"Pourtant, le jour de la Pentecôte, il descendit sur les disciples pour demeurer avec eux à jamais (cf Jean 14,16); l'Église se manifesta publiquement devant la multitude, la diffusion de l'Évangile commença avec la prédication; enfin fut préfigurée l'union des peuples dans la catholicité de la foi, par l'Église de la Nouvelle Alliance, qui parle toutes les langues, comprend et embrasse dans sa charité toutes les langues, et triomphe ainsi de la dispersion de Babel"(Ad Gentes 4, 5-12). 44

DREWERMANN, Eugen, La parole qui guérit, p. 235 Il revient donc aux agents pastoraux de peser de tout son poids anthropologique le non-dit des demandeurs.

$44 \quad$ Il me semble que les Pères du Concile ne parlaient pas seulement dans ce texte des différentes langues comme le français, l'anglais, l'espagnol, etc. Considérant l'univers sémantique varié de chaque individu, les francophones, par exemple, parlent plusieurs langues même s'ils s'expriment uniquement en français. Un mot peut avoir plusieurs sens selon celui qui le dit et le contexte où il l'emploie. Pour être plus précis, il aurait fallu que je distingue davantage la notion de "langue" et de "langage". Mais étant donné la complexité de cette problématique, je m'autorise à utiliser indifféremment langue et langage pour décrire le processus constitutif de la parole humaine (n'en déplaise aux puristes!). Le langage se définit comme le potentiel théorique de communication tandis que la langue comme l'application pratique par un individu ou un groupe d'individus de ce potentiel. (Voir VENDRYES, Joseph, Le langage, l'Évolution de l'humanité, Paris, Albin Michel, 1968.) La religion et le langage constituent deux volets essentiels de toute culture humaine. L'âme d'un peuple influence sa manière de se comprendre et de communiquer. En retour, la religion et le langage influencent les gens qui en usent. Ces deux réalités se retrouvent inextricablement liées. On ne peut les démêler. Notre culture française d'Amérique du Nord en présente un bel exemple: sans la religion catholique qui s'est intimement liée à la défense de la langue française, nul doute qu'on ne la parlerait plus aujourd'hui après deux cents ans de domination anglaise. À l'instar de la religion, le langage naît du pouvoir humain de "symboliser" la réalité. Le processus pour s'approcher de Dieu ressemble un peu au processus linguistique le plus évocateur: l'art de la poésie. Celle-ci constitue l'instrument le plus puissant que possède une langue pour évoquer des réalités "inexprimables". Tout l'art poétique réside dans la capacité de faire dire plus aux mots que leur simple définition. Tout l'art religieux réside dans la capacité de faire accéder à une réalité qui dépasse le cadre de la simple définition objective des faits. Langue et religion constituent donc des réalités "vivantes". Elles naissent de la vie. La vie favorise les transformations du vocabulaire parce qu'elle multiplie les causes 
Ce n'est pas aux gens de parler la langue de l'Église. C'est à l'Église attentive à l'Esprit qu'est confiée la mission de reconnaître et de proclamer les merveilles de Dieu dans la langue de chaque personne et de chaque peuple.

"Au fond les rites sont l'expression d'une quête d'humanisation et ils jouent d'abord en ce lieu avant de pouvoir se justifier par une logique verbale. Malheureusement il semble que la formation intellectuelle que nous recevons en tant qu'agents-es de pastorale nous conduise à perdre de vue cet ancrage existentiel où sont situés les demandeurs, en même temps que les conditions d'abordage d'un cheminement positif avec eux. En gros c'est comme si on reprochait aux personnes demanderesses de ne pas avoir suivi nos cours de théologie. Or, les sacrements sont davantage de l'ordre de la praxis que du logos." 45

Je crois qu'en étant vigilants par rapport à ces défis, les artisans de la pratique sacramentelle font l'expérience de la fécondité missionnaire d'un dialogue vrai avec toutes les personnes qui se présentent en respectant leur propre langage. Sinon, le dialogue de sourds risque de se poursuivre si les accueillants n'ont pas d'abord le souci de "décoder" la demande de leurs interlocuteurs.

"Au lieu de manquer le rendez-vous sous prétexte que les personnes ne correspondent pas à l'attente, ou encore au schéma type du croyant, une rencontre aura lieu, porteuse de joie, ouverte à un cheminement commun dans le respect des différences et l'ouverture à l'inédit de Celui qui se fait proche quand deux ou trois acceptent de faire route ensemble. Le visage de l'Église s'enrichira de traits originaux dans l'accueil de personnes de toute

qui agissent sur les mots. Une langue ou une religion qui ne s'adaptent pas aux nouvelles réalités deviennent incapables d'exprimer le vécu des personnes. Elles ne "parlent" plus ou ne "se parlent" plus. L'affectivité constitue sans doute l'aspect de notre vécu qui "affecte" le plus la langue et la religion. L'affectivité humaine nourrit le sentiment religieux, qui se découvre comme le reflet de nos luttes intérieures et des joies de notre existence. Elle englobe aussi dans son cadre de sentiments vécus le langage. Ainsi, l'affectivité pénètre le langage grammatical, le dépouille et le désagrège. C'est par l'action de l'affectivité que s'explique en grande partie l'instabilité des grammaires. Les gens se posent ardemment la question religieuse, la question du sens que doit prendre leur vie. Mais ils ne peuvent plus dans le contexte actuel se contenter des réponses religieuses toutes faites d'autrefois. Ils demandent des réponses adaptées à notre temps, des réponses d'ordre expérientiel en mots d'aujourd'hui, des réponses qui tiennent compte des sensibilités d'aujourd'hui. Mais l'Église ne semble pas posséder de nouveaux mots ni même comprendre ceux utilisés par les gens de cette culture moderne.

45

BOUCHARD, Luc, "Apologie de l'expression liturgique, Points de repères en pastorale sacramentelle", in Prêtre et Pasteur, juin 1993, p. 349. 
langue, culture, condition sociale au lieu d'être la reproduction étriquée de la même image. Elle aura visage catholique ouvert et accueillant comme Celui du Christ qui la rassemble en déjouant les exclusions des experts du Temple et le légalisme des pharisiens de toutes les époques de son aventure historique." 46

Les rites de passage offrent de nombreuses pierres d'attente pour une découverte du Dieu Vivant, source de toute vie. Accuellir et écouter ce qui se passe dans la profondeur de l'expérience des personnes qui demandent un rite de passage constituent un chemin essentiel pour découvrir le mystère. Quel que soit le langage utilisé pour l'exprimer, cette dimension est présente dans la vie de toute personne.

"Si elle est en veilleuse, peu actualisée, la démarche sacramentelle peut contribuer à l'éveiller, à la développer, à la faire émerger en pleine conscience. En permettant aux personnes de faire l'expérience du langage rituel symbolique, l'Église ne transgresse pas sa mission. Elle contribue à la croissance de l'humain et éventuellement à son déploiement spirituel. Toute recherche de sens ouvre le chemin vers Dieu, même si le parcours reste souterrain. Le silence des lentes germinations est plus efficace que les bavardages religieux faciles. Célébrer un événement de la vie humaine a toujours un sens, même si ce sens n'est pas explicitement croyant, même si ce sens n'est pas formulé dans le langage de la confession de foi." 47

46

DUFOUR, Simon, TREMBLAY, Éric, "Lieu de mission et de présence au monde", p.25. "Pourtant c'est bien là que réside la source véritable de la puissance cléricale. C'est là que s'affirme sans contestation possible cette langue de spécialistes qui a le don de provoquer l'étonnement admiratif du simple peuple. C'est là que s'ancre l'autorité véritable des clercs. C'est le sanctuaire des experts, de ces gardiens compétents qui transmettent le trésor de la foi chrétienne avec ce qu'elle a d'unique, d'indubitable, et son indépassable pouvoir eschatologique de salut. C'est une sorte de secret jalousement scellé dans des mots,...."(DREWERMANN, Eugen, Les fonctionnaires de Dieu, p.128).

47 DUFOUR, Simon, TREMBLAY, Éric, "Lieu de mission et de présence au monde", p.21. "Dans le fond, il s'agit ici des conséquences de l'effondrement de toutes les structures établies, autrement dit de la nécessité d'enterrer une bonne fois un certain style de pastorale. Celle qui consiste à utiliser rites et règles canoniques pour faire descendre sur les gens une grâce salvifique divine accumulée comme un dépôt sacré. Maintenant, il s'agit de transformer toutes les formes d'expression de la foi chrétienne en une gerbe de propositions dans lesquelles les gens pourraient eux-mêmes découvrir une source de salut"(DREWERMANN, Eugen, Les fonctionnaires de Dieu, p.194-195). 


\subsubsection{Le ritualisme ou une ritualité symbolique significative}

Quand il est possible de se rejoindre au niveau des profondeurs de l'expérience humaine au coeur de la relation pastorale, les horizons du mystère s'ouvrent et un certain discernement de l'oeuvre de Dieu peut s'effectuer. Mais pour cela, il faut dépasser le souci des règles et des comportements. Il est nécessaire de créer un climat de confiance et d'amour. Telle devrait être la première préoccupation en pastorale des sacrements. Ensuite seulement on pourra chercher comment symboliser rituellement ce vécu partagé en puisant dans le trésor de la foi chrétienne des matériaux de sens qui soient pour nous force d'intégration et fondement d'une appartenance significative. Encore ici, il faut éviter le ritualisme. Célébrer devient un art dans lequel le sens humain et chrétien se construit à travers la ritualité symbolique, dans une recherche de signification liée à la vie des personnes impliquées. Sans cela, on fait jouer des mécanismes rituels qui tournent à vide, car ils ne sont pas enracinés dans la vie. De plus, comme le dit si bien Guy LAPOINTE, il faut croire au travail de la célébration chrétienne au coeur des situations humaines et croire au rite en lui-même comme chemin d'ouverture vers la foi au Dieu de la Vie.

"Je veux signifier par là l'urgence de ré-inscrire les sacrements dans leur vie et de prendre le risque des situations humaines avec leurs ambiguittés. Pour y arriver, deux choses: croire au travail de la célébration chrétienne au coeur de ces situations: croire au travail du rite en faisant le pari que dans le moment et l'espace d'une célébration, la vie peut s'ouvrir à la foi, se réveiller et que les questions portées par l'Évangile peuvent rejoindre les personnes. N'est-ce pas retrouver les intuitions et les chemins d'incarnation? Les sacrements chrétiens ne sont-ils pas, comme en un moment poétique, l'émergence de la mémoire évangélique dans des situations fondamentales de la vie humaine. /.../ Une nouvelle praxis célébratoire demande à être instaurée. La fonction herméneutique, celle de la recherche de sens, gagnerait à prendre le pas sur celle de l'enseignement. En ce sens, il importe de redonner à notre langage liturgique une liberté d'expression qui aide les groupes célébrants à exprimer ce qu'ils vivent, ce qu'ils découvrent, leur malaise et leur goût de la vie et aussi de l'Évangile. Pour y arriver, il me semble y avoir deux conditions. D'abord, favoriser le partage d'une parole intelligente, sensible, moins "catéchétique", plus liée à même l'événement et faire soupçonner que cette parole inspirée de l'Évangile pourra ouvrir l'espace pour Dieu et pour la mémoire chrétienne. Ensuite, ouvrir les gestes à la 
nouveauté de l'événement, gestes qui suggèrent sans jamais arriver à dire ce que les gens vivent. Mais n'est-ce pas le rôle de toute célébration et même de l'Évangile de suggérer ce qu'on arrive jamais à pouvoir dire vraiment? Les célébrations peuvent ainsi, et elles le sont souvent, devenir des lieux privilégiés d'éducation de la foi." 48

Nous avons alors un choix à faire pour les rencontres de préparation aux sacrements et les célébrations elles-mêmes lesquelles peuvent être axées sur l'offre institutionnelle ou sur la vie des personnes. Dans le premier cas, les interventions pastorales tournent facilement au jugement de valeur. Malheureusement plusieurs rencontres et célébrations sacramentelles sont plus centrées sur le rite à expliquer, les messages à transmettre que sur l'accueil et l'écoute des personnes. Il faut renverser cette attitude. Commencer par l'accueil, l'écoute, le dialogue vrai, sans arrière-pensée, avec le souci de découvrir ce qui se trame dans la profondeur de la vie de ces paroissiens aimés de Dieu au sein des défis de leur vie.

"À peine entrée dans le ministère, au bout de quelques jours seulement, les dés seront jetés. Consciemment ou non, le prêtre aura choisi: ou bien les quatre-vingt-dix-neuf brebis qui (apparemment) n'ont pas besoin de revenir au bercail, ou bien la centième qui s'est égarée et qui serait perdue s'il n'allait pas à sa recherche jusqu'à ce qu'il l'ait retrouvée, comme le fait Jésus (Mt 18, 12-14; Lc 15, 1-7). Dans le premier cas, il se conformera toujours plus étroitement à son rôle officiel et aux impératifs de son surmoi; il n'aura aucun contact avec ceux qui sont en dehors du bercail, ou tout au plus des contacts décevants et rebutants pour les uns et pour les autres. Dans le deuxième cas, il aura des rapports très difficiles et parfois très tendus, intérieurement avec la censure de sa conscience, et extérieurement avec ses supérieurs et ses confrères. Par contre, il se sentira proche des marginaux et, au moins de temps en temps, il pourra ouvrir à ceux qui avaient depuis longtemps perdu foi en eux-mêmes le chemin qui les conduit à eux-mêmes et à Dieu. Dans le premier cas, il demandera autoritairement aux autres d'apprendre ce qu'il a lui-même appris de l'Église. Dans le second, il oubliera éventuellement l'enseignement de celle-ci, pour apprendre des autres ce que Jésus voulait qu'il apprenne et que son Église devrait apprendre: écouter Dieu parler par la souffrance et les besoins des autres, un Dieu qui n'est pas celui des morts, mais celui des vivants (Mc 12, 27)."49

48

pp.364-365. 49

LAPOINTE, Guy, "La pratique des sacrements: risquer la situation présente",

DREWERMANN, Eugen, Les fonctionnaires de Dieu, p.99 "C'est moi qui ferai paître mon troupeau, et c'est moi qui le ferai reposer, déclare le Seigneur Dieu! La brebis perdue, je la chercherai. Celle qui est blessée, je la soignerai. Celle qui est faible, je lui rendrai des forces. Je la ferai paître avec justice"(Ez 34, 15-16). 
Le travail pastoral répond aux règles du donner-recevoir et il n'y a pas de vrai don possible sans la disposition à recevoir. "Être", c'est inséparablement se donner en se recevant et recevoir en se donnant. La relation pastorale est un lieu de conversation authentique "aller-retour" où les convertis sont dans les deux camps. Il est de nécessité que des témoins existent pour nous transmettre la tradition de foi qui remonte à Jésus et pour nous mettre en contact avec lui. Cette dimension du témoignage est structurante de notre expérience de foi. C'est par ce qu'il est en lui-même qu'un témoin agit sur les autres. Il le fait d'ailleurs, en grande partie, à son insu. Son silence est souvent plus efficace que sa parole. Un témoin ne s'impose pas comme témoin. Il renvoie à ce qu'il a vu ou expérimenté pour "donner à voir" aux autres, c'est-à-dire pour leur permettre à leur tour de se faire une opinion, d'avoir une connaissance de la réalité ou de la personne rejointe par le témoignage. Le témoignage n'est pas un moyen de vente sous pression. Les signes distinctifs au nom du témoignage... mais s'agit-il de témoignage ou de publicité? L'approche pastorale est une manière d'être où nous sommes transformés à mesure que nous nous approchons des autres dans l'accueil et le respect. L'autre n'est pas que la cible de mon activité pastorale mais il est aussi celui en qui je suis invité à reconnaître Jésus dont je prétends par ailleurs témoigner. L'intervenant pastoral doit donc aspirer à devenir un témoin significatif. Non pas un témoin qui a dûment préparé son témoignage mais qui, au fil de l'entretien, se laisse aller à se dire, sans autre appui que l'Esprit-Saint qui parle autant à travers les silences, les maladresses de langage, les intonations, les hésitations qu'à travers les clairs énoncés.

"Il nous semble permis de conclure: la responsabilité inconditionnelle du témoignage est parfaitement compatible avec le désintéressement le plus entier et avec le respect intégral d'autrui. Je dois porter témoignage, éventuellement devant toi. Je n'ai aucune visée à ton sujet. Je puis espérer que le plus d'hommes possible, et notamment toi-même, 
découvriront la richesse de l'évangile, même s'ils le comprennent et le font leur d'une manière toute différente... mais cela n'est pas ma responsabilité." 50

Dieu seul respecte absolument la liberté de l'être humain. Il la crée: ce n'est pas pour la pétrifier ou la violer. C'est pourquoi jamais il ne crie ni ne s'impose. Il suggère, il propose, il invite. Il ne dit pas "Je veux", mais "si tu veux...."

\subsection{Croissance humaine, croissance spirituelle}

"Il est plus difficile d'initier l'homme à la vie spirituelle qu'aux activités scientifiques. La vie spirituelle demande beaucoup plus I.../ car pour prendre sa taille, elle exige que le tout de l'homme soit mis en oeuvre"(LÉGAUT, Marcel). 51

La dimension spirituelle est située au sein des multiples composantes de la personne. Les recherches récentes en psychologie religieuse nous ont révélé le lien étroit entre le développement de la foi et les périodes de transition, de changement et de crise dans une vie. Le développement de la foi n'advient pas de façon uniforme durant la vie adulte mais se produit de façon variée et en lien direct à certains temps du cycle de la vie adulte. Dans la perspective du cycle de vie, les questionnements de l'adulte, ses remises en question, ses insatisfactions, ses réajustements sont l'expression d'un travail développemental et doivent être considérés comme des indices et des occasions de croissance humaine et spirituelle. Il est de plus en plus urgent dans le monde Temps de la Patience: étude sur le témoignage, Paris, Cerf, 1976, p. 140.

51 LÉGAUT, Marcel, Travail de la foi, Paris, Desclée de Brouwer, 1989, p. 141. "Avant d'être un véritable croyant, il faut être un vivant véritable; si modeste soit son destin"(LÉGAUT, Marcel, Introduction à l'intelligence du passé et de l'avenir du christianisme, France, AubierMontaigne, 1970, p.81). "Pourquoi être chrétien? C'est avec cette question très directe que nous avons ouvert ce livre? La réponse est tout aussi directe: pour être véritablement humain"(KUNG, Hans, Être chrétien, Paris, Seuil, 1978, p. 707). "C'est précisément de cette finitude incontournable qu'au cours de l'histoire le sentiment religieux ne cesse de resurgir"(SCHILLEBEECKX, E., L'histoire des hommes, récit de Dieu, Paris, Cerf, 1992, p. 350. [Cogitatio Fidei \# 166] ). 
pastoral de s'initier à des approches qui veulent aider les adultes à comprendre les enjeux psychologiques et religieux des étapes de leur développement personnel. La spiritualité la plus cohérente, lorsqu'elle n'est pas inspirée par une véritable expérience de la vie dégénère facilement en activités cérébrales ou en débordements sentimentaux. Notre Dieu est le Dieu de la Vie. La vie même est linstrument le plus efficace de notre développement.

\subsubsection{Le développement psychosocial de l'adulte}

Les Pères du Concile ont invité les pasteurs à un enseignement catéchétique qui tienne compte du développement humain de l'adulte en s'inspirant des découvertes scientifiques modernes.

"Que, dans la pastorale, on ait une connaissance suffisante des principes de la théologie, mais aussi des découvertes scientifiques profanes, notamment de la psychologie et de la sociologie, et qu'on en fasse usage: de la sorte, les fidèles à leur tour seront amenés à une plus grande pureté et maturité dans leur vie de foi"( Gaudium et Spes \#62,2)

"Dans cet enseignement, on adoptera l'ordre et la méthode qui conviennent non seulement à la matière dont il s'agit, mais encore au caractère, aux facultés, à l'âge et aux conditions de vie des auditeurs" (Christus Dominus n 14 ).

"L'activité missionnaire possède un lien intime avec la nature humaine elle-même et ses aspirations."(Ad Gentes 8, 1-2)

L'annonce de Dieu est alors indissociable du patient accompagnement des personnes dans les conditions et réalités de leur existence. Il est ainsi important que les intervenants pastoraux aient une plus grande formation en psychologie des adultes et en andragogie religieuse pour comprendre les différentes étapes de leur développement pour une approche plus fructueuse.

"Essentiellement, le christianisme n'est pas une doctrine, mais une communication existentielle, et tant que l'Église ne permettra pas à l'individu de découvrir lui-même, clairement, par expérience, les images capables de cadrer les différents domaines et stades de sa maturation et de son développement personnels, il tiendra toujours à 
interpréter l'écriture sainte ou l'annonce de la foi à travers une multiplicité compensatrice de doctrines rationnelles et objectivistes, et, à les imposer au nom d'un magistère infaillible." 52

Les études récentes en psychologie nous permettent de porter un regard nouveau sur le processus de la naissance à une vie adulte. Elles nous facilitent la réinterprétation en mots d'aujourd'hui des réalités humaines fondamentales présentes dans le coeur des personnes: jeu des dynamismes de vie en soi, mystère du mal, appel de l'infini, désir de survivre à la mort, etc. La décision de croire ou non se trouve intimement liée au développement psycho-affectif de la personne. La psychologie nous permet donc de comprendre le processus humain qui aboutit à la prise en compte responsable de sa vie à l'âge adulte. La vie intérieure se transforme tout au cours du cycle de vie. Il est alors important pour un intervenant pastoral de connaître les enjeux psychosociaux avec lesquels l'adulte est aux prises. Il existe plusieurs théories et modèles sur ces différents enjeux. Renée HOUDE a bien synthétisé dans un tableau quelques études de spécialistes reconnus dans ce domaine. Ces auteurs adoptent la perspective du cycle de vie et privilégient une lecture psychosociale du développement de l'adulte. Le développement est saisi à travers des rythmes qui découpent le cycle de vie en saisons, en stages, en phases, en passages (anticipation, rupture, apprivoisement, intégration).

"Tableau 11.1

Comparaison des phases du cycle de vie adulte selon les différents auteurs

\begin{tabular}{|c|c|c|c|c|c|c|c|}
\hline Âge & Jung & Erickson & Bühler & Havighurst & Levinson & Gould & Vaillant \\
\hline 15 & & & $\begin{array}{l}\text { Expansion } \\
\text { des buts } \\
(16-25)\end{array}$ & $\begin{array}{l}\text { Jeune adulte } \\
(18-30)\end{array}$ & $\begin{array}{l}\text { Transition } \\
\text { du jeune adulte } \\
(17-22)\end{array}$ & $\begin{array}{l}\text { Quitter le } \\
\text { monde de } \\
\text { ses parents } \\
(16-22)\end{array}$ & \\
\hline 20 & Jeunesse & $\begin{array}{c}\text { Intimité } \\
\text { Vs }\end{array}$ & & & $\begin{array}{l}\text { Entrée dans } \\
\text { le monde adulte }\end{array}$ & $\begin{array}{l}\text { Ne plus être } \\
\text { l'enfant de }\end{array}$ & $\begin{array}{l}\text { Intimité } \\
\text { Vs }\end{array}$ \\
\hline
\end{tabular}


Isolement

25

30

35

40 Maturité Générativité

VS

Stagnation

45

50

55

60 Vieillesse Intégrité

Vs désespoir
Culmination

(26-40)
$(22-28)$

Transition de

la trentaine

(28-33)

Mitan de la vie Établissement (30-35)

(33-40)

personne Isolement

(22-28)

S'ouvrir à ce

qu'il y a à

lintérieur de soi

(28-34)

Consolidation de carrière Vs autodestruction

La décennie du milieu de la vie

Transition de la quarantaine (40-45)

Entrée dans le mitan de la vie adulte (45-50)

Transition de la cinquantaine (50-55)

Vie adulte Point culminant avancée de la vie adulte (55 et plus) (55-60)

Transition de la vieillesse
Générativité VS stagnation

Au-delà du milieu de la vie (45 et plus)
Maintien du sens

Vs rigidité

Satisfaction de soi ou sentiment d'échec (65 et plus)

En approfondissant ces théories on découvre que d'un auteur à l'autre, la terminologie varie. On parle de stages, de périodes, de phases, d'étapes, de passages et le sens qu'on donne à ces portions de temps change également: crise, transition, transformation, stabilité, rites de passage. D'un modèle à l'autre, la durée des stades n'est pas la même. Chaque auteur avance des idées complémentaires aux autres. Selon C. G. JUNG,

53 HOULE, Renée, Les temps de la vie, Le développement psychosial de l'adulte selon la perspective du cycle de vie, Boucherville, Gaëtan Morin, 1991, pp. 296-297. 
l'adulte se développe par la voie de l'individuation à travers les quatre temps qui scandent une vie: l'enfance, la jeunesse, la maturité et la vieillesse. ${ }^{54}$ Selon E. H. ERIKSON, l'adulte se développe en traversant des crises psychosociales de caractère normatif; chaque crise implique un enjeu de croissance spécifique qui oscille entre deux polarités. 55 Pour C. BÜHLER, c'est en mettant des buts, en essayant de les atteindre, en évaluant son tir et en réajustant sa cible que l'adulte évolue, démarquant par le fait même les principaux mouvements du cycle de vie.56 Pour D.J. LEVINSON, l'évolution de la structure de vie est le lieu privilégié du développement adulte. La structure de vie est la résultante d'une interaction complexe entre le monde socioculturel d'une personne, les aspects de son self qui s'y expriment et sa participation dans le monde à travers les différents rôles qu'elle détient et la façon dont elle les joue. 57 Pour R.L. GOULD, devenir adulte c'est lentement se métamorphoser sans que jamais il n'y ait de terme à cette métamorphose puisque tant et aussi longtemps qu'il y a vie, il y a oscillement entre la conscience d'enfant et la conscience d'adulte. 58 G.E. VAILLANT adhère au découpage en stades tels que décrits par E.H. ERIKSON en suggérant de leur ajouter un stade de consolidation de carrière et un stade de maintien de sens. ${ }^{59}$ En lisant ces spécialistes, nous découvrons que la cartographie du monde adulte ressemble encore à une mosaïque aux contours

54 JUNG, C.G., "The Stages of Life", in J. Campbell (édit.), The Portable Jung, New York, Viking, 1971, pp. 3-22.

55 ERIKSON, E.H., The Life Cycle Completed: A Review, New York, Norton and Co., $1982,108 \mathrm{p}$.

56 BÜHLER, C., The Course of Human Life: A Study of Goals in the Humanistic Perspective, New York, Sprinter, 1968, 422p.

57 LEVINSON, D.J., "The Seasons of a Man's Life", in L. R. Allman et D.T. Jaffe (édit.)., Readings in Adult Psychology, Contemporary Perspectives, New York, Harper and Row, 1982, pp. 103-107.

58 GOULD, R.L., Transformations: Growth and Change in Adult Life, New York, Simon and Schuster, 1978, 343 p. 
imprécis. Les cycles ne possèdent ni la même clarté ni la même importance selon les modèles étudiés.

La plupart des auteurs insistent pour qu'on ne prenne jamais les indications d'âge à la lettre mais qu'on les considère plutôt comme un indice. L'âge n'est pas le seul facteur de changement; il n'est jamais un facteur exclusif mais il est en interaction avec de multiples autres facteurs: le sexe, la race, la génération, la classe sociale, les différences dans l'adaptation sociale, la santé, les ressources financières, le statut professionnel et le statut matrimonial. En somme, l'âge est une variable parmi d'autres qui a une valeur d'indice non de cause et qui n'est pas normative. De plus, cet âge est moins chronologique que social et s'inscrit dans les changements de sociétés. Les événements de vie ont également un pouvoir catalyseur évident et ils affectent la trajectoire développementale. Chaque vie est à l'oeuvre sur tous les fronts à la fois et ces fronts agissent les uns sur les autres. Chaque adulte est comme un chef d'orchestre qui dirige les cuivres, les cordes, les bois et les percussions ou comme un commandant d'armée qui avance sur tous les fronts. Comme on le voit, tous ces modèles, comme l'ensemble de la présente thèse, exigent encore une fois une épistémologie systémique de la réalité humaine.

\subsubsection{Linsuffisance de la formation des intervenants pastoraux}

Pourquoi ai-je trouvé important de parler "en vrac" de tous ces modèles et théories psychologiques selon la perspective du cycle de vie? Pour tout simplement démontrer que les intervenants pastoraux doivent tenir compte de ces études sur le développement psychosocial de l'adulte et de celles concernant plus explicitement le 
développement de la foi. $60 \mathrm{Il}$ me semble qu'actuellement les formations universitaire et diocésaine données n'investissent pas suffisamment dans l'approfondissement de ces différentes approches. Notre pédagogie pastorale doit obligatoirement se baser sur la dynamique entre le processus de croissance humaine et le développement de la foi chrétienne. Pour atteindre cela, il faut réviser la formation donnée dans les facultés de théologie et les services diocésains.

"....l'Office des catéchistes a une très grande importance. Leur formation doit donc être tellement menée à bien et accommodée au progrès culturel..."(Ad Gentes 17, 8-9)

"Pour une part importante, il faut le reconnaitre, le drame de la situation de l'éducation des adultes dans l'Église du Québec a trait à l'orientation majeure de l'entreprise formative, présentement plus occupée à habiliter aux charges pastorales qu'à assister le devenir des croyants. Il faut en prendre acte: nos pratiques de formation s'effectuent peu en rapport avec les réalités sociales et l'histoire des baptisés. /.../ Quand on s'ouvre aux théories du

60

À ma connaissance, c'est James W. FOWLER qui a le plus consacré d'efforts en ce domaine. À partir de 359 interviews réalisées de 1971 à 1981, il a élaboré un véritable modèle du développement de la foi du croyant, qui fait l'objet d'un de ses ouvrages: Stages of Faith: The psychology of Human Development and the Quest for Meaning, San Francisco, Harper and Row, 1981, 332 pages. Deux articles en font état en français dans la revue Concilium: "Théologie et psychologie dans l'étude du développement de la foi" ( $\mathrm{n}^{\circ} 176$, juin 1982, pp. 145-150) et "Une introduction progressive à la foi" ( $\mathrm{n}^{\circ}$ 194, septembre 1984, pp. 77-87). [La foi intuitive-projective (4-8 ans), la foi mythico-littérale (7-12 ans), la foi synthético-conventionnelle (à partir de 12 ans; peut se prolonger dans la vie adulte), la foi individuelle réflexive (vers 17-18 ans; parfois 35-40 ans; certains n'y parviennent jamais), la foi conjonctive ou paradoxale de consolidation (pas avant 40 ans), la foi universalisante (très rare).] Voir aussi - COMTE, Robert, "La structuration de la foi personnelle", in Christus, $\mathrm{n}^{\circ} 143$, juillet 1989, pp.264-275. et "Etapes de la vie adulte et évolution spirituelle", in Catéchèse , n 120 , juillet 1990, pp.23-34.; C.N.E.R., Formation chrétienne des adultes: Un guide théorique et pratique pour la catéchèse, Paris, Desclée de Brouwer, 1986, 312p.; GIGUÈRE, Paul-André, Une foi adulte, L'horizon du croyant, Ottawa, Novalis, 1991.; GIRARD, Raymond, Éducation à la foi et développement humain, Québec, Presses de l'université du Québec, 1992, 428 p. ; En collaboration, sous la direction de GRAND'MAISON, Jacques, Vers un nouveau conflit de générations, Profils sociaux et religieux des 20-35 ans et Une génération bouc-émissaire, Enquête sur les baby-boomers, Montréal, Fides, 1993. [Cahiers d'études pastorales \# 14 et \#15]; GROOME, Thomas H., Sharing Faith, A Comprehensive Approach to Religious Education and Pastoral Ministry, San Francisco, Harper and Row, 1991. [Mes études au Boston College m'ont permis de connaître cet auteur et son approche]; GY, Pierre-Marie, "La notion chrétienne d'initiation", in La Maison-Dieu, n¹32, 1977, p.33-54.; HÉTU, Jean-Luc, Psychologie de l'expérience intérieure, Montréal, Méridien, 1983, 198p.; LINN Dennis et Matthew et FABRICANT Sheila, Le développement de l'homme en huit étapes, Guérison des souvenirs, Paris, DDB, 1992.; OSER, F.; GMUNDER, P. et RIDEZ, L., L'homme et son développement religieux, Paris, Cerf, 1991, 348p.; MOINGT Joseph, La transmission de la foi, Paris, Fayard, 1976, pp.120129.;WHITEHEAD, Evelyn Eaton \& James D., Les étapes de l'âge adulte: Évolution psychologique et religieuse, Paris, Centurion, 1990, 268p. 
développement de la foi, auxquelles ont conduit des études menées en relation avec les divers schémas de la croissance humaine aux plans psycho-social, cognitif et moral, il devient aussi plus manifeste que cette centration de notre pratique sur le savoir-faire apostolique pose problème /../ À privilégier la formation à la prise de responsabilités pastorales, on peut se demander jusqu'à quel point nous permettons vraiment à l'adulte d'assumer, au plus près, dans la foi, ce que chaque âge ou étape de sa vie fait de lui. On peut même se demander si nous ne sommes pas en train de faire fi de cette vieille conception de la théologie scolastique: la grâce construit sur la nature."61

Même si toute la théorisation des sciences humaines peut être considérée comme des outils intéressants, il est important de ne pas l'absolutiser et de croire que le réel profond de l'être demeure toujours complexe. La profondeur de la personne ne restera en dernier lieu accessible qu'à la personne elle-même avec ce qu'elle a de plus précieux pour elle: son manque, sa faim, ses désirs, ses blessures, les consolations, le pardon et le plaisir qu'elle en tire. Toute science ou tout savoir rationnel ne sont-ils pas à la fois réducteurs et impérialistes par nature? La science impose souvent son langage à ceux qu'elle devrait entendre, leur volant parfois, avec leur parole, leur chance de symboliser, de découvrir en eux le sens de ce qu'ils éprouvent.

L'intervenant pastoral doit tendre, même s'il possède des connaissances en psychologie, en andragogie ou dans d'autres champs des sciences humaines, à être avant tout un accompagnateur spirituel. Le psychologue professionnel écoute celui qui lui demande de l'aide et puis le renvoie à lui-même. Le psychologue aide ainsi la personne à se trouver elle-même pour qu'elle puisse devenir autonome. L'accompagnateur spirituel renvoie plutôt son interlocuteur au Seigneur par le moyen des différentes pratiques spirituelles de la tradition ecclésiale. L'attention de celui qui est accompagné est attirée vers son Dieu qui lui est présent, un Dieu qui lui propose d'entrer en relation avec Lui, tel qu'il est avec ses capacités et ses fragilités. Le guide

61 DROUIN, Gilles, "L'éducation de la foi des adultes au Québec, Essai d'analyse de la situation", in Église canadienne, volume 26, numéro 10, septembre 1993, p.301. 
spirituel renvoie celui qui le consulte au Seigneur pour quil puisse se découvrir tel qu'il est et recevoir de Lui son existence. Les paroissiens n'ont-ils pas davantage besoin d'accompagnateurs spirituels que des "fonctionnaires de Dieu"?

\subsection{Mourir à 1 "idéologie" communautaire ${ }^{62}$}

Le mot "communauté" est l'expression la plus utilisée d'une manière abusive. Il nous arrive souvent de confondre le "collectif" et le "communautaire". Il semble qu'il y ait une idéologie très répandue dans les Églises diocésaines de généraliser et de tendre à "collectiviser" au lieu de "communautariser". Plutôt que d'inviter les paroissiens à vivre de façon personnalisée et communautaire, certains permanents ecclésiaux leur demandent de s'adapter à tout prix à la collectivité ecclésiale et de s'efforcer de satisfaire aux réglements. Il y a un malentendu à dissiper. Par exemple, une célébration pour plusieurs bébés en même temps n'est pas plus communautaire que la célébration pour un seul bébé. Communautaire n'est pas synonyme de collectif. Un réseau familial qui présente un bébé peut être très communautaire et même plus qu'un regroupement de cinq familles qui se connaissent très peu. Il peut arriver que ce soit plus pratique mais ce n'est pas pour autant plus communautaire. La foi naît et grandit dans l'effort que chaque personne apporte à devenir elle-même et ce devenir n'est atteint que grâce à la présence des autres. Comme nous l'avons approfondi précédemment, il s'avère essentiel de personnaliser

62

"Un raisonnement ouvert et libre de préjugé idéologique devrait ressembler à un dialogue platonicien: c'est un processus d'examen, de recherches, de vérifications et d'éclaircissements progressifs débouchant finalement sur un point qui apparaît digne de foi, éventuellement sur une "vérité". Le raisonnement idéologique procède en sens inverse: il cherche par tous les moyens que la pensée contemporaine met à sa disposition à fonder ce qui, d'avance, est déjà pour lui une vérité. C'est un cercle vicieux; ce qui est prouvé est posé comme le fondement des arguments mis en oeuvre; c'est le toit qui soutient les fondations. /... La conséquence en est inévitable: l'appareil idéologique édifié pour calmer l'angoisse comporte une contradiction de base entre l'insécurité ontologique fondamentale et l'existence personnelle et, loin de la résoudre, il la pérennise"(DREWERMANN, Eugen, Les fonctionnaires de Dieu, p.118; p. 142). 
les démarches pour rejoindre la profondeur de la vie de la personne rencontrée. À ce titre, certaines politiques pastorales mises en place au nom du principe "communautaire" doivent être révisées.

\subsubsection{Surgissement de différentes sortes de communautés}

La société actuelle est en train de faire naître d'autres sortes de communautés. Cependant, l'imaginaire de la majorité des intervenants pastoraux est meublé par un seul et unique modèle de communauté très "idéologique". Pourtant, nous l'avons vu au chapitre dixième, au départ de l'expérience croyante, on ne parlait de communauté qu'au pluriel. Les traces du Nouveau Testament ne font que révéler la longue histoire des premières générations pour dire les divergences et les convergences de leur vie face à la personne de Jésus. Nous devons alors mourir à cette conception "idéologique" de la "véritable" communauté chrétienne et être attentifs pour découvrir les "embryons communautaires" que le Dieu Vivant est en train de "mettre au monde" dans notre société moderne. Le sociologue Michel MAFFESOLI croit que nous vivons actuellement un temps du retour aux tribus, à une socialité à dominante empathique et à une recherche de groupe où la dimension "émotive" est davantage présente.

"...le va-et-vient constant qui s'établit entre la massification croissante et le développement des micro-groupes que j'appellerai "tribus". Il s'agit là de la tension fondatrice qui me paraît caractériser la socialité en cette fin de siècle./.../ En bref, et en donnant à ces termes leur acception la plus forte, on peut dire que l'on assiste tendanciellement au remplacement d'un social rationalisé par une socialité à dominante empathique. /.../ De même l'utilisation constante du terme anglais feeling dans le cadre des relations interpersonnelles mérite attention; il servira de critère pour mesurer la qualité des échanges, pour décider de leur poursuite ou du degré de leur approfondissement. /.../ Pour formuler une 'loi' sociologique, je dirai comme un leitmotiv que ce qui est privilégié est moins ce à quoi chacun volontairement va adhérer (perspective contractuelle et 
mécanique) que ce qui est émotionnellement commun à tous (perspective sensible et organique). $" 63$

Ces changements sociaux produisent des retombées dans le domaine religieux. Danièle HERVIEU-LÉGER a bien nommé cette réalité.

"Mais, aujourd'hui, on constate l'expansion, dans l'ensemble du champ religieux, d'une religion de communautés émotionnelles, qui présente, sous une forme également atténuée, les traits de l'émotionnalisme communautaire dessiné par M. Weber." 64

Il ne faut pas analyser ces changements d'une manière négative. C'est grâce entre autres à ceux-ci que la famille "élargie" prend de plus en plus d'importance dans notre société. Cette prise de conscience doit alors remettre en question la manière de célébrer les rites de passage et peut-être même le lieu des célébrations sacramentelles. Guy LAPOINTE nomme avec justesse cette problématique.

"Par exemple, observer que dans la culture actuelle, la famille élargie joue un rôle de plus en plus significatif. Il s'agit de participer à des baptêmes ou à des mariages pour nous rendre compte de l'impact de tel ou tel événement et que, à bien y penser, nous sommes souvent en face des communautés constituées et qu'on trouve, dans ces groupes, des personnes qui recherchent des lieux significatifs de réflexion et de célébrations pour y retrouver un peu d'écho de leur foi. Si l'incarnation est interprétée comme le désir de Dieu de se révéler au coeur de la vie, des situations et des drames humains, il serait temps de pousser dans ces directions. Bien sûr, les lieux traditionnels que sont nos églises resteront pour certains plus significatifs dans des occasions privilégiées de leur vie, mais pour d'autres, la maisonnée (la tribu), avec ses relations d'amis et de voisinage, pourra être un lieu plus significatif pour retrouver un sens à la mémoire chrétienne." 65

MAFFESOLI, Michel, Le temps des tribus, le déclin de l'individualisme dans les sociétés de masse, Méridiens, Klincksieck, 1988, p.15; p.23; p.34.

64 HERVIEU-LÉGER, Danièle, CHAMPION, Françoise, Vers un nouveau christianisme?, Paris, Cerf, 1986, p. 349

65 LAPOINTE, Guy, "La pratique des sacrements: risquer la situation présente", pp.365-366. Je me réjouis que pour l'initiation sacramentelle, certaines paroisses ont opté pour des rencontres de cuisine ou de salon au lieu d'être dans des lieux qui indisposent les parents par leur froideur ou leur étrangeté. Selon que l'on privilégie l'échange entre les intervenants pastoraux et les demandeurs ou un enseignement magistral, le lieu des rencontres est déterminant. 
J'ai vécu ces derniers temps quelques célébrations de baptême et de l'eucharistie dans des maisons familiales. J'ai été étonné dans chacune d'elle de tout ce qui a été apprécié: la qualité des échanges, de l'intériorité, la personnalisation de la célébration, etc. En même temps, j'ai été confronté à la difficulté de trouver une paroisse dont les responsables acceptaient d'enregistrer le baptême de l'enfant. À chaque fois, j'ai reçu un accueil froid et subi des propos agressifs de certains collègues concernant cette approche. Ils me disaient: "Ton baptême n'est pas communautaire puisqu'il n'a pas lieu dans l'église et avec d'autres parents". "Tu encourages l'individualisme des gens." C'est toujours étonnant de constater à quel point "l'idéologie" peut "ravager" la conscience pastorale de bien des intervenants. Pourtant un retour à la tradition chrétienne nous fait rappeller que même la Cène est née dans le cadre de la domesticité. Il nous arrive facilement de perdre la mémoire concernant certaines pages de l'Évangile et de l'histoire.

\begin{abstract}
"Or, on ne pourra jamais oublier, même si on l'a fait dans la tradition théologique et pastorale, que la Cène est née dans le cadre de l'hospitalité et de la domesticité. C'est dans ce cadre que l'eucharistie s'est développée pendant plusieurs siècles. Il n'est pas impossible que, dans la mise en oeuvre présente et à venir de l'action pastorale, il soit devenu nécessaire, pour retrouver sens et significations à la pratique eucharistique, de célébrer dans le contexte de la famille agrandie. Les signes et le langage symbolique liés à l'eucharistie ont d'abord été liés à la maison et non au bâtiment d'église. La Parole évangélique a comme caractéristique de devoir être partagée et le pain doit retrouver sa signification liée au geste de fraction. Ces actions ne sont pas extensibles à l'infini. Sortis du cadre domestique élargi, gestes et Parole risquent de devenir le plus souvent insignifiants. Le paradigme de la célébration eucharistique restera toujours, quoi qu'on en pense et en dise, celui du repas de petits groupes et non, comme l'histoire semble l'avoir trop longtemps expérimenté, celui des eucharisties de foule./.../ Pourtant, dans les meilleurs moments de l'Évangile vécue à travers les siècles, les communautés chrétiennes ont réappris à s'asseoir à la table du Seigneur, conscientes des enjeux qu'un tel geste suppose et permet. À bien y penser, c'est très souvent autour d'une table que se joue l'avenir du monde. C'est vrai pour la résolution des grands conflits pour faciliter l'ouverture à la paix; c'est aussi vrai pour la foi chrétienne vécue dans le temps. "66
\end{abstract}




\subsubsection{Identité et identification chrétiennes "confondues"67}

Un autre malentendu est également à dissiper. Nous confondons régulièrement le concept d"'identité" et d'"identification" dans le monde pastoral. Nous avons eu récemment un bel exemple dans le document Risquer l'Avenir. ${ }^{68} \mathrm{La}$ question de l'identité chrétienne n'est pas une question d'identification. ${ }^{69}$ On y répond

"en se référant à l'inspiration d'une personne, ce qui est le noyau identitaire, plus qu'en s'enfermant dans des normes, des règles et des pratiques réglémentées. L'identité du chrétien est celle d'un disciple qui essaie de suivre un maître mais aussi celle d'un disciple qui trace sa propre voie dans l'élaboration de son chemin à la suite de Jésus. La fidélité de l'être chrétien n'est pas un obstacle mais un appel à la création et à l'innovation."70

Selon M. BRETON, notre identité personnelle relève de notre responsabilité d'adulte naissant (adolescent) et notre identité chrétienne appartient à notre responsabilité personnelle et prend les traits que nous donnons à notre croissance humaine. Notre vie spirituelle est le lieu où se construit quotidiennement notre identité chrétienne. La tentation est toujours présente de vouloir se sécuriser par des critères et des normes claires. C'est si facile pour des chrétiens de chercher à s'enfermer dans des cadres "rigides".

"Il existe dans l'Église d'ici /.../ une complicité, pour ne pas dire une complaisance, à vouloir régler les questions d'identité en termes d'identification, à vouloir sécuriser les

67 Je me suis beaucoup inspiré du texte d'un entretien spirituel que Jean-Claude BRETON a partagé à une communauté religieuse à l'été 1993 pour rédiger cette réflexion sur la différence entre l'identité et l'identification.

68 Je crois que le bilan de Risquer l'Avenir s'en tient plus au plan de l'identification qu'à celui de l'identité. Il me semble que c'est l'obsession par excellence du document. On promeut une identification chrétienne pour faire lever toute confusion. Une identification (que les auteurs confondent avec l'identité) qui semble fuir tout rapport d'altérité au monde et à l'Évangile.

69 Les recherches d'E.H. ERIKSON ont été éclairantes sur ce point. Dans son volume Identity and the Life Cycle (New York et Londres, Norton and Co., 191 pages), il fait une distinction éclairante entre identification et identité.

70 BRETON, Jean-Claude, L'identité chrétienne, Notes personnelles, Retraite aux Pères de Sainte-Croix, Lac Simon, 9-12 août 1993, p. 10. 
fidèles en leur offrant des critères et des conditions d'appartenance sûrs et précis./.../ Ce n'est pas mauvais en soi pour le début d'une croissance spirituelle. À des moments de la vie, il devient parfois nécessaire de s'en remettre à des repères extérieurs pour oser faire un pas de plus dans notre vie de foi. Il peut être utile à la vie spirituelle d'une personne et d'un groupe de s'interroger sur leur identité, mais si c'est pour tout de suite se mettre en quête de réponses sécurisantes et garanties, cela peut devenir stérile./.../ Dans le domaine de la foi et de la vie spirituelle, je ne peux pas renoncer à ma responsabilité, sous peine de renoncer à ma foi et à ma vie./.../ Il peut être spirituellement fécond de s'interroger sur son identité chrétienne, oui, cela peut-être fécond, mais à une condition. Que cette interrogation ne porte pas d'abord sur une conformité à des normes extérieures mais qu'elle soit une occasion de prendre conscience de notre être croyant." 71

Des disciples de Jésus Christ sont des êtres humains qui aspirent à l'autonomie et au sens de la responsabilité audacieuse. Ils désirent "conduirent" leur baptême et devenir "maîtres" de leur croissance spirituelle. Ils doivent constamment choisir entre le "vertige" de la foi et la recherche de sécurité. "Rappelons-le encore: la grande tentation qui guette le croyant en train de devenir un croyant adulte, c'est-à-dire le croyant exposé au vertige de la foi responsable, la grande tentation est la recherche de sécurité."72

\section{Il est important de réfléchir sur l'identité chrétienne. L'approfondissement de} cette problématique peut être source de fécondité évangélique.

\footnotetext{
"La question de l'identitié chrétienne, quand elle est posée justement en termes d'identité, peut s'avérer d'une grande fécondité spirituelle, parce qu'elle nous confronte à nos responsabilités eu égard à notre croissance spirituelle. Elle est aussi féconde parce qu'elle nous renvoie à la personne de Jésus, dont le nom du Christ qualifie notre manière de croire. La question de notre identité chrétienne, bien posée et livrée à un examen sérieux, nous fait prendre conscience du risque que nous assumons comme croyants, à chaque fois que nous disons, ou sous-entendons, "je crois"."73
} 
Une identité qui soit une réalité dynamique et audacieuse à l'exemple de celle de Jésus. Le but de la vie spirituelle est vraiment de permettre à chacun de devenir lui-même, d'aller au bout des exigences intérieures auxquelles il se reconnaît obligé de répondre pour être fidèle à lui-même et à son être disciple.

\begin{abstract}
"Nous entrons en communauté motivés par un objectif commun. Mais à mesure que nous grandissons spirituellement nous devrions devenir de plus en plus differents, à mesure que cet idéal commun est façonné par notre cheminement spirituel commun. Dans la plupart des communautés, c'est exactement le contraire qui se passe. On entre différent et la communauté s'efforce de nous modeler tous pareils." 74
\end{abstract}

\title{
13.8 Acquis de recherche éclairants
}

Ce chapitre nomme plusieurs enjeux importants dont nous devons tenir compte au niveau de la pédagogie pastorale. Ces enjeux sont tellement nombreux que cette partie de recherche aurait pu constituer en elle-même un sujet de thèse. Que retenir de ce parcours? Je ressaisis toutes ces problématiques en deux pointes lumineuses. La paroisse de demain peut avoir un avenir fructueux à condition qu'elle consente à demeurer un lieu de "passage" pour le "tout-venant". De plus, les intervenants pastoraux doivent accueillir les demandes sacramentelles comme des cadeaux du Seigneur qui les invite à contempler les semences du Verbe secrètement cachées dans le coeur de chaque personne humaine.

Propos de Marcel LÉGAUT rapportés de mémoire par Jean-Claude BRETON lors d'une conférence donnée aux moniales dominicaines à Montréal. Voir aussi LÉGAUT, Marcel, Devenir soi et rechercher le sens de sa propre vie, Paris, Aubier-Montaigne, 1981, 153p. JeanClaude BRETON a beaucoup approfondi les questions concernant l'identité personnelle et la croissance sirituelle dans sa thèse de doctorat soutenue à l'Université de Montréal. Voir BRETON, Jean-Claude, Foi en soi et confiance fondamentale, Dialogue avec Marcel Légaut et Erick Erikson, Paris, Le Cerf, 1987; voir aussi du même auteur Approche contemporaine de la vie spirituelle, Montréal, Bellarmin, 1990, 191p. M. BRETON est un penseur significatif pour moi. 


\subsubsection{La paroisse, un lieu de "passage" pour le "tout-venant"}

Nous n'avons pas affaire à des "cas" en pastorale, ni même à des "dossiers", fussent-ils bien montés et classés à souhait. La personne, avec son mystère et tout ce qu'elle porte de limites mais aussi de richesses, doit toujours demeurer au centre de notre intervention pastorale. C'est un fait bien connu: la pastorale paroissiale nous situe en face du 'tout-venant". Et comme nous l'avons vu précédemment, la personne périphérique d'appartenance, dans la définition de son statut religieux, attribue une importance moins grande à l'institution paroissiale que n'en accorde la personne nucléïque. Et on comprend que ce seul fait puisse entraîner une foule de problèmes, de tensions, de résistances et de malentendus de tous genres. Quand les gens résistent, ce n'est pas toujours qu'ils ont tort ou qu'ils ne comprennent rien. Leurs réticences peuvent parfois nous interpeller, nous questionner: Que se passe-t-il au juste? Se pourrait-il que nous ayons oublié de considérer quelque chose? Qu'est-ce que leur réaction nous dit au juste, par-delà les apparences?

L'Église a été définie à Vatican II par l'expression "Peuple de Dieu". Les êtres humains ne cheminent pas au même rythme. La catholicité de l'Église ne nous oblige-t-elle pas à accepter que chaque croyant chemine à des pas variés? L'intervenant pastoral doit choisir entre imposer son rythme au paroissien ou comme Jésus avec les disciples d'Emmaus, décider de marcher non pas en avant de l'autre mais à côté de lui pour se réchauffer mutuellement par leurs questionnements sur le mystère de la vie et de la foi.

\footnotetext{
"Il nous faut alors nous reprendre pour nous-mêmes l'expression du Concile Vatican II, qui définit l'Église comme un "Peuple en marche", c'est-à-dire la communauté de tous les baptisés en cheminement mais à des pas variés: il y a le peleton de tête, le gros des troupes, ceux qui ferment la marche ou qui ne sont pas encore entrés dans la marche tout en y portant intérêt, etc. L'Église, qu'on le veuille ou non, c'est tout ça! En pareille circonstance, il devient plus que nécessaire de privilégier le langage de la persuasion à
} 
celui de l'obligation et de la contrainte. Ce dernier, comme le démontre la pratique, provoque la plupart du temps des levées de boucliers et rend le dialogue pénible, voire quasi impossible. "A ce moment-là, on ferme nos écouteurs", avouait cette personne rencontré lors d'une visite paroissiale."75

Cette option pour l'accueil inconditionnel du paroissien ne va pas sans risques. C'est clair. Mais ce sont les risques inhérents à l'Évangile: le risque de frapper à la porte sans forcer l'entrée et le risque de voir lever l'ivraie dans le champ de l'amour. Cette option requiert des intervenants pastoraux qu'ils accomplissent au mieux leur travail sans se prendre pour les seuls constructeurs. Car "Si le Seigneur ne bâtit la maison, c'est en vain que peinent les bâtisseurs" (Ps 126). Les accueillants doivent fonder leur espérance sur le fait que l'accompagnement offert aux demandeurs aura été pour eux l'occasion d'un véritable pas en direction de l'Évangile, un pas qui fera ensuite son chemin d'une manière que Dieu connait. Quoi qu'il en soit, les intervenants pastoraux auront accompli leur mission, comme dit Saint Paul, de "planter" et "d'arroser"; le reste, c'est-à-dire la croissance, est l'oeuvre de Dieu ( 1 Co 3, 6-8 ).

"S'appuyant sur ce schéma biblique, l'Église devrait considérer que sa première obligation consiste à tenir ouverte la vie inspirée par les conseils évangéliques, de façon assez analogue à la pratique "indienne" où toutes les orientations restent possibles, et donc admettre un système souple de passerelles permettant aux individus d'adapter leur forme de vie à la situation psychologique du moment sans rien renier des idéaux du christianisme. C'est ce qui devrait se passer si l'Église avait vraiment le souci du premier bien des personnes qui, dans ses rangs, cherchent un chemin vers Dieu. Or, tout à l'inverse, elle fait l'impossible pour empêcher un tel système de transition et pour forcer à accepter l'alternative tranchée du travail professionnel ou de la pauvreté, de l'existence bourgeoise $o u$ du cénobitisme, du mariage ou du célibat. Cela ne montre pas seulement qu'elle est plus soucieuse de la tranquillité de l'institution que de la vie concrète des personnes; cela révèle en même temps son incroyable peur de la liberté humaine, tant qu'elle ne l'a pas enserrée dans l'étroit corset de ses lois et de ses réglements."76

Le catholicisme aura un avenir prometteur si sa trame fondamentale est constituée d'un mouvement d'ouverture et d'accueil face à tout-venant. Mais l'analyse des textes les 
plus récents de Jean-Paul II donne des inquiétudes. Avec lui et certains "hauts fonctionnaires" de la curie romaine, le catholicisme prend plutôt visage de fermeture, de repli sur soi et de défense conservatrice. Pourtant, les Pères du Concile n'avaient-ils pas invité l'Église à demeurer constamment ouverte à tous les êtres humains? "....L'Église, en vertu des exigences intimes de sa propre catholicité et obéissant au commandement de son fondateur (cf. Marc 16,16), est tendue de tout son effort vers la prédication de l'Évangile à tous les hommes" (Ad Gentes 1,2-5). L'Église Catholique a à choisir constamment entre deux types d'Église différents. Elle peut choisir d'être une Église de type "confessant", c'est-à-dire faite de personnes motivées et convaincues et tendant de ce fait à recouvrir un certain nombre de caractéristiques de type "secte" en sociologie des religions. Elle peut au contraire être une Église de type "multutidiniste" comme disent les sociologues, c'est-à-dire ouverte à tous sans autre condition que l'adhésion à quelques propositions de sens.

Nous sommes également invités à franchir certains deuils sur notre imaginaire de communauté en termes de continuité et de globalité. Nous devons davantage concevoir la communauté comme un "lieu de passage". De plus, nous l'avons vu au chapitre dixième, la signification biblique du mot paroisse nous invite même à aller dans ce sens. Il est fait du préfixe par, qui veut dire 'ailleurs', 'à côté', 'pas ici'; et du mot oikos qui évoque maison. La paroisse a ainsi un sens original de nature essentiellement pascale. Être paroissial, c'est être citoyen de la maison de Dieu, alors que l'on vit encore en ce monde. Être paroissial, c'est faire le passage incessant de ce monde au Père par le Christ: "Vous êtes des étrangers et des voyageurs". La paroisse est le lieu de l'exode chrétien. Sa signification biblique rappelle aux intervenants pastoraux qu'ils sont appellés à accompagner les gens lorsqu'ils "passent" pour un rite de "passage" dans le but d'approfondir le sens de leur vie et de leur foi. En les centrant sur Jésus-Christ, le grand "passeur", Celui-ci opère des "déplacements" dans leur 
coeur, lieu de la maison de Dieu. À Son contact, les intervenants pastoraux et les paroissiens deviennent autres grâce à un dialogue rempli d'écoute amoureuse. Ils ont par la suite davantage le goût de voyager, c'est-à-dire d'aller vers l'autre que l'on considère comme un étranger (ou un distant) pour s'enrichir de lui. Dans ce contexte, le paroissien (qu'il soit "nucléique" ou "périphérique") est toujours en exode, en passage incessant de son monde à celui de l'autre et de l'Autre, en continuelle route vers une plus grande libération personnelle et communautaire grâce à ce qui est différent de lui. De plus, si l'intervenant pastoral a tendance à vouloir imposer au paroissien de "rester avec lui" en l'interpellant trop souvent sur sa pratique dominicale, le grand passeur-transgresseur par excellence Jésus le Christ l'aide à accepter que celuici ne fasse que "passer". Le Seigneur amène l'intervenant pastoral à se centrer plutôt sur la chaleur intérieure vécue au coeur de la rencontre lorsque l'autre (et l'Autre) a (ont) passé ("Et ils se dirent l'un à l'autre: "notre coeur ne brûlait-il pas en nous tandis qu'il nous parlait en chemin....[Lc 24,32]").

"Il faut davantage penser la communauté comme un espace transitoire, une sorte de transit permanent, qui permette de passer dans le monde avec, à certains moments significatifs de la vie des rappels d'Évangile liés possiblement aux grands moments d'intensité et d'émotions liés à la naissance, aux choix de vie, de mort. Qu'il reste toujours des groupes pour qui, vivre en Église, c'est épouser un des modèles de nos communautés paroissiales, cela est hautement souhaitable et significatif. Mais tout l'héritage chrétien ne pourra plus se concentrer dans ces groupes. La "vérité" évangélique sera toujours plus large. /.../ On devra dans l'avenir penser des communautés plus ouvertes, plus ponctuelles, avec des relais significatifs. Comme ce le fut dans le passé, l'éducation de la foi se fera de multiples manières, mais elle se déroulera souvent dans l'espace sacramentel, s'il reste ouvert à ses ancrages humains et aux expériences de créativité. En fait, un imaginaire de communauté qui demande à être revisité et à se reconstruire. Si nous nous enfermons dans des cadres rigides qui ne peuvent que mener au ghetto, nous éviterons alors de prendre le risque de la marche, de "transiter" dans le monde et avec lui. Pourtant, la mémoire de l'Évangile est à ce prix. /.../ En face de besoins nouveaux, l'Église a toujours su prendre des initiatives et changer sa discipline. On est peut-être rendu en un de ces temps où les changements sont appelés et rendus nécessaires. Il y va de la qualité de la mémoire chrétienne dans un contexte social, culturel et religieux qui a très rapidement évolué. En fait, dans tout ce débat autour de la pratique sacramentelle, se joue le rapport intelligent et cordial à l'ouverture aux autres, à Dieu et à la mémoire évangélique. Il est important que nous apprenions à penser et à passer. Faire en sorte que les communautés chrétiennes soient des lieux de passage où l'on "transite" vers quelque part, sans jamais nous arrêter en chemin. Les sacrements deviendront des lieux de 
passage de la vie à la vie et de la vie à la mort. Les liens se font et se défont à même ces passages. On pourra aller jusqu'à dire que la communauté se fait et se défait à même ces passages. Reste que l'identite, même celle liée à la tradition, est un pays que l'on n'atteint jamais." 77

L'Église doit accueillir tous les chrétiens en marche vers la plénitude du salut. La paroisse n'est pas le reste des parfaits ni le rassemblement de ceux qui sont arrivés et n'ont plus aucune hésitation ni aucune faiblesse. Elle doit embrasser les différences dans la vitesse de croissance évangélique (1 Co VIII-X). L'accueil du paroissien en luimême est l'occasion d'affirmer la dignité de chaque baptisé et le respect de sa conscience et de concrétiser une des conséquences de la redécouverte du sacerdoce baptismal à Vatican II. Enfin, le souci de l'accueil de ce "tout-venant" est l'une des conditions pour que l'Église maintienne une surface de contact suffisamment large avec la société pour ne pas se voir réléguée au rang d'une secte (au sens sociologique du terme). Les enjeux, on le voit, sont donc importants; d'où la nécessité d'un nouveau paradigme de pédagogie pastorale tel que sommairement développé dans le présent chapitre.

\subsubsection{La richesse des sacrements dans le catholicisme}

Les sacrements sont encore aujourd'hui gestes sauveurs de Dieu: parfois pur don inconditionnel qui réveille la foi; don qui se poursuit, qui ouvre une histoire, un cheminement; parfois réponse à l'appel d'une démarche de foi préalablement amorcée. Parfois points de départ, parfois points de relance et de soutien. Toujours points de structuration de la foi, rarement points d'arrivée. Le rite est donc porteur de quelque

LAPOINTE, Guy, "La pratique des sacrements: risquer la situation présente", pp. 363-364; p.366. "L'identité chrétienne ne séjourne pas dans un passé brillant, elle se trouve dans le mouvement même, dans le passage, elle opère des sorties, mouvement exodal et pascal nécessaire à la vitalité de la culture chrétienne. Cet exode permanent ne constituerait-il sa spécificité?( ALDER, Gilbert, "La culture chrétienne: survie ou conversion", in Catéchèse, $\mathrm{n}^{\circ} 114$, janvier 1989, p. 72.). 
chose. Par lui, se creusent les attitudes qui rendent possible la rencontre du Dieu Vivant. Bien sûr, nous ne savons pas toujours où cela nous conduira. Nous ne possédons pas l'avenir. Mais là encore, il s'agit de mériter confiance et de faire confiance. Cela signifie concrètement: valoriser d'abord ce que vit la personne (malgré ses difficultés à l'exprimer) et les signes de la présence et de l'action de Dieu dans sa vie; cultiver un dialogue qui relance parce qu'il se fait "Bonne Nouvelle"; donner sens et révéler le Vivant à partir de l'expérience.

"Les lieux sacramentels sont à ce point privilégiés par beaucoup, parce qu'ils rejoignent les grandes dimensions de l'existence. À travers l'accueil, la catéchèse, on participe à ce que tel événement dans la vie d'une famille ou d'un groupe puisse être l'occasion d'ouvrir les participants aux grandes interrogations sur la vie, sur la mort, comme on le voit souvent dans les textes évangéliques. Et de la façon avec laquelle on ouvre ces interrogations, il est fort possible que ces situations révèlent quelque chose de l'Évangile, de la mémoire chrétienne, et qu'elles finissent par parler de Dieu. La vie, dans ces moments privilégiés, n'est pas lieu de la rigidité, ni même de l'accueil ouvert ou sélectif. Tout se passe bien au-delà, à ce point de rencontre où les êtres humains s'ouvrent à l'Autre, retrouvant, pour un moment, un goût de leurs racines et cherchant en l'Autre et dans les autres une reconnaissance de ce qui se vit. Je pense à ce qua écrit Maurice BELLET: Qu'est-ce qui nous reste quand il ne reste rien? Ceci: que nous soyons humains envers les humains, qu'entre nous demeure l'entre nous qui nous fait hommes." Nous sommes problablement aux abords de l'Évangile, là où le temps de Jésus rejoint celui des humains. Le lieu de la célébration reste ce moment poétique où toute espérance est permise toute mémoire capable de retrouver force et racine."78

Plusieurs intervenants travaillant en pastorale sociale ne se gênent pas pour dire que les pasteurs qui oeuvrent en paroisse sont toujours en train de faire de la liturgie et devraient sortir plutôt de la sacristie pour aller dans le monde, le lieu véritable de l'évangélisation. Les rédacteurs de l'étude Risquer l'Avenir vont également dans ce sens. Cette manière de concevoir l'évangélisation est limitée et ne nous mène nulle part. Elle nous cantonne en plus dans le perpétuel dualisme entre l'Église et le monde. Les fonctions pastorales (sacerdotale, prophétique et royale) peuvent être présentes en 
même temps dans une seule intervention pastorale qu'importe où celle-ci se déroule.

Ce n'est pas parce qu'elle a lieu sur un coin d'une rue que celle-ci est automatiquement "promotion du Royaume de Dieu". Tout dépend de ce qui est vécu au coeur de la relation pastorale.

"Quant à la proposition suivante: "......Nous avons voulu plutôt souligner que l'urgence pastorale, pour les communautés, ne se situait pas présentement au niveau de la liturgie (168). À la suite d'une telle affirmation, ne semble-t-il pas qu'on coupe les dernières branches sur lesquelles on était assis. N'y-a-t-il pas ici une fausse interprétation des célébrations sacramentelles dans leur relation à l'évangélisation et l'engagement. Pourquoi les célébrations ne seraient-elles pas encore des lieux pertinents et même privilégiés, d'une éducation de la foi? /.../ Ainsi en est-il des fonctions qui organisent le christianisme. Pas une d'elles ne peut prétendre circonscrire "la" vérité de la vie et de la foi. Elles renvoient les unes et aux autres d'une manière qui ne ferme jamais le sens, n'autorise ni la répétition ni l'alternative, et ne clôt un lieu que dans l'acte d'en permettre un autre. Chacune de ces expériences renvoie donc à d'autres, évitant ainsi les compartimentations devenues incertaines: la prière renvoie à l'engagement; la liturgie, à l'éthique; les élaborations de chaque génération, aux précédentes ou aux futures, articulées entre elles par un silencieux travail sur la limite. Lévénement évangélique traverse la vie sans pouvoir être "saisi" nulle part. Jésus est toujours l'Autre /.../ Les sacrements sont, certes, gestes et paroles de foi liés à une mémoire, mais ils renvoient à l'éthique et à la prière en même temps qu'à une expérience de vie dans une société donnée. Ils sont, de ce fait, indissociablement gestes des cultures, à dimensions politique et sociale. Bien malin serait celui qui voudrait penser les sacrements chrétiens, et proposer une ré-interprétation de leur pratique en voulant, sous prétexte de revenir à une identité chrétienne musclée, leur redonner une sorte de virginité mythique. Ce n'est ni un hommage à rendre au "beau risque" de l'incarnation, ni une façon ouverte de risquer l'avenir."79

Mais, comme le répète souvent Guy LAPOINTE, pour que les célébrations soient des lieux d'éducation de la foi, celles-ci ne doivent pas être de simples répétitions de formules mais être des haltes qui mettent en route vers un ailleurs ou vers un vivre autrement. "Le danger est grand de consentir à revenir à la routine, de s'en remettre au rite à exécuter, d'enfermer le souvenir dangereux de Jésus dans le rituel au risque de tout étouffer." 80 Les êtres humains peuvent difficilement naître à eux-mêmes et accéder à la parole, au goût de vivre sans entrer dans des relations symboliques

Ibid., pp.362-363.

LAPOINTE, Guy, "Prenez et mangez. Le défi de l'utopie évangélique", p.208. 
significatives, sources de relations sensées et de désir. Encore aujourd'hui, plusieurs présidents ne sont pas libres par rapport au rituel des différentes célébrations sacramentelles. Que devrait-on faire pour aider ceux-ci à plus d'audace et de créativité pour une ritualité symbolique plus significative? Les catholiques sont guettés non pas par le fondamentalisme biblique mais par le fondamentalisme ritualiste.

Culturellement, la grande majorité des gens de chez nous appartiennent au catholicisme. Et nous aurions tort de bouder ce fait en lui tournant le dos au nom de la pureté évangélique. Même dans sa recherche de signes qui peut apparaître superficielle au premier regard, la religion populaire constitue un terreau propice à une nouvelle évangélisation. Et il nous appartient, comme intervenants pastoraux, d'évangéliser cette recherche balbutiante et sincère. N'était-ce pas aussi l'attitude de Jésus qui savait s'étonner de la moindre question des gens et ne manquait pas de valoriser le moindre geste de foi chez les personnes?

"Célébrer les sacrements, c'est à la fois rendre célèbre un acte gratuit de Dieu et la réponse d'une personne concrète. Et l'exigence première, c'est que cet acte soit bien vécu. /.../ Il faut donc revisiter notre conception des sacrements et voir en eux des occasions de vivre la foi, de l'exprimer et de la faire sienne. /.../ La question n'est donc pas de savoir quoi faire avec les distants qui demandent des sacrements et ne veulent-rien-savoir-d'autresaprès, mais bien plutôt de se dire: quelle chance nous avons!" 81

Les symboles de la tradition spirituelle du catholicisme permettent d'éveiller en chaque croyant le niveau le plus profond de son existence. Mais cela ne se fait pas automatiqument. Une qualité d'accompagnement offerte à quelqu'un peut l'aider à atteindre le nappe d'eau divine souterraine en lui. Toutefois, sans vigilance quotidienne, il est tellement facile de "déconnecter" un paroissien en recherche de son puits d'eau vive et de le "brancher" sur notre "réseau" qui a des "réserves" bien limitées! 
"En termes abstraits mais rapides, je dirai que la religion catholique n'a pas été nourrissante pour moi parce qu'elle ne s'est jamais adressée, intéressée à ma faim, à mon désir et qu'elle m'apparaissait comme fonctionnant dans les zones périphériques des êtres, dans ces zones superficielles et extérieures que j'ai appelées dans mon modèle la zone des besoins: avoir, savoir, devoir, pouvoir. Avoir: la richesse collective de l'Église; savoir: le puissant appareillage dogmatique; pouvoir: la hiérarchie, la puissance dite spirituelle; devoir: la morale, la vertu. Je remarquai que les ecclésiastiques qui me parlaient de religion étaient presque toujours savants, presque toujours dominateurs et souvent vertueux. Mais qu'ils fussent des amoureux perpétuels, des enfants embrasés, de belles créatures vivantes, des ressuscités du matin, des êtres balayés par le grand vent du désir souverainement répandu à la pentecôte, non vraiment cela ne paraissait point. Leur existence ne me semblait pas aventureuse, aventurée, souverainement libre, profondément animée, amplement répandue, largement ouverte, vivement menée, gaillardement inventée comme aurait pu l'être celle d'hommes conscients que le désir incarné mène à la mort, donc à un plus de vie par la résurrection. Il m'apparaissait au contraire que ce qui était du domaine religieux était renfermé, rigide, préformé, préjoué, prédigéré, prépensé, pressenti par un autre. Aucun doute vivant, aucune folie jaillissante, aucun élan dérangeant, aucun illogisme enfantin, aucune beauté naturelle ne venait me dire que le Dieu de ces gens-là était vivant, désirant, gracieux, nourrissant et enivrant comme du pain et du vin, ardent comme un berger ou un fiancé. /.../ Évidemment! nous étions dans la religion de l'évidence compacte, de la certitude de granit, de la croyance monolithique, de la cohérence sans faille, de la logique sans fissure. Où étaient donc les grandes ruptures, les grandes cassures de l'Évangile: le pain rompu où se reconnaissait Jésus, le flacon et les outres brisés, les filets rompus, le rideau du temple déchiré, le temple lui-même détruit, la robe partagée, le coeur ouvert par la lance? /.../ Au lieu de cette rupture, de cette errance permanente et joyeuse, la religion me paraissait le paradigme, le modèle même de la certitude éternelle, de la croyance immuable, du comportement prescrit et inscrit." 82 


\title{
TROISIÈME PARTIE
}

\author{
VERS UN RÉAMÉNAGEMENT \\ DE LA PASTORALE PAROISSIALE \\ EN MILIEU URBAIN
}


"On ne peut pas prévoir le futur mais, par contre, on peut l'inventer"(Aurelio PECCI). 1

Le moment est venu de penser l'avenir de l'organisation de la pastorale paroissiale en milieu urbain à partir de ce que j'ai appris jusqu'à maintenant dans le parcours doctoral en approfondissant la paroisse comme un réseau complexe d'interrelations selon une perspective systémique. Depuis le début, je suis allé "à doses massives" mais c'est à dessein. On ne saurait être "réducteur" devant des enjeux aussi importants. Les grands changements sociaux, économiques et culturels du milieu canadien-français et les réorientations ecclésiologiques des dernières années ont fait naître une pastorale plus complexe. Une problématique d'ensemble de la réalité paroissiale en contexte urbain aide à élaborer une pastorale qui ne soit pas en circuit fermé où la moindre difficulté met en échec parce qu'on ne peut la situer globalement. Cette troisième partie de thèse constitue ainsi une synthèse pratique dégageant les

Certains se refusent tout bonnement à interroger l'avenir. Ils estiment que cela nourrit le pessimisme. Ils demandent que l'on fasse davantage confiance. L'Esprit ne manquera pas de pourvoir aux besoins de son Église. J'ai voulu me situer ici au-delà du pessimisme et de l'optimisme de convenance. Devant la situation paroissiale actuelle, j'estime que la lucidité vaut mieux que le faire semblant. Et qu'aucun providentialisme ne saurait nous dispenser de l'action responsable. La dernière partie de cette thèse se présente comme une invitation à faire une histoire responsable pour l'avenir de la pastorale paroissiale en milieu urbain. Il faut en effet défataliser cet avenir et découvrir qu'il peut être un faisceau de projets, de possibles, d'espérance. Si l'avenir dépend de l'Esprit, il dépend aussi de nous. Je suggérerai des orientations pour l'action car l'avenir est aussi à la mesure de notre liberté et de notre responsabilité individuelle et communautaire. Déjà, durant les années d'études doctorales, j'ai collaboré avec le vicaire général, un vicaire épiscopal et un théologien de mon Église locale pour écrire un document sur l'avenir du diocèse de Chicoutimi intitulé: "L'Église de Dieu qui est à Chicoutimi, une Église en marche... dans la foulée conciliaire" [ Document de travail pour le Conseil Presbytéral, Diocèse de Chicoutimi, 14 septembre 1993, 19p.]. Ce document est à l'étude depuis l'automne 1993. En suivant de près l'évolution des échanges au Conseil Presbytéral, je constate à quel point les perspectives évoquées dans ce document de travail se heurtent à de fortes résistances. Je suis toujours étonné de constater à quel point la nouveauté fait peur. Je citerai celui-ci à quelques reprises dans cette dernière partie touchant plus explicitement l'intervention et la prospective. 
conséquences concrètes pour l'agir pastoral des univers de sens que nous ont ouverts les outils théoriques de compréhension des défis observés.

La critique est facile. Il est plus difficile de construire. J'ai bien conscience que ce ne sont pas quelques lignes d'une thèse de doctorat qui peuvent prétendre changer radicalement une situation. J'aurais la naïveté de croire cependant que, dans une solidarité étroite avec le peuple de Dieu, il est toujours possible d'apporter sa pierre à l'édifice, ne serait-ce qu'en inspirant quelque peu l'action à entreprendre. La théologie ne peut plus se contenter de se déployer dans un ciel lointain et par là-même serein. Elle doit aussi prendre des risques. La théologie pratique, la théologie contextuelle, la praxéologie pastorale nous poussent à aller dans ce sens. Ces manières de "faire théologie" prennent le risque d'un discours théologique répondant aux questions profondes posées par la pratique des personnes et des communautés, pleinement insérées dans une culture particulière. La source de l'entreprise théologique conduite dans cette perspective n'est plus le sens déjà codé mais le sens qui s'exprime dans la vie du peuple croyant au sein des pratiques historiques concrètes. La dernière partie de cette thèse constitue également un moyen privilégié pour militer en faveur de l'émergence d'une ecclésiologie empirique, qui soit en liaison avec la réalité théologique, historique, pastorale, spirituelle et juridique de l'Église en un lieu. ${ }^{2}$

Cette troisième partie est divisée en deux chapitres. La réflexion sur la mission de la paroisse dans le contexte d'aujourd'hui constitue la première section du quatorzième chapitre. La paroisse n'a aucune raison d'exister si elle ne se vit pas comme servante du Royaume de Dieu. Pour vivre cette mission, cette institution

2

La diversité des contextes culturels qui sont le lieu des pratiques pastorales détermine des ecclésiologies différentes. À leur tour, les représentations de l'Église influencent l'action pastorale. Mais l'ecclésiologie n'appartient pas plus aux études pastorales qu'à la théologie systématique: elle se construit à partir de plusieurs langages. La théologie de l'Église se situe ainsi à un carrefour. 
ecclésiale doit demeurer ouverte à tous et au service de tous. Je nomme dans la seconde partie de ce chapitre des acquis ecclésiologiques actuels à retenir pour une réorganisation ministérielle dans le contexte urbain. Je souligne ainsi les domaines où les mentalités ont évolué au cours des dernières années favorisant l'acquisition progressive d'un certain nombre de convictions sur lesquelles nous pouvons nous appuyer pour risquer le présent et dont nous devons nous inspirer pour véritablement risquer l'avenir de la paroisse et de l'Église. Je note par la suite l'importance d'une vigilance constante sur la question du pouvoir en Église si on désire réellement opérer des changements institutionnels afin de faire advenir des chrétiens-sujets dans les diverses communautés ecclésiales. Je termine ce quatorzième chapitre par des suggestions pratiques concernant la gestion des ressources pastorales dans une Église locale.

Le quinzième chapitre est divisé en quatre parties. Je montre premièrement limportance de structurer la pastorale paroissiale en tenant compte du milieu naturel $\mathrm{du}$ paroissien et de sa manière d'être dans le contexte moderne d'aujourd'hui. J'analyse par la suite trois manières différentes d'aménager la paroisse dans le contexte urbain : -la ville comme fédération de paroisses, -la paroisse-ville (ou super-paroisse) comme fédération de communautés, -un renforcement de la zone (région) pastorale avec de réels pouvoirs juridiques. Je termine ce dernier chapitre sur une note d'espérance. 


\section{CHAPITRE 14}

\section{D'INCONTOURNABLES HORIZONS}

\subsection{La mission de la paroisse}

L'homme n'a pas besoin d'autre chose dans le monde, nous dit Simone WEIL, que quelqu'un qui fasse attention à lui.

La paroisse actuelle continue de servir à plusieurs personnes de signe de référence au christianisme de la grande Église. Elle n'est pas simplement un lieu d'identification et d'appartenance mais elle constitue plus souvent encore un lieu de référence reconnu pour son système symbolique et ses rituels adaptés aux saisons de la vie. Or, le fait que l'existence paroissiale permette à des personnes de recourir à la référence chrétienne à différents moments importants de la vie n'est pas à négliger. La paroisse comporte des atouts majeurs pour la mission: proximité des milieux de vie, ouverture au tout-venant et premier lieu d'accueil de l'Église, capacité de mettre des personnes en contact, moyen de créer des lieux de solidarité pour venir en aide aux différents besoins humains d'un milieu, etc. Le but de la pastorale paroissiale ne consiste pas "à faire la paroisse" mais à permettre que des humains approfondissent le sens de leur vie et de leur foi et donnent leur adhésion au Dieu de Jésus Christ au sein d'un peuple en processus de libération et de salut. Même dans un contexte comme le nôtre, caractérisé par la multiplicité des appartenances et la diversité des centres d'intérêts, la paroisse continue de toucher à quelque chose de profond dans la culture et dans la dimension sacrée de la personne. Parce qu'elle demeure une réalité à forte charge symbolique, la paroisse est le terrain où doit être portée, de manière sugnificative, la mission commune du peuple de Dieu: de toutes les nations, faire des 
disciples. La paroisse de l'avenir n'a donc d'autre mission que d'inventer pour aujourd'hui et demain des routes d'Évangile pour les paroissiens en marche vers une plus grande humanisation de leur vie et de leurs lieux d'insertion.

\subsubsection{La Paroisse, une institution au service du Royaume de Dieu}

Nous l'avons vu au chapitre dixième, le Règne de Dieu fut la raison d'être de Jésus, l'expression privilégiée de son espérance, le moteur de sa vie. Le Royaume de Dieu, c'est l'Amour du Père, un amour qui embrasse tout, qui libère et transforme en profondeur. Suivre Jésus, ce n'est pas quitter le "monde" pour "pratiquer les vertus évangéliques". C'est accepter d'être, avec Lui, au coeur des villes, au coeur des villages, au coeur des maisons, au coeur des "foules" pour faire advenir le Règne de Dieu. La paroisse, comme l'ensemble de l'Église ne prend son sens ultime que dans la promotion de l'avènement du Règne de Dieu, elle doit être tout entière à son service. Elle est un des fruits, des signes et des moyens du Règne de Dieu. Elle est ainsi "sacrement" du Royaume de Dieu.

\footnotetext{
"Est-il nécessaire de réaffirmer que l'Église est sacrement de salut. Elle se doit d'être signe de salut dans notre belle région du Saguenay-Lac-Saint-Jean. Nous avons, comme communauté chrétienne, cette importante et essentielle mission de poser des signes du Royaume pour être source d'espérance, de vie et d'amour pour tous ceux et celles qui vivent ici, chez nous, le lourd défi de la quotidienneté. Nous avons, comme communauté témoin du Christ ressuscité, à être pour le monde un cadeau, une source, une lumière, un levain. /.../ Nous avons à investir temps et efforts pour que notre Église soit de plus en plus communautaire, convaincue de la nécessité de vivre intensément la communion fraternelle. Nous n'avons pas à hésiter pour encourager et favoriser le soutien et le développement de communautés, grandes ou petites, paroissiales ou autres. Nous ne pouvons rester indifférents à tout ce qui permet la naissance et la croissance de réelles communautés." 3
} 
L'Église en mission, c'est une Église créatrice de son avenir. L'Église doit tenter constamment de faire grandir le Royaume dans les coeurs et dans le monde. La paroisse constitue un des lieux privilégiés pour servir cette croissance du Règne au coeur d'une portion du peuple de Dieu. La paroisse n'a aucune raison d'exister si elle ne se vit pas comme servante du Royaume de Dieu au coeur du monde. Il nous arrive facilement d'oublier cette mission fondamentale au coeur de l'action pastorale, particulièrement dans les comités paroissiaux. Nous sommes tellement préoccupés par les tâches à remplir que nous ne portons pas suffisamment un regard plus critique pour vérifier si les activités offertes aident les paroissiens à être davantage saisis par le Christ afin de pouvoir faire advenir solidairement un monde plus juste et fraternel.

"Que doivent faire les communautés chrétiennes pour vivre l'authentique conformité que l'Évangile réclame? Seraient-elles invitées avant tout à conserver une mémoire infaillible de l'histoire évangélique? L'essentiel est ailleurs: les disciples de tous les temps sont appelés d'abord à demeurer ouverts à la générosité créatrice que Jésus a incarnée, alors jaillira à travers eux la Parole communiquant la vie, celle que leur donnera de créer des relations "ressuscitantes" et d'irriguer ainsi le sous-sol des sociétés. Voilà la fidélité exigée de ceux qui professent que la gloire de Dieu se révèle dans son amour incarné. Les communautés chrétiennes ont donc vocation d'imaginer sans cesse les formes de la justice et de la fraternité dont ont soif les exclus. C'est ainsi que l'Évangile conserve son identité à travers l'histoire mouvante des hommes et des civilisations. Tel est "l'invariant" du christianisme depuis qu'a surgi en Palestine un amour inventant des relations surprenantes au risque de se perdre et d'être crucifié: un amour en proie à l'espérance."4

La paroisse n'est donc pas là uniquement pour assurer sa survie mais pour faire advenir le Règne de Dieu dans les milieux humains où s'enracinent les êtres. ${ }^{5}$ Elle ne

4 BARDE, Alain, L'Évangile découvert par les marginaux d'hier et espéré par ceux d'aujourd'hui, Paris, Cerf, 1983, pp. 93-94.

5 "Edifier le Règne de Dieu, c'est conduire l'humanité à sa pleine humanité" (CHARRON, A., "La paroisse évangélisatrice d'aujourd'hui", in Prêtre et pasteur., novembre 1991, p.620.). "La transformation du monde, tendre à ce que la société soit plus heureuse, plus humaine, veiller à ce que la terre se rénove, ces tâches sont confiées à l'homme. Vaincre la souffrance et le mal partout où nous les rencontrons avec tous les moyens disponibles de la science et de la technique, de l'aide solidaire et, s'il le faut (après avoir épuisé tous les autres moyens), par la rébellion contre les puissances mauvaises. C'est là notre mission et notre tâche, au milieu de la finitude et de la contingence. Dieu ne le prendra pas en charge, même s'il est vrai que notre agir se déroule en la 
peut pas être un lieu figé ni un espace clos mais elle doit servir au mouvement de transfiguration dans le Christ. Cette institution ecclésiale doit offrir des lieux pour que le paroissien puisse investir dans des relations personnalisées (petits groupes- relations courtes) et des réseaux de solidarité (grands groupes - relations longues) afin de pouvoir parcourir le difficile chemin de la personnalisation de son expérience spirituelle et approfondir l'importance de la solidarité fraternelle. Seule la communion (vécue en communauté; non pas le grégarisme ni le collectivisme) peut nous permettre de découvrir davantage la présence de Dieu dans notre vie personnelle et communautaire et de trouver comment exprimer fidèlement par nos paroles et nos actes ce que le Dieu de Jésus-Christ attend de nous après nous avoir remis debout par son Amour libérateur.

\begin{abstract}
"Au lieu de vouloir faire entrer nos contemporains dans une Église aménagée depuis longtemps, ne pourrait-on dépenser autant d'efforts pour les aider à être chrétiens dans leur lieu et leur temps, en développant eux-mêmes une véritable intelligence chrétienne de leur culture? Tel est, dans la logique de la Pentecôte, le prix qu'une Église doit payer pour être missionnaire?" 6
\end{abstract}

présence salvifique et absolue de Dieu auprès de nous, et bien que ce soit notre affaire, cette affaire tient à coeur à Dieu même. /.../ La venue du Royaume de Dieu est une grâce mais une grâce qui n'est efficace que dans et par l'agir des hommes et non en dehors, au-dessus ou par derrière. /.../ L'Église n'a d'avenir que si elle ne se replie pas de manière introvertie sur elle-même en tant qu'Église instituée, mais qu'elle se tourne vers l'extérieur, s'oriente vers l'autre, vers tout l'humain de tout humain partout dans le monde. Qu'elle cesse donc de se soucier de sa perpétuation historique, de sa propre position de puissance spirituelle en ce monde. /.../ Dieu a commencé dans l'histoire lorsqu'un homme a dit "Dieu". Il nous semble entendre Dieu dire: "Marche, oeuvre de mes mains, oeuvre de mon amour, tu n'es pas seul. Marche et dans ta démarche tu liras la trace de mon amour"(SCHILLEBEECKX' Edward, L'histoire des hommes, récit de Dieu, Paris, Cerf, 1992, p. 348, p. 352, p. 368.).

6 LEGRAND, H., "La réalisation de l'Eglise en un lieu", in Initiation à la pratique de la théologie, Dogmatique II, Tome III, Paris, Cerf, 1983, p.161. 


\subsubsection{La paroisse urbaine et la ville}

La paroisse en ville doit avoir comme mission d'unir les solidarités des différents sujets croyants et communautés présentes dans le milieu urbain. Elle les unit pour que chaque baptisé devienne davantage un disciple du Ressuscité et chaque communauté une terre 'fertilisante' du Royaume de Dieu. Sa mission est d'être et de susciter le peuple de Dieu dans la ville, à partir de la ville et avec la substance de la ville. Les agents pastoraux doivent même coopérer avec les dirigeants politiques de la ville pour être des alliés afin de solutionner les nombreux problèmes urbains d'aujourd'hui. En suivant de près le troisième sommet des grandes villes du monde qui s'est déroulé à Montréal du 15 au 18 octobre 1991 et qui a réuni les dirigeants de 24 grandes municipalités, j'ai davantage pris conscience des énormes défis des villes actuelles: le flot de gens qui viennent s'établir dans les villes, l'étalement urbain ${ }^{7}$, la

7

Les banlieues sont devenues le nouveau coeur de notre civilisation. Les citoyens fuient les centres-villes vers les périphéries. Les villes se développent désormais autour des réseaux d'autoroutes alors qu'avant elles rayonnaient à partir d'un centre. Ce faisant, les citoyens laissent les grosses villes agoniser, aux prises avec des problèmes sociaux qui les dépassent.

Selon de récentes statistiques, l'étalement urbain est un phénomène qui s'accentuera dans les années futures. Les résultats d'un sondage CROP publié dans la revue de l'Actualité de janvier 1993 sont significatifs sur ce point. À la question posée: "Si j'avais le choix de mon lieu de résidence en l'an

2000:

citadin

banlieusard

campagnard

total:
- Je vivrais en ville

$35 \%$

$3 \%$

$2 \%$
- Je vivrais en banlieue

$27 \%$

$60 \%$

$7 \%$
- Je vivrais à la campagne

$38 \%$

$37 \%$

$91 \%$

Les deux tiers des citadins rêvent de quitter le bitume pour s'installer dans un coin vert, soit à la campagne (38\%), soit en banlieue (27\%). Les banlieusards rêvent aussi d'un coin plus champêtre et plieraient bagage (37\%). Seuls les campagnards - neuf sur dix- sont presque unanimement heureux chez eux et ont l'intention d'y rester. La table d'analystes est unanime à lier ce besoin de campagne aux principales anxiétés relevées par le sondage: crainte d'une montée de la violence et de la drogue (37\% pensent qu'il y en aura plus). L'attrait de la ville est plus puissant chez les personnes agées (29\% veulent y vivre) et celles plus démunies. [ Les résultats reposent sur 602 entrevues téléphoniques effectuées du 22 au 29 octobre 1992. Le taux de collaboration a été de 70\%. La marge d'erreur globale est de 4\%.- Voir L'Actualité, vol. 18, n 1, p. 29 ss.] Voir aussi VEAR, Danny, "L'étalement urbain, un mal inévitable", in Le Devoir, 8 octobre 1992, p. A-3; COMTOIS, Claude, PLOEGAERTS, Léon, "Vie de banlieue, l'étalement urbain annonce-t-il le fatal déclin de Montréal?", in Le Devoir, 
gestion des déchets et des égouts, l'engorgement de la circulation, la pollution de l'air, la pénurie d'eau potable, l'augmentation du taux de chômage et de la pauvreté, les affrontements sociaux et ethniques, etc. ${ }^{8}$ Ces problèmes doivent intéresser tout autant les intervenants pastoraux (bénévoles et permanents) que l'ensemble des paroissiens. Déjà grâce aux paroisses et aux diverses congrégations religieuses, plusieurs services ont été créés dans le milieu urbain pour résoudre l'un ou l'autre de ces problèmes. Nous n'avons qu'à penser à la Saint-Vincent-de-Paul, aux "popotes roulantes", aux "soupes populaires", aux maisons pour les sans-abri, pour les exclus du monde du travail (les personnes sur l'aide sociale et l'assurance-chômage), aux maisons de quartier, aux comptoirs alimentaires et vestimentaires, aux lieux d'accueil pour les itinérants, aux comités d'accueil pour les nouveaux arrivants, etc. Les paroisses et les communautés religieuses doivent continuer à soutenir ces organismes et à promouvoir d'autres solutions pour relever les défis humains actuels et futurs dans le contexte urbain et rural. 9

Pour répondre à la croissance spirituelle des baptisés, la paroisse doit également offrir des services qui répondent aux besoins des paroissiens et non uniquement aux besoins définis par la hiérarchie. Et ces services paroissiaux doivent avoir comme objectif de faire en sorte que les paroissiens puissent devenir des "sujets"

27 novembre 1992,p. B-8; VEAR, Danny, "L'étalement urbain va continuer si les baby-boomers se comportent comme ceux qui les ont précédés", in Le Devoir, 28 novembre 1992, p. A-2; WILSEY, Jean-Pierre, "Auto-bungalow-dodo, les choix politiques en faveur du projet de société-banlieue risque de provoquer des situations explosives", in Le Devoir, 10 mars 1993, p. A-9.

8 Voir GAUTHIER, G.," "30 sommet des grandes villes du monde", in La Presse, Montréal, 16 octobre 1991, p.A-5; 17 octobre 1991, p.A-4; 18 octobre 1991, p.A-4. Voir aussi CHARTRAND, Luc, "Les villes n'ont plus de coeur", in L'Actualité, 15 novembre 1992, pp. 23-24. 9

Nous retrouvons de nombreux enjeux sociaux dans les milieux urbains. Toutefois, nous ne devons pas oublier ceux présents dans les milieux ruraux. Plusieurs municipalités de la région du Saguenay-Lac-Saint-Jean sont en voie de désintégration. Les responsables de l'animation pastorale dans ces paroisses rurales doivent poursuivre leur soutien aux dirigeants de ces municipalités surtout dans le contexte actuel où les pouvoirs politiques attachent plus ou moins d'importance à la situation de ces villages en si graves difficultés de croissance. 
capables de vivre leur baptême, de s'émerveiller de la présence du Dieu Vivant dans leur vie, de découvrir les germes du Royaume en émergence dans leur milieu d'insertion (travail, loisirs, bénévolat); en somme de devenir des "artisans d'humanité"

"La paroisse est le milieu de génération et de formation de l'homme, non pas selon telle ou telle qualification, telle spécialité, mais simplement dans sa qualité foncière d'homme, la paroisse engendre et forme des hommes simplement selon cette nouvelle existence et cette qualité de membres du second Adam; sans qualification spéciale." 10

Être paroissien en milieu urbain, c'est donc participer à un réseau qui fait de chacun un citoyen responsable de bâtir une ville qui se construit selon les grandes orientations du projet de Dieu révélé en Jésus Christ. C'est ainsi participer à un réseau qui stimule le défi de devenir humain à la manière de Jésus. ${ }^{11}$

\subsubsection{La paroisse urbaine et la liturgie}

Depuis longtemps, la paroisse a mauvaise conscience essentiellement parce qu'elle s'occupe de la liturgie, cette liturgie qui pèse souvent comme un reproche. 12 Mais il ne peut y avoir de vie chrétienne sans célébration. La célébration est l'instant de

10

CONGAR, Y. M.-J., Mission de la paroisse, in Structures sociales et pastorale paroissiale , Congrès de l'Union des oeuvres catholiques de France, Lille, 1948, p.53.

11 "Simplement, ici encore, on se sera décrispé, ayant tout subordonné à la seule question véritablement essentielle du point de vue de la mission: comment aider ces personnes à entendre et à accueillir la Parole du Christ comme une Bonne Nouvelle pour elles aujourd'hui? (CHAUVET, Louis-Marie, Les sacrements, Parole de Dieu au risque du corps, Paris, Éd. Ouvrières, 1993, p. 215. [Vivre, Croire, Célébrer]).

12 Ce reproche est justifié en certaines circonstances: -lorsque les célébrations offertes (de par leur ritualisme) ne réussissent pas à nourrir la vie spirituelle des paroissiens ou -lorsque la vie paroissiale repose uniquement sur la liturgie. Pour concrétiser l'ensemble de sa mission, la paroisse doit offrir diverses activités: célébrations liturgiques, accompagnement des paroissiens lors des rites de passage, activités caritatives, comités et mouvements paroissiaux, ressourcement et formation des bénévoles, implication dans des initiatives du milieu socio-économique, appui des oeuvres supervisées par des communautés religieuses, etc.). 
communion où le Ressuscité se donne et pénètre jusqu'au plus profond de l'existence humaine. Il s'ensuit également qu'il n'y a pas de célébration sans vie offerte car la célébration n'est pas un acte mis à part dont on s'acquitterait pour être en règle, mais le noyau d'un fruit. La liturgie et la vie sont donc en interaction: la liturgie nourrit la vie, la vit nourrit la liturgie. C'est le même Jésus qui est le Seigneur de l'une et l'autre. Dans la liturgie, il est célébré; dans la vie, il est imité. La liturgie contribue à structurer l'identité croyante suivant l'inspiration originale de Jésus le Christ dès l'instant qu'elle laisse résonner la Parole vivante du Ressuscité et qu'elle suscite ainsi une vigilance active à poursuivre audacieusement l'oeuvre de libération et d'humanisation de notre monde. Les disciples ne peuvent longtemps suivre le Maître s'ils ne s'arrêtent pas de temps en temps pour l'écouter et le fêter.

\begin{abstract}
"La vie urbaine est agitée, d'un rythme rapide, multiple dans ses formes. Elle tend à la dispersion /../. C'est pourquoi, la liturgie a une fonction de recueillement. Mais cette fonction doit tenir compte des conditions de l'homme des villes. L'homme de la campagne vivait isolé toute la semaine /.../ Il aimait la présence de nombreuses personnes $/ . . . /$ Ce que l'homme de la ville désire et attend, insconsciemment peutêtre, est tout différent. Il a besoin de recueillement et de silence./.../ De plus, l'homme de la ville n'entre pas de plain-pied dans l'assemblée liturgique: il s'attend à être accueilli et introduit. Et il désire que l'accueil soit en même temps discret, exempt de pressions indésirables et marqué d'un caractère de personnalité/.../ La vie liturgique ne doit pas être 'sauvage' et ignorer les règles de la civilisation urbainel.../ Il faut que la liturgie soit pour les chrétiens des villes une illumination. Elle doit représenter de manière suggestive leur rôle dans la ville, le sens de l'histoire de la communauté humaine qui est vécue dans la ville." 13
\end{abstract}

Notre contexte social contemporain où l'individu est bousculé par les rythmes du travail, les exigences de la famille et les sollicitations de toutes parts ne favorise pas toujours le recueillement et l'intériorité nécessaires à la vie spirituelle et à la foi. La paroisse doit alors offrir des oasis nécessaires à la survie spirituelle. Il serait important dans une ville de présenter différents styles de célébrations. Telle communauté pourrait 
offrir une célébration plus familiale, une autre communauté dans le milieu urbain pourrait axer davantage sa célébration sur la dimension sociale de la foi, une autre communauté pourrait être plus préoccupée par une intelligence de la foi au coeur de la liturgie, etc.. $\mathrm{Ou}$, tenant compte de l'absence de coïncidence entre chaque assemblée dominicale et la communauté, on aurait peut-être avantage à susciter la formation d'une certaine communauté, plus restreinte que la paroisse, autour de chaque assemblée dominicale. À cette fin, on pourrait sans trop d'effort repérer les personnes assidues à telle assemblée et, avec leur concours, donner peu à peu une identité particulière, un cachet propre à chaque assemblée dominicale. Point n'est question d'élever des frontières entre chacune, mais un grand pas serait effectué dans le bon sens si des "noyaux" de paroissiens se formaient en liaison avec chaque assemblée et leur donnaient consistance. De plus, même si je continue à penser qu'il faut privilégier le dimanche comme temps du rassemblement d'Église en signe et en continuité symbolique avec l'événement de la résurrection de Jésus, il y a de plus en plus de chrétiens qui ne peuvent participer normalement à la célébration dominicale pour diverses raisons. Nous l'avons vu au chapitre huitième, le phénomène de l'industrialisation et de l'urbanisation a complètement modifié le rapport de l'homme au temps. Malheureusement, plusieurs intervenants pastoraux sont restés "à l'heure de la campagne". Nous n'avons qu'à écouter leurs propos dans le débat actuel sur l'ouverture des commerces le dimanche. Une théologie rigide du "jour du Seigneur" n'est pas adaptée à la pastorale urbaine; comme le reste, elle fut élaborée dans le cadre d'une civilisation rurale. Il faut inventer d'autres formes de célébrations en d'autres temps dans le but de mieux respecter les rythmes divers des paroisiens "modernes".

\footnotetext{
"Par contre, on ne saurait écarter du revers de la main une institution qui a fait ses preuves comme lieu d'intégration sociale. La liturgie paroissiale peut sans aucun doute continuer de jouer un rôle social important dans la mesure où elle assumera les enjeux de la conjoncture culturelle actuelle. Ce qui suppose cependant que l'on renonce aux prétentions hégémoniques avec toutes les exigences de conformisme que l'on a pu avoir, et que l'on
} 
accepte d'être un lieu de sens parmi d'autres dans la mosaïque culturelle. Un lieu ouvert, pluriforme..." 14

\subsubsection{Quatre dimensions de la vie communautaire se compénétrant}

On connaît dans le monde pastoral plusieurs grilles d'analyse largement utilisées qui distinguent dans la vie d'une communauté chrétienne quatre dimensions: signification, fraternité, mission et célébration. Mais celles-ci tendent parfois à compartimenter l'action pastorale. Ces dimensions de la vie ne sont pas à opposer ni à regarder comme étanches; elles se compénétrent et se complètent l'une l'autre. L'assemblée liturgique constitue, par elle-même, un lieu d'intégration de toutes les dimensions de la vie de chaque communauté chrétienne. C'est là que la foi et la mission, en plus de trouver un lieu privilégié de ressourcement, voit se réaliser, comme cela est possible, leur propre visée: la communion avec Dieu et la communion des croyants entre eux. C'est là également que la fraternité chrétienne trouve son mode d'expression (non pas de réalisation) le plus plénier: elle s'y exprime sous un mode symbolique qui évoque à la fois son origine: la réconciliation de tous en Jésus, sa condition d'exister présentement: la communion dans l'Esprit, et ce à quoi elle est appelée en définitive: la vie en plénitude sans fin avec le Père. La liturgie n'est pas toute la vie chrétienne de chacun et d'une communauté mais elle en constitue le centre et le creuset. Il en va de même de la dimension liturgique de la fonction pastorale. La fonction liturgique du pasteur n'est pas une fonction parmi d'autres; c'est une fonction qui, tout en supposant un exercice réel des autres pour revêtir totalement son sens, les

CAMPBELL, Michel, "Les lieux de la liturgie dans la société urbaine", in Communauté chrétienne, $\mathrm{n}^{\circ}$ 154, juillet-août 1987, p. 278. Voir aussi LESSARD, Marc-A., "Liturgie, culture et paroisse: une perspective sociologique", in Liturgie, Foi et Culture, vol. 23, n 119, septembre 1989, pp. 11-19. Dans ce même numéro, lire également ARCAND, Michelle, "Obstacles et chances de la liturgie", pp. 20-25. 
intégre et les unifie. 15 La liturgie aura toujours un rôle important dans l'expérience chrétienne du citadin. Dans le contexte moderne d'aujourd'hui, je crois que la liturgie aura un rôle de plus en plus grand comme acte intégrateur dans la communauté. Il ne faut jamais négliger cette fonction psycho-sociale d'intégration communautaire offerte par la liturgie. 16

\subsection{Une pédagogie pastorale construisant la "catholicité"}

C'est un fait bien connu: la pastorale paroissiale nous situe en face du 'toutvenant". L'Église a été définie à Vatican II par l'expression "Peuple de Dieu". Nous savons que les êtres humains ne cheminent pas au même rythme. La catholicité de l'Église nous oblige alors à accepter que chaque croyant chemine à des pas variés. Nous avons vu au chapitre précédent que le développement de la foi n'advient pas de façon uniforme durant la vie adulte mais se produit de façon variée et en lien direct à certains temps de la vie adulte. L'intervenant pastoral doit ainsi accepter de marcher

15

La liturgie est un lieu privilégié d'évangélisation mais elle l'est selon la manière dont on célébre. Plusieurs intervenants pastoraux opposent liturgie (ou la sacramentalisation en général) et évangélisation. Ils ont une conception réduite de l'évangélisation. Ils considèrent l'évangélisation comme la première étape de l'éducation de la foi, suivie de la catéchisation et ensuite de la célébration. C'est une fausse piste de croire qu'il faut évangéliser les paroissiens au lieu de vouloir les sacramentaliser. En réalité, la véritable question est la suivante: comment être évangélisateur dans la manière d'accompagner les paroissiens et de célébrer. La liturgie constitue un lieu propice à l'évangélisation si ce qui est offert au coeur de la célébration rejoint la profondeur humaine des croyants.

16 Il aurait été intéressant d'être plus explicite sur ce point puisque la réflexion sur la fonction psycho-sociale de la liturgie nous conduit directement à un débat complexe de la relation entre la religion et la culture. En travaillant à l'intégration psycho-sociale d'une personne, on nourrit un élément fondamental de la culture. Je me permets de parler rapidement du binôme religion-culture en m'inspirant de la réflexion de Paul TILLICH sur ce débat (voir de cet auteur Théologie de la culture, Éd. Planète, 1968, pp. 92ss.). Quand celui-ci affirme que la religion est la substance de la culture et que cette dernière est la forme de la religion; quand il soutient de plus que tout individu, toute culture ou toute civilisation est happée ( grasped by ) par un sens ultime (ultimate concern ) qui a un statut divin, il dégage ce qui lui paraît être la structure de fonctionnement de tout individu, de toute civilisation, de toute culture et, partant, de toute religion. Actuellement, l'Église semble avoir renoncé à maintenir la place centrale que TILLICH reconnaissait à la religion dans toute culture et toute civilisation. 
non pas en avant du paroissien mais à côté de lui pour se réchauffer mutuellement par leurs questionnements sur le mystère de la vie et de la foi. Les permanents ecclésiaux doivent concevoir l'ensemble des différentes demandes des paroissiens comme des cadeaux du Seigneur qui les invite à contempler les semences du Verbe secrètement cachées dans le coeur de chaque personne humaine. Il est urgent alors de développer un nouveau paradigme de pédagogie pastorale qui accepte le rythme de cheminement des paroissiens. 17 Des changements institutionnels sont certes essentiels pour renouveler la pastorale paroissiale en milieu urbain mais ils ne suffisent pas. Il faut également s'intéresser de près à la pédagogie pastorale utilisée. Celle-ci constitue un élément-clé dans le développement communautaire et la responsabilisation des personnes. Il est important de présenter des suggestions pratiques aux paroisses pour que leur pastorale prenne mieux en compte les besoins spirituels des croyants selon les

17

Je le répète, les intervenants pastoraux doivent se donner une plus grande formation les aidant à tenir compte des études sur le développement psychosocial de l'adulte et de celles concernant plus explicitement le développement de la foi. Mon rêve est que les Grands Séminaires dans les Églises locales se transforment en Maisons de ministères. Nous investissons beaucoup actuellement au niveau de la formation des candidats au presbytérat. La formation donnée aux autres ministres avant et après leur reconnaissance officielle demeure insuffisante (celle des prêtres après leur ordination l'est également !). Pourquoi ne pas profiter des ressources matérielles, intellectuelles et spirituelles de ces institutions ecclésiales pour offrir une formation permanente de plus grande qualité à tous les ministres (ordonnés, institués et mandatés)? C'est tout l'ensemble de l'Église diocésaine qui profiterait des retombées d'une meilleure formation. De plus, une formation donnée entre les différents agents pastoraux permettrait une plus grande symphonie ministérielle. "Lorsque je pense au leadership chrétien de l'avenir, je suis convaincu qu'il devra être théologique. Pour ce faire, de profonds changements devront se produire dans les séminaires et les centres de formation chrétienne. Ceux-ci doivent devenir des endroits où les personnes sont formées à discerner les signes des temps. Cette formation ne peut donc pas être purement intellectuelle. Elle requiert une profonde formation spirituelle qui implique toute la personne, le corps, l'esprit et le coeur (NOUWEN, Henri, Au nom de Jésus, Réflexions sur le leadership chrétien, Outremont, Novalis, 1991, pp. 40-41). "Il n'en reste pas moins que le travail intellectuel dans l'Église reste un enjeu majeur. Il a à surmonter un antiintellectualisme tenace, donc une méfiance assez profonde. /.../ Des problèmes nouveaux surgissent devant lesquels l'intelligence catholique risque d'être prise de court si personne n'a acquis les outils intellectuels nécessaires pour les affronter. Or aujourd'hui d'une part, la diminution du nombre des hommes bien formés fait problème (et leur surcharge en responsabilités pastorales ou administratives diverses les détourne de la recherche fondamentale) d'autre part, la tendance au repli sur l'affirmation identitaire favorise peu les vocations à l'audace de la pensée. On peut espérer aussi que du sein du laïcat sortiront des hommes et des femmes capables de prendre le relais"(VALADIER, Paul, L'Église en Procès, France, Flammarion, 1987, p. 201.). 
périodes de la vie humaine dans le contexte de la modernité. Et de plus, en ce domaine de l'éducation de la foi comme en d'autres, il n'est pas possible que chaque paroisse d'un diocèse ait un service d'éducation de la foi de qualité, un service qui se fasse de multiples façons et qui se déroulera souvent dans l'espace sacramentel s'il reste ouvert à ses ancrages humains et aux expériences de créativité. La collaboration entre les paroisses peut être une voie possible. Une autre occasion pour constituer une pastorale urbaine mieux coordonnée. Le dialogue entre les intervenants pastoraux et les paroissiens (qu'ils soient "nucléiques" ou "périphériques"[distants]) doit donc demeurer ouvert au cheminement de croissance du tout-venant auquel s'adresse entre autres la pastorale sacramentelle pour répondre à la véritable catholicité de l'Église et aux défis de la nouvelle évangélisation.

\subsubsection{Une Paroisse de type "multitudiniste"}

"La paroisse doit être la maison ouverte à tous et au service de tous ou comme se plaisait à dire Jean XXIII, la fontaine du village à laquelle tout le monde vient étancher sa soif." 18

Il faut répondre aux demandes des paroissiens comme Jésus l'a fait au coeur d'un dialogue simple, accueillant et sincère. Le Seigneur part de ce qu'il a en main. Il nous demande d'avancer non pas en partant de ce qu'on souhaiterait avoir mais de ce qu'il place sur notre chemin. Les paroissiens ne se mettent pas en marche si on ne leur fait pas confiance. Accueillir avec attention leurs demandes à travers les différents services paroissiaux peut devenir un lieu de conversion et de cheminement de la part des deux parties (intervenant pastoral (accueillant) VS paroissien). Il est important de faire confiance à l'Esprit qui travaille le coeur des personnes. Cela exige souplesse de 
l'action pastorale. Les rites de passage offrent particulièrement de nombreuses pierres d'attente pour une découverte du Dieu vivant, source de toute vie. 19 Accueillir et écouter ce qui se passe dans la profondeur de l'expérience des personnes qui demandent un rite de passage constituent un chemin essentiel pour découvrir le mystère.

"Le premier seuil à franchir concerne l'acceptation de cette tâche pastorale comme une mission particulièrement importante et urgente pour l'Église d'aujourd'hui. Avec la participation à la catéchèse, la préparation des baptême et des mariages constitue l'une des sources principales de renouvellement des communautés chrétiennes, en ville notamment, et particulièrement dans les banlieues. Il ne fait guère de doute, à nos yeux, que cette source est appelée à se gonfler encore dans une société "post-moderne" où tant de personnes éprouvent le besoin de retrouver des repères et de se repositionner sur le plan religieux. Cela requiert que les diocèses, les paroisses, les services, les aumôneries développent un véritable souci stratégique dans cette direction." 20

La paroisse de demain peut avoir un avenir fructueux à condition qu'elle consente à demeurer un lieu de "passage" pour le "tout-venant". Nous sommes alors invités à franchir certains deuils sur notre imaginaire de communauté en termes de continuité et de globalité. Les permanents ecclésiaux doivent concevoir positivement la communauté comme un "lieu de passage". De plus, nous l'avons vu au chapitre dixième, la signification biblique du mot paroisse nous invite même à aller dans ce sens. Il est fait du préfixe par, qui veut dire 'ailleurs', 'à côté', 'pas ici'; et du mot oikos qui évoque maison. La paroisse a ainsi un sens original de nature essentiellement pascale. La paroisse est le lieu de l'exode chrétien. Sa signification biblique rappelle aux intervenants pastoraux qu'ils sont appellés à accompagner les gens lorsqu'ils "passent" dans le but d'approfondir le sens de leur vie et de leur foi. En les centrant sur

Il faut donc revoir notre conception des sacrements et découvrir en eux des occasions de croissance spirituelle où des gens peuvent approfondir des morceaux d'évangile. Les symboles de la tradition spirituelle du catholicisme permettent d'éveiller en chaque croyant le niveau le plus profond de son existence. 
Jésus-Christ, le grand "passeur", celui-ci opère des "déplacements" dans leur coeur, lieu de la maison de Dieu. À Son contact, les agents pastoraux et les paroissiens deviennent autres grâce à un dialogue rempli d'écoute amoureuse. Ils ont par la suite davantage le goût de voyager, c'est-à-dire d'aller vers l'autre que l'on considère comme un étranger (ou un distant) pour s'enrichir de lui. Dans ce contexte, le paroissien (qu'il soit "nucléique" ou "périphérique") est toujours en exode, en passage incessant de son monde à celui de l'autre et de l'Autre, en continuelle route vers une plus grande libération personnelle et communautaire grâce à ce qui est différent de lui. ${ }^{21} \mathrm{La}$ paroisse doit donc se considérer comme un rassemblement auquel Dieu appelle de manière diversifiée et par modes d'allégeance multiformes.

\subsection{Une réorganisation ministérielle}

Nous avons vu au chapitre onzième qu'il n'y a pas seulement le phénomène de l'urbanisation qui a remis en question la vie paroissiale et sa structure. Vatican II a voulu opérer un grand tournant dans la vie ecclésiale pour amener tous les baptisés à devenir des sujets chrétiennement plus libres et responsables. Des pas significatifs ont été faits depuis ce concile pour engager davantage l'ensemble des baptisés dans le devenir de l'Église. Dans l'ensemble des paroisses sont apparus des noyaux de chrétiens cherchant ensemble à mettre en oeuvre les orientations conciliaires. Ces noyaux varient d'après les objectifs de leur rassemblement et selon le pouvoir réel qui est laissé pour un véritable travail de création d'ensemble. Mentionnons les Conseils paroissiaux de Pastorale (C.P.P.), les équipes liturgiques, etc. Il y a des comités paroissiaux où prêtres et bénévoles collaborent dans une nouvelle conscience ecclésiale et un nouveau partage des tâches. Il y a là un véritable acquis puisque c'est impossible

21 faire advenir une respectant davantage la conscience et la dignité des personnes. 
d'avoir une communauté dynamique s'il n'y a pas de membership fort. Nous pouvons également parler de l'avènement des équipes pastorales, des agents pastoraux laïques, des diacres permanents et des différents synodes paroissiaux et diocésains. Toutefois, même si la coresponsabilité a progressé, les résultats sont encore inégaux. Pour accéder au renouveau, des changements institutionnels sont essentiels afin de susciter des chrétiens-sujets sans lesquels aucun changement paroissial véritable n'est possible.

\subsubsection{Des acquis ecclésiologiques actuels à retenir et à perpétuer}

Comme je l'ai mentionné à la fin du chapitre onzième, nous ne pouvons pas attendre la convocation de Vatican III et la parution d'un autre Code de droit canonique pour renouveler la paroisse. En attendant le Grand Soir, il y a des possibles porteurs d'avenir déjà présents dans différentes communautés paroissiales. Il est ainsi important de souligner les domaines où les mentalités ont évolué au cours des dernières années, favorisant l'acquisition progressive d'un certain nombre de convictions sur lesquelles nous pouvons nous appuyer dans l'avenir pour renouveler la paroisse et l'Église.

\subsubsection{Soutenir le "membership"}

Phénomène marquant depuis plus de trente ans: de nombreux croyants, femmes et hommes, participent à la vie et à la mission de l'Église. Le chapitre quatrième a démontré l'importance du "membership" dans le dynamisme communautaire. Depuis quelques années, nous sommes véritablement en présence d'un phénomène assez nouveau au coeur de la vie des paroisses: elles peuvent compter sur des noyaux de bénévoles ayant une formation et capables de plus en plus d'une pensée articulée au niveau de la vie de foi et de la pratique pastorale. En regard d'un passé encore récent, c'est là un saut qualitatif remarquable qui manifeste le tournant 
dans lequel les paroisses se sont engagées. Davantage, cette émergence de bénévoles formés et assumant des responsabilités pastorales diverses montre à elle seule que le modèle traditionnel de la paroisse a changé.

La vitalité d'une Église ne se calcule pas d'abord au nombre de permanents à son service mais à l'engagement de ses membres. Les communautés paroissiales peuvent avoir un avenir prometteur si de plus en plus des paroissiens deviennent des croyants autonomes et responsables. Cependant, nous faisons beaucoup d'activités pastorales en paroisse sans nous soucier suffisamment de la croissance spirituelle des bénévoles au coeur de leur engagement. Un engagement peut dynamiser davantage la foi des bénévoles lorsque nous sommes moins centrés sur le 'faire-ensemble' mais plus sur 'l'être-ensemble'. De plus, nous devons consacrer du temps pour évaluer le travail dans les comités paroissiaux. Sans évaluation, il est beaucoup plus facile de s'installer dans une routine paroissiale et de perdre un sens critique indispensable à la vitalité communautaire. L'évaluation permet ainsi une remise en question permanente de l'animation pastorale de la paroisse. 22 Nous devons être attentifs à ces points mentionnés.

La nécessité la plus impérieuse en paroisse est vraiment cette volonté de former des responsables, reconnus comme tels et qui agissent vraiment en responsables. Mais on ne devient pas responsables sans payer le prix qu'il faut pour s'informer, se former et répondre de ses choix et de ses décisions. Les paroisses ont besoin des responsables qui lancent des initiatives, préparent les décisions, assument ces décisions (avec le risque permanent de se faire critiquer), élaborent les projets, les paroisses catholiques du Québec, Tome 1, Trois-Rivières, Pastor, 1992, 264p. 
soutiennent, les renouvellent. Des paroissiens qui se sentent responsables de l'originalité chrétienne de leur paroisse et qui refusent toute compromission mettant gravement en cause cette originalité. Pour arriver à cet objectif, il faut investir dans une qualité de formation et d'accompagnement du membership. L'Église diocésaine de Chicoutimi est consciente de ce défi. Les membres du Conseil Presbytéral ont déjà voté cette proposition: "Offrir une formation pastorale continue et permanente afin de favoriser une plus grande implication des laïques et de rendre possible une réponse adéquate aux nouvelles réalités." 23

\subsubsection{Encourager l'engagement des agents pastoraux laïques et} limplication des diacres permanents

L'arrivée des agents de pastorale laïques dans les différentes paroisses du diocèse a fait prendre conscience à plusieurs croyants des transformations majeures vécues par l'Église. Alors qu'autrefois la vie interne des paroisses était maintenue presqu'exclusivement par les membres du clergé, voilà qu'aujourd'hui des "laiques" prennent part à son organisation et à son animation. Leur présence est une réponse à l'appel lancé par l'Esprit qui cherche à former davantage une Église Peuple de Dieu, tout entière responsable. Ces agents apportent manifestement une note de jeunesse au sein d'un personnel où les jeunes ne sont pas nombreux et où les prêtres ont une moyenne d'âge d'environ soixante ans. La présence des agents et des agentes de pastorale laïques a donc été un facteur important de rajeunissement des effectifs dans l'Église locale. Même si les bénévoles constituent des ressources précieuses pour le dynamisme d'une paroisse, cette institution ecclésiale a besoin de "ministres permanents" engagés à son service. Une prise en charge communautaire ne peut se 
faire sans s'appuyer sur un service d'accompagnement permanent. Mais la multiplication rapide des agents de pastorale laïques ne manque pas de poser de manière inédite la question des rapports entre les ministres ordonnés et les autres ministres. Nous devons poursuivre notre réflexion théologique sur leur apport dans l'Église tout en encourageant l'engagement de ces agents pastoraux en paroisse.

Les diacres permanents sont également des ressources humaines de plus en plus précieuses dans les paroisses, particulièrement dans les équipes pastorales. Je rappelle mon intuition à savoir que l'Esprit-Saint, par le moyen des diacres permanents, est en train de travailler subtilement la mentalité des paroissiens et des permanents ecclésiaux dans le but de faire changer la politique concernant l'accession au ministère presbytéral (l'ordination des femmes et des hommes mariés). Mais actuellement le diocèse de Chicoutimi et d'autres Églises locales doivent encore s'approprier ce ministère. ${ }^{24}$ Cette articulation du diaconat avec les autres ministères et services dans l'Église reste à faire. Cependant cela ne doit pas empêcher les différentes paroisses de soutenir les personnes qui se sentent appelées à exercer le ministère diaconal en leur sein.

"L'avènement des agents pastoraux laïques et des diacres permanents constituent une richesse de l'Esprit pour notre Église. À travers cela se fait une redécouverte de la diversité des ministères. Cela pose le chantier de leur cohésion et d'un meilleur travail de collaboration comme le révèle le document de travail élaboré par le Service des ministères: "Pour la cohésion...". Comme Église, nous sommes donc confrontés à un double défi: celui d'abord de respecter la nouvelle compréhension du ministère ordonné issue de Vatican II et celui d'articuler harmonieusement les divers ministères dans la présidence pastorale des communautés." 25

24

Voir aussi PEPPER, Marc, "Le diaconat permanent en tension et en questions" in Entre l'arbre et l'écorce, CHARRON, Jean-Marc, GAUTHIER, Jean-Marc, dir., Montréal, Fides, pp. 107-112. [CEP \#14]. 


\subsubsection{Gérer avec sagesse les ressources presbytérales}

Dans l'ensemble des ressources humaines en pastorale paroissiale les prêtres occupent une place importante. Mais cette place n'est plus exclusive comme elle l'était autrefois. De plus, les données d'observation au chapitre cinquième ont révélé que la moyenne d'âge chez les prêtres augmente avec une constance remarquable et que la courbe du presbytérium du diocèse de Chicoutimi se déplace comme un bloc monolithique, si bien qu'en 2002, il y aura deux fois moins de prêtres dans cette Église locale, soit plus ou moins 75 ministres ordonnés en deça de l'âge de la retraite (dont moins de 50 prêtres de disponibles pour le ministère paroissial pour 95 paroisses ${ }^{26}$ ). Comme la moyenne d'âge des prêtres augmente en même temps que leur nombre diminue, il est évident que l'ordre actuel des choses en paroisse ne pourra subsister longtemps. Habituées qu'elles étaient à pouvoir compter chacune sur 'son' prêtre (capitaine d'équipe) ou 'ses' prêtres, plusieurs paroisses se sont vues dans l'obligation de partager avec la paroisse voisine ou les paroisses avoisinantes le ou les prêtres disponible(s). Une telle situation nous presse d'envisager l'avenir autrement. Non pas un avenir lointain mais un avenir proche, c'est-à-dire d'ici cinq ans, dix ans au plus tard. Déjà, en 1993, 32\% des paroisses du diocèse de Chicoutimi n'ont pas de prêtres résidants. De plus, plusieurs prêtres se sentent dépassés par les exigences nouvelles de la pastorale paroissiale d'aujourd'hui. Le système paroissial est un 'tue-prêtre" ou un "gruge monde". Dans l'ensemble des diocèses du Québec, les Offices du clergé constatent une augmentation considérable des congés de maladie ces dernières années

26

Au 31 décembre 1993, il y avait seulement 67,2 prêtres sur une possibilité de 223 qui travaillaient officiellement en paroisse dans le diocèse de Chicoutimi. Voir COUTURE, Jean-Guy, Mgr, Clergé diocésain, 31 décembre 1993, Document confidentiel, Statistiques personnelles, Diocèse de Chicoutimi, $5 \mathrm{p}$. Je crois que si la politique de l'accession au presbytérat ne change pas, il me semble plus réaliste de prévoir uniquement 40 prêtres de disponibles pour le ministère paroissial en I'an 2000. Une preuve suffisante pour investir dans la recherche d'audacieuses solutions. 
chez les prêtres de tous âges travaillant en pastorale paroissiale. 27 C'est le système paroissial dans sa globalité qu'il faut remettre en question. Les exigences du système sont souvent plus fortes que la volonté du permanent lui-même. Il ne serait pas surprenant que ce problème d'équilibre humain des permanents (et des bénévoles aussi) s'accentue dans les prochaines années si l'aménagement pastoral n'est pas sérieusement remis en question. Nous confions à toutes ces personnes de plus en plus de responsabilités sans toutefois réviser la structure paroissiale. Nous ne pouvons plus longtemps fonctionner avec le modèle pastoral actuel et il n'est plus possible de conserver en paroisse cette structure datant d'une autre époque. Combler les besoins au fur et à mesure qu'ils se présentent en regroupant deux ou trois paroisses parce qu'elles sont devenues sans ministre ordonné et qu'il n'est plus possible d'y affecter un curé, confier à certains prêtres toutes sortes d'activités disparates au point qu'ils ne sachent plus s'occuper d'aucune, c'est peut-être une nécessité du moment, mais ce n'est pas une politique saine et constructive de remembrement des paroisses et de répartition des énergies presbytérales.

Le nombre des prêtres est à la baisse. Devant les chiffres, certains diront que l'Esprit n'abandonne pas son Église. Qu'il sera là, toujours présent au milieu de son peuple et que jamais il ne laissera son Église sans prêtres. Certitude de foi, certes! Mais cette proclamation de foi ne doit pas conduire à se croiser les bras en attendant l'Esprit. S'impose à notre conscience croyante le devoir de prévoyance. Nous avons notamment le devoir de prévoir et d'analyser tout ce qui concerne le ministère presbytéral, sa place, son rôle et sa signification dans la vie d'une communauté. plus en plus de responsabilités importantes dans les paroisses sont confrontés au même problème. Leur équilibre personnel et celui de leur famille demeurent aussi menacés présentement. L'institution paroissiale prend souvent le pas sur la vie des paroissiens et des permanents. 
"Nous n'avons pas fini de bien saisir la compréhension du ministère des prêtres en fidélité à Vatican II. Plusieurs prêtres ne voient pas bien comment ils peuvent travailler avec d'autres ministres (diacres permanents, agents pastoraux) sans perdre une partie de leur identité. Par exemple, plusieurs redoutent des ministres extraordinaires du baptême, du mariage et des funérailles. Alors que Vatican II nous invite précisément à sortir de cette perspective sacerdotale (expert du culte) pour entrer dans une perspective presbytérale (présidence de la communauté par l'unification de la communauté, la coordination des charismes, le service de la Parole, l'accomplissement des divers engagés). Une juste compréhension de la théologie des ministères de Vatican II est un enjeu essentiel pour la réalisation d'une Église-communion. /.../ Il faut définir les rôles des différents ministères, spécialement le rôle du prêtre par rapport à l'ensemble des responsabilités pastorales à assumer. " 28

Nous avons à prévoir la manière dont le service presbytéral sera vraiment offert aux communautés. De même nous avons à rechercher les meilleures façons d'insérer le ministère du prêtre dans la symphonie des autres ministères et dans l'ensemble du collège des agents pastoraux. Pour faire face à l'avenir, on peut penser l'aménagement des ressources humaines en pastorale à partir de deux aspects bien différents. Si l'on s'arrête au manque de prêtres, les options et la prospective s'établissent en fonction des effectifs de prêtres, de leur répartition actuelle ou future, de leur recrutement, etc. Tout le reste, avenir des paroisses, place et rôle des autres ministères, aménagement des services pastoraux, etc., s'aligne à partir du facteur premier: la disponibilité des prêtres. On peut prendre un autre point de départ, celui de la communauté et de ses besoins pastoraux, c'est-à-dire non plus à partir des prêtres disponibles mais, des communautés à animer. Alors les options et la prospective s'établissent en fonction des communautés existantes, de leurs attentes, de leurs besoins, mais aussi de leurs

28

L'Église de Dieu qui est à Chicoutimi...., p. 13, p. 18. La reprise récente de la réflexion intensive sur le ministère presbytéral a permis de déployer sa signification en le situant dans la totalité du Corps du Christ, relié à l'ensemble du Peuple de Dieu dans sa plénitude et sa catholicité. C'est un progrès significatif. Mais les ajustements pastoraux ont encore pour effet de cantonner de plus en plus les prêtres dans l'univers des sacrements, en faisant d'eux des commis-voyageurs du rite. Les prêtres, avec leur voiture-ambulance "urgence-pastorale" circulent rapidement dans les territoires paroissiaux sans avoir suffisamment de temps pour offrir une qualité d'accompagnement. Il faut poursuivre nos efforts de réflexion afin de centrer le ministère ordonné plus sur le "faire signe" que sur le "pouvoir faire". 
possibilités et de leurs ressources propres. Entre ces diverses options, un choix pastoral reste à faire, un choix déterminant pour la concertation des efforts et l'harmonisation des ministères. Chacune des options commande des investissements et des stratégies parfois assez semblables mais orientés différemment, parfois tout bonnement irréconciliables. Pour ma part, mon choix va sans hésiter dans le sens des options découlant des besoins de la communauté. Mon espérance est nourrie du fait que les autorités ecclésiales du diocèse de Chicoutimi ont opté également pour cette orientation.

\begin{abstract}
"Il a été clairement défini que l'aménagement des ressources humaines en pastorale dans notre diocèse devrait être pensé en fonction des besoins des communautés chrétiennes. En faisant ce choix, les membres du Conseil Presbytéral en 1988 évitaient le piège des solutions à court terme, des solutions sans avenir et ouvraient par le fait même la voie à des formes nouvelles de prise en charge communautaire. Le choix d'une telle orientation suppose donc un changement de mentalité chez l'ensemble du peuple de Dieu." 29
\end{abstract}

Mais il reste encore de grands pas à franchir avant que cette option pour la communauté et ses besoins pastoraux devienne réellement effective.

\title{
14.3.1.4 Privilégier la structure de l'équipe pastorale
}

Parmi les pratiques ministérielles privilégiées à l'occasion de réaménagements pastoraux au cours de la dernière décennie, il faut noter l'effort pour mettre en place des équipes pastorales. Ces efforts doivent se poursuivre dans la promotion de la structure de l'équipe pastorale dans les prochains aménagements pastoraux. Grâce à ce type de nomination, on assiste au développement d'un "pastorat" auquel plusieurs baptisés sont associés. L'avénement des équipes pastorales dans les 
Églises locales est ainsi une des plus belles preuves du désir réel de quelques bénévoles d'assumer de plus en plus des responsabilités importantes en fidélité au sacerdoce baptismal. Ma joie est de savoir que l'objectif du diocèse de Chicoutimi est vraiment d'encourager les paroisses à s'articuler autour d'une équipe pastorale (cf. canon 517,2).

\begin{abstract}
"Parmi les formules de prise en charge communautaire, il nous semble que l'équipe pastorale paroissiale soit la formule à privilégier actuellement, d'abord parce qu'elle nous apparaît la formule la plus cohérente avec la conception de l'Église-communion. C'est une formule qui nous permet aussi de gérer avec sagesse la diminution des prêtres et l'augmentation du nombre des agents pastoraux lä̈ques bénévoles et rémunérés. Elle ne nous centre pas sur la décroissance des ministres ordonnés mais sur le défi de gérer l'avenir de notre Église avec espérance grâce à l'Esprit qui est en train de donner à l'Eglise des ministères nouveaux et renouvelés. /.../ Que le diocèse favorise la formation d'équipes pastorales paroissiales et offre aux zones et aux paroisses des ressources pour les aider dans la réalisation de leur plan d'action." 30
\end{abstract}

Le comité diocésain sur l'avenir des communautés de l'Église locale de Chicoutimi a déjà préparé un excellent "document d'accompagnement pour les communautés paroissiales sur la route d'une plus grande prise en charge communautaire". 31 L'équipe pastorale permet de préparer avec courage l'Église de demain. Le centre de gravité est donc placé dans la communauté, laquelle doit, comme telle, rendre dans la commune prise en main des responsabilités, un témoignage évangélique par la proclamation de la Bonne Nouvelle et le service. Certains intervenants pastoraux ont peur dans cette nouvelle structure ecclésiale de perdre du pouvoir et en même temps des bénévoles, en fidélité à leur appel baptismal, réclament de plus en plus de reconnaissance dans les

$30 \quad$ L'Église de Dieu qui est à Chicoutimi...., p. 18

31 COMITÉ DIOCÉSAIN DUR L'AVENIR DES COMMUNAUTÉS, Bâtir ensemble.... Collaborer pour l'avenir, document d'accompagnement, Évêché de Chicoutimi, 1993, 101p. Ce document est divisé en quatre chapitres: la sensibilisation, la mise en route du projet, le choix d'une formule d'animation et la mise en place de la formule adoptée. 
orientations futures de leur communauté paroissiale. Il ne faudrait pas que ces peurs et ces tensions paralysent le changement vers des équipes pastorales paroissiales. 32

J'ai montré au chapitre onzième l'importance pour l'avenir de ne jamais plus nommer juridiquement seul le ministre ordonné responsable d'une paroisse. Quelques frères et soeurs dans la foi doivent être mandatés avec lui et avoir de réels pouvoirs comme le prêtre, afin que chaque membre de l'équipe pastorale puisse s'interpeller fraternellement. Il n'est possible de favoriser le processus d'authentification des signes des temps qu'en communauté de frères et soeurs égaux en droit et en dignité. Le danger est grand de monopoliser le pouvoir et d'éteindre l'Esprit lorsque le ministre ordonné est canoniquement reconnu seul responsable de la communauté. Actuellement, les paroisses s'engagent de plus en plus à appuyer les ministresresponsables de l'équipe pastorale. Cette expérience pastorale montre que cette entreprise n'est pas toujours facile. De la part de paroissiens, il y a des résistances à accepter que des ministères jusqu'ici assumés par des prêtres soient désormais exercés par d'autres chrétiens. Les changements de mentalité ne s'opèrent jamais rapidement. Ils sont toujours le fruit de longues maturations. Que cette perspective de long terme ne nous décourage pas. La mise en route en vaut la peine. Il faut faire confiance aux chrétiens pour parvenir enfin à obtenir des modèles de ministères qui ne seront certainement pas sans répercussion sur les autres aspects de la vie ecclésiale.

32 Voir aussi CENTRE DIOCÉSAIN, Les équipes pastorales mandatés en paroisse dans le diocèse de Saint-Jean-Longueuil, février 1994, 19p. 


\subsubsection{5 Être audacieux dans l'avènement de nouveaux ministères}

Après Vatican II, les défis de la pastorale paroissiale (marquée en particulier par la diminution du nombre des prêtres) ont donné lieu à des pratiques nouvelles quant à l'organisation des services et des ministères ecclésiaux (agents de pastorale laïques, diacres permanents, bénévoles mandatés, équipes pastorales). Ces initiatives n'ont pas pu se prendre autrement que sous le mode d'essais et de tâtonnements, d'échecs même; elles ont souvent provoqué des conflits. Tout ce bouillonnement, loin d'inviter à revenir à la théologie d'avant Vatican II, pousse à comprendre avec plus de cohérence encore l'Église que nous sommes maintenant invités à vivre. Mais dans l'Église d'aujourd'hui, particulièrement concernant l'émergence des nouveaux ministères, des résistances tenaces s'opposent à la mise en place des orientations conciliaires.

La situation actuelle des paroisses exige de faire advenir de plus en plus de ministères nouveaux (ex: l'accession des femmes à des ministères, la présidence des célébrations de baptême, de mariage, de funérailles par des baptisés mandatés par la communauté, etc.). Toutefois la version officielle de l'Église concernant cette problématique ne nous aide guère à la créativité mais plutôt à demeurer dans le statut quo. Pourtant, les études sur les réseaux d'incarnation du christianisme au chapitre dixième nous ont éclairés suffisamment sur l'importance d'éviter une sorte de monolithisme du ministère et de favoriser plutôt l'éclosion de toutes les figures ministérielles nécessaires à la vie de l'Église. À chaque étape de leur développement, les premières communautés ont été confrontées à des besoins nouveaux. C'est en fonction de ces besoins qu'elles ont créé des structures et des ministères, tandis que d'autres ont disparu parce qu'ils ne correspondaient plus à la situation nouvelle (ex: Les Douze, les Sept, les ministres des communautés pauliniennes, etc.). Chaque 
communauté locale a résolu les principaux problèmes concrets concernant la vie des ministres en se montrant souple et inventive dans l'adaptation aux diverses situations. Les premiers chrétiens ont expérimenté que le dessein de Dieu était vaste autant que ses dons divers et multiples. De plus, les leaders des différentes communautés apostoliques ont eu cette vigilance constante de faire en sorte que les responsabilités de quelques-uns ne confisquent jamais la consistance du corps ecclésial où tous les disciples sont égaux en dignité et en droit. Nous devons nous laisser interpeller par leur créativité et la malléabilité de leurs structures communautaires. La manière de vivre et d'organiser les ministères constitue un enjeu majeur pour la vitalité des communautés paroissiales, l'accomplissement de la mission et l'avènement d'une Église vraiment servante du monde. Il est donc primordial d'avoir une vigilance sur le "hiérarchique" en poursuivant la valorisation du sacerdoce baptismal et la responsabilisation des différents conseils paroissiaux. Il faut continuer à promouvoir la participation la plus large possible des chrétiens à tous les niveaux hiérarchiques de l'Église. C'est un des seuls moyens pour combattre le "SCL" (syndrome clerc-laïc) et ainsi faire naître l'anticorps "CM" (communauté-ministères). Toutefois, les autorités ecclésiales devront être vigilantes pour éviter de trop "bureaucratiser" les nouveaux ministères. L'Église tombe parfois dans ce piège de la bureaucratisation à outrance. Finalement, les ministères nouveaux ne doivent pas être vus comme une simple suppléance au manque de prêtres mais comme une richesse suscitée par l'Esprit pour que l'Église réponde aux défis de la mission d'aujourd'hui.

\subsubsection{Une question capitale: celle du pouvoir en Église}

Le foisonnement ecclésiologique de Vatican II a produit des acquis. Il a permis un meilleur partage de la responsabilité pastorale, une atténuation de la dichotomie clercs/ laïcs, un partenariat hommes/femmes un peu plus équilibré, la 
montée de la participation dans les instances où se décide la vie des Églises. Cependant, Vatican II a posé les germes pour faire naître une Église plus communionnelle mais n'en a pas dégagé toutes les implications. Le Concile a cherché à convertir des mentalités mais a oublié de transformer les structures de l'Église. Un des principaux problèmes en paroisse est vraiment encore celui de la dynamique ecclésiale. Celle-ci fonctionne sans même être influencée par la densité de la vie des gens et de leurs besoins. Cette dynamique institutionnelle de l'Église est à sens unique. Elle engendre toujours aujourd'hui des sujets (les clercs) et des objets (les laïcs, les clercs situés aux échelons inférieurs de la hiérarchie et quelques-uns à l'échelon supérieur). Le type de relations ecclésiales fait des ministres ordonnés le seul sujet véritable de l'Église. De plus, le Nouveau Code remet dans les mains du clergé tout le pouvoir. Les laïcs sont inévitablement condamnés à la condition d'objet. Le seul droit ecclésial du laïcat est un droit à la passivité. Le Code de 1983 est encore actuellement plus un frein qu'un accélérateur dans l'Église. La conception de la paroisse est tout axée sur le curé. Les "fidèles" n'ont pas de poids juridique. Il existe toujours une distorsion entre les promesses conciliaires et les décrets d'application. La défaillance du droit perçue après le Concile demeure avec ce Nouveau Code. La paroisse demeure une "cellule" de l'Église locale atteinte comme tout l'organisme ecclésial du "SCL". Je le répète de nouveau, les questions aujourd'hui capitales dans l'Église sont des questions de pouvoirs, de droit et non uniquement de théologie. Des procédures de pouvoir se sont cristallisées dans l'Église romaine. ${ }^{33}$ Aussi longtemps que l'autocritique de cette

33

Nous en avons de beaux exemples dans l'Église lorsque nous "assistons" à la nomination d'un nouvel évêque. En écrivant ces lignes, il remonte en moi la situation ecclésiale que nous avons récemment vécu dans l'Église du Québec. En décembre 1993, les autorités vaticanes ont nommé M. Raymond Dumais comme évêque du diocèse de Gaspésie. Mais lorsqu'en janvier 1994, elles ont appris que ce prêtre avait signé la lettre des 60 théologiens interpellant les évêques du Canada sur le contenu de l'encyclique Veritatis Splendor, Rome a retardé la nomination officielle de ce prêtre comme évêque. Il a été convoqué rapidement au Vatican. Il a dû s'expliquer. Selon de "bonnes" sources, le responsable de la nomination des évêques à la curie romaine lui aurait suggéré de remettre sa démission. Le système institutionnel de l'Église catholique peut difficilement admettre un candidat 
cristallisation ne sera pas menée, aucun espoir de réel renouvellement communautaire, aucune liberté dans l'Église ne seront sérieux. Un droit a donné visage à l'Église, un droit devra modifier ce visage. De ce point de vue, la théologie risque souvent de n'être qu'idéologie. Derrière les obstacles actuels dans l'Église sont en jeu des manières de concevoir la liberté, la pluralité, l'unité, la vérité ainsi que tous les autres concepts doctrinaux et finalement le visage qu'a pris l'Église romaine. Mais il est également naïf d'envisager une redistribution du pouvoir dans le catholicisme sans une sorte de révolution mentale et surtout spirituelle.

\begin{abstract}
"Un des changements auquel invite le concile, c'est de dépasser une conception d'Église axée sur la dimension organisationnelle et juridique afin de mieux développer la dimension spirituelle essentielle à l'existence de l'Église. L'Église-communion n'est possible que dans le dynamisme de la communion au Dieu Vivant annoncé par JésusChrist et expérimenté dans l'Esprit. L'"aggiornamento" souhaité par Jean XXIII ne sera possible que dans ce ressourcement en profondeur de la vie des Églises. Voilà pourquoi, il importe de recentrer la vie de nos communautés sur la Bonne Nouvelle du Christ et de mettre en oeuvre le plus adéquatement possible les grandes fonctions pastorales qui rendent possible l'expérience de l'Évangile du Christ." 34
\end{abstract}

Dans les années 1970, il est apparu que dans l'Église post-conciliaire des choix décisifs devaient être faits au niveau des moyens et relais à mettre en oeuvre: ou bien s'orienter vers la mise en place d'un réseau de communautés et de ministères "pauliniens", dans le sens d'une diversification des ministères, repenser le ministère du prêtre dans le contexte paroissial, donner une place institutionnelle aux femmes ou bien accorder la priorité au maintien et à la sécurité de l'appareil, de la hiérarchie catholique traditionnelle. L'autorité "suprême" a finalement privilégié l'appareil clérical. La stratégie adoptée par Jean-Paul II renforçant l'image traditionnelle du prêtre, refusant l'ordination d'hommes mariés et de femmes, manifeste, vingt ans après, ses conséquences. Dès maintenant et à terme plus ou moins lointain, elle ruine la vie des

à l'épiscopat qui n'accepte pas en entier toutes ses doctrines. La docilité à la curie romaine est plus importante que la fidélité évangélique....

L'Église de Dieu qui est à Chicoutimi...., p. 10. 
paroisses. Que faudrait-il faire pour s'en sortir? Organiser un synode diocésain dans les Églises locales sur les sujets les plus controversés en Église et promouvoir la remontée des débats jusqu'à la curie romaine, convoquer un nouveau concile Vatican III et encourager un travail commun entre dogmaticiens et canonistes pour la rédaction d'un nouveau Code fidèle aux décisions conciliaires? Je le répète, il faut penser à toutes ces solutions et favoriser le plus possible des lieux de pratiques synodales dans les milieux ecclésiaux. Le dynamisme de l'Église catholique et surtout un service qualifié de l'avènement du Royaume de Dieu en dépendent.

\subsubsection{Suggestions concrètes}

Trois suggestions pratiques concernant les ressources pastorales permanentes dans l'Église terminent le présent chapitre.

\subsubsection{La gestion des ressources humaines au niveau diocésain}

La gestion des différents agents pastoraux (prêtres, religieux, diacres permanents, laïcs) devraient se faire uniquement au niveau diocésain et non plus dans certaines circonstances au niveau paroissial ou sectoriel. L'affectation des différents ministres pastoraux, la définition des tâches, le nombre de postes par communauté et la formation des permanents devraient être supervisés par un bureau de personnel pour l'ensemble du diocèse de Chicoutimi. Cette suggestion n'est pas nouvelle mais vu l'importance des enjeux reliés à la gestion des ressources humaines, je suggère que les autorités diocésaines mettent sur pied le plus rapidement possible ce bureau du personnel. Quelques marguilliers ou quelques membres de Conseil d'administration de différentes corporations ecclésiales ont parfois déjà pris dans ce domaine des décisions qui ont eu des conséquences malheureuses dans quelques communautés et 
chez certaines intervenants pastoraux. Seule une organisation des ministères au niveau de l'Église locale peut assurer une répartition équitable des ressources humaines, une formation adéquate, des conditions de travail et de salaire justes et une permanence d'emploi. Ce bureau du personnel aurait la charge de veiller à l'ensemble des conditions de travail touchant les diverses catégories d'agents de pastorale. Il serait responsable des questions relatives à la sélection du personnel, à la rémunération et à la mutation des agents de pastorale. Il interviendrait ainsi au moment des nominations et des affectations. Il assumerait la responsabilité propre de la gérance de l'ensemble du personnel pastoral en fonction des besoins et de l'avenir des communautés.

\subsubsection{Conditions de salaire et de travail pour les différents ministres}

Nous devrions tendre vers une échelle salariale unique pour tous les agents pastoraux du diocèse (qu'il soit évêque, prêtre, religieux, diacre permanent ou laiic). Cette échelle tiendrait compte du nombre d'années de scolarité et d'expérience de l'intervenant pastoral. Cela permettrait à chacun des permanents ecclésiaux de choisir librement son milieu de vie. Cela éviterait également de laisser croire aux différentes communautés qu'il coûte moins cher d'engager un prêtre qu'un autre agent pastoral. Il y aurait là enfin une mesure bien concrète pour éviter d'entretenir la division clerc-laïc qui paralyse le projet pastoral et qui crée deux solitudes au lieu d'un véritable partenariat. Seule elle ne peut réaliser un vrai partenariat mais elle constitue un élément non négligeable. 


\subsubsection{Un Conseil des ministres}

En fidélité aux intuitions conciliaires et en continuité avec les pas que le diocèse de Chicoutimi a franchis pour accéder à une coresponsabilité plus réelle entre les différents agents pastoraux, nous serions peut-être prêts à mettre sur pied un Conseil des ministres où les représentants seraient choisis à travers les différents agents pastoraux (prêtres, religieux, diacres permanents, laïcs). Avec un peu de créativité, il serait facile de concilier cela avec le droit. Nous pourrions avec les délégués prêtres faire le Conseil presbytéral. Cependant, ce conseil ne fonctionnerait pas à côté mais à l'intérieur du Conseil des ministres. Une des responsabilités des membres serait de réfléchir rapidement sur des priorités pastorales au niveau de l'Église locale. Assistons-nous trop souvent dans les paroisses, dans les zones (régions) pastorales et au niveau diocésain à un apostolat au jour le jour, se contentant de répondre le mieux possible aux problèmes posés mais sans une réelle vision d'ensemble?

En proposant de telles suggestions pour des réalisations concrètes, je suis conscient de bousculer bien des intervenants pastoraux. Ceux-ci de même que les communautés ne sont pas tous rendus au même point dans la réflexion. C'est pourquoi il faut accepter les lenteurs, les cheminements différents et même parfois les échecs. Mais il me semble qu'en travaillant vers ces incontournables horizons, nous serions davantage en mesure d'accueillir et de mettre à profit les divers dons et services suscités par l'Esprit pour son Église. L'Église de Dieu à Chicoutimi pourrait alors retrouver un nouveau souffle salutaire non seulement pour les communautés mais aussi pour l'ensemble des agents pastoraux. 


\section{CHAPITRE 15}

\section{LES AVENUES PRATIQUES}

Les lignes qui suivent se proposent d'ouvrir un chemin d'espérance pour le renouvellement de la pastorale paroissiale en milieu urbain. Un chemin que d'autres ont essayé de tracer depuis Vatican II. ${ }^{1}$ J'analyse dans ce chapitre les forces et les limites de certains scénarios possibles de réaménagements pastoraux en tenant compte des "pointes lumineuses" dégagées de l'observation participante de quatre paroisses du diocèse de Chicoutimi [Saint-Dominique de Jonquière, Saint-Jean-l'Évangéliste de Bégin, Saint-Jude d'Alma, Saint-Léon] [paroissiens, bénévoles, permanents] (chap. deux à cinq), de la problématisation des défis observés ( chap. six), de la tradition historique paroissiale (chap. sept), des conséquences du phénomène de l'urbanisation (chap. huit), de la culture moderne (chap. neuf), de la fidélité aux réseaux d'incarnation du christianisme (chap. dix), des changements ecclésiologiques du dernier Concile (chap. onze), de la conception conciliaire de la paroisse et du renouveau canonique (chap. douze) et finalement de la paroisse, comme lieu de passage pour le "toutvenant" (chap. treize). C'est un défi exigeant puisqu'il faut tenir compte en même temps de l'"épaisseur" historique concrète des institutions, des itinéraires personnels et

1

Nous n'avons qu'à penser au projet NIP (Nouvelle Image de la Paroisse) qui a amorcé une pédagogie de changement plus articulée à ce niveau. Mais on peut se demander si l'importance très grande accordée encore au territoire, de même que le souci de rejoindre tout le monde, ne déboucheront pas sur une nouvelle forme d'encadrement social 'religieux' plutôt que sur le renouvellement d'un tissu communautaire. Ce questionnement a surgi lorsque j'ai participe à trois journées de réflexion sur la vision NIP données à la paroisse Sacré-Coeur de Montréal du 27 au 30 avril 1993. Cette paroisse vit ce projet depuis quelques années. Voir CAPPELLARO, J.B., La paroisse communion de communautés, Trad. de l'espagnol par Pierre Lefebvre, Québec, SMM, 1986, 96 p. [Service pour un Monde Meilleur] ; CAPPELLARO, J.B., LIUT, J., CANESSO, L., COSSU, F., McNABB, J., De la masse au Peuple de Dieu, projet pastoral, traduction établie à partir de l'edition italienne: "Da massa a populo di dio", 203p. 
communautaires, de la lourdeur des mentalités, des paniques, des peurs du changement, etc. Je prends pourtant le risque, à l'aide de quelques propositions commentées, de définir ce que pourraient être les grands axes d'une politique renouvelée de la paroisse en milieu urbain.

\subsection{Une priorité: une structure ecclésiale épousant le milieu humain du paroissien}

La structure ecclésiale ne doit pas être une réalité immuable: pour répondre à ses objectifs, elle doit s'adapter dans le temps et dans l'espace à la structure sociale qui est première, perpétuellement mouvante et qui de ce chef, doit commander les formes d'implantation et d'activité de l'Église et leur constante évolution. La structure sociale a fortement évolué ces dernières années par suite du développement prodigieux des techniques engendrant par réactions en chaîne l'industrialisation, l'urbanisation, la sécularisation, la mécanisation des moyens de production et d'exploitation, la mobilité par la multiplication des moyens de transport, le déplacement des populations, le pluralisme, etc. Si cette évolution s'accomplit, du moins dans les pays occidentaux, selon certaines constantes dans la mesure où les données historiques, géographiques et sociales sont à peu près semblables, il est cependant nécessaire de souligner qu'elle présente des aspects différents de pays en pays, de région à région selon le stade auquel elle est arrivée ici ou là. Il ne m'est évidemment pas possible de traiter du renouvellement de la structure paroissiale en contexte urbain en tenant compte de toutes les distinctions qu'il faudrait y apporter en fonction de chaque situation nationale et régionale. Je traiterai le sujet à partir de la région qui est la 
mienne: la région du Saguenay-Lac-St-Jean et je demanderai au lecteur de faire les adaptations qui s'imposent pour sa propre région. ${ }^{2}$

L'ensemble de la recherche-action m'a plus que jamais convaincu de limportance de structurer la pastorale paroissiale en tenant compte du milieu humain naturel du paroissien. Les paroissiens d'aujourd'hui ont été influencés par le processus de la modernité. Être moderne, c'est vivre dans un monde qui n'est plus celui d'hier et qu'il faut aborder avec d'autres méthodes. Les valeurs de la modernité ont façonné les paroissiens qui sont devenus autres. Le paroissien d'aujourd'hui vit dans une société post-industrielle où la plupart de ses activités définissent sa vie en des appartenances multiples. Le paroissien ne s'identifie pas seulement à sa paroisse. Il possède plusieurs réseaux d'appartenance. La taux de mobilité des paroissiens est très élevé dans le milieu urbain. Cette mobilité n'est pas que spatiale; plus profondément, elle est d'ordre culturel. Ce n'est pas seulement l'être humain physique qui se déplace, mais bien les enjeux humains fondamentaux. Le paroissien désire avoir la gérance de sa liberté, y compris une liberté face au territoire. L'homme "moderne" refuse toute institution qui désirerait contrôler l'ensemble de sa vie. On l'a maintes fois dit: l'avènement de la modernité coïncide avec l'avènement de l'individu. Alors que dans une société traditionnelle l'individu se comprend et est compris par rapport à sa place dans l'ensemble social, dans une société marquée par la modernité (selon un processus

2

Même s'il arrive souvent de généraliser au sujet de nos villes, il ne faudrait cependant pas oublier que celles-ci ne sont pas toutes de même type. Elles ne sont pas toutes également urbaines. Comme nous l'avons vu au chapitre huitième, être "urbaine", pour une agglomération ou pour la population qui l'habite, n'est pas seulement une question de volume ou de densité de population. C'est aussi une question d'hétérogénéité et de complexité sociales. C'est encore davantage une question de mentalité. Nos villes diffèrent les unes des autres selon leur degré de proximité psychologique comme aussi selon la région ou le type d'industrie qui les ont fait naître. La ville de Chicoutimi est différente de celle de Québec et il en va de même pour la métropole de Montréal. Il ne faut donc jamais oublier cette grande diversité de situations existant entre les villes et qui résulte à la fois de leur évolution historique, de leur développement géographique, économique et démographique, de leur situation religieuse, etc. 
d'ailleurs jamais achevé), l'individu est renvoyé à lui-même, élevé au rang de référence première et dernière. On est passé ainsi d'une appartenance totalisante à une appartenance sociale dans laquelle l'individu est invité à faire des choix. La recherche de liberté, chez l'urbain, se traduit par le choix de ses relations, de ses groupes d'appartenance, de sa messe dominicale, de la paroisse et même de tel prêtre plutôt que tel autre. Acceptons-nous véritablement le paroissien actuel tel qu'il est? 3

Le phénomène de l'urbanisation a profondément marqué les assises de la vie paroissiale, particulièrement dans les villes. Les étroites frontières des paroisses ne sont plus que de simples limites administratives sans signification sociale. La ville a fait également éclater le voisinage comme lieu privilégié de socialisation. L'univers urbain a dissocié les deux pôles "résidence" et "travail" mais la pastorale paroissiale n'a pas tellement assumé cette mutation. L'industrialisation de l'ère technique a généré l'urbanisation comme type de civilisation même dans la plupart des milieux ruraux. ${ }^{4}$

3

Nous l'avons vu au chapitre neuvième, derrière le débat de l'acception du paroissien en lui-même, il y a un enjeu fondamental: celui du rapport Église-monde. Vatican II a marqué un changement d'esprit dans le rapport de l'Église au monde moderne. Dans la Constitution sur l'Église dans le monde de ce temps, l'institution ecclésiale est invitée à se tourner vers la société. Loin de se complaire à désigner les malheurs du temps, le Concile a reconnu que l'Église reçoit beaucoup du monde ( $L G 44,1-3$ ). Là est l'originalité du Concile: il a rompu avec les conceptions d'un catholicisme assiégé et il a ouvert la voie à une relation sans peur ni timidité avec le monde moderne. Le fait est cependant que près de trente ans après le Concile, l'Église connaît plutôt une période où dominent les interrogations et les doutes sur les "ouvertures" récentes. Tout se passe comme si, se manifestait assez largement, ou plus particulièrement chez certains responsables un souci de serrer les freins. La liberté et l'autonomie des personnes (des paroissiens) font toujours peur à l'Église officielle. La modernité dans le Magistère de Jean-Paul II est jugée selon un schéma plutôt rigide qui ne la reconnaît uniquement lorsqu'elle peut s'adapter et permettre l'affirmation de la nouvelle chrétienté. Le mariage devient de plus en plus difficile entre le catholicisme et la modernité sous son pontificat. Nous avons alors plus de difficulté à accepter le paroissien en lui-même avec toutes les valeurs de la modernité qu'il porte dans son être. Il est des façons d'insister non sans complaisance sur les maux de nos sociétés modernes qui relèvent plus du pharisaïsme de la mauvaise conscience que d'une attitude d'espérance. La méfiance et la peur devant les valeurs de la modernité ont comme conséquence immédiate en contexte démocratique de dévaloriser le message chrétien. Il faut plus que tout pour l'Église institutionnelle une sympathie pour le paroissien d'aujourd'hui tel qu'il est, dans ses affaissements comme dans ses grandeurs, abordé avec le regard tendre de Dieu.

$4 \quad$ Plusieurs paroissiens "ruraux" s'identifient encore à leur paroisse territoriale puisque dans cette réalité la paroisse coïncide généralement avec la communauté sociologique. Cependant, 
La paroisse urbaine est restée "à l'heure de la campagne." Pendant plusieurs années, on s'est efforcé de contenir l'évolution et de résoudre les problèmes pastoraux selon les cadres anciens. On a essayé de sauver la paroisse territoriale née de la société rurale pour n'avoir pas à repenser la pastorale urbaine sur de nouvelles bases car tout à coup on s'est aperçu que la paroisse créée pour donner les soins spirituels à 500-1000 personnes, contenait jusqu'à 9000,11000 ou 50000 baptisés et plus encore dans certains pays (ex: en Amérique Latine). On a multiplié les paroisses. On a essayé de les rajeunir. Depuis quelques années, on peut dire qu'une grande partie des efforts de la pastorale urbaine a été consacrée à tenter de sauver la paroisse pour n'avoir pas à remettre en question les concepts fondamentaux. On a mis sur pied toute une série d'institutions paroissiales de telle sorte que la paroisse s'est vue transformée en un centre social, une société en réduction enkystée dans la société moderne. On peut donc dire que le monde urbain s'est développé à une allure très rapide et que la société qu'il engendre se retrouve en état de changement social continuel alors que l'Égliseinstitution a évolué à un rythme beaucoup plus lent.

dire que la paroisse rurale du Québec s'identifie territorialement à une municipalité administrative n'est plus vrai dans plusieurs situations et nous conduit à devoir tenir compte des multiples réalités culturelles et socio-économiques des milieux. Le paroissien "rural" ne s'est pas moins urbanisé culturellement que les résidents de la ville. Au Canada français, on a cru pendant longtemps que la crise de la paroisse ne concernait que le milieu urbain. Mais l'attention ainsi accordée à la paroisse urbaine a certainement trop fait perdre de vue que le milieu rural, lui aussi, a beaucoup évolué. Le milieu rural connaît depuis quelques années des changements très profonds, on pourrait parler de révolution socio-économique, dans sa structure et dans sa mentalité. Par exemple, depuis plusieurs années, le centre de la vie quotidienne des ruraux n'est plus le village mais la petite ville avoisinante et parfois même la grande ville plus éloignée. Le milieu rural ne présente plus le caractère de cohérence et d'homogénéité qui, autrefois, le marquait. Comme le milieu urbain, le milieu rural est maintenant devenu pluraliste. Aujourd'hui déjà, et demain davantage, l'unité sociale significative n'est plus le village mais bien la région. À l'analyse, le visage de l'actuel monde rural nous apparaît radicalement nouveau. La cohérence sociale d'autrefois est maintenant et à jamais révolue, il en faudra une nouvelle qui tiendra compte des modifications subies par le milieu rural. Il en va de même pour la pastorale. Face à une situation nouvelle, il faut préparer des réponses pastorales, nouvelles elles aussi. Nous constatons donc que le manichéisme inhérent à l'antithèse ville-campagne tend depuis quelques années à perdre de sa virulence devant le phénomène de l'urbanisation omniprésente. 
Les Églises locales du Québec ont fait des efforts pour naviguer à travers les grands changements sociaux créés par les phénomènes de l'industrialisation et de l'urbanisation et pour réviser leurs organisations institutionnelles. Ce mouvement d'ouverture s'est accompli de deux manières: par le haut et par le bas. Les diocèses eux-mêmes ont établi de nouvelles structures en instaurant des services diocésains. Ils ont cherché à animer et à stimuler les paroisses dans leur rôle propre en leur fournissant l'instrumentation pratique. Durant toutes ces périodes, un travail a été réalisé au ras du sol. Groupées en secteurs, en zones ou en régions pastorales, les paroisses ont appris un peu plus à se connaître, à dialoguer, à échanger, à collaborer. Mais la conception de l'organisation pastorale au Québec (et ailleurs dans le monde) n'a pas été capable d'intégrer tout ce qui ne venait pas de l'organisation territoriale locale. Même les efforts de pastorale d'ensemble des dernières années dans les diocèses ont été souvent axés essentiellement sur une coordination des unités géographiques polyvalentes que sont la paroisse, le secteur, la zone (région) pastorale. La conception de l'agglomération urbaine en tant qu'unité de base devant orienter toute la vision et l'organisation de la pastorale est une attitude qui n'a pas encore atteint réellement les autorités ecclésiales. L'action pastorale en ville exige une attitude ouverte au phénomène urbain. Plusieurs intervenants pastoraux éprouvent de la difficulté à accueillir le paroissien "urbain" puisqu'ils considèrent négativement l'ensemble des valeurs de la vie urbaine.

L'urbanisation est une manière de vivre, une manière de se situer, une manière de considérer les choses, une manière de comprendre et d'interpréter mentalement le monde devant de nouveaux types d'humains. Urbanism as a way of life. Lieu de marché et de commerce, lieu de circulation et de concentration intense des choses et des humains, lieu d'échanges rapides des idées et de l'information, lieu de spectacles et de fêtes, lieu de proximité et de distance, la ville donne au temps et à 
l'espace une autre dimension. Les gens y développent une autre façon de vivre. Globalement, le paroissien urbain s'identifie davantage comme citoyen d'une ville ou de tel quartier dans les grandes métropoles que comme résident sur le territoire de telle paroisse. Son milieu humain naturel est la ville. Il se sent plus concerné par les enjeux humains de "sa" ville que de sa paroisse territoriale. La plupart de ces activités se déroulent sur des théâtres géographiques divers dont le dénominateur commun spatial est la ville. Ce n'est pas en restant chez lui mais en se déplaçant vers les divers centres de la vie citadine que le paroissien urbain peut s'intégrer socialement.

Il faut obligatoirement détruire le schéma simpliste d'une appartenance à l'Église qui se voudrait totalisante par le territoire paroissial actuel en milieu urbain. Nous avons besoin d'une structure pastorale répondant aux divers besoins des paroissiens dans une ville. Le véritable 'esprit paroissial' n'est plus l'appartenance à un territoire déterminé mais l'appartenance au milieu humain global du paroissien qu'est l'ensemble de la ville. 5 Mon souhait est donc que nous brisions cette indépendance des paroisses urbaines actuelles pour retrouver une structure pastorale de base pour l'ensemble de la ville. L'Église doit s'adapter à la ville dans ses structures et dans ses services. Par conséquent, il faut que les structures ecclésiales s'assouplissent et n'imposent plus une série d'actes sur la simple base d'une localisation territoriale. Il ne sert à rien de vouloir maintenir ou refaire l'ancienne "communauté paroissiale". L'histoire et la sociologie encouragent cette restauration de la paroisse orientée vers la ville comme phénomène total. Comme nous l'avons vu au chapitre septième, on retrouve là une pratique séculaire de l'Église ancienne, dans la ligne de la catholicité de

5

Je le répète, c'est vrai pour le genre de ville comme celui de la région du SaguenayLac-Saint-Jean où nous retrouvons des populations urbaines se situant entre 15,000 et 65,000 habitants. La problématique est différente pous les grandes villes de 100,000 et plus et pour les métropoles. Dans ces cas-ci, ce n'est pas seulement la paroisse qu'il faut remettre en question mais même la taille des diocèses. 
la paroisse originelle au service d'un christianisme qui fut au départ un phénomène urbain. 6

\subsection{Différentes structures pastorales possibles}

Une nouvelle structure pastorale pour les paroisses urbaines doit être créée.

\section{Les autorités diocésaines de Chicoutimi sont préoccupées par ce questionnement} depuis quelques années.

"Le choc de la culture moderne, en particulier le phénomène urbain, pose des défis de réorganisation de l'Église, dans sa présence à la société actuelle avec sa mouvance et son éclatement. Notre Église, et ce particulièrement en milieu urbain, doit suggérer certaines pistes de réaménagement de la structure pastorale dans une ecclésiologie de communion. Déjà dans les agglomérations urbaines, les prêtres et les agents pastoraux ont pointé ce chantier de réflexion. Il y a déjà plus de 25 ans que le diocèse a cherché à réorganiser la pastorale dans une ligne d'une pastorale d'ensemble: création des zones pastorales, renouveau de la curie diocésaine, création des services diocésains, création des grands conseils, etc. Ces organisations ont rendu d'énormes services mais il reste du chemin à parcourir."7

Que devrait être cette structure pastorale paroissiale ayant comme unité de base l'ensemble d'une ville? Quel aménagement serait le plus aidant pour que le paroissien urbain se définisse comme un citoyen d'une ville ayant la responsabilité chrétienne d'accueillir et de faire émerger le Royaume de Dieu dans son milieu et, de ce fait

6

Ce qui définit aujourd'hui les structures du peuple chrétien dans les limites des paroisses ou des diocèses, ce sont des décisions administratives. C'est l'attribution d'un prêtre à tel territoire qui définit la paroisse. Autrefois, c'était l'existence d'un peuple constitué en unité sociale par les liens de la ville ou d'une autre agglomération qui appelait la formation d'une paroisse et l'élection d'un clergé pour cette paroisse. L'image idéale de l'Église locale ou de la paroisse que nous laisse l'antiquité chrétienne est celle de la communauté des chrétiens qui se savent responsables d'une ville et exercent leur mission sous la direction d'un corps de ministres présidés par un évêque ou en dépendance du corps épiscopal d'une manière adaptée aux circonstances. Quant au diocèse, il n'est qu'une création administrative réunissant un certain nombre d'Églises locales pour les maintenir en contact avec le collège épiscopal et avec la communion universelle des Églises. La juridiction ne dépend pas de faits administratifs mais avant tout de faits humains.

$7 \quad$ Église de Dieu qui est à Chicoutimi, une Église en marche...dans la foulée conciliaire, Évêché de Chicoutimi, document de travail du Conseil Presbytéral, 14 septembre 1993, p.15. 
contribuer à rendre sa ville plus humaine? Des possibilités s'offrent à nous. Actuellement, l'Église diocésaine de Chicoutimi et plusieurs autres Églises locales ont choisi comme structure pastorale la fédération de paroisses dans une zone pastorale regroupant les paroisses urbaines et rurales d'une région administrative. Deux autres scénarios peuvent être envisagés pour réaménager la structure pastorale paroissiale en milieu urbain. La concentration des caractéristiques de la ville nous conduit ou bien à supprimer les paroisses territoriales telles que nous les connaissons pour faire place à une "super-paroisse" dans une ville ou dans un quartier d'une métropole (la ville deviendrait une seule paroisse avec plusieurs secteurs pastoraux et diverses communautés chrétiennes) ou bien à donner une importance accrue aux zones (régions) pastorales avec les pouvoirs juridiques nécessaires à leur fonctionnement. 8 J'analyse dans les prochaines lignes les forces et les limites de ces trois manières différentes d'aménager une structure ecclésiale dans le milieu urbain.

\subsubsection{La ville, une fédération de paroisses}

La plupart des diocèses ont choisi comme modèle structurel dans le milieu urbain la fédération de paroisses. Ce modèle est intéressant mais il a une certaine fructuosité à la condition que la paroisse s'ouvre à son "au-delà" et à son "en deça".

8

Que l'on choisisse l'un ou l'autre des aménagements pastoraux suggérés, il ne faudra jamais oublier de consulter les paroissiens. Les vrais permanents dans les paroisses sont les paroissiens. Il est donc nécessaire que ceux-ci soient informés et participent à la venue de nouvelles formes d'aménagements pastoraux. Si les paroissiens ne sont pas partie prenante à la recherche de solutions, ils auront le sentiment d'être étrangers à la décision et seront peu enclins à collaborer à sa mise sur pied. Mais rien sans doute n'est aussi essentiel que dialoguer avec les différents partenaires de ce renouveau pastoral, de discerner avec eux sur le terrain des besoins de la mission, de soutenir les paroissiens les plus engagés et de prévoir auprès du plus grand nombre des efforts de sensibilisation et d'information. Les informer en mots simples et non pas en sortant toutes les expressions de notre "quincaillerie ecclésiastique". 
"La paroisse est trop petite pour répondre adéquatement à tous les besoins de l'évangélisation, pour le faire avec compétence en tous points et pour rejoindre le plus grand nombre. N'y a-t-il pas dans les cercles ecclésiastiques une surestimation de la paroisse, comme si elle devait tout faire? Mais la paroisse est aussi trop grande pour nouer le tissu d'une réelle communauté chrétienne. Elle doit s'ouvrir à la fois à son "audelà" et à son "en-deçà". La paroisse doit s'ouvrir, au-delà, sur l'Église de la ville ou de la région rurale, parce que la ville ou la région sont la réalité psycho-sociale élargie actuelle où se passe la vie de travail, de loisirs, de commerce, de culture, de relations humaines, avec ses services spécialisés /.../ La paroisse doit encore cultiver son en deça. Sur son territoire même, elle doit créer et nourrir des groupes-relais, sinon de petites communautés de base, pour que les paroissiens puissent y trouver un espace humain de mise en commun, de recherche, d'expérimentation de l'expérience chrétienne et communautaire." 9

Avec l'augmentation de la population dans les villes, quelques pasteurs proposent la création de nouvelles paroisses. Dans une lettre pastorale adressée le 7 janvier 1991 aux prêtres et aux fidèles de son archidiocèse, Mgr Rembert WEAKLAND, archevêque de Milwaukee aux États-Unis va dans ce sens.

\begin{abstract}
"Nous avons trouvé, cependant, que lorsqu'une paroisse dépasse le nombre de 2500 familles environ, elle devient trop grande et doit être partagée pour fonder une nouvelle paroisse. Bien que, ainsi que nous l'avons dit, nous n'ayons pas chiffré le minimum requis pour une paroisse, le nombre de 400 familles apparaît idéal pour commencer une nouvelle paroisse. Même s'il y aura toujours des exceptions, nous voulons continuer de créer de telles paroisses dès que le besoin s'en fait sentir. Il ne serait pas sage, en cette période de notre histoire d'essayer de réunir plusieurs paroisses existantes en des mégaparoisses. La tendance, en réalité, doit aller dans l'autre direction de façon à préserver une atmosphère familiale." 10
\end{abstract}

Je suis très réticent à la création de nouvelles petites paroisses en contexte urbain. Cette vision pastorale qui valorise la base de l'unité de voisinage ne s'adresse qu'à une minorité de personnes très marginale du milieu urbain. Il y a dans cette vision une survivance du ruralisme. De plus, une simple division des paroisses en unités plus petites, allant même jusqu'à retrouver des unités de quartier, ne résout pas le problème

CHARRON, André, "La paroisse évangélisatrice d'aujourd'hui", in Prêtre et pasteur, novembre 1991, p. 617.

10 WEAKLAND, R., Mgr, "La création de nouvelles paroisses et le manque de prêtres", in La Documentation Catholique, no 2026, 21 avril 1991, p.396. 
fondamental de la pastorale urbaine. Comme on l'a vu, ce problème exige de poser la question dans un cadre beaucoup plus large et de réfléchir à la fois dans un régistre sociologique sur ce qu'est une société urbaine et dans un régistre théologique sur la relation entre le mystère de l'Église, le peuple de Dieu et l'institution paroissiale en milieu urbain. Également, nous ne pouvons plus concevoir sociologiquement la paroisse comme une grande famille. Plusieurs intervenants pastoraux essaient de sauver quelque chose du naufrage: ils se raccrochent au public qui va s'amenuisant de plus en plus. Les paroisses peuvent se multiplier, elles n'en perdront pas moins leur public. On aura beau accuser le manque d'esprit paroissial ou d'esprit communautaire, rien n'y fera. Car ce n'est pas mauvaise volonté de la part des paroissiens. C'est le style de vie urbain qu'on accuse de détruire l'Église. Quelle inconscience! C'est l'Église qui tarde à s'adapter aux nouvelles réalités de la société urbaine.

La structure de la ville comme fédération de paroisses présente de sérieuses limites. L'une d'elles est la difficulté de créer dans cet aménagement une réelle solidarité entre l'ensemble des agents pastoraux lorsque ceux-ci sont nommés pour une paroisse bien précise en milieu urbain. Aucun pouvoir juridique ne leur demande de se soucier du devenir humain et social de l'ensemble de la ville. C'est pour cette raison que plusieurs d'entre eux s'isolent dans leur paroisse territoriale et viennent rarement aux rencontres de secteur ou de zone pastorale regroupant l'ensemble des agents pastoraux d'une région administrative. Une telle collaboration organique avec d'autres dépend de l'ouverture d'esprit et de la bonne volonté de chaque permanent ecclésial. De plus, l'état actuel de la législation provoque des difficultés concrètes bien connues. Les autorités ecclésiales du diocèse de Chicoutimi commencent à nommer des prêtres "in solidum" pour quelques paroisses en milieu urbain. Ils doivent "jongler" à chaque fois avec le code de droit canonique puisque, dans certaines de ces paroisses, il y a des équipes pastorales et dans d'autres, il n'y en a pas. Un ministre 
ordonné est nommé curé de telle paroisse, modérateur de l'équipe pastorale de l'autre paroisse, etc.... etc.... Un vrai casse-tête qui ne satisfait ni les paroissiens, ni les prêtres eux-mêmes, ni les autres ministres mandatés et institués. Également, cet aménagement pastoral ne permet pas de "dénouer" le verrou juridique actuel concernant les paroisses. Ce scénario exige la nomination d'un prêtre pour chaque paroisse. Cette manière de faire occasionne déjà de nombreux problèmes à court terme et surtout à long terme. Nous n'avons qu'à penser au nombre restreint de prêtres disponibles pour les cinq ou dix prochaines années si l'Église institutionnelle ne révise pas les critères d'accession au ministère presbytéral. Les ressources presbytérales seront insuffisantes pour combler concrètement les besoins. ${ }^{11}$ De plus, les ressources financières des paroisses ne sont pas intarissables. Pendant combien de temps chaque paroisse pourra-t-elle soutenir un personnel aussi nombreux que celui exigé par un tel quadrillage et des équipements matériels d'une lourdeur excessive?

\subsubsection{La paroisse-ville, une fédération de communautés}

Je propose la solution de la "super-paroisse" en sachant par ailleurs les nombreuses résistances du milieu pastoral et théologique concernant ce scénario. Il me semble que ce qui nous empêche d'imaginer comme possible la "super-paroisse" (ou la paroisse-ville), c'est que nous avons développé une accoutumance à un type d'organisation paroissiale de la même façon qu'un organisme développe une accoutumance à un médicament. Nous croyons ne plus pouvoir nous passer du système paroissial tel que nous le connaissons. La paroisse s'est acquise, au long des années, des titres qui la font passer pour l'élément stable et permanent dans la pastorale, au point d'en être intouchable et quelque peu "imperméable" aux remises en

11 Je rappelle mes pronostics pour l'an 2000 au diocèse de Chicoutimi. Je prévois qu'environ seulement 40 prêtres seront disponibles pour 95 paroisses. 
cause. Une tradition vivante doit toujours préserver pour demain ses chances de création. Autrement, sous les apparences de la continuité et de la fidélité, il n'y a au mieux, qu'une honorable sclérose.

Le modèle structurel de la paroisse-ville m'est venu à l'idée à la suite de l'expérience pastorale, des lectures théologiques et sociologiques et du partage de réflexions avec quelques confrères agents pastoraux du diocèse de Chicoutimi et d'ailleurs. Ce modèle n'est pas entièrement nouveau, déjà en Europe, certains diocèses sont passés d'une multitude de paroisses à des unités consistantes et charpentées ( ex: de 700 paroisses à 70 unités pastorales). Il y a une diversité de noms et de figures selon les contextes. Mais la réalité est là. Dans plusieurs diocèses européens, elle se vit: c'est l'unité pastorale qui sert de point d'appui à tout le dispositif paroissial. ${ }^{12}$ Ici au Québec, nous devons penser sérieusement à la possibilité de la paroisse-ville comme moyen de réaménager la pastorale en milieu urbain même si celle-ci exigerait des changements juridiques dans la loi des fabriques et également dans le code du droit ecclésiastique. De toute façon, je le répète encore une fois, qu'importe le scénario choisi, un jour ou l'autre, nous n'aurons plus le choix de dénouer en Église l'impasse juridique actuelle concernant les paroisses et les ministères.

La paroisse actuelle "tombe" dans la ville comme un événement mais elle se mêle très peu à la ville. D'autre part, la paroisse demeure isolée de la dynamique urbaine, la dimension la plus vivante dans la ville, la plus urbaine lui échappe. L'idée s'impose alors qu'il faut partir de la ville elle-même et que celle-ci doit être divisée selon les structures de la vie sociale, tandis qu'actuellement les paroisses sont des blocs erratiques difficiles à intégrer dans une pastorale d'ensemble. Il me semble meilleur de catholique, 23 décembre 1990, n²018, p. 1103. 
retourner à la plus ancienne tradition et d'appeler paroisse la communauté de la ville tout entière. Tous les chrétiens de la ville forment une seule paroisse et leur esprit paroissial, c'est leur appartenance à l'Église de leur ville.

"Le chrêtien naît dans une maternité et y est baptisé. Il fait sa première communion souvent où il reçoit sa formation catéchétique. Il est confirmé dans une Église principale; il exerce l'apostolat dans des mouvements indépendants du cadre paroissial traditionnel, dans des milieux qui ignorent cette paroisse et ainsi de suite. Il est inutile et absurde de vouloir lutter contre cette évolution. Le chrétien qui agit ainsi se trouve toujours dans sa paroisse. C'est l'Église de la ville, avec ses innombrables structures et services. Il les utilise suivant sa plus grande commodité. Il ne doit pas se sentir prisonnier d'une communauté fermée qui s'intitule paroissiale." 13

Cette nouvelle structure pastorale devrait toutefois respecter les territoires actuels des paroisses. Les années ont fait émerger des communautés qu'il faut absolument continuer à promouvoir. Je reconnais qu'il est très dangereux pour la foi de notre peuple de supprimer les territoires paroissiaux qui ont été le centre d'identification spirituelle et de référence au christianisme pour des générations de famille au Saguenay-Lac-St-Jean et qui ont joué un rôle vital pour faire grandir leurs membres dans leur union à Dieu. De toute façon, un quadrillage territorial sera toujours utile pour servir à définir certaines fonctions administratives. Toutefois, pour ces paroisses, nous pourrions songer à les appeler communautés ou fraternités chrétiennes ou "églises-relais" de la super-paroisse. Dans chacune d'elles, nous pourrions nommer une femme ou un homme responsable de l'animation. ${ }^{14}$ Cependant, pour les paroisses rurales entourant une région urbaine, il faudrait que celles-ci gardent leur indépendance responsables de communautés pour l'ensemble de la paroisse-ville. Cette manière de "gérer" les ressources presbytérales me semble plus sage et prometteuse. Nous dénouons alors le verrou juridique (1 prêtre - 1 paroisse ) qui nous ferme toutes les portes au renouveau . 
tout en s'articulant à la ville à laquelle elles se rattachent. ${ }^{15}$ L'unité sociale n'est plus le village isolé, mais le village intégré à la région. Sa survie comme unité locale dépend de son intégration. On ne peut donc plus considérer isolément les paroisses actuelles étant donné l'aspect régional de la vie rurale d'aujourd'hui. Si plusieurs villages gardent leur individualité propre, il faut néanmoins considérer qu'ils réagissent de plus en plus au sein des ensembles régionaux que sont le secteur, la zone, la région. Leur personnalité psychologique et religieuse ne s'affirme concrètement qu'au sein de ce contexte régional dans lequel l'insère tout le réseau de ses relations économiques, sociales, culturelles. Pastoralement, le paroissien rural doit être en communion avec la structure pastorale urbaine afin de pouvoir bénéficier de services que sa petite paroisse ne peut lui offrir, comme à d'autres niveaux de son expérience humaine. 16

15

Les enjeux du débat actuel sur les paroisses rurales pour l'avenir de l'Église sont trop importants pour être délaissés au niveau de la réflexion. Il me semble qu'il faut combattre l'idée bureaucratique de fusion des paroisses rurales qui prend pour fait accompli l'actuel refus de réenvisager le ministère des prêtres, qui préfere punir les paroissiens, enlever aux villages leur âme, négliger personnes âgées et enfants et surtout inverser l'ordre des responsabilités: "à vous de vous déplacer" semble-t-on dire aux "ruraux"; quand la tradition consiste à dire: "choisissons parmi vous des pasteurs". Il serait dommageable de perdre de vue ce que la paroisse exprime comme valeur symbolique, comme possibilité d'autonomie locale, de vie locale, de pouvoir local. Certes une paroisse sans aucune communauté ne serait plus une paroisse mais la paroisse est un soutien institutionnel à l'existence d'une communauté. Les autorités diocésaines de Chicoutimi ont été vigilantes sur ce point. L'évêque titulaire de cette Église locale rappelle constamment cette priorité pastorale de soutenir les petites paroisses rurales. "C'est ce qui nous a amenés, au Conseil presbytéral, à faire une réflexion sur l'avenir des petites communautés chrétiennes et à prendre l'option de favoriser leur survie. Nous en sommes venus à la conclusion que le meilleur moyen d'assurer leur avenir était de les aider à prendre en charge leur existence"(COUTURE, Jean-Guy Mgr, Bâtir ensemble.... Collaborer pour l'avenir, document d'accompagnement pour les communautés paroissiales sur la route d'une plus grande prise en charge communautaire, Évêché de Chicoutimi, 1993, p. iii.). Voir aussi CôTÉ, Charles, Désintégration des régions, Le sous-développement durable au Québec, Chicoutimi, Ed. JCL, 1991; COLLECTIF, VACHON, Bernard, dir., Le Québec rural dans tous ses états, Montréal, Boréal, 1991, 311p.; SOLIDARITÉ RURALE, Actes des états généraux du monde rural, Montréal, les 3, 4 et 5 février 1991, 193p.; RIOUX, Christian, "Touche pas à mon village", in L'Actualité, 1 mai 1993, pp. 36-40; VILLENEUVE, Florent, "Foi chrétienne et régions en voie de désintégration sociale et économique", in Pluralisme culturel et foi chrétienne, Montréal, Fides, 1993, pp. 339-350. [ Héritage et Projet \#50].

16 Au diocèse de Chicoutimi, les autorités ecclésiales viennent de nommer une équipe "in solidum" pour les deux paroisses de la ville de Roberval (Notre-Dame-de-Roberval [5315h.] et Saint-Jean-de-Brébeuf [4604h.]) et une paroisse rurale (Sainte-Hedwidge [814h.]). Cette nomination est intéressante mais la situation va se compliquer lorsqu'une équipe pastorale va être formée dans 


\subsubsection{La nécessité d'une analyse sociologique de la ville}

Le modèle de paroisse-ville (super-paroisse) nécessiterait une analyse sociologique du milieu urbain en quelques étapes. Il importerait en un premier temps d'étudier plus profondément les différentes fonctions de la ville, leur réalisation concrète et de voir ensuite comment la pastorale urbaine peut s'y situer. Cette vision d'ensemble serait indispensable car bon nombre de fonctions sont centralisées et ne se retrouvent pas à l'échelon d'un quartier ou d'un secteur. La deuxième étape consisterait à diviser la ville en zones géographiques. Des divisions fondamentales existent déjà dans la plupart des villes (zones séparées par une rivière, par des voies ferrées, etc.). En troisième lieu, on peut imaginer à l'intérieur de ces zones, tout au moins dans les grandes villes, un certain nombre de secteurs. Il n'est pas possible d'envisager le planning géographique des paroisses dans une ville, sans par le fait même, poser la question d'un plan pastoral. La ville est une entité vivante, elle est un tissu de relations sociales, elle est en perpétuelle évolution. Pour un planning d'ensemble qui dépasse le simple découpage spatial, il faut connaître la ville dans son mouvement évolutif. Le planning paroissial est alors la résultante d'une connaissance sociologique et d'un plan d'action général. Une ville est une réalité complexe. Pour une analyse sociologique rigoureuse, il faut donc faire une description géographique du milieu, son évolution historique, sa population totale et son mode de vie actuel, ses facteurs écologiques: topologie naturelle, dispositions des surfaces bâties, trafics et rues commerçantes, ses industries et ses commerces, ses édifices publics, récréatifs et culturels, son type de population (confession religieuse, allégeances politiques, professions type - les

l'une ou l'autre des trois paroisses. Le droit n'autorise pas la nomination d'une équipe pastorale mixte pour plusieurs paroisses. Seuls des prêtres peuvent être nommés de la sorte ("in solidum"). C'est pour cette raison qu'il faut toucher au statut juridique de la paroisse sans cela nous allons nous trouver avec une structure ecclésiale trop lourde et très bureaucratique. 
catégories professionnelles, les groupes ethniques et linguistiques), les écoles; les unités écologiques: les quartiers et voisinages, les centres locaux; les tendances de développement, les problèmes d'ordre urbain, etc.

\subsubsection{Un réseau de communautés diversifiées}

L'organisation territoriale actuelle de la paroisse dans les milieux urbains ressemble à un 'enclos' enfermant une portion de fidèles catholiques dans les limites d'un territoire afin de pouvoir mieux vérifier si ceux-ci n'ont pas contrevenu aux réglements ecclésiaux du 'système juridique paroissial'. Un enclos enferme un peuple dans les limites d'un territoire ${ }^{17}$; un réseau évoque davantage une attraction, localisée certes, mais aux frontières mouvantes. La paroisse-ville (super-paroisse) deviendrait alors un réseau de communautés diversifiées où seraient respectées les différentes intensités d'appartenance. Les intervenants pastoraux doivent inventer, à l'intérieur du cadre paroissial urbain, un niveau d'appartenance plus restreint en invitant des paroissiens à se réunir dans de petites communautés fraternelles qui pourraient constituer les cellules de base de la paroisse où il serait possible aux chrétiens de prendre la parole, de partager, de fraterniser, de lire l'Écriture, d'interpréter le vécu et de s'entraider. Comme le suggère Guy LAPOINTE dans ces écrits des dernières années, je pense aussi à la création d'une assemblée (ekklésia) intermédiaire entre la famille et la grande assemblée paroissiale. Une telle assemblée intermédiaire, en outre, pourrait être considérée comme une véritable communauté, flexible, mobile, diversifiée, proche des réalités humaines. Son appui sociologique devrait être celui des groupes naturels formés par la famille et ses relations immédiates de parenté, de voisinage, d'amitié, de services, de loisirs et d'occupation. Du point de vue du nombre une telle assemblée

L'enclos nous amène à valoriser uniquement l'espace comme facteur de rassemblement. 
devrait être à la mesure de l'habitation commune (la maisonnée), quel qu'en soit le type concret. M. LAPOINTE croit que cette nouvelle communauté devrait être pourvue de sa liturgie propre. 18 Il serait tout à fait insuffisant de penser à une simple "réduction" de la liturgie actuelle de la grande assemblée paroissiale. Notre tradition ecclésiale mieux comprise devrait nous permettre de créer dans notre contexte des formes liturgiques adaptées à l'univers culturel des membres de ces communautés. 19

"Devant la fragmentation et la dissolution de la religion à la carte, la paroisse peut et doit offrir ces lieux de recomposition. Les gens ont besoin de "se ramasser", de se retrouver à quelques-uns pour se ressourcer, reprendre les questions de fond, se confronter avec leurs certitudes et incertitudes, vérifier leurs croyances, articuler leur foi avec leur projet de vie." 20

La petite commmunauté offrirait un lieu de partage et de participation; la grande paroisse apporterait à ces communautés le soutien indispensable et aux paroissiens des services que seul un grand organisme avec des ressources suffisantes peut donner. On ne saurait trop encourager la formation de noyaux communautaires ou de groupes de

18

Voir LAPOINTE, Guy, "L'avenir de la célébration liturgique dans le cadre paroissial", in Liturgie et Vie chrétienne: de l'assemblée à la communauté, n99, pp.11-25. Je me suis beaucoup inspiré de cet article pour rédiger ces lignes.

19

Pourvue d'une liturgie propre, l'ekklèsia de base devrait naturellement disposer ainsi d'un service pastoral particulier. Il va sans dire que ce service serait très étendu. Or, c'est très précisément ici, à mon avis, que se pose, en ses données les plus authentiques et les plus pressantes, le problème actuel du célibat dans le service pastoral de l'Église. Pour ma part, je ne vois pas d'autres solutions sur ce point, qu'un retour franc et universel à la liberté primitive. Car il ne s'agit pas de nous demander ce qui serait le mieux en soi. Il s'agit de savoir si nous sommes en mesure de répondre aux nécessités présentes de l'Église. Même avec les admirables et encore immenses réserves d'invention et de générosité, il faut reconnaître que nous sommes débordés de toutes parts. Et tout ce que nous pouvons prévoir, c'est que les nécessités pastorales seront plus grandes demain. Ces nécessités sont prioritaires: ce sont elles qui doivent guider ici nos choix et nos décisions. Après tout, il n'apparaît pas que Jésus lui-même en ait jugé autrement lorsqu'il s'est entouré de disciples et qu'il s'est adjoint les Douze. La sacralisation actuelle du célibat ecclésiastique sert très peu les intérêts de l'espérance de l'Évangile. "Car peut-on parler de "pastorale" quand dans certaines régions du Brésil, un prêtre unique à toutes les peines du monde à visiter au moins une fois l'an "ses" paroisses"(DREWERMANN, Eugen, Les fonctionnaires de Dieu, Paris, Albin Michel, 1993, p. 197.). 
personnes intéressées à la réflexion chrétienne sur leur vécu, à des célébrations particulières de leur foi, à des projets missionnaires dans le milieu. Chaque personne désirant approfondir sa foi a besoin d'une communauté plus restreinte, d'un rassemblement qui met en contact avec d'autres vécus et invite à l'accueil, l'écoute et la conversation. Il serait intéressant que ces communautés se réunissent pour faire ensemble leur eucharistie. "Qu'au moment des temps forts de l'année chrétienne, ces diverses communautés se rassemblent dans une symbolique plus large, ce regroupement prendra alors tout son sens parce que chacun et chacune participeront à ces célébrations avec, au coeur, une expérience bien vivante. Des communautés chrétiennes à dimension humaine ne peuvent naître qu'à ce prix dans notre contexte urbain. Le temps n'est-il pas venu de vivre ce passage, d'essayer cette pâque?"21

\begin{abstract}
"Un chrétien vivra en communauté avec tel groupe, ira à la messe à telle église qui l'attire par sa vie liturgique, cherchera des informations dans tel institut qui lui apporte des réponses utiles, se mariera dans tel sanctuaire qui lui rappellera les engagements de la famille, cherchera l'orientation de tel prêtre de telle résidence, et ainsi de suite. Il n'est nullement nécessaire que tout cela se fasse au même endroit. Ou plutôt, tout cela se fait au même endroit, puisque c'est dans la même ville, et donc dans la même paroisse." 22
\end{abstract}

La formation de petites communautés serait à privilégier en paroisse mais il faudrait toujours respecter les paroissiens qui refuseraient d'en faire partie. Le goût de se rencontrer en petits groupes n'est pas le goût de tout le monde et il faut tenir compte des paroissiens qui ne veulent appartenir à aucun groupe. La structure paroissiale ne doit pas être une structure uniformisante qui étouffe les particularités légitimes.

Dans ce nouvel aménagement structurel, la paroisse vise essentiellement à favoriser la communication entre personnes et entre communautés croyantes. Elle se 
voit appelée à se situer de plus en plus dans un réseau de rassemblements diversifiés: (communautés claniques de la famille et des amis ${ }^{23}$, communautés de complicité spirituelle, rassemblements de quartier, groupes-relais 24 , associations de chrétiens à caractère stable [instituts religieux, instituts séculiers, association de fidèles au sens du nouveau code], mouvements, lieux de solidarité [travail, bénévolat, loisirs], grands rassemblements dominicaux, etc.); ce qui, de toute évidence, dépasse l'identification classique de la paroisse avec la communauté. La paroisse met en relation des communautés aux visages différents. La paroisse deviendrait donc un heureux équilibre entre l'enclos et l'anonymat. Elle deviendrait un lieu assez restreint pour qu'il soit possible de créer des liens avec d'autres, un lieu où l'on pourrait être écouté et appelé par son nom et où l'on pourrait prendre la parole. Enfin, elle deviendrait un lieu assez vaste pour éviter les encadrements étouffants, c'est-à-dire l'uniformité et le sectarisme. La paroisse serait alors plus marquée par son pôle ecclésial que par son "enclos territorial".

"Cette façon de faire correspondrait à ce qui se vit dans la société où la plupart des gens ont leur vie définie par des appartenances multiples. La paroisse n'aurait plus cette marque d'appartenance totalisante, ce qui d'ailleurs rejoindrait la réalité avec plus de justesse. Se poserait alors le problème de l'animation presbytérale de ces communautés. Évidemment, cette proposition suppose que la structure presbytérale trouve des façons de sortir de son unidimensionnalité et que les voies d'accès à ce service soient vraiment en accord avec les besoins nouveaux des chrétiens." 25

23

"À l'âge de la post-modernité, où importent les rencontres de pairs, il faudrait privilégier les petits groupes. Compte tenu des rythmes actuels de la vie sociale et des appartenances partielles, il faudra exploiter les communautés claniques de la famille et des amis: lors des regroupements naturels autour d'un baptême, d'un mariage, d'un décès, d'un événement marquant, on répondra à l'intensité de présence et à la demande de sens, en évangélisant la référence chrétienne résiduelle dans un effort particulier d'herméneutique et d'imagination"(CHARRON, André, "Le service pastoral de la foi dans le contexte culturel actuel", in Pastorale Québec, 30 juin 1993, p. 242.).

24 Voir à ce sujet CHARRON, André, " "Adultes et foi", des groupes de base en paroisse", in Communauté chrétienne, $\mathrm{n}^{\circ}$ 94, juillet-août 1977, pp. 408-414. p.24.

LAPOINTE, Guy, "L'avenir de la célébration liturgique dans le cadre paroissial", 


\subsubsection{Un réaménagement ministériel dans une paroisse-ville}

Le modèle paroisse-ville (ou super-paroisse) exigerait une réorganisation complète des ministères permanents. ${ }^{23}$ Quelques possibilités s'offrent à nous. J'ose en proposer une qui, à mon avis, pourrait être fructueuse en pastorale paroissiale urbaine. Encore une fois, cette suggestion a pour but de stimuler une réflexion sur les ministères dans l'Église.

Tous les ministres ordonnés et mandatés seraient nommés membres de la grande équipe pastorale de la ville. ${ }^{24}$ On pourrait appeler cette équipe pastorale de la ville un collège ministériel constitué des presbytres, des diacres permanents et des autres baptisés mandatés sous la direction d'un modérateur, responsable de la croissance de l'unité entre les membres de ce collège et la promotion d'une réelle solidarité dans leur mission commune. Ce modérateur pourrait être un délégué de l'évêque. ${ }^{25} \mathrm{Ce}$ collège offrirait une manière privilégiée d'unifier les ministères au lieu de se retrouver avec plusieurs catégories de ministres travaillant en parallèles. De plus, nous ne pouvons préparer l'avenir des ministères si pratique et réflexion ne cheminent pas ensemble en s'interrogeant mutuellement. Également, en nommant les agents pastoraux à une échelle urbaine, cela éviterait qu'un agent pastoral s'isole ou ne se sente

23

Je proposerai plus loin le scénario d'une importance accrue donnée à la zone (région) pastorale avec des pouvoir juridiques réels. Le réaménagement ministériel proposé ici conviendrait également pour ce scénario.

24

Si l'on constate chez les permanents ecclésiaux oeuvrant en milieu urbain un certain pessimisme et un découragement devant l'échec apparent des efforts apostoliques, c'est en partie parce qu'on n'est pas arrivé encore à se hausser à cet échelon urbain et à considérer en une fois tous les aspects de l'action apostolique. Un des défis actuels est de faire passer les agents pastoraux de préoccupations strictement locales à des préoccupations plus globales. De plus, la manière de nommer les prêtres actuellement dans le milieu urbain est un moyen sûr de les conduire à un burnout!

25

Rappelons que dans l'Eglise des premiers siècles, il y avait un évêque par ville et c'était lui qui présidait le 'sénat ecclésiastique' de l'époque. La solution ne serait-elle pas d'augmenter le nombre d'évêques ou de vicaires épiscopaux? 
pas concerné par l'ensemble des enjeux pastoraux de la ville. Chaque agent pastoral serait en plus nommé dans un milieu particulier: soit dans une équipe d'animation d'une communauté chrétienne (les anciennes paroisses), soit pour une pastorale plus particulière: pastorale hospitalière, scolaire, jeunesse, auprès des personnes âgées, des divorcés-remariés, des 'marginaux' (ou ceux 'qu'on marginalise'), etc. ou soit plus spécialisée dans un domaine théologique, spirituel, sociologique, psychologique (ceci dans le but de s'occuper du ressourcement et de l'approfondissement intellectuel des membres du collège ministériel et des baptisés des équipes d'animation des différentes communautés chrétiennes). Le rôle des agents pastoraux serait davantage diversifié et se rattacherait toujours à une double responsabilité, à l'échelon local (communauté chrétienne ou milieu spécialisé) et à l'échelon urbain (paroisse).

Selon cette conception, la nécessité et l'originalité du ministère presbytéral demeurent essentielles. Je dirais même que ce réaménagement ministériel remettrait en valeur la fraternité sacramentelle, c'est-à-dire l'appartenance à la LOP (Ligue de l'Ordre Presbytéral) ${ }^{26}$. C'est le collège presbytéral de la ville qui veillerait plus particulièrement à la croissance de l'unité entre les communautés et les différents intervenants. Les responsabilités des membres du collège presbytéral seraient alors communes avant d'être individuelles et toutes les missions individuelles seraient assumées au nom du presbytérium. 27 Dans l'ensemble des responsabilités d'une ville, les tâches seraient réparties suivant les talents et les grâces de chacun. Nous avons été habitués à une grande uniformité presbytérale. Cette hypothèse de réorganisation ministérielle serait plus respectueuse des prêtres eux-mêmes. Il est impensable que chaque prêtre de la

26 Rappelons-le, faire partie d'une "ligue" sans toutefois vouloir promouvoir une "ligne de partie".

27 Cette réorganisation ministérielle exigerait la révision du pouvoir de juridiction des prêtres sur les territoires paroissiaux. Il faudrait que les prêtres aient le pouvoir de juridiction pour l'ensemble de la ville. 
ville puisse se spécialiser dans tous les domaines pastoraux à la fois. Si le milieu urbain est complexe, la pastorale en ville ne l'est pas moins. Il importe donc que certains prêtres soient particulièrement qualifiés dans les domaines de la liturgie, de l'initiation sacramentelle, de la pastorale sociale, de la sociologie, de la psychologie, de la morale ou de la théologie. Cette prise en charge commune de l'ensemble du territoire de la ville par l'organisation du travail en complémentarité et spécialisation laisse entrevoir la possibilité de solutions à des problèmes inhérents à la réalité urbaine d'aujourd'hui insolubles sans cette organisation régionale. Que l'on songe aux services d'éducation de la foi impossible à mettre sur pied dans chaque milieu, soit faute de compétences pour en assumer l'entreprise, soit faute de ressources ou de clientèle suffisantes pour en assurer la viabilité, la rentabilité. Ces déficiences tombent dès qu'on aborde ces problèmes à une échelle plus large, celle de la prise en charge effective de toutes les réalités d'ordre économique, professionnel, culturel, social, scolaire qui dépassent le cadre territorial actuel des paroisses. Il n'y a pas de solution locale à un problème régional. En fait, tout ce travail d'aménagement doit être préparé dans les esprits et dans les coeurs par une pédagogie appropriée. Il doit être réalisé par étapes successives et progressives. On ne peut imaginer redresser en un tournemain la situation mais il faut montrer que si nos espérances légitimes sont souvent déçues, c'est en partie parce que nos méthodes apostoliques ne sont plus adaptées. Il est une inquiétude apostolique salutaire sans laquelle aucune action n'est possible: celle qui naît d'une critique saine et réfléchie de notre travail et qui nous amène progressivement à accepter les sacrifices qu'exigent nécessairement les innovations et les adaptations de nos méthodes pastorales. Un changement d'orientation de ce travail est toujours pénible et il faut vraiment une claire perception de sa nécessité pour l'accepter.

La transformation de la pastorale paroissiale en milieu urbain pourrait ainsi être un moyen privilégié de renouveler la forme et l'exercice des ministères de l'Église 
(épiscopal, presbytéral, diaconal et mandaté). Chaque paroisse actuelle qu'on dénommerait désormais communauté ou fraternité chrétienne aurait le droit de continuer d'être assurée d'une équipe d'animation. ${ }^{28}$ Toute communauté chrétienne et toute paroisse-ville (super-paroisse) devraient avoir les ministères indispensables à leur vie: des ministères qui amèneraient les paroissiens à devenir les premiers responsables de la vie communautaire. Pour atteindre cet objectif, il faut reconnaître et promouvoir de nouveaux ministères qui feraient en sorte que la vie et la mission de l'Église ne reposent plus principalement sur les épaules de quelques agents pastoraux mais soient portées par les baptisés des communautés chrétiennes et de la grande communauté paroissiale. Nous sommes sujets de ce dont nous sommes responsables. Si la communauté ne se tient pas responsable d'elle-même, aucun prêtre, si dynamique soitil, ne réussira à rendre les membres responsables de leur communauté.

\subsubsection{La ville et les lieux de culte}

Une ville doit pouvoir mettre à la disposition des chrétiens autant d'assemblées liturgiques qu'il est nécessaire pour répondre aux besoins de silence, de ressourcement, d'appartenance communautaire. Leur distribution dans le tissu de la ville dépend des différents besoins à satisfaire; il n'y a aucun sens à vouloir lier les citadins à telle église déterminée. Un homme de la ville a besoin de communautés chrétiennes. Mais rien ne dit qu'il doive nécessairement participer à la messe du dimanche avec cette communauté, ni qu'il doive s'y marier ou recevoir toute sa formation chrétienne. Il est urgent de réfléchir au nombre et à l'utilisation des églises en milieu urbain. Il me semble qu'il serait plus facile de se pencher sur cette question si les agents pastoraux faisaient partie d'un collège ministériel pour l'ensemble de la ville. mes réticences concernant la politique de vouloir faire advenir une équipe pastorale dans chaque paroisse urbaine actuelle. 
Mes six années d'expériences pastorales me prouvent la difficulté de considérer ce problème dans la structure pastorale actuelle. Chaque curé et chaque conseil de Fabrique défendent leur nombre de messes et "leur clocher" pour des raisons pas toujours pastorales. ${ }^{29}$ Pouvons-nous en Église nous payer encore longtemps le luxe d'avoir 'un esprit de clocher' dans le milieu urbain? Seule une réflexion approfondie par l'ensemble des agents pastoraux d'une ville pourrait aider à trouver des solutions efficaces pour répartir les heures des messes dans les différents lieux de culte de la ville et pour trouver les moyens de maximiser leur utilisation et financer leurs coûts d'entretien. 30 nécessité d'avoir ou non un Conseil de fabrique et un C.P.P. dans chacune.des anciennes paroisses appellées désormais communautés ou fraternités chrétiennes ou églises-relais. Il me semble qu'il serait plus fructueux d'avoir un seul C.P.P. et un seul Conseil de fabrique par ville et un conseil de direction dans chacune des communautés. De plus, depuis quelques années, nous constatons qu'il y a parfois beaucoup de tension entre le C.P.P. et le Conseil de Fabrique. Les membres du C.P.P. votent des orientations pastorales qui ont des conséquences financières importantes pour la communauté. Il arrive que ces orientations ne puissent pas se réaliser puisque les marguilliers ne donnent pas suffisamment l'appui financier à leur concrétisation. Les membres du C.P.P. accusent alors les marguilliers de n'avoir pas de vision pastorale dans la gestion des biens de la communauté et à leur tour les membres du Conseil de Fabrique accusent leurs collègues du C.P.P. de manquer de réalisme financier dans le choix de leurs priorités pastorales. Comment concilier ce problème qui risque de s'aggraver à mesure que les C.P.P. vont s'accroître dans les diocèses et prendre davantage d'importance dans la prise en charge communautaire? La solution ne serait-elle pas de faire un seul Conseil avec les membres du C.P.P. et les marguilliers, d'autant plus que dans certains milieux, il y a un manque de ressources pour faire fonctionner toutes ces structures? Le système pastoral actuel est au-delà de nos possibilités réelles.

30

Au diocèse de Montréal, quelques comités ont été mis sur pied pour repenser l'utilisation des églises et des presbytères dans la grande métropole. Différents professionnels de divers milieux sont membres de ces comités (architecte, urbaniste, homme d'affaires, intervenant communautaire, etc.). Il faut former ce genre de comité dans les Églises locales. Les problèmes financiers deviennent de plus en plus sérieux pour plusieurs Fabriques. L'urgence de la situation exige une réflexion approfondie sur les enjeux financiers en Église. Voir le dossier "Les finances de l'Église", in Communauté chrétienne, vol. 2, n 15, novembre 1991, pp. 9-16. 


\subsubsection{La zone (région) pastorale avec de réels pouvoirs juridiques}

Le deuxième scénario possible pour renouveler la structure paroissiale en milieu urbain serait de proposer un réaménagement donnant une importance accrue à la zone (région) pastorale avec les pouvoirs juridiques nécessaires à son fonctionnement. Ce sont ces pouvoirs dont elle est privée actuellement. C'est pour cette raison que cette structure pastorale n'a pas donné les résultats escomptés depuis sa création. La zone (région) pastorale est toujours coincée entre les paroisses et le diocèse. J'aime comparer la structure de la zone pastorale à une automobile dont l'essence est controlée par les paroisses et le volant est conduit par les autorités diocésaines. La zone ou la région pastorale est donc une structure "bidon" parce qu'on ne lui a jamais donné les possibilités "politiques" pour devenir un aménagement significatif. 31

La zone (région) région pastorale pourrait être une structure pastorale efficace à la condition qu'elle devienne un lieu d'autorité. Nous pourrions garder les paroisses actuelles mais certains pouvoirs devraient être donnés à la zone pastorale comme ceux de la gestion pastorale de l'ensemble des paroisses, de la gestion des ressources humaines des milieux en concertation avec les autorités diocésaines, de la gestion financière, etc. L'ensemble des agents pastoraux devraient être nommés au niveau de la zone avec des responsabilités particulières dans l'une ou l'autre des paroisses ou dans d'autres secteurs spécialisés. 32 Les permanents ecclésiaux

La plus belle preuve du peu de signification de cette structure ecclésiale aux yeux des permanents est le fait que presque aucun de ceux-ci ne désirent être président d'une zone (région) pastorale. Lorsque j'étais curé de la paroisse Saint-Jude d'Alma, nous avons dû choisir un nouveau président. Sur dix-huit candidatures proposées, seize ont refusé d'être éligibles à l'élection. Lorsqu'un poste de leadership n'intéresse presque plus personne, il y a de sérieuses questions à se poser sur l'importance accordée à la responsabilité offerte.

Voir description du collège ministériel décrit précédemment. 
recevraient leur rémunération du bureau de la région pastorale. Nous devrions alors réviser le financement des différents paliers ecclésiaux. J'ai découvert dans ma pratique pastorale que la façon d'aménager le financement des institutions religieuses dépend de la vision d'Église que l'on se fait. 33 Si l'on est convaincu que la paroisse territoriale actuelle peut encore tout faire par elle-même en milieu urbain, on ne voit pas pourquoi elle devrait financer les structures d'une zone pastorale. Tout ce que j'ai élaboré précédemment prouve le contraire. C'est pour cette raison que ce scénario exigerait deux paliers de finances: un palier pour les services locaux dans les paroisses territoriales et un autre palier pour les services communs au niveau de la zone pastorale. Les paroisses devraient alors faire parvenir un pourcentage élevé de leur revenu au bureau de la région pastorale pour entre autres, défrayer les coûts des ressources humaines que leur octroient les ministres ecclésiaux assumant une animation pastorale dans leurs milieux communautaires. Il faudrait donc un service administratif commun à toutes les paroisses rurales et urbaines d'une zone pastorale. Seule une telle mise en commun financière permettrait de mettre sur pied des services de formation et d'entraide. Déjà, organiser pastoralement d'une façon complète chaque paroisse est devenu pratique impossible dans le contexte d'aujourd'hui.

Il existe dans chacune des zones pastorales du diocèse de Chicoutimi un regroupement des agents pastoraux permanents (appelé le R.A.P.P.). Les membres de ce regroupement se réunissent de six à dix fois par année selon les coutumes des régions elles-mêmes. La plupart des permanents sortent déçus de ces rencontres puisque celles-ci sont trop centrées sur l'organisationnel et pas suffisamment sur un

Plusieurs Églises locales ont des difficultés financières. Il est intéressant d'analyser où celles-ci coupent dans les dépenses. Ce sont le plus souvent les services diocésains et les zones (régions) pastorales qui subissent en premier les coupures. Nous n'évaluons pas suffisamment les conséquences théologiques de nos options financières en Église. Je souhaite que nous investissions autant d'énergie dans l'avenir dans la recherche de nouveaux moyens de financement que dans les recherches de coupures budgétaires. 
partage d'une vision pastorale et d'un ressourcement commun. Ces tables de réflexion seraient plus stimulantes si les intervenants pastoraux se penchaient sur de grandes orientations pastorales et qu'on laissait par la suite la liberté à chacun d'appliquer cellesci en respectant la spécificité et l'originalité particulières du milieu. Le problème actuel est qu'on dépense des énergies considérables pour uniformiser les politiques d'application des orientations et qu'il ne reste plus le temps pour réfléchir ensemble sur leurs enjeux théologiques et pastoraux. Les permanents deviennent agressifs parce qu'ils sentent que les autorités ecclésiales ne respectent pas suffisamment les particularités des communautés. Ils aiment réfléchir sur des orientations pastorales mais ils désirent conserver leur liberté dans le choix des modalités d'application dans leurs champs d'intervention. Une collégialité ministérielle doit exister avant tout pour la réflexion commune, la recherche de consensus dans les grandes orientations, le ressourcement, la communion et non pour les modalités d'application. Comme orientation, les membres d'un R.A.P.P. peuvent s'entendre par exemple sur l'importance de l'accueil inconditionnel dans toutes les demandes sacramentelles mais ils doivent laisser à chaque paroisse la liberté dans la manière d'accompagner les paroissiens lors des rites de passage à partir des diverses ressources de leur milieu.

Même si je privilégie le scénario (paroisse-ville) pour renouveler la pastorale paroissiale en milieu urbain, je crois qu'un renforcement de la zone pastorale avec des pouvoirs juridiques réels serait une perspective structurelle intéressante. Cependant, si les autorités ecclésiales ne veulent pas donner certains pouvoirs à la (zone) région pastorale, il me sera difficile de véritablement croire à cette structure ecclésiale. 


\subsection{Que sera l'Église à l'an 2000?}

D'ici l'an 2000, beaucoup de données nous sont étrangères et cependant certains pronostics, approximatifs au moins, ne semblent pas hors de portée. Le nombre de prêtres, de diacres permanents, de laïcs engagés peut être prévu. Les évolutions démographiques sont globalement connues. Nombre de réalités humaines retiennent déjà l'attention. À partir de ces points de visée, il ne paraît pas totalement impossible d'esquisser un calendrier de réalisations, avec des objectifs intermédiaires suffisamment ciblés: d'ici trois ans, six ans, neuf ans.... On voit assez rapidement les investissements nécessaires à ce type de programmation en termes d'interpellation et de formation de personnes, en termes aussi d'argent, de redistribution des ressources, de changement dans les mentalités. Cette forme de planification qui est monnaie courante dans la société actuelle serait-elle interdite au peuple chrétien? Certes, elle ne cherche pas à tout prévoir et moins encore à court-circuiter les initiatives de l'Esprit, mais ne pourrait-elle pas contribuer à inventer un avenir responsable?

"La situation actuelle des paroisses et l'évolution des pratiques ministérielles provoquent des réactions diverses: crainte face à l'avenir des communautés, enthousiasme devant le dynamisme de nombreux laïcs, inquiétude devant la crise du ministère ordonné, désillusion devant les blocages institutionnels, agressivité à cause des relations de pouvoir ou d'inégalité, espoirs nourris à propos d'un nouveau visage de l'Église. Quoi qu'il en soit, les faits nouveaux qui appellent des changements d'attitude et des restaurations sont incontournables. Le défi consistera à gérer le changement de manière responsable avec la conscience de l'urgence sans repliement continuel sur les solutions de remplacement qui ne font pas appel à la créativité chrétienne ou qui portent atteinte au véritable sens de l'Église. "37

Il ne faudra jamais oublier que dans nos recherches pour inventer un nouveau visage de la paroisse et de l'Église, c'est la communauté baptismale et sa mission ministères au Québec: situation, questions, défis, p. 29. 
d'évangélisation qui doivent toujours passer au premier plan et non la défense d'un système institutionnel.

Il est possible que l'Église n'ait pas le courage de refondre ses structures dans le milieu urbain de demain. Si elle fait ce choix, elle doit consentir à ne jouer qu'un rôle secondaire en marge des humains qui désirent rendre leur ville plus humaine. J'espère le contraire puisque c'est la vocation de l'Église elle-même qui risquerait d'être en jeu.

"L'Église trahirait son message qui demande à être proclamé et répandu, non point mis sous le boisseau; elle ne remplirait pas la tâche qui est sienne dans une société sécularisée, celle d'être la figure d'une logique de gratuité, d'unité et de communication. /.../ il fait comprendre que, quelles que soient les maladresses ou les fautes, l'Église ne peut pas renoncer à cette présence sociale sous peine de renoncer au sens de sa mission; il ne s'agit donc pas d'une tâche supplémentaire qu'elle s'accorderait une fois ancrée l'évangélisation; il ne s'agit pas non plus de conquérir des positions privilégiées ou de dicter à une société ignorante de ses buts ce qu'elle a à faire et comment y parvenir; il s'agit de témoigner au sein de l'histoire des processus affectifs par lesquels cette histoire s'accomplit vraiment sans s'abîmer dans les impasses du technocratisme ou du totalitarisme. /../ En réalité la question n'est pas celle d'une visibilité à tout prix, mais celle d'une visibilité qui fasse sens en cohérence avec le message évangélique et avec ses destinataires. 38

L'humanité est entrée depuis quelques années dans une ère où le changement devient une situation normale et l'adaptation au changement, une valeur de base. Les progrès techniques sont en effet constants et s'influencent mutuellement. Ils changent régulièrement les conditions biologiques, psychologiques et sociales de la personne humaine ( du paroissien) et l'entraînent dans des relations sans cesse renouvelées avec la nature et les individus. Du point de vue ecclésial, tout ceci est fondamental, tant au

VALADIER, Paul, L'Église en procès, Catholicisme et société moderne, France, Flammarion, 1987, pp. 94-95, p. 195. "Il faut donc servir la culture, notre culture. Il n'y a pas lieu de la bouder, ni de craindre son altérité, ni de jouer les prophètes de malheur. Il faut entrer en sympathie avec l'homme moderne et aider à mener notre culture au bout de son meilleur dynamisme. Mais cela se fera, de la part des chrétiens et des agents d'Église, sur le mode de la contribution, non pas sur celui du contrôle"(CHARRON, André, "Le service pastoral de la foi dans le contexte culturel actuel", p. 240.). 
plan des structures pastorales qu'à celui des valeurs religieuses. Un monde en changement exige des structures très souples, susceptibles d'être modifiées en fonction de l'évolution sociale. Comme on le voit, le problème est fort complexe et est loin d'être épuisé. Souhaitons que, pas à pas, la réflexion théologique à partir des pratiques pastorales pertinentes se poursuive pour toujours mieux préciser la mission de la paroisse dans un monde urbain en continuelle mutation.

\subsection{Sur une note d'espérance}

Je suis presqu'arrivé à la fin de mon parcours doctoral. J'aimerais terminer sur une note d'espérance. Même si j'ai nommé de nombreux défis présents en pastorale paroissiale en milieu urbain, même si ceux-ci peuvent paraître au premier abord insurmontables, il demeure que je suis confiant en l'avenir de la paroisse. Mes six années d'expériences pastorales m'ont permis de connaître plusieurs paroissiens d'une grande qualité humaine et spirituelle. J'ai été témoin à maintes reprises de l'oeuvre du Dieu Vivant au coeur de diverses communautés croyantes. Le Seigneur fait naître de plus en plus de baptisés "debout" qu'aucune institution même "religieuse" ne pourrait "rasseoir". Ces disciples de Jésus Christ veulent davantage s'engager au coeur de l'Église pour faire advenir un monde plus juste et fraternel. Ils sont capables d'être critiques envers l'Église institutionnelle lorsque les orientations de celles-ci ne respectent pas suffisamment la conscience et la dignité des croyants. L'Esprit-Saint, par ces paroissiens autonomes et responsables, ne cesse de questionner les dynamiques structurelles de l'Église.

Les quelques scénarios proposés à différents niveaux (institutionnel, réorganisation ministérielle, réaménagements pastoraux, pédagogie de la foi, etc.) pour renouveler l'Église ne sont pas irréalisables. Déjà dans ma pratique pastorale, j'ai été 
témoin de la fructuosité de certains scénarios que j'ai risqués avec d'autres frères et soeurs dans la foi pour dynamiser la pastorale paroissiale en milieu urbain. Une paroisse prend un autre visage lorsque nous prenons le temps entre les bénévoles et les permanents pour nous ressourcer et nous former ensemble. Une paroisse devient plus dynamique lorsque nous partageons le leadership de la communauté au sein d'une équipe pastorale et lorsque nous favorisons les pratiques synodales. Une paroisse est davantage une fontaine d'eau vive à laquelle le paroissien peut venir étancher sa soif lorsque les intervenants pastoraux offrent une qualité d'accueil et d'accompagnement au "tout-venant". On retrouve une grande vitalité dans une paroisse si l'on accepte le paroissien "moderne" tel qu'il est avec son nouveau rapport à l'espace et au temps. Ces expériences positives vécues en paroisse nourrissent mon espérance et me donnent de l'énergie pour continuer à contribuer au renouvellement de l'institution paroissiale. Je suis conscient que pour que l'Église soit toujours en marche vers l'avenir, elle doit être une Église du courage et de l'audace. 


\section{CONCLUSION - INTÉGRATION}

Que conclure? À la fin de ce parcours doctoral, je suis plus véritablement convaincu que l'évolution et la transformation de la pastorale paroissiale en milieu urbain doivent être poursuivies assez rapidement en raison de l'importance de l'enjeu: l'ensemble des autres formes d'Église qui se cherchent ne déboucheront pas si la paroisse ne bouge pas. On compte depuis plusieurs années, des retards et des engourdissements institutionnels qui portent préjudice à l'ensemble des paroissiens. On constate des manques de réflexion approfondie qui provoquent des crispations douloureuses. L'avenir de la paroisse urbaine n'est certes pas la préoccupation directe de tous les chrétiens et même de tous les agents pastoraux. Il n'en reste pas moins que personne ne saurait tenir cette réalité pour une question négligeable: c'est là, à mon avis, que se jouera pour une bonne part l'avenir de l'Église.

L'ensemble de cette recherche doctorale autorise la confirmation de mon hypothèse de sens. Pour renouveler la paroisse dans le but de mieux assurer la mission de l'Église en réponse au phénomène de l'urbanisation en contexte moderne, deux défis doivent être affrontés: il faut une réforme institutionnelle pour faire surgir une structure pastorale qui soit fonctionnelle par rapport à la dynamique urbaine et il faut également un renouveau des pédagogies pastorales pour répondre à la culture actuelle et aux exigences d'incarnation de l'Évangile. C'est à ces conditions que l'Église et la paroisse elle-même pourront retrouver une pertinence en cette fin de $X X^{\circ}$ siècle marquée par une soif spirituelle dont le phénomène du Nouvel Âge constitue une manifestation. Au carrefour de ces deux conditions l'Église doit redevenir capable d'engendrer les humains à une qualité de vie spirituelle. Les orientations fondamentales de l'ecclésiologie conciliaire de 
Vatican II (la synodalité de l'Église, la dimension communautaire plus affirmée, le renouvellement des ministères, l'explicitation de la mission de l'Église) sont réellement des manières de répondre aux défis des phénomènes de l'urbanisation et de la modernité. Une remise en question en profondeur des pédagogies pastorales d'accompagnement de la foi est aussi un moyen privilégié pour une ressaisie de la mission de l'Église, en particulier celle de la paroisse, comme service du Royaume dans la croissance des personnes et le devenir des collectivités.

Les conditions socio-historiques influencent la mise en place des structures qui évoluent moins vite que la vie. Beaucoup de défis actuels apparaissent insurmontables parce qu'on ne refait pas le même chemin, parce qu'on ne retourne pas à la vie pour repenser les formes institutionnelles nouvelles à instaurer. Dans le passé, des paroisses ont été créées pour répondre à des aspirations et à des besoins dans une conjoncture donnée. Aujourd'hui, on cherche à rajeunir ces paroisses, à les adapter. On a beau changer les méthodes, les objectifs, le leadership et même le membership, l'opération semble toujours celle de la pièce neuve sur un vieux vêtement. De plus, changer un seul aspect ne donne habituellement rien. C'est un changement global qu'il faut d'où l'intérêt de la méthode systémique dans cette thèse. La paroisse est un produit de l'histoire. Elle n'a donc rien d'immuable. Il est ainsi normal que ses fonctions soient différentes actuellement de ce qu'elles étaient au cours des derniers siècles. Depuis plusieurs années, on a réussi à définir la paroisse par un schéma idéal qu'on lui impose comme étant sa vocation, faisant confiance au temps pour le réaliser. Mais la réalité paroissiale ne peut se définir en projetant sur elle un schéma idéal: on ne peut donner à une communauté n'importe quelle tâche à remplir, sans voir si cette tâche est contenue dans ses possibilités historiques. Il faut avoir le courage d'envisager en quelque sorte le problème de la paroisse urbaine dans son ensemble et de le regarder en dehors des problématiques habituelles considérées comme immuables (c'est ce que j'ai essayé humblement de 
faire dans cette thèse). Toute vie religieuse a besoin d'institutions pour s'appuyer, pour rendre réel et constant le sens d'une appartenance. Ce serait de l'angélisme que d'affirmer le contraire. Pour répondre à un besoin, l'on crée une institution et c'est nécessaire car l'action qui ne débouche pas au niveau institutionnel se condamne au "happening", à l'éphémère ou à l'impuissance. Pendant un temps plus ou moins long, l'institution demeure parfaitement adaptée à la fonction qu'on lui assigne puis, vient un moment où, les conditions ayant changé et l'institution vieilli, elle répond plus difficilement aux besoins. L'institution paroissiale n'a pas à échapper à cette loi; pendant un temps, parfaitement adaptée à sa fonction, elle donne aujourd'hui de moins en moins de résultats pastoraux probants, particulièrement dans le milieu urbain. Il est important que l'institution ne soit jamais une fin en soi, elle doit rester un moyen au service des besoins qui l'ont fait naître. La paroisse ne peut plus limiter son action aux frontières de son territoire ni exiger de ses membres une appartenance exclusive: ce serait marcher à contre-courant des tendances nouvelles. Les humains n'ont pas à s'adapter à la paroisse de jadis, mais c'est celle-ci qui doit évoluer; le changement continu est une condition du monde moderne. Nous sommes à l'âge des structures en mouvement et la paroisse n'y échappera pas si elle veut être de son temps. La pastorale urbaine devra avoir autant de réalisme que la sociologie urbaine si elle veut se créer des instruments adaptés pour rejoindre les humains concrets dans leurs réseaux diversifiés de solidarités. La paroisse urbaine devra donc passer par l'épreuve qui pourrait bien être l'épreuve d'une certaine mort. C'est précisément cette mort qui peut donner sens à l'être-ensemble de type paroissial. Sinon, la paroisse sombrera dans l'insignifiance. Mort à soi-même, mort à ses certitudes: autant de passages et autant de pâques qui peuvent déboucher sur une vie nouvelle pour la grande communauté des croyants. La paroisse sera alors significative du mystère chrétien, mystère pascal de mort et de VIE. Mais 
n'oublions pas que ce qui est vivant n'est jamais parfait et ce qui est parfait risque de ne plus être vivant!

L'approche systémique dont j'ai usé dans cette thèse doctorale pour réfléchir sur la pastorale paroissiale en milieu urbain élimine certaines distorsions et amputations apportées par le savoir discursif et linéaire. Comme je l'ai dit dans le premier chapitre, elle se prête bien à l'étude des phénomènes complexes puisqu'elle situe la réflexion dans une problématique d'ensemble. Seule une synthèse de différents aspects peut donner un tableau plus complet de la réalité. Une étude est d'autant plus fructueuse lorsqu'elle exprime la complexité du réel et s'attaque à la diversité des enjeux. Cette approche m'a également donné la possibilité d'exploiter davantage la circularité dialectique de la méthode praxéologique. La notion de causalité circulaire que l'approche systémique sous-tend permet ainsi d'éviter certaines naïvetés dogmatiques, réductrices et simplificatrices dans la compréhension dialectique des pratiques pastorales.

Du fait que j'ai utilisé avec liberté différentes méthodologies dans ce parcours doctoral, je termine ce travail avec une plus grande passion pour la recherche-action. Il est stimulant de faire de la recherche lorsqu'on considère les différentes étapes de l'une ou l'autre des méthodologies comme des "balises de navigation" et non comme des "rails d'une voie ferrée" à suivre obligatoirement. Il n'est jamais simple de "gérer" les angoisses d'un chercheur. Je me réjouis de n'avoir pas "succombé" à la tentation de les calmer par la sécurité qu'offre l'obéissance stricte aux méthodes. J'ai été vigilant concernant cet enjeu pour éviter d'attraper le "virus intellectuel" qu'est 1'"obsession" méthodologique. En écrivant ces dernières lignes de conclusion qui constitue la "phase terminale" de la thèse, je goûte la joie d'être toujours bien vivant. Cette recherche doctorale ne m'a pas rendu malade! Mais pour éviter de le devenir tout au cours de cette longue aventure, j'ai 
dû prendre quotidiennement le risque d'être "sujet" de la recherche, c'est-à-dire de faire "acte de théologie" à partir des défis que les pratiques pastorales m'ont révélés. Je serai plus en mesure dans les prochains mois (suite aux résultats des membres du jury concernant cette thèse!) d'évaluer le prix de ma fidélité intérieure à tous ces choix.

J'ai le goût de poursuivre mes recherches sur l'institution paroissiale à partir de l'approche de la "théologie pratique". En terminant cette thèse de doctorat en théologie / études pastorales, je suis étonné des nombreuses découvertes que j'ai réalisées grâce à la praxéologie. L'utilisation de cette méthodologie de recherche pour les études de troisième cycle m'a une fois de plus convaincu que la pratique doit précéder la systématisation théorique. Cette dernière doit toujours être une réalité miroir. La réalité source, c'est l'expérience vécue de la communauté. Également, cette démarche réflexive m'a permis de prendre conscience du fait que le théologien d'aujourd'hui doit écouter et apprendre autant qu'il doit parler et enseigner. Faute d'écouter et d'apprendre le théologien risque, je le crains, d'obscurcir plutôt que d'illuminer les chemins de l'Église nouvelle issue de l'ancienne. Je sens une nécessité intérieure de toujours me tenir proche du terrain paroissial dans les prochaines années si je veux continuer à réfléchir sur cette institution ecclésiale. Certaines parties de la réflexion de théologie pastorale ne peuvent venir qu'en se confrontant à des pratiques concrètes. Le point de validation le plus pertinent de toute forme de théologie pratique se retrouve dans les expériences sur le terrain. L'essai dans l'histoire est le point d'intégration de toutes les composantes d'une recherche. S'il y a des aspects que nous avons oubliés au niveau théorique, la pratique nous les révèle rapidement. Plusieurs théologiens veulent prendre option pour la "théologie pratique". En fréquentant plusieurs d'entre eux au cours de ces dernières années d'études, j'ai constaté que certains parmi eux se sont "jetés" dans la réflexion épistémologique afin de pouvoir 
augmenter "la cote de crédit" de cette approche théologique. Ces efforts intellectuels sont nécessaires mais la crédibilité de la théologie pratique va se faire lorsque des théologiens vont risquer d'être des partenaires dans une pratique pour nourrir leur réflexion. Les théologiens peuvent véritablement aider la cause de la "théologie pratique" à la condition que nous ne passions pas le reste de nos vies à lire à ce sujet mais que nous osions cheminer avec des acteurs sur le terrain des pratiques où est la vie. Je suis conscient de la difficulté à opter pour ce choix. Il faut une bonne solidité intérieure pour réfléchir à partir des enjeux de la pratique. Il est toujours insécurisant de remettre sans cesse en question nos théories "miracles" et nos "solutions" à toute épreuve. C'est moins angoissant de lire et de lire, de lire et de répéter nos lectures. Il est plus difficile de lire la vie, de confronter cette lecture avec d'autres points de vue, de garder silence et par la suite de risquer quelques mots pour nommer les défis observés sur le terrain. ${ }^{1}$ Si nous désirons renouveler les pratiques pastorales et les pensées théologiques, nous devons susciter des recherches et des échanges plus ouverts entre les spécialistes du "dire" et les experts du "faire", en somme, entre tous les interprètes des différents terrains théologiques et pastoraux.

Il faut continuer à creuser le vieux fond paroissial pour en faire jaillir du neuf, tout en étant soucieux du fondamental et de la nouveauté. Une des conséquences graves de Vatican II est qu'aucune attention n'a été véritablement accordée à la base pastorale, c'est-à-dire aux communautés paroissiales. Jusqu'à maintenant, la vie m'a donné le privilège de consacrer plusieurs années de mon temps à un effort de réflexion sur la paroisse. Même si cette thèse comporte plusieurs pages (et sans doute trop!), je suis conscient que de nombreux aspects

$1 \quad$ II n'est pas plus facile pour les intervenants pastoraux de se laisser déranger par des questionnements théologiques sur les défis de leur pratique. Il y a aussi un risque d'absolutiser l'action et de déconsidérer l'importance de la réflexion. 
restent encore à approfondir. Je souhaite retrouver des conditions favorables dans les prochaines années pour poursuivre mes recherches sur la dynamique paroissiale en approfondissant particulièrement la piste théologique nommée au chapitre douzième, soit celle de la réflexion sur les réelles possibilités de la poursuite de la logique ecclésiologique du dernier concile jusqu'au niveau de la paroisse en considérant celle-ci comme une Église en un lieu ("une Église en laquelle est vraiment présente et agissante l'Église du Christ, une, sainte, catholique et apostolique"- $C D$ 11). La paroisse pourrait alors devenir une Église-Sujet dans sa relation avec les autres paroisses du diocèse, également Églises-Sujets. La mission de l'Église diocésaine (elle-même Église-Sujet avec les autres diocèses) serait entre autres de favoriser la concorde, la cohésion et la synodalité des communautés paroissiales présidées par l'ensemble des divers ministres avec l'évêque comme modérateur du grand collège ministériel diocésain. Cette manière de considérer la paroisse comme une véritable Église en un lieu amènerait à considérer le ministère de la présidence ecclésiale en lui-même et non plus en dépendance de l'Ordre épiscopal.

Quand on termine un doctorat, ce n'est pas la fin d'une longue réflexion, c'est le début d'une pensée en cheminement un peu plus articulée.... N'est-ce pas? Je souhaite continuer le dialogue fécond amorcé dans cette thèse avec tous ceux et celles qui sont passionnés par la vie des humains et qui ont le goût d'ouvrir l'avenir de l'humanité en réfléchissant avec honnêteté sur les défis à affronter pour que demain soit. 


\section{Bibliographie}

Dans cette bibliographie n'apparaissent que les articles et ouvrages ayant été cités pour cette étude (total: 354 )

\section{Les méthodologies de recherche (31)}

A. VAN DER VAN, Johannes, "The empirical approach in practical theology: why and How?", Nijmegen University - The Netherlands, Lecture at Montreal University, February 12, 1993, 13p.

AUDINET, J., "La théologie pastorale, une ecclésiologie pratique", in Témoin du Christ ,Liégé, P. A., dir., Paris, Cerf, 1980, pp. 153-169.

BERTALANFFY, Ludwig von, General System theory,Théorie générale des systèmes, traduit par Jean Benoîst Chabrol, Paris, Dunod, 1987, 298p.,

BERTEN, Ignace, Pour une théologie contextuelle, in Lumière et Vie , $\mathrm{n}^{\circ} 200$, pp.63-70.

BOFF, Clodovis, Théorie et Pratique, La méthode des théologies de la libération, Paris, Cerf, 1990, 404p.

COLLECTIF, Actes du Colloque: "L'observation dans la recherche en éducation", UQAC, Département des Sciences de l'Éducation, Ed. Jacqueline Thériault, 1990, 16p.

COLLECTIF, DESLAURIERS, J.P., dir., La recherche qualitative: résurgences et convergences , Chicoutimi, UQAC, 1985, 169p. ["Renouveau Méthodologique"-(GRIR) Groupe de recherche et d'intervention régionales]

- Le renouveau méthodologique en sciences humaines: recherche et méthodes qualitatives, Actes du colloque de Chicoutimi, UQAC, 1985, 108p. ["Renouveau Méthodologique" - (GRIR) Groupe de recherche et d'intervention régionales] 
DE ROSNAY, Joël, Le macroscope: vers une vision globale, Paris, Seuil, 1975, $295 p$.

DENIS, Philippe, "L'essor de la théologie contextuelle", in L'Actualité religieuse dans le monde, $\mathrm{n}^{\circ}$ 97, 15 février 1992, pp. 38-39.

DESMARAIS, Danielle, Trajectoire professionnelle et expérience du chomâge ouvrier des récits de vie et leurs significations multiples, Thèse de doctorat en anthropologie, Université de Montréal, octobre 1989, pp. 79-168.

DILLON, John A. Jr. , Foundations of General Systems Theory, U.S.A., Intersystems Publications, 1983.

DUFOUR, Simon et BOUCHARD, Nicole, "Les conditions d'une véritable andragogie et ses enjeux pour la théologie pratique", Intervention au Congrès Francophone de Théologie pratique à Lausanne, UQAC, mars 1992, 24p.

DURAND, Daniel, La systémique, Paris, Presses universitaires de France, 1979, $127 \mathrm{p}$.

HAMEL, Jacques, Dufour Stéphane, et FORTIN Dominic, L'enquête de terrain en sciences sociales. L'approche monographique et les méthodes qualitatives, Montréal, Éd. Saint-Martin, 1992, 183p.

LE GROUPE CFC - Management et ressources humaines, Session : "Gestion du changement organisationnel", Document de travail \#2: Analyse systémique et changement organisationnel, Québec, Mai 1993, 18p.

LE MOIGNE, Jean-Louis, La théorie du système général: théorie de la modélisation, Paris, Presses universitaires de France, 1977, 258p.

LECLERC, Gérard, L'observation de l'homme - Une histoire des enquêtes sociales, Paris, Seuil, 1979, 362p. [Sociologie]

LEMIEUX, André, Comment présenter un projet de recherche: approche systémique, Théorie et pratique, Montréal, Éd. Ville-Marie, 1981, 103p. 
LONERGAN, Bernard, Pour une méthode en théologie, Montréal, Fides, 1978, 468p. [ Cogitatio fidei, \#93]

MAFFESOLI, Michel, Le temps des tribus, Le déclin de l'individualisme dans les sociétés de masse, Paris, Meridiens Klincksieck, 1988, 284 p. [Livre de Poche, biblio, essais, \#12]

MARLÉ, René, "Théologie pratique et spirituelle", in Initiation à la pratique de la théologie, Tome 1: Introduction, Paris, Cerf, 1982, pp. 287-297.

MÉNARD, Camil, "L'urgence d'une théologie pratique nord-américaine comme théorie critique de l'agir chrétien au service de la société", in Seul ou avec les autres? Le salut chrétien à l'épreuve de la solidarité, Montréal, Fides, 1992, pp. 297-318. [Héritage et Projet, \#48]

MONGEAU, Pierre, La pensée systémique: historique et concept, Thèse de doctorat, Montréal, Université de Montréal, 1979.

NADEAU, Jean-Guy ,"Pour l'observation praxéologique d'une pratique pastorale" , in Sciences pastorales , $\mathrm{n}^{\circ} 3,1984$, pp.119-130.

-"Pour une science de l'action pastorale. Le souci de la pertinence pratique", in Les études pastorales à l'Université - Pastoral Studies in the University Setting, Ottawa-Paris-Londres, Les Presses de l'Université d'Ottawa, 1990, pp. 136-157.

POUPART, Jean, "La méthode qualitative en sciences humaines: une approche à redécouvrir", in Apprentissage et Socialisation, volume 4, numéro 1, 1981, pp.41-47.

RICOEUR, P. et al., NADEAU, J.G., dir., L'interprétation, un défi de l'action pastorale: Actes du Colloque 1987 du GREP, Montréal, Fides, 1989, 280p. [Cahiers d'études pastorales, \# 6]

SHEA, John, "Une approche de la théologie pastorale, Herméneutique pastorale", in Chicago Studies, 1973.

TREMBLAY, Eric, Rapport de participation au Congrès Francophone de Théologie Pratique, Lausanne, 26 au 31 mai 1992, 26p. 
ZULEHNER, P.M., "Théologie pratique", in Dictionnaire de théologie, Paris, Cerf, 1988, pp. 790-795.

2. Recherches sociologiques et réflexions pastorales (54)

ASSEMBLÉE DES ÉVÊQUES DU QUEBEC, Risquer l'avenir, Bilan d'enquête et prospectives du comité de recherche de l'AEQ sur les communautés chrétiennes locales, Montréal, Fides, 1992, 227p. [L'Église aux quatre vents]

-L'Église du Québec 1988-1993 à l'occasion de la visite ad limina 1993, les évêques du Québec font le bilan de la situation, Montréal, Fides, 1993, 92p. [L'Église aux quatre vents]

COMITÉ DE RECHERCHE DE L'AEQ SUR LES COMMUNAUTÉS CHRÉTIENNES LOCALES, L'Avenir des communautés chrétiennes, Rapport du congrès provincial tenu à Montréal en octobre 1992, Montréal, Fides, 1993, 128p. [L'Église aux quatre vents].

COMITÉ ORGANISATEUR, PICHER, Jean., dir., Rapport de la première étape du synode, Québec, 27 mai 1993,60p.

BÉLIVEAU, Jules, "Oui massif des québéçois au sacerdoce des femmes, in La Presse, Montréal, 3 avril 1993, pp. A-1, A-2.

BIBBY, Réginald, La religion à la carte, Pauvreté et potentiel de la religion au Canada, Montréal, Fides, 1988, 382p.

BOIVIN, Normand, "La population du Saguenay-Lac-Saint-Jean diminue légèrement et vieillit plus vite", in Progrès-Dimanche, 9 mai 1993, p. 27.

BOUCHARD, Pierre, "La pratique religieuse chez les catholiques francophones de Montréal", in Prêtre et Pasteur, vol. 94, n 1, janvier 1991, pp. 38-45.

CAMPBELL, Michel M., CHARRON, Jean-Marc, "Avenir et destin de la paroisse", in Le christianisme d'ici a-t-il un avenir?, Montréal, Fides, 1987, pp. 111- 118. [ Héritage et Projet, \# 40] 
CAPELLARO, Juan-Baptista, La paroisse communion de communauté, Kinshasa, CEP-Centre d'études pastorales, 1982, 96p. [Eglise demain, \# 2]

CAPELlARO, J. B., LIUT, J., CANESSO, L., COSSU, F., MC NABB, J., De la masse au Peuple de Dieu, traduction établie à partir de l'édition italienne: $D a$ massa a popolo di dio, 1984, 153p.

CHANCELLERIE DU DIOCÈSE DE CHICOUTIMI, Statistiques officielles, Annuaires diocésains de 1990, 1991, 1992, 1993, 1994.

CHARRON, André, "La paroisse évangélisatrice d'aujourd'hui", in Prêtre et Pasteur, vol. 94, n¹0, novembre 1991, pp. 615-625.

CHARRON, Jean-Marc, GAUTHIER, Jean-Marc, Entre l'arbre et l'écorce, un monde pastoral en tension, Montréal, Fides, 1993, 308p.

[Cahiers d'études pastorales, \# 14]

CHEVALIER, André, La paroisse post-moderne - Faire l'Église aujourd'hui l'exemple du Québec, Montréal, Paulines, 1992, 373p.

[Brèches théologiques, \#15]

COLLECTIF, "Les paroisses: Mort lente ou Renouveau", in Lumière et Vie, Tome XXV, $\mathrm{n}^{\circ}$ 123, juin-juillet 1975, 104p.

COLLECTIF, TREMBLAY, Eric, dir., Rapport de l'étude socio-économique de la Municipalité de Bégin, Archives municipales, 1980, 199p.

COLLECTIF, VACHON, Bernard, dir., Le Québec rural dans tous ses états, Montréal, Boréal, 1991, 311p.

COLLECTIF, Actes des états généraux du monde rural, Tant vaut le village, tant vaut le pays, Montréal, les 3, 4 et 5 février 1991, document rédigé sous la supervision du mouvement québécois Solidarité Rurale, 193p.

COLLECTIF, LESAGE, Louis, dir., "Les finances de l'Église", in Communauté chrétienne, vol. 2, $\mathrm{n}^{\circ} 15$, novembre 1991, pp. 9-16.

COMEAU, Maurice. "Vers une nouvelle image de la paroisse", in Prêtre et Pasteur, vol. 86, n' 7, juillet-août 1983, pp. 410-416. 
COMITÉ DE RÉFLEXION, Rapport synthèse du comité d'étude sur l'animation pastorale en milieu urbain, Diocèse de Saint-Hyacinthe, septembre 1986, 27p.

COMITÉ D'ÉTUDE SUR LA PASTORALE URBAINE, L'Église de Sept-îles s'interroge sur son avenir, Projet de pastorale urbaine, Document de travail, Diocèse de Baie-Comeau, 1990, 17p.

COMMISSION DIOCÉSAINE DE RECHERCHE PASTORALE, Mission et coresponsabilité, Chicoutimi, Secrétariat de la commission, 1977, 191p.

COMMUNAUTÉ DIOCÉSAIN SUR L'AVENIR DES COMMUNAUTÉS, Bâtir ensemble... Collaborer pour l'avenir, Document d'accompagnement, Diocèse de Chicoutimi, 1993, 101p.

CONSEIL DES AFFAIRES SOCIALES ET DE LA FAMILLE, Rapport de la situation socio-économique de la région du Saguenay Lac-Saint-Jean, Gouvernement du Québec, Publications officielles, 1986.

CÔTÉ, Charles, Désintégration des régions, Le sous-développement durable au Québec, Chicoutimi, Ed. JCL, 1991, 261p.

DUMONT, Fernand, "La paroisse, une communauté", in Communauté Chrétienne, vol. $1, \mathrm{n}^{\circ} 1$, janvier-février 1962, pp. 21-30.

- "La crise actuelle est celle d'une dissociation entre l'Église et la croyance au Christ", in $R N D, \mathrm{n}^{\circ} 3$, mars 1993, pp. 16-28.

DUMONT, Rapport, L'Église du Québec, un héritage, un projet , Montréal, Fides, 1972, 323p. [ Commission d'étude sur les laïcs et l'Église]

FARLY,Clément, "Pratiques de renouveau communautaire", in Communauté chrétienne, vol. 25, $\mathrm{n}^{\circ} 147$, mai-juin 1986, pp. 223-233.

GARNEAU, Jean-Yves, "Des homélies pour vivre", in Prêtre et Pasteur, vol. 93, $\mathrm{n}^{\circ} 7$, juillet 1990 , p. 385.

GRAND'MAISON' Jacques, "Sur le terrain des complicités", in Communauté chrétienne: "Les passeurs de la foi, L'enjeu d'une nouvelle évangélisation", vol. 2, n 16 , décembre 1991, pp. 7-20. 
- Dossier 1: Rapport de recherche-Faculté de théologie, Université de Montréal et Diocèse de St-Jérôme, Document de travail, 1992, 13p.

GUÉRARD, Y. F.,"L'équipe pastorale en paroisse: un fruit issu d'un projet diocésain.", in Prêtre et Pasteur, vol. 89, n 4, avril 1986, pp.238-245.

HÉBRARD, Monique, "Connues mais pas reconnues", in L'actualité religieuse dans ce monde, ${ }^{\circ} 108,15$ février 1993, pp. 35-39.

LEVASSEUR, Jean-Marie et TURMEL, André, L'évaluation pastorale au Québec, Les pratiques évaluatives en usage dans les paroisses catholiques du Québec, L'enquête, tome 1, Trois-Rivières, Pastor, 1992, 264p.

LEWIS, Oscar, The children of Sanchez, Autobiography of Mexican Family, New York, Randow House, 1961, 499p.

MÉNARD, Nathalie, "Dans la région - Le taux de chômage reste très élevé", in Le Quotidien, 7 août 1993, p.4.

MORISSETTE, Pierre, La pastorale en milieu urbain, Diocèse de Québec, Service de la pastorale, $1977,48 \mathrm{p}$. [pro manuscripto]

PRESSE CANADIENNE, "Le Saguenay conserve son record peu enviable", in Le Quotidien, 10 juillet 1993, p.7.

ROCHER, Guy, "Repères pour une société en mutation", in FORCES: "Vingt-cinq ans d'évolution du québec et regard sur l'avenir", numéro 100, Hiver 19921993, pp.15-20.

SERVICE DE LA PASTORALE COMMUNAUTAIRE, L'équipe pastorale en paroisse, Diocèse de Saint-Jean Longueuil, document de travail, 1985, 21 p.

SERVICE DE RECHERCHE, ROY, Gilles, dir., Analyse des résultats de l'enquête sur la vie et le ministère des prêtres du diocèse de Saint-Jean-Longueuil, 30 octobre 1991, 79p.

SERVICE DIOCÉSAIN DES COMMUNAUTÉS CHRÉTIENNES, Opération Avenir 8-8, Chicoutimi, Archives diocésaines, 1987, 13p. 
SERVICE DIOCÉSAIN DES MINISTÈRES, Face à l'avenir, Les ressources humaines en pastorale, Diocèse de Chicoutimi, 1988, 47p.

SOM inc, Étude sur la pratique religieuse des catholiques de la région métropolitaine de Montréal pour les Pères du Saint-Sacrement, mars 1990, $115 \mathrm{p}$ - Synthèse in Prêtre et Pasteur :"Sondage sur l'eucharistie", vol. 95, $\mathrm{n}^{\circ} 2$, février 1991, pp. 66-104.

STATISTIQUE CANADA, Profils- Rapport du recensement de 1991, Données intégrales, Catalogue \# 95-325, Canada, 1993, pp. 395- 449.

- Rapports des recensements canadiens de 1961, 1966, 1971, 1976, 1981, 1986 et 1991.

SUTTER, Jacques, "Transformations culturelles et crises du clergé catholique français", in Prêtres, Pasteurs et Rabbins dans la société contemporaine, VIe Colloque du Centre de sociologie du protestantisme, Paris, Cerf, 1982.

TREMBLAY, Diane-Gabriel et VAN SCHENDEL, Vincent, Économie du Québec, Montréal, Éd. Saint-Martin, 1991.

TREMBLAY,Eric. Procès-Verbaux produits et recueillis au cours des années de travail pastoral, Paroisses Saint-Dominique de Jonquière, Saint-Jude d'Alma et de St-Léon, 1984-1986, 1987-1991.

VILLENEUVE, Florent, Foi chrétienne et Région en voie de désintégration, in Pluralisme culturel et foi chrétienne, Actes du Congrès de la Société Canadienne française de Théologie tenu à Montréal du 30 octobre au 1 novembre 1992, Montréal, Fides, 1993, pp. 339-350.

[Héritage et Projet, \# 50].

WEAKLAND, Rembert Mgr, "La création de nouvelles paroisses et le manque de prêtres", in La Documentation catholique, $\mathrm{n}^{\circ} 2026$, avril 1991, pp. 395-401.

\section{3. Éclairage historique (29)}

ALBERIGO, Giuseppe, "Du seizième siècle à Vatican II", in La Maison-Dieu, $1986, n^{\circ} 165$, pp. 49-71. 
ARNOLD, F.X., Proclamation de la foi et Communauté de foi, Bruxelles, in Lumen Vitae, ${ }^{\circ}$ 9, 1956, pp. 50-56.

AUBRUN, M., La paroisse en France des origines au XV siècle, Paris, Picard, 1986, 269p.

CHRISTOPHE, Paul, L'Église dans l'histoire des hommes, Des origines au $X V^{o}$ siècle, Limoges, Droguet et Ardant, 1982, 582p.

CHRISTOPHE, Paul, L'Église dans l'histoire des hommes, Du XV'siècle à nos jours, Limoges, Droguet et Ardant, 1983, 632p.

COLLECTIF, Histoire de la Paroisse, Actes de la Onzième Rencontre d'Histoire Religieuse tenue à Fontevraud les 2 et 3 octobre 1987, Angers, Presses de l'Université d'Angers, 1988, 233p.

COLLECTIF, Situation et Avenir du catholicisme québéçois, Entre le temple et l'exil, Ottawa, Leméac,1982, 236p.

-Situation et Avenir du catholicisme québéçois, Milieux et Témoignages, Ottawa, Leméac, 1982, 266p.

CROCE, P.W., La paroisse de la théologie à la pratique, Paris, Cerf, 1961, 156p.

DE LABRIOLLE, Pierre, Paroecia, in Rech. Sc. Rel., 18, 1928, pp. 60-72.

DUMONT, Fernand, dir., La société québéçoise après 30 ans de changements, Québec, Institut québéçois de recherche sur la culture, 1990, 358p.

FAIVRE, Alexandre, Les laïcs aux origines de l'Eglise, Paris, Centurion ,1984, 296p. [Chrétiens dans l'histoire]

FERRETTI, Lucia, Entre voisins, la société paroissiale en milieu urbain SaintPierre-Apôtre de Montréal 1848-1930, Montréal, Boréal, 1992, 261p.

FLORISTAN, Casiono, "La paroisse à la lumière de l'histoire" in La Paroisse, communauté eucharistique, Essai d'une théologie Pastorale de la Paroisse, Paris, P. Lethielleux, 1963, pp. 41-52.

FRISQUE, J., "La paroisse, centre d'évangélisation", in Paroisse et Liturgie, 
$\mathrm{n}^{\circ} 59,1963, \mathrm{pp} .148-154$.

GAUDEMET, J., Le gouvernement de l'Église à l'époque classique, t. VIII, de l'Histoire de Droit et des Institutions de l'Église en Occident, vol. 2, Paris, 1979, pp. 217-304.

HENRI M.A. et CHELINI J., La longue marche de l'Église, Paris/Bruxelles, Elsevier/Bordas, 1981, 442p.

HOFFMANN, J., "L'Église et son origine", in Initiation à la pratique de la théologie, Dogmatique II, tome III, Paris, Cerf, 1983. pp.55-141.

IMBART, DE LA TOUR, Pierre, Les origines religieuses de la France, Les paroisses rurales $d u I V^{\circ}$ au $X I^{\circ}$ siècle, Paris, Picard, réimpression de l'édition de 1900, 1979, 354p.

LACROIX, Benoît, La religion de mon père, Montréal, Bellarmin, 1986, 306p.

LE BRAS, G., Les institutions ecclésiastiques de la chrétienté médiévale, tome XII de l'Histoire de l'Église, vol. 2, Paris, 1964, pp. 404-423.

LECLERCQ, H. , "Paroisses rurales", in Dictionnaire d'archéologie chrétienne et de liturgie, tome treizième, deuxième partie, Paris, Letouzey et Ané, 1938, col. 2198- 2235 .

MANDOUSSE, André, et al., "Hippolyte de Rome", in Histoire des saints et de la sainteté chrétiennee, Tome II: La semence des martyrs, 33-313", Paris, Hachette, 1987.

MARTIMORT, A.G., L'Église en prière, chap. II: La concélébration eucharistique, Paris, DDB, 1983, pp. 238-246.

PARÉ, Marius Mgr, ancien évêque de Chicoutimi, L'Église au Diocèse de Chicoutimi, tome 1: Germination et Formation 1535-1888, Chicoutimi, 1983, 579p.

PASSICOS J., "Paroisse", in Catholicisme, hier, aujourd'hui, demain, Paris, Le Touzey \& Ané, 1984, col. 671-691. 
VOISINE, Nive, BEAULIEU, André et HAMELIN, Jean, Histoire de l'Église catholique au Québec 1608-1970, Montréal, Fides, 1971, 112p.

[ Commission d'étude sur les laïcs et l'Église, Première annexe au rapport]

VOISINE, Nive, HAMELIN, Jean et GAGNON, Nicole, Histoire du Catholicisme québéçois, Le XX o siècle, Tome I: 1898-1940, Montréal, Boréal espress, 1984, 504p.

- Histoire du Catholicisme québéçois, Le XX'o siècle, tome II: 1940 à nos jours, Montréal, Boréal espress, 1984, 425p.

4. L'urbanisation et les défis pastoraux

ANTOINE, J., Le phénomène urbain, Paris, Aubier - Montaigne, 1965, 259 p. [Recherches économiques et sociales]

BEAUCHAMP, André, "Trouver Dieu en ville?", in Relations, n564, pp. 240-243.

BEZERRA, Jearson Lucas, Urbanisation et exclusion, Textes des conférences du Congrès de l'Entraide missionnaire 1993: Un monde en déplacement, Montréal, Ahuntsic, 10-11-12 septembre 1993, pp. 35-41.

BODZENTA, Erich, "Critères de planning paroissial urbain", in Paroisses urbaines, paroisses rurales, $5^{\circ}$ conférence internationale de sociologie religieuse, Paris, Caterman, 1958, pp. 143-150.

BROCKMÖLLER, Clément, civilisation industrielle et religion, Traduit de l'allemand par Paul DÉMANN, Paris, Desclée et Cie, 1968, 248p.

[ Religion et sociétés contemporaines]

CADRIN, Daniel, "Les premiers chrétiens en ville", in Communauté chrétienne, $\mathrm{n}^{\circ}$ 154, juillet-août 1987, pp. 261-269.

CAMPBELL, Michel, "Les lieux de la liturgie dans la société urbaine", in Communauté chrétienne, $\mathrm{n}^{\circ} 154$, juillet-août 1987, pp. 270- 278. 
CARRIER Hervé, PIN, Émile, Essais de sociologie religieuse, Paris, SPES, 1967, 587p.

CELAM, "La pastorale dans les grandes villes latino-américaines", in Documentation catholique, $\mathrm{n}^{\circ} 1843,2$ janvier 1983, pp. 59-62.

CHARRIER, Jean-Bernard, Citadins et ruraux, Paris, Presses universitaires de France, 1970, 128p. [Que sais-je?]

CHARTRAND, Luc, "Les villes n'ont plus de coeur-Interview avec Robert Fishman", in Actualité, 15 novembre 1992, pp. 23-26.

COLLECTIF, L'urbanisation au Québec: rapport du groupe de travail sur l'urbanisation, Québec, Editeur officiel du Québec, 1976, 347p.

COLLECTIF, Urbanisation et pastorale, $72^{\circ}$ Congrès national de pastorale de France, Paris, Fleureus, 1967, 268p.

COMBLIN, Joseph, Théologie de la ville, Paris, Editions universitaires, 1968, pp.303-416.

COMTOIS, Claude, PLOEGAERTS, Léon, "Vie de banlieue, l'étalement urbain annonce-t-il le fatal déclin de Montréal?" , in Le Devoir, 27 novembre 1992, p. B-8.

CONNAN, F. et BARREAU, J-C., Demain, la paroisse, Paris, Cerf, 1966, 126p.

CROP, "L'avenir et nous 2000, Sondage pour l'Actualité - TVA, in L'Actualité, janvier 1993, vol. 18, n 1, pp. 26-29.

DRAKAKIS-SMITH, David, Urbanisation in developing world, London, Dover, N.H. Croom Helm, 1986, 265p.

DUMONT, Jacques-J., Urbanisation et problèmes religieux, Louvain, Centre de recherches socio-religieuses, 1966, 324p.

FALARDEAU, Jean-Charles, "Les paroisses dans nos villes: aujourd'hui et demain", in Communauté chrétienne, $\mathrm{n}^{\circ} 24$, vol. 4, nov.-déc. 1965, pp. 481-489. 
FICHTER, Joseph, H., Social Relations in the Urban Parish, The University of Chicago Press, 1954, 263p.

- "La paroisse urbaine comme groupe social", in Paroisses urbaines, Paroisses rurales, $5^{\circ}$ conférence internationale de sociologie religieuse, Paris, Caterman, 1958, pp. 84-94.

FORTIN, Andrée, ROMPRÉ, David, La sociabilité urbaine au Saguenay, Vie associative, solidarités et dynamique communautaire, Québec, Centre interuniversitaire SOREP, 1993, 147p.

GAUTHIER, Gilles, "3 ${ }^{\circ}$ sommet des grandes villes du monde", in La Presse, Montréal, 16 octobre 1991, p. A-5; 17 octobre 1991, p. A-4; 18 octobre 1991, p. A-4.

HERVIEU - Léger, Danièle, Vers un nouveau Christianisme, Introduction à la sociologie du Christianisme occidental, Paris, Cerf, 1986, 395p.

[Sciences humaines et religions]

HOUTART, François, "Faut-il abandonner la paroisse dans la ville moderne?", in N.R.T., vol. 77, $\mathrm{n}^{\circ}$ 6, juin 1955, pp.602-613.

HOUTART, F. et Rémy, J., Milieu urbain et communauté chrétienne, Mame, ParisTours, 1968, 390p.

JOLIF, Jean-Yves, "La ville, projet humain", in Lumière et Vie, n 90, pp.83-94.

LEFEBVRE, Henri, Du rural à l'urbain, Paris, Anthropos, 1977, 285p.

LESSARD, Marc-A., "Liturgie, culture et paroisse: une perspective sociologique", in Liturgie, Foi et Culture, vol. 23, n 119, septembre 1989, pp. 11-19.

MEEKS, Wayne A., The first Urban Christians, The Social World of the Apostle Paul, Yale University Press, New Haven and London, 1983.

MONTMINY, Jean-Paul, "Repenser la pastorale des milieux ruraux", in Communauté chrétienne, ${ }^{\circ} 24$, vol. 4, nov.- déc. 1965, pp.490-499.

MONTMINY Jean-Paul et LESSARD Marc-André, L'urbanisation de la société canadienne-française, Québec, Les presses de l'Université Laval, 1967, 209p. 
RAMBAUD, Placide, Société rurale et urbanisation, Paris, Seuil, 1974, 348p.

REMI, J., "Communauté et Assemblée liturgique dans une vie sociale en voie d'urbanisation", in La Maison-Dieu , $\mathrm{n}^{\circ}$ 91, 1967, pp. 76-104.

REMY,J., HIERNAUX, J.P. et SERVAIS, E., "Le phénomène paroissial aujourd'hui-éléments pour une interrogation sociologique", in Lumière et Vie, $\mathrm{n}^{\circ} 123$, pp. 25-36.

RÉMY, J. et VOYÉ, Liliane, La ville et l'urbanisation, Modalités d'analyse sociologique, Bruxelles, Cabay, 1982, 252p.

- La ville: vers une nouvelle définition? , Paris, L'Harmattan, 1992, 173p. [Ville et entreprise]

ROBERT, Georges, "L'explosion urbaine mondiale" - 1) "Chaos ou maîtrise" in Le Devoir, 22 avril 1992, p. B-8.

ROULEAU, Jean-Paul, Chicoutimi: contexte socio-religieux et adaptation pastorale, Québec, Université Laval, Centre de recherche em sociologie religieuse, 1968, 237p.

TARDIF, Francine, "La ville: attraits, peurs et défis", in Relations, octobre 1990, $\mathrm{n}^{\circ} 564$, p. 232.

TREMBLAY, Paul, "Le citadin et Dieu", in Prêtre et Pasteur, vol. 92, n6, juin 1989, pp. 322-328.

VEAR, Danny, "L'étalement urbain, un mal inévitable", in Le Devoir, 8 octobre 1992, p. A-3.

- "L'étalement urbain va continuer si les baby-boomers se comportent comme ceux qui les ont précédés", in Le Devoir, 28 novembre 1992, p. A-2.

VOYÉ, L., La paroisse vue par le sociologue, in La paroisse dans l'Église d'aujourd'hui, Louvain-la-Neuve, 1981. 
WILSEY, Jean-Pierre, "Auto-bungalow-dodo, les choix politiques en faveur du projet de société-banlieue risque de provoquer des situations explosives", in Le Devoir, 10 mars 1993, p. A-9.

ASSOCIATION DES AGENTS ET AGENTES DE PASTORALE LAIQUES DU DIOCĖSE DE CHICOUTIMI, Identité et insertion des agents et agentes de pastorale laïques dans le diocèse de Chicoutimi, Document de réflexion diocésaine, Chicoutimi, 1993,18p.

AUDET, Jean-Paul, Mariage et célibat dans le service pastoral de l'église, Paris, Oriante, 1967, 161p.

BAUSCH, William J., Ministry, Traditions - Tensions - Transitions , Connecticut, Twenty-third publications, 1982, 176p.

BERGERON, Yvonne, Partenaires en Église, Femmes et hommes à part égales, Montréal, Paulines, 1991, 121p.

- "Les prêtres craignent de perdre le pouvoir", entrevue à CHARETTE, Donald, in Le Soleil, 15 novembre 1992, p. A-9.

BRISEBOIS, Mireille, Saint Paul: Introduction à Saint Paul et à ses lettres, Montréal, Ed. Paulines, 1984, 173p.

BURKART, Gary P., The parish life coordinator, Sheed and Ward, 1992, 140p.

CHARRON, André, "Laïcs et clercs: des catégories à dépasser, voire à supprimer", in Relations clercs-laïcs, analyse d'une crise, Montréal, Fides, 1985, pp. 147-196. [Cahiers d'études pastorales ,\#1]

COLLECTIF "KRISIS", Des Ministères nouveaux? , Montréal, Paulines, 1985, $243 p$.

COLLECTIF, Laïcs: l'inconfort et la différence, in Communauté chrétienne, vol. $26, \mathrm{n}^{\circ} 151$, janvier-février $1987,96 \mathrm{p}$. 
COMITÉ DES MINISTÈRES DE L'AEQ, Les nouvelles pratiques ministérielles, Document de réflexion, Montréal, Fides, 1993, 165p.

[L'Église aux quatre vents]

-Communautés et ministères au Québec: Situation, questions, défis, Montréal, Fides, 1993, 36p. [L'Église aux quatre vents]

CONGAR, Yves, Ministères et communion ecclésiale, Paris, Cerf, 1971, 264p. [Théologie sans frontières].

DELORME, Jean, dir., Le ministère et les ministères dans le Nouveau Testament, Paris, Seuil, 1974, 540p. [Parole de Dieu]

DENIS, Henri, "La théologie du presbytérat de Trente à Vatican II", in Vatican II, Les prêtres, formation, ministères et vie, Paris, Cerf, 1968, pp. 193-232. [Unam Sanctam, \# 68]

DIDIER, R., dir., Le ministère sacerdotal, Un dossier théologique, Lyon, Profac, 1970.

DUFOUR, Simon, "Les origines du rapport clerc-laïc", in Prêtre et Pasteur, volume $89, \mathrm{n}^{\circ} 4$, avril 1986, pp.206-216.

- "Le presbytérat dans la mission de l'Eglise", in Prêtre et Pasteur, vol. 90, nº , avril 1987, pp. 224-236.

DUFOUR, Simon, PARENT, RÉMI, Les Ministères, Paris-Montréal, CenturionPaulines, 1993, 102p. [Parcours, la bibliothèque de formation chrétienne]

GRELOT, P., Église et ministères, Pour un dialogue critique avec Edward Schillebeeckx, Paris, Cerf, 1983, 282p.

GUETNY, Jean-Paul, dir., Dossier: "Les clercs", in ARM, $\mathrm{n}^{\circ} 144$, 5 septembre 1993, pp. 24-47.

GUTIERREZ, Gustavo, Praxis de libération et foi chrétienne, in Lumen Vitae, vol. XXIX, nº 2, 1974, pp. 227-254. 
HUBERT, Bernard Mgr, "Les ministères dans une Église-communion", in Église Canadienne, vol. 19, $\mathrm{n}^{\circ}$ 8, 19 décembre 1985, pp. 231-232.

JEAN-PAUL II, Exhortation apostolique post-synodale Christifideles Laici (Les fidèles laïcs), Montréal, Fides, 1989, 208p. [L'Église aux quatre vents].

- Pasteurs selon mon coeur, Exhortation post-apostolique sur la formation des prêtres dans les circonstances actuelles, Montréal, Paulines, 1992, 229p.

KEARNEY, Peter, "Trouve-t-on dans le Nouveau Testament des motifs de changer l'organisation de l'Église?", in Concilium, n8 80, 1972, pp. 53-66.

KRUBY, K., "La notion d'ordination dans la tradition juive", in La Maison-Dieu, $\mathrm{n}^{\circ}$ 102, Paris, 1970 , pp. 52-72.

LE CENTRE CANADIEN D'OECUMÉNISME, "Déclaration du Dialogue anglican-catholique romain du Canada sur l'expérience du ministère des femmes au Canada", in Oecuménisme, n 103, septembre 1991, pp. 4-25.

LEMAIRE, André, Les ministères aux origines de l'Église, Paris, Cerf, 1971, 249p. [ Lectio Divina , \# 68]

- "Des services aux ministères: les services ecclésiaux dans les deux premiers siècles", in Concilium, $\mathrm{n}^{\circ}$ 80, 1972, pp. 39-51.

- Les ministères dans l'Église, France, Centurion, 1974, 127p. [Croire et Comprendre]

- "Les Épîtres de Paul: la diversité des ministères, in Le ministère et les ministères selon le Nouveau Testament, Dossier Exégétique et Réflexion Théologique , Paris, Seuil, 1974, pp. 57-73. [Parole de Dieu]

PARENT, Rémi, Une Église de baptisés pour surmonter l'opposition clercslaïcs, Montréal, Paulines, 1987, 212p.

- Prêtres et Evêques, Le service de la présidence ecclésiale, Montréal, Paulines et Cerf, 1992, 316p. [Brèches théologiques, \#12] 
RADEMACHER, William J., Lay ministry, a theological, spiritual and pastoral handbook, New York, Crossroad, 1991, 274p.

RIGAL, Jean, Le courage de la mission, Paris, Cerf, 1985, 192p.

- Ministères dans l'Église, aujourd'hui et demain, Paris, DDB, 1991, 348p.

SCHILLEBEECKX, E., Le ministère dans l'Église, Paris, Cerf, 1981, $211 \mathrm{p}$.

- Plaidoyer pour le peuple de Dieu, Histoire et théologie des ministères dans l'Église, Paris, Cerf, 1987, 304p. [Théologie]

SWEETSER, Thomas, WISNIEWSKI HOLDEN, Carol, Leadership in a successful parish, San Francisco, Harper and Row, 1987, 204p.

TILLARD, Jean-Marie. "L'Église catholique et la pluralité des ministères", in Église Canadienne, vol. XVI, n 5, 4 novembre 1982, pp. 139-144.

THEISSEN, G., The Social Setting of Pauline Christianity: Essays on Corinth, Philadelphia, Fortresse Press, 1982.

VENETZ, Hermann-Joseph, C'est ainsi que l'Église a commencé, Paris, Cerf, 1986.

WASSELYNCK, R., Les Prêtres, Élaboration du decret de Vatican II, Histoire et genèse des textes conciliaires, 2 fasc., Paris, Desclée, 1968.

6. Ecclésiologie, droit canonique et modernité (94)

ARENDT, H., Condition de l'homme moderne, Traduction de: The Human Condition, Paris, Cerf, Paris, Calmann-Lévy, 1988, 406p.

ASSEMBLÉE DES ÉVEQUES DU QUÉBEC, Guide canonique et pastoral au service des paroisses, Montréal, Fides, 1991, 255p. 
BAUM, Gregory, "La modernité, Perspective sociologique", in Concilium, $\mathrm{n}^{\circ} 244,1992, \mathrm{pp} .15-23$.

BAUSCH, William J., The hands-on parish, Reflections and suggestions for Fostering Community, Connecticut, twenty-third publications, 1991, 220p.

BELLET Maurice, L'Église morte ou vive, Paris, DDB, 1991, 183p.

BLANQUART, Paul, "Nouvel individu et avenir du christianisme", in Lumière et Vie, $\mathrm{n}^{\circ} 184$, pp. 65-82.

-" "Postmarxisme" et "postmodernité" - Quelle présence de l'Église?", in Concilium, $\mathrm{n}^{\circ} 244,1992$, pp. 153-162.

BOFF, Léonardo, Église, charisme et pouvoir, Paris, Lieu Commun, 1985, 284p.

- Église en genèse, Les communautés de base réinventent l'Église, Paris, Cerf,1977, 253p.

BRENNAM Patrick J., Re-Imagining the Parish, New York, Crossroad, 1990, $151 p$.

CECC, "Synthèse des travaux du Synode extraordinaire des évêques", in Église Canadienne, vol. 19, no 9, 2 janvier 1986, pp. 259-268

- "Vingt ans de promotion du laïcat en Église - synthèse des rapports des diocèses-", in Église Canadienne, vol.20, n8 ,18 décembre 1986, pp. 233-242.

CENTRE DIOCÉSAIN, Les équipes pastorales mandatés en paroisse dans le diocèse de Saint-Jean-Longueuil, février 1994, 19p.

CESARI, Constance Colonna, Urbi et Orbi, Enquête sur la géopolitique vaticane, Paris, Ed. de la découverte, 1992, 279p.

CHARRON, André, "Les caractéristiques théologiques d'une communauté chrétienne vivante en paroisse", in Communauté Chrétienne: Les Paroissiens, avenir de la paroisse, vol. 17, n 197, janvier-février 1978, pp.17-52. 
- "Quelques traits de la culture québécoise actuelle", in Pastorale

Québec: "Le service pastoral de la foi dans le contexte culturel actuel", vol. 105, no 9,30 juin 1993, pp. 223-245.

CHOUINARD, P., "Les expressions "Église locale" et "Église particulière" dans Vatican II", in Studia canonica, \#6, 1972, pp. 115-161.

CODE DE DROIT CANONIQUE, Texte officiel et traduction française par la Société internationale de droit canonique, Ottawa, CECC, 1984, 363p.

CODEX IURIS CANONICI, Romae, Typis poliglottis Vaticanis, 1917.

\section{CONFERENCIA GENERAL DEL EPISCOPADO LATINO AMERICANO}

$\left(\mathrm{IV}^{\circ}\right)$, Nueva evangelizacion promocion humana cultura cristiana,

Conclusiones, Santo Domingo, 12-28 de Octubre de 1992, 86p.

COFFY, R., L'Église signe de salut au milieu des hommes, Paris, Centurion, 1972, 92p. [Assemblée Plénière de l'Épiscopat français- Lourdes 1991]

COLLECTIF, Les Églises après Vatican II. Dynamisme et Prospective. Actes du Colloque international de Bologne, Paris, Beauchesne, 1981, 260p. [Théologie Historique, \# 61]

COLLECTIF KRISIS, Chemin faisant...en quête d'Église, Montréal, Paulines, 1991, 221p. [Pastorale et Vie, \#10]

COLLECTIF, PELCHAT, Marc et VIAU, Marcel, dir., Un peuple ensemble, Montréal, Paulines, 1990, 133p.

COMITÉ "AD HOC" DU CP, "L'Église de Dieu qui est à Chicoutimi, une Église en marche... dans la foulée conciliaire", Document de travail pour le Conseil Presbytéral, Diocèse de Chicoutimi, 14 septembre 1993, 19p.

COMITÉ DE THÉOLOGIE DE L'AEQ, Mission de l'Église et culture québécoise, Réflexion sur les liens entre foi et culture, Montréal, Fides, 1992, 51p. [L'Église aux quatre vents]

CONCILE OECUMENIQUE VATICAN II, Constitutions, Décrets, Déclarations, Paris, Centurion, 1967, 1012p. 
CONGRÉGATION POUR LA DOCTRINE DE LA FOI, Déclaration sur la question de l'admission des femmes au sacerdoce ministériel Inter insigniores, 15 octobre 1976: AAS 69, 1977, pp. 98-116.

CONSTITUTION APOSTOLIQUE, Catéchisme de l'Église catholique, Paris, Name/Plon, 1992, 676p.

CONGAR, Yves, Tous responsables dans l'Église, Paris, Le Centurion, 1973. - Les Églises après Vatican II, Paris, Beauchesne, 1981.

DEJAIVE, G., "L'Église particulière dans le mystère de l'Église", in Un tournant décisif de l'ecclésiologie de Vatican II , Paris, Beauchesne, 1978, pp. 13-22. [Le point théologique, \#31].

DENIS, Henri, Église qu'as-tu fait de ton concile? Paris, Centurion, 1985, 248p.

- L'Église, Les quatres portes du Temple, Paris, DDB, 1991,184p.

DILLENSCHNEIDER, Clément, La paroisse et son curé dans le mystère de l'Église, Paris, Alsatia, 1965, 197p.

DOLAN, P. Jay, APPLEBY, R. Scott, BYRNE, Patricia, CAMPBELL, Debra, Transforming Parish, The changing roles of catholic clergy, laity, and women religious, New York, Crossroad, 1990, 336p.

DUFOUR, Simon, BÉLISLE, Denis, BOUCHARD, Nicole, HUDON-MIOR, Jocelyne, "La sécularisation, être chrétien au coeur du monde", in Présence, vol. 1, no 7, décembre 1992, pp. 11-19.

DULLES, Avery, "L'Église, sacrement et fondement de la foi", in Problèmes et perspectives de théologie fondamentale, Paris- Montréal, R. LATOURELLE et G. O'COLLINS ed., 1982, 489p.

DUQUOC, Christian, Des Églises provisoires, Essai d'ecclésiologie oecuménique, Paris, Cerf, 1985, 118p.

FOSTER M. Patricia, SWEETSER, P. Thomas, Transforming the parish, Models for the future, Kansas City, Sheed and Ward, 1993, 241p. 
GAUCHET, M., "La religion de la sortie de la religion", in Autrement, $\mathrm{n}^{\circ} 75$, décembre 1985, pp. 11-15.

GEFFRÉ, Claude, JOSSUA, Jean-Pierre, "Pour une interprétation théologique de la modernité", in Concilium, $\mathrm{n}^{\circ} 244$, pp. 7-11.

GRAND'MAISON, Jacques, La paroisse en concile, Ottawa, Fides, 1966, 300p.

GROOTAERS, Jan, De Vatican II à Jean-Paul II, Le grand tournant de l'Église catholique, Paris, Centurion, 1981, 255p.

GUETNY, Jean-Paul. dir., Dossier: "Église, qu'as-tu fait de ton Concile?", in $A R M, \mathrm{n}^{\circ} 117,15$ décembre 1993, pp. 19-41.

HERVIEU-LÉGER, D., Vers un christianisme de communautés émotionnelles?, in L'État des religions dans le monde, Montréal et Paris, Boréal et $\mathrm{La}$ Découverte- Le Cerf, 1987, pp. 507-509.

JEAN, Daniel, La place des paroissiens et paroissiennes dans les aménagements des communautés paroissiales, Mémoire de maîtrise, UQAC-Université de Montréal, avril 1989, 147p.

JEAN-PAÚL II, "Construisez la maison de tous les disciples du Christ", Allocution aux représentants des paroisses à Utrecht, in La Documentation Catholique, $\mathrm{n}^{\circ} 1898,16$ juin 1985 , p. 632.

- "Vie diocésaine et vie paroissiale, discours aux évêques français de la région sud-ouest", in La Documentation catholique, $\mathrm{n}^{\circ} 2046$, 15 mars 1992, p. 259.

- "Le Pape reçoit les Évêques du Québec", in L'Osservatore Romano, $\mathrm{n}^{\circ} 19,11$ mai 1993, pp. 2-3.

JEANNIÈRE, Abel, "Qu'est-ce que la modernité?", in Nouveau Dialogue, mai 1992, pp. 4-9.

KERKHOFS, Jan, "L'Église locale de Vatican II jusqu'à nos jours", in La MaisonDieu, $\mathrm{n}^{\circ} 165,1986$, pp. 73-100. 
KOMONCHAK, J.A., "L'Église universelle, communion d'Églises locales", in Concilium, \# 166, juin 1981, pp. 55-64.

KUNG, Hans, Qu'est-ce que l'Église? Belgique, DDB, 1972, 207p.

LANGEVIN, Gilles, "Modernité, foi et moralité selon Charles Taylor", in Nouveau Dialogue, mai 1992, pp. 15-18.

LANNE, É., "L'Église locale et l'Église universelle: actualité et portée du thème", in Irenikon, $\mathrm{n}^{\circ} 43,1970$, pp. 490-495.

LEGRAND, Hervé, "La délimitation des diocèses", in La charge pastorale des évêques, Paris, Cerf, 1969, 466p. [Unam Sanctam, \# 74]

- "Inverser Babel: mission de l'Église", in Spiritus, \# 43, 1970, pp. 323-331.

- "L'Église se réalise en un lieu", in Initiation à la pratique de la théologie Dogmatique II, tome III, Paris, Cerf, 1983, pp.142-345.

LOHFINK, Gerhard, L'Église que voulait Jésus, Paris, Cerf, 1985, 196p.

MARC, Gabriel, "L'Évangile face aux enjeux de la prochaine décennie", in Actes du Congrès de l'Entraide missionnaire 1992: D'un "nouvel" ordre mondial à une "nouvelle" évangélisation, Montréal, Collège Ahunstic, 11-13 septembre 1992, pp. 73-87.

MONNOT, Patrice, "Les laïcs et le pouvoir de gouvernement au sein de la curie romaine", in Praxis juridique et religion, n³, Cerdic, 1986, pp.173-184.

NAUD, André, Le Magistère incertain, Montréal, Fides, 1987, 265p. [Héritage et Projet, \# 39]

PAGE, Roch, Les Églises particulières, tome 1, Montréal, Paulines, 1985, 205p.

PARENT, Rémi, Communion et pluralité de l'Église, Pour une pratique de l'Unité ecclésiale, Montréal, Fides ,1980, 262p. [Héritage et Projet, \#24]

- L'Église, c'est vous!, Montréal, Paulines, 1982, 119p. 
PAUL VI, "Diocèse, Paroisse et Communauté de base", Allocution adressée aux participants de la XXI ${ }^{\circ}$ semaine italienne d'aggiornamento pastoral, 9 septembre 1971, in La Documentation Catholique, 3 octobre 1971, pp. 857858.

PEELMAN, Achiel, L'inculturation, l'Église et les cultures, Paris-Canada, DescléeNovalis, 1989. 197p.

PELCHAT Marc, "Ecclésiologie théologique et ecclésiologie contextuelle. L'ecclésiologie dans les études pastorales", in Les études pastorales à l'Université - Pastoral Studies in the University Setting, Ottawa-ParisLondres, Les Presses de l'Université d'Ottawa, 1990, pp. 159-176.

PÉRISSER, Jean-Claude, La paroisse, Commentaires des Canons 515-572, Paris, Tardy, 1989, 279p. [Le nouveau droit ecclésial, Commentaire du Code de Droit Canonique - Le Peuple de Dieu].

PIE X, Vehementer Nos, in Acta Sanctae Sedis , \# 39, 1906, 89 p.

POULAT, Émile, "Catholicisme et modernité, un procès d'exclusion mutuelle", in Sociologie et sociétés, vol. XXII, n 2, octobre 1990, pp. 25-31.

PROVENCHER, Normand, "Vers une ecclésiologie totale", in Église et Théologie, $\mathrm{n}^{\circ} 15,1984$, pp. 81-93.

RATZINGER, J., MAIER, H., Démocratisation dans l'Église, Possibilités, limites, risques, Traduit de l'allemand par Gérard-Philippe NYSSER, Paris, Apostolat des éditions, 1971, 93p. [Le Point, \#22]

RATZINGER, Joseph, "Aux évêques de l'Église catholique, sur certains aspects de l'Église comprise comme communion", Lettre de la Congrégation pour la Doctrine de la foi, in La Documentation Catholique, $\mathrm{n}^{\circ} 2055,2$ et 16 août 1992, pp. 729-734.

RIGAL, Jean, Préparer l'avenir de l'Église, Paris, Cerf, 1990, 194p.

- Le mystère de l'Église, fondements théologiques et perspectives pastorales, Paris, Cerf, 1992, 275p. 
ROULEAU, Jean-Paul, "Le christianisme et la modernité, l'affrontement de deux logiques", in Nouveau Dialogue, mai 1992, pp. 10-14.

ROUTHIER, Gilles, "'Église locale" ou "Église particulière", querelle sémantique ou option théologique?", in Studia canonica, \#25, 1991, pp. 277-334.

- La réception de Vatican II dans une Église locale, L'exemple de la pratique synodale au Diocèse de Québec (1982-1987), Université de Paris-Sorbonne (Paris IV), 1991, T.IV, pp. 1079-1080 et pp. 1095-1110.

RUDGE, P. F., L'Église à l'heure du management, Traduction de S. Martineau, Paris, Mame-Fayard, 1971, 230p.

RUIZ, Samuel Don, L'utopie chrétienne: libérer l'homme, Montréal, Départ, 1971, 157p.

SCHILLEBEECKX, Edward, L'histoire des hommes, récit de Dieu, Paris, Cerf, 1992, 381p. [ Cogitatio fidei , \#166]

SWEETSER, Thomas, Successful Parishes, How they meet the challenge of change, San Francisco, Harper and Row, 1983, 254 p.

TAYLOR, Charles, Grandeurs et misères de la modernité, Montréal, Bellarmin, 1991, 151p. [L'essentiel]

TILLARD, Jean-Marie R., Église d'Églises, L'ecclésiologie de communion, Paris, Cerf, 1987, 415p.

- Chair de l'Église, chair du Christ, Aux sources de

l'ecclésiologie de communion, Paris, Cerf, 1992, 168p.

[ Cogitatio Fidei, \# 168]

TILLICH, Paul, Théologie de la culture, Éd. Planète, 1968.

- Dynamique de la foi, Belgique, Casterman, 1968, 140p.

[Cahiers de l'actualité religieuse]

TURBANTI, Giovanni, " "Moderne" et "antimoderne" dans la préparation du concile et dans les indications de Jean XXIII", in Concilium, $\mathrm{n}^{\circ} 224$, 1992, pp. 119-129. 
TREMBLAY, Eric, Dynamique de la paroisse et projet communautaire, Mémoire de maîtrise, UQAC - Université de Montréal, 1987, 148p.

VALADIER, Paul, L'Église en procès, Paris, Champs-Flammarion, 1989, 241p.

- "Chances du message chrétien dans le monde de demain", in Concilium , n² 244, 1992, pp. 143-152.

WILLAIME, Jean-Paul, "L'individualisme est-il un fléau moderne?", in ARM, $\mathrm{n}^{\circ} 116,15$ novembre 1993, pp. 21-23.

7. Croissance humaine - croissance spirituelle- rites de passage (56)

BARDE, Alain, L'Évangile découvert par les marginaux d'hier et espéré par ceux d'aujourd'hui, Paris, Cerf, 1983, pp. 93-94.

BELLET, Maurice, Incipit ou le commencement, Paris, Desclée de Brouwer, 1992, $79 \mathrm{p}$.

BOUCHARD, Luc, "Apologie de l'expression liturgique, Points de repères en pastorale sacramentelle", in Prêtre et Pasteur, juin 1993, pp. 348-355.

BREEMEN, Pierre Van, Tu as du prix à mes yeux, Montréal, Bellarmin, 1986, $158 \mathrm{p}$.

BRETON, Jean-Claude, Foi en soi et confiance fondamentale, Dialogue avec Marcel Légaut et Erick Erikson, Paris, Le Cerf, 1987, 358p. [Nouvelle Série, \# 13]

- Approche contemporaine de la vie spirituelle, Montréal, Bellarmin, 1990, 191p.

BÜHLER, C., The Course of Human Life: A Study of Goals in the Humanistic Perspective, New York, Sprinter, 1968, 422p. 
BÜHLER, Pierre, "Foi et humour", Une petite dramatique de la foi chrétienne d'après DURRENMATT, in Bulletin du Centre Protestant d'Études, $28^{\circ}$ année, $\mathrm{n}^{\circ} 3$, Genève, juin $1976,101 \mathrm{p}$.

CHAUVET, Louis-Marie, Symbole et sacrement: une relecture sacramentelle de l'existence chrétienne, Paris, Cerf, 1987, 582p. [ Cogitatio fidei, \# 144]

- Les sacrements, Parole de Dieu au risque du corps, Paris, Éd. Ouvrières, mai 1993. [Croire, Vivre, Célébrer]

COMTE, Robert, "La structuration de la foi personnelle", in Christus, $\mathrm{n}^{\circ} 143$, juillet 1989, pp.264-275. et "Etapes de la vie adulte et évolution spirituelle", in Catéchèse, $\mathrm{n}^{\circ} 120$, juillet 1990, pp. 23-34.

C.N.E.R., Formation chrétienne des adultes: Un guide théorique et pratique pour la catéchèse, Paris, Desclée de Brouwer, 1986, 312p.

DE CERTEAU, Michel, L'Étranger ou l'union dans la différence, Paris, DDB, 1991, 208p.

DEPERNE, Jacques, "Entrevue avec Taisen DESHIMARU, Bouddhisme, Signe extérieure de richesse intérieure", in ARM, Dossier: "Dieu a-t-il de l'humour", 15 janvier 1994, pp. 23-24.

DUFOUR, Simon, Devenir libre dans le Christ, Éduquer la foi aujourd'hui , Québec, Anne Sigier, 1987, 221p.

DUFOUR, Simon, TREMBLAY, Éric, "Lieu de mission et de présence au monde", in Liturgie, Foi et Culture, volume 27, Printemps 1993, pp. 17-25.

-"Pour un sens à la vie", in RND: L'Église d'ici a-t-elle un avenir?, ${ }^{\circ} 1$, janvier 1994, pp. 9-11.

DREWERMANN, Eugen, La parole qui guérit, Paris, Cerf, 1991, 333p.

- L'essentiel est invisible * Une lecture psychanalytique du Petit Prince, Paris, Cerf, 1992, 166p. 
DROUIN, Gilles, "L'éducation de la foi des adultes au Québec, Essai d'analyse de la situation", in Église canadienne, volume 26, numéro 10, septembre 1993, pp. 299-304.

ERICKSON, Erik H., Luther avant Luther, Psychanalyse et histoire, traduit de l'américain par GODNEFF, Nina, Paris, Flammarion, 1968, 330p.

-The Life Cycle Completed: A Review, New York, Norton and Co. , 1982, 108p.

FOWLER, James W., Stages of Faith: The Psychology of Human Development and the Quest for Meaning. San Francisco, Harper and Row, 1981, 332p.

- "Théologie et psychologie dans l'étude du développement de la foi", in Concilium, ${ }^{\circ} 176,1982$, pp. 145-150.

-"Une introduction progressive à la foi", in Concilium, $\mathrm{n}^{\circ} 194$, 1984, pp. 77-87.

GIGUÈRE, Paul-André, Une foi adulte, L'horizon du croyant , Ottawa, Novalis, 1991, 177p.

GIRARD, Irénée, Pour un dialogue plus fécond en pastorale baptismale, Mémoire de maîtrise, Montréal, 1989, 203p.

GIRARD, Raymond, Éducation à la foi et développement humain, Québec, Presses de 1'Université du Québec, 1992, 428 p.

GOSSELIN, Gilles, "Fondements psychosociaux des motifs de participation des adultes en éducation de la foi", in Sciences pastorales , $\mathrm{n}^{\circ} 11,1992$, pp. 35-66.

GOULD, R.L., Transformations: Growth and Change in Adult Life, New York, Simon and Schuster, 1978, 343 p.

GRAND'MAISON, Jacques, Vers un nouveau conflit de générations, Profils sociaux et religieux des 20-35 ans et Une génération bouc-émissaire, Enquête sur les baby-boomers, Montréal, Fides, 1993. [Cahiers d'études pastorales, \# 14 et \# 15] 
GROOME, Thomas H., Sharing Faith, A Comprehensive Approach to Religious Education and Pastoral Ministry, San Francisco, Harper and Row,1991. 596p.

GY, Pierre-Marie, "La notion chrétienne d'initiation", in La Maison-Dieu, n¹32, 1977, pp.33-54.

HÉTU, Jean-Luc, Psychologie de l'expérience intérieure, Montréal, Méridien, $1983,198 \mathrm{p}$.

HOULE, Renée, Les temps de la vie, Le développement psychosial de l'adulte selon la perspective du cycle de vie, Boucherville, Gaëtan Morin, 1991, 357p.

JACQUEMONT, Patrick, JOSSUA, Jean-Pierrre et QUELQUEJEU, Bernard, Le Temps de la Patience: étude sur le témoignage, Paris, Cerf, 1976, 165p.

JEAN-PAUL II, Le Rédempteur de l'homme, Lettre encyclique "Redemptor hominis", Montreal, Fides, 4 mars 1979, 104p. [ L'Église aux quatre vents]

JUNG, C.G., "The Stages of Life", in J. Campbell (édit.), The Portable Jung, New York, Viking, 1971, pp. 3-22.

KUNG, Kang, Etre chrétien, Paris, Seuil, 794p.

LAPOINTE, Guy, "Prenez et mangez, Le défi de l'utopie évangélique", in Prêtre et Pasteur, vol. 96, n² , avril 1993, pp. 200-210.

-"La pratique des sacrements: risquer la situation présente", in Prêtre et pasteur, juin 1993, pp. 356-366.

LÉGAUT, Marcel, Introduction à l'intelligence du passé et de l'avenir du christianisme, France, Aubier-Montaigne, 1970, 402p.

- Devenir soi et rechercher le sens de sa propre vie , Paris, Aubier-Montaigne, 1981, 153p.

-Travail de la foi, Paris, Desclée de Brouwer, 1989, 175p.

LEVINSON, D.J., "The Seasons of a Man's Life", in L. R. Allman et D.T. Jaffe (édit.)., Readings in Adult Psychology, Contemporary Perspectives, New York, Harper and Row, 1982, pp. 103-107. 
LINN Dennis et Matthew et FABRICANT Sheila, Le développement de l'homme en huit étapes, Guérison des souvenirs, Paris, DDB, 1992, 215p.

MOINGT Joseph, "Le message des sacrements", in La transmission de la foi, Paris, Fayard, 1976, pp.120-129.

NOUWEN, Henri J.M., Au nom de Jésus, Réflexions sur le leadership chrétien, Ottawa, Novalis, 1991, 49p.

OFFICE DE CATÉCHÈSE DU QUÉBEC, Dossiers d'andragogie religieuse, Tome 1: Principes d'andragogie religieuse, Ottawa, Novalis, 47p.

OSER, F.; GMUNDER, P. et RIDEZ, L., L'homme et son développement religieux, Paris, Cerf, 1991, 348p.

TREMBLAY, Eric, DUFOUR, Simon, RADA, Alejandro, "Les pratiques d'initiation sacramentelle dans le diocèse de Chicoutimi", in L'initiation sacramentelle des enfants, Étude de la politique de l'Église du Québec, Montréal, Fides, pp. 191-219. [Cahier d'études pastorales, \# 3 ]

VAILLANT, G.E., Adaptation to Life, Boston, Little Brown, 1977, 396p.

VALLERY, Jacques, Passages, Paroles de sens, Paroles de foi, Bruxelles, Ed. Lumen Vitae, 1988, 202p.

VANIER, Jean, Le corps brisé, Retour vers la communion, Montréal, Bellarmin, $1989,153 \mathrm{p}$.

VARILLON, François, L'humilité de Dieu, Paris, Centurion, 1974, 160p.

WHITEHEAD, Evelyn Eaton \& James D., Les étapes de l'âge adulte: Évolution psychologique et religieuse, Paris, Centurion, 1990, 268p. 